\title{
One-dimensional computer modeling of electrical conductivity through methane and synthesis gas flames
}

Jonathan Patrick Lilly

West Virginia University

Follow this and additional works at: https://researchrepository.wvu.edu/etd

\section{Recommended Citation}

Lilly, Jonathan Patrick, "One-dimensional computer modeling of electrical conductivity through methane and synthesis gas flames" (2006). Graduate Theses, Dissertations, and Problem Reports. 1777. https://researchrepository.wvu.edu/etd/1777

This Thesis is protected by copyright and/or related rights. It has been brought to you by the The Research Repository @ WVU with permission from the rights-holder(s). You are free to use this Thesis in any way that is permitted by the copyright and related rights legislation that applies to your use. For other uses you must obtain permission from the rights-holder(s) directly, unless additional rights are indicated by a Creative Commons license in the record and/ or on the work itself. This Thesis has been accepted for inclusion in WVU Graduate Theses, Dissertations, and Problem Reports collection by an authorized administrator of The Research Repository @ WVU. For more information, please contact researchrepository@mail.wvu.edu. 


\title{
One-Dimensional Computer Modeling of Electrical Conductivity through Methane and Synthesis Gas Flames
}

\author{
Jonathan Patrick Lilly \\ BSEE, BSCpE, West Virginia University \\ Thesis \\ Submitted to \\ The College of Engineering and Mineral Resources \\ at \\ WEST VIRGINIA UNIVERSITY \\ in partial fulfillment of the requirements for the degree of \\ Master of Science in Electrical Engineering \\ Examining Committee Members: \\ Dr. Roy S. Nutter Jr. (Committee Chair) \\ Dr. Mark A. Jerabek \\ Dr. Powsiri Klinkhachorn
}

Lane Department of Computer Science and Electrical Engineering

Morgantown, West Virginia

2006 


\begin{abstract}
One-Dimensional Computer Modeling of Electrical Conductivity through Methane and Synthesis Gas Flames

Jonathan Patrick Lilly

The purpose of this work has been to produce and test simulation software to accurately model the effects of charged species and applied electric fields on the current conducted through methane and methane-doped synthesis gas flames. Comparison with existing experimental data generated at NETL has been conducted on a variety of published reaction mechanisms.
\end{abstract}




\section{Acknowledgment}

The research for this thesis was conducted as part of the continuing work on the Combustion Control and Diagnostic Sensor (CCADS) project at the National Energy Technology Laboratory (NETL) in Morgantown, West Virginia. The position was made available as under the Department of Energy's (DOE), Oak Ridge Associated Universities (ORAU) through the Oak Ridge Institute for Science and Education (ORISE).

Special thanks to David Huckaby, Benjamin Chorpening, Jimmy Thornton, and Clark Robinson who made my experience at NETL quite imformative and enjoyable. Also, to Dr. Roy S. Nutter, who chose me for this research and advised me throughout my graduate training. 


\section{Table of Contents}

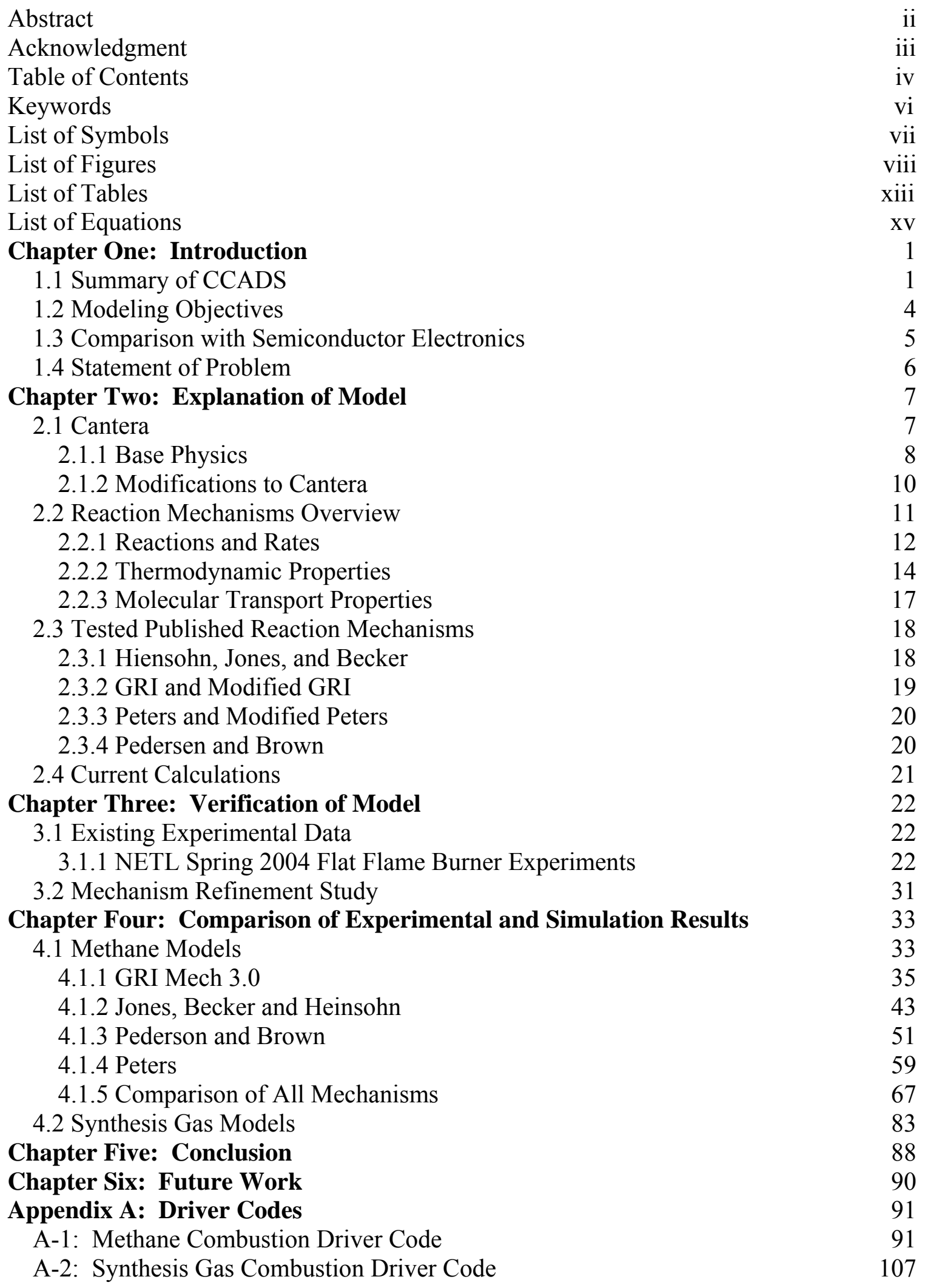


B-1: Listing of Jones, Heinsohn and Becker Mechanism 121

B-2: Listing of Modified GRI 3.0 Mechanism 131

B-3: Listing of Pederson and Brown Mechanism 172

B-4: Listing of Peters Mechanism 191

Appendix C: Utilities Codes 208

C-1: nameParse 208

C-2: parseChemkin2 219

Appendix D: Output File Formats 232

D-1: CSV Simulation Output File $\quad 232$

D-2: CTML Simulation Output File 233

D-3: Running Current Output File 236

Appendix E: Plots of Results 237

E-1: V-I Plots of Methane Combustion Using GRI Mech 3.0 237

E-2: V-I Plots of Methane Combustion Using Jones, Becker and Heinsohn 247

E-3: V-I Plots of Methane Combustion Using Pederson and Brown 257

E-4: V-I Plots of Methane Combustion Using Peters 267

E-5: Plots of Methane Combustion Using Four Mechanisms 277

E-6: Plots of Synthesis Gas Combustion Using Pederson and Brown 286

Bibliography 


\section{Keywords}

Adaptive Grid

Arrhenius Function

Cantera

Charged Species

Charged Species Interaction

Chemical Kinetics

Chemical Transport Properies

Combustion

Combustion Control and Diagnostics Sensor (CCADS)

Conduction Current Density

Conductivity

Current Density

Diffusion

Diffusion Flux

Diffusivity

Drift

Dynamic Pressure Oscillation

Electric Field

Electric Potential

Electrostatic Drift Flux

Energy Conservation

Enthalpy

Entropy

Equivalence Ratio

Flame Ionization

Flashback

Flat Flame Burner

Homogeneous Reaction
Ionization Current

In-situ Combustion State Monitoring Lean Blow-off

Lennard-Jones Collision Diameter

Lennard-Jones Well Depth

Lindemann Falloff Reaction

Mass Conservation

Mass Flux

Methane

Molecular Transport

NASA Thermodynamic Polynomial

$\mathrm{No}_{x}$

One-Dimensional Computer Model

Premixed Combustion

Python

Reaction Rate Coefficient

Rotational Relaxation Collision Number

Saturation Current

Species Conservation

Specific Heat

Synthesis Gas

Thermal Conduction

Third-Body Collision Efficiencies

Three Body Reaction

Turbine Engine

Viscosity

XML 


\section{List of Symbols}

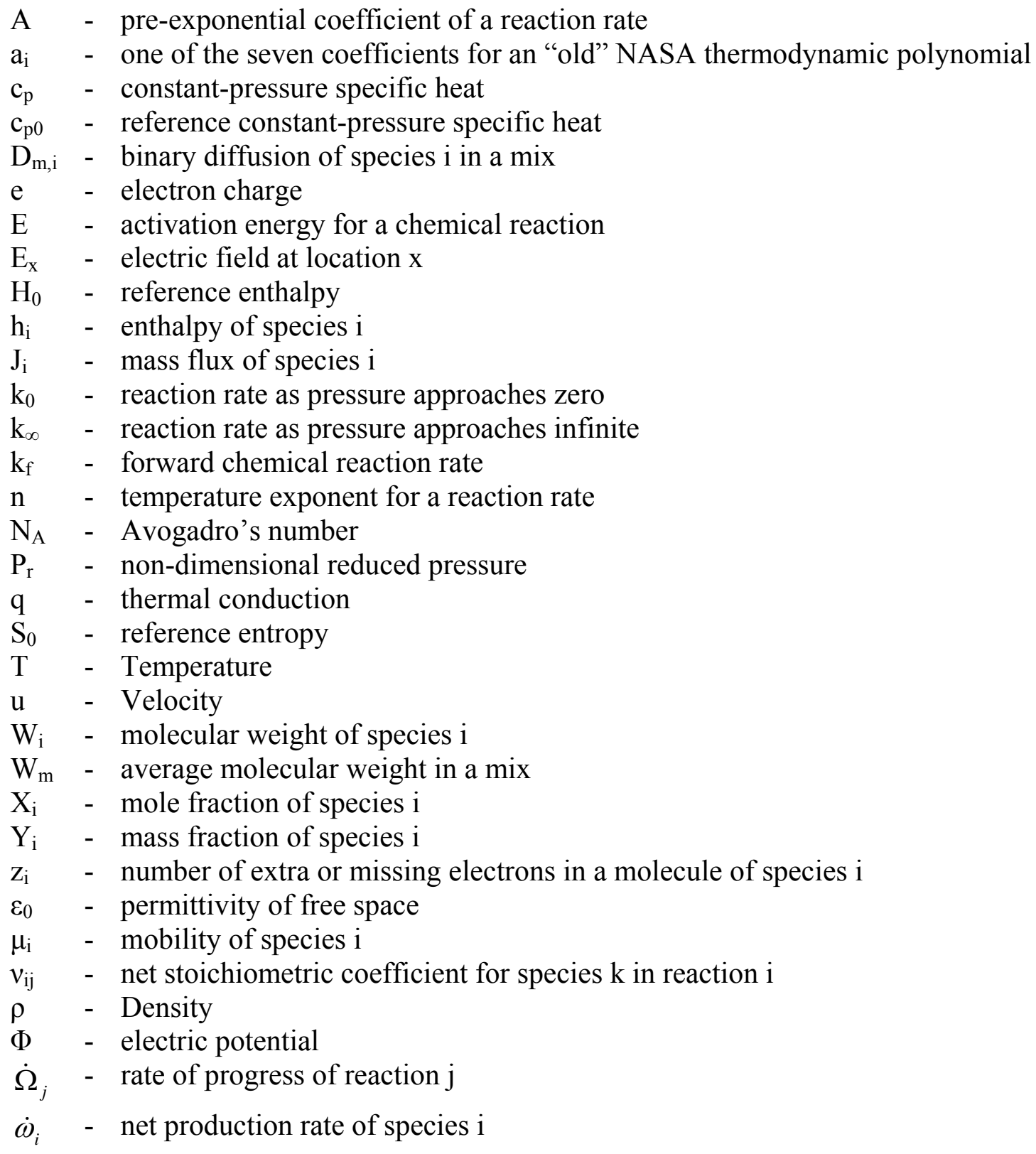




\section{List of Figures}

1-1 Basic CCADS Cross-Section

2-1 Example of "cti" File Reaction Entry

2-2 Example of "cti” File Three Body Reaction Entry

2-3 Example of “cti” File Entry for a Lindemann Falloff Reaction

2-4 NASA Polynomial Entry for Methane

2-5 Plot of the Specific Heat of Methane Calculated from the NASA Polynomial

2-6 Plot of the Enthalpy of Methane Calculated from the NASA Polynomial

2-7 Plot of the Entropy of Methane Calculated from the NASA Polynomial

2-8 Constant Thermodynamic Data Entry for $\mathrm{C}_{3} \mathrm{H}_{3}+$

3-1 Illustration of Flat Flame Burner Mount on an Adjustable Stage Control

3-2 Flat Flame Burner with Grid Electrode

3-3 Simplified Electrical Connection for Flat Flame Burner and Grid Electrode

3-4 Experimental Methane Data with Constant Air Flow and Forward Voltage

3-5 Experimental Methane Data with Constant Air Flow and Negative Voltage

3-6 Experimental Methane Data with Constant Methane Flow and Forward Voltage

3-7 Experimental Synthesis Gas Data with Varying Methane Concentrations Added

4-1 Simple Diagram of Saturation Current and Conductivity

4-2 Saturation Currents Using GRIMech3.0 with Methane in Experiment 1

4-3 Saturation Currents Using GRIMech3.0 with Methane in Experiment 2

4-4 Saturation Currents Using GRIMech3.0 with Methane in Experiment 3

4-5 Conductivity Using GRIMech3.0 with Methane in Experiment 1

4-6 Conductivity Using GRIMech3.0 with Methane in Experiment 2

4-7 Conductivity Using GRIMech3.0 with Methane in Experiment 3

4-8 Saturation Current Using Jone, Becker and Heinsohn with Methane in Experiment 1

4-9 Saturation Current Using Jone, Becker and Heinsohn with Methane in Experiment 2

4-10

4-11 Conductivity Using Jone, Becker and Heinsohn with Methane in Experiment 1

4-12 Conductivity Using Jone, Becker and Heinsohn with Methane in Experiment 2

4-13 Conductivity Using Jone, Becker and Heinsohn with Methane in Experiment 3

4-14 Saturation Current Using Pederson and Brown with Methane in Experiment 1

4-15 Saturation Current Using Pederson and Brown with Methane in Experiment 2

4-16 Saturation Current Using Pederson and Brown with Methane in Experiment 3

4-17 Conductivity Using Pederson and Brown with Methane in Experiment 1

4-18 Conductivity Using Pederson and Brown with Methane in Experiment 2

4-19 Conductivity Using Pederson and Brown with Methane in Experiment 3

4-20 Saturation Current Using Peters with Methane in Experiment 1

4-21 Saturation Current Using Peters with Methane in Experiment 2

4-22 Saturation Current Using Peters with Methane in Experiment 3

4-23 Conductivity Using Peters with Methane in Experiment 1

4-24 Conductivity Using Peters with Methane in Experiment 2

4-25 Conductivity Using Peters with Methane in Experiment 3 
Temperature vs. Air Flow for Methane Combustion Using All Mechanisms in

Experiment 1 with Mobility $=0.40 \mathrm{~m}^{2} / \mathrm{Vs}$

Temperature vs. Methane Flow for Methane Combustion Using All Mechanisms

in Experiment 2 with Mobility $=0.40 \mathrm{~m}^{2} / \mathrm{Vs}$

Temperature vs. Air Flow for Methane Combustion Using All Mechanisms in

4-28 Experiment 3 with Mobility $=0.40^{2} / V s$

Position of CH Peak Consentration vs. Air Flow for Methane Combustion Using

4-29 All Mechanisms in Experiment 1with Mobility $=0.40^{2} / \mathrm{Vs}$

Position of CH Peak Consentration vs. Air Flow for Methane Combustion Using

4-30 All Mechanisms in Experiment 2 with Mobility $=0.40 \mathrm{~m}^{2} / \mathrm{Vs}$

Position of CH Peak Consentration vs. Methane Flow for Methane Combustion

4-31 Using All Mechanisms in Experiment 3 with Mobility $=0.40 \mathrm{~m}^{2} / \mathrm{Vs}$

4-32 Example of Typical CH Profiles for Each Mechanism During Methane

Combustion

Saturation Currents vs. Air Flow for Methane Combustion Using All

4-33 Mechanisms in Experiment 1 with Mobility $=0.40 \mathrm{~m}^{2} / \mathrm{Vs}$

Saturation Currents vs. Air Flow for Methane Combustion Using All

4-34 Mechanisms in Experiment 2 with Mobility $=0.40 \mathrm{~m}^{2} / \mathrm{Vs}$

Saturation Currents vs. Air Flow for Methane Combustion Using All

4-35 Mechanisms in Experiment 3 with Mobility $=0.40 \mathrm{~m}^{2} / \mathrm{Vs}$

Conductivity vs. Air Flow for Methane Combustion Using All Mechanisms in

4-36 Experiment 1 with Mobility $=0.40 \mathrm{~m}^{2} / \mathrm{Vs}$

Conductivity vs. Air Flow for Methane Combustion Using All Mechanisms in

4-37 Experiment 2 with Mobility $=0.40 \mathrm{~m}^{2} / \mathrm{Vs}$

Conductivity vs. Air Flow for Methane Combustion Using All Mechanisms in

4-38 Experiment 3 with Mobility $=0.40 \mathrm{~m}^{2} / \mathrm{Vs}$

4-39 Temperature vs. Methane Flow Using GRIMech3.0 for Methane-Doped Synthesis Gas Combustion

Position of Peak CH Concentration vs. Methane Flow Using GRIMech3.0 for

4-40 Methane-Doped Synthesis Gas Combustion

4-41 Conductivity vs. Methane Flow Using GRIMech3.0 for Methane-Doped Synthesis Gas Combustion

4-42 Saturation Current vs. Methane Flow Using GRIMech3.0 for Methane-Doped Synthesis Gas Combustion

C-1 Example of Filename a Methane Flame Model Output File

C-2 Example of Filename for a Synthesis Gas Flame Model Output File

C-3 Example of a Chemkin2 Format Thermodynamic Polynomial Data Entry 
D-1 CSV Simulation Output File Truncated Example

D-2 CTML Output File Truncated Example

D-3 Example of Running Current Output File Using Methane and Air

D-4 Example of Running Current Output File Using Synthesis Gas and Air

E-1 Voltage vs. Current with Methane for GRI Experiment 1-1

E-2 Voltage vs. Current with Methane for GRI Experiment 1-2

E-3 Voltage vs. Current with Methane for GRI Experiment 1-3

E-4 Voltage vs. Current with Methane for GRI Experiment 1-4

E-5 Voltage vs. Current with Methane for GRI Experiment 1-5

E-6 Voltage vs. Current with Methane for GRI Experiment 1-6

E-7 Voltage vs. Current with Methane for GRI Experiment 2-1

E-8 Voltage vs. Current with Methane for GRI Experiment 2-2

E-9 Voltage vs. Current with Methane for GRI Experiment 2-3

E-10 Voltage vs. Current with Methane for GRI Experiment 2-4

E-11 Voltage vs. Current with Methane for GRI Experiment 2-5

E-12 Voltage vs. Current with Methane for GRI Experiment 2-6

E-13 Voltage vs. Current with Methane for GRI Experiment 3-1

E-14 Voltage vs. Current with Methane for GRI Experiment 3-2

E-15 Voltage vs. Current with Methane for GRI Experiment 3-3

E-16 Voltage vs. Current with Methane for GRI Experiment 3-4

E-17 Voltage vs. Current with Methane for GRI Experiment 3-5

E-18 Voltage vs. Current with Methane for GRI Experiment 3-6

E-19 Voltage vs. Current with Methane for Jones, Becker and Heinsohn Experiment $1-1$

E-20 Voltage vs. Current with Methane for Jones, Becker and Heinsohn Experiment $1-2$

Voltage vs. Current with Methane for Jones, Becker and Heinsohn Experiment $1-3$

E-22 Voltage vs. Current with Methane for Jones, Becker and Heinsohn Experiment $1-4$

E-23

Voltage vs. Current with Methane for Jones, Becker and Heinsohn Experiment $1-5$

E-24 Voltage vs. Current with Methane for Jones, Becker and Heinsohn Experiment $1-6$

E-25 2-1

E-26 Voltage vs. Current with Methane for Jones, Becker, and Heinsohn Experiment 2-2

E-27 Voltage vs. Current with Methane for Jones, Becker, and Heinsohn Experiment 2-3

E-28

Voltage vs. Current with Methane for Jones, Becker, and Heinsohn Experiment $2-4$

E-29 Voltage vs. Current with Methane for Jones, Becker, and Heinsohn Experiment $2-5$

E-30

Voltage vs. Current with Methane for Jones, Becker, and Heinsohn Experiment 2-6 
Voltage vs. Current with Methane for Jones, Becker, and Heinsohn Experiment 3-1

Voltage vs. Current with Methane for Jones, Becker, and Heinsohn Experiment 3-2

Voltage vs. Current with Methane for Jones, Becker, and Heinsohn Experiment 3-3

Voltage vs. Current with Methane for Jones, Becker, and Heinsohn Experiment 3-4

Voltage vs. Current with Methane for Jones, Becker, and Heinsohn Experiment 3-5

Voltage vs. Current with Methane for Jones, Becker, and Heinsohn Experiment 3-6

E-37 Voltage vs. Current with Methane for Pederson and Brown Experiment 1-1

E-38 Voltage vs. Current with Methane for Pederson and Brown Experiment 1-2

E-39 Voltage vs. Current with Methane for Pederson and Brown Experiment 1-3

E-40 Voltage vs. Current with Methane for Pederson and Brown Experiment 1-4

E-41 Voltage vs. Current with Methane for Pederson and Brown Experiment 1-5

E-42 Voltage vs. Current with Methane for Pederson and Brown Experiment 1-6

E-43 Voltage vs. Current with Methane for Pederson and Brown Experiment 2-1

E-44 Voltage vs. Current with Methane for Pederson and Brown Experiment 2-2

E-45 Voltage vs. Current with Methane for Pederson and Brown Experiment 2-3

E-46 Voltage vs. Current with Methane for Pederson and Brown Experiment 2-4

E-47 Voltage vs. Current with Methane for Pederson and Brown Experiment 2-5

E-48 Voltage vs. Current with Methane for Pederson and Brown Experiment 2-6

E-49 Voltage vs. Current with Methane for Pederson and Brown Experiment 3-1

E-50 Voltage vs. Current with Methane for Pederson and Brown Experiment 3-2

E-51 Voltage vs. Current with Methane for Pederson and Brown Experiment 3-3

E-52 Voltage vs. Current with Methane for Pederson and Brown Experiment 3-4

E-53 Voltage vs. Current with Methane for Pederson and Brown Experiment 3-5

E-54 Voltage vs. Current with Methane for Pederson and Brown Experiment 3-6

E-55 Voltage vs. Current with Methane for Peters Experiment 1-1

E-56 Voltage vs. Current with Methane for Peters Experiment 1-2

E-57 Voltage vs. Current with Methane for Peters Experiment 1-3

E-58 Voltage vs. Current with Methane for Peters Experiment 1-4

E-59 Voltage vs. Current with Methane for Peters Experiment 1-5

E-60 Voltage vs. Current with Methane for Peters Experiment 1-6

E-61 Voltage vs. Current with Methane for Peters Experiment 2-1

E-62 Voltage vs. Current with Methane for Peters Experiment 2-2

E-63 Voltage vs. Current with Methane for Peters Experiment 2-3

E-64 Voltage vs. Current with Methane for Peters Experiment 2-4

E-65 Voltage vs. Current with Methane for Peters Experiment 2-5

E-66 Voltage vs. Current with Methane for Peters Experiment 2-6

E-67 Voltage vs. Current with Methane for Peters Experiment 3-1

E-68 Voltage vs. Current with Methane for Peters Experiment 3-2

E-69 Voltage vs. Current with Methane for Peters Experiment 3-3

E-70 Voltage vs. Current with Methane for Peters Experiment 3-4 
E-71 Voltage vs. Current with Methane for Peters Experiment 3-5

E-72 Voltage vs. Current with Methane for Peters Experiment 3-6

E-73 Voltage vs. Current with Methane for All Mechanisms Experiment 1-1

E-74 Voltage vs. Current with Methane for All Mechanisms Experiment 1-2

E-75 Voltage vs. Current with Methane for All Mechanisms Experiment 1-3

E-76 Voltage vs. Current with Methane for All Mechanisms Experiment 1-4

E-77 Voltage vs. Current with Methane for All Mechanisms Experiment 1-5

E-78 Voltage vs. Current with Methane for All Mechanisms Experiment 1-6

E-79 Voltage vs. Current with Methane for All Mechanisms Experiment 2-1

E-80 Voltage vs. Current with Methane for All Mechanisms Experiment 2-2

E-81 Voltage vs. Current with Methane for All Mechanisms Experiment 2-3

E-82 Voltage vs. Current with Methane for All Mechanisms Experiment 2-4

E-83 Voltage vs. Current with Methane for All Mechanisms Experiment 2-5

E-84 Voltage vs. Current with Methane for All Mechanisms Experiment 2-6

E-85 Voltage vs. Current with Methane for All Mechanisms Experiment 3-1

E-86 Voltage vs. Current with Methane for All Mechanisms Experiment 3-2

E-87 Voltage vs. Current with Methane for All Mechanisms Experiment 3-3

E-88 Voltage vs. Current with Methane for All Mechanisms Experiment 3-4

E-89 Voltage vs. Current with Methane for All Mechanisms Experiment 3-5

E-90 Voltage vs. Current with Methane for All Mechanisms Experiment 3-6

E-91 Voltage vs. Current with Synthesis Gas for GRI Run 1

E-92 Voltage vs. Current with Synthesis Gas for GRI Run 2

E-93 Voltage vs. Current with Synthesis Gas for GRI Run 3

E-94 Voltage vs. Current with Synthesis Gas for GRI Run 4

E-95 Voltage vs. Current with Synthesis Gas for GRI Run 5 


\section{List of Tables}

3-1 Methane Experimental Conditions

3-2 Synthesis Gas Experimental Conditions in SLPM

3-3 Synthesis Gas Experimental Conditions in $\mathrm{kg} / \mathrm{s}$

3-4 Experimental Methane Combustion V-I Curve Characteristics to $90 \%$ of the Maximum Current

3-5 Experimental Synthesis Gas Combustion V-I Curve Characteristics to $90 \%$ of the Maximum Current

V-I Curve Characteristics to $90 \%$ of Maximum Current Using GRIMech 3.0

4-1 with Electron Mobility of $0.36 \mathrm{~m}^{2} / \mathrm{Vs}$

Table 4-2: V-I Curve Characteristics to $90 \%$ of Maximum Current Using

4-2 GRIMech 3.0 with Electron Mobility of $0.40 \mathrm{~m}^{2} / \mathrm{Vs}$

V-I Curve Characteristics to $90 \%$ of Maximum Current Using GRIMech 3.0

4-3 with Electron Mobility of $0.44 \mathrm{~m}^{2} / \mathrm{Vs}$

V-I Curve Characteristics to $90 \%$ of Maximum Current Using Jones, Becker,

4-4 and Heinsohn with Electron Mobility of $0.36 \mathrm{~m}^{2} / \mathrm{Vs}$

V-I Curve Characteristics to $90 \%$ of Maximum Current Using Jones, Becker,

4-5 and Heinsohn with Electron Mobility of $0.40 \mathrm{~m}^{2} / \mathrm{Vs}$

Table 4-6: V-I Curve Characteristics to 90\% of Maximum Current Using Jones,

4-6 Becker, and Heinsohn with Electron Mobility of $0.40 \mathrm{~m}^{2} / \mathrm{Vs}$

V-I Curve Characteristics to $90 \%$ of Maximum Current Using Pederson and

4-7 Brown with Electron Mobility of $0.36 \mathrm{~m}^{2} / \mathrm{Vs}$

V-I Curve Characteristics to $90 \%$ of Maximum Current Using Pederson and

4-8 Brown with Electron Mobility of $0.40 \mathrm{~m}^{2} / \mathrm{Vs}$

V-I Curve Characteristics to $90 \%$ of Maximum Current Using Pederson and

4-9 Brown with Electron Mobility of $0.44 \mathrm{~m}^{2} / \mathrm{Vs}$

V-I Curve Characteristics to $90 \%$ of Maximum Current Using Peters with

4-10 Electron Mobility of $0.36 \mathrm{~m}^{2} / \mathrm{Vs}$

V-I Curve Characteristics to $90 \%$ of Maximum Current Using Peters with

4-11 Electron Mobility of $0.40 \mathrm{~m}^{2} / \mathrm{Vs}$

V-I Curve Characteristics to $90 \%$ of Maximum Current Using Peters with

4-12 Electron Mobility of $0.44 \mathrm{~m}^{2} / \mathrm{Vs}$

Experimental and Modeled V-I Curve Slopes to 90\% of Maximum Current for

4-13 All Mechanisms Using Methane Combustion with Mobility $=0.40 \mathrm{~m}^{2} / \mathrm{Vs}$

4-14 Experimental and Modeled Voltage at $90 \%$ of Maximum Current for All 
Mechanisms Using Methane Combustion with Mobility $=0.40 \mathrm{~m}^{2} / \mathrm{Vs}$

Experimental and Modeled Current at $90 \%$ of Maximum for All Mechanisms

4-15 Using Methane Combustion with Mobility $=0.40 \mathrm{~m}^{2} / \mathrm{Vs}$

V-I Curve Characteristics to $90 \%$ of Maximum Current Using GRIMech 3.0

4-16 with Electron Mobility of $0.36 \mathrm{~m}^{2} / \mathrm{Vs}_{\mathrm{s}}$ for Synthesis Gas Combustion

V-I Curve Characteristics to 90\% of Maximum Current Using GRIMech 3.0

4-17 with Electron Mobility of $0.40 \mathrm{~m}^{2} / \mathrm{Vs}$ for Synthesis Gas Combustion

V-I Curve Characteristics to $90 \%$ of Maximum Current Using GRIMech 3.0

4-18 with Electron Mobility of $0.44 \mathrm{~m}^{2} / \mathrm{Vs}_{\mathrm{s}}$ for Synthesis Gas Combustion

A-1 Constructor Inputs for Methane Combustion Modeling Code

A-2 Constants Included in the EFSim_NG_Current Class

A-3 Class Methods for EFSim_NG_Current Class

A-4 Constructor Inputs for Synthesis Gas Combustion Modeling Code

A-5 Constants Included in the EFSim_Syngas_Current Class

A-6 Class Methods for EFSim_Syngas_Current Class

C-1 List of Filename Labels for Methane Flame Model Output Files

C-2 List of Filename Labels for Synthesis Gas Flame Model Output Files

C-3 Table of Constant Values Included in the nameParse Class

C-4 Function Descriptions for the nameParse Class

C-5 Table of Constants Used by the parseChemkin2 Code

C-6 Class Methods for the ThermoData Class Contained in parseChemkin2 Code

C-7 Standalone Methods Contained in the parseChemkin2 Code 


\section{List of Equations}

1-1 Electron Current Density within Semiconductors

1-2 Hole Current Density within Semiconductors

1-3 Charge Carrier Drift Velocity within Applied Electric Field

2-1 Mass Conservation Equation

2-2 Species Conservation Equation

2-3 Energy Conservation Equation

2-4 Species Production Rate

2-5 Mass Flux Equation

2-6 Gauss's Law in One-Dimension

2-7 Electric Field Equation

2-8 Modified Arrhenius Reaction Rate

2-9 Calculation of One-Dimensional Reduced Pressure for Lindemann Falloff Reactions

2-10 Calculation of Pressure-Dependant Reaction Rate Coefficient for Lindemann Falloff Reactions

2-11 Derivation of Non-Dimensional Specific Heat from a NASA Thermodynamic Data Polynomial

2-12 Derivation of Non-Dimensional Enthalpy from a NASA Thermodynamic Data Polynomial

2-13 Derivation of Non-Dimensional Entropy from a NASA Thermodynamic Data Polynomial

2-14 Calculation of Enthalpy Using Constant Specific Heat Approximation

2-15 Calculation of Entropy Using Constant Specific Heat Approximation

2-16 Chemical Equation for Production of Electrons and $\mathrm{HCO}^{+}$Ions for the Jones, Becker and Heinsohn Mechanism

2-17 Chemical Equation for Production $\mathrm{H}_{3} \mathrm{O}+$ Ions from $\mathrm{HCO}^{+}$Ions for the Jones, Becker and Heinsohn Mechanism

2-18 Chemical Equation for Destruction of Electrons and $\mathrm{H}_{3} \mathrm{O}^{+}$Ion for the Jones, Becker and Heinsohn Mechanism

2-19 Chemical Equation for Destruction of $\mathrm{CH}$ and Production of $\mathrm{CHO}^{+}$Ions and Electrons for the Pedersen and Brown Mechanism

2-20 Chemical Equation for Destruction of Electronically Excited $\mathrm{CH}$ and Production of $\mathrm{CHO}^{+}$Ions and Electrons for the Pedersen and Brown Mechanism

2-21 Chemical Equation for Destruction of $\mathrm{CHO}^{+}$Ions and Production of $\mathrm{H}_{3} \mathrm{O}^{+}$Ions for the Pedersen and Brown Mechanism

2-22 Chemical Equation for Destruction of $\mathrm{H}_{3} \mathrm{O}^{+}$Ions and Production of $\mathrm{C}_{2} \mathrm{H}_{3} \mathrm{O}^{+}$Ions for the Pedersen and Brown Mechanism Chemical Equation for Destruction of $\mathrm{CHO}^{+}$Ion and Production of $\mathrm{CH}_{3}{ }^{+}$Ions

2-23 for the Pedersen and Brown Mechanism Chemical Equation for Destruction of $\mathrm{H}_{3} \mathrm{O}^{+}$Ions and Production of $\mathrm{CH}_{3}{ }^{+}$Ions for the Pedersen and Brown Mechanism Chemical Equation for Destruction of $\mathrm{CH}_{3}{ }^{+}$Ions and Production of $\mathrm{C}^{3} \mathrm{H}_{3}{ }^{+}$Ions for the Pedersen and Brown Mechanism 
2-26 Chemical Equation for Destruction of $\mathrm{C}_{3} \mathrm{H}_{3}{ }^{+}$Ions and Production of $\mathrm{C}_{2} \mathrm{H}_{3} \mathrm{O}_{+}$Ion for the Pedersen and Brown Mechanism

2-27 Chemical Equation for Production of $\mathrm{C}_{2} \mathrm{H}_{3} \mathrm{O}^{+}$Ions and Destruction of $\mathrm{CH}_{3}{ }^{+}$Ions for the Pedersen and Brown Mechanism

2-28 Chemical Equation for Destruction of $\mathrm{H}_{3} \mathrm{O}^{+}$Ion and Electrons for the Pedersen and Brown Mechanism

2-29 Chemical Equation for Destruction of $\mathrm{C}_{3} \mathrm{H}_{3}{ }^{+}$Ion and Electrons for the Pedersen and Brown Mechanism

2-30 Chemical Equation for Destruction of $\mathrm{CH}_{3}{ }^{+}$Ion and Electrons for the Pedersen and Brown Mechanism 


\section{Chapter One: Introduction}

\subsection{Summary of CCADS}

The Combustion Control and Diagnostics Sensor (CCADS) project is a sensor project meant to assist in turbine engines running with lean premixed air and fuel under conditions leading to low $\mathrm{NO}_{\mathrm{x}}$, low unburnt hydrocarbon, and high efficiency (Thornton et al., 2004). This goal is accomplished by allowing for increased stability of combustion in turbines for premixed air and fuel approaching the lean blow-off limit through the use of in-situ combustion state monitoring. This sensor is currently being developed by the U.S. Department of Energy's National Energy Technology Laboratory in Morgantown, West Virginia and Woodward Industrial Controls as part of a Cooperative Research and Development Agreement (CCRDA).

CCADS works by inferring flame characteristics based on the movement and generation of charged species within a flames combustion zone. The system makes use of a set of two electrodes, the guard electrode and the sense electrode. These electrodes are electrically isolated and side by side on the center body of the premixing nozzle (Thornton et al., 2004). The sense electrode is located closer to the inlet than the guard electrode, as illustrated in Figure 1-1. 


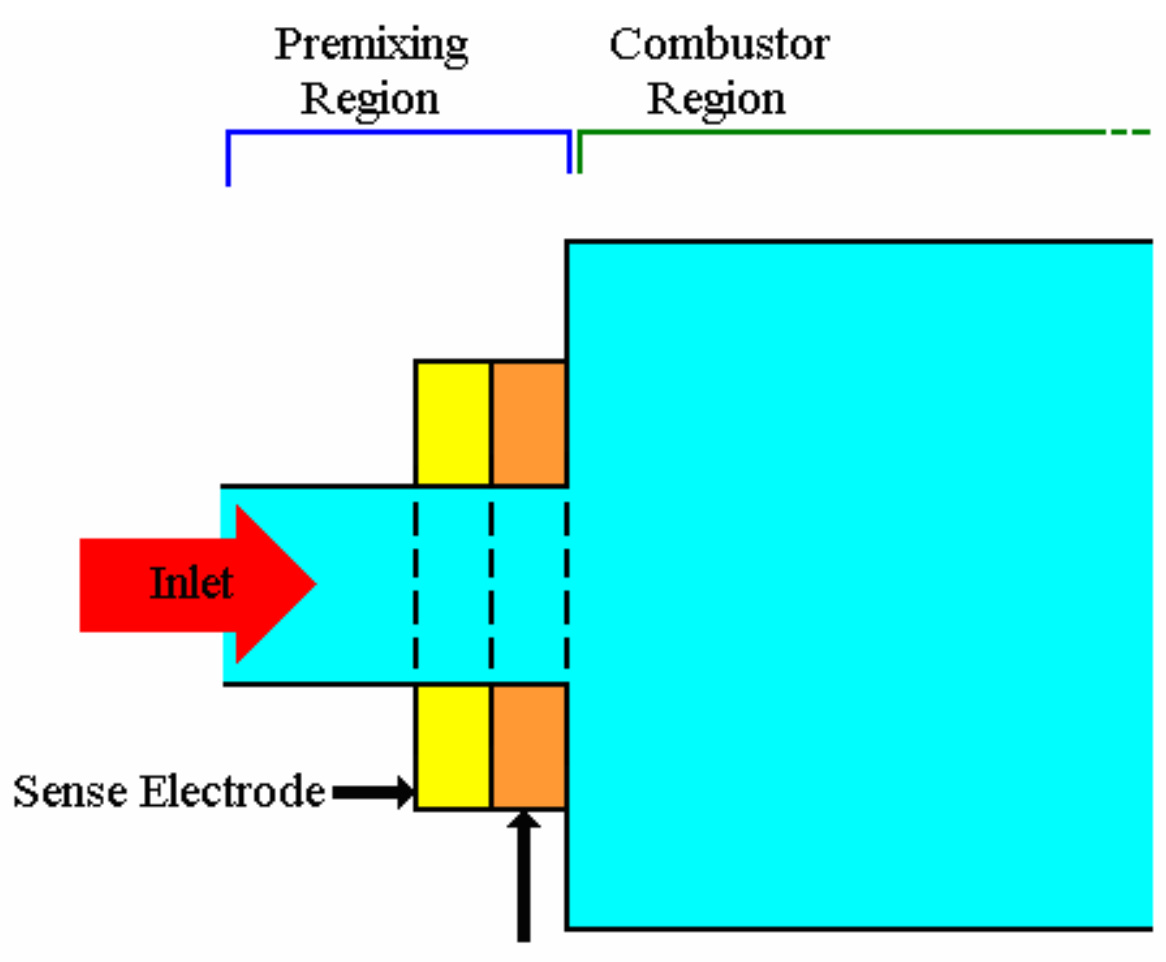

Guard Electrode

Figure 1-1: Basic CCADS Cross-Section

During operation, an equal electrical potential is applied to both the guard and the sense electrodes. Due to the electrode arrangement, under normal combustion conditions ionization current will be generated in the guard electrode only because the negative ions in the flame are preferentially attracted to the guard electrode when the flame is in the combustor region. If the flame enters the premixing region, however, ionization current will be detected through the sense electrode. This effect allows the sensor to detect flame flashback into the mixing chamber, a condition with the potential to cause significant hardware damage due to hot spots in the incomplete gas mixture. The response time of the sensor is fast enough to detect incipient flashback, allowing for corrective action to be taken (Thornton et al., 2004).

In addition to flashback, the CCADS sensor is capable of detecting incipient lean blow-off, a condition in which the flame goes out due to low fuel content in the premixed 
combustion gas. Insipient lean blow-out is detected by detecting precursor events in which the flame momentarily extinguishes and reignites. These events can be detected because ionization current is only produced in the guard electrode when a flame is actively burning (Thornton et al., 2004).

Another feature which CCADS can monitor is dynamic pressure oscillations within a combustor. Dynamic pressure oscillations can lead to hardware failure due to heat transfer and vibration. Most modern turbine engines make use of a dynamic pressure transducer to detect pressure oscillations, but it has been shown that a correlation exists between the signal produced by a dynamic pressure transducer and the frequency of the ionization current in the CCADS guard electrode (Benson et al., 2003).

Finally, in addition to detecting the abnormal combustion conditions already discussed, CCADS may be used to provide a reasonably accurate measurement of the equivalence ratio of the premixed fuel under certain operating conditions. A link between current generated through the CCADS electrodes and equivalence ratia has been found experimentally, but there has not yet been success in calculating the connection quantitatively. However, the measurement of equivalence ratio may be incorrect under certain operating conditions such as in the presence of dynamic pressure oscillations and factors such as flame location and combustion temperature may further complicate the estimates.

Equivalence ratio is a ratio of the air and fuel in a combustion mixture in relation to a perfect mixture. An equivalence ratio of exactly one indicates that a mixture contains exactly enough air to combust all fuel in the mixture. This perfect mix is known as a stoichiometric mixture. Mixtures with an equivalence ratio greater than one are 
called "rich" mixtures and do not contain enough air to combust all of the fuel. Mixtures with equivalence ratios less than one are called "lean" mixtures and contain more than enough air for full combustion. CCADS may be used to measure the equivalence ratio in lean mixtures because the average current detected by the sensor's guard electrode increases as a linear function of increasing equivalence ratio in lean burning flames (Thornton et al., 2004).

\subsection{Modeling Objectives}

As part of the CCADS project, a one-dimensional computer model of flame ionization is being developed. The goal of this model is to predict ionization currents at various equivalence ratios in premixed air fuel mixtures. The mixtures used in this research include methane or syngas and air, but the model should be capable of working with other fuel types if a suitable reaction mechanism model is built. The real-world representation of the target for this model is a flat flame burner like the one illustrated in Section 3.1.1.

Combustion is a chemical kinetic process in which large numbers of chemical species are generated, destroyed, and diffuse within a combustion zone. In modeling of combustion it simply is not possible to model every molecule exactly because of the large amount of computational resources that would be required for an ideal model, and as a result some approximations are necessary. An almost limitless number of chemical species may be produced within a real flame, but a model cannot represent an unlimited number of species. As a result, a likely subset of reactions must be used to model flame chemistry. For these chemical subsets, various published reaction mechanisms were used. A second approximation is the use of grids in which representations of species 
concentrations, temperatures, velocity and other flame properties are stored for various known positions, rather than an exact map of all molecules within the flame. Also, the interactions of species within the flame must be modeled based on real-world physics. However, in order to decrease computation time, it is common practice to ignore certain effects that do not play a significant role in a given application.

Modeling software is readily available which produces reasonably accurate representations of chemical kinetics within flames, but the available modeling software lacks the ability to accurately model the interactions of charged particles and applied electric fields within a combustion zone. The reason for this neglected functionality is that for most applications the interactions of charged species do not play a significant role. The charged species within a methane flame account for an almost insignificant proportion of the total mass within the flame, and in synthesis gas combustion, charges species are almost nonexistent. For CCADS, however, these charged species interactions are a vital interest.

\subsection{Brief Comparison with Semiconductor Electronics}

Although the goal of this research is to model charged particle movement within a combustion zone, there are some useful similarities with the field of semiconductor electronics. For example, the conduction current density given in Equation 1-1 for electrons and Equation 1-2 for holes (Streetman et al., 2000) follows the same form as the mass flux equation used in this modeling software as shown in Equation 2-5. In semiconductors and in combustion gas, current is produced by diffusion of charged particles and drift within applied electric fields.

$$
J_{n}(x)=q \mu_{n} n(x) E(x)+q D_{n} \frac{d n(x)}{d x}
$$




$$
J_{p}(x)=q \mu_{p} p(x) E(x)-q D_{p} \frac{d p(x)}{d x}
$$

As can also be seen in this research, ionization current reaches saturation once a high enough field is applied. Once saturation is reached in a flame, the current no longer increases with a higher applied field. In semiconductors, this effect is a result of reaching maximum drift velocity. A formula for drift velocity is shown in Equation 1-3 (Streetman et al., 2000).

$$
v_{d} \cong \frac{\mu E}{1+\mu E / v_{s}}
$$

\subsection{Statement of Problem}

The purpose of this research was to test and provide input for the modification and extension of a one-dimensional reaction simulation code to incorporate the effects of charged species and applied electric fields. This modification and extension included automation of the code to perform multiple similar simulations, processing of simulation outputs in order to calculate currents within the simulated combustion flames, and provide verification by comparison with existing experimental data. Although this model may be applied to many types of fuels with the use of appropriate reaction mechanisms, the scope of simulation and experimentation was limited to methane and synthesis gas combustion. Synthesis gas is a mixture of $\mathrm{CO}$ and $\mathrm{H} 2$ derived as an alternative fuel from cooking coal, but in this work, the trace hydrocarbons in synthesis gas are ignored. 


\section{Chapter Two: Explanation of Model}

\subsection{Cantera}

The goal of this project was to produce a one-dimensional model of premixed flames and apply the model to simulations with varying fuel mixes and flow rates. This model includes production, transport, and destruction of charged species and the effects of an applied electric field. Much work has already been accomplished in the area of simulation of chemical kinetics problems, including the development of a variety of programs meant to simulate chemical kinetics and transport. However, these programs generally ignore the effects of electrically charged species and applied electric fields within the reaction zone because charged species make up a very small proportion of the total mass of the system and in general practice an electric field is not applied across combustion zones. However, it is possible to use an existing program as a starting point for this model, but the original program must be modified in order to incorporate the effects of charged species and applied electric fields.

As a starting point for this model, a program called Cantera was chosen for use. Cantera is a set of chemical kinetic libraries written and maintained by Dr. David Goodwin, a professor of Mechanical Engineering at the California Institute of Technology (Goodwin, 2005, Object-Oriented Software for Reactive Flows). Cantera was written in order to accomplish many of the same tasks as the well known and widely used Chemkin program, which was developed at Sandia National Laboratories but is now maintained and distributed by Reaction Design. Cantera also contains additional functionality not available with Chemkin such as reactor networks and a Matlab interface. However, unlike Chemkin, Cantera is an open source program and, as a result, 
it can be freely downloaded and modified. Cantera is available in source and binary distributions on its Sourceforge project webpage (Goodwin, 2005, Sourceforge.net: Project Info - Cantera). In addition, Cantera includes interfaces for C++, Python, FORTRAN, and Matlab. For the simulation performed for this project, the Python interface was used. Python interpreters can be freely downloaded online (Python Software Foundation, 2005).

The following sections will discuss some of the inner workings of the Cantera program and changes necessary to incorporate electric field effects and charged species interactions.

\subsubsection{Base Physics}

In order to properly model flame, a chemical kinetics and transport program must satisfy the same physical rules as a real-world flame. This goal requires that certain conservation equations must be adhered to when finding a solution to a simulated flame object. The conservation equations built into the original version of Cantera include Mass, Species, and Energy conservation as given below (Kee et al., 2003).

$$
\begin{gathered}
\frac{d}{d x}(\rho u)=0 \\
\rho u \frac{d Y_{i}}{d x}+\frac{d}{d x} J_{i}=\dot{\omega}_{i} W_{i} \\
\rho u c_{p} \frac{d T}{d x}+\frac{d q}{d x}+\left(\sum_{i} J_{i} c_{p, i}\right) \frac{d T}{d x}=-\sum_{i} \dot{\omega}_{i} h_{i} W_{i}
\end{gathered}
$$

In equation 2-2 and 2-3, the terms $\dot{\omega}_{i}$ and $J_{i}$ are given by equations 2-4 (Kee, 2003) and 2-5 (Eraslan et al., 1988) respectively. 


$$
\begin{gathered}
\dot{\omega}_{i}=\sum_{j} v_{i j} \dot{\Omega}_{j} \\
J_{i}=\rho Y_{i} z_{i} \mu_{i} E_{x}-D_{m, i} \frac{W_{i}}{W_{m}} \frac{d X_{i}}{d x}
\end{gathered}
$$

Equation 2-1 is used to maintain mass conservation. In Cantera, this is accomplished by maintaining a constant mass flux at each grid point in a onedimensional flame. Each grid point represents a slice of the flame at a specific distance from the burner. Data expressing the state of the combustion mixture is stored at each grid point including species mass fractions and temperature.

Equation 2-2 represents the conservation of species within a combustion reaction. Molecules of a species may be created or eliminated through the use of balanced chemical reactions, but the total number of atoms of each element comprising the molecules must remain the same. As illustrated in this equation, the total mass of a given species may increase or decrease as a result of chemical reactions, given by the term on the right-hand-side of equation. The mass of species at any grid point is affected by the gas velocity, which is accounted for in first term on the left-hand-side of equation 2-2, and diffusion as shown in the second term of the same equation.

The final pre-packaged conservation equation is for the energy. Equation 2-3 accounts for movement of thermal energy within the flame due to bulk motion, thermal conduction and diffusion in the three terms on the left-hand-side, respectively. The term on the right-hand-side corresponds to heat generation through chemical reactions.

Equation 2-4 provides the production rate of each chemical species. This production rate is based on the results of all reactions which create or destroy molecules 
of each simulated species. A more in-depth description of reaction rates can be found in section 2.2.1 or in the document Defining Phases and Interfaces (Goodwin, 2003).

Equation 2-5 is used to compute the mass flux of each species at each grid point within a simulation. Two major processes are responsible for mass flux within the reaction zone, diffusion flux and electrostatic drift flux. The first process, which is given in the standard version of Cantera, involves movement of molecules through flux of species due to relative differences in gas composition. The results of the effect are computed in the second term on the right-hand-side of equation 2-5. The second source of mass flux is drift of charged species caused by an applied electric field, which was not actually included in the base version of Cantera.

\subsubsection{Modifications to Cantera}

As discussed in section 2.1, significant modification to Cantera was required in order to calculate the effects of applied electric fields and charged species. The most significant modification was the addition of one governing equation (Pederson et al., 1993).

$$
\begin{gathered}
\varepsilon_{0} \frac{d E_{x}}{d x}=\left(N_{A} e\right) \sum_{i} z_{i} \frac{\rho Y_{i}}{W_{i}} \\
E_{x}=-\frac{d \Phi}{d x}
\end{gathered}
$$

Equation 2-6 represents Gauss's Law. Using Gauss's Law allows for the electric potential to be calculated at each grid point within a modeled flame object. This equation links the total charge at each grid point to the change in electric field at each grid point. The net charge at each grid point is found in the right hand side of equation 2-6 by finding the summation of the number of each charge carriers multiplied by each carrier's 
respective charge. Also, the permittivity of a gas mix is approximated to be equivalent to that of free space. However, although the modified Cantera stores a values for $\mathrm{E}_{\mathrm{x}}$, values of $\Phi$ are used for calculations. The electric field, $E_{x}$, can be calculated from the electric potential, $\Phi$, using Equation 2-7.

\subsection{Reaction Mechanism Overview}

A Reaction Mechanism is the set of information concerning possible elements, chemical species, and chemical reactions within a combustion fluid mixture. A wide variety of reactions and species are possible during combustion, but it is not feasible to model every reaction and species perfectly. As a result, reaction mechanisms are actually subsets of the real chemical processes within a reaction zone. It is possible to produce mechanisms for certain types of conditions such as rich or lean fuel mixes and use of specific fuels by adjusting reaction rates within the mechanism to fit the desired conditions, which the authors of GRIMech 3.0 have done to improve performance in calculating lean flame composition.

Three main types of information are required for a reaction mechanism. These types of information include thermodynamic properties of each species, molecular transport properties for each species, and a list of all reactions including reactants, products, and reaction rates. These properties will be discussed in more detail in sections

\subsection{1 through 2.2.3.}

Cantera uses two file formats for reaction mechanism files. The first format is the Cantera "cti" file format. "cti" files are actually valid Python scripts, but are also meant to be fairly simple for a human operator to interpret. The second type of format used by Cantera is the "ctml" format. The "ctml" file format is a variation of the XML format, 
and it is meant to be easily parsed for use by computer. Cantera automatically generates "ctml" files from "cti" files, making direct manipulation of "ctml" files by a human operator unnecessary. As a result, the "cti" format will be used in all mechanism examples.

\subsubsection{Reactions and Rates}

Although Cantera can handle many types of reactions, only three types have been used in the reaction mechanisms assembled for this project. These types are homogeneous, three body, and falloff reactions. Because this topic is already well documented, only a short overview is provided here. More information on reactions and rates in Cantera is available in section 4.3 of the document, Defining Phases and Interfaces (Goodwin, 2003).

All three reaction types used include entries for the reaction equation. For the reaction equation, a string representing a balanced chemical equation is used. This equation string is delimited by spaces and uses the symbols "=" or " $<=>$ " for reversible reactions or "=>" for nonreversible reactions (Goodwin, 2005: Defining Phases and Interfaces).

In addition to the balanced chemical equation, all reactions must include an entry for the reaction rate coefficient. Cantera assumes all rate coefficients to be in the form of a modified Arrhenius function as illustrated in equation 2-8.

$$
k_{f}(T)=A T^{n} \exp (-E / R T)
$$

The simplest of the three types of reactions used is the homogeneous pressureindependent reaction. For this type of entry, Cantera uses the "reaction" type in the "cti" 
file, and only the equation and rate coefficients are required for a full entry as shown in Figure 2-1.

reaction( $\left." \mathrm{CH} 4+0=\mathrm{CH} 3+\mathrm{OH}^{\prime}, \quad[4.07000 \mathrm{E}+14,0,7040]\right)$

Figure 2-1: Example of “cti” File Reaction Entry

The next most common reaction type in the studied mechanisms is the three body reaction. This type of reaction involves the use of a molecule of a species which does not react in addition to the reacting species. This non-reacting species provides or absorbs energy which stabilizes the reaction. In the chemical equation for this reaction type, the third body is listed simply as ' $\mathrm{M}$ ', and the rate coefficients are still required. In addition to the required arguments, an optional string may be provided which gives the collision efficiencies for different third-body molecules. An example of the listing for this type of reaction is provided in Figure 2-2.

three_body_reaction( "H2O2 + M => OH + OH + M", [1.692E+24, - 2.00, 202.29],

Figure 2-2: Example of “cti” File Three Body Reaction Entry

The final type of reaction included is the Lindemann falloff reaction. This type of reaction differs from the previous two in that this reaction is pressure dependent. These reactions have two sets of rate coefficients, one for pressures approaching zero and one for pressures approaching infinity. Equations 2-9 and 2-10 show how these two sets of reaction rate coefficients are used to derive a rate coefficient for the reaction equation (Goodwin, 2005: Defining Phases and Interfaces). Figure 2-3 gives an example of an entry for this type of reaction within a Cantera "cti" file.

$$
P_{r}=\frac{k_{0}[M]}{k_{\infty}}
$$




$$
k_{f}\left(T, P_{r}\right)=k_{\infty}\left(\frac{P_{r}}{1+P_{r}}\right)
$$

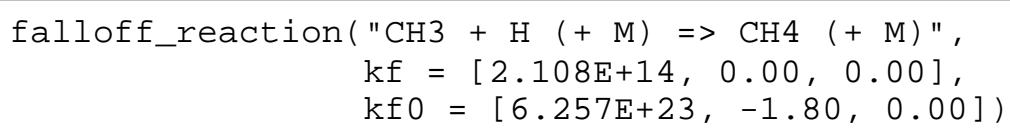

Figure 2-3: Example of Cantera “cti” File Entry for a Lindemann Falloff Reaction

\subsubsection{Thermodynamic Properties}

The thermodynamic properties of the species within a reaction mixture used by Cantera include values for specific heat, entropy and enthalpy at range of temperatures. Cantera can use a few different formats for storing the thermodynamic data. These formats include the old NASA thermodynamic polynomial format and constant specific heat format.

The old NASA thermodynamic polynomial format has been used as the preferred format because it can be used to interpolate each of the thermodynamic properties at varying temperatures within a defined range rather than performing approximations with a single set of constants. The NASA polynomial format was produced and documented by Bonnie McBride and Sanford Gordon of NASA's Glen Research Center, and detailed information can be found for this format in NASA's documentation (Gordon et al, 1994).

Rather than holding exact values for each of the thermodynamic properties, the old NASA thermodynamic polynomial format stores two sets of seven coefficients for polynomial interpolation of the thermodynamic data. Each set of seven coefficients corresponds to a interpolation in one temperature range. The valid temperature range for each polynomial must also be provided in the entry. An example of a NASA thermodynamic data entry can be seen in Figure 2-4. 


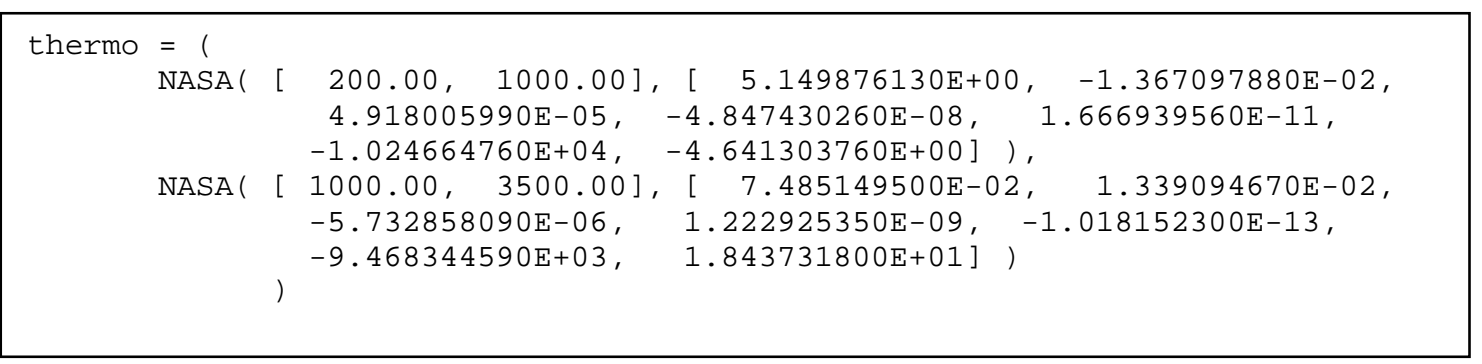

Figure 2-4: NASA polynomial entry for Methane.

In Figure 2-4, the thermo encloses two NASA polynomials, one for a high temperature range and the other for a low range. Each NASA entry contains one set of NASA polynomial constants. The temperature range for each polynomial is provided in the first grouping within square brackets in each NASA entry. The second grouping contains the seven polynomial coefficients for the entry. For example, in Figure 2-4, the temperature range for the first NASA polynomial is 200.0 to 1000.0 Kelvin, and the seven polynomial coefficients for the first temperature range are the seven numbers enclosed in square brackets following the temperature range.

The non-dimensional values for specific heat, entropy, and enthalpy for any temperature within the valid range of the polynomial can be found using the following equations (Gordon et al, 1994).

$$
\begin{gathered}
\frac{C_{p 0}}{R}=a_{1}+a_{2} T+a_{3} T^{2}+a_{4} T^{3}+a_{5} T^{4} \\
\frac{H_{0}}{R T}=a_{1}+\frac{a_{2}}{2 T}+\frac{a_{3}}{3 T^{2}}+\frac{a_{4}}{4 T^{3}}+\frac{a_{5}}{5 T^{4}}+\frac{a_{6}}{T} \\
\frac{S_{0}}{R}=a_{1} \ln (T)+a_{2} T+\frac{a_{3}}{2} T^{2}+\frac{a_{4}}{3} T^{3}+\frac{a_{5}}{4} T^{4}+a_{7}
\end{gathered}
$$

In order to convert the non-dimensional values resulting from equations 2-11 and 2-13 to the proper units simply multiply by the form of the ideal gas constant with the 
desired units. For equation 2-12, multiply by the ideal gas constant and the temperature in Kelvin to convert to the proper units.

A Python program to plot curves for the thermodynamic properties given the NASA polynomials in Chemkin format is provided in Appendix C. Figures 2-5 through 2-7 provide an example of the polynomial curves for methane as output by the previously mentioned program. This program was written with the purpose of checking NASA polynomials for possible discontinuities between temperature ranges, which could result in erroneous results and failure of the model to converge on a solution.

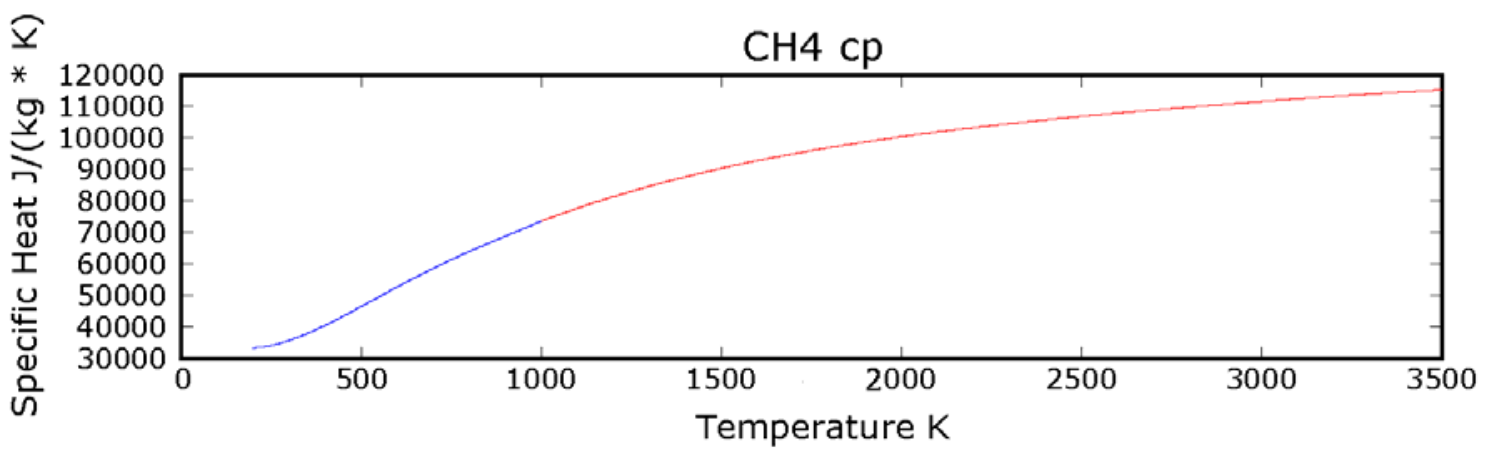

Figure 2-5: Plot of the Specific Heat of Methane Calculated from the NASA Polynomial

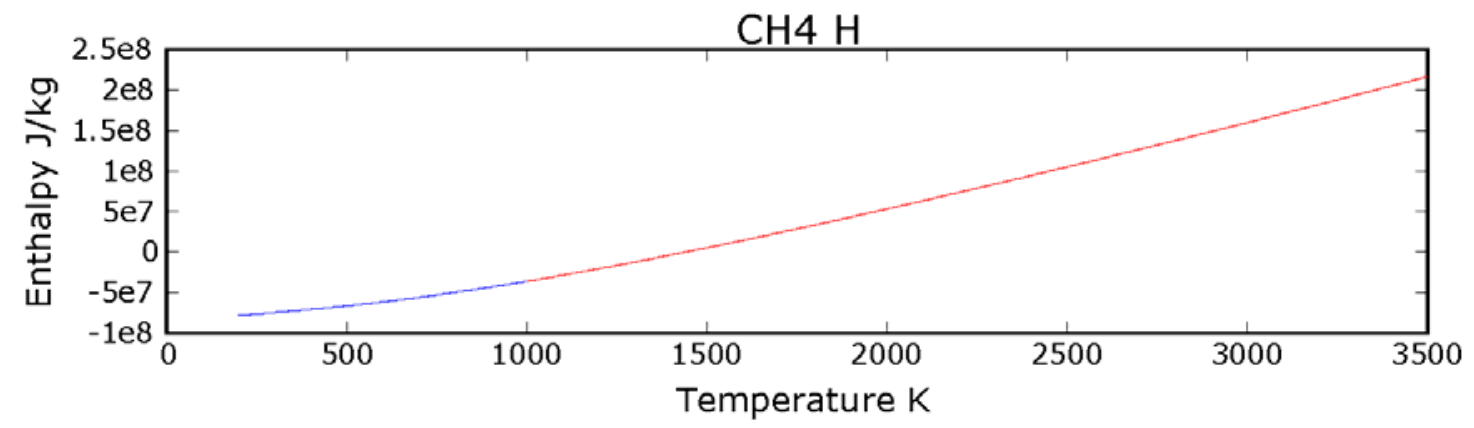

Figure 2-6: Plot of the Enthalpy of Methane Calculated from the NASA Polynomial 


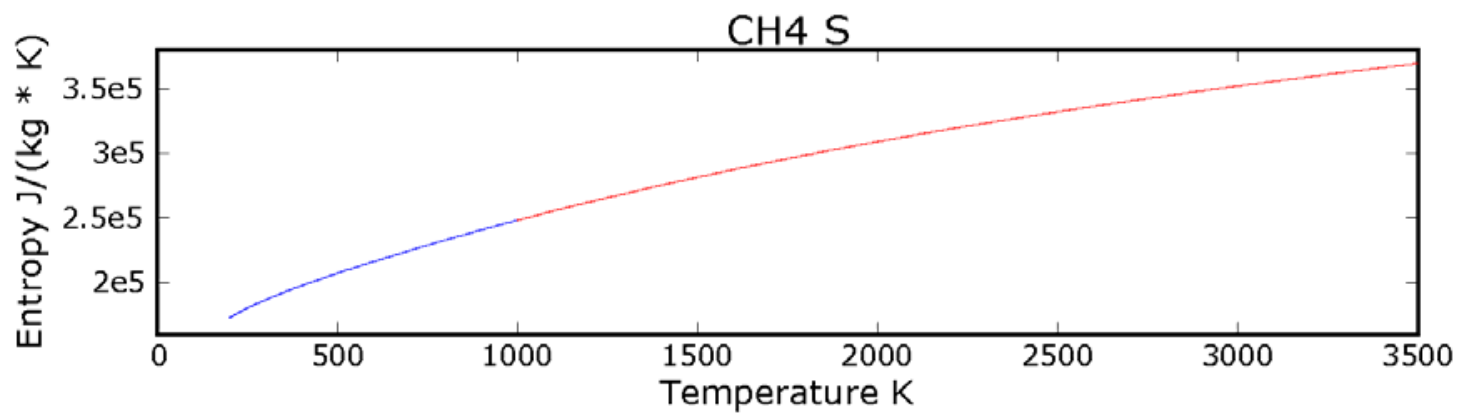

Figure 2-7: Plot of the Entropy of Methane Calculated from the NASA Polynomial

A second format used by Cantera for the thermodynamic properties is the constant specific heat format. This format allows for the use of a constant value for the specific heat of a given species, and entropy and enthalpy consistant with the constant specific heat and base values of entropy and enthalpy given at a single reference temperature using the following equations.

$$
\begin{gathered}
\frac{H_{0}(T)}{R T}=H_{0}\left(T_{0}\right)+C_{p 0}\left(T-T_{0}\right) \\
\frac{S_{0}(T)}{R}=S_{0}\left(T_{0}\right)+c_{p 0} \ln \left(T / T_{0}\right)
\end{gathered}
$$

Because the use of constants is not as accurate as the NASA polynomial format, it was only used when a NASA polynomial could not be found for a desired chemical species. Figure 2-8 shows an example of a "cti" file entry for constant thermodynamic data.

$$
\begin{aligned}
& \text { thermo }=\text { const_cp }(\mathrm{t} \odot=298.15 \text {, } \\
& \text { he }=\left(255.0,{ }^{\prime}{ }^{\mathrm{cal}} / \mathrm{mol}{ }^{\prime}\right) \text {, } \\
& \mathrm{s} \odot=\left(59.0,{ }^{\prime} \mathrm{cal} / \mathrm{K} / \mathrm{mol}{ }^{\prime}\right) \text {, } \\
& \left.\mathrm{cp} \odot=\left(14.1,{ }^{\prime} \mathrm{cal} / \mathrm{K} / \mathrm{mol}{ }^{\prime}\right)\right) \text {, }
\end{aligned}
$$

Figure 2-8: Constant thermodynamic data entry for $\mathrm{C}_{3} \mathrm{H}_{3}+$

\subsubsection{Molecular Transport Properties}

The final type of species data which Cantera uses is the molecular transport data. The purpose of the transport data is to calculate coefficients such as viscosity and species 
diffusivities which help model the effects of non-reactive species interactions. In order to calculate these properties, Cantera uses a set of at least four properties for each species. These properties include the species geometry, Lennard-Jones collision diameter, Lennard-Jones well depth, and the rotational relaxation collision number at 298 Kelvin. A more detailed entry may be used as described in figure 4.6 of the document, Defining Phases and Interfaces (Goodwin, 2003).

\subsection{Tested Published Reaction Mechanisms}

As part of this research, a sampling of published reaction mechanisms was used. These mechanisms include the Hiensohn, Jones and Becker mechanism for methane, GRI 3.0 mechanism, a mechanism by Norbert Peters, a mechanism published by Timothy Pederson and Robert C. Brown, and modified forms of the GRI 3.0 and Norbert Peters mechanisms.

\subsubsection{Hiensohn, Jones, and Becker}

The Hiensohn, Jones and Becker mechanism is a mechanism developed for the study of opposed-jet diffusion flames. The original purposes of this mechanism were to develop a model of the opposed-jet diffusion flame which possesses a good treatment of fluid flow, but also contains a realistic set of chemical reactions and transport properties, and to investigate the effect of a simplified model of an electric field upon such a flame (Jones et al., 1972).

The reason for using this mechanism for the CCADS project is that the mechanism is fairly small, and thus requires less computational time than the more extensive mechanisms making it ideal for model developement. This mechanism contains nineteen species and thirty-one reactions, which is significantly less than the 
other three mechanisms used in this research. Also, this mechanism contains a simple model for charged particle chemistry which may be added with caution to larger neutral species reaction mechanisms. The full mechanism file is provided in the Appendix B, but the included charge particle reactions are given in the chemical equations below (Jones et al., 1972).

$$
\begin{gathered}
\mathrm{CH}+\mathrm{O} \rightarrow \mathrm{HCO}^{+}+e^{-} \\
\mathrm{HCO}^{+}+\mathrm{H}_{2} \mathrm{O} \rightarrow \mathrm{CO}+\mathrm{H}_{3} \mathrm{O}^{+} \\
\mathrm{H}_{3} \mathrm{O}^{+}+e^{-} \rightarrow \mathrm{H}_{2} \mathrm{O}+\mathrm{H}
\end{gathered}
$$

In the above equations, the presence of three charged species is given. Equation 2-16 shows one possible path for the formation of electrons. Equation 2-17 shows the formation of the $\mathrm{HCO}^{+}$ion, which is used in the production of the more abundant $\mathrm{H}_{3} \mathrm{O}^{+}$ ion in equation 2-18.

\subsubsection{GRI and Modified GRI}

The GRI 3.0 mechanism is an extensive and wide ranging mechanism developed by the Gas Research Institute. Cantera includes a hard-coded version of the GRI mechanism within its source code, but a full version of this mechanism in Chemkin II format is freely available for download on the GRI Mechanism authors' webpage. The unmodified version of GRI 3.0 contains fifty-three chemical species and 325 reactions, which causes it to be computationally expensive. However, GRI 3.0 contains no charged species, and as a result, cannot be used to model charged particle generation and movement without modification. The only modification made to allow charged species chemistry was the addition of the three charged species transport and thermodynamic data plus three charged species reactions provided for the Jones, Heinsohn and Becker mechanism described in section 2.2.4 of this document. 
A full listing of the Cantera "cti" file for the modified version of the GRI 3.0 mechanism is given is Appendix B.

\subsubsection{Peters and Modified Peters}

The Peters mechanism is a mechanism designed to represent neutral species reactions within premixed methane-air flames. The unmodified version of this reaction mechanism contains thirty-one species and 107 reactions, which is more complex than the Jones, Becker and Heinsohn mechanism, but not as detailed as the GRI 3.0 mechanism. The modified version of this mechanism contains the charges species and reactions from the Jones, Becker and Heinsohn mechanism discussed in section 2.2.4 (Peters, 1992).

A full listing of the Cantera "cti" file for the modified version of the Peters mechanism is given is Appendix B.

\subsubsection{Pedersen and Brown}

The Pedersen and Brown mechanism was designed for the study of electric field effects within methane flames in order to attempt to control blowoff limits, flame speed and soot formation by the application of electric fields (Pedersen et al, 1993). The Pedersen and Brown mechanism contains eighty-five reactions and total of thirty-five chemical species including five charged species. This mechanism contains many additional charged species reactions which were not included in the three previously mentioned reaction mechanisms. These charged species reactions are given below.

$$
\begin{gathered}
\mathrm{CH}+\mathrm{O} \rightarrow \mathrm{CHO}^{+}+e^{-} \\
\mathrm{CH}{ }^{*}+\mathrm{O} \rightarrow \mathrm{CHO}^{+}+e^{-} \\
\mathrm{CHO}^{+}+\mathrm{H}_{2} \mathrm{O} \rightarrow \mathrm{H}_{3} \mathrm{O}^{+}+\mathrm{CO} \\
\mathrm{H}_{3} \mathrm{O}^{+}+\mathrm{C}_{2} \mathrm{H}_{2} \rightarrow \mathrm{C}_{2} \mathrm{H}_{3} \mathrm{O}^{+}+\mathrm{H}_{2} \\
\mathrm{CHO}^{+}+\mathrm{CH}_{2} \rightarrow \mathrm{CH}_{3}^{+}+\mathrm{CO}
\end{gathered}
$$




$$
\begin{gathered}
\mathrm{H}_{3} \mathrm{O}^{+}+\mathrm{CH}_{2} \rightarrow \mathrm{CH}_{3}^{+}+\mathrm{H}_{2} \mathrm{O} \\
\mathrm{CH}_{3}^{+}+\mathrm{C}_{2} \mathrm{H}_{2} \rightarrow \mathrm{C}_{3} \mathrm{H}_{3}^{+}+\mathrm{H}_{2} \\
\mathrm{C}_{3} \mathrm{H}_{3}^{+}+\mathrm{H}_{2} \mathrm{O} \rightarrow \mathrm{C}_{2} \mathrm{H}_{3} \mathrm{O}^{+}+\mathrm{CH}_{2} \\
\mathrm{CH}_{3}^{+}+\mathrm{CO}_{2} \rightarrow \mathrm{C}_{2} \mathrm{H}_{3} \mathrm{O}^{+}+\mathrm{O} \\
\mathrm{H}_{3} \mathrm{O}^{+}+e^{-} \rightarrow \mathrm{H}_{2} \mathrm{O}+\mathrm{H} \\
\mathrm{C}_{3} \mathrm{H}_{3}^{+}+e^{-} \rightarrow \mathrm{C}_{2} \mathrm{H}_{2}+\mathrm{CH} \\
\mathrm{CH}_{3}^{+}+e^{-} \rightarrow \mathrm{CH}_{2}+\mathrm{H}
\end{gathered}
$$

In the above equations, $\mathrm{CH}^{*}$ represents electronically excited $\mathrm{CH}$ molecules. The electronically excited $\mathrm{CH}$ molecules react 2000 times faster than non-excited $\mathrm{CH}$ molecules (Pederson and Brown, 1993). Also, equation 2-29 has been modified from the form provided by Pederson and Brown because the original document listed some of the reaction products simply as "products" rather than providing a full balanced chemical equation.

For a complete listing of the Cantera "cti" format mechanism file, see Appendix

B.

\subsection{Current Calculations}

During a simulation run, an output file to store simulation current values may be created simply by specifying a filename for the results. The file format for these types of files is given in detail in Appendix D-3. The column labeled "current" containied within

the output file is actually a current density $\left(\mathrm{A} / \mathrm{m}^{2}\right)$, but the real current (A) can be derived simply by multiplying the current density by the burner's area because this simulation represents a one-dimensional line through an axialsymetric system, resulting in uniform current density. 


\section{Chapter Three: Verification of Model}

\subsection{Existing Experimental Data}

In order to verify this modeling software, simulations were run for which experimental data already existed. The source of the experimental data for comparison was Christopher Hill's research at NETL in the first half of 2004. His research included experimental measurements of currents within both methane-air and synthesis gas-air premixed flat flames.

These experiments were conducted with the purpose of aiding the understanding of flame ionization and transport. Both methane and methane-doped synthesis gas were tested using similar experimental setups resulting in V-I curves found by taking measurements with varying applied electrical potentials across a flame. In addition, a flat flame burner was used for the experimentation, which provided for the use of a computationally simpler one-dimension model because the properties of a flat flames are the same above nearly the entire burner area.

\subsubsection{NETL Spring 2004 Flat Flame Burner Experiments}

Christopher Hill, a former intern at the Morgantown NETL location, conducted experiments on lean combustion with both methane and methane doped synthesis gas fuels. These experiments were conducted on a porous disk flat flame burner mounted on an adjustable stage control, which positioned the burner in relation to a stationary grid electrode mounted above the burner. This setup is illustrated in Figures 3-1 through 3-3. As shown if Figure 3-3, an electric field was applied through the flame by using the burner itself as a second electrode and applying an electric potential between the grid electrode and the burner. 


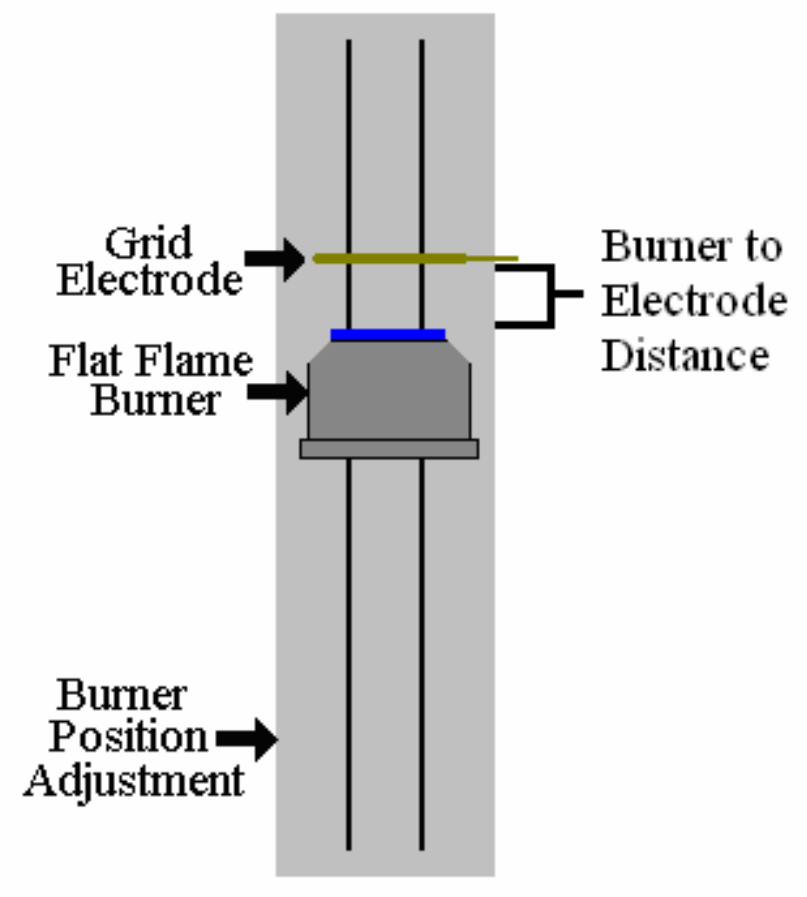

Figure 3-1: Illustration of Flat Flame Burner Mounted on an Adjustable Stage Control

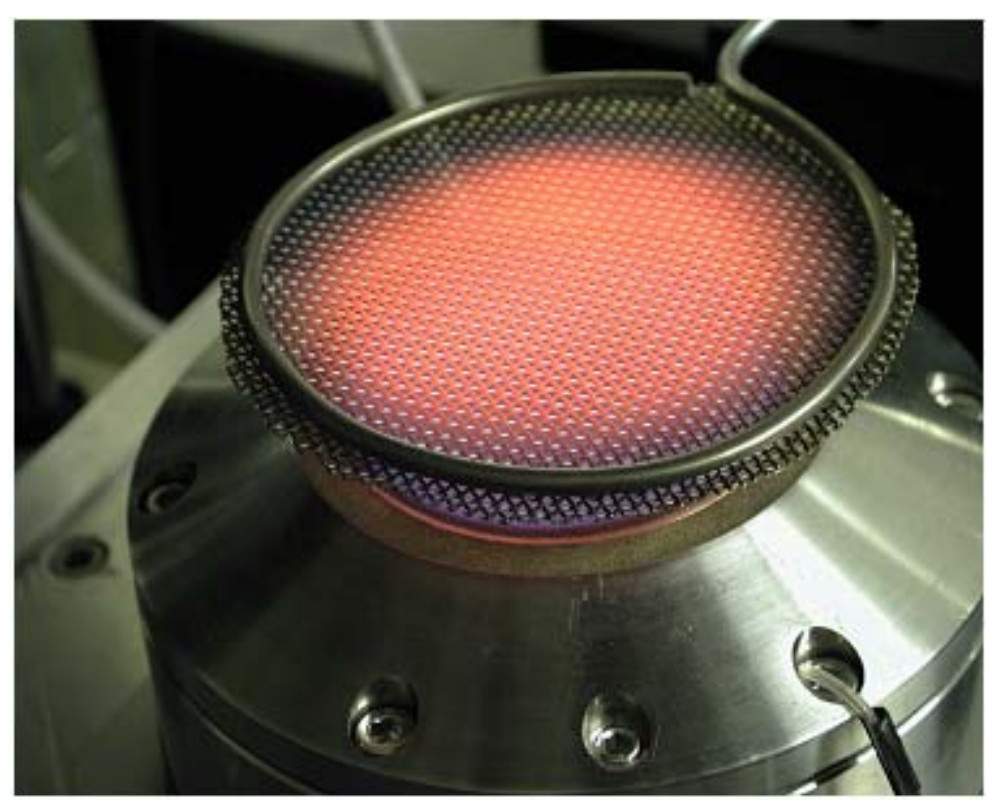

Figure 3-2: Flat Flame Burner with Grid Electrode 


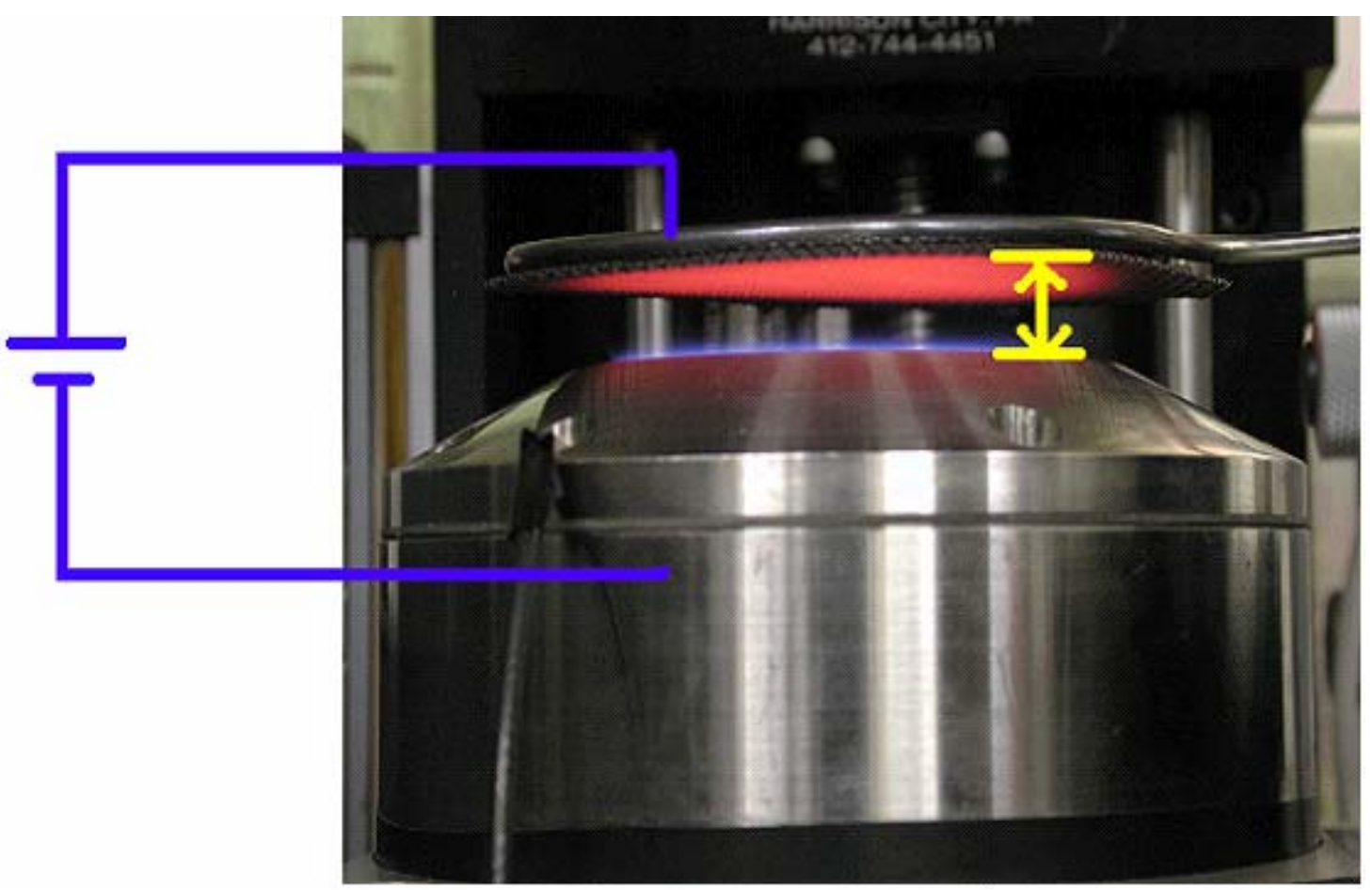

Figure 3-3: Simplified Electrical Connection for Flat Flame Burner and Grid Electrode 
Table 3-1 states the mixture conditions for Chris Hill's methane experiments.

\begin{tabular}{|c|c|c|c|c|c|}
\hline $\begin{array}{c}\text { Experiment } \\
\text { Number }\end{array}$ & $\begin{array}{c}\text { Air Flow } \\
\text { (SLPM) }\end{array}$ & $\begin{array}{c}\text { Air Flow } \\
\mathbf{( k g / s )}\end{array}$ & $\begin{array}{c}\text { Methane } \\
\text { (SLPM) }\end{array}$ & $\begin{array}{c}\text { Methane } \\
\text { (kg/s) }\end{array}$ & $\begin{array}{c}\text { Burner- } \\
\text { Electrode } \\
\text { Distance } \\
\text { (cm) }\end{array}$ \\
\hline $1-1$ & 10.00 & 0.000215483 & 1.00 & $1.19 \times 10^{-5}$ & 1.60 \\
\hline $1-2$ & 11.00 & 0.000237032 & 1.00 & $1.19 \times 10^{-5}$ & 1.60 \\
\hline $1-3$ & 12.00 & 0.00025858 & 1.00 & $1.19 \times 10^{-5}$ & 1.60 \\
\hline $1-4$ & 13.00 & 0.000280128 & 1.00 & $1.19 \times 10^{-5}$ & 1.60 \\
\hline $1-5$ & 14.00 & 0.000301677 & 1.00 & $1.19 \times 10^{-5}$ & 1.60 \\
\hline $1-6$ & 15.00 & 0.000323225 & 1.00 & $1.19 \times 10^{-5}$ & 1.60 \\
\hline $2-1$ & 10.00 & 0.000215483 & 1.00 & $1.19 \times 10^{-5}$ & 0.20 \\
\hline $2-2$ & 11.00 & 0.000237032 & 1.00 & $1.19 \times 10^{-5}$ & 0.20 \\
\hline $2-3$ & 12.00 & 0.00025858 & 1.00 & $1.19 \times 10^{-5}$ & 0.20 \\
\hline $2-4$ & 13.00 & 0.000280128 & 1.00 & $1.19 \times 10^{-5}$ & 0.20 \\
\hline $2-4$ & 14.00 & 0.000301677 & 1.00 & $1.19 \times 10^{-5}$ & 0.20 \\
\hline $2-6$ & 15.00 & 0.000323225 & 1.00 & $1.19 \times 10^{-5}$ & 0.20 \\
\hline $3-1$ & 10.00 & 0.000215483 & 1.00 & $1.19 \times 10^{-5}$ & 1.60 \\
\hline $3-2$ & 10.00 & 0.000215483 & 0.91 & $1.09 \times 10^{-5}$ & 1.60 \\
\hline $3-3$ & 10.00 & 0.000215483 & 0.83 & $9.91 \times 10^{-6}$ & 1.60 \\
\hline $3-4$ & 10.00 & 0.000215483 & 0.77 & $9.19 \times 10^{-6}$ & 1.60 \\
\hline $3-5$ & 10.00 & 0.000215483 & 0.71 & $8.47 \times 10^{-6}$ & 1.60 \\
\hline $3-6$ & 10.00 & 0.000215483 & 0.67 & $8.00 \times 10^{-6}$ & 1.60 \\
\hline & & $3-1.200$ & \\
\hline
\end{tabular}

Table 3-1: Methane Experimental Conditions

Tables 3-2 and 3-3 state the mixtures used for the synthesis gas experiments.

\begin{tabular}{|c|c|c|c|c|c|c|}
\hline Experiment & $\begin{array}{c}\text { Air } \\
\text { Flow }\end{array}$ & CO Flow & H2 Flow & CH4 Flow & N2 Flow & $\begin{array}{c}\text { Burner-Electrode } \\
\text { Distance (cm) }\end{array}$ \\
\hline 1 & 10.00 & 1.2361 & $9.99 \mathrm{E}-01$ & $4.00 \mathrm{E}-02$ & $3.95 \mathrm{E}-01$ & 2.00 \\
\hline 2 & 10.00 & 1.2361 & $9.99 \mathrm{E}-01$ & $8.00 \mathrm{E}-02$ & $3.95 \mathrm{E}-01$ & 2.00 \\
\hline 3 & 10.00 & 1.2361 & $9.99 \mathrm{E}-01$ & $1.20 \mathrm{E}-01$ & $3.95 \mathrm{E}-01$ & 2.00 \\
\hline 4 & 10.00 & 1.2361 & $9.99 \mathrm{E}-01$ & $1.40 \mathrm{E}-01$ & $3.95 \mathrm{E}-01$ & 2.00 \\
\hline 5 & 10.00 & 1.2361 & $9.99 \mathrm{E}-01$ & $1.60 \mathrm{E}-01$ & $3.95 \mathrm{E}-01$ & 2.00 \\
\hline
\end{tabular}

Table 3-2: Synthesis Gas Experimental Conditions in SLPM 


\begin{tabular}{|c|c|c|c|c|c|c|}
\hline Experiment & Air Flow & CO Flow & H2 Flow & CH4 Flow & N2 Flow & $\begin{array}{c}\text { Burner-Electrode } \\
\text { Distance (cm) }\end{array}$ \\
\hline 1 & $\begin{array}{c}1.97 \mathrm{E}- \\
04\end{array}$ & $\begin{array}{c}2.36 \mathrm{E}- \\
05\end{array}$ & $1.37 \mathrm{E}-06$ & $4.37 \mathrm{E}-07$ & $7.53 \mathrm{E}-06$ & 2.00 \\
\hline 2 & $\begin{array}{c}1.97 \mathrm{E}- \\
04\end{array}$ & $\begin{array}{c}2.36 \mathrm{E}- \\
05\end{array}$ & $1.37 \mathrm{E}-06$ & $8.74 \mathrm{E}-07$ & $7.53 \mathrm{E}-06$ & 2.00 \\
\hline 3 & $\begin{array}{c}1.97 \mathrm{E}- \\
04\end{array}$ & $\begin{array}{c}2.36 \mathrm{E}- \\
05\end{array}$ & $1.37 \mathrm{E}-06$ & $1.31 \mathrm{E}-06$ & $7.53 \mathrm{E}-06$ & 2.00 \\
\hline 4 & $\begin{array}{c}1.97 \mathrm{E}- \\
04\end{array}$ & $\begin{array}{c}2.36 \mathrm{E}- \\
05\end{array}$ & $1.37 \mathrm{E}-06$ & $1.53 \mathrm{E}-06$ & $7.53 \mathrm{E}-06$ & 2.00 \\
\hline 5 & $\begin{array}{c}1.97 \mathrm{E}- \\
04\end{array}$ & $\begin{array}{c}2.36 \mathrm{E}- \\
05\end{array}$ & $1.37 \mathrm{E}-06$ & $1.75 \mathrm{E}-06$ & $7.53 \mathrm{E}-06$ & 2.00 \\
\hline
\end{tabular}

Table 3-3: Synthesis Gas Experimental Conditions in kg/s

Figures 3-4 through 3-7 are plots that show the results of Christopher Hill's experiments. These results will be compared with the simulation results in Chapter 4 of this document. Tables 3-4 and 3-5 show slopes and values of the experimental current curve up to ninety percent of the maximum current. 


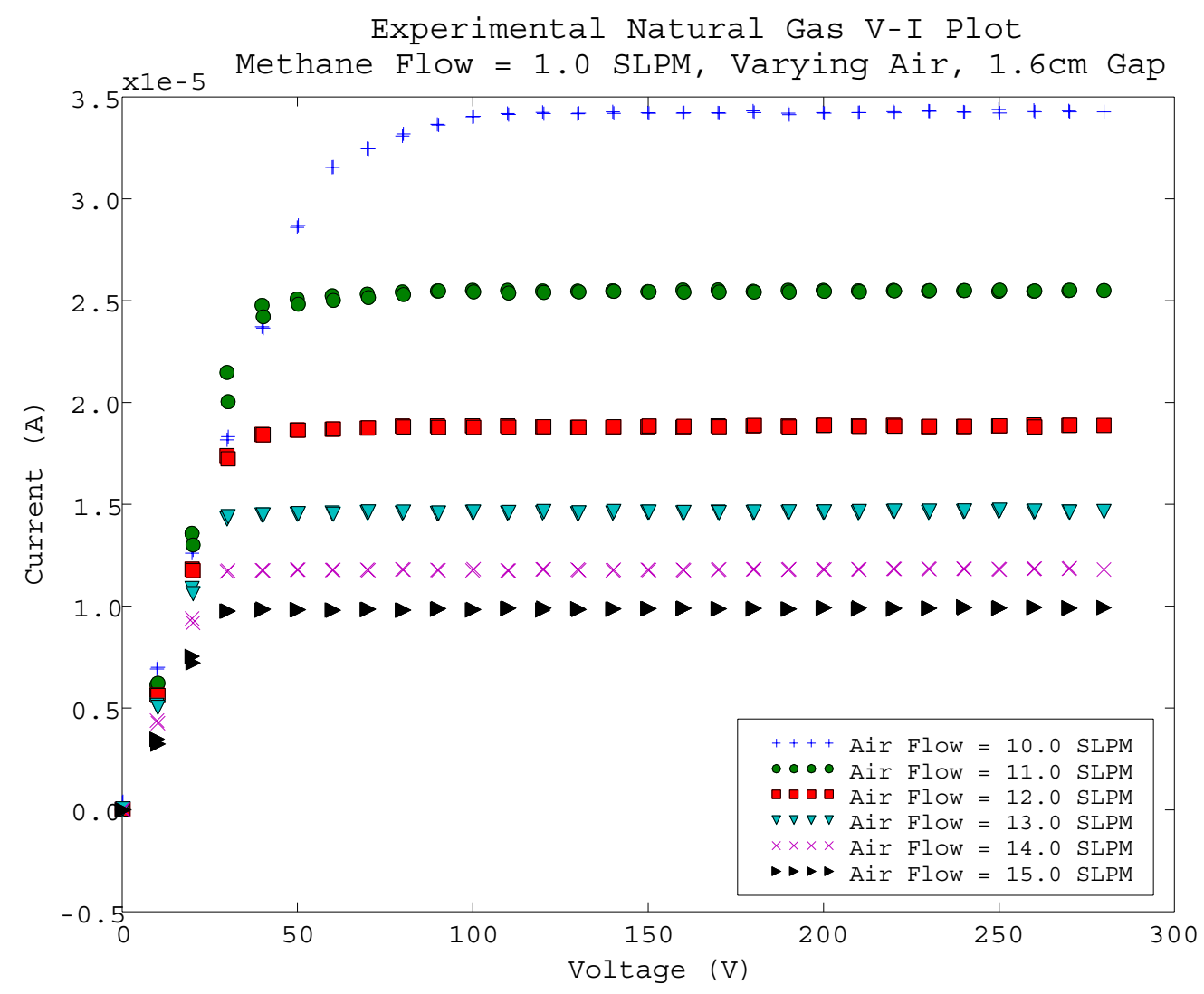

Figure 3-4: Experimental Methane Data with Constant Air Flow and Forward Voltage 


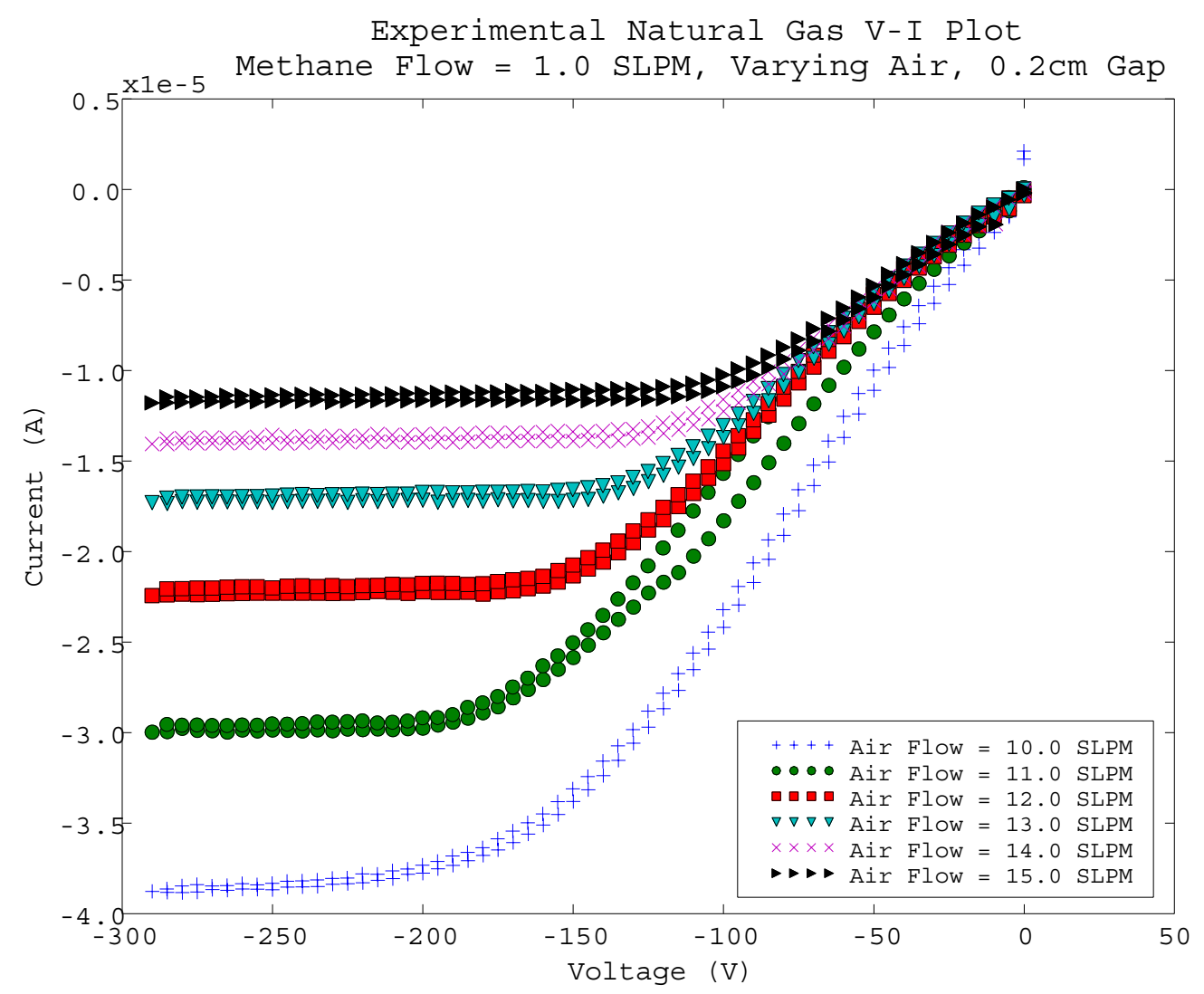

Figure 3-5: Experimental Methane Data with Constant Air Flow and Negative Voltage 
Experimental Natural Gas V-I Plot

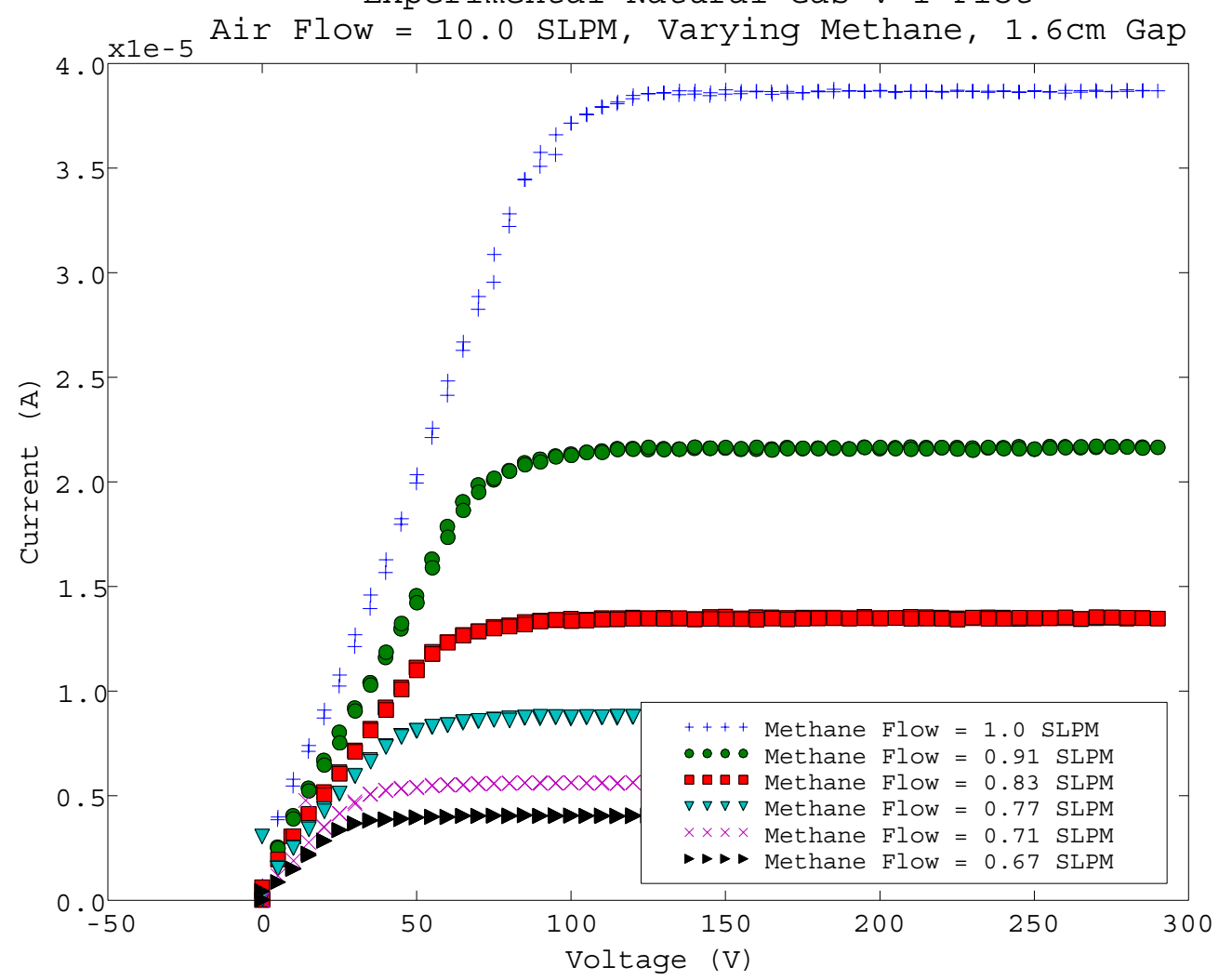

Figure 3-6: Experimental Methane Data with Constant Methane Flow and Forward Voltage 


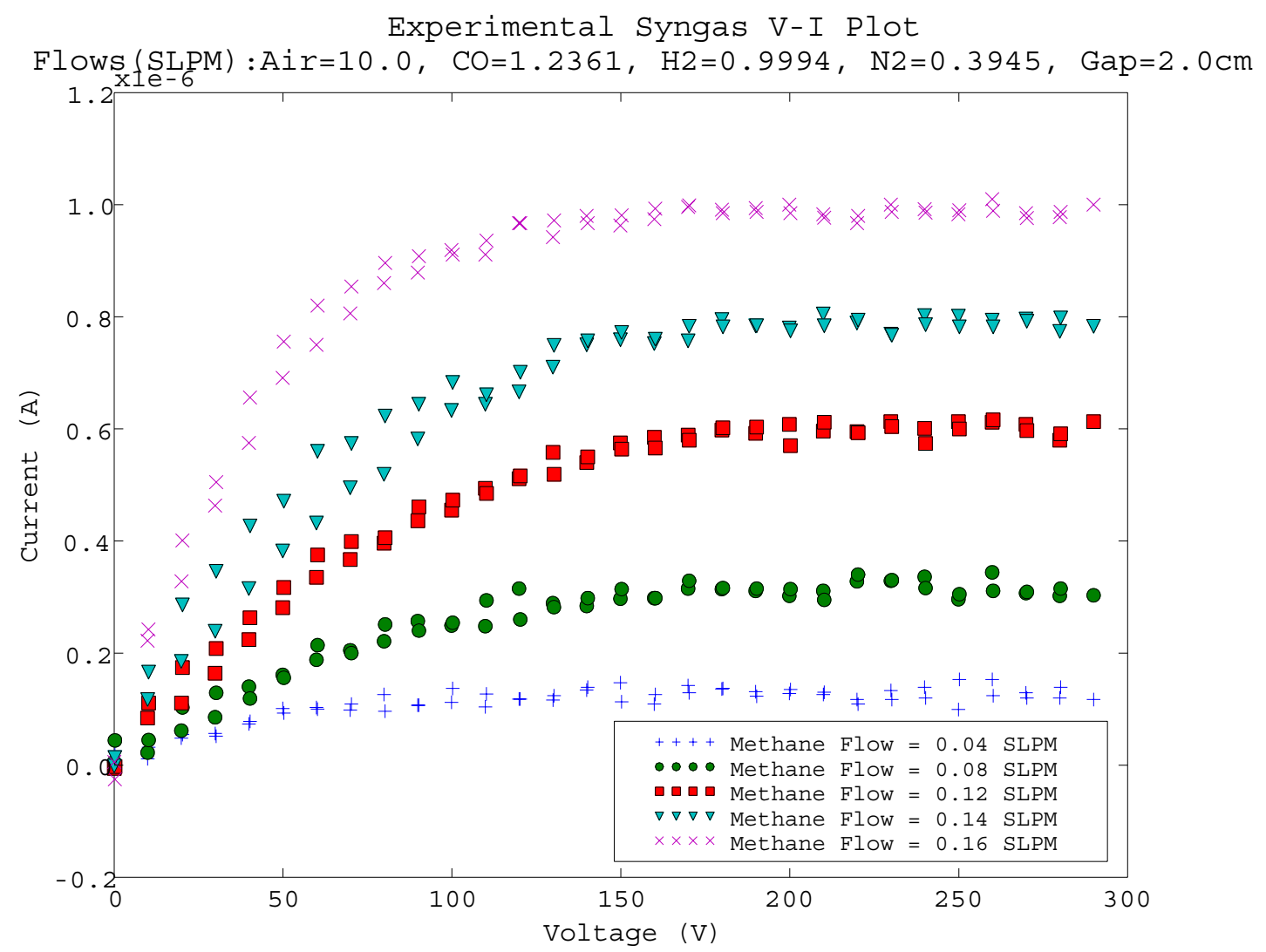

Figure 3-7: Experimental Synthesis Gas Data with Varying Methane Concentrations Added 


\begin{tabular}{|c|c|c|c|}
\hline \multirow{2}{*}{$\begin{array}{c}\text { Experiment } \\
\text { Number }\end{array}$} & \multicolumn{3}{|c|}{$\begin{array}{c}\text { Experimental Methane Combustion V-I Curve } \\
\text { Characteristics to 90\% of Peak Current }\end{array}$} \\
\cline { 2 - 4 } & Slope & Current & Voltage \\
\hline $1-1$ & $5.2152 \mathrm{e}-007$ & $3.1549 \mathrm{e}-005$ & 59.876 \\
\hline $1-2$ & $6.2169 \mathrm{e}-007$ & $2.4767 \mathrm{e}-005$ & 39.878 \\
\hline $1-3$ & $5.8133 \mathrm{e}-007$ & $1.7386 \mathrm{e}-005$ & 29.894 \\
\hline $1-4$ & $4.7797 \mathrm{e}-007$ & $1.4281 \mathrm{e}-005$ & 29.894 \\
\hline $1-5$ & $3.9118 \mathrm{e}-007$ & $1.1692 \mathrm{e}-005$ & 29.894 \\
\hline $1-6$ & $3.2688 \mathrm{e}-007$ & $9.7458 \mathrm{e}-006$ & 29.894 \\
\hline $2-1$ & $2.301 \mathrm{e}-007$ & $-3.511 \mathrm{e}-005$ & -159.96 \\
\hline $2-2$ & $1.6769 \mathrm{e}-007$ & $-2.7077 \mathrm{e}-005$ & -159.95 \\
\hline $2-3$ & $1.4466 \mathrm{e}-007$ & $-2.058 \mathrm{e}-005$ & -139.95 \\
\hline $2-4$ & $1.287 \mathrm{e}-007$ & $-1.5781 \mathrm{e}-005$ & -119.95 \\
\hline $2-5$ & $1.1904 \mathrm{e}-007$ & $-1.2695 \mathrm{e}-005$ & -104.95 \\
\hline $2-6$ & $1.071 \mathrm{e}-007$ & $-1.0889 \mathrm{e}-005$ & -99.949 \\
\hline $3-1$ & $3.8242 \mathrm{e}-007$ & $3.5078 \mathrm{e}-005$ & 89.953 \\
\hline $3-2$ & $2.8371 \mathrm{e}-007$ & $1.9859 \mathrm{e}-005$ & 69.943 \\
\hline $3-3$ & $1.9529 \mathrm{e}-007$ & $1.2334 \mathrm{e}-005$ & 59.947 \\
\hline $3-4$ & $1.0109 \mathrm{e}-007$ & $8.102 \mathrm{e}-006$ & 49.945 \\
\hline $3-5$ & $1.3053 \mathrm{e}-007$ & $5.2605 \mathrm{e}-006$ & 39.949 \\
\hline $3-6$ & $1.0804 \mathrm{e}-007$ & $3.7985 \mathrm{e}-006$ & 34.946 \\
\hline
\end{tabular}

Table 3-4: Experimental Methane Combustion V-I Curve Characteristics to 90\% of the Maximum Current

\begin{tabular}{|c|c|c|c|}
\hline \multirow{2}{*}{$\begin{array}{c}\text { Run } \\
\text { Number }\end{array}$} & \multicolumn{3}{|c|}{$\begin{array}{c}\text { Experimental Synthesis Gas Combustion V-I Curve } \\
\text { Characteristics to 90\% of Peak Current }\end{array}$} \\
\cline { 2 - 4 } & Slope & Current & Voltage \\
\hline 1 & $9.99 \mathrm{E}-10$ & $1.39 \mathrm{E}-07$ & 140.18 \\
\hline 2 & $2.58 \mathrm{E}-09$ & $3.15 \mathrm{E}-07$ & 119.85 \\
\hline 3 & $4.34 \mathrm{E}-09$ & $5.58 \mathrm{E}-07$ & 129.85 \\
\hline 4 & $5.77 \mathrm{E}-09$ & $7.49 \mathrm{E}-07$ & 130.19 \\
\hline 5 & $9.15 \mathrm{E}-09$ & $9.19 \mathrm{E}-07$ & 99.866 \\
\hline
\end{tabular}

Table 3-5: Experimental Synthesis Gas Combustion V-I Curve Characteristics to $\mathbf{9 0 \%}$ of the

\subsection{Mechanism Refinement Study}

\section{Maximum Current}

The mechanism refinement study performed as part of this research has been conducted by performing simulations using a variety of published reaction mechanisms, and comparing simulation results with the experimental data obtained at NETL. Each of the mechanisms used for this research is discussed in Chapter 2, and a full listing of the Cantera "cti" format mechanism files appear in Appendix B. 
Each mechanism was chosen based on certain characteristics such as mechanism size and amount of previous use. The Jones, Becker and Heinsohn mechanism was used because it provides built-in support for charged species interactions and its small size, which allows for expedited computation. The Pederson and Brown mechanism is an intermediate-sized reaction mechanism with a more extensive set of charged species than the Jones, Becker and Heinsohn mechanism. The original form of the Peters mechanism included only charge neutral species, but included comprehensive documentation of the purpose of each set of reactions for combustion simulation. GRI Mechanism 3.0 has been included because it is a commonly-used and well-refined mechanism for combustion simulation, but its large size generally results in significantly longer simulation times than with the smaller Jones, Becker, and Heinsohn mechanism. By running each mechanism and comparing the results with the experimental results given in Section 3.1, it is possible to determine how well each mechanism performs in calculating electrical current within a flat flame. In addition, some potential problems with each mechanism can be observed using species mass or mole fractions which have not been recorded for the experimental flames, but are calculated in the simulated flame objects. 


\section{Chapter Four: Comparison of Experimental and Simulation Results}

\subsection{Methane Models}

This section will give a comparison of the methane simulations with the experimental data explained in Chapter Three of this document. For the methane combustion simulation, four different reaction mechanisms were used:

1) GRI with Jones, Becker and Heinsohn charged species chemistry

2) Jones, Becker and Heinsohn

3) Pederson and Brown

4) Norbert Peters with Jones, Becker and Heinsohn charged species chemistry

All four of these reaction mechanisms are discussed in Chapter Two, and the full listings of the Cantera 'cti' files for each mechanism are given in Appendix B.

In addition to the use of multiple reaction mechanisms, three different constant electron mobilities were used with each reaction mechanism. These electron mobilities were $0.36,0.4$, and $0.44 \mathrm{~m}^{2} / V_{s}$. These mobilities were selected by using the value of 0.4 $\mathrm{m}^{2} / \mathrm{Vs}_{\mathrm{s}}$ as the default electron mobility within the gas mixture as stated by Goodings et al. in "Current-Voltage Characteristics in a Flame Plasma", and taking testing at $\pm 10 \%$ of this base value.

For this research, two properties of the V-I profiles were of prime importance. These properties include the slope of the curve from zero volts and continuing until the peak current level is approached. This slope equals the conductivity of the simulated flame. The second important feature is the peak current level, which is known as the saturation current. Both of these properties are illustrated in the following figure. 


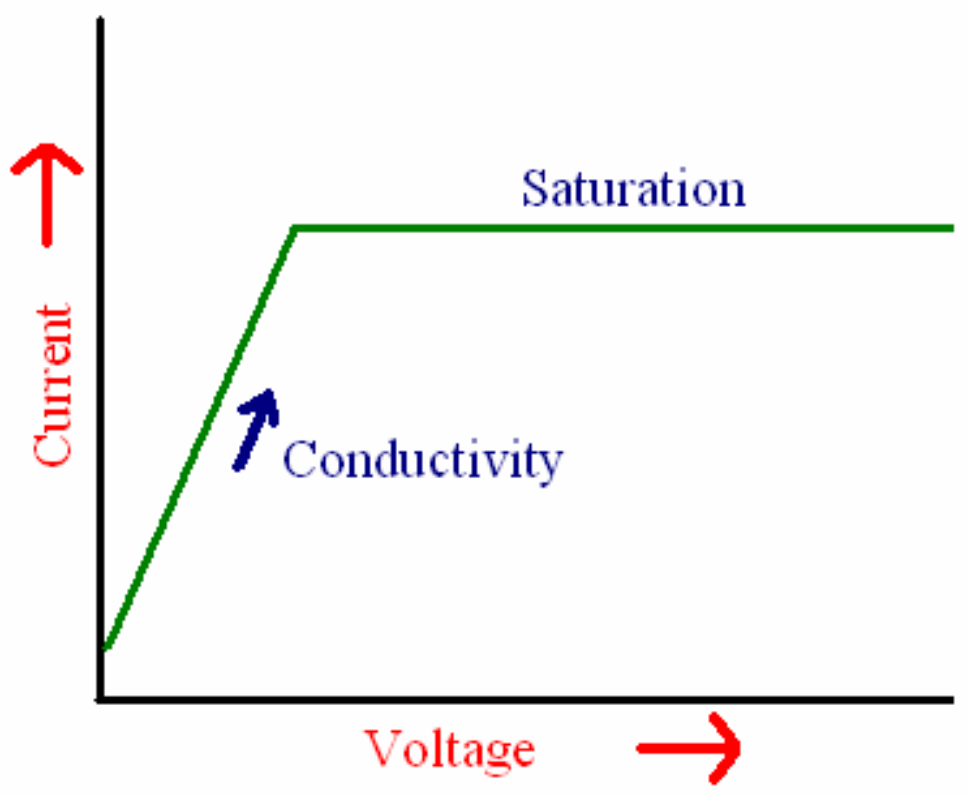

Figure 4-1: Simple Diagram of Saturation Current and Conductivity

The above figure also corresponds to the type of V-I curve generated in semiconductors using, in which carrier velocity increases until a maximum or saturation velocity is reached. This property for semiconductors is illustrated in Equation 1-3.

For the methane combustion experiments, experiment one represents increasing air with a forward bias. Experiment two is increasing air with a reverse bias, and experiment three is decreasing methane with a forward bias. In all three experiments, either air or methane is held constant. 


\subsubsection{GRI Mech 3.0}

The modified GRIMech 3.0 was one of the two best mechanisms used in this research for predicting electrical characteristics of a burning natural gas flame. In addition, it is a highly researched, widely used mechanism for varying types of fossil fuel combustion, and as a result, tends to predict bulk properties of the flames such as flame position and temperature fairly well.

A brief check of the V-I curve plots in Appendix E show that overall, the prediction of the saturation currents, although not perfect, was fairly close in many cases. One notable feature in the V-I curves is that for the higher equivalence ratio tests, the saturation current is in very good agreement with the experimental results, but as the equivalence ratio is lowered, this mechanism has a tendancy to underpredict the saturation

However, the conductivity, illustrated by the V-I curve slopes, overpredicts the experimental measurements with all three of the tested mobility values. The error in conductivity decreases with the electron mobility, which indicates that a lower value for the mobility may lead to significantly better results. The reasonable predictions of saturation current coupled with the high predictions for conductivity result in the saturation current being reached at much lower voltages than shown in the experimental results.

The following tables show key properties of the V-I curve up to $90 \%$ of the saturation current for each of three tested mobility values. 


\begin{tabular}{|c|c|c|c|c|c|c|}
\hline \multirow{3}{*}{$\begin{array}{c}\text { Experiment } \\
\text { Number }\end{array}$} & \multicolumn{6}{|c|}{$\begin{array}{l}\text { GRIMech 3.0 Methane Combustion Curve Characteristics to 90\% of } \\
\text { Peak Current with Mobility }=0.36 \mathrm{~m}^{2} / \mathrm{Vs}\end{array}$} \\
\hline & \multicolumn{2}{|c|}{ Slope } & \multicolumn{2}{|c|}{ Current } & \multicolumn{2}{|c|}{ Voltage } \\
\hline & Modeled & Difference & Modeled & Difference & Modeled & Difference \\
\hline $1-1$ & $5.8420 \mathrm{E}-07$ & $6.2680 \mathrm{E}-08$ & $3.4372 \mathrm{E}-05$ & $2.8230 \mathrm{E}-06$ & 56 & -3.876 \\
\hline $1-2$ & $6.3416 \mathrm{E}-07$ & $1.2470 \mathrm{E}-08$ & $2.0473 \mathrm{E}-05$ & $-4.2940 \mathrm{E}-06$ & 30 & -9.878 \\
\hline $1-3$ & 7.4579E-07 & $1.6446 \mathrm{E}-07$ & $1.3252 \mathrm{E}-05$ & $-4.1340 \mathrm{E}-06$ & 16 & -13.894 \\
\hline $1-4$ & $7.3492 \mathrm{E}-07$ & $2.5695 \mathrm{E}-07$ & $9.2683 \mathrm{E}-06$ & $-5.0127 \mathrm{E}-06$ & 11 & -18.894 \\
\hline $1-5$ & $6.6715 \mathrm{E}-07$ & $2.7597 \mathrm{E}-07$ & $7.1708 \mathrm{E}-06$ & $-4.5212 \mathrm{E}-06$ & 9 & -20.894 \\
\hline $1-6$ & $5.6255 \mathrm{E}-07$ & $2.3567 \mathrm{E}-07$ & $5.5646 \mathrm{E}-06$ & $-4.1812 \mathrm{E}-06$ & 8 & -21.894 \\
\hline $2-1$ & $1.9075 \mathrm{E}-06$ & $1.6774 \mathrm{E}-06$ & $\begin{array}{c}-3.6781 \mathrm{E}- \\
05 \\
\end{array}$ & $-1.6710 \mathrm{E}-06$ & -23 & 136.96 \\
\hline $2-2$ & $1.4851 \mathrm{E}-06$ & $1.3174 \mathrm{E}-06$ & $\begin{array}{c}-2.1396 \mathrm{E}- \\
05\end{array}$ & $5.6810 \mathrm{E}-06$ & -18 & 141.95 \\
\hline $2-3$ & $1.2513 \mathrm{E}-06$ & $1.1066 \mathrm{E}-06$ & $\begin{array}{c}-1.3578 \mathrm{E}- \\
05 \\
\end{array}$ & $7.0020 \mathrm{E}-06$ & -14 & 125.95 \\
\hline $2-4$ & $1.1210 \mathrm{E}-06$ & $9.9230 \mathrm{E}-07$ & $\begin{array}{c}-9.3950 \mathrm{E}- \\
06\end{array}$ & $6.3860 \mathrm{E}-06$ & -11 & 108.95 \\
\hline $2-5$ & $1.0306 \mathrm{E}-06$ & $9.1156 \mathrm{E}-07$ & $\begin{array}{c}-7.0619 \mathrm{E}- \\
06\end{array}$ & $5.6331 \mathrm{E}-06$ & -9 & 95.95 \\
\hline $2-6$ & $9.2959 \mathrm{E}-07$ & $8.2249 \mathrm{E}-07$ & $\begin{array}{c}-5.7668 \mathrm{E}- \\
06 \\
\end{array}$ & $5.1222 \mathrm{E}-06$ & -8 & 91.949 \\
\hline $3-1$ & $5.8420 \mathrm{E}-07$ & $2.0178 \mathrm{E}-07$ & $3.4372 \mathrm{E}-05$ & $-7.0600 \mathrm{E}-07$ & 56 & -33.953 \\
\hline $3-2$ & $6.0448 \mathrm{E}-07$ & $3.2077 \mathrm{E}-07$ & $1.6395 \mathrm{E}-05$ & $-3.4640 \mathrm{E}-06$ & 25 & -44.943 \\
\hline $3-3$ & $5.9640 \mathrm{E}-07$ & 4.0111E-07 & $8.1473 \mathrm{E}-06$ & $-4.1867 \mathrm{E}-06$ & 12 & -47.947 \\
\hline $3-4$ & $4.8862 \mathrm{E}-07$ & $3.8753 \mathrm{E}-07$ & $4.6745 \mathrm{E}-06$ & $-3.4275 \mathrm{E}-06$ & 8 & -41.945 \\
\hline $3-5$ & $3.1236 \mathrm{E}-07$ & $1.8183 \mathrm{E}-07$ & $2.7262 \mathrm{E}-06$ & $-2.5343 \mathrm{E}-06$ & 7 & -32.949 \\
\hline $3-6$ & $2.3066 \mathrm{E}-07$ & $1.2262 \mathrm{E}-07$ & $1.8354 \mathrm{E}-06$ & $-1.9631 \mathrm{E}-06$ & 6 & -28.946 \\
\hline
\end{tabular}

Table 4-1: V-I Curve Characteristics to $90 \%$ of Maximum Current Using GRIMech 3.0 with Electron Mobility of $0.36 \mathrm{~m}^{2} / \mathrm{Vs}$ 


\begin{tabular}{|c|c|c|c|c|c|c|}
\hline \multirow{3}{*}{$\begin{array}{c}\text { Experiment } \\
\text { Number }\end{array}$} & \multicolumn{6}{|c|}{$\begin{array}{c}\text { GRIMech 3.0 Methane Combustion V-I Curve Characteristics to } 90 \% \\
\text { of Peak Current with Mobility }=0.40 \mathrm{~m}^{2} / \mathrm{Vs}\end{array}$} \\
\hline & \multicolumn{2}{|c|}{ Slope } & \multicolumn{2}{|c|}{ Current } & \multicolumn{2}{|c|}{ Voltage } \\
\hline & Modeled & Difference & Modeled & Difference & Modeled & Difference \\
\hline $1-1$ & $6.3966 \mathrm{E}-07$ & $1.1814 \mathrm{E}-07$ & $3.4428 \mathrm{E}-05$ & $2.8790 \mathrm{E}-06$ & 51 & -8.876 \\
\hline $1-2$ & $7.2509 \mathrm{E}-07$ & $1.0340 \mathrm{E}-07$ & $2.0427 \mathrm{E}-05$ & $-4.3400 \mathrm{E}-06$ & 26 & -13.878 \\
\hline $1-3$ & $8.4554 \mathrm{E}-07$ & $2.6421 \mathrm{E}-07$ & $1.3249 \mathrm{E}-05$ & $-4.1370 \mathrm{E}-06$ & 14 & -15.894 \\
\hline $1-4$ & $8.0666 \mathrm{E}-07$ & $3.2869 \mathrm{E}-07$ & $9.3561 \mathrm{E}-06$ & $-4.9249 \mathrm{E}-06$ & 10 & -19.894 \\
\hline $1-5$ & $7.1039 \mathrm{E}-07$ & $3.1921 \mathrm{E}-07$ & $6.9446 \mathrm{E}-06$ & $-4.7474 \mathrm{E}-06$ & 8 & -21.894 \\
\hline $1-6$ & $5.5937 \mathrm{E}-07$ & $2.3249 \mathrm{E}-07$ & $5.6134 \mathrm{E}-06$ & $-4.1324 \mathrm{E}-06$ & 8 & -21.894 \\
\hline 2-1 & $1.9104 \mathrm{E}-06$ & $1.6803 \mathrm{E}-06$ & $\begin{array}{c}-3.6770 \mathrm{E}- \\
05 \\
\end{array}$ & $-1.6600 \mathrm{E}-06$ & -23 & 136.96 \\
\hline $2-2$ & $1.4878 \mathrm{E}-06$ & $1.3201 \mathrm{E}-06$ & $\begin{array}{c}-2.1388 \mathrm{E}- \\
05\end{array}$ & $5.6890 \mathrm{E}-06$ & -18 & 141.95 \\
\hline $2-3$ & $1.2532 \mathrm{E}-06$ & $1.1085 \mathrm{E}-06$ & $\begin{array}{c}-1.3571 \mathrm{E}- \\
05\end{array}$ & $7.0090 \mathrm{E}-06$ & -14 & 125.95 \\
\hline $2-4$ & $1.1224 \mathrm{E}-06$ & $9.9370 \mathrm{E}-07$ & $\begin{array}{c}-9.3891 \mathrm{E}- \\
06\end{array}$ & $6.3919 \mathrm{E}-06$ & -11 & 108.95 \\
\hline $2-5$ & $1.0327 \mathrm{E}-06$ & $9.1366 \mathrm{E}-07$ & $\begin{array}{c}-7.0585 \mathrm{E}- \\
06\end{array}$ & $5.6365 \mathrm{E}-06$ & -9 & 95.95 \\
\hline $2-6$ & $9.3177 \mathrm{E}-07$ & $8.2467 \mathrm{E}-07$ & $\begin{array}{c}-5.7643 \mathrm{E}- \\
06 \\
\end{array}$ & $5.1247 \mathrm{E}-06$ & -8 & 91.949 \\
\hline $3-1$ & $6.3966 \mathrm{E}-07$ & $2.5724 \mathrm{E}-07$ & $3.4428 \mathrm{E}-05$ & $-6.5000 \mathrm{E}-07$ & 51 & -38.953 \\
\hline $3-2$ & $6.8154 \mathrm{E}-07$ & 3.9783E-07 & $1.6388 \mathrm{E}-05$ & $-3.4710 \mathrm{E}-06$ & 22 & -47.943 \\
\hline $3-3$ & $6.4571 \mathrm{E}-07$ & $4.5042 \mathrm{E}-07$ & $8.1736 \mathrm{E}-06$ & $-4.1604 \mathrm{E}-06$ & 11 & -48.947 \\
\hline $3-4$ & $4.8809 \mathrm{E}-07$ & $3.8700 \mathrm{E}-07$ & $4.7265 \mathrm{E}-06$ & $-3.3755 \mathrm{E}-06$ & 8 & -41.945 \\
\hline $3-5$ & $3.3892 \mathrm{E}-07$ & $2.0839 \mathrm{E}-07$ & $2.6077 \mathrm{E}-06$ & $-2.6528 \mathrm{E}-06$ & 6 & -33.949 \\
\hline $3-6$ & $2.2735 \mathrm{E}-07$ & $1.1931 \mathrm{E}-07$ & $1.8452 \mathrm{E}-06$ & $-1.9533 \mathrm{E}-06$ & 6 & -28.946 \\
\hline
\end{tabular}

Table 4-2: V-I Curve Characteristics to $90 \%$ of Maximum Current Using GRIMech 3.0 with Electron Mobility of $0.40 \mathrm{~m}^{2} / \mathrm{Vs}$ 


\begin{tabular}{|c|c|c|c|c|c|c|}
\hline \multirow{3}{*}{$\begin{array}{c}\text { Experiment } \\
\text { Number }\end{array}$} & \multicolumn{6}{|c|}{$\begin{array}{c}\text { GRIMech 3.0 Methane Combustion V-I Curve Characteristics to } 90 \% \\
\text { of Peak Current with Mobility }=0.44 \mathrm{~m}^{2} / \mathrm{Vs}\end{array}$} \\
\hline & \multicolumn{2}{|c|}{ Slope } & \multicolumn{2}{|c|}{ Current } & \multicolumn{2}{|c|}{ Voltage } \\
\hline & Modeled & Difference & Modeled & Difference & Modeled & Difference \\
\hline $1-1$ & $7.0403 \mathrm{E}-07$ & $1.8251 \mathrm{E}-07$ & $3.4334 \mathrm{E}-05$ & $2.7850 \mathrm{E}-06$ & 46 & -13.876 \\
\hline $1-2$ & $8.1438 \mathrm{E}-07$ & $1.9269 \mathrm{E}-07$ & $2.0399 \mathrm{E}-05$ & $-4.3680 \mathrm{E}-06$ & 23 & -16.878 \\
\hline $1-3$ & $9.1012 \mathrm{E}-07$ & $3.2879 \mathrm{E}-07$ & $1.3348 \mathrm{E}-05$ & $-4.0380 \mathrm{E}-06$ & 13 & -16.894 \\
\hline $1-4$ & $8.7213 \mathrm{E}-07$ & $3.9416 \mathrm{E}-07$ & $9.2309 \mathrm{E}-06$ & $-5.0501 \mathrm{E}-06$ & 9 & -20.894 \\
\hline $1-5$ & $7.0818 \mathrm{E}-07$ & $3.1700 \mathrm{E}-07$ & 7.0059E-06 & $-4.6861 \mathrm{E}-06$ & 8 & -21.894 \\
\hline $1-6$ & $5.5641 \mathrm{E}-07$ & $2.2953 \mathrm{E}-07$ & $5.6528 \mathrm{E}-06$ & $-4.0930 \mathrm{E}-06$ & 8 & -21.894 \\
\hline 2-1 & $1.9108 \mathrm{E}-06$ & $1.6807 \mathrm{E}-06$ & $\begin{array}{c}-3.6744 \mathrm{E}- \\
05\end{array}$ & $-1.6340 \mathrm{E}-06$ & -23 & 136.96 \\
\hline $2-2$ & $1.4902 \mathrm{E}-06$ & $1.3225 \mathrm{E}-06$ & $\begin{array}{c}-2.1383 \mathrm{E}- \\
05\end{array}$ & $5.6940 \mathrm{E}-06$ & -18 & 141.95 \\
\hline $2-3$ & $1.2555 \mathrm{E}-06$ & $1.1108 \mathrm{E}-06$ & $\begin{array}{c}-1.3567 \mathrm{E}- \\
05\end{array}$ & $7.0130 \mathrm{E}-06$ & -14 & 125.95 \\
\hline $2-4$ & $1.1245 \mathrm{E}-06$ & $9.9580 \mathrm{E}-07$ & $\begin{array}{c}-9.3855 \mathrm{E}- \\
06\end{array}$ & $6.3955 \mathrm{E}-06$ & -11 & 108.95 \\
\hline $2-5$ & $1.0345 \mathrm{E}-06$ & $9.1546 \mathrm{E}-07$ & $\begin{array}{c}-7.0556 \mathrm{E}- \\
06\end{array}$ & 5.6394E-06 & -9 & 95.95 \\
\hline $2-6$ & $9.3337 \mathrm{E}-07$ & $8.2627 \mathrm{E}-07$ & $\begin{array}{c}-5.7621 \mathrm{E}- \\
06\end{array}$ & $5.1269 \mathrm{E}-06$ & -8 & 91.949 \\
\hline $3-1$ & 7.0403E-07 & $3.2161 \mathrm{E}-07$ & $3.4334 \mathrm{E}-05$ & $-7.4400 \mathrm{E}-07$ & 46 & -43.953 \\
\hline $3-2$ & $7.5136 \mathrm{E}-07$ & $4.6765 \mathrm{E}-07$ & $1.6528 \mathrm{E}-05$ & $-3.3310 \mathrm{E}-06$ & 20 & -49.943 \\
\hline $3-3$ & $6.9711 \mathrm{E}-07$ & $5.0182 \mathrm{E}-07$ & $8.1183 \mathrm{E}-06$ & $-4.2157 \mathrm{E}-06$ & 10 & -49.947 \\
\hline $3-4$ & $4.8657 \mathrm{E}-07$ & $3.8548 \mathrm{E}-07$ & 4.7664E-06 & $-3.3356 \mathrm{E}-06$ & 8 & -41.945 \\
\hline $3-5$ & $3.3653 \mathrm{E}-07$ & $2.0600 \mathrm{E}-07$ & $2.6251 \mathrm{E}-06$ & $-2.6354 \mathrm{E}-06$ & 6 & -33.949 \\
\hline $3-6$ & $2.2319 \mathrm{E}-07$ & $1.1515 \mathrm{E}-07$ & $1.8537 \mathrm{E}-06$ & $-1.9448 \mathrm{E}-06$ & 6 & -28.946 \\
\hline
\end{tabular}

Table 4-3: V-I Curve Characteristics to 90\% of Maximum Current Using GRIMech 3.0 with Electron Mobility of $0.44 \mathrm{~m}^{2} / \mathrm{Vs}$

With this mechanism, the saturation current using all three mobilities appears to be nearly the identical. Although the simulated saturation current are fairly close to the experimental values in many cases, there is a tendency for the underprediction of saturation current as the equivalence ratio is lowered. 


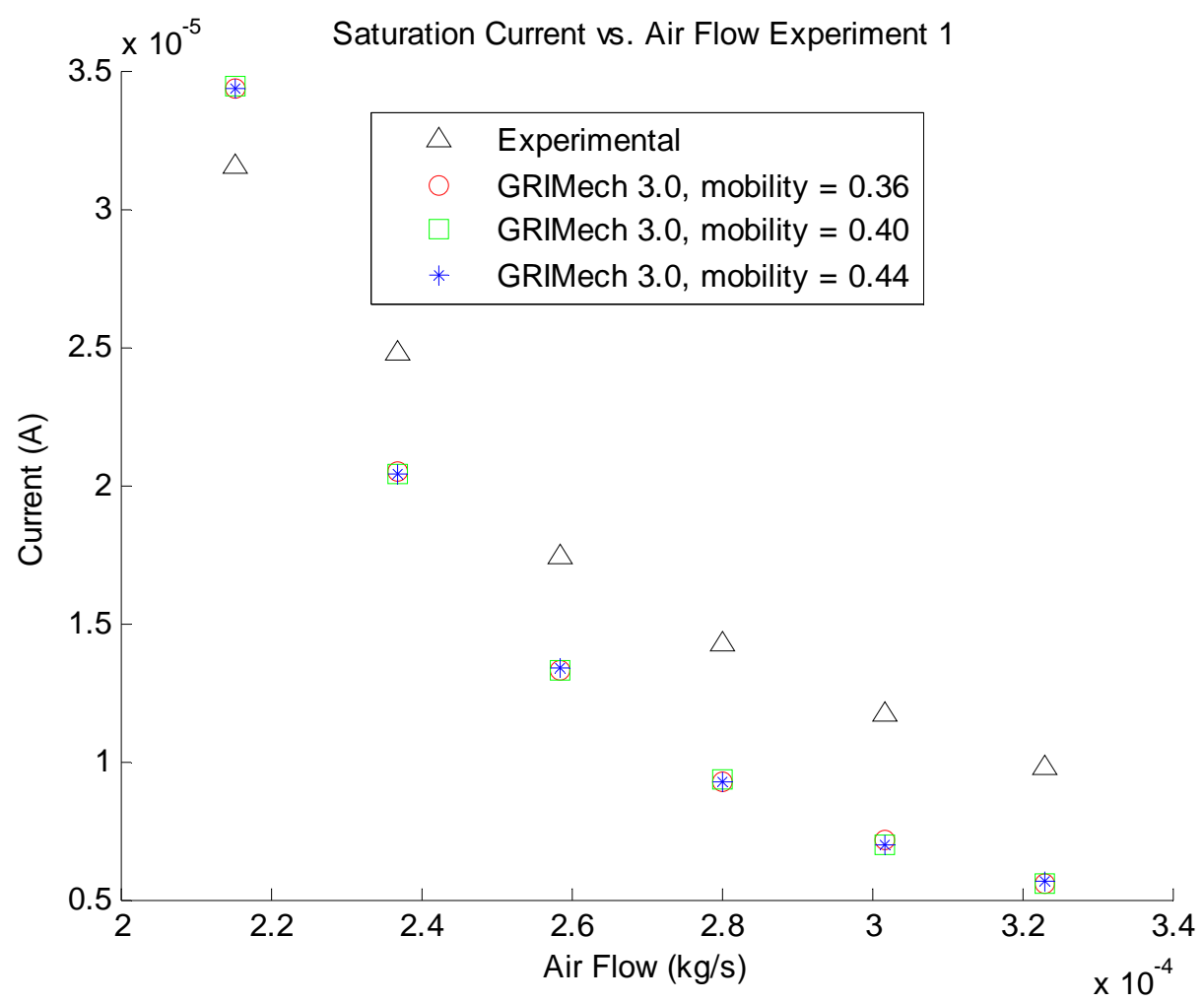

Figure 4-2: Saturation Currents Using GRIMech3.0 with Methane in Experiment 1

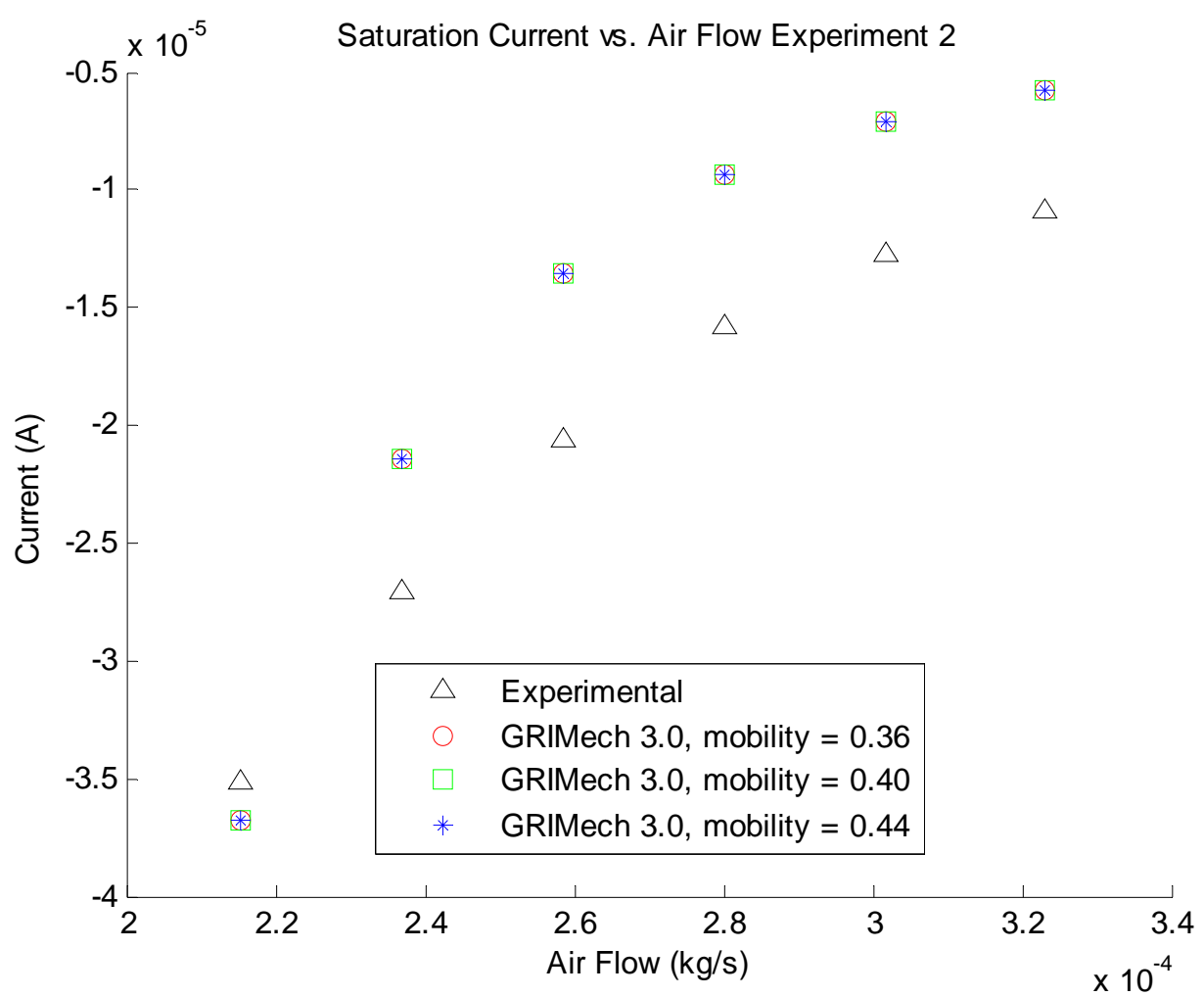

Figure 4-3: Saturation Currents Using GRIMech3.0 with Methane in Experiment 2 


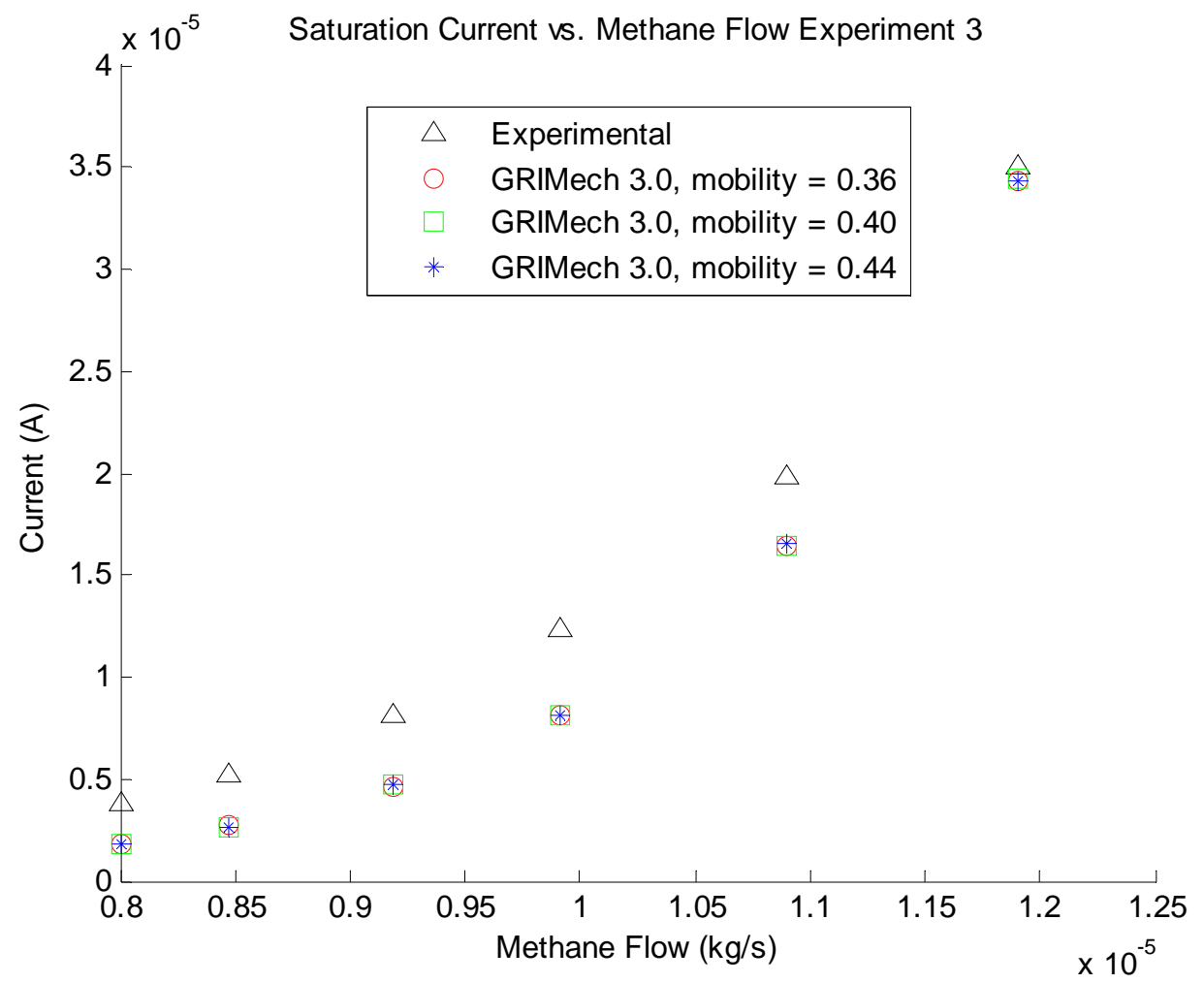

Figure 4-4: Saturation Currents Using GRIMech3.0 with Methane in Experiment 3

Although this mechanism overpredicted the conductivity values using the three tested mobility values, a significant improvement can be seen using the lowest of the tested mobility values, especially in experiments one and three which both had a burner to electrode distance of $1.6 \mathrm{~cm}$. Additionally, there appears to be decreased sensitivity to mobility changes as the air flow is increased. These effects can be seen in the following plots. 


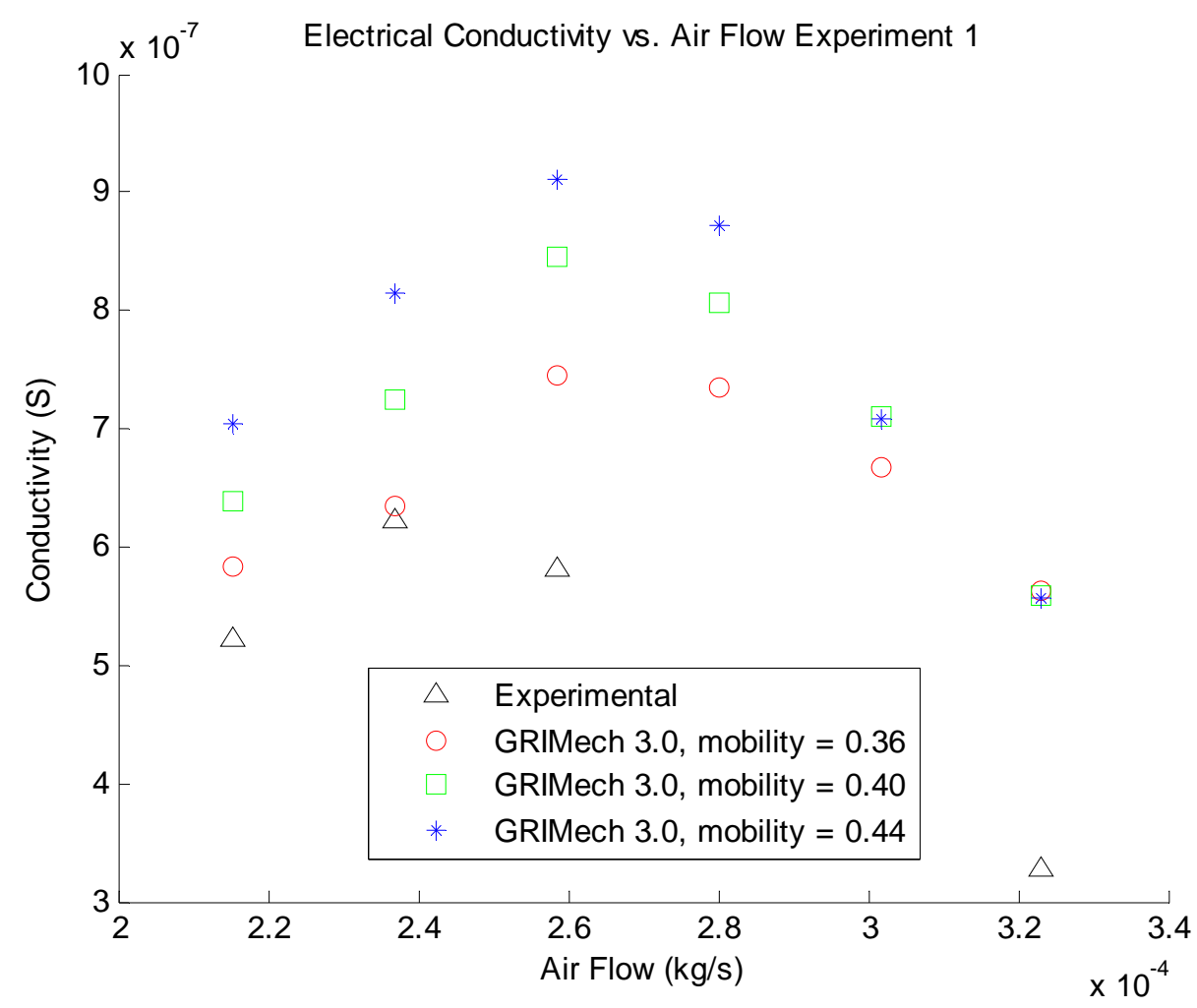

Figure 4-5: Conductivity Using GRIMech3.0 with Methane in Experiment 1

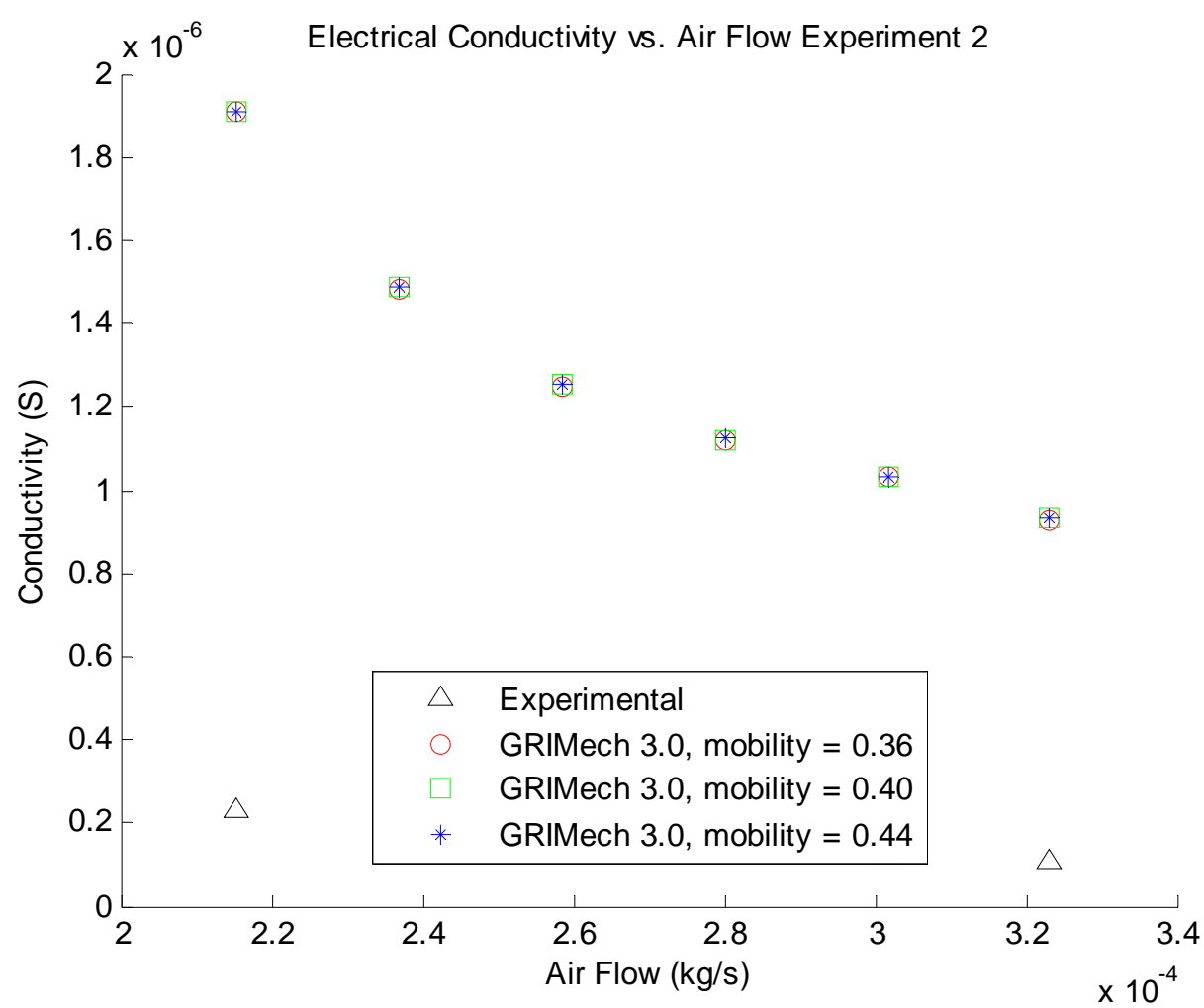

Figure 4-6: Conductivity Using GRIMech3.0 with Methane in Experiment 2 


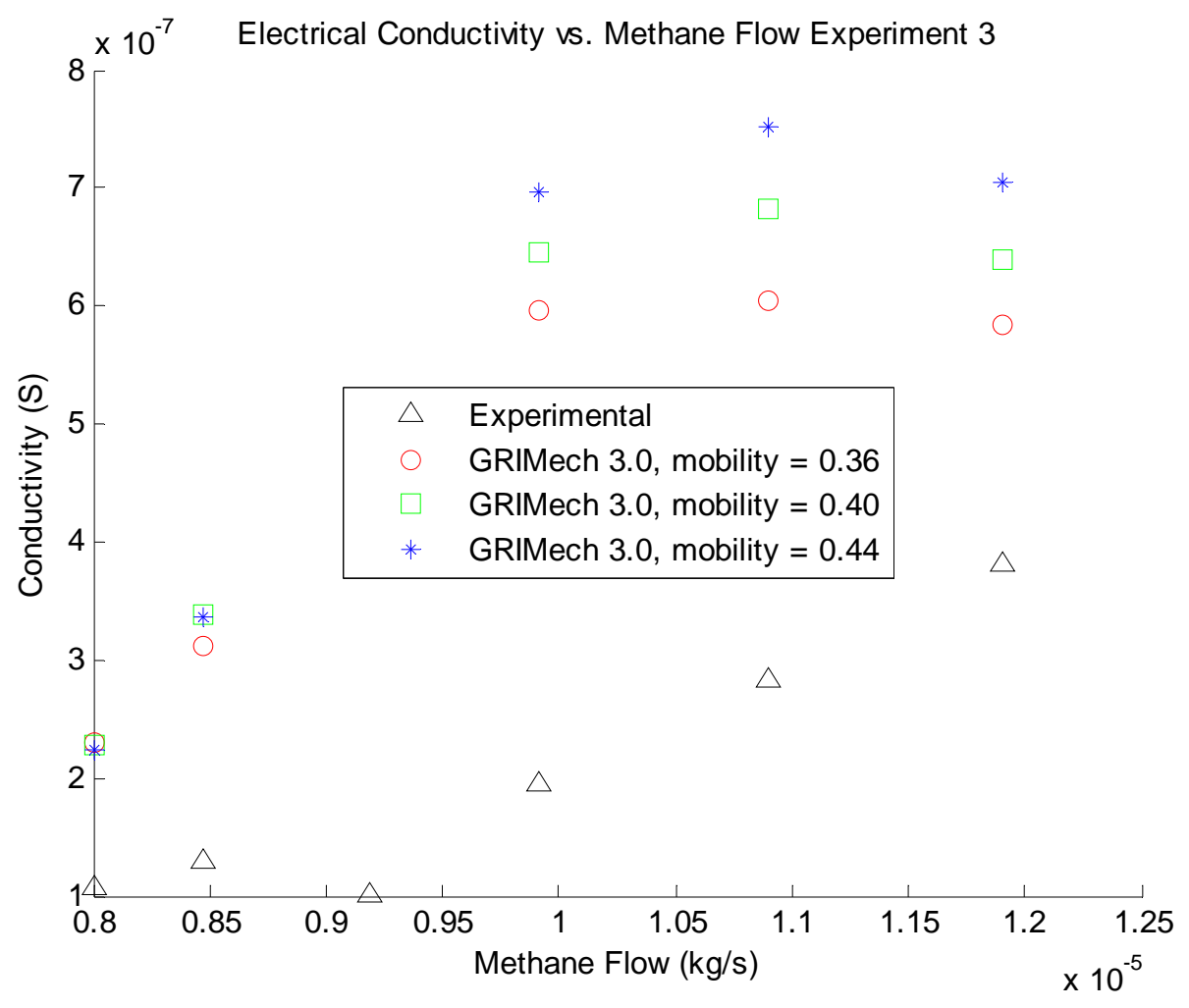

Figure 4-7: Conductivity Using GRIMech3.0 with Methane in Experiment 3 


\subsubsection{Jones, Becker and Heinsohn}

The Jones, Becker and Heinsohn mechanism was one of the best two mechanism for predicting electrical characteristics of a burning methane flame. It had originally been designed for the purpose of simulation of electrical properties of flame.

Observation of the V-I curve plots in Appendix E reveals that the prediction of the saturation currents are reasonably close in most instances. The best agreement for the saturation current values can be observed towards the middle equivalence ratios in the tested range of 0.67 to 1.0 , with underestimates approaching the stochiometric value of 1.0 and overpredictions approaching lean blow-off.

However, the conductivity, illustrated by the V-I curve slopes, remains noticably higher than experimentally shown with all tested mobility values. The conductivity error decreases with the electron mobility. This finding indicates that lowering the mobility may result in significantly better predictions of conductivity. The close predictions of saturation current together with excessive predictions for conductivity cause the saturation current to be reached at lower voltages than shown in the experimental data.

The following tables show properties of the V-I curves up to $90 \%$ of the saturation current for each of tested mobily value. 


\begin{tabular}{|c|c|c|c|c|c|c|}
\hline \multirow{3}{*}{$\begin{array}{c}\text { Experiment } \\
\text { Number }\end{array}$} & \multicolumn{6}{|c|}{$\begin{array}{c}\text { Jones, Becker, and Heinsohn Methane Combustion V-I Curve } \\
\text { Characteristics to } 90 \% \text { of Peak Current with Mobility }=0.36 \mathrm{~m}^{2} / \mathrm{Vs}\end{array}$} \\
\hline & \multicolumn{2}{|c|}{ Slope } & \multicolumn{2}{|c|}{ Current } & \multicolumn{2}{|c|}{ Voltage } \\
\hline & Modeled & Difference & Modeled & Difference & Modeled & Difference \\
\hline $2-1$ & $\begin{array}{c}1.0400 \mathrm{E}- \\
06\end{array}$ & $8.0990 \mathrm{E}-07$ & $\begin{array}{c}-2.8200 \mathrm{E}- \\
05\end{array}$ & $6.9100 \mathrm{E}-06$ & -38 & 121.96 \\
\hline $2-2$ & $\begin{array}{c}8.9500 \mathrm{E}- \\
07\end{array}$ & $7.2731 \mathrm{E}-07$ & $\begin{array}{c}-2.1500 \mathrm{E}- \\
05\end{array}$ & $5.5770 \mathrm{E}-06$ & -35 & 124.95 \\
\hline $2-3$ & $\begin{array}{c}8.1000 \mathrm{E}- \\
07\end{array}$ & $6.6534 \mathrm{E}-07$ & $\begin{array}{c}-1.7400 \mathrm{E}- \\
05\end{array}$ & $3.1800 \mathrm{E}-06$ & -32 & 107.95 \\
\hline $2-4$ & $\begin{array}{c}\text { 7.5000E- } \\
07\end{array}$ & $6.2130 \mathrm{E}-07$ & $\begin{array}{c}-1.5000 \mathrm{E}- \\
05\end{array}$ & $7.8100 \mathrm{E}-07$ & -30 & 89.95 \\
\hline $2-5$ & $\begin{array}{c}\text { 7.0700E- } \\
07\end{array}$ & $5.8796 \mathrm{E}-07$ & $\begin{array}{c}-1.3000 \mathrm{E}- \\
05\end{array}$ & $-3.0500 \mathrm{E}-07$ & -28 & 76.95 \\
\hline $2-6$ & $\begin{array}{c}6.6500 \mathrm{E}- \\
07\end{array}$ & $5.5790 \mathrm{E}-07$ & $\begin{array}{c}-1.1900 \mathrm{E}- \\
05\end{array}$ & $-1.0110 \mathrm{E}-06$ & -27 & 72.949 \\
\hline $3-2$ & $\begin{array}{c}5.7400 \mathrm{E}- \\
07\end{array}$ & $2.9029 \mathrm{E}-07$ & $\begin{array}{c}1.6300 \mathrm{E}- \\
05\end{array}$ & $-3.5590 \mathrm{E}-06$ & 27 & -42.943 \\
\hline $3-3$ & $\begin{array}{c}5.7000 \mathrm{E}- \\
07\end{array}$ & $3.7471 \mathrm{E}-07$ & $\begin{array}{c}1.0500 \mathrm{E}- \\
05\end{array}$ & $-1.8340 \mathrm{E}-06$ & 17 & -42.947 \\
\hline $3-4$ & $\begin{array}{c}6.2900 \mathrm{E}- \\
07\end{array}$ & $5.2791 \mathrm{E}-07$ & $\begin{array}{c}\text { 7.5000E- } \\
06\end{array}$ & $-6.0200 \mathrm{E}-07$ & 11 & -38.945 \\
\hline $3-5$ & $\begin{array}{c}\text { 7.0300E- } \\
07\end{array}$ & $5.7247 \mathrm{E}-07$ & $\begin{array}{c}5.3600 \mathrm{E}- \\
06\end{array}$ & $9.9500 \mathrm{E}-08$ & 7 & -32.949 \\
\hline $3-6$ & $\begin{array}{c}\text { 7.7500E- } \\
07\end{array}$ & $6.6696 \mathrm{E}-07$ & $\begin{array}{c}4.2800 \mathrm{E}- \\
06\end{array}$ & $4.8150 \mathrm{E}-07$ & 5 & -29.946 \\
\hline
\end{tabular}

Table 4-4: V-I Curve Characteristics to $90 \%$ of Maximum Current Using Jones, Becker, and Heinsohn with Electron Mobility of $0.36 \mathrm{~m}^{2} / \mathrm{Vs}$ 


\begin{tabular}{|c|c|c|c|c|c|c|}
\hline \multirow{3}{*}{$\begin{array}{l}\text { Experiment } \\
\text { Number }\end{array}$} & \multicolumn{6}{|c|}{$\begin{array}{c}\text { Jones, Becker, and Heinsohn Methane Combustion V-I Curve } \\
\text { Characteristics to } \mathbf{9 0 \%} \text { of Peak Current with Mobility }=0.40 \mathrm{~m}^{2} / \mathrm{Vs}\end{array}$} \\
\hline & \multicolumn{2}{|c|}{ Slope } & \multicolumn{2}{|c|}{ Current } & \multicolumn{2}{|c|}{ Voltage } \\
\hline & Modeled & Difference & Modeled & Difference & Modeled & Difference \\
\hline $1-1$ & $6.4100 \mathrm{E}-07$ & $1.1948 \mathrm{E}-07$ & $2.6600 \mathrm{E}-05$ & $-4.9490 \mathrm{E}-06$ & 40.00 & -19.876 \\
\hline $1-2$ & $6.9700 \mathrm{E}-07$ & $7.5310 \mathrm{E}-08$ & $2.0500 \mathrm{E}-05$ & $-4.2670 \mathrm{E}-06$ & 28.00 & -11.878 \\
\hline $1-3$ & $7.5600 \mathrm{E}-07$ & $1.7467 \mathrm{E}-07$ & $1.6800 \mathrm{E}-05$ & $-5.8600 \mathrm{E}-07$ & 21.00 & -8.894 \\
\hline $1-4$ & $8.4000 \mathrm{E}-07$ & $3.6203 \mathrm{E}-07$ & $1.4400 \mathrm{E}-05$ & $1.1900 \mathrm{E}-07$ & 16.00 & -13.894 \\
\hline $1-5$ & $9.8600 \mathrm{E}-07$ & $5.9482 \mathrm{E}-07$ & $1.2700 \mathrm{E}-05$ & $1.0080 \mathrm{E}-06$ & 12.00 & -17.894 \\
\hline $1-6$ & $1.0800 \mathrm{E}-06$ & $7.5312 \mathrm{E}-07$ & $1.1600 \mathrm{E}-05$ & $1.8542 \mathrm{E}-06$ & 10.00 & -19.894 \\
\hline 2-1 & $1.0500 \mathrm{E}-06$ & $8.1990 \mathrm{E}-07$ & $\begin{array}{c}-2.8200 \mathrm{E}- \\
05\end{array}$ & $6.9100 \mathrm{E}-06$ & -38.00 & 121.96 \\
\hline $2-2$ & $9.0100 \mathrm{E}-07$ & 7.3331E-07 & $\begin{array}{c}-2.1500 \mathrm{E}- \\
05\end{array}$ & $5.5770 \mathrm{E}-06$ & -35.00 & 124.95 \\
\hline $2-3$ & $8.1500 \mathrm{E}-07$ & $6.7034 \mathrm{E}-07$ & $\begin{array}{c}-1.7400 \mathrm{E}- \\
05\end{array}$ & $3.1800 \mathrm{E}-06$ & -32.00 & 107.95 \\
\hline $2-4$ & $7.5500 \mathrm{E}-07$ & $6.2630 \mathrm{E}-07$ & $\begin{array}{c}-1.5000 \mathrm{E}- \\
05\end{array}$ & $7.8100 \mathrm{E}-07$ & -30.00 & 89.95 \\
\hline $2-5$ & $7.1200 \mathrm{E}-07$ & $5.9296 \mathrm{E}-07$ & $\begin{array}{c}-1.3000 \mathrm{E}- \\
05\end{array}$ & $-3.0500 \mathrm{E}-07$ & -28.00 & 76.95 \\
\hline $2-6$ & $6.7000 \mathrm{E}-07$ & $5.6290 \mathrm{E}-07$ & $\begin{array}{c}-1.1900 \mathrm{E}- \\
05\end{array}$ & $-1.0110 \mathrm{E}-06$ & -27.00 & 72.949 \\
\hline $3-1$ & $6.4100 \mathrm{E}-07$ & $2.5858 \mathrm{E}-07$ & $2.6600 \mathrm{E}-05$ & $-8.4780 \mathrm{E}-06$ & 40.00 & -49.953 \\
\hline $3-2$ & $6.6600 \mathrm{E}-07$ & $3.8229 \mathrm{E}-07$ & $1.6100 \mathrm{E}-05$ & $-3.7590 \mathrm{E}-06$ & 23.00 & -46.943 \\
\hline $3-3$ & $6.4500 \mathrm{E}-07$ & $4.4971 \mathrm{E}-07$ & $1.0500 \mathrm{E}-05$ & $-1.8340 \mathrm{E}-06$ & 15.00 & -44.947 \\
\hline $3-4$ & $6.9000 \mathrm{E}-07$ & 5.8891E-07 & $7.5200 \mathrm{E}-06$ & $-5.8200 \mathrm{E}-07$ & 10.00 & -39.945 \\
\hline $3-5$ & $8.2700 \mathrm{E}-07$ & $6.9647 \mathrm{E}-07$ & $5.4400 \mathrm{E}-06$ & $1.7950 \mathrm{E}-07$ & 6.00 & -33.949 \\
\hline $3-6$ & $9.5200 \mathrm{E}-07$ & $8.4396 \mathrm{E}-07$ & $4.2400 \mathrm{E}-06$ & $4.4150 \mathrm{E}-07$ & 4.00 & -30.946 \\
\hline
\end{tabular}

Table 4-5: V-I Curve Characteristics to $\mathbf{9 0 \%}$ of Maximum Current Using Jones, Becker, and Heinsohn with Electron Mobility of $0.40 \mathrm{~m}^{2} / \mathrm{Vs}$ 


\begin{tabular}{|c|c|c|c|c|c|c|}
\hline \multirow{3}{*}{$\begin{array}{l}\text { Experiment } \\
\text { Number }\end{array}$} & \multicolumn{6}{|c|}{$\begin{array}{l}\text { Jones, Becker, and Heinsohn Methane Combustion V-I Curve } \\
\text { Characteristics to } 90 \% \text { of Peak Current with Mobility }=0.44 \mathrm{~m}^{2} / \mathrm{Vs}\end{array}$} \\
\hline & \multicolumn{2}{|c|}{ Slope } & \multicolumn{2}{|c|}{ Current } & \multicolumn{2}{|c|}{ Voltage } \\
\hline & Modeled & Difference & Modeled & Difference & Modeled & Difference \\
\hline $1-1$ & $7.1100 \mathrm{E}-07$ & $1.8948 \mathrm{E}-07$ & $2.6700 \mathrm{E}-05$ & $-4.8490 \mathrm{E}-06$ & 36.00 & -23.876 \\
\hline $1-2$ & $7.7900 \mathrm{E}-07$ & $1.5731 \mathrm{E}-07$ & $2.0600 \mathrm{E}-05$ & $-4.1670 \mathrm{E}-06$ & 25.00 & -14.878 \\
\hline $1-3$ & $8.7200 \mathrm{E}-07$ & $2.9067 \mathrm{E}-07$ & $1.6700 \mathrm{E}-05$ & $-6.8600 \mathrm{E}-07$ & 18.00 & -11.894 \\
\hline $1-4$ & $9.6900 \mathrm{E}-07$ & 4.9103E-07 & $1.4600 \mathrm{E}-05$ & $3.1900 \mathrm{E}-07$ & 14.00 & -15.894 \\
\hline $1-5$ & $1.1700 \mathrm{E}-06$ & 7.7882E-07 & $1.2700 \mathrm{E}-05$ & $1.0080 \mathrm{E}-06$ & 10.00 & -19.894 \\
\hline $1-6$ & $1.3300 \mathrm{E}-06$ & $1.0031 \mathrm{E}-06$ & $1.1500 \mathrm{E}-05$ & $1.7542 \mathrm{E}-06$ & 8.00 & -21.894 \\
\hline 2-1 & $1.0500 \mathrm{E}-06$ & $8.1990 \mathrm{E}-07$ & $\begin{array}{c}-2.8100 \mathrm{E}- \\
05\end{array}$ & 7.0100E-06 & -38.00 & 121.96 \\
\hline $2-2$ & $9.0500 \mathrm{E}-07$ & 7.3731E-07 & $\begin{array}{c}-2.1500 \mathrm{E}- \\
05\end{array}$ & $5.5770 \mathrm{E}-06$ & -35.00 & 124.95 \\
\hline $2-3$ & $8.1700 \mathrm{E}-07$ & $6.7234 \mathrm{E}-07$ & $\begin{array}{c}-1.7400 \mathrm{E}- \\
05\end{array}$ & $3.1800 \mathrm{E}-06$ & -32.00 & 107.95 \\
\hline $2-4$ & $7.6000 \mathrm{E}-07$ & $6.3130 \mathrm{E}-07$ & $\begin{array}{c}-1.5000 \mathrm{E}- \\
05\end{array}$ & $7.8100 \mathrm{E}-07$ & -30.00 & 89.95 \\
\hline $2-5$ & $7.1500 \mathrm{E}-07$ & $5.9596 \mathrm{E}-07$ & $\begin{array}{c}-1.3000 \mathrm{E}- \\
05\end{array}$ & $-3.0500 \mathrm{E}-07$ & -28.00 & 76.95 \\
\hline $2-6$ & $6.7400 \mathrm{E}-07$ & $5.6690 \mathrm{E}-07$ & $\begin{array}{c}-1.1800 \mathrm{E}- \\
05\end{array}$ & $-9.1100 \mathrm{E}-07$ & -27.00 & 72.949 \\
\hline $3-1$ & $7.1100 \mathrm{E}-07$ & $3.2858 \mathrm{E}-07$ & $2.6700 \mathrm{E}-05$ & $-8.3780 \mathrm{E}-06$ & 36.00 & -53.953 \\
\hline $3-2$ & $7.3400 \mathrm{E}-07$ & $4.5029 \mathrm{E}-07$ & $1.6300 \mathrm{E}-05$ & $-3.5590 \mathrm{E}-06$ & 21.00 & -48.943 \\
\hline $3-3$ & $7.4800 \mathrm{E}-07$ & $5.5271 \mathrm{E}-07$ & $1.0500 \mathrm{E}-05$ & $-1.8340 \mathrm{E}-06$ & 13.00 & -46.947 \\
\hline $3-4$ & $7.7500 \mathrm{E}-07$ & $6.7391 \mathrm{E}-07$ & $7.5800 \mathrm{E}-06$ & $-5.2200 \mathrm{E}-07$ & 9.00 & -40.945 \\
\hline $3-5$ & $9.8400 \mathrm{E}-07$ & $8.5347 \mathrm{E}-07$ & $5.4300 \mathrm{E}-06$ & $1.6950 \mathrm{E}-07$ & 5.00 & -34.949 \\
\hline $3-6$ & $9.6800 \mathrm{E}-07$ & $8.5996 \mathrm{E}-07$ & $4.3400 \mathrm{E}-06$ & $5.4150 \mathrm{E}-07$ & 4.00 & -30.946 \\
\hline
\end{tabular}

Table 4-6: V-I Curve Characteristics to $90 \%$ of Maximum Current Using Jones, Becker, and Heinsohn with Electron Mobility of $0.40 \mathrm{~m}^{2} / \mathrm{Vs}$

The values of for the saturation currents found by this mechanism were nearly the same for all all tested mobility values, which is shown in the following figures, and in most cases, were in good agreement with the experimental values. This fact can be seen in the following figures. 


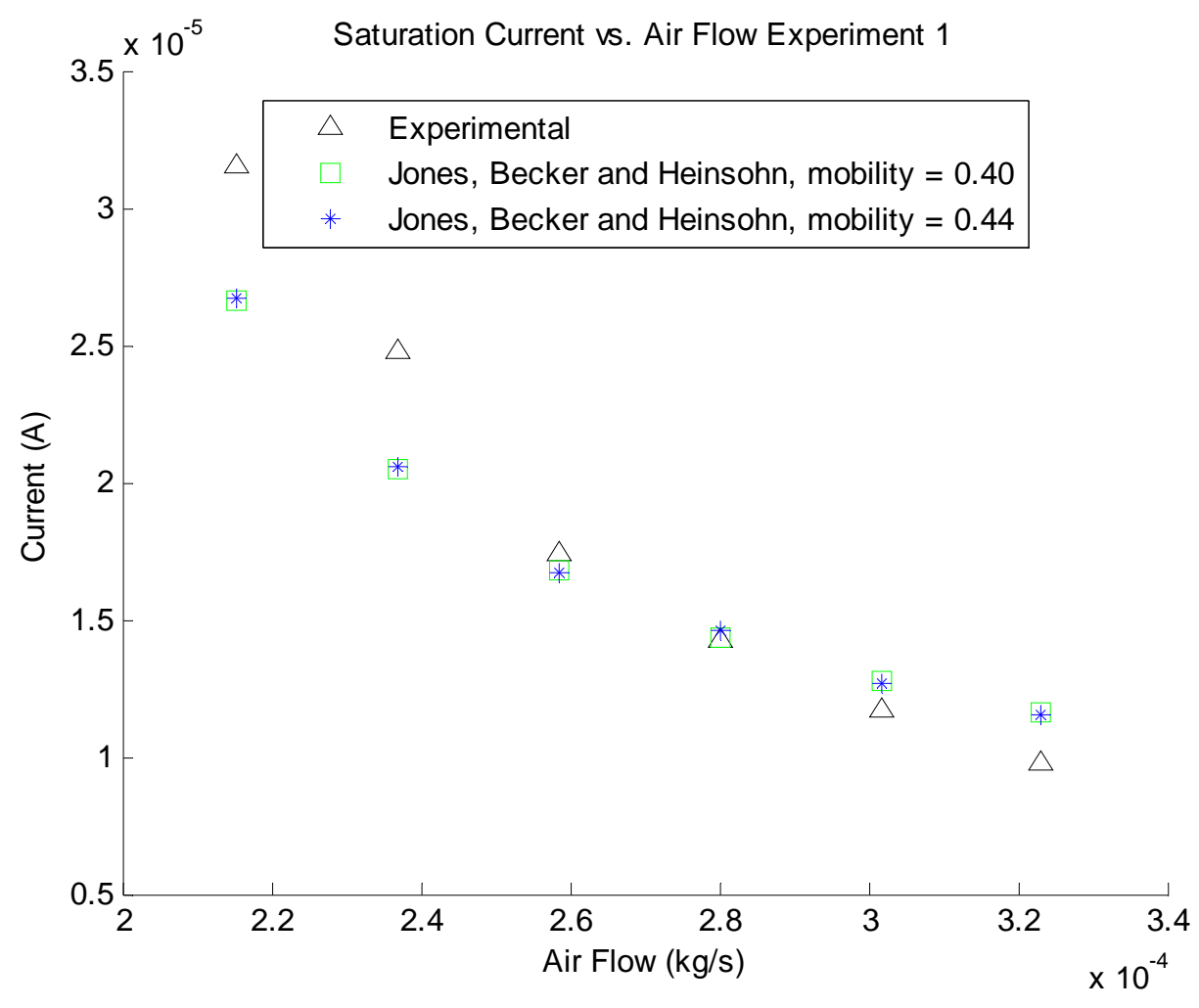

Figure 4-8: Saturation Current Using Jone, Becker and Heinsohn with Methane in Experiment 1

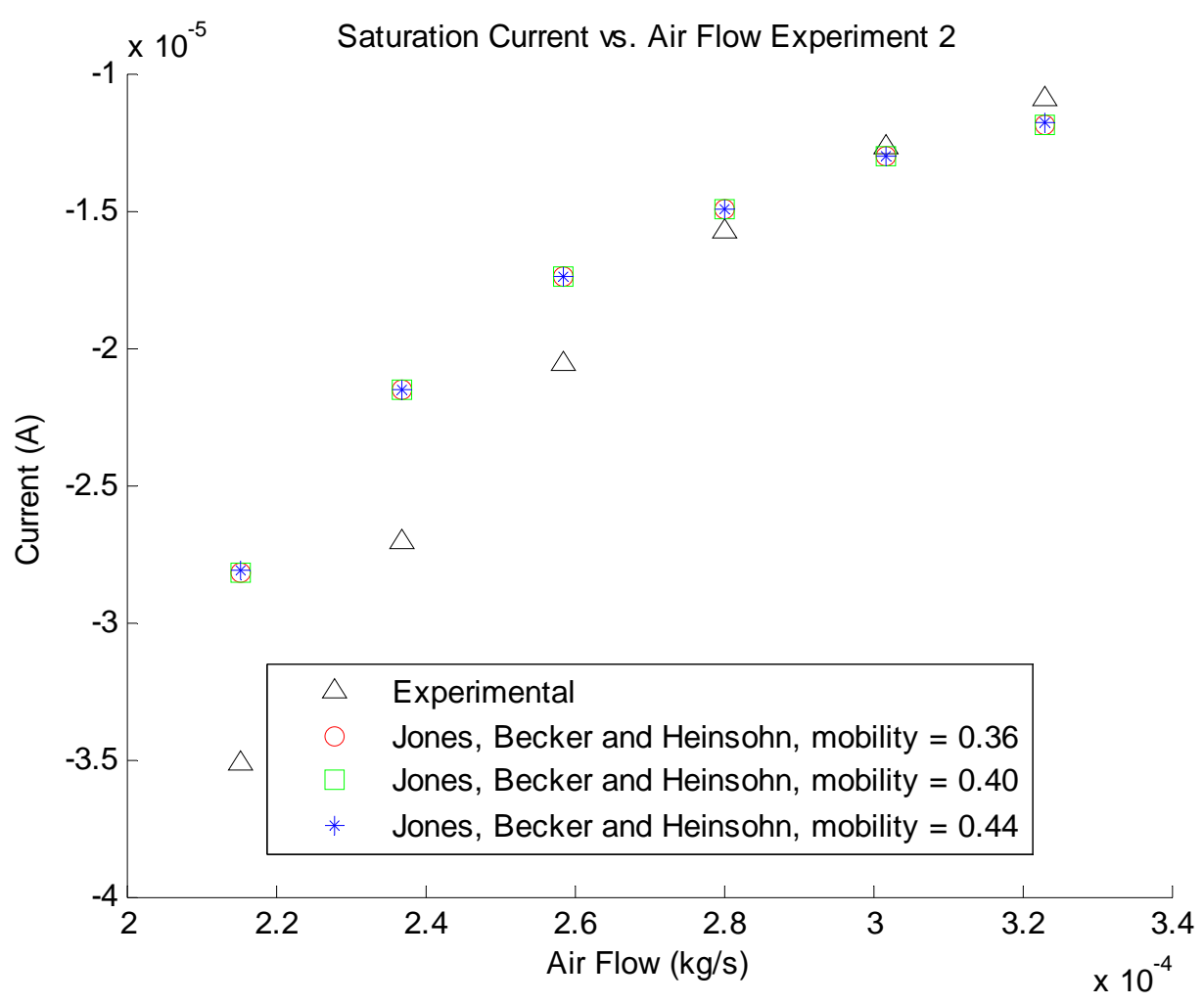

Figure 4-9: Saturation Current Using Jone, Becker and Heinsohn with Methane in Experiment 2 


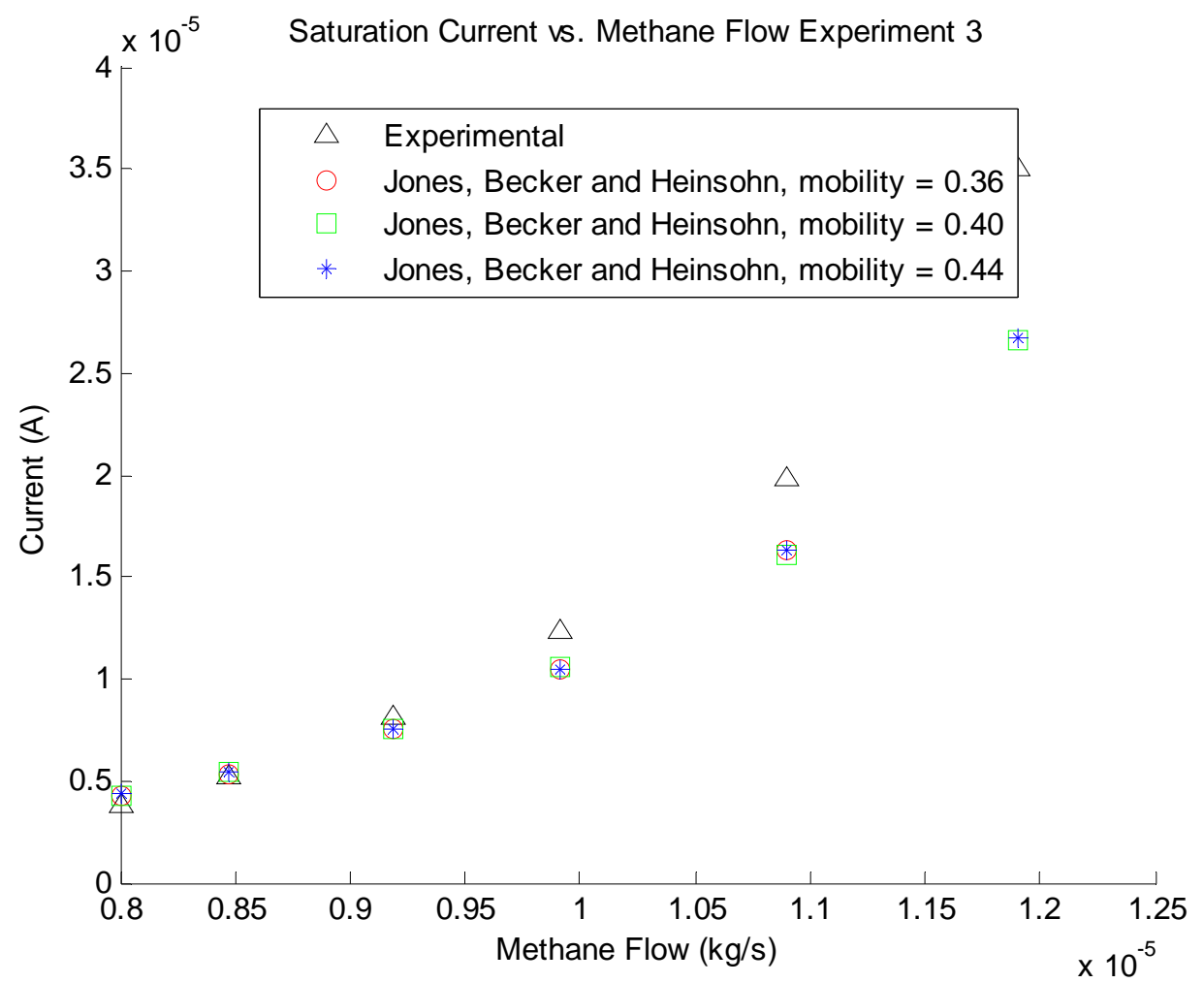

Figure 4-10: Saturation Current Using Jone, Becker and Heinsohn with Methane in Experiment 3

In all tested cases, the simulated conductivity is higher than the experimental conductivity, but there is a significant drop in simulated conductivity as the mobility is lowered. This effect is evident in the following figures. 


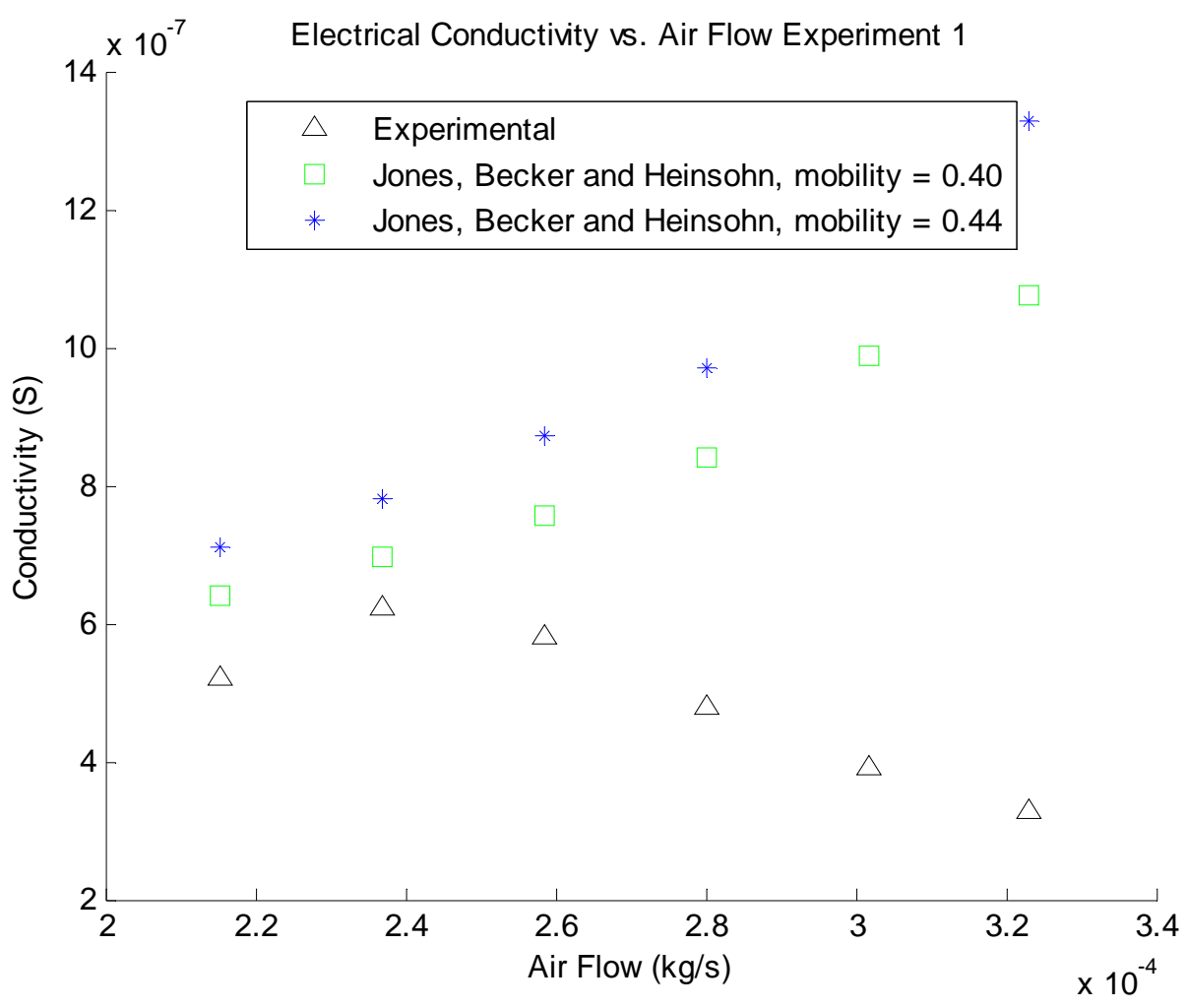

Figure 4-11: Conductivity Using Jone, Becker and Heinsohn with Methane in Experiment 1

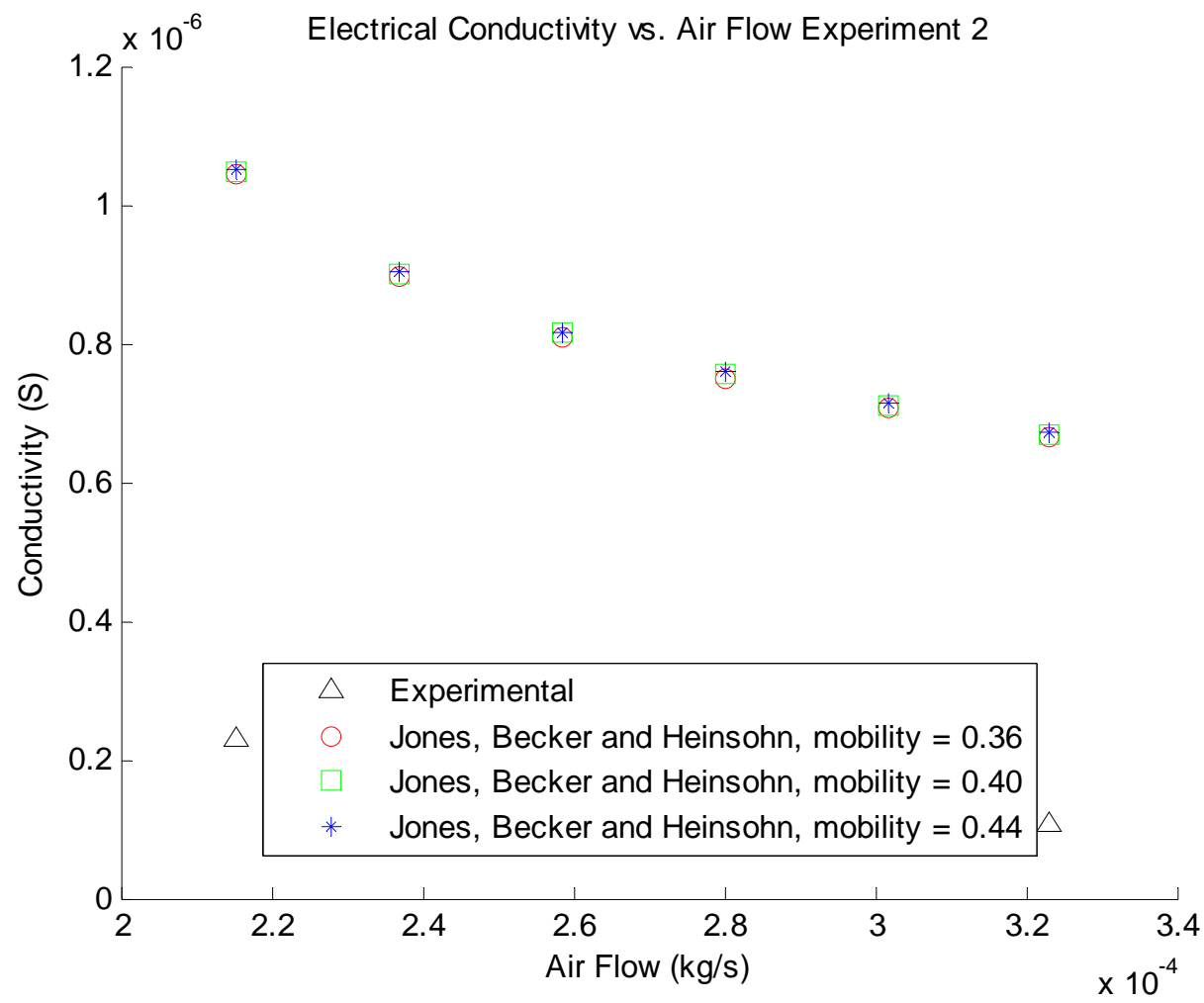

Figure 4-12: Conductivity Using Jone, Becker and Heinsohn with Methane in Experiment 2 


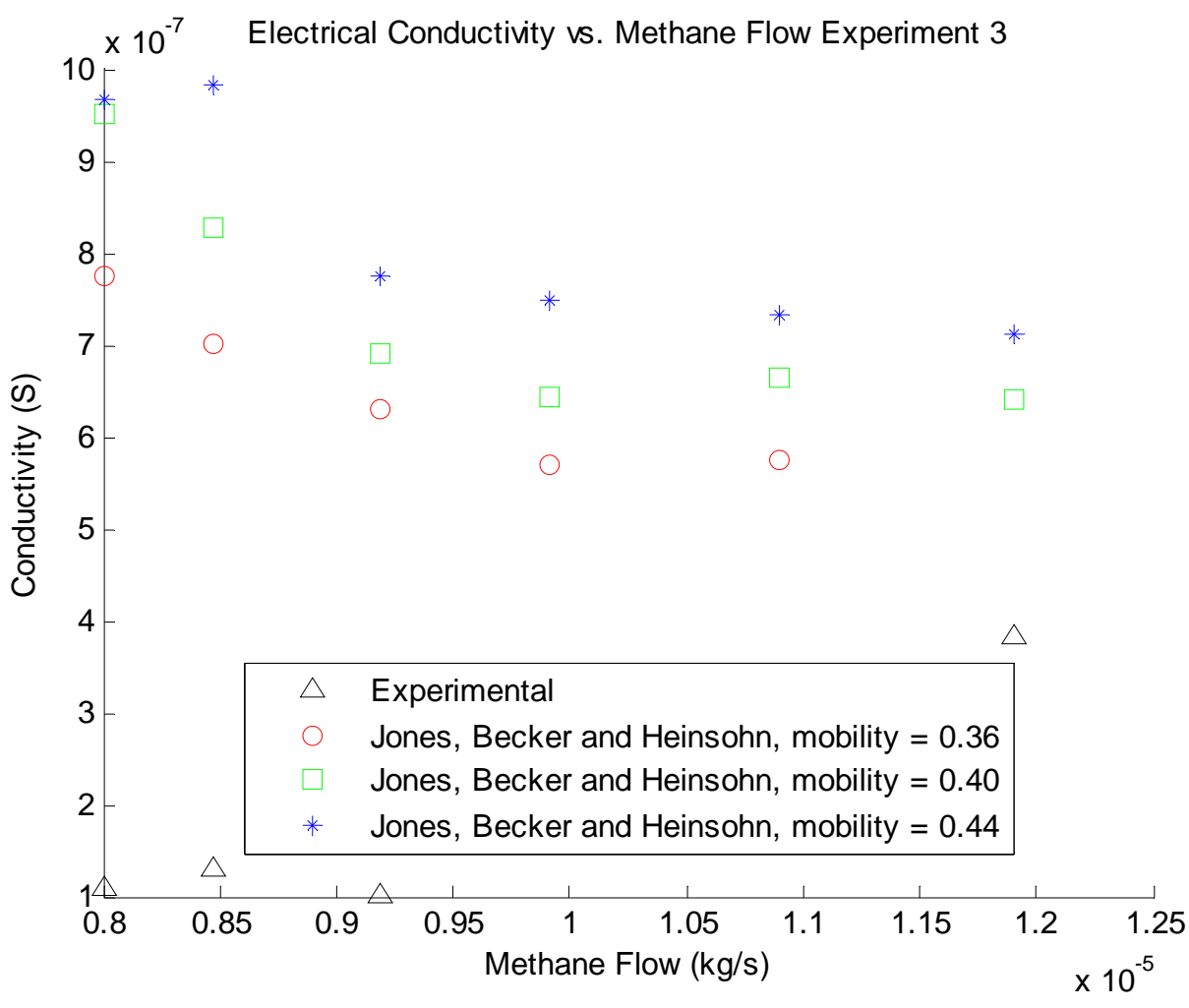

Figure 4-13: Conductivity Using Jone, Becker and Heinsohn with Methane in Experiment 3 


\subsubsection{Pederson and Brown}

In this research, the Pederson and Brown mechanism was the worst performing mechanism out of the four. Very little charged particle concentrations were predicted, resulting in extremely low saturation currents, and unreliable predictions for conductivity. One potential source of errors may be in the use of a scanner and optical character recognition software for retrieving the reaction rate values. In addition, this mechanism used a different set of charged particle reactions than the other three mechanisms.

The following tables show properties of the V-I curves generated by this mechanism based on existing experiments up to $90 \%$ of the saturation current for each of tested mobily values. 


\begin{tabular}{|c|c|c|c|c|c|c|}
\hline \multirow{3}{*}{$\begin{array}{c}\text { Experiment } \\
\text { Number }\end{array}$} & \multicolumn{6}{|c|}{$\begin{array}{l}\text { Pederson and Brown Methane Combustion V-I Curve Characteristics } \\
\text { to } 90 \% \text { of Peak Current with Mobility }=0.36 \mathrm{~m}^{2} / \mathrm{Vs}\end{array}$} \\
\hline & \multicolumn{2}{|c|}{ Slope } & \multicolumn{2}{|c|}{ Current } & \multicolumn{2}{|c|}{ Voltage } \\
\hline & Modeled & Difference & Modeled & Difference & Modeled & Difference \\
\hline $1-1$ & $1.0100 \mathrm{E}-06$ & $4.8848 \mathrm{E}-07$ & $2.6900 \mathrm{E}-06$ & $-2.8859 \mathrm{E}-05$ & 2.00 & -57.876 \\
\hline $1-2$ & $3.0900 \mathrm{E}-07$ & $-3.1269 \mathrm{E}-07$ & $4.5500 \mathrm{E}-07$ & $-2.4312 \mathrm{E}-05$ & 1.00 & -38.878 \\
\hline $1-3$ & $1.1500 \mathrm{E}-07$ & $-4.6633 \mathrm{E}-07$ & $1.6900 \mathrm{E}-07$ & $-1.7217 \mathrm{E}-05$ & 1.00 & -28.894 \\
\hline $1-4$ & $3.3400 \mathrm{E}-08$ & $-4.4457 \mathrm{E}-07$ & $9.3100 \mathrm{E}-08$ & $-1.4188 \mathrm{E}-05$ & 2.00 & -27.894 \\
\hline $1-5$ & $2.0700 \mathrm{E}-08$ & $-3.7048 \mathrm{E}-07$ & $5.7100 \mathrm{E}-08$ & $-1.1635 \mathrm{E}-05$ & 2.00 & -27.894 \\
\hline $1-6$ & $0.0000 \mathrm{E}+00$ & $-3.2688 \mathrm{E}-07$ & $0.0000 \mathrm{E}+00$ & $-9.7458 \mathrm{E}-06$ & 0.00 & -29.894 \\
\hline $2-1$ & $3.9700 \mathrm{E}-07$ & $1.6690 \mathrm{E}-07$ & $\begin{array}{c}-2.6500 \mathrm{E}- \\
06\end{array}$ & $3.2460 \mathrm{E}-05$ & -11.00 & 148.96 \\
\hline $2-2$ & $1.4600 \mathrm{E}-07$ & $-2.1690 \mathrm{E}-08$ & $\begin{array}{c}-4.7900 \mathrm{E}- \\
07\end{array}$ & $2.6598 \mathrm{E}-05$ & -5.00 & 154.95 \\
\hline $2-3$ & $8.2700 \mathrm{E}-08$ & $-6.1960 \mathrm{E}-08$ & $\begin{array}{c}-1.7600 \mathrm{E}- \\
07\end{array}$ & $2.0404 \mathrm{E}-05$ & -3.00 & 136.95 \\
\hline $2-4$ & $4.1900 \mathrm{E}-08$ & $-8.6800 \mathrm{E}-08$ & $\begin{array}{c}-9.7200 \mathrm{E}- \\
08\end{array}$ & $1.5684 \mathrm{E}-05$ & -3.00 & 116.95 \\
\hline $2-5$ & $3.5900 \mathrm{E}-08$ & $-8.3140 \mathrm{E}-08$ & $\begin{array}{c}-5.9000 \mathrm{E}- \\
08\end{array}$ & $1.2636 \mathrm{E}-05$ & -2.00 & 102.95 \\
\hline $2-6$ & $2.3700 \mathrm{E}-08$ & $-8.3400 \mathrm{E}-08$ & $\begin{array}{c}-4.1600 \mathrm{E}- \\
08\end{array}$ & $1.0847 \mathrm{E}-05$ & -2.00 & 97.949 \\
\hline $3-1$ & $1.0100 \mathrm{E}-06$ & $6.2758 \mathrm{E}-07$ & $2.6900 \mathrm{E}-06$ & $-3.2388 \mathrm{E}-05$ & 2.00 & -87.953 \\
\hline $3-2$ & $2.4600 \mathrm{E}-07$ & $-3.7710 \mathrm{E}-08$ & $3.6200 \mathrm{E}-07$ & $-1.9497 \mathrm{E}-05$ & 1.00 & -68.943 \\
\hline $3-3$ & $6.6100 \mathrm{E}-08$ & $-1.2919 \mathrm{E}-07$ & $9.6400 \mathrm{E}-08$ & $-1.2238 \mathrm{E}-05$ & 1.00 & -58.947 \\
\hline $3-4$ & $1.5600 \mathrm{E}-08$ & $-8.5490 \mathrm{E}-08$ & $4.3300 \mathrm{E}-08$ & $-8.0587 \mathrm{E}-06$ & 2.00 & -47.945 \\
\hline $3-5$ & $0.0000 \mathrm{E}+00$ & $-1.3053 \mathrm{E}-07$ & $0.0000 \mathrm{E}+00$ & $-5.2605 \mathrm{E}-06$ & 0.00 & -39.949 \\
\hline $3-6$ & $4.2700 \mathrm{E}-09$ & $-1.0377 \mathrm{E}-07$ & $1.1500 \mathrm{E}-08$ & $-3.7870 \mathrm{E}-06$ & 2.00 & -32.946 \\
\hline
\end{tabular}

Table 4-7: V-I Curve Characteristics to $90 \%$ of Maximum Current Using Pederson and Brown with Electron Mobility of $0.36 \mathrm{~m}^{2} / \mathrm{Vs}$ 


\begin{tabular}{|c|c|c|c|c|c|c|}
\hline \multirow{3}{*}{$\begin{array}{c}\text { Experiment } \\
\text { Number }\end{array}$} & \multicolumn{6}{|c|}{$\begin{array}{r}\text { Pederson and Brown Methane Combustion V-I Curve Characteristics } \\
\text { to } 90 \% \text { of Peak Current with Mobility }=0.40 \mathrm{~m}^{2} / \mathrm{Vs}\end{array}$} \\
\hline & \multicolumn{2}{|c|}{ Slope } & \multicolumn{2}{|c|}{ Current } & \multicolumn{2}{|c|}{ Voltage } \\
\hline & Modeled & Difference & Modeled & Difference & Modeled & Difference \\
\hline $1-1$ & $1.0000 \mathrm{E}-06$ & $4.7848 \mathrm{E}-07$ & $2.7300 \mathrm{E}-06$ & $-2.8819 \mathrm{E}-05$ & 2.00 & -57.876 \\
\hline $1-2$ & $3.0900 \mathrm{E}-07$ & $-3.1269 \mathrm{E}-07$ & $4.5800 \mathrm{E}-07$ & $-2.4309 \mathrm{E}-05$ & 1.00 & -38.878 \\
\hline $1-3$ & $1.1500 \mathrm{E}-07$ & $-4.6633 \mathrm{E}-07$ & $1.7000 \mathrm{E}-07$ & $-1.7216 \mathrm{E}-05$ & 1.00 & -28.894 \\
\hline $1-4$ & $3.3100 \mathrm{E}-08$ & $-4.4487 \mathrm{E}-07$ & $9.3300 \mathrm{E}-08$ & $-1.4188 \mathrm{E}-05$ & 2.00 & -27.894 \\
\hline $1-5$ & $2.0500 \mathrm{E}-08$ & $-3.7068 \mathrm{E}-07$ & $5.7200 \mathrm{E}-08$ & $-1.1635 \mathrm{E}-05$ & 2.00 & -27.894 \\
\hline $1-6$ & $1.4200 \mathrm{E}-08$ & $-3.1268 \mathrm{E}-07$ & $3.9200 \mathrm{E}-08$ & $-9.7066 \mathrm{E}-06$ & 2.00 & -27.894 \\
\hline 2-1 & $4.0000 \mathrm{E}-07$ & $1.6990 \mathrm{E}-07$ & $\begin{array}{c}-2.6500 \mathrm{E}- \\
06\end{array}$ & $3.2460 \mathrm{E}-05$ & -11.00 & 148.96 \\
\hline $2-2$ & $1.4800 \mathrm{E}-07$ & $-1.9690 \mathrm{E}-08$ & $\begin{array}{c}-4.7900 \mathrm{E}- \\
07 \\
\end{array}$ & $2.6598 \mathrm{E}-05$ & -5.00 & 154.95 \\
\hline $2-3$ & $8.3100 \mathrm{E}-08$ & $-6.1560 \mathrm{E}-08$ & $\begin{array}{c}-1.7600 \mathrm{E}- \\
07 \\
\end{array}$ & $2.0404 \mathrm{E}-05$ & -3.00 & 136.95 \\
\hline $2-4$ & $5.1300 \mathrm{E}-08$ & $-7.7400 \mathrm{E}-08$ & $\begin{array}{c}-7.5400 \mathrm{E}- \\
08\end{array}$ & $1.5706 \mathrm{E}-05$ & -2.00 & 117.95 \\
\hline $2-5$ & $3.1800 \mathrm{E}-08$ & $-8.7240 \mathrm{E}-08$ & $\begin{array}{c}-5.1000 \mathrm{E}- \\
08 \\
\end{array}$ & $1.2644 \mathrm{E}-05$ & -2.00 & 102.95 \\
\hline $2-6$ & $2.1300 \mathrm{E}-08$ & $-8.5800 \mathrm{E}-08$ & $\begin{array}{c}-3.7000 \mathrm{E}- \\
08 \\
\end{array}$ & $1.0852 \mathrm{E}-05$ & -2.00 & 97.949 \\
\hline $3-1$ & $1.0000 \mathrm{E}-06$ & $6.1758 \mathrm{E}-07$ & $2.7300 \mathrm{E}-06$ & $-3.2348 \mathrm{E}-05$ & 2.00 & -87.953 \\
\hline $3-2$ & $2.4700 \mathrm{E}-07$ & $-3.6710 \mathrm{E}-08$ & $3.6400 \mathrm{E}-07$ & $-1.9495 \mathrm{E}-05$ & 1.00 & -68.943 \\
\hline $3-3$ & $6.5700 \mathrm{E}-08$ & $-1.2959 \mathrm{E}-07$ & $9.7000 \mathrm{E}-08$ & $-1.2237 \mathrm{E}-05$ & 1.00 & -58.947 \\
\hline $3-4$ & $1.5400 \mathrm{E}-08$ & $-8.5690 \mathrm{E}-08$ & $4.3400 \mathrm{E}-08$ & $-8.0586 \mathrm{E}-06$ & 2.00 & -47.945 \\
\hline $3-5$ & $7.2900 \mathrm{E}-09$ & $-1.2324 \mathrm{E}-07$ & $1.9400 \mathrm{E}-08$ & $-5.2411 \mathrm{E}-06$ & 2.00 & -37.949 \\
\hline $3-6$ & $4.2400 \mathrm{E}-09$ & $-1.0380 \mathrm{E}-07$ & $1.1500 \mathrm{E}-08$ & $-3.7870 \mathrm{E}-06$ & 2.00 & -32.946 \\
\hline
\end{tabular}

Table 4-8: V-I Curve Characteristics to $90 \%$ of Maximum Current Using Pederson and Brown with Electron Mobility of $0.40 \mathrm{~m}^{2} / \mathrm{Vs}$ 


\begin{tabular}{|c|c|c|c|c|c|c|}
\hline \multirow{2}{*}{$\begin{array}{c}\text { Experiment } \\
\text { Number }\end{array}$} & \multicolumn{3}{|c|}{$\begin{array}{r}\text { Pederson and Brown Methane Combustion V-I Curve Characteristics } \\
\text { to 90\% of Peak Current with Mobility }=\mathbf{0 . 4 4} \mathrm{m}^{2} / \text { Vs }\end{array}$} \\
\cline { 2 - 7 } & \multicolumn{2}{|c|}{ Slope } & \multicolumn{2}{c|}{ Current } & \multicolumn{2}{c|}{ Voltage } \\
\cline { 2 - 7 } & Modeled & Difference & Modeled & Difference & Modeled & Difference \\
\hline $1-1$ & $9.7989 \mathrm{E}-07$ & $4.5837 \mathrm{E}-07$ & $2.7200 \mathrm{E}-06$ & $-2.8829 \mathrm{E}-05$ & 2.00 & -57.876 \\
\hline $1-2$ & $3.0639 \mathrm{E}-07$ & $-3.1530 \mathrm{E}-07$ & $4.6119 \mathrm{E}-07$ & $-2.4306 \mathrm{E}-05$ & 1.00 & -38.878 \\
\hline $1-3$ & $1.1387 \mathrm{E}-07$ & $-4.6746 \mathrm{E}-07$ & $1.7094 \mathrm{E}-07$ & $-1.7215 \mathrm{E}-05$ & 1.00 & -28.894 \\
\hline $1-4$ & $3.2769 \mathrm{E}-08$ & $-4.4520 \mathrm{E}-07$ & $9.3451 \mathrm{E}-08$ & $-1.4188 \mathrm{E}-05$ & 2.00 & -27.894 \\
\hline $1-5$ & $2.0383 \mathrm{E}-08$ & $-3.7080 \mathrm{E}-07$ & $5.7260 \mathrm{E}-08$ & $-1.1635 \mathrm{E}-05$ & 2.00 & -27.894 \\
\hline $2-1$ & $4.0197 \mathrm{E}-07$ & $1.7187 \mathrm{E}-07$ & $\begin{array}{c}-2.6490 \mathrm{E}- \\
06\end{array}$ & $3.2461 \mathrm{E}-05$ & -11.00 & 148.96 \\
\hline $2-2$ & $1.4850 \mathrm{E}-07$ & $-1.9190 \mathrm{E}-08$ & $\begin{array}{c}-4.7892 \mathrm{E}- \\
07\end{array}$ & $2.6598 \mathrm{E}-05$ & -5.00 & 154.95 \\
\hline $2-3$ & $8.3474 \mathrm{E}-08$ & $-6.1186 \mathrm{E}-08$ & $\begin{array}{c}-1.7627 \mathrm{E}- \\
07\end{array}$ & $2.0404 \mathrm{E}-05$ & -3.00 & 136.95 \\
\hline $2-4$ & $4.2126 \mathrm{E}-08$ & $-8.6574 \mathrm{E}-08$ & $\begin{array}{c}-9.7240 \mathrm{E}- \\
08\end{array}$ & $1.5684 \mathrm{E}-05$ & -3.00 & 116.95 \\
\hline $2-5$ & $3.6003 \mathrm{E}-08$ & $-8.3037 \mathrm{E}-08$ & $\begin{array}{c}-5.8985 \mathrm{E}- \\
08\end{array}$ & $1.2636 \mathrm{E}-05$ & -2.00 & 102.95 \\
\hline $2-6$ & $2.3786 \mathrm{E}-08$ & $-8.3314 \mathrm{E}-08$ & $\begin{array}{c}-4.1633 \mathrm{E}- \\
08\end{array}$ & $1.0847 \mathrm{E}-05$ & -2.00 & 97.949 \\
\hline $3-1$ & $9.7989 \mathrm{E}-07$ & $5.9747 \mathrm{E}-07$ & $2.7200 \mathrm{E}-06$ & $-3.2358 \mathrm{E}-05$ & 2.00 & -87.953 \\
\hline $3-2$ & $2.4178 \mathrm{E}-07$ & $-4.1930 \mathrm{E}-08$ & $3.6619 \mathrm{E}-07$ & $-1.9493 \mathrm{E}-05$ & 1.00 & -68.943 \\
\hline $3-3$ & $6.5535 \mathrm{E}-08$ & $-1.2976 \mathrm{E}-07$ & $9.7825 \mathrm{E}-08$ & $-1.2236 \mathrm{E}-05$ & 1.00 & -58.947 \\
\hline $3-4$ & $2.8132 \mathrm{E}-08$ & $-7.2958 \mathrm{E}-08$ & $4.1054 \mathrm{E}-08$ & $-8.0609 \mathrm{E}-06$ & 1.00 & -48.945 \\
\hline $3-5$ & $6.8537 \mathrm{E}-09$ & $-1.2368 \mathrm{E}-07$ & $1.9445 \mathrm{E}-08$ & $-5.2411 \mathrm{E}-06$ & 2.00 & -37.949 \\
\hline $3-6$ & $4.2071 \mathrm{E}-09$ & $-1.0383 \mathrm{E}-07$ & $1.1560 \mathrm{E}-08$ & $-3.7869 \mathrm{E}-06$ & 2.00 & -32.946 \\
\hline
\end{tabular}

Table 4-9: V-I Curve Characteristics to $90 \%$ of Maximum Current Using Pederson and Brown with Electron Mobility of $0.44 \mathrm{~m}^{2} / \mathrm{Vs}$

The following figures show that for each of the tested mobilities, the saturation current is underpredicted by one or more orders of magnitude. 


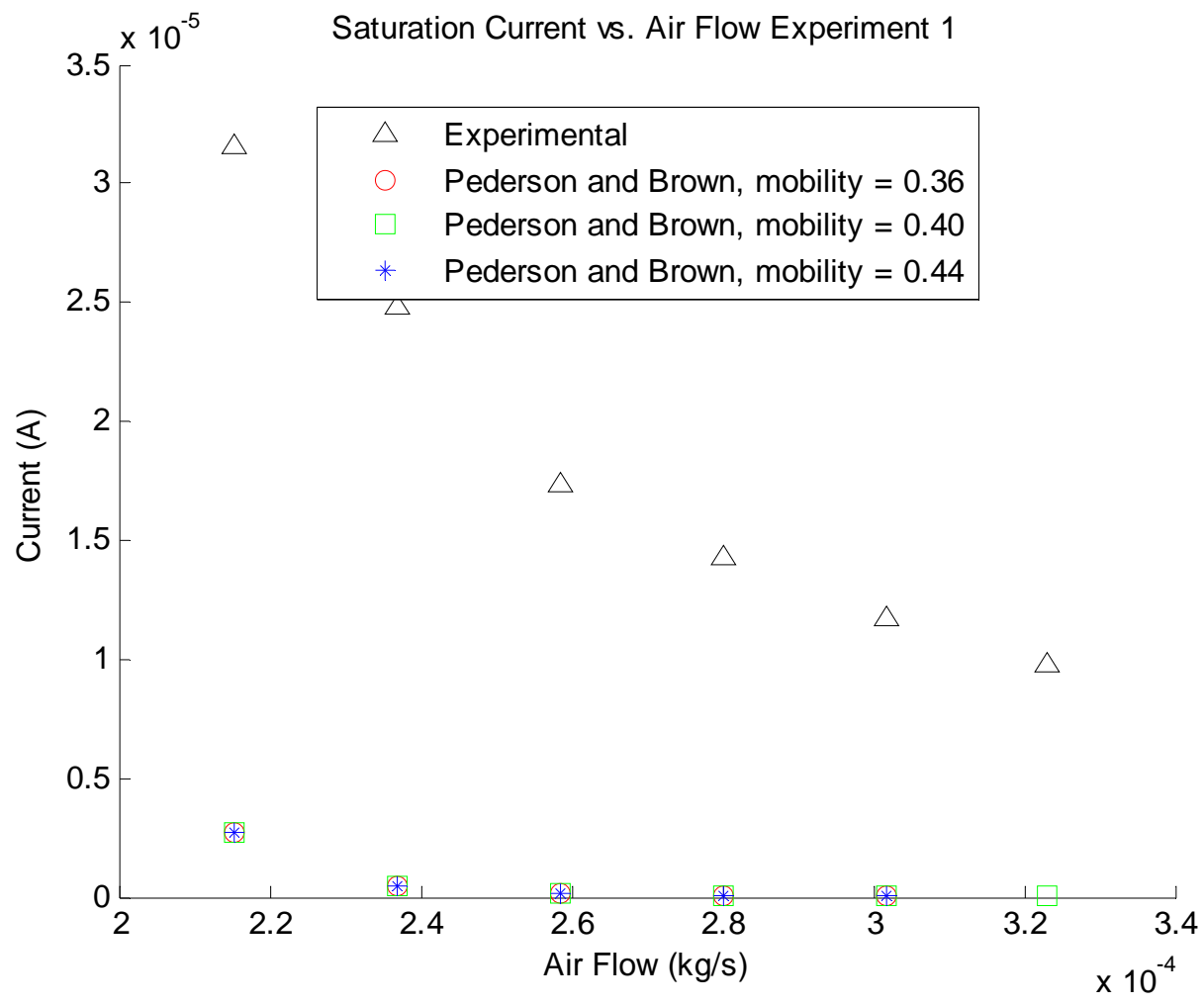

Figure 4-14: Saturation Current Using Pederson and Brown with Methane in Experiment 1

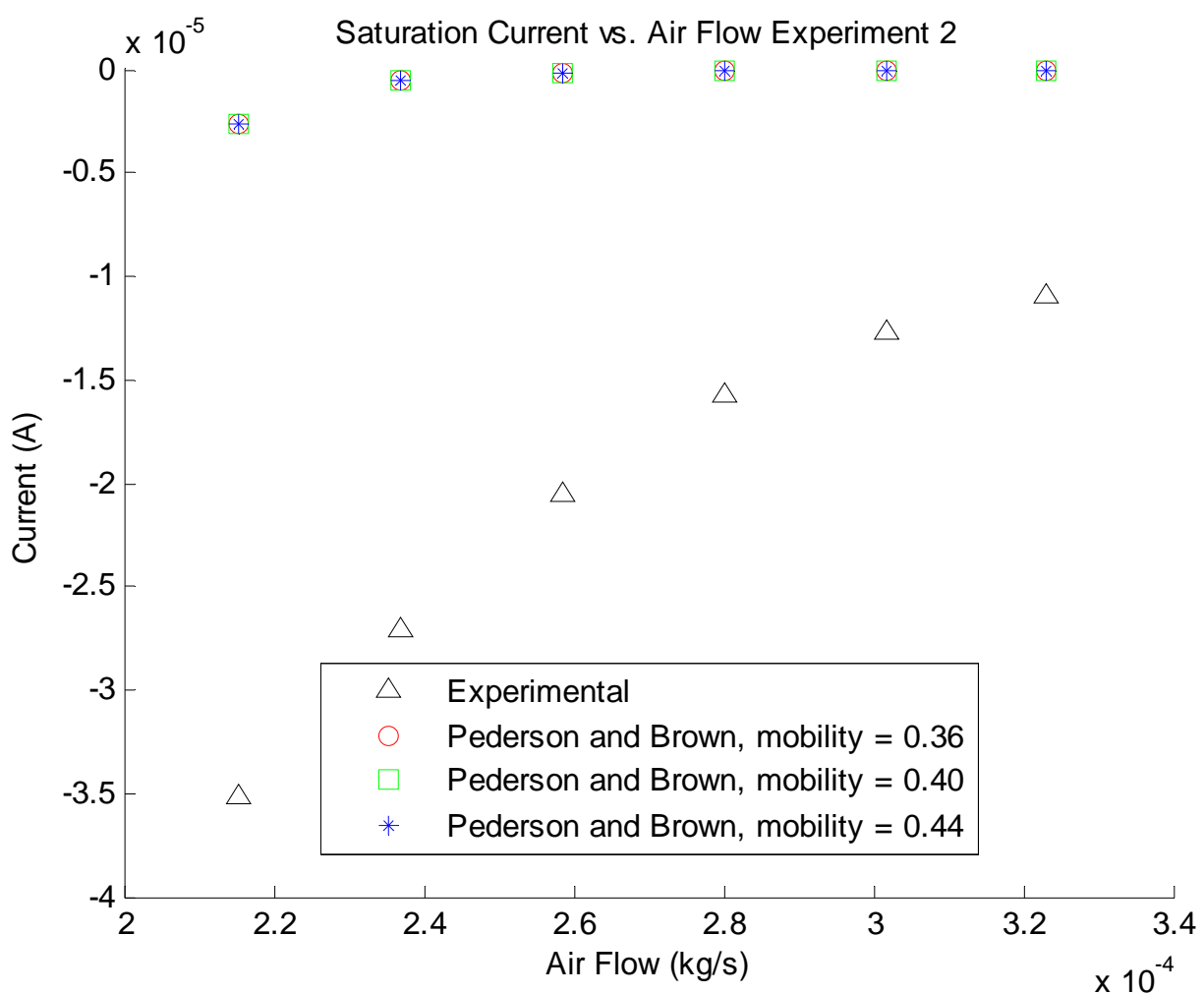

Figure 4-15: Saturation Current Using Pederson and Brown with Methane in Experiment 2 


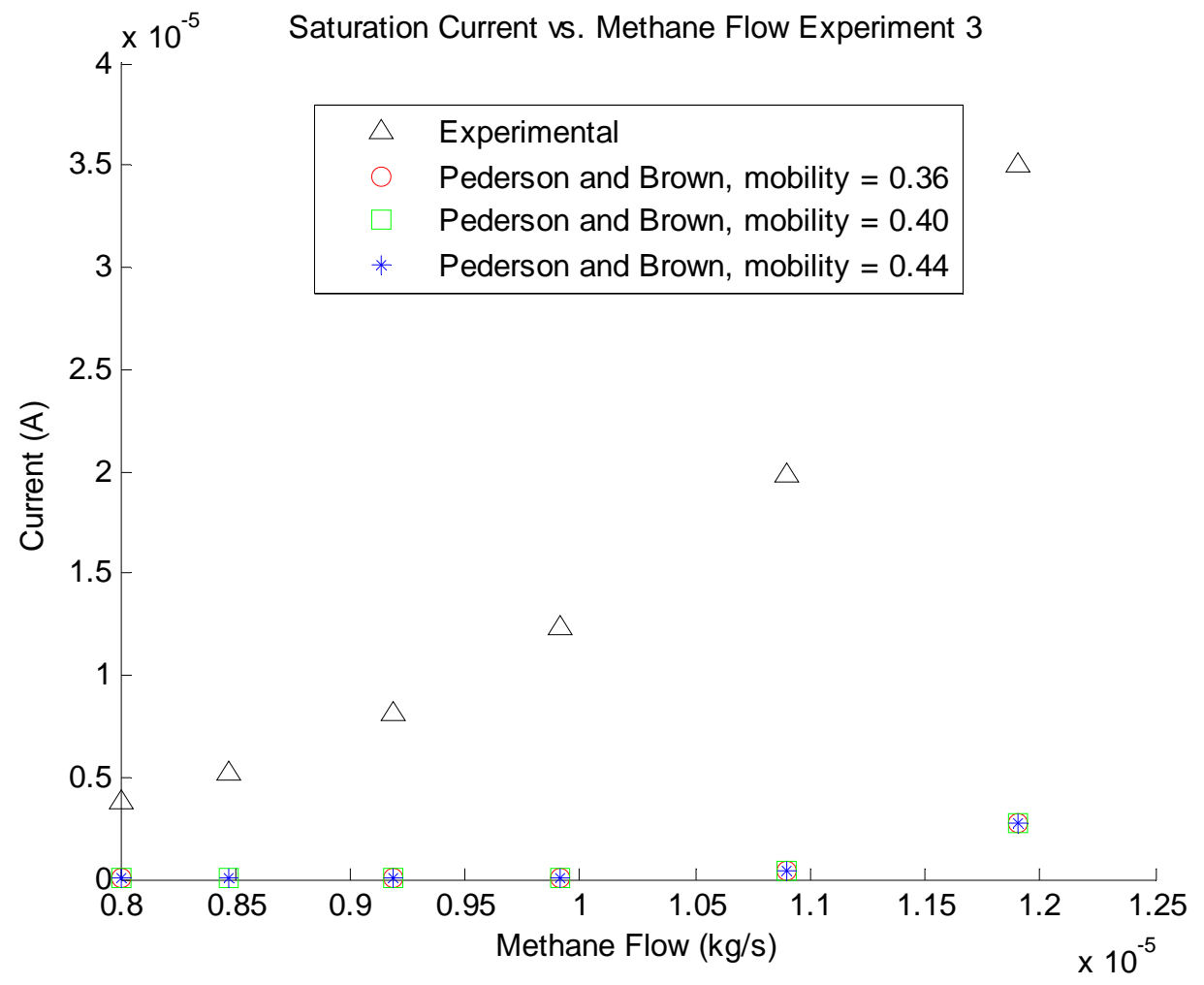

Figure 4-16: Saturation Current Using Pederson and Brown with Methane in Experiment 3

In nearly all of the simulated experiments, the conductivity for this mechanism actually underpredicted the experimental values, although there are a few exceptions as seen in the following figures. However, the problems with the low charged particle concentration and saturation currents makes these conductivity predictions unreliable. 


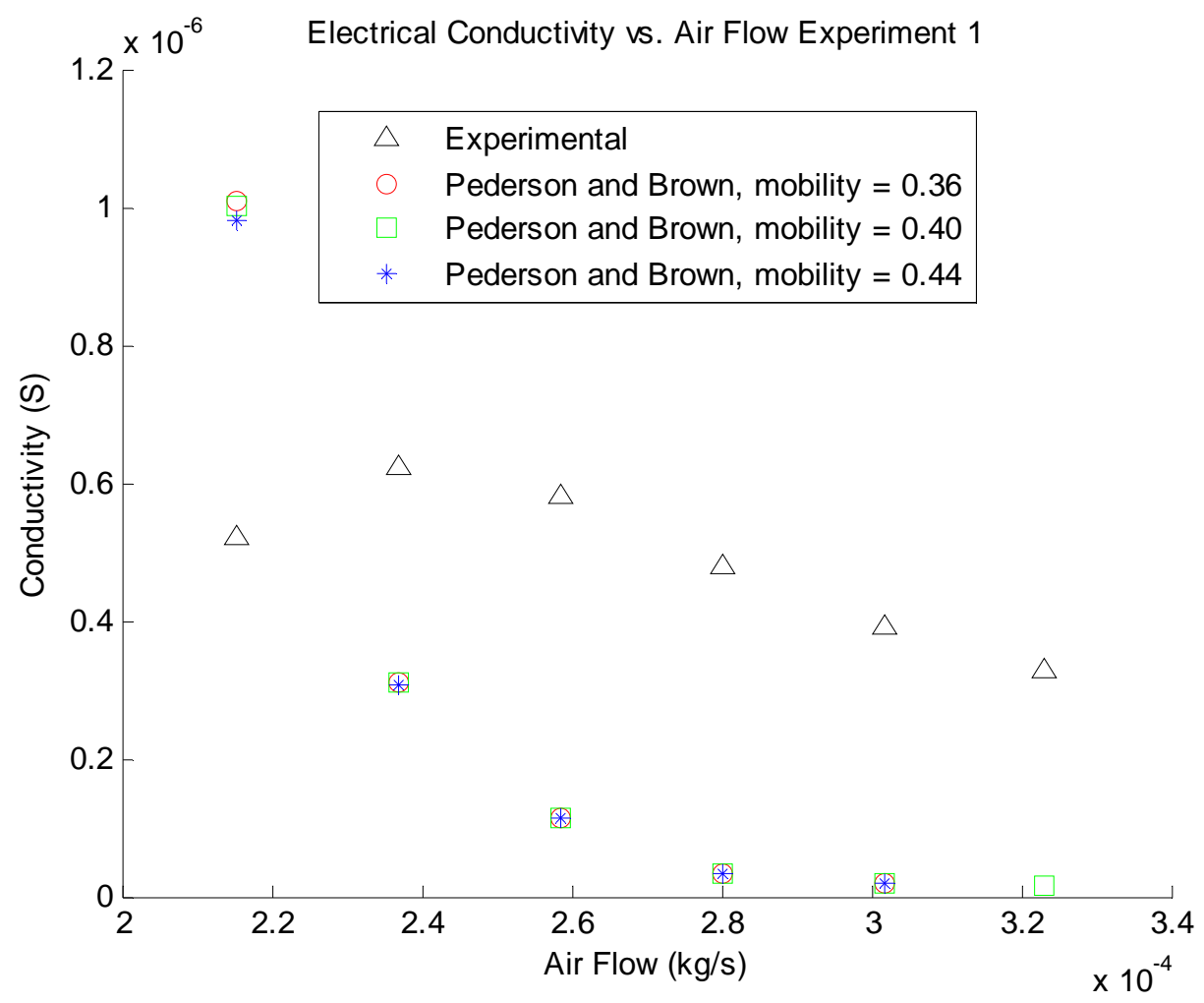

Figure 4-17: Conductivity Using Pederson and Brown with Methane in Experiment 1

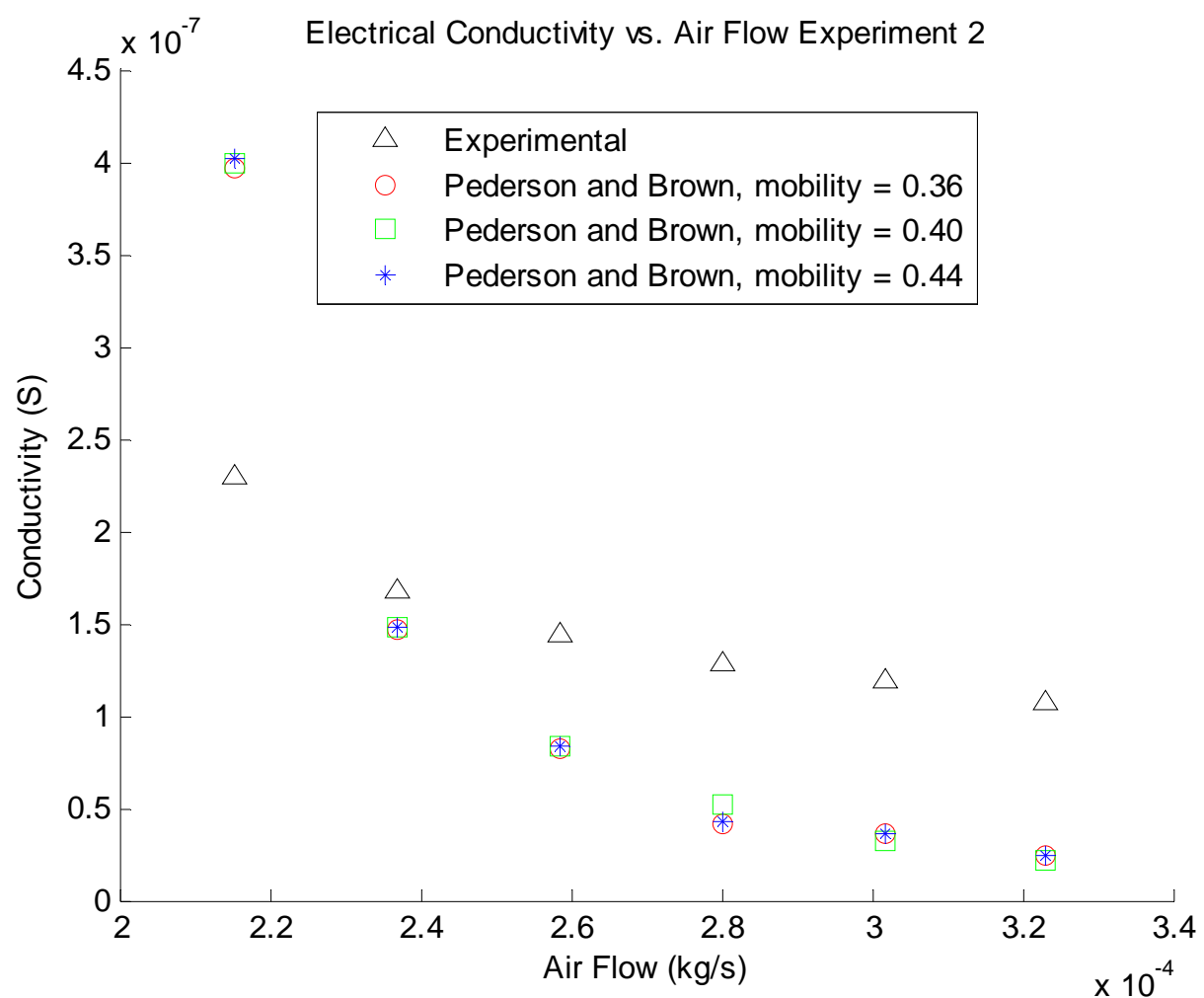

Figure 4-18: Conductivity Using Pederson and Brown with Methane in Experiment 2 


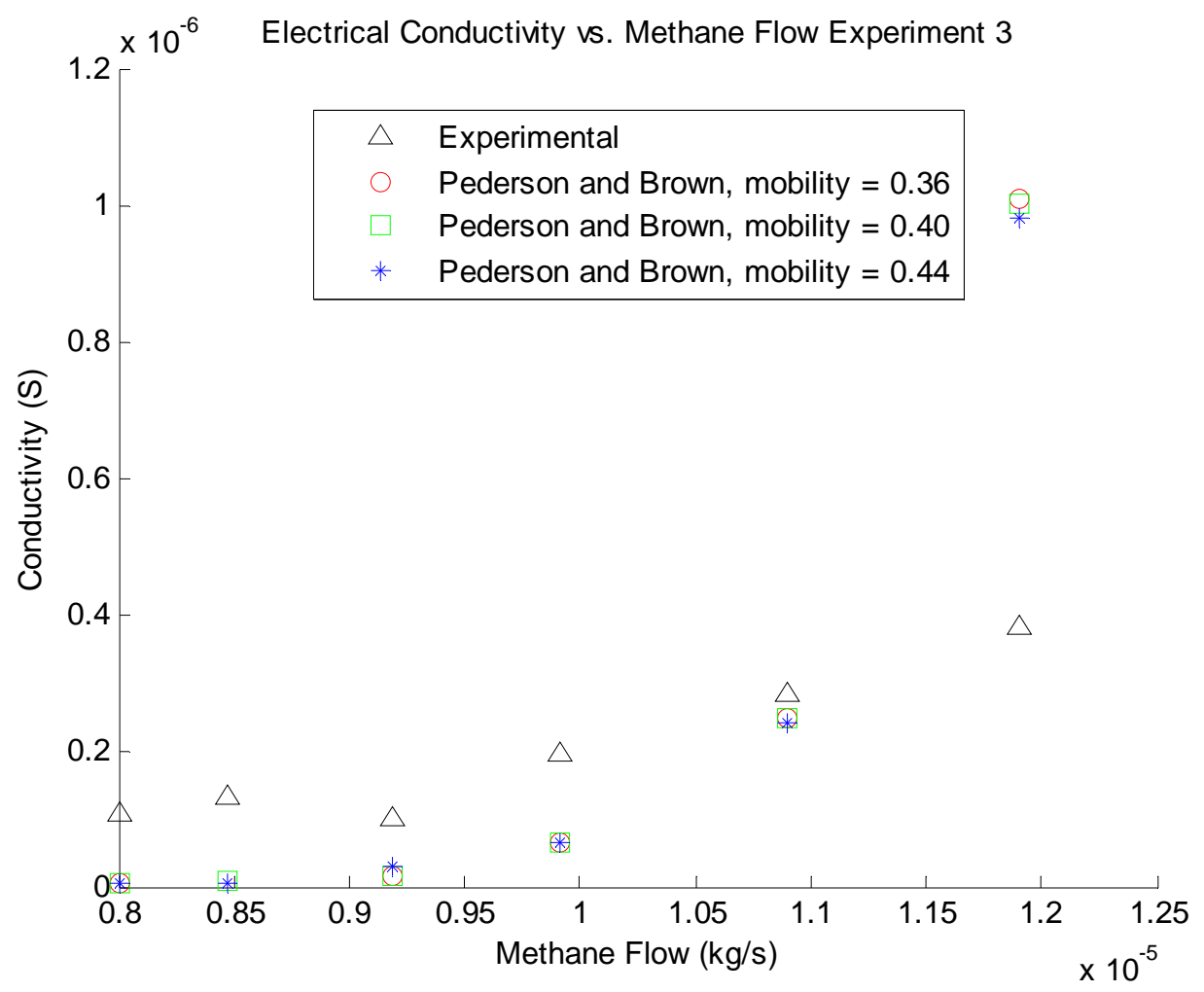

Figure 4-19: Conductivity Using Pederson and Brown with Methane in Experiment 3 


\subsubsection{Peters}

The modified Peters mechanism did not perform as well as the Jones, Becker and Heinsohn or GRIMech 3.0. However it did have some success in predicting general trends for the electrical properties of natural gas flames.

The V-I curve plots in Appendix E quickly reveal that the prediction of the saturation currents are significantly too high in all instances. The actual value of the error appears to be lower for the most lean experiments.

The conductivity, illustrated by the V-I curve slopes, is significantly higher than the conductivity shown in the lab tests. The error with conductivity decreases with the electron mobility.

The following tables show properties of the V-I curves up to $90 \%$ of the saturation current for each of the tested mobily values. 


\begin{tabular}{|c|c|c|c|c|c|c|}
\hline \multirow{3}{*}{$\begin{array}{c}\text { Experiment } \\
\text { Number }\end{array}$} & \multicolumn{6}{|c|}{$\begin{array}{r}\text { Pederson and Brown Methane Combustion V-I Curve Characteristics } \\
\text { to } 90 \% \text { of Peak Current with Mobility }=0.36 \mathrm{~m}^{2} / \mathrm{Vs}\end{array}$} \\
\hline & \multicolumn{2}{|c|}{ Slope } & \multicolumn{2}{|c|}{ Current } & \multicolumn{2}{|c|}{ Voltage } \\
\hline & Modeled & Difference & Modeled & Difference & Modeled & Difference \\
\hline $1-1$ & $9.3342 \mathrm{E}-07$ & $4.1190 \mathrm{E}-07$ & $1.5457 \mathrm{E}-04$ & $1.2302 \mathrm{E}-04$ & 163.00 & 103.124 \\
\hline $1-2$ & $8.1003 \mathrm{E}-07$ & $1.8834 \mathrm{E}-07$ & $8.8866 \mathrm{E}-05$ & $6.4099 \mathrm{E}-05$ & 107.00 & 67.122 \\
\hline $1-3$ & $8.1107 \mathrm{E}-07$ & $2.2974 \mathrm{E}-07$ & $5.6366 \mathrm{E}-05$ & $3.8980 \mathrm{E}-05$ & 67.00 & 37.106 \\
\hline $1-4$ & $7.7691 \mathrm{E}-07$ & $2.9894 \mathrm{E}-07$ & $3.9164 \mathrm{E}-05$ & $2.4883 \mathrm{E}-05$ & 48.00 & 18.106 \\
\hline $1-5$ & $8.8662 \mathrm{E}-07$ & $4.9544 \mathrm{E}-07$ & $2.9277 \mathrm{E}-05$ & $1.7585 \mathrm{E}-05$ & 31.00 & 1.106 \\
\hline $1-6$ & $9.1855 \mathrm{E}-07$ & $5.9167 \mathrm{E}-07$ & $2.2957 \mathrm{E}-05$ & $1.3211 \mathrm{E}-05$ & 23.00 & -6.894 \\
\hline $2-1$ & $4.0648 \mathrm{E}-06$ & $3.8347 \mathrm{E}-06$ & $\begin{array}{c}-1.6317 \mathrm{E}- \\
04\end{array}$ & $-1.2806 \mathrm{E}-04$ & -43.00 & 116.96 \\
\hline $2-2$ & $2.9359 \mathrm{E}-06$ & 2.7682E-06 & $\begin{array}{c}-9.3014 \mathrm{E}- \\
05\end{array}$ & $-6.5937 \mathrm{E}-05$ & -35.00 & 124.95 \\
\hline $2-3$ & $2.3669 \mathrm{E}-06$ & $2.2222 \mathrm{E}-06$ & $\begin{array}{c}-5.8580 \mathrm{E}- \\
05\end{array}$ & $-3.8000 \mathrm{E}-05$ & -28.00 & 111.95 \\
\hline $2-4$ & $2.0791 \mathrm{E}-06$ & $1.9504 \mathrm{E}-06$ & $\begin{array}{c}-3.9754 \mathrm{E}- \\
05\end{array}$ & $-2.3973 \mathrm{E}-05$ & -22.00 & 97.95 \\
\hline $2-5$ & $1.9030 \mathrm{E}-06$ & $1.7840 \mathrm{E}-06$ & $\begin{array}{c}-2.9630 \mathrm{E}- \\
05\end{array}$ & $-1.6935 \mathrm{E}-05$ & -18.00 & 86.95 \\
\hline $3-1$ & $9.3342 \mathrm{E}-07$ & $5.5100 \mathrm{E}-07$ & $1.5457 \mathrm{E}-04$ & $1.1949 \mathrm{E}-04$ & 163.00 & 73.047 \\
\hline $3-2$ & $7.4680 \mathrm{E}-07$ & $4.6309 \mathrm{E}-07$ & $7.2927 \mathrm{E}-05$ & $5.3068 \mathrm{E}-05$ & 95.00 & 25.057 \\
\hline $3-3$ & $6.9421 \mathrm{E}-07$ & $4.9892 \mathrm{E}-07$ & $3.5616 \mathrm{E}-05$ & $2.3282 \mathrm{E}-05$ & 49.00 & -10.947 \\
\hline $3-4$ & $6.8047 \mathrm{E}-07$ & $5.7938 \mathrm{E}-07$ & $2.0372 \mathrm{E}-05$ & $1.2270 \mathrm{E}-05$ & 28.00 & -21.945 \\
\hline $3-5$ & $5.8794 \mathrm{E}-07$ & $4.5741 \mathrm{E}-07$ & $1.1656 \mathrm{E}-05$ & $6.3955 \mathrm{E}-06$ & 18.00 & -21.949 \\
\hline $3-6$ & $4.7814 \mathrm{E}-07$ & $3.7010 \mathrm{E}-07$ & $8.1009 \mathrm{E}-06$ & $4.3024 \mathrm{E}-06$ & 15.00 & -19.946 \\
\hline
\end{tabular}

Table 4-10: V-I Curve Characteristics to $90 \%$ of Maximum Current Using Peters with Electron Mobility of $0.36 \mathrm{~m}^{2} / \mathrm{Vs}$ 


\begin{tabular}{|c|c|c|c|c|c|c|}
\hline \multirow{3}{*}{$\begin{array}{c}\text { Experiment } \\
\text { Number }\end{array}$} & \multicolumn{6}{|c|}{$\begin{array}{r}\text { Pederson and Brown Methane Combustion V-I Curve Characteristics } \\
\text { to } \mathbf{9 0 \%} \text { of Peak Current with Mobility }=\mathbf{0 . 4 0} \mathrm{m}^{2} / \mathrm{Vs}\end{array}$} \\
\hline & \multicolumn{2}{|c|}{ Slope } & \multicolumn{2}{|c|}{ Current } & \multicolumn{2}{|c|}{ Voltage } \\
\hline & Modeled & Difference & Modeled & Difference & Modeled & Difference \\
\hline $1-1$ & $1.0023 \mathrm{E}-06$ & $4.8078 \mathrm{E}-07$ & $1.5499 \mathrm{E}-04$ & $1.2344 \mathrm{E}-04$ & 152.00 & 92.124 \\
\hline $1-2$ & $8.8115 \mathrm{E}-07$ & $2.5946 \mathrm{E}-07$ & $8.8739 \mathrm{E}-05$ & $6.3972 \mathrm{E}-05$ & 98.00 & 58.122 \\
\hline $1-3$ & $9.0168 \mathrm{E}-07$ & $3.2035 \mathrm{E}-07$ & $5.6301 \mathrm{E}-05$ & $3.8915 \mathrm{E}-05$ & 60.00 & 30.106 \\
\hline $1-4$ & $8.6687 \mathrm{E}-07$ & $3.8890 \mathrm{E}-07$ & $3.9306 \mathrm{E}-05$ & $2.5025 \mathrm{E}-05$ & 43.00 & 13.106 \\
\hline $1-5$ & $9.7720 \mathrm{E}-07$ & $5.8602 \mathrm{E}-07$ & $2.9324 \mathrm{E}-05$ & $1.7632 \mathrm{E}-05$ & 28.00 & -1.894 \\
\hline $1-6$ & $1.0556 \mathrm{E}-06$ & $7.2872 \mathrm{E}-07$ & $2.3079 \mathrm{E}-05$ & $1.3333 \mathrm{E}-05$ & 20.00 & -9.894 \\
\hline $2-1$ & 4.0674E-06 & $3.8373 \mathrm{E}-06$ & $\begin{array}{c}-1.6314 \mathrm{E}- \\
04\end{array}$ & $-1.2803 \mathrm{E}-04$ & -43.00 & 116.96 \\
\hline $2-2$ & $2.9386 \mathrm{E}-06$ & $2.7709 \mathrm{E}-06$ & $\begin{array}{c}-9.2998 \mathrm{E}- \\
05\end{array}$ & $-6.5921 \mathrm{E}-05$ & -35.00 & 124.95 \\
\hline $2-3$ & $2.3696 \mathrm{E}-06$ & $2.2249 \mathrm{E}-06$ & $\begin{array}{c}-5.8568 \mathrm{E}- \\
05\end{array}$ & $-3.7988 \mathrm{E}-05$ & -28.00 & 111.95 \\
\hline $2-4$ & $2.0819 \mathrm{E}-06$ & $1.9532 \mathrm{E}-06$ & $\begin{array}{c}-3.9746 \mathrm{E}- \\
05\end{array}$ & $-2.3965 \mathrm{E}-05$ & -22.00 & 97.95 \\
\hline $2-5$ & $1.9056 \mathrm{E}-06$ & $1.7866 \mathrm{E}-06$ & $\begin{array}{c}-2.9625 \mathrm{E}- \\
05\end{array}$ & $-1.6930 \mathrm{E}-05$ & -18.00 & 86.95 \\
\hline $3-1$ & $1.0023 \mathrm{E}-06$ & $6.1988 \mathrm{E}-07$ & $1.5499 \mathrm{E}-04$ & $1.1991 \mathrm{E}-04$ & 152.00 & 62.047 \\
\hline $3-2$ & $8.1140 \mathrm{E}-07$ & $5.2769 \mathrm{E}-07$ & $7.2725 \mathrm{E}-05$ & $5.2866 \mathrm{E}-05$ & 87.00 & 17.057 \\
\hline $3-3$ & $7.6660 \mathrm{E}-07$ & $5.7131 \mathrm{E}-07$ & $3.5466 \mathrm{E}-05$ & $2.3132 \mathrm{E}-05$ & 44.00 & -15.947 \\
\hline $3-4$ & $7.3403 \mathrm{E}-07$ & $6.3294 \mathrm{E}-07$ & $2.0511 \mathrm{E}-05$ & $1.2409 \mathrm{E}-05$ & 26.00 & -23.945 \\
\hline $3-5$ & $6.1981 \mathrm{E}-07$ & $4.8928 \mathrm{E}-07$ & $1.1692 \mathrm{E}-05$ & $6.4315 \mathrm{E}-06$ & 17.00 & -22.949 \\
\hline $3-6$ & $5.0226 \mathrm{E}-07$ & $3.9422 \mathrm{E}-07$ & $8.0254 \mathrm{E}-06$ & $4.2269 \mathrm{E}-06$ & 14.00 & -20.946 \\
\hline
\end{tabular}

Table 4-11: V-I Curve Characteristics to $90 \%$ of Maximum Current Using Peters with Electron Mobility of $0.40 \mathrm{~m}^{2} / \mathrm{Vs}$ 


\begin{tabular}{|c|c|c|c|c|c|c|}
\hline \multirow{3}{*}{$\begin{array}{c}\text { Experiment } \\
\text { Number }\end{array}$} & \multicolumn{6}{|c|}{$\begin{array}{r}\text { Pederson and Brown Methane Combustion V-I Curve Characteristics } \\
\text { to } 90 \% \text { of Peak Current with Mobility }=0.44 \mathrm{~m}^{2} / \mathrm{Vs}\end{array}$} \\
\hline & \multicolumn{2}{|c|}{ Slope } & \multicolumn{2}{|c|}{ Current } & \multicolumn{2}{|c|}{ Voltage } \\
\hline & Modeled & Difference & Modeled & Difference & Modeled & Difference \\
\hline $1-1$ & $1.0711 \mathrm{E}-06$ & $5.4958 \mathrm{E}-07$ & $1.5494 \mathrm{E}-04$ & $1.2339 \mathrm{E}-04$ & 142.00 & 82.124 \\
\hline $1-2$ & $9.4779 \mathrm{E}-07$ & $3.2610 \mathrm{E}-07$ & $8.8823 \mathrm{E}-05$ & $6.4056 \mathrm{E}-05$ & 91.00 & 51.122 \\
\hline $1-3$ & $9.9576 \mathrm{E}-07$ & 4.1443E-07 & $5.6141 \mathrm{E}-05$ & $3.8755 \mathrm{E}-05$ & 54.00 & 24.106 \\
\hline $1-4$ & $1.0306 \mathrm{E}-06$ & $5.5263 \mathrm{E}-07$ & $3.9286 \mathrm{E}-05$ & $2.5005 \mathrm{E}-05$ & 36.00 & 6.106 \\
\hline $1-5$ & $1.0522 \mathrm{E}-06$ & $6.6102 \mathrm{E}-07$ & $2.9450 \mathrm{E}-05$ & $1.7758 \mathrm{E}-05$ & 26.00 & -3.894 \\
\hline $1-6$ & $1.1011 \mathrm{E}-06$ & 7.7422E-07 & $2.3017 \mathrm{E}-05$ & $1.3271 \mathrm{E}-05$ & 19.00 & -10.894 \\
\hline $2-1$ & 4.0697E-06 & $3.8396 \mathrm{E}-06$ & $\begin{array}{c}-1.6313 \mathrm{E}- \\
04\end{array}$ & $-1.2802 \mathrm{E}-04$ & -43.00 & 116.96 \\
\hline $2-2$ & $2.9410 \mathrm{E}-06$ & 2.7733E-06 & $\begin{array}{l}-9.2985 \mathrm{E}- \\
05\end{array}$ & $-6.5908 \mathrm{E}-05$ & -35.00 & 124.95 \\
\hline $2-3$ & $2.3695 \mathrm{E}-06$ & $2.2248 \mathrm{E}-06$ & $\begin{array}{c}-5.8512 \mathrm{E}- \\
05\end{array}$ & $-3.7932 \mathrm{E}-05$ & -28.00 & 111.95 \\
\hline $2-4$ & $2.0831 \mathrm{E}-06$ & $1.9544 \mathrm{E}-06$ & $\begin{array}{c}-3.9719 \mathrm{E}- \\
05\end{array}$ & $-2.3938 \mathrm{E}-05$ & -22.00 & 97.95 \\
\hline $2-5$ & $1.9050 \mathrm{E}-06$ & $1.7860 \mathrm{E}-06$ & $\begin{array}{c}-2.9592 \mathrm{E}- \\
05\end{array}$ & $-1.6897 \mathrm{E}-05$ & -18.00 & 86.95 \\
\hline $2-6$ & $1.8055 \mathrm{E}-06$ & $1.6984 \mathrm{E}-06$ & $\begin{array}{c}-2.3553 \mathrm{E}- \\
05\end{array}$ & $-1.2664 \mathrm{E}-05$ & -15.00 & 84.949 \\
\hline $3-1$ & $1.0711 \mathrm{E}-06$ & $6.8868 \mathrm{E}-07$ & $1.5494 \mathrm{E}-04$ & $1.1986 \mathrm{E}-04$ & 142.00 & 52.047 \\
\hline $3-2$ & $9.1718 \mathrm{E}-07$ & $6.3347 \mathrm{E}-07$ & $7.2924 \mathrm{E}-05$ & $5.3065 \mathrm{E}-05$ & 77.00 & 7.057 \\
\hline $3-3$ & $8.2343 \mathrm{E}-07$ & $6.2814 \mathrm{E}-07$ & $3.5627 \mathrm{E}-05$ & $2.3293 \mathrm{E}-05$ & 41.00 & -18.947 \\
\hline $3-4$ & $7.9098 \mathrm{E}-07$ & $6.8989 \mathrm{E}-07$ & $2.0514 \mathrm{E}-05$ & $1.2412 \mathrm{E}-05$ & 24.00 & -25.945 \\
\hline $3-5$ & $6.5153 \mathrm{E}-07$ & $5.2100 \mathrm{E}-07$ & $1.1656 \mathrm{E}-05$ & $6.3955 \mathrm{E}-06$ & 16.00 & -23.949 \\
\hline $3-6$ & $5.0527 \mathrm{E}-07$ & $3.9723 \mathrm{E}-07$ & $8.1271 \mathrm{E}-06$ & $4.3286 \mathrm{E}-06$ & 14.00 & -20.946 \\
\hline
\end{tabular}

Table 4-12: V-I Curve Characteristics to $\mathbf{9 0 \%}$ of Maximum Current Using Peters with Electron Mobility of $0.44 \mathrm{~m}^{2} / \mathrm{Vs}$

The following figures show that the saturation current is overpredicted in all cases with this mechanism, although the values are closer in cases with lower equivalence ratios. 


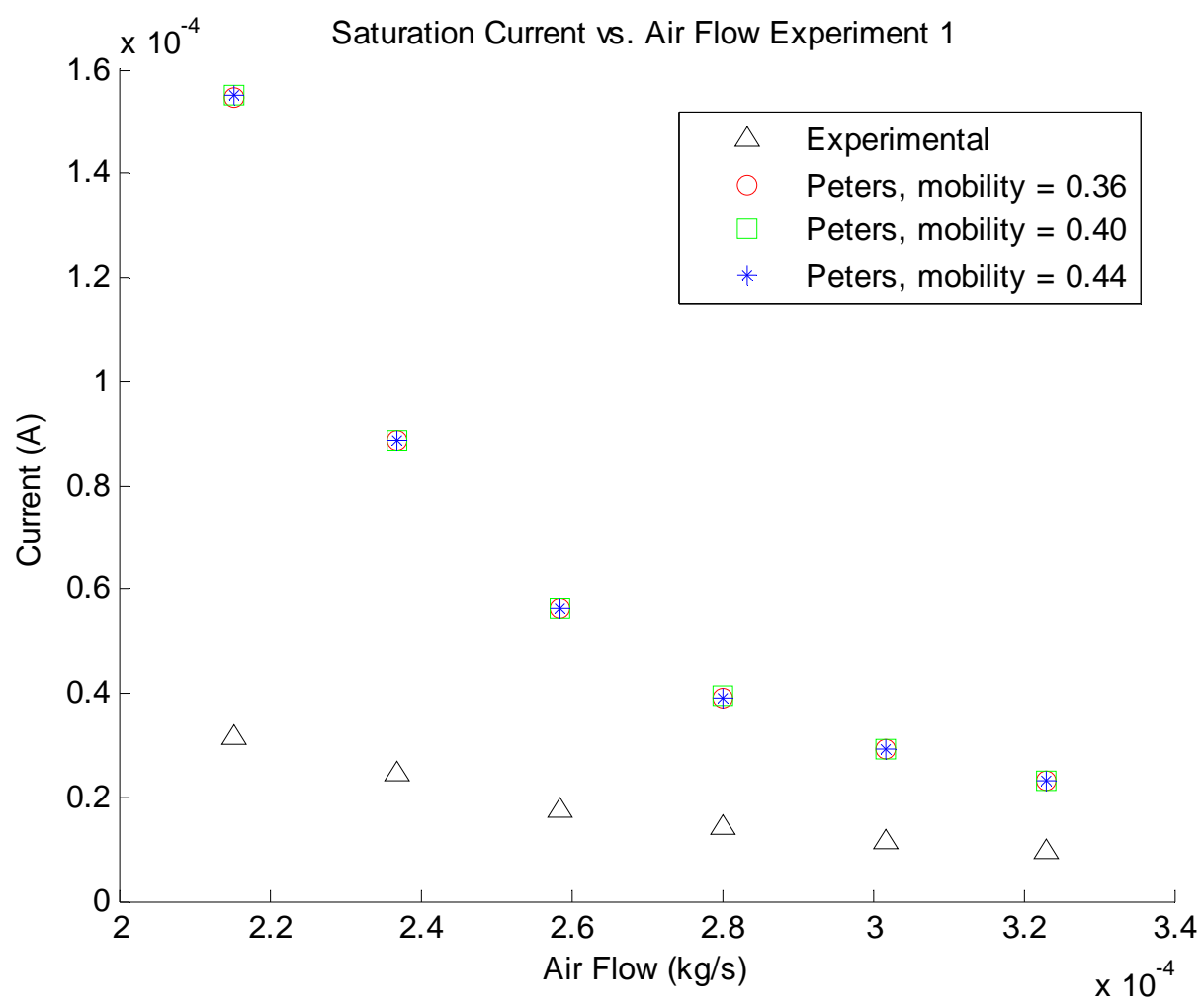

Figure 4-20: Saturation Current Using Peters with Methane in Experiment 1

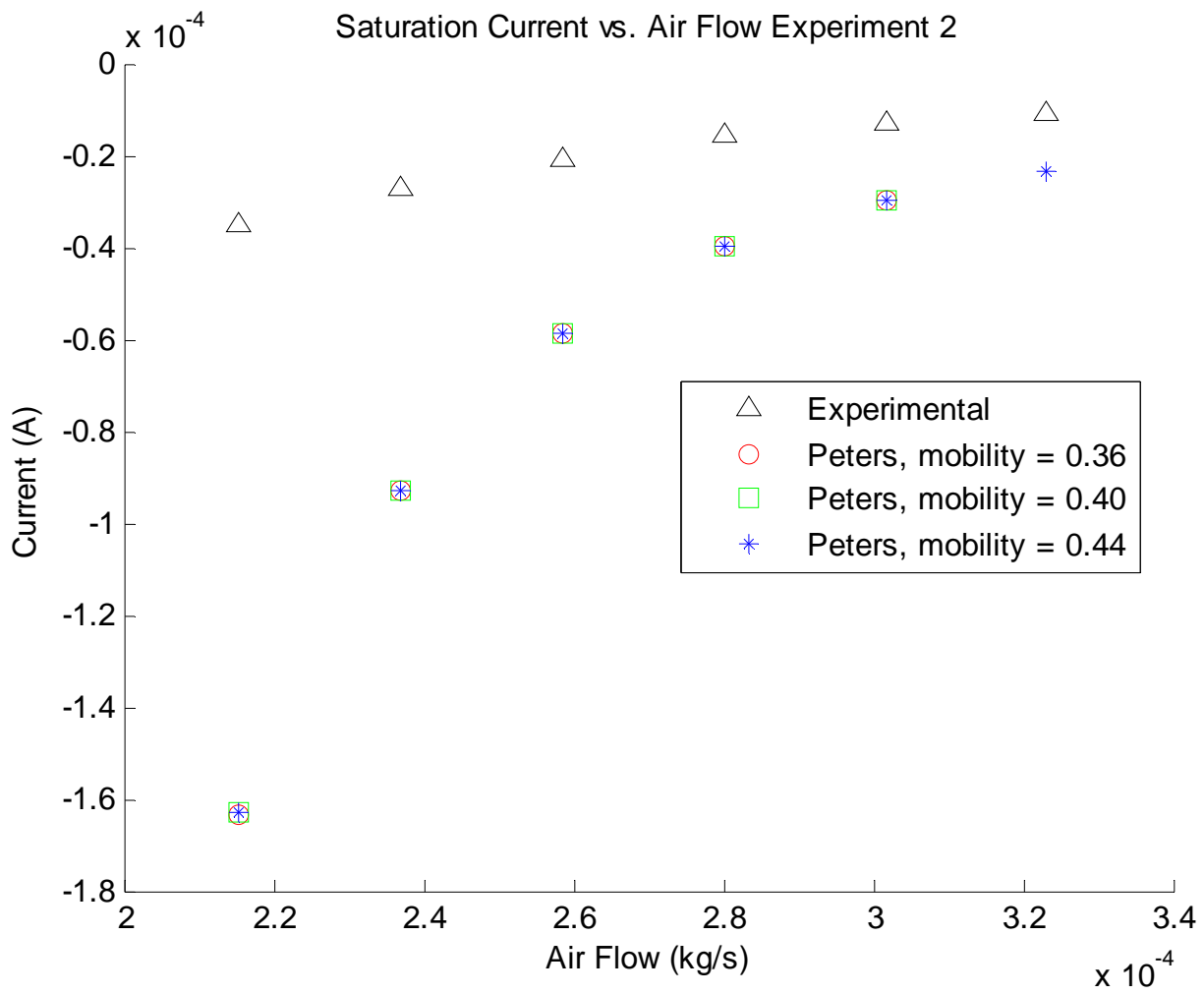

Figure 4-21: Saturation Current Using Peters with Methane in Experiment 2 


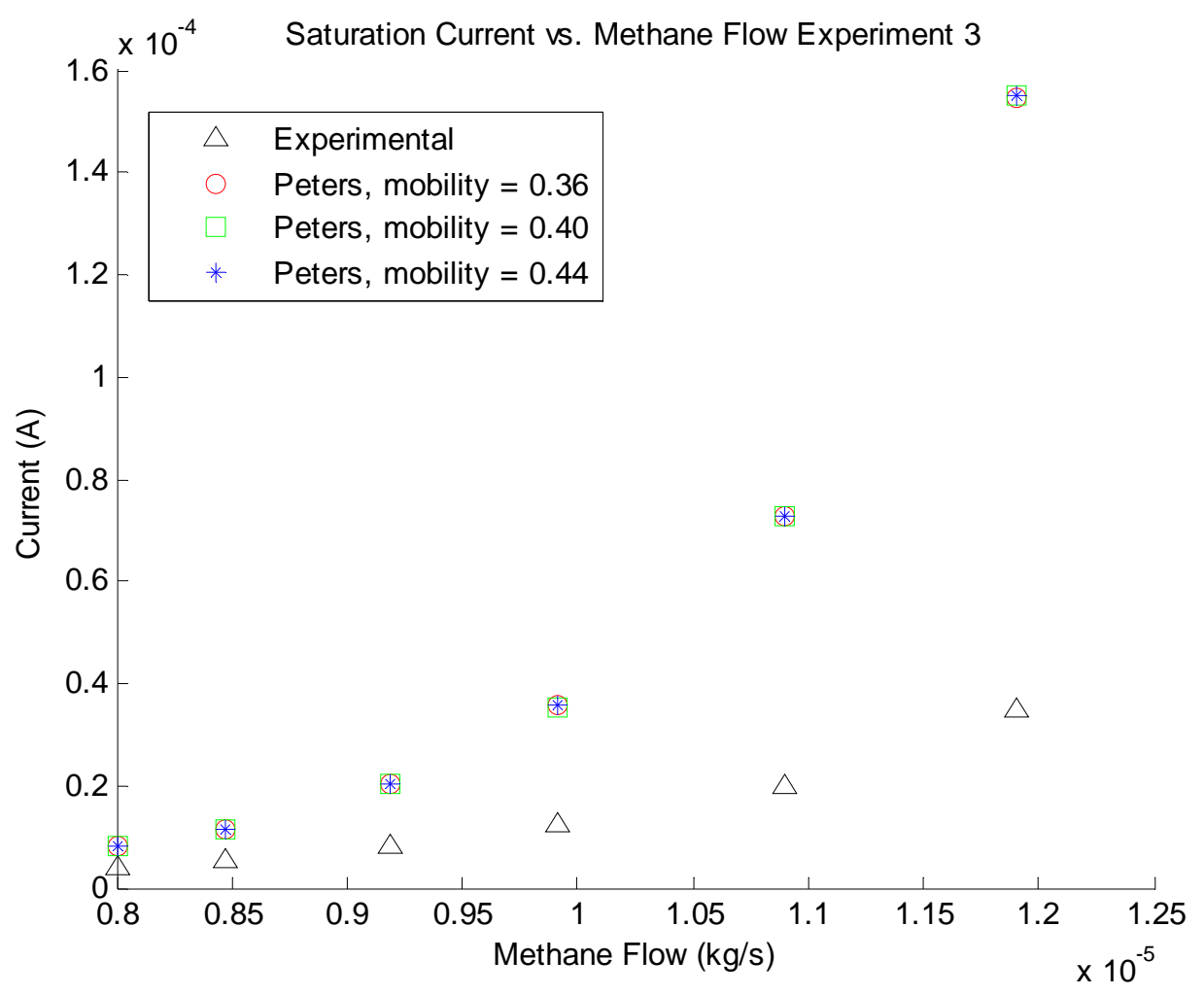

Figure 4-22: Saturation Current Using Peters with Methane in Experiment 3

The simulated conductivity using the tested mobilities is significantly higher than the experimental values for all of the natural gas simulations. For experiments one and three, which had a burner to electrode distance of $1.6 \mathrm{~cm}$, there was a noticeable reduction of the simulated conductivity with decreased mobility values, but for experiment 2 , which had a burner to electrode distance of just $0.2 \mathrm{~cm}$, this effect was not noticeable. 


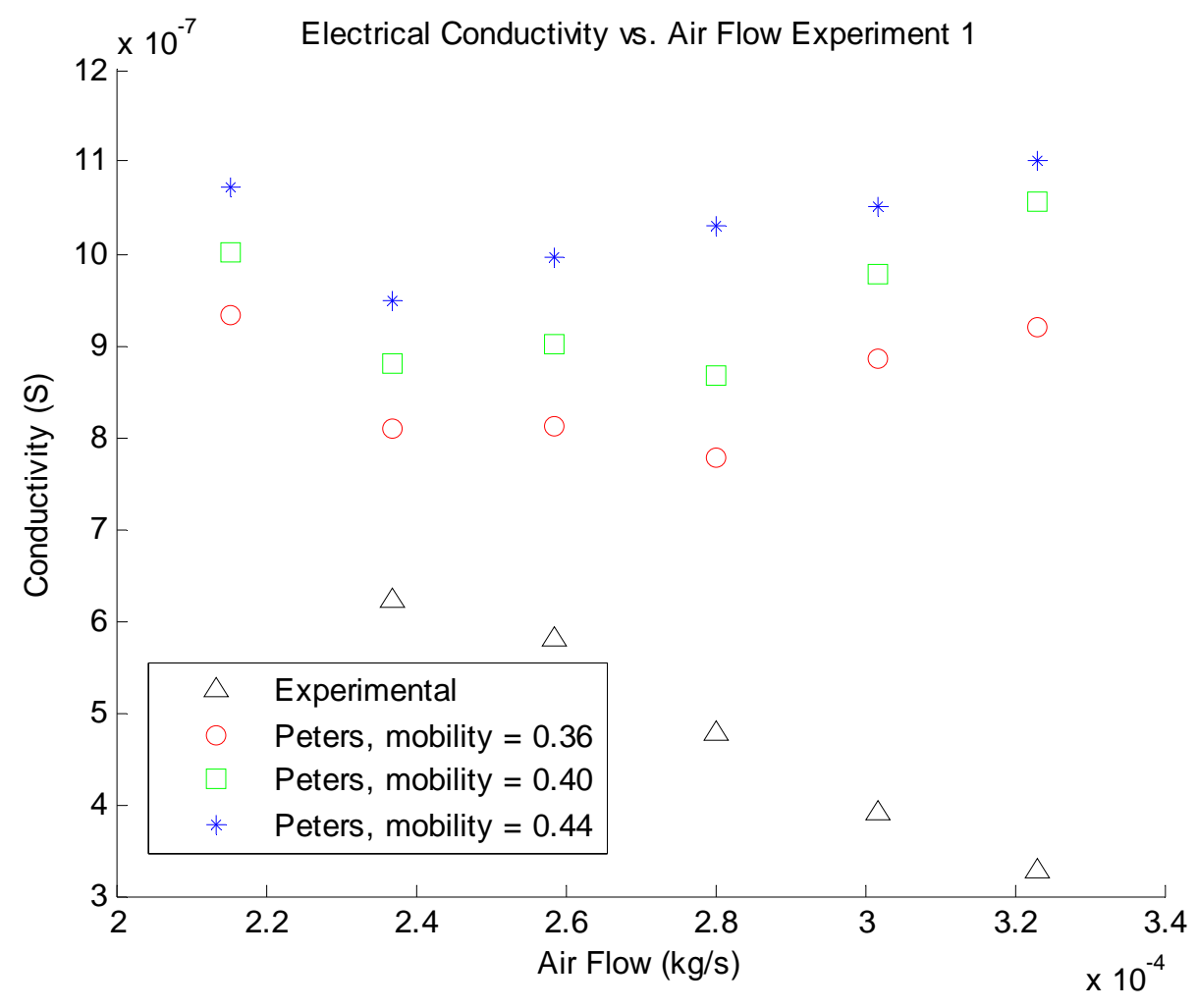

Figure 4-23: Conductivity Using Peters with Methane in Experiment 1

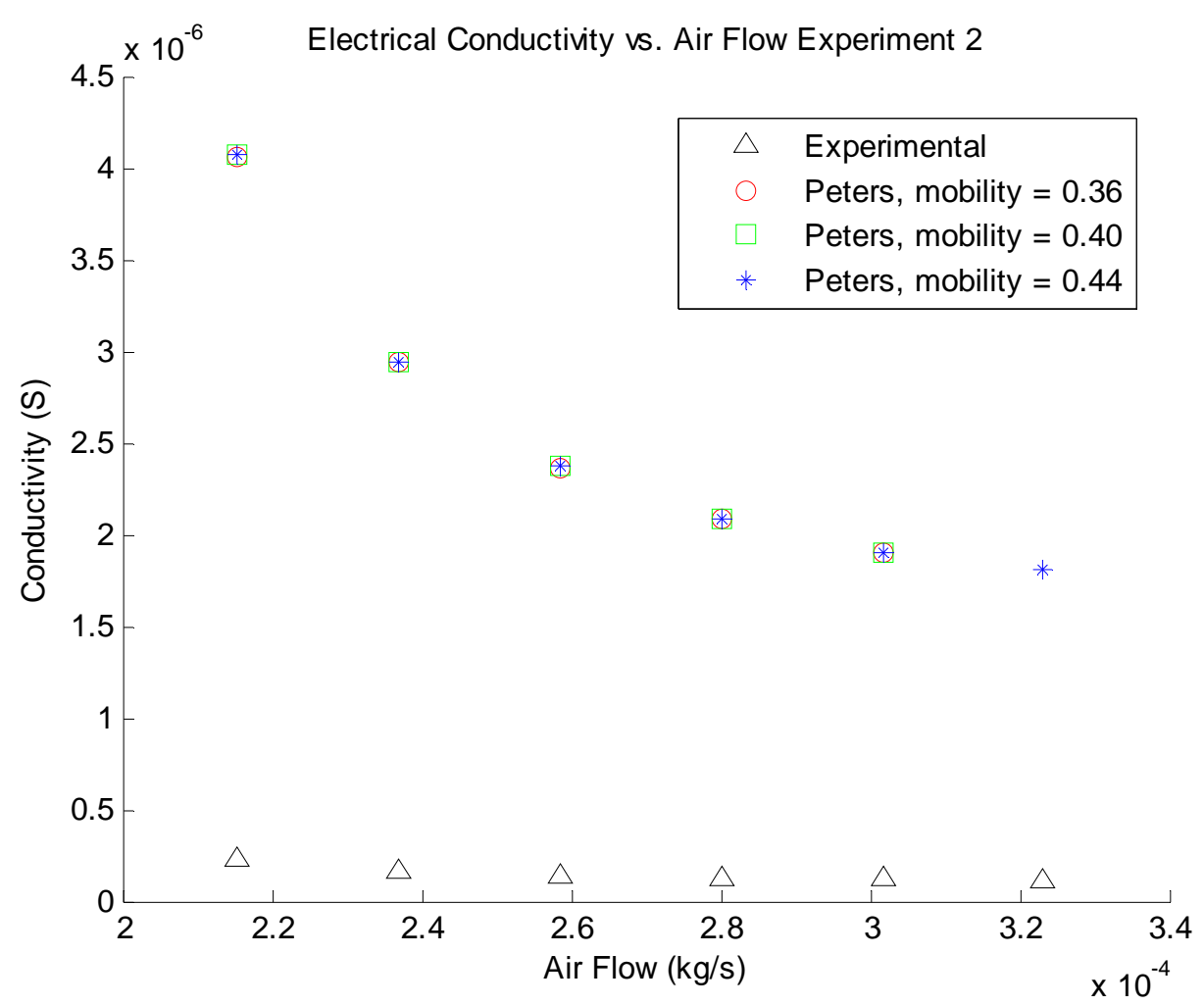

Figure 4-24: Conductivity Using Peters with Methane in Experiment 2 


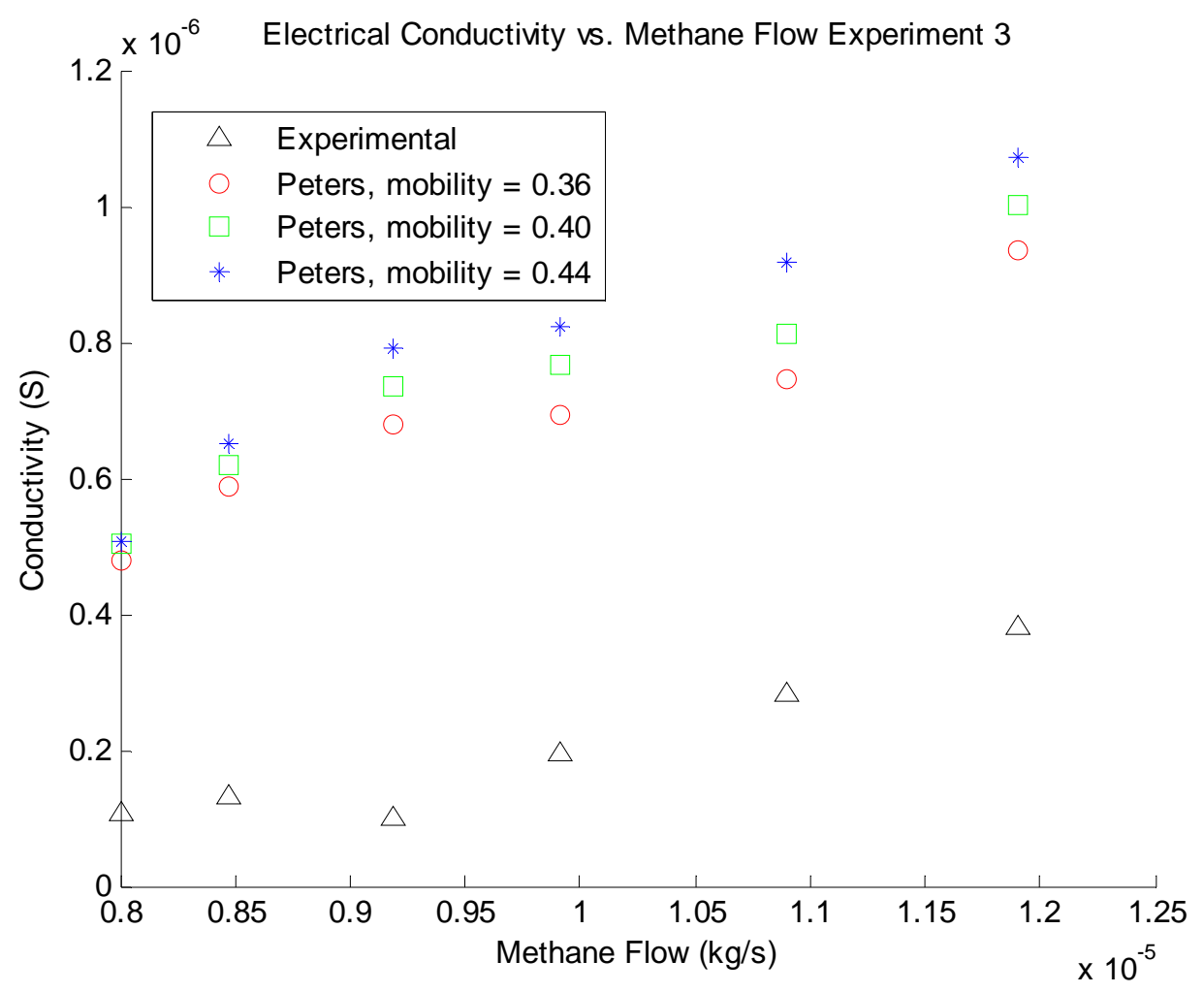

Figure 4-25: Conductivity Using Peters with Methane in Experiment 3 


\subsubsection{Comparison of All Mechanisms}

Among the four reaction mechanisms used in this research, two stand out strongly as being best able to predict methane flame electrical properties. These two reaction mechanism are the Jones, Becker and Heinsohn and the modified GRIMech 3.0. The Peters mechanism shows some potential for use in predicting electrical properties of simulated methane flames, but there is a flaw within the mechanism that results in overprediction of saturation currents. In this particular study, the Pederson and Brown mechanism performed very poorly at predicting flame electrical properties.

Among the three best performing mechanisms, the flame conductivity was

consistently overpredicted using mobility values of $0.36 \mathrm{~m}^{2} / \mathrm{Vs}_{\mathrm{s}}, 0.40 \mathrm{~m}^{2} / \mathrm{Vs}_{\mathrm{s}}$, and $0.44 \mathrm{~m}^{2} / \mathrm{Vs}_{\mathrm{s}}$, but generally, an improvement was apparent as the mobility was decreased, which suggests that a lower mobility value should be used. The performance of the Pederson and Brown mechanism was very poor for electrical properties, and the conductivity values calculated by this mechanism are believed to be unreliable as a result.

The following tables summarize the properties of the V-I curves for simulations run with each mechanism in addition to the experimental findings. Remember that the slope of the V-I curve is equivalent to conductivity. 


\begin{tabular}{|c|c|c|c|c|c|}
\hline \multirow{2}{*}{$\begin{array}{l}\text { Experiment } \\
\text { Number }\end{array}$} & \multicolumn{5}{|c|}{ Experimental and Modeled V-I Curve Slope to $90 \%$ of Peak } \\
\hline & Experimental & $\begin{array}{c}\text { GRIMech } \\
3.0\end{array}$ & $\begin{array}{c}\text { Jones, Becker and } \\
\text { Heinsohn }\end{array}$ & $\begin{array}{l}\text { Pederson } \\
\text { and Brown }\end{array}$ & Peters \\
\hline $1-1$ & $5.215200 \mathrm{E}-07$ & $\begin{array}{l}6.396600 \mathrm{E}- \\
07\end{array}$ & $6.405300 \mathrm{E}-07$ & $1.003300 \mathrm{E}-06$ & $\begin{array}{c}1.002300 \mathrm{E}- \\
06\end{array}$ \\
\hline $1-2$ & $6.216900 \mathrm{E}-07$ & $\begin{array}{l}7.250900 \mathrm{E}- \\
07 \\
\end{array}$ & $6.966500 \mathrm{E}-07$ & $3.093700 \mathrm{E}-07$ & $\begin{array}{l}8.811500 \mathrm{E}- \\
07\end{array}$ \\
\hline $1-3$ & $5.813300 \mathrm{E}-07$ & $\begin{array}{l}8.455400 \mathrm{E}- \\
07\end{array}$ & $7.557800 \mathrm{E}-07$ & $1.145500 \mathrm{E}-07$ & $\begin{array}{l}9.016800 \mathrm{E}- \\
07\end{array}$ \\
\hline $1-4$ & 4.779700E-07 & $\begin{array}{l}8.066600 \mathrm{E}- \\
07\end{array}$ & $8.398100 \mathrm{E}-07$ & $3.308100 \mathrm{E}-08$ & $\begin{array}{l}8.668700 \mathrm{E}- \\
07\end{array}$ \\
\hline $1-5$ & $3.911800 \mathrm{E}-07$ & $\begin{array}{l}7.103900 \mathrm{E}- \\
07\end{array}$ & $9.861100 \mathrm{E}-07$ & $2.049000 \mathrm{E}-08$ & $\begin{array}{l}9.772000 \mathrm{E}- \\
07\end{array}$ \\
\hline $1-6$ & $3.268800 \mathrm{E}-07$ & $\begin{array}{l}5.593700 \mathrm{E}- \\
07 \\
\end{array}$ & $1.076800 \mathrm{E}-06$ & $1.420500 \mathrm{E}-08$ & $\begin{array}{c}1.055600 \mathrm{E}- \\
06\end{array}$ \\
\hline $2-1$ & $2.301000 \mathrm{E}-07$ & $\begin{array}{l}1.910400 \mathrm{E}- \\
06\end{array}$ & $1.048000 \mathrm{E}-06$ & $3.997800 \mathrm{E}-07$ & $\begin{array}{l}4.067400 \mathrm{E}- \\
06 \\
\end{array}$ \\
\hline $2-2$ & $1.676900 \mathrm{E}-07$ & $\begin{array}{l}1.487800 \mathrm{E}- \\
06\end{array}$ & $9.006300 \mathrm{E}-07$ & $1.475900 \mathrm{E}-07$ & $\begin{array}{l}2.938600 \mathrm{E}- \\
06\end{array}$ \\
\hline $2-3$ & $1.446600 \mathrm{E}-07$ & $\begin{array}{l}1.253200 \mathrm{E}- \\
06\end{array}$ & $8.154000 \mathrm{E}-07$ & $8.310900 \mathrm{E}-08$ & $\begin{array}{l}2.369600 \mathrm{E}- \\
06\end{array}$ \\
\hline $2-4$ & $1.287000 \mathrm{E}-07$ & $\begin{array}{l}1.122400 \mathrm{E}- \\
06\end{array}$ & $7.551800 \mathrm{E}-07$ & $5.134100 \mathrm{E}-08$ & $\begin{array}{l}2.081900 \mathrm{E}- \\
06\end{array}$ \\
\hline $2-5$ & $1.190400 \mathrm{E}-07$ & $\begin{array}{c}1.032700 \mathrm{E}- \\
06\end{array}$ & $7.115700 \mathrm{E}-07$ & $3.176200 \mathrm{E}-08$ & $\begin{array}{l}1.905600 \mathrm{E}- \\
06\end{array}$ \\
\hline $2-6$ & $1.071000 \mathrm{E}-07$ & $\begin{array}{l}9.317700 \mathrm{E}- \\
07\end{array}$ & $6.697900 \mathrm{E}-07$ & $2.134200 \mathrm{E}-08$ & --- \\
\hline $3-1$ & $3.824200 \mathrm{E}-07$ & $\begin{array}{l}6.396600 \mathrm{E}- \\
07\end{array}$ & $6.405300 \mathrm{E}-07$ & $1.003300 \mathrm{E}-06$ & $\begin{array}{l}1.002300 \mathrm{E}- \\
06\end{array}$ \\
\hline $3-2$ & $2.837100 \mathrm{E}-07$ & $\begin{array}{c}6.815400 \mathrm{E}- \\
07 \\
\end{array}$ & $6.655600 \mathrm{E}-07$ & $2.465600 \mathrm{E}-07$ & $\begin{array}{c}8.114000 \mathrm{E}- \\
07\end{array}$ \\
\hline $3-3$ & $1.952900 \mathrm{E}-07$ & $\begin{array}{l}6.457100 \mathrm{E}- \\
07\end{array}$ & $6.445300 \mathrm{E}-07$ & $6.569200 \mathrm{E}-08$ & $\begin{array}{c}7.666000 \mathrm{E}- \\
07\end{array}$ \\
\hline $3-4$ & $1.010900 \mathrm{E}-07$ & $\begin{array}{l}4.880900 \mathrm{E}- \\
07\end{array}$ & $6.900300 \mathrm{E}-07$ & $1.539300 \mathrm{E}-08$ & $\begin{array}{c}7.340300 \mathrm{E}- \\
07\end{array}$ \\
\hline $3-5$ & $1.305300 \mathrm{E}-07$ & $\begin{array}{l}3.389200 \mathrm{E}- \\
07\end{array}$ & $8.269500 \mathrm{E}-07$ & $7.294900 \mathrm{E}-09$ & $\begin{array}{l}6.198100 \mathrm{E}- \\
07\end{array}$ \\
\hline $3-6$ & $1.080400 \mathrm{E}-07$ & $\begin{array}{l}2.273500 \mathrm{E}- \\
07\end{array}$ & $9.520100 \mathrm{E}-07$ & 4.239000E-09 & $\begin{array}{c}5.022600 \mathrm{E}- \\
07\end{array}$ \\
\hline
\end{tabular}

Table 4-13: Experimental and Modeled V-I Curve Slopes to $90 \%$ of Maximum Current for All Mechanisms Using Methane Combustion with Mobility $=0.40 \mathrm{~m}^{2} / \mathrm{Vs}$ 


\begin{tabular}{|c|c|c|c|c|c|}
\hline \multirow{2}{*}{$\begin{array}{c}\text { Experiment } \\
\text { Number }\end{array}$} & \multicolumn{5}{|c|}{ Experimental and Modeled Voltage at $90 \%$ of Peak Current } \\
\hline & Experimental & $\begin{array}{c}\text { GRIMech } \\
3.0 \\
\end{array}$ & $\begin{array}{c}\text { Jones, Becker and } \\
\text { Heinsohn }\end{array}$ & $\begin{array}{c}\text { Pederson } \\
\text { and Brown }\end{array}$ & Peters \\
\hline $1-1$ & 59.876 & 51 & 40 & 2 & 152 \\
\hline $1-2$ & 39.878 & 26 & 28 & 1 & 98 \\
\hline $1-3$ & 29.894 & 14 & 21 & 1 & 60 \\
\hline $1-4$ & 29.894 & 10 & 16 & 2 & 43 \\
\hline $1-5$ & 29.894 & 8 & 12 & 2 & 28 \\
\hline $1-6$ & 29.894 & 8 & 10 & 2 & 20 \\
\hline $2-1$ & -159.96 & -23 & -38 & -11 & -43 \\
\hline $2-2$ & -159.95 & -18 & -35 & -5 & -35 \\
\hline $2-3$ & -139.95 & -14 & -32 & -3 & -28 \\
\hline $2-4$ & -119.95 & -11 & -30 & -2 & -22 \\
\hline $2-5$ & -104.95 & -9 & -28 & -2 & -18 \\
\hline $2-6$ & -99.949 & -8 & -27 & -2 & --- \\
\hline $3-1$ & 89.953 & 51 & 40 & 2 & 152 \\
\hline $3-2$ & 69.943 & 22 & 23 & 1 & 87 \\
\hline $3-3$ & 59.947 & 11 & 15 & 1 & 44 \\
\hline $3-4$ & 49.945 & 8 & 10 & 2 & 26 \\
\hline $3-5$ & 39.949 & 6 & 6 & 2 & 17 \\
\hline $3-6$ & 34.946 & 6 & 4 & 2 & 14 \\
\hline
\end{tabular}

Table 4-14: Experimental and Modeled Voltage at $90 \%$ of Maximum Current for All Mechanisms Using Methane Combustion with Mobility $=\mathbf{0 . 4 0} \mathrm{m}^{2} / \mathrm{Vs}$ 


\begin{tabular}{|c|c|c|c|c|c|}
\hline \multirow{2}{*}{$\begin{array}{l}\text { Experiment } \\
\text { Number }\end{array}$} & \multicolumn{5}{|c|}{ Experimental and Modeled Current at $90 \%$ of Peak } \\
\hline & Experimental & $\begin{array}{c}\text { GRIMech } \\
3.0\end{array}$ & $\begin{array}{c}\text { Jones, Becker and } \\
\text { Heinsohn }\end{array}$ & $\begin{array}{c}\text { Pederson } \\
\text { and Brown }\end{array}$ & Peters \\
\hline $1-1$ & $3.1549000 \mathrm{E}-05$ & $\begin{array}{c}3.4428000 \mathrm{E}- \\
05\end{array}$ & $2.6630000 \mathrm{E}-05$ & $2.7251000 \mathrm{E}-06$ & $\begin{array}{c}1.5499000 \mathrm{E}- \\
04\end{array}$ \\
\hline $1-2$ & $2.4767000 \mathrm{E}-05$ & $\begin{array}{c}2.0427000 \mathrm{E}- \\
05\end{array}$ & $2.0510000 \mathrm{E}-05$ & $4.5822000 \mathrm{E}-07$ & $\begin{array}{c}8.8739000 \mathrm{E}- \\
05\end{array}$ \\
\hline $1-3$ & $1.7386000 \mathrm{E}-05$ & $\begin{array}{c}1.3249000 \mathrm{E}- \\
05\end{array}$ & $1.6824000 \mathrm{E}-05$ & $1.6984000 \mathrm{E}-07$ & $\begin{array}{l}5.6301000 \mathrm{E}- \\
05\end{array}$ \\
\hline $1-4$ & $1.4281000 \mathrm{E}-05$ & $\begin{array}{c}9.3561000 \mathrm{E}- \\
06\end{array}$ & $1.4376000 \mathrm{E}-05$ & $9.3304000 \mathrm{E}-08$ & $\begin{array}{c}3.9306000 \mathrm{E}- \\
05\end{array}$ \\
\hline $1-5$ & $1.1692000 \mathrm{E}-05$ & $\begin{array}{c}6.9446000 \mathrm{E}- \\
06\end{array}$ & $1.2738000 \mathrm{E}-05$ & $5.7166000 \mathrm{E}-08$ & $\begin{array}{l}2.9324000 \mathrm{E}- \\
05\end{array}$ \\
\hline $1-6$ & $9.7458000 \mathrm{E}-06$ & $\begin{array}{c}5.6134000 \mathrm{E}- \\
06 \\
\end{array}$ & $1.1625000 \mathrm{E}-05$ & $3.9151000 \mathrm{E}-08$ & $\begin{array}{c}2.3079000 \mathrm{E}- \\
05 \\
\end{array}$ \\
\hline $2-1$ & $-3.5110000 \mathrm{E}-05$ & $\begin{array}{c}- \\
3.6770000 \mathrm{E}- \\
05 \\
\end{array}$ & $-2.8158000 \mathrm{E}-05$ & $-2.6498000 \mathrm{E}-06$ & $\begin{array}{c}- \\
1.6314000 \mathrm{E}- \\
04 \\
\end{array}$ \\
\hline $2-2$ & $-2.7077000 \mathrm{E}-05$ & $\begin{array}{c}- \\
2.1388000 \mathrm{E}- \\
05\end{array}$ & $-2.1530000 \mathrm{E}-05$ & $-4.7895000 \mathrm{E}-07$ & $\begin{array}{c}- \\
9.2998000 \mathrm{E}- \\
05\end{array}$ \\
\hline $2-3$ & $-2.0580000 \mathrm{E}-05$ & $\begin{array}{c}- \\
1.3571000 \mathrm{E}- \\
05\end{array}$ & $-1.7429000 \mathrm{E}-05$ & $-1.7628000 \mathrm{E}-07$ & $\begin{array}{c}- \\
5.8568000 \mathrm{E}- \\
05\end{array}$ \\
\hline $2-4$ & $-1.5781000 \mathrm{E}-05$ & $\begin{array}{c}- \\
9.3891000 \mathrm{E}- \\
06\end{array}$ & $-1.4966000 \mathrm{E}-05$ & $-7.5428000 \mathrm{E}-08$ & $\begin{array}{c}- \\
3.9746000 \mathrm{E}- \\
05\end{array}$ \\
\hline $2-5$ & $-1.2695000 \mathrm{E}-05$ & $\begin{array}{c}- \\
7.0585000 \mathrm{E}- \\
06 \\
\end{array}$ & $-1.3029000 \mathrm{E}-05$ & $-5.0980000 \mathrm{E}-08$ & $\begin{array}{c}- \\
2.9625000 \mathrm{E}- \\
05\end{array}$ \\
\hline $2-6$ & $-1.0889000 \mathrm{E}-05$ & $\begin{array}{c}- \\
5.7643000 \mathrm{E}- \\
06\end{array}$ & $-1.1881000 \mathrm{E}-05$ & $-3.7027000 \mathrm{E}-08$ & --- \\
\hline $3-1$ & $3.5078000 \mathrm{E}-05$ & $\begin{array}{c}3.4428000 \mathrm{E}- \\
05\end{array}$ & $2.6630000 \mathrm{E}-05$ & $2.7251000 \mathrm{E}-06$ & $\begin{array}{c}1.5499000 \mathrm{E}- \\
04\end{array}$ \\
\hline $3-2$ & $1.9859000 \mathrm{E}-05$ & $\begin{array}{c}1.6388000 \mathrm{E}- \\
05\end{array}$ & $1.6126000 \mathrm{E}-05$ & 3.6409000E-07 & $\begin{array}{c}7.2725000 \mathrm{E}- \\
05\end{array}$ \\
\hline $3-3$ & $1.2334000 \mathrm{E}-05$ & $\begin{array}{c}8.1736000 \mathrm{E}- \\
06\end{array}$ & $1.0537000 \mathrm{E}-05$ & $9.7015000 \mathrm{E}-08$ & $\begin{array}{l}3.5466000 \mathrm{E}- \\
05\end{array}$ \\
\hline $3-4$ & $8.1020000 \mathrm{E}-06$ & $\begin{array}{c}4.7265000 \mathrm{E}- \\
06\end{array}$ & $7.5195000 \mathrm{E}-06$ & $4.3369000 \mathrm{E}-08$ & $\begin{array}{c}2.0511000 \mathrm{E}- \\
05\end{array}$ \\
\hline $3-5$ & $5.2605000 \mathrm{E}-06$ & $\begin{array}{c}2.6077000 \mathrm{E}- \\
06\end{array}$ & $5.4365000 \mathrm{E}-06$ & $1.9420000 \mathrm{E}-08$ & $\begin{array}{c}1.1692000 \mathrm{E}- \\
05\end{array}$ \\
\hline $3-6$ & $3.7985000 \mathrm{E}-06$ & $\begin{array}{c}1.8452000 \mathrm{E}- \\
06 \\
\end{array}$ & $4.2400000 \mathrm{E}-06$ & $1.1549000 \mathrm{E}-08$ & $\begin{array}{c}8.0254000 \mathrm{E}- \\
06\end{array}$ \\
\hline
\end{tabular}

Table 4-15: Experimental and Modeled Current at 90\% of Maximum for All Mechanisms Using Methane Combustion with Mobility $=\mathbf{0 . 4 0} \mathrm{m}^{2} / \mathrm{Vs}$

A comparision of the some major flame properties for all four mechanisms

reveals a few interesting features. One notable feature is that there is a low temperature 
and high temperature pairs of mechanisms. This was an unintended effect, but the reason for this effect becomes more apparent when the concentration of species $\mathrm{CH}$ is considered. Within flame spectrometry, the presence of $\mathrm{CH}$ is often used as an indicator of flame position. Applying this principal to the simulated flame objects reveals that the colder mechanisms, Jones, Becker and Hiensohn and Pederson and Brown, have flame positions much closer to the burner than the warmer mechanisms, GRIMech 3.0 and Peters. Both in reality and in the simulation, the water cooled burner acted as a heat sink, which means a flame that is positioned closer to the burner will loose more heat to the burner than one that burns further away. The next three figures show peak flame temperatures for each mechanism, and are immediately followed by plots of the distance from the burner of the maximum $\mathrm{CH}$ concentration for each test case.

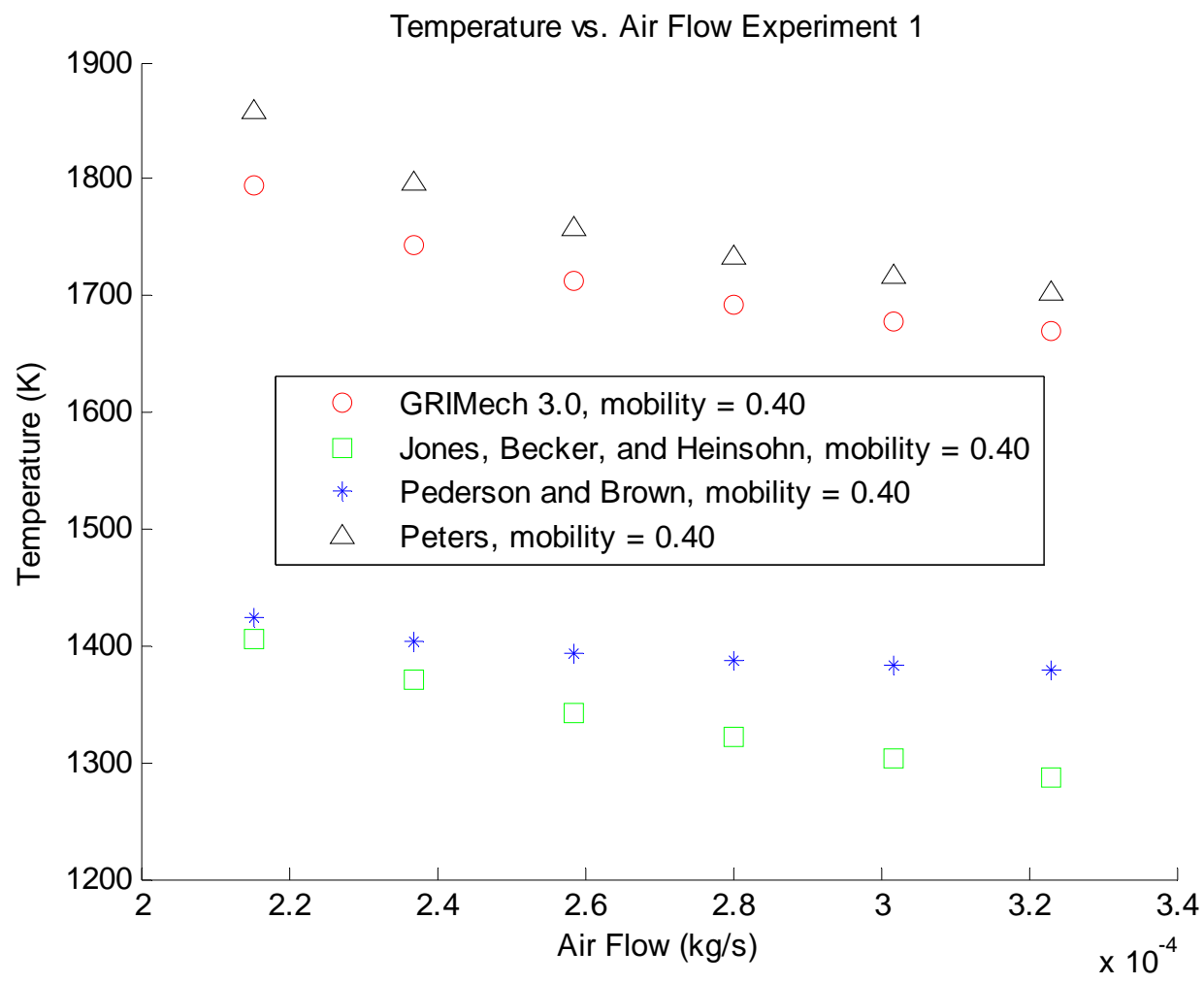

Figure 4-26: Temperature vs. Air Flow for Methane Combustion Using All Mechanisms in Experiment 1 with Mobility $=0.40 \mathrm{~m}^{2} / \mathrm{Vs}$ 


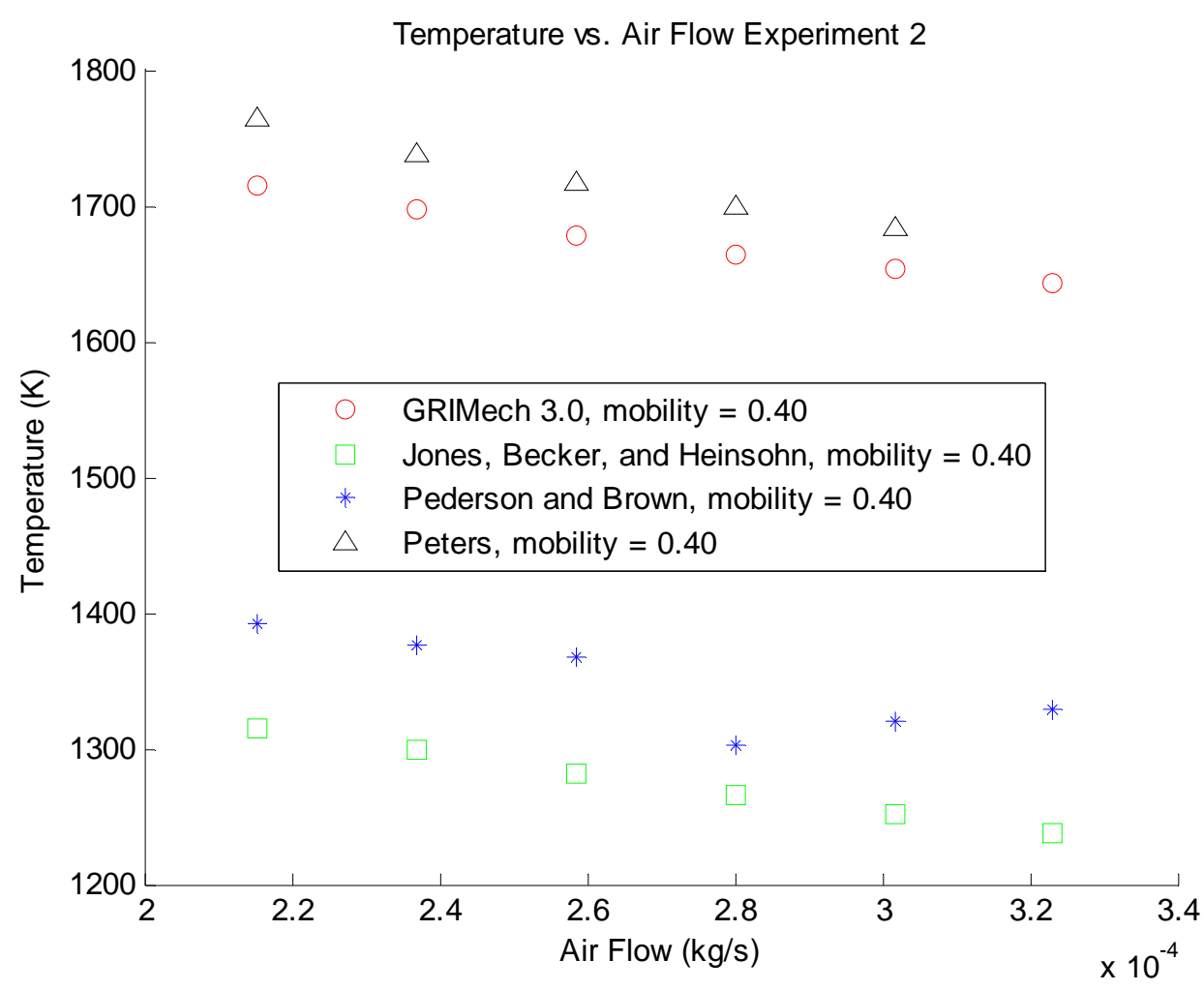

Figure 4-27: Temperature vs. Methane Flow for Methane Combustion Using All Mechanisms in Experiment 2 with Mobility $=0.40 \mathrm{~m}^{2} / \mathrm{Vs}$ 


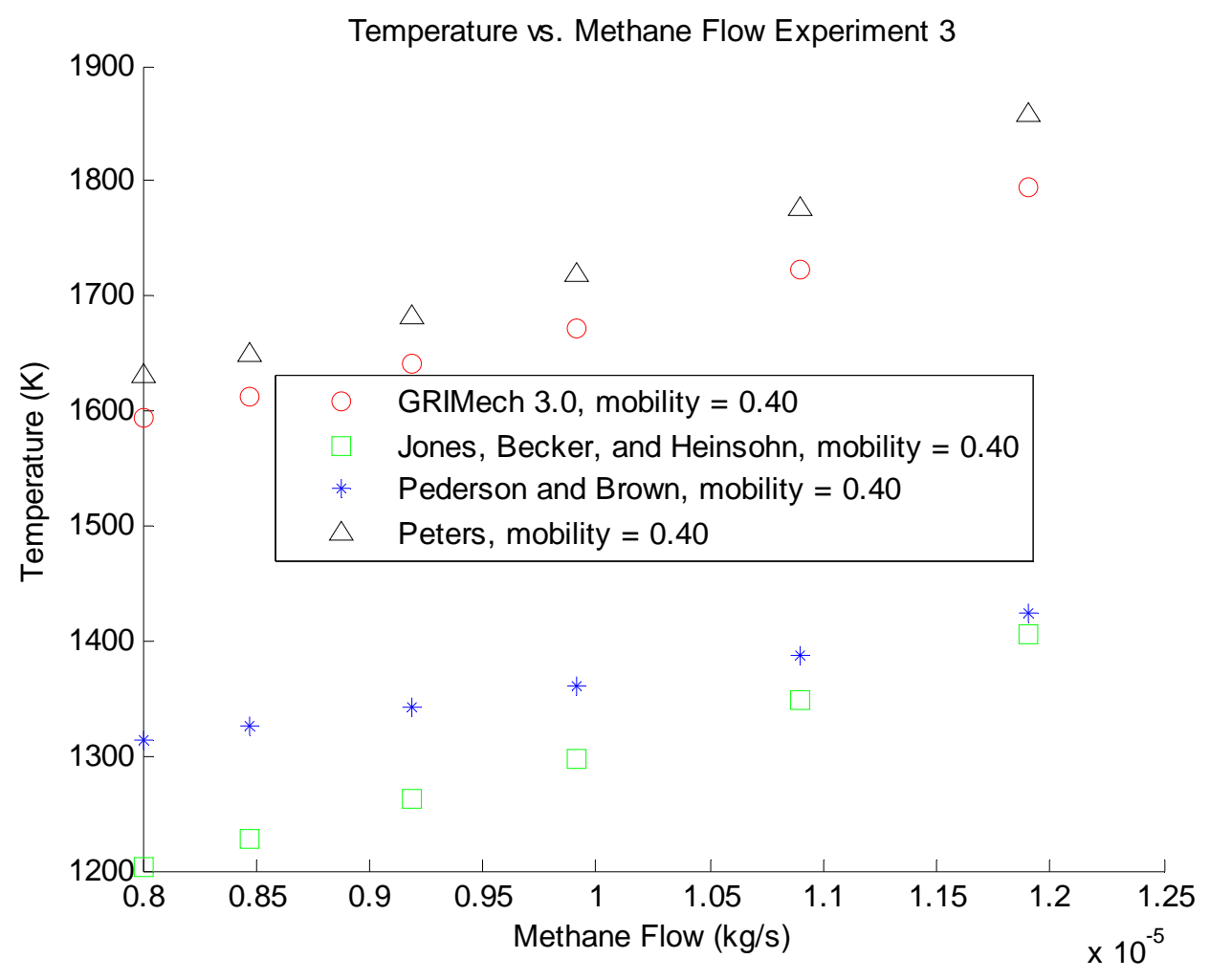

Figure 4-28: Temperature vs. Air Flow for Methane Combustion Using All Mechanisms in Experiment 3 with Mobility $=0.40 \mathrm{~m}^{2} / \mathrm{Vs}$ 


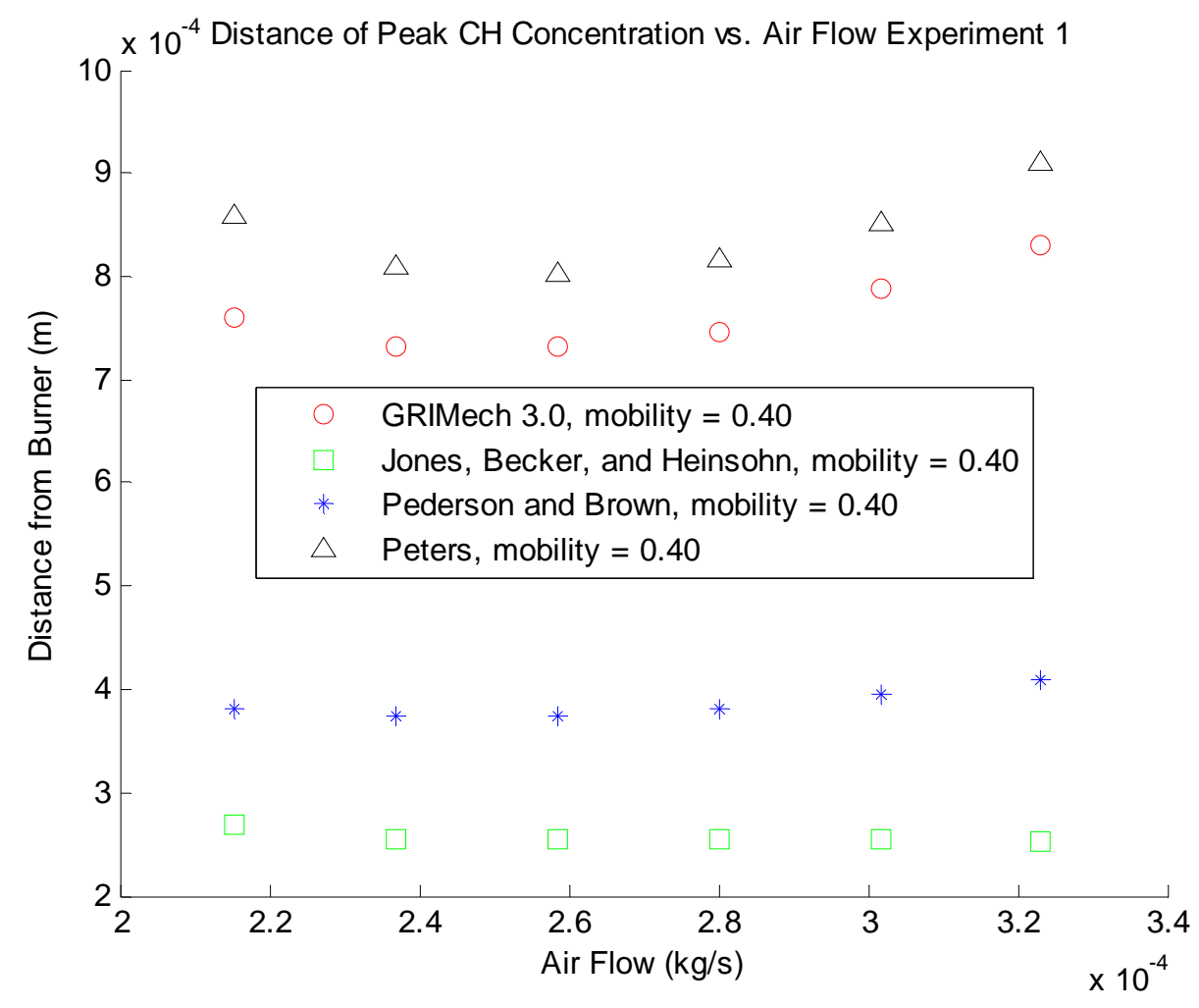

Figure 4-29: Position of CH Peak Consentration vs. Air Flow for Methane Combustion Using All Mechanisms in Experiment 1with Mobility $=0.40 \mathrm{~m}^{2} / \mathrm{Vs}$ 


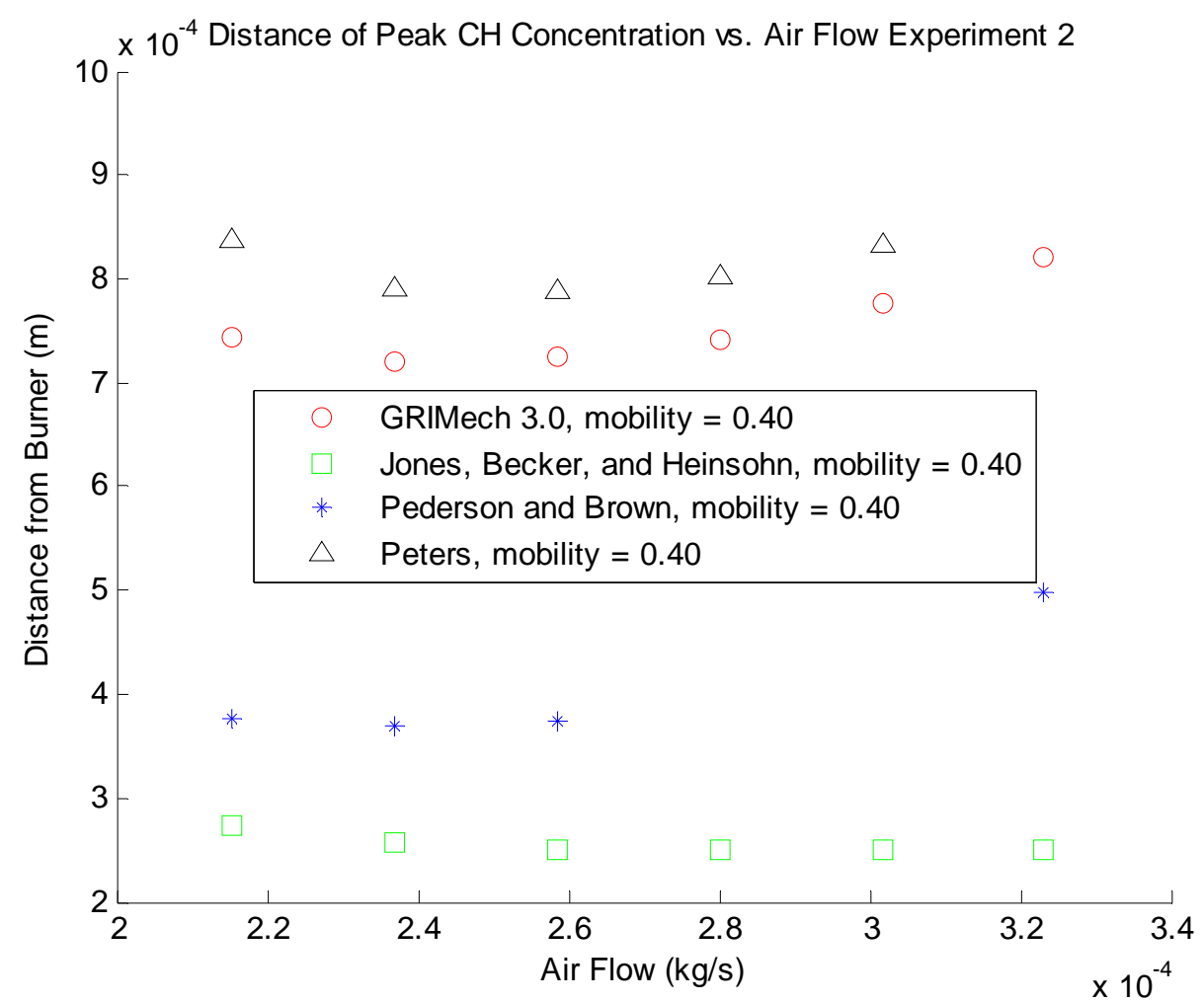

Figure 4-30: Position of CH Peak Consentration vs. Air Flow for Methane Combustion Using All Mechanisms in Experiment 2 with Mobility $=0.40 \mathrm{~m}^{2} / \mathrm{Vs}$ 


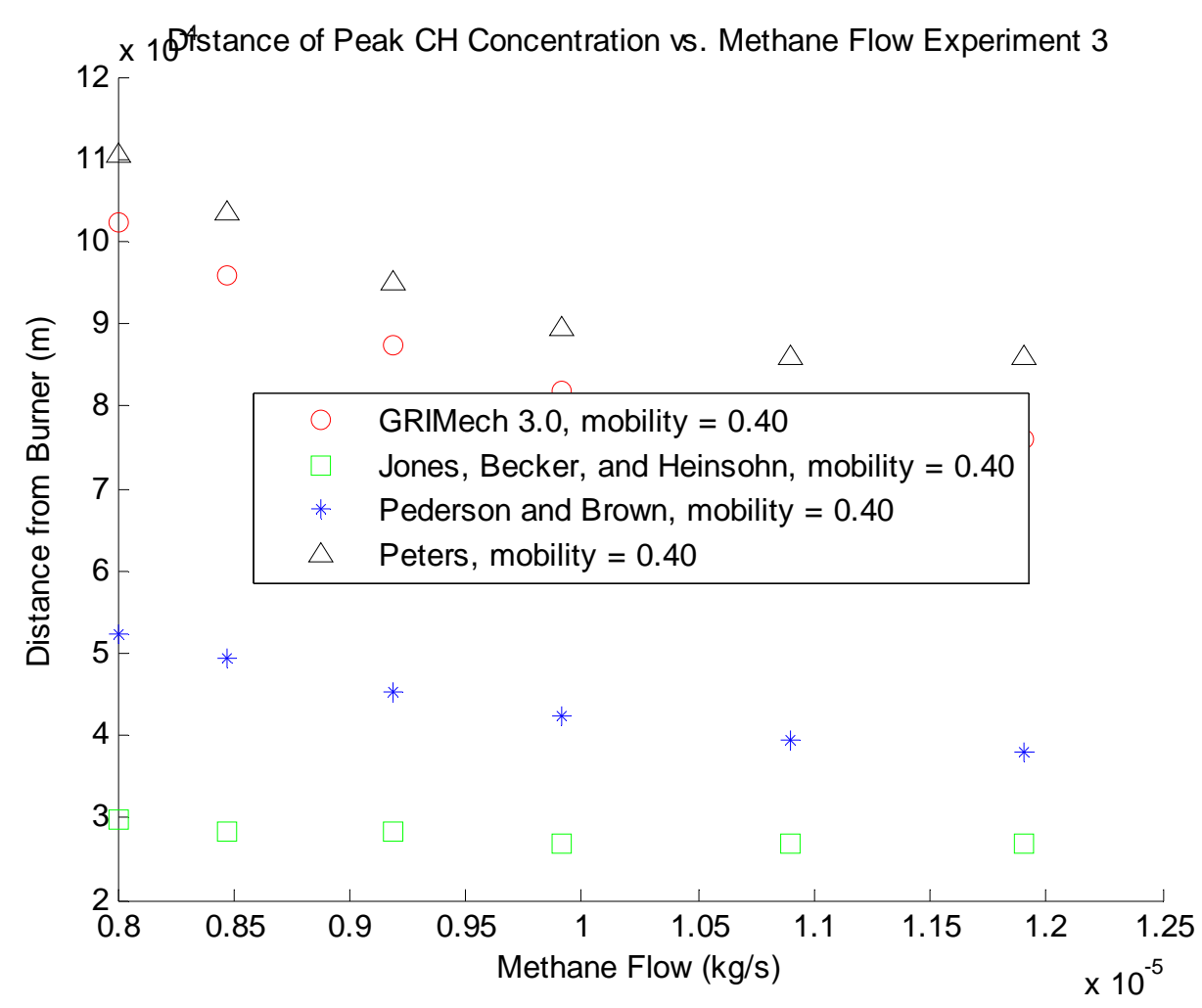

Figure 4-31: Position of CH Peak Consentration vs. Methane Flow for Methane Combustion Using All Mechanisms in Experiment 3 with Mobility $=0.40 \mathrm{~m}^{2} / \mathrm{Vs}$

Another interesting point concerning $\mathrm{CH}$ is the fact that it is a precursor molecule for all of the positive species $\mathrm{HCO}^{+}$and $\mathrm{H}_{3} \mathrm{O}^{+}$. This could explain the problem with overestimation of saturation current by the Peters mechanism because the concentration of $\mathrm{CH}$ generated by this mechanism was significantly higher than in all other mechanisms. This could result in overproduction of charged species and, as a result, overprediction of current. An example of the $\mathrm{CH}$ concentrations is shown in the following figure. 


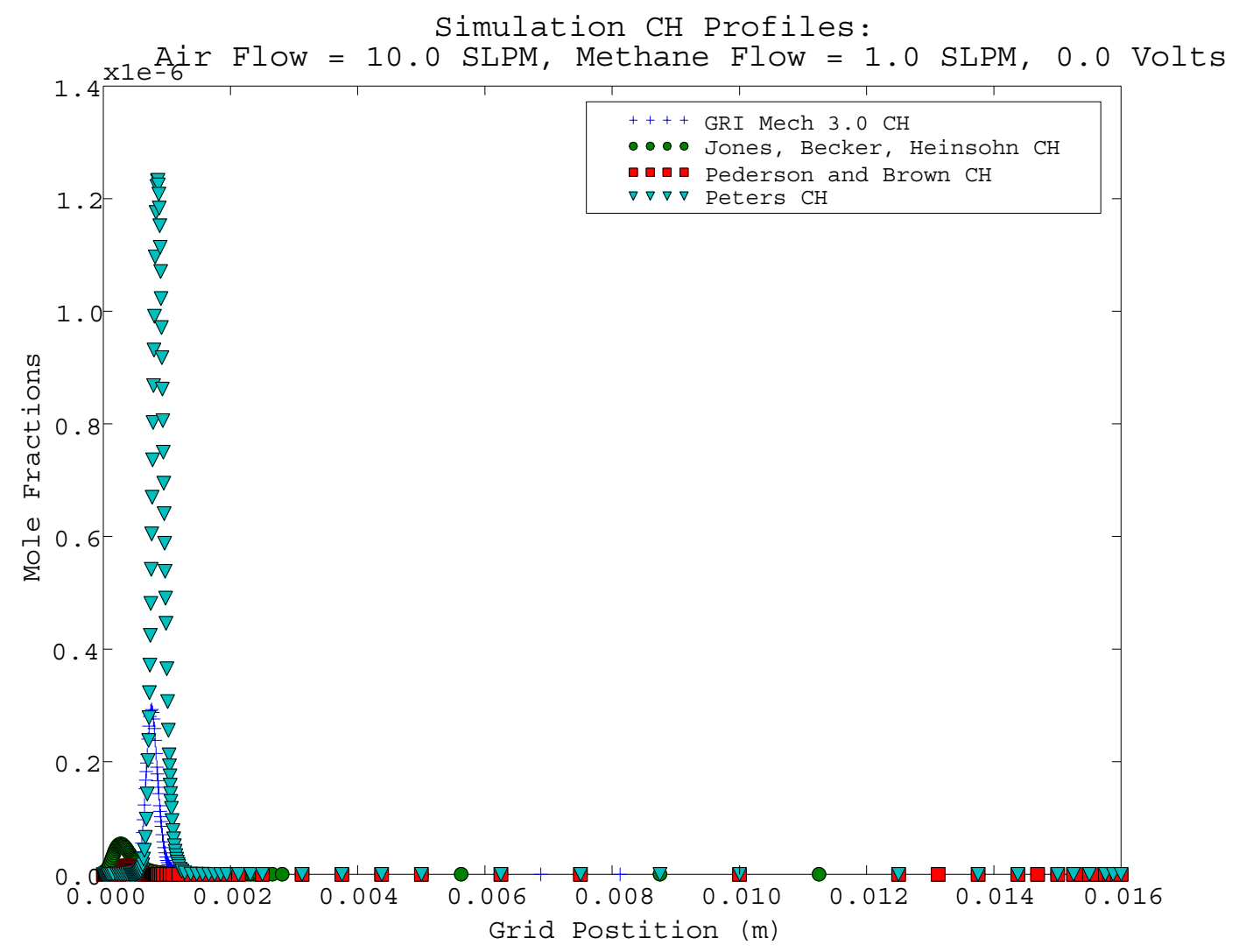

Figure 4-32: Example of Typical CH Profiles for Each Mechanism During Methane Combustion The figures below show a comparison of the experimental and simulated saturation currents for each mechanism. The Jones, Becker and Heinsohn and GRIMech 3.0 both show good agreement with the experimental data. 


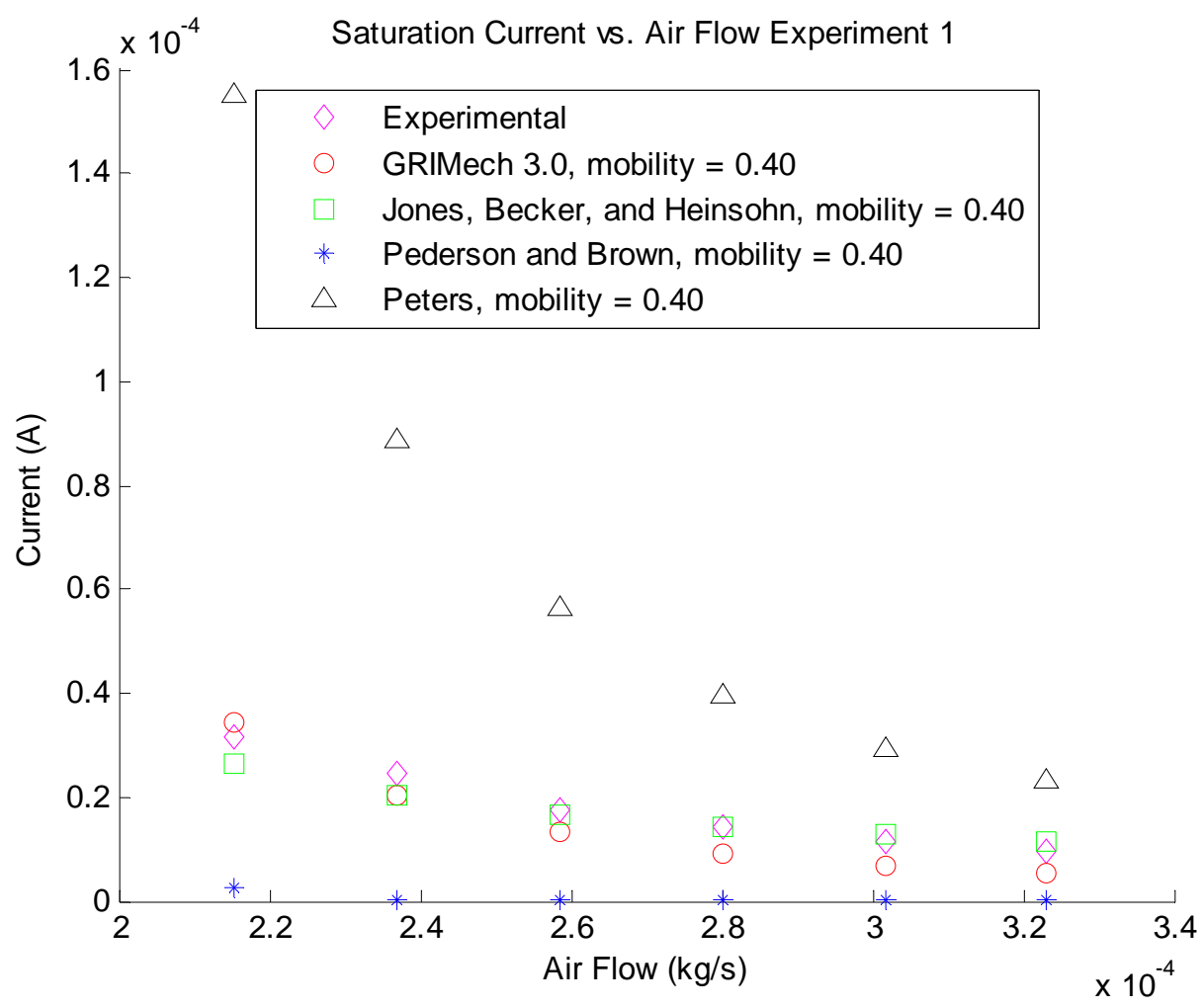

Figure 4-33: Saturation Currents vs. Air Flow for Methane Combustion Using All Mechanisms in Experiment 1 with Mobility $=0.40 \mathrm{~m}^{2} / \mathrm{Vs}$

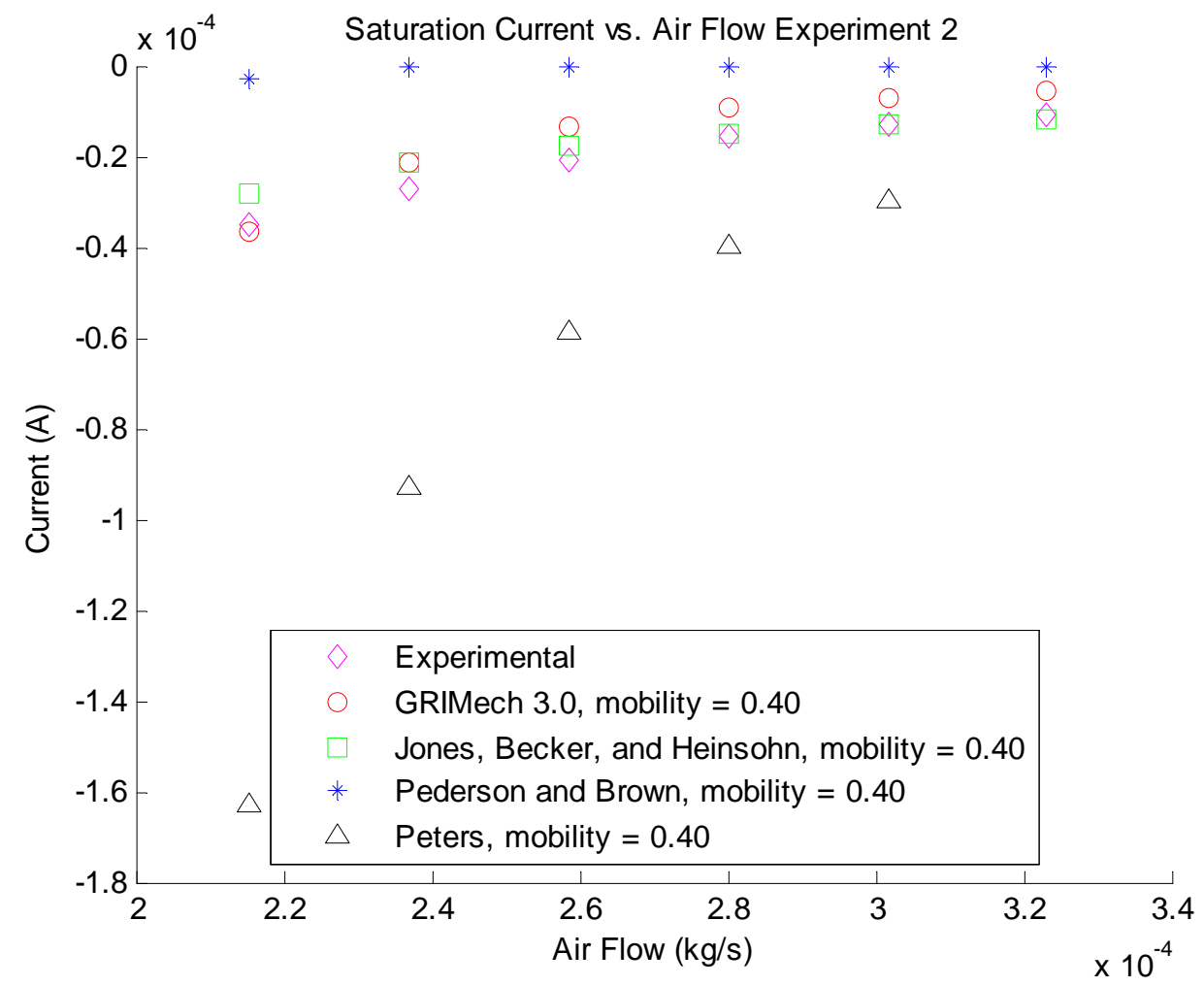


Figure 4-34: Saturation Currents vs. Air Flow for Methane Combustion Using All Mechanisms in Experiment 2 with Mobility $=0.40 \mathrm{~m}^{2} / \mathrm{Vs}$

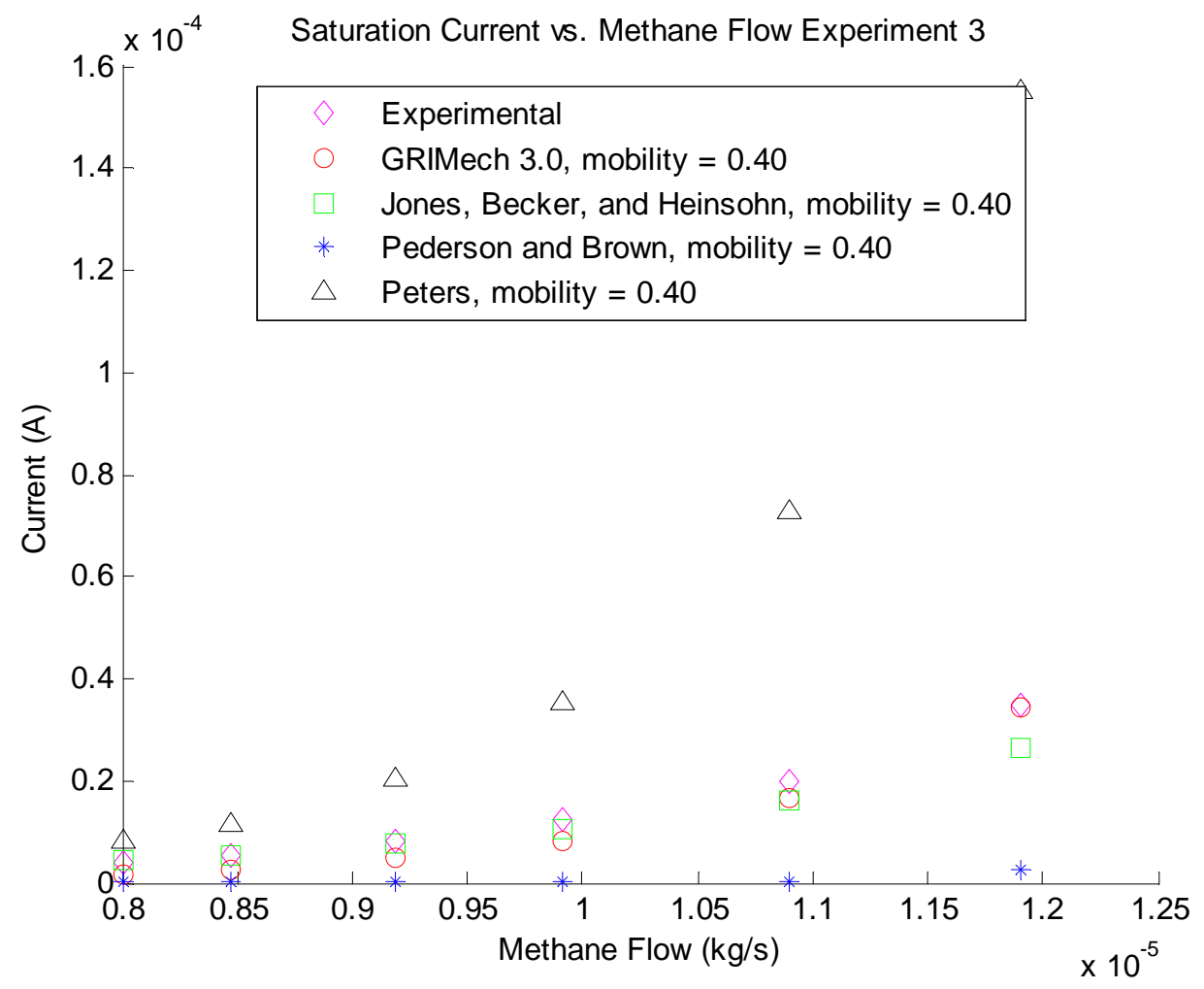

Figure 4-35: Saturation Currents vs. Air Flow for Methane Combustion Using All Mechanisms in Experiment 3 with Mobility $=0.40 \mathrm{~m}^{2} / \mathrm{Vs}$

For all mechanisms except Pederson and Brown, the saturation current is almost always significantly to high. This fact is shown in the following plots. 


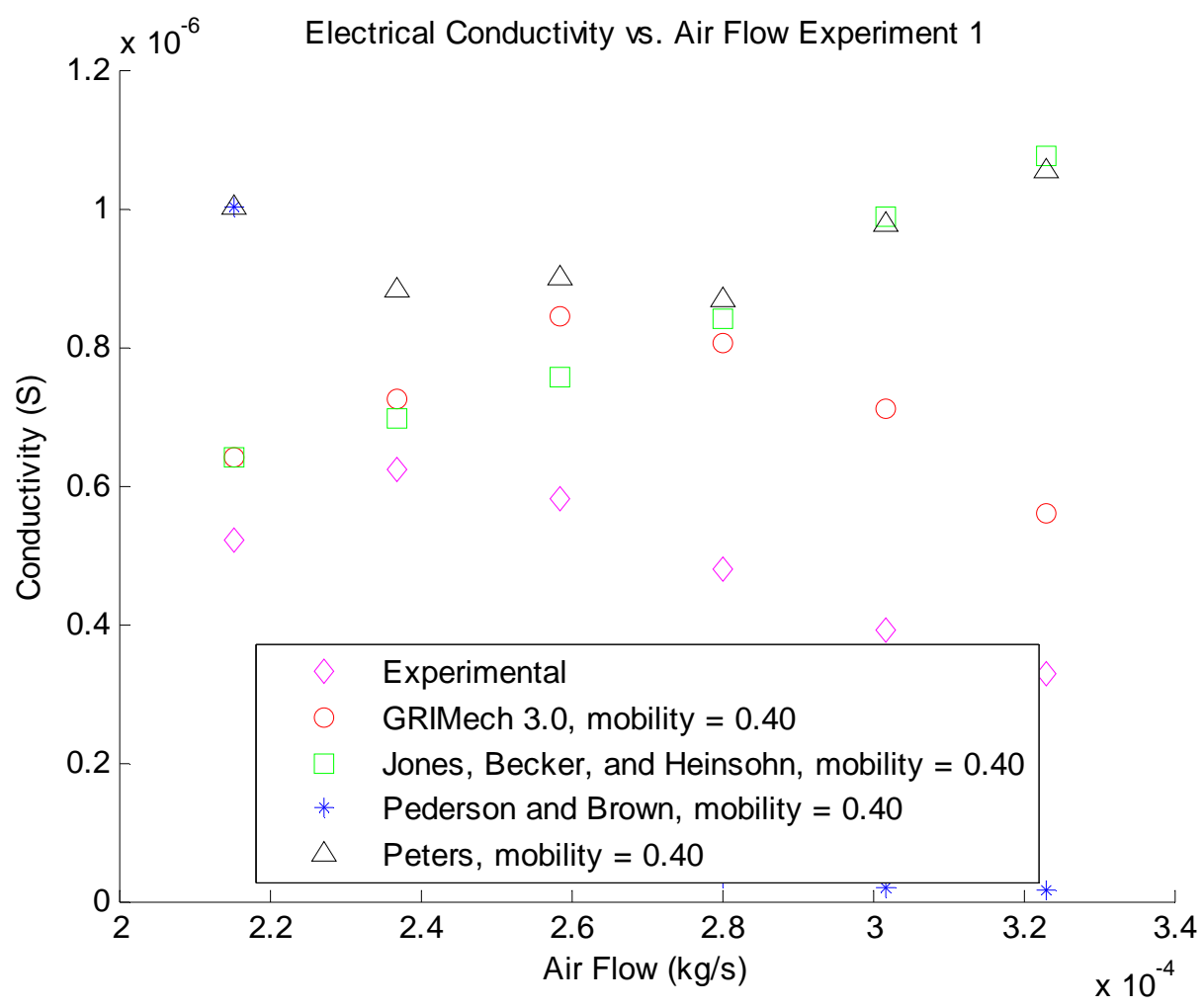

Figure 4-36: Conductivity vs. Air Flow for Methane Combustion Using All Mechanisms in Experiment 1 with Mobility $=0.40 \mathrm{~m}^{2} / \mathrm{Vs}$ 


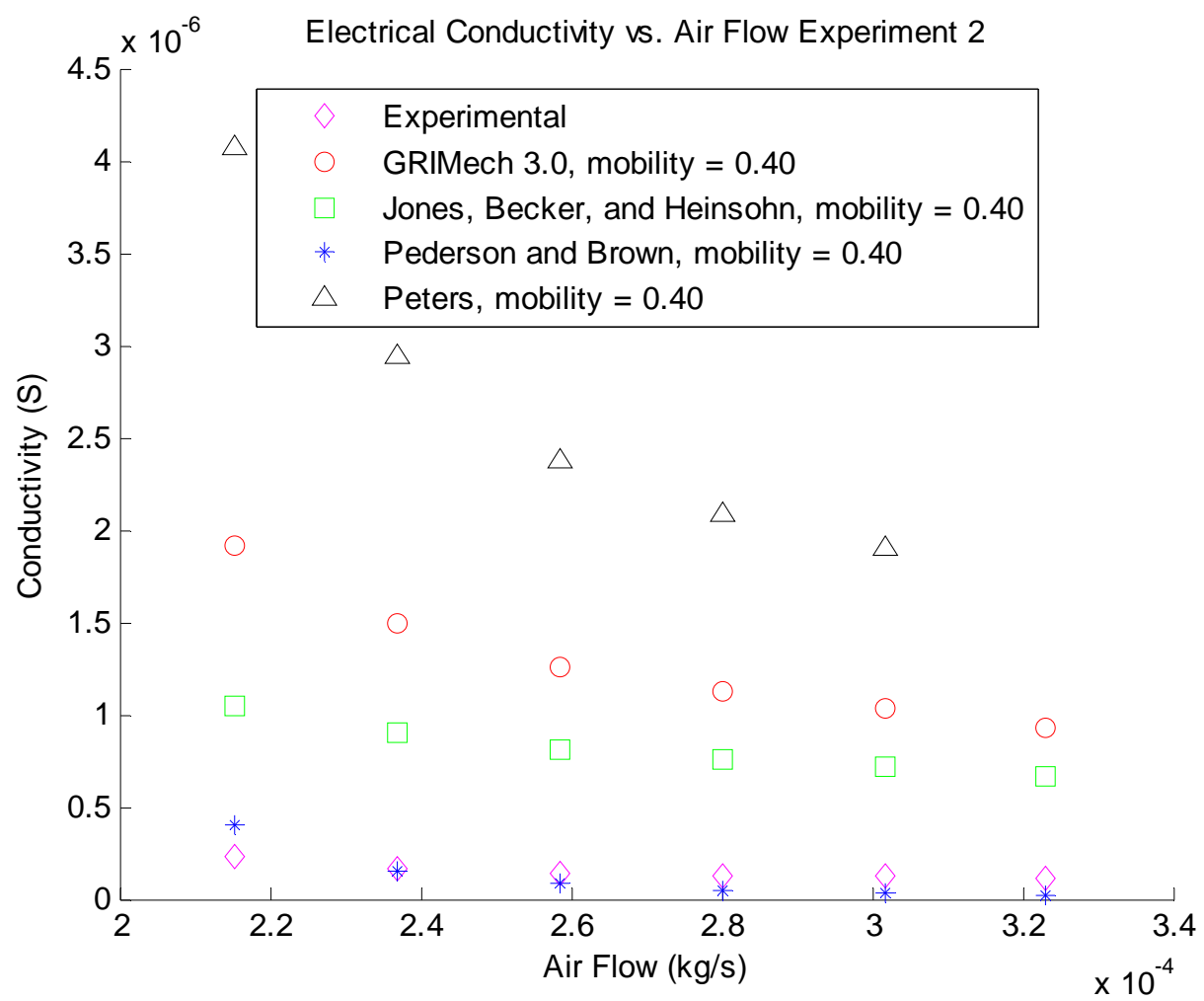

Figure 4-37: Conductivity vs. Air Flow for Methane Combustion Using All Mechanisms in Experiment 2 with Mobility $=0.40 \mathrm{~m}^{2} / \mathrm{Vs}$ 


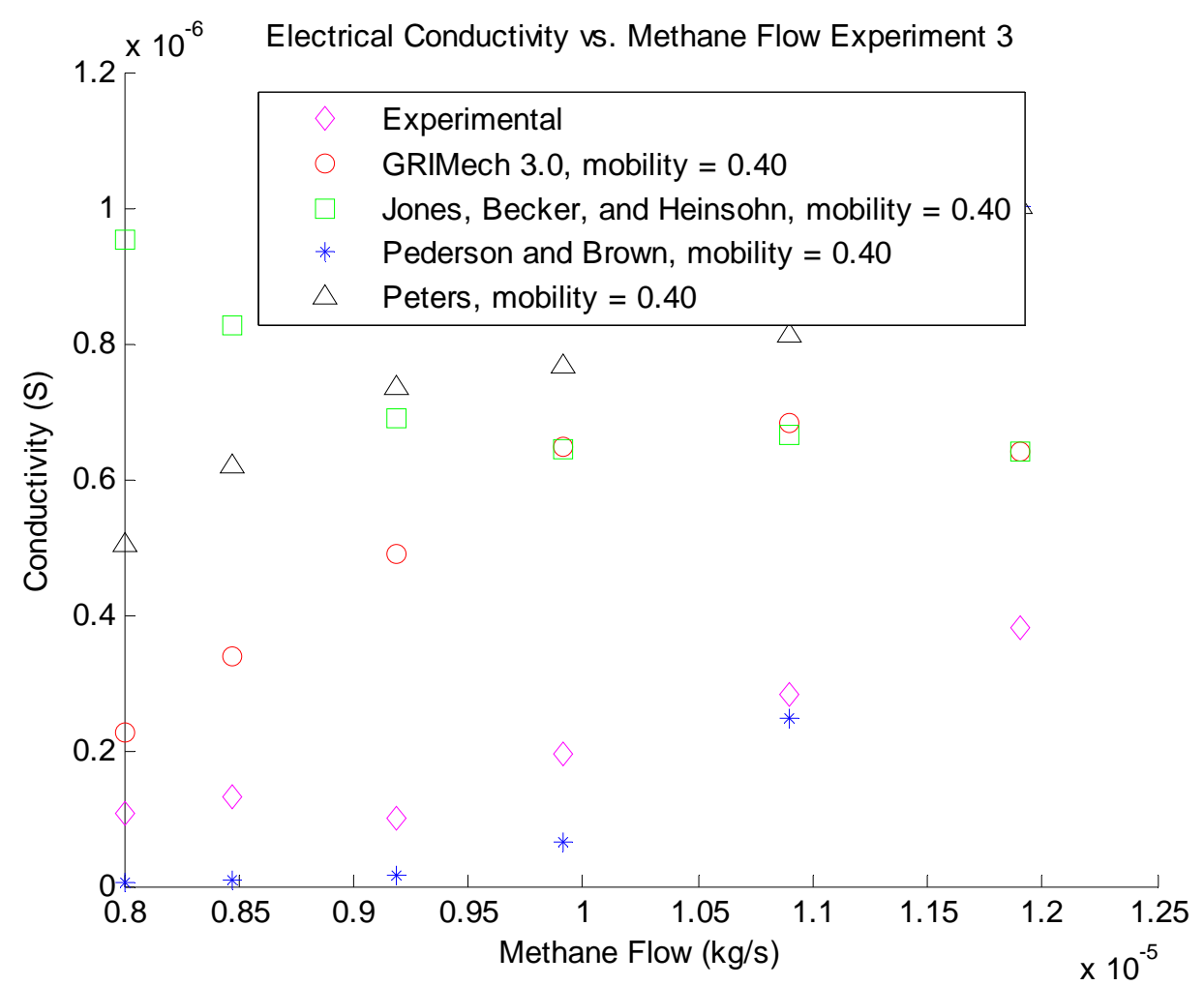

Figure 4-38: Conductivity vs. Air Flow for Methane Combustion Using All Mechanisms in Experiment 3 with Mobility $=0.40 \mathrm{~m}^{2} / \mathrm{Vs}$ 


\subsection{Synthesis Gas Models}

For the synthesis gas models, only one reaction mechanism was used. This mechanism was the modified version of the GRIMech 3.0 which is discussed in Chapter Two, and the listing of the Cantera 'cti' file containing this mechanism is given in Appendix B. The choice to use only this reaction mechanism was made because of extreme difficulty achieving convergence with the other reaction mechanisms mentioned in this paper using synthesis gas. One likely explanation for this problem is the fact that the mechanisms used in this research had been designed for use in natural gas combustion, but the only hydrocarbon within the combustion gas mix for the synthesis gas experiments was the varying, but small amounts of methane added in order to increase the generation of charged molecules formed during combustion. A more ideal reaction mechanism for synthesis gas would place a higher focus on reactions involving hydrogen gas and carbon monoxide, the main constituents of synthesis gas.

As with the methane models, the synthesis gas models were run using three

different mobilities: $0.36,0.40$, and $0.44 \mathrm{~m}^{2} / \mathrm{Vs}_{\mathrm{s}}$. With all tested mobilities, and with all mixtures of methane added, the simulated saturation current was underpredicted. Also, the conductivity found in the model was extremely high. The low saturation current and high conductivity resulted in saturation at extremely low voltages in the simulated flame. The major V-I curve properties can be seen in the tables below. 


\begin{tabular}{|c|c|c|c|c|c|c|}
\hline \multirow{3}{*}{$\begin{array}{c}\text { Run } \\
\text { Number }\end{array}$} & \multicolumn{5}{|c|}{$\begin{array}{c}\text { Pederson and Brown Synthesis Gas Combustion V-I Curve } \\
\text { Characteristics to 90\% of Peak Current with Mobility }=\mathbf{0 . 3 6}^{\mathrm{m}^{2}} / \mathrm{Vs}\end{array}$} \\
\cline { 2 - 7 } & \multicolumn{2}{|c|}{ Slope } & \multicolumn{2}{c|}{ Current } & \multicolumn{2}{c|}{ Voltage } \\
\cline { 2 - 7 } & Modeled & Difference & Modeled & Difference & Modeled & Difference \\
\hline 1 & $3.8115 \mathrm{E}-08$ & $3.7116 \mathrm{E}-08$ & $8.2008 \mathrm{E}-08$ & $-5.6992 \mathrm{E}-08$ & 0.75 & -139.43 \\
\hline 2 & $5.5204 \mathrm{E}-08$ & $5.2624 \mathrm{E}-08$ & $2.3173 \mathrm{E}-07$ & $-8.3270 \mathrm{E}-08$ & 2.00 & -117.85 \\
\hline 3 & $1.2312 \mathrm{E}-07$ & $1.1878 \mathrm{E}-07$ & $4.4304 \mathrm{E}-07$ & $-1.1496 \mathrm{E}-07$ & 2.00 & -127.85 \\
\hline 4 & $1.7234 \mathrm{E}-07$ & $1.6657 \mathrm{E}-07$ & $5.7791 \mathrm{E}-07$ & $-1.7109 \mathrm{E}-07$ & 2.00 & -128.19 \\
\hline 5 & $1.7204 \mathrm{E}-07$ & $1.6289 \mathrm{E}-07$ & $7.9091 \mathrm{E}-07$ & $-1.2809 \mathrm{E}-07$ & 3.00 & -96.866 \\
\hline
\end{tabular}

Table 4-16: V-I Curve Characteristics to 90\% of Maximum Current Using GRIMech 3.0 with Electron Mobility of $0.36 \mathrm{~m}^{2} / V_{s}$ for Synthesis Gas Combustion

\begin{tabular}{|c|c|c|c|c|c|c|}
\hline \multirow{2}{*}{$\begin{array}{c}\text { Run } \\
\text { Number }\end{array}$} & \multicolumn{6}{|c|}{$\begin{array}{c}\text { Pederson and Brown Synthesis Gas Combustion V-I Curve } \\
\text { Characteristics to 90\% of Peak Current with Mobility }=\mathbf{0 . 4 0} \mathrm{m}^{2} / \mathrm{Vs}\end{array}$} \\
\cline { 2 - 7 } & \multicolumn{2}{|c|}{ Slope } & \multicolumn{2}{c|}{ Current } & \multicolumn{2}{c|}{ Voltage } \\
\cline { 2 - 7 } & Modeled & Difference & Modeled & Difference & Modeled & Difference \\
\hline 1 & $3.6205 \mathrm{E}-08$ & $3.5206 \mathrm{E}-08$ & $8.2536 \mathrm{E}-08$ & $-5.6464 \mathrm{E}-08$ & 0.75 & -139.43 \\
\hline 2 & $5.2548 \mathrm{E}-08$ & $4.9968 \mathrm{E}-08$ & $2.3243 \mathrm{E}-07$ & $-8.2570 \mathrm{E}-08$ & 2.00 & -117.85 \\
\hline 3 & $1.1821 \mathrm{E}-07$ & $1.1387 \mathrm{E}-07$ & $4.4534 \mathrm{E}-07$ & $-1.1266 \mathrm{E}-07$ & 2.00 & -127.85 \\
\hline 4 & $1.6684 \mathrm{E}-07$ & $1.6107 \mathrm{E}-07$ & $5.8218 \mathrm{E}-07$ & $-1.6682 \mathrm{E}-07$ & 2.00 & -128.19 \\
\hline 5 & $2.2335 \mathrm{E}-07$ & $2.1420 \mathrm{E}-07$ & $7.4068 \mathrm{E}-07$ & $-1.7832 \mathrm{E}-07$ & 2.00 & -97.866 \\
\hline
\end{tabular}

Table 4-17: V-I Curve Characteristics to 90\% of Maximum Current Using GRIMech 3.0 with Electron Mobility of $0.40 \mathrm{~m}^{2} / \mathrm{Vs}_{\mathrm{s}}$ for Synthesis Gas Combustion

\begin{tabular}{|c|c|c|c|c|c|c|}
\hline \multirow{3}{*}{$\begin{array}{c}\text { Run } \\
\text { Number }\end{array}$} & \multicolumn{5}{|c|}{$\begin{array}{c}\text { Pederson and Brown Synthesis Gas Combustion V-I Curve } \\
\text { Characteristics to 90\% of Peak Current with Mobility }=\mathbf{0 . 4 4}\end{array} \mathrm{m}^{2} / \mathrm{Vs}$} \\
\cline { 2 - 7 } & \multicolumn{2}{|c|}{ Slope } & \multicolumn{2}{c|}{ Current } & \multicolumn{2}{c|}{ Voltage } \\
\cline { 2 - 7 } & Modeled & Difference & Modeled & Difference & Modeled & Difference \\
\hline 1 & $3.4469 \mathrm{E}-08$ & $3.3470 \mathrm{E}-08$ & $8.2981 \mathrm{E}-08$ & $-5.6019 \mathrm{E}-08$ & 0.75 & -139.43 \\
\hline 2 & $5.0170 \mathrm{E}-08$ & $4.7590 \mathrm{E}-08$ & $2.3296 \mathrm{E}-07$ & $-8.2040 \mathrm{E}-08$ & 2.00 & -117.85 \\
\hline 3 & $1.1381 \mathrm{E}-07$ & $1.0947 \mathrm{E}-07$ & $4.4722 \mathrm{E}-07$ & $-1.1078 \mathrm{E}-07$ & 2.00 & -127.85 \\
\hline 4 & $1.6149 \mathrm{E}-07$ & $1.5572 \mathrm{E}-07$ & $5.8570 \mathrm{E}-07$ & $-1.6330 \mathrm{E}-07$ & 2.00 & -128.19 \\
\hline 5 & $2.1722 \mathrm{E}-07$ & $2.0807 \mathrm{E}-07$ & $7.4645 \mathrm{E}-07$ & $-1.7255 \mathrm{E}-07$ & 2.00 & -97.866 \\
\hline
\end{tabular}

Table 4-18: V-I Curve Characteristics to 90\% of Maximum Current Using GRIMech 3.0 with Electron Mobility of $\mathbf{0 . 4 4} \mathrm{m}^{2} / \mathrm{Vs}_{\mathrm{s}}$ for Synthesis Gas Combustion 


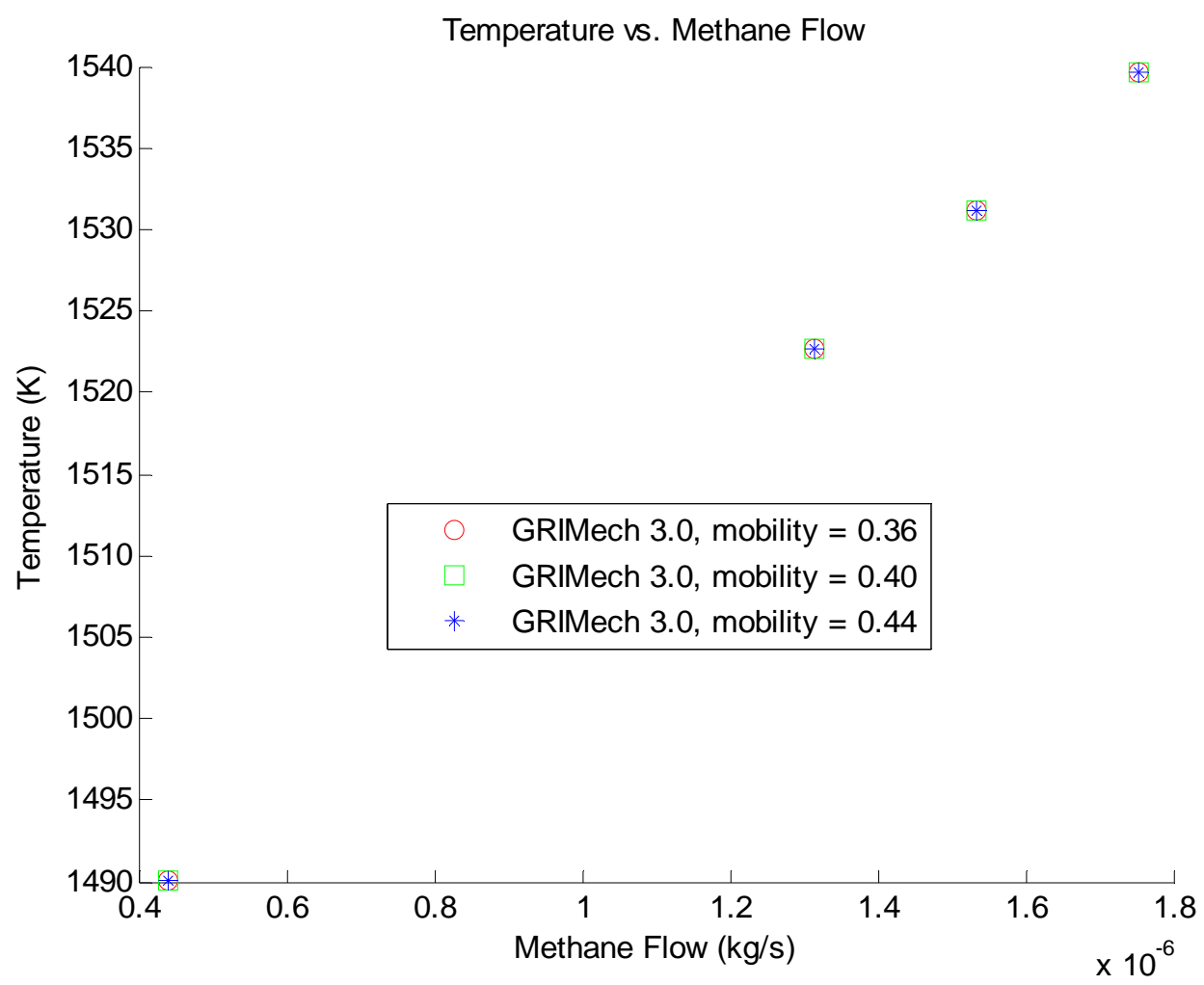

Figure 4-39: Temperature vs. Methane Flow Using GRIMech3.0 for Methane-Doped Synthesis Gas Combustion

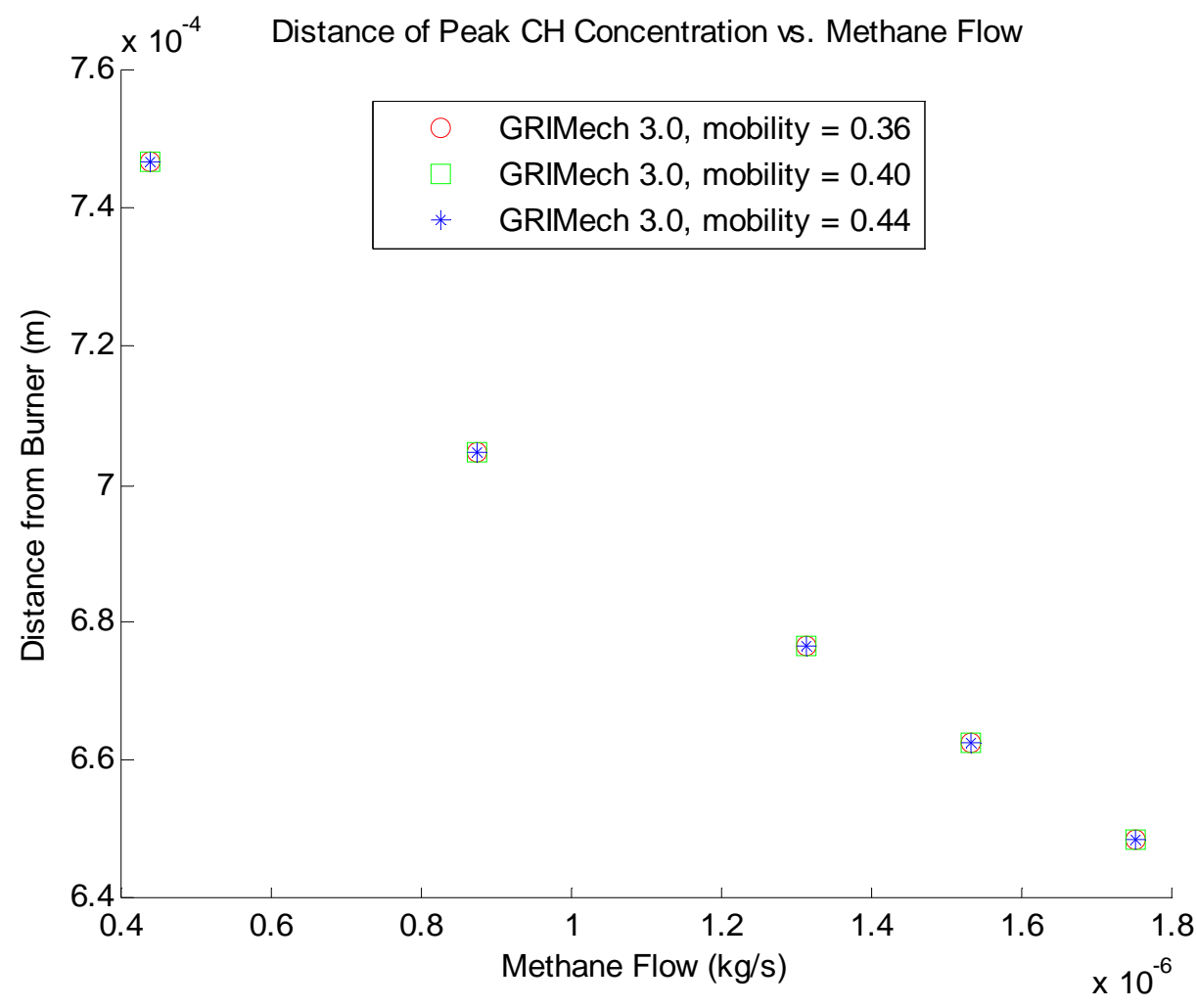

Figure 4-40: Position of Peak CH Concentration vs. Methane Flow Using GRIMech3.0 for MethaneDoped Synthesis Gas Combustion 


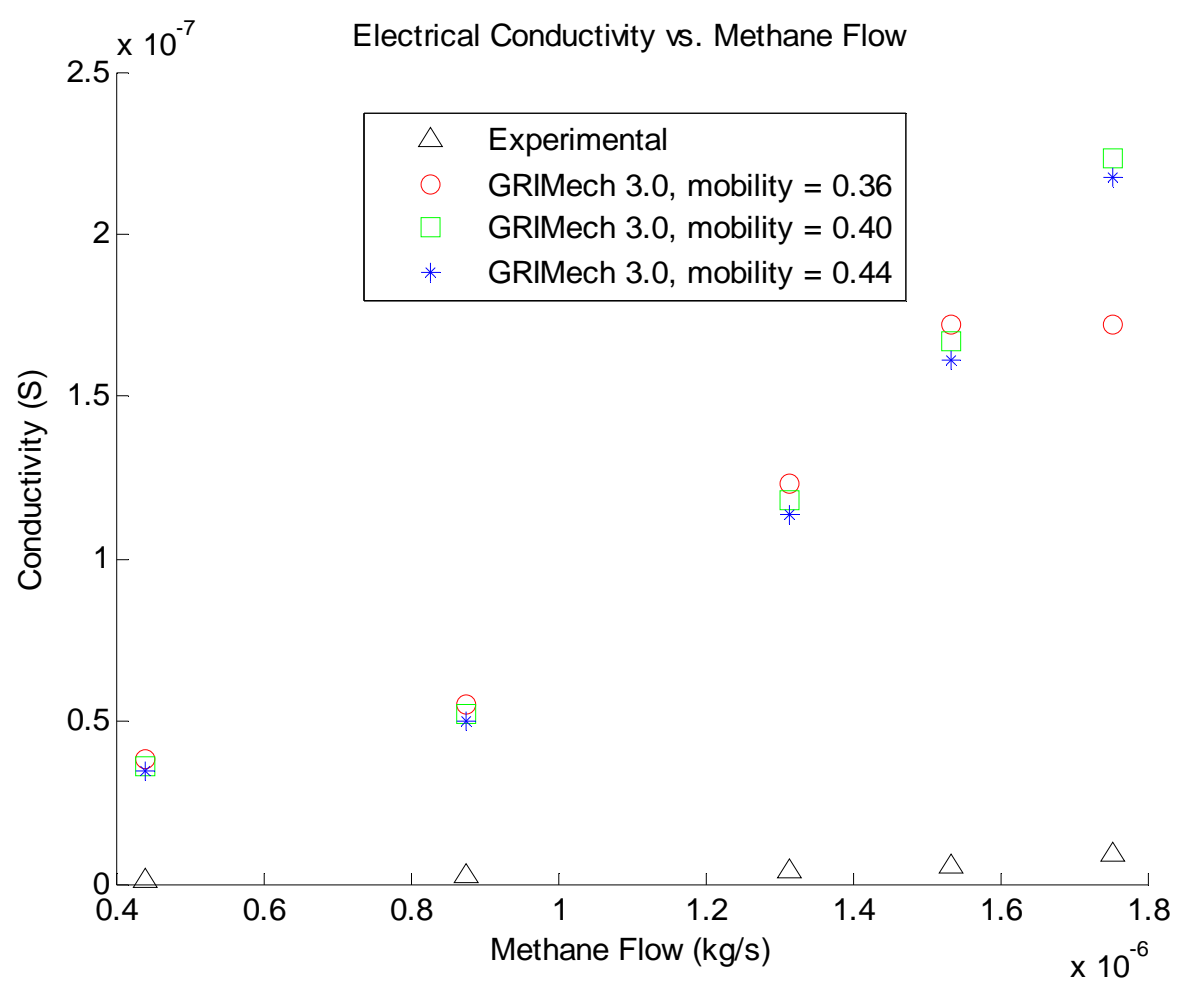

Figure 4-41: Conductivity vs. Methane Flow Using GRIMech3.0 for Methane-Doped Synthesis Gas Combustion

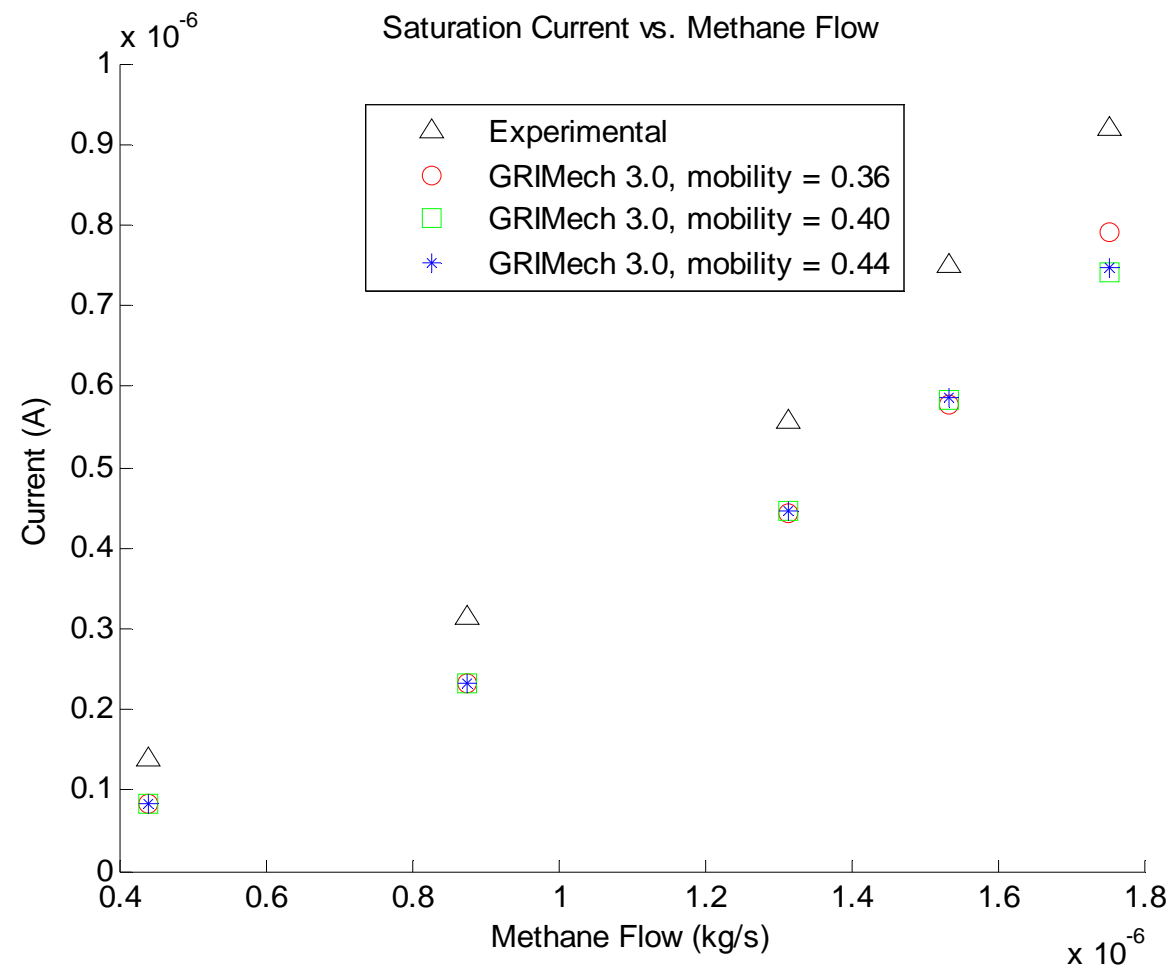

Figure 4-42: Saturation Current vs. Methane Flow Using GRIMech3.0 for Methane-Doped Synthesis Gas Combustion 
In the preceeding figures, a few tendancies can be seen. As the methane concentration increases, the temperature of the simulated flame increases and the distance between the burner and the flame decreases. As predicted experimentally, the conductivity increases with methane concentration, but the conductivity values are overestimated in all cases. Also, the saturation currents found are not shown to be extremely far off the experimental values, but are consistently overpredicted.

Because of the difficulties with convergence for three of the mechanisms in this research and questionable results from the fourth, it is believed that a completely different mechanism will be needed to accurately predict synthesis gas flame electrical properties. 


\section{Chapter Five: Conclusion}

This work modifed and extended a one-dimensional chemical kinetics simulation code to incorporate the effects of charged species and applied electric fields. This code was then used to compare existing experimental data with simulation results calculated with the use of four different published reaction mechanisms.

This code was based upon the Cantera chemical kinetics simulation code and was extended to incorporate the effects of applied electric fields. By incorportating Gauss' Law, this extension included the ability to specify an applied electric potential and allow for movement of charged species within the simulated flame. This movement in addition to diffusion now includes drift caused by the electric field. Analysis of simulation results using charged species demonstrated rising current with rising voltage until reaching a maximum charge carrier velocity. This saturation current effect has been demonstrated experimentally.

This code requires chemical reaction mechanisms as input. A reaction mechanism is simply sets of all possible reactions, elements, chemical species, and respective properties. Four published reaction mechanisms were tested.

Two of these mechanisms, modified GRIMech 3.0 and Jones, Becker and Hiensohn, found saturation values close to the experimental values. Although both mechanisms exhibit different temperatures and flame position, the charged species reactions interacted with neutral species reactions and transport to produce similar results largely due to the position and quantity of $\mathrm{CH}$, a major precursor to charged species generation. The Peters mechanism using the same charged reactions and species,

consistently overpredicted saturation currents because of overprediction of $\mathrm{CH}$. The 
Pederson and Brown mechanism consistently underpredicted currents and proved to be unstable.

All simulated stable mechanisms seemed to overpredict the flame conductivity when compared to the available measured data. This result indicates that the value of 0.4 $\mathrm{m}^{2} / \mathrm{Vs}$ for the electron mobility too high, which is not in agreement with the paper by Goodings et al., the source used for the electron mobility value. Decreasing electron mobility to $0.36 \mathrm{~m}^{2} / V \mathrm{~s}$ improved the calculated conductivity, but even that value overpredicted conductivity. 


\section{Chapter Six: Future Work}

From the results seen so far in this research, some ideas for future work are apparent. One point that stands out is the need to attempt simulations with lower values for electron mobility. Given the magnitude of the error in electrical conductivity, the use

of a value as low as $0.04 \mathrm{~m}^{2} / \mathrm{Vs}$, which is one tenth of the base value used in this research, may not be unreasonable. Secondly, further reaction mechanism refinement for charged particle chemistry should prove extremely useful for improving the accuracy of the simulation predictions for saturation currents. This refinement should include the addition of other less numerous charged species in addition to electrons, $\mathrm{HCO}+$ and $\mathrm{H} 3 \mathrm{O}+$, especially negative charge carriers. In these models, the electrons were used as the only negative carriers, but their small size and weight allows them to travel significantly faster than the molecule sized positive charge carriers.

In addition, additional verification of the original experimental setup my be very useful. Some significant parameters such as space charge, high temperature effects on metal electrodes, and oxidation of the electrode may not have been taken fully into account. 


\section{Appendix A: Driver Codes}

\section{A-1: Methane Combustion Driver Code}

Description:

Although the modified version of Cantera is capable of running simulations in the same manner as the standard version of Cantera, an additional python program has been written in order to simplify the task of running multiple similar simulations that differ only by applied voltage. The EFSim_NG_Current program has been written in order to allow for easy reuse of the flame objects while running these similar simulations. By allowing for reuse of flame objects, the computation time can be greatly reduced because the system only needs to acquire a full solution to one case in a set of similar simulations, and the solutions to the remaining case may be found by using the fully solved case as a starting point for finding the solutions to the remaining cases.

Reuse of flame objects is computationally advantageous when the major properties of the flame are not expected to change significantly between simulated cases. This advantage can be used for these simulations because the only species which are expected to change greatly as a result of changing the applied voltages are the charged species, which make up an extremely small fraction of the mass within the flame. The assumption that neutral species, flame position, and temperature profile do not change significantly by changing the applied voltage is based on the use of reasonably small voltages. If the applied voltage through the flame is increased to the order of kilovolts, then the effects of ionic wind would need to be taken into account which would void this assumption. For the purposes of the CCADS project, voltages high enough to generate a 
significant ionic wind are not necessary. As a result, ionic wind effects have not been included in this model.

Finally, although the code does not enforce the use of small voltage steps when changing voltage, the use of small steps in voltage level is recommended and used in this research in order to further save computation time. For example, all simulations demonstrated in this document were produced by starting at zero applied voltage. Multiple small voltage increases were made between zero and one volt, and only one volt increments were used thereafter.

\section{Code Overview:}

All of the code used to streamline methane combustion simulation is included in a set of two classes. The EFSim_NG_Current class holds all of the functions needed to setup a simulation given the equivalence ratio and mass flow rates of the premixed gas used for combustion. The EFSim_NG_Current_mass class extends the EFSim_NG_Current class to allow for simulations with known flow rates of air and fuel in the premixed gas. This extension adds only an additional constructor for use in setting up a simulation.

The following table gives a listing of the constructor inputs for each of the two classes. 


\begin{tabular}{|c|c|c|c|}
\hline Class & Input Name & Purpose & Units \\
\hline \multirow[t]{8}{*}{ EFSim_NG_Current } & phi & $\begin{array}{l}\text { Equivalence ratio of the desired } \\
\text { gas mixture }\end{array}$ & --- \\
\hline & m_dot_total & $\begin{array}{l}\text { Mass flux of air and fuel } \\
\text { combined. }\end{array}$ & $\mathrm{kg} / \mathrm{s}$ \\
\hline & area & $\begin{array}{l}\text { Burner area of simulated flame } \\
\text { object }\end{array}$ & $\mathrm{m}^{2}$ \\
\hline & rxmech & $\begin{array}{l}\text { Filename of the Cantera "cti" file } \\
\text { containing the desired reaction } \\
\text { mechanism file. }\end{array}$ & --- \\
\hline & rxmix & $\begin{array}{l}\text { Name of the mix type within the } \\
\text { reaction mechanism file to use for } \\
\text { the simulation. }\end{array}$ & --- \\
\hline & use_efield & $\begin{array}{l}\text { Boolean flag used to denote if an } \\
\text { applied electric field will be used } \\
\text { in the desired simulation. }\end{array}$ & --- \\
\hline & applied_voltage & $\begin{array}{l}\text { Initial applied voltage for the } \\
\text { simulation object. }\end{array}$ & $\mathrm{V}$ \\
\hline & current_file & $\begin{array}{l}\text { Name of file to use for current } \\
\text { calculation performed while } \\
\text { running the flame object. }\end{array}$ & --- \\
\hline \multirow[t]{8}{*}{ EFSim_NG_Current_mass } & m_dot_air & $\begin{array}{l}\text { Mass flux of air in the methane } \\
\text { and air mix. }\end{array}$ & $\mathrm{kg} / \mathrm{s}$ \\
\hline & m_dot_fuel & $\begin{array}{l}\text { Mass flux of fuel in the methane } \\
\text { and air mix. }\end{array}$ & $\mathrm{kg} / \mathrm{s}$ \\
\hline & area & $\begin{array}{l}\text { Burner area of simulated flame } \\
\text { object }\end{array}$ & $\mathrm{m}^{2}$ \\
\hline & rxmech & $\begin{array}{l}\text { Filename of the Cantera "cti" file } \\
\text { containing the desired reaction } \\
\text { mechanism file. }\end{array}$ & --- \\
\hline & rxmix & $\begin{array}{l}\text { Name of the mix type within the } \\
\text { reaction mechanism file to use for } \\
\text { the simulation. }\end{array}$ & --- \\
\hline & use_efield & $\begin{array}{l}\text { Boolean flag used to denote if an } \\
\text { applied electric field will be used } \\
\text { in the desired simulation. }\end{array}$ & --- \\
\hline & applied_voltage & $\begin{array}{l}\text { Initial applied voltage for the } \\
\text { simulation object. }\end{array}$ & $\mathrm{V}$ \\
\hline & current_file & $\begin{array}{l}\text { Name of file to use for current } \\
\text { calculation performed while } \\
\text { running the flame object. }\end{array}$ & --- \\
\hline
\end{tabular}

Table A-1: Constructor Inputs for Methane Combustion Modeling Code. 
Within the EFSim_NG_Current class a set of "constants" is included. Howerver, these values may be easily modified by the user, and the responsibility of leaving these values constant is given to the program's user. These constants are listed in the table below.

\begin{tabular}{|l|l|l|}
\hline Constant Name & \multicolumn{1}{|c|}{ Purpose } & Value \\
\hline N2_PERCENT & Percent by mass of $\mathrm{N}_{2}$ in air & 0.76708 \\
\hline $\mathrm{O} 2 \_$PERCENT & Percent by mass of $\mathrm{O}_{2}$ in air & 0.23292 \\
\hline SAFR & Stoichiometric Air Fuel Ratio by mass & 17.0194 \\
\hline N2_MW & Molecular weight of $\mathrm{N}_{2}$ & 28.0134 \\
\hline $\mathrm{O} 2 \_M W$ & Molecular weight of $\mathrm{O}_{2}$ & 31.9998 \\
\hline FUEL_MW & Molecular weight of $\mathrm{CH}_{4}$ & 16.13782 \\
\hline
\end{tabular}

Table A-2: Constants Included in the EFSim_NG_Current Class

The remainder of the functions used for setting up and running simulations are include directly within the EFSim_NG_Current class, but are accessible and useable by the EFSim_NG_Current_mass class. These functions are described in the table below. 


\begin{tabular}{|c|c|c|c|c|}
\hline Function & Purpose & Input & Description & Units \\
\hline init & Class constructor & * see Table A-1 & & \\
\hline del & $\begin{array}{l}\text { Class destructor } \\
\text { used to close all } \\
\text { open file before } \\
\text { disposing of } \\
\text { simulation object }\end{array}$ & --- & --- & $\begin{array}{l}-- \\
-1\end{array}$ \\
\hline \multirow[t]{10}{*}{ initialize } & \multirow{10}{*}{$\begin{array}{l}\text { Used to initialize a } \\
\text { BurnerFlame or } \\
\text { BurnerFlame_efield } \\
\text { object for use in } \\
\text { simulation }\end{array}$} & pressure & $\begin{array}{l}\text { Gas pressure to use } \\
\text { in the simulation }\end{array}$ & Pascal \\
\hline & & temperature & $\begin{array}{l}\text { Burner temperature } \\
\text { to use in the } \\
\text { simulation }\end{array}$ & $\mathrm{K}$ \\
\hline & & initial_grid & $\begin{array}{l}\text { List of the initial } \\
\text { set of grid points to } \\
\text { use in the } \\
\text { simulation. }\end{array}$ & $\mathrm{m}$ \\
\hline & & refine_grid & $\begin{array}{l}\text { Indicates if a } \\
\text { simulation should } \\
\text { attempt to add grid } \\
\text { points as needed. } 1 \\
\text { indicates that points } \\
\text { may be added, and } \\
0 \text { indicates that } \\
\text { points should not } \\
\text { be added }\end{array}$ & --- \\
\hline & & log_level & $\begin{array}{l}\text { Indicates the level } \\
\text { of diagnostic output } \\
\text { to produce during a } \\
\text { simulation. } 1 \text { is the } \\
\text { minimum, and } 5 \text { is } \\
\text { the maximum }\end{array}$ & --- \\
\hline & & tol_ss & $\begin{array}{l}\text { Steady state error } \\
\text { tolerance. }\end{array}$ & --- \\
\hline & & tol_ts & $\begin{array}{l}\text { Transient state error } \\
\text { tolerance }\end{array}$ & --- \\
\hline & & max_jacobian & $\begin{array}{l}\text { Used to limit the } \\
\text { reuse of jacobian } \\
\text { matrices during } \\
\text { calculations }\end{array}$ & --- \\
\hline & & refine_ratio & $\begin{array}{l}\text { Ratio used to } \\
\text { determine a need } \\
\text { for solution } \\
\text { refinement }\end{array}$ & $\begin{array}{ll}-- \\
\end{array}$ \\
\hline & & refine_slope & Slope used to & --- \\
\hline
\end{tabular}




\begin{tabular}{|c|c|c|c|c|}
\hline & & & $\begin{array}{l}\text { determine a need } \\
\text { for solution } \\
\text { refinement }\end{array}$ & \\
\hline & & refine_curve & $\begin{array}{l}\text { Curve used to } \\
\text { determine a need } \\
\text { for solution } \\
\text { refinement }\end{array}$ & --- \\
\hline & & time_step & $\begin{array}{l}\text { Length of time } \\
\text { steps to use while } \\
\text { finding steady state } \\
\text { solutions }\end{array}$ & $\mathrm{S}$ \\
\hline & & time_refine & $\begin{array}{l}\text { List of number of } \\
\text { timesteps to take at } \\
\text { a time while } \\
\text { finding a solution }\end{array}$ & --- \\
\hline & & electron_mobility & $\begin{array}{l}\text { Electron mobility } \\
\text { to be used in a } \\
\text { simulation }\end{array}$ & $m^{2} / V s$ \\
\hline & & init_param & $\begin{array}{l}\text { Normalized starting } \\
\text { flame position used } \\
\text { to aid in flame } \\
\text { calculation by } \\
\text { allowing an } \\
\text { improved initial } \\
\text { guess. }\end{array}$ & --- \\
\hline setElectronModel & $\begin{array}{l}\text { Function used to set } \\
\text { the electron } \\
\text { mobility within the } \\
\text { flame object }\end{array}$ & $\begin{array}{ll}-- \\
\end{array}$ & -- & --- \\
\hline setFlame & $\begin{array}{l}\text { Function used to } \\
\text { allow for the use of } \\
\text { an externally } \\
\text { created } \\
\text { BurnerFlame or } \\
\text { BurnerFlame_efield } \\
\text { object for a } \\
\text { simulation. }\end{array}$ & new_flame & $\begin{array}{l}\text { The BurnerFlame } \\
\text { or } \\
\text { BurnerFlame_efield } \\
\text { object to use in a } \\
\text { simulation. }\end{array}$ & --- \\
\hline createFlame & $\begin{array}{l}\text { Function intended } \\
\text { for internal use in } \\
\text { creating a } \\
\text { BurnerFlame or } \\
\text { BurnerFlame_efield } \\
\text { object }\end{array}$ & --- & --- & --- \\
\hline setOptionalProperties & $\begin{array}{l}\text { Function intended } \\
\text { for internal use in } \\
\text { setting optional }\end{array}$ & --- & --- & --- \\
\hline
\end{tabular}




\begin{tabular}{|c|c|c|c|c|}
\hline & $\begin{array}{l}\text { properties given as } \\
\text { inputs to the } \\
\text { initialize function }\end{array}$ & & & \\
\hline setElectricField & $\begin{array}{l}\text { Function intended } \\
\text { for internal use in } \\
\text { initially setting up } \\
\text { an electric field for } \\
\text { the flame object }\end{array}$ & --- & --- & --- \\
\hline initFlame & $\begin{array}{l}\text { Used to call } \\
\text { Cantera's initialize } \\
\text { function on the } \\
\text { flame object and } \\
\text { flag the flame } \\
\text { object as initialized }\end{array}$ & --- & --- & --- \\
\hline presolve & $\begin{array}{l}\text { This function } \\
\text { solves the flame } \\
\text { object with the } \\
\text { energy equations } \\
\text { turned off in order } \\
\text { to derive a better } \\
\text { initial solution } \\
\text { before running a } \\
\text { true simulation }\end{array}$ & --- & --- & --- \\
\hline \multirow[t]{2}{*}{ solve } & \multirow{2}{*}{$\begin{array}{l}\text { This function } \\
\text { solves the flame } \\
\text { object with the } \\
\text { energy equation } \\
\text { turned on and saves } \\
\text { the resulting output } \\
\text { files. }\end{array}$} & xml_dir & $\begin{array}{l}\text { Name of directory } \\
\text { in which to store } \\
\text { results in XML file } \\
\text { format }\end{array}$ & --- \\
\hline & & csv_dir & $\begin{array}{l}\text { Name of directory } \\
\text { in which to store } \\
\text { results in CSV file } \\
\text { format }\end{array}$ & --- \\
\hline change_voltage & $\begin{array}{l}\text { Function used to } \\
\text { change the voltage } \\
\text { between runs of } \\
\text { similar simulations }\end{array}$ & new_volt & $\begin{array}{l}\text { Value for the new } \\
\text { applied voltage }\end{array}$ & $\mathrm{V}$ \\
\hline str_ & $\begin{array}{l}\text { Function used to } \\
\text { display class } \\
\text { constants and } \\
\text { variables }\end{array}$ & --- & --- & --- \\
\hline
\end{tabular}

Table A-3: Class Methods for EFSim_NG_Current Class

As a result of running simulations with these programs, three different types of output files are generated. The first type is a solution in Cantera's 'ctml' file format. The second type is also a solution, but this solution is in comma separated value ('csv') 
format. The third potential output file is a file listing the currents for each simulation run.

All three of these files formats are documented in Appendix D. The names for the first

two files are generated using the nameParse class, which is specified in Appendix C.

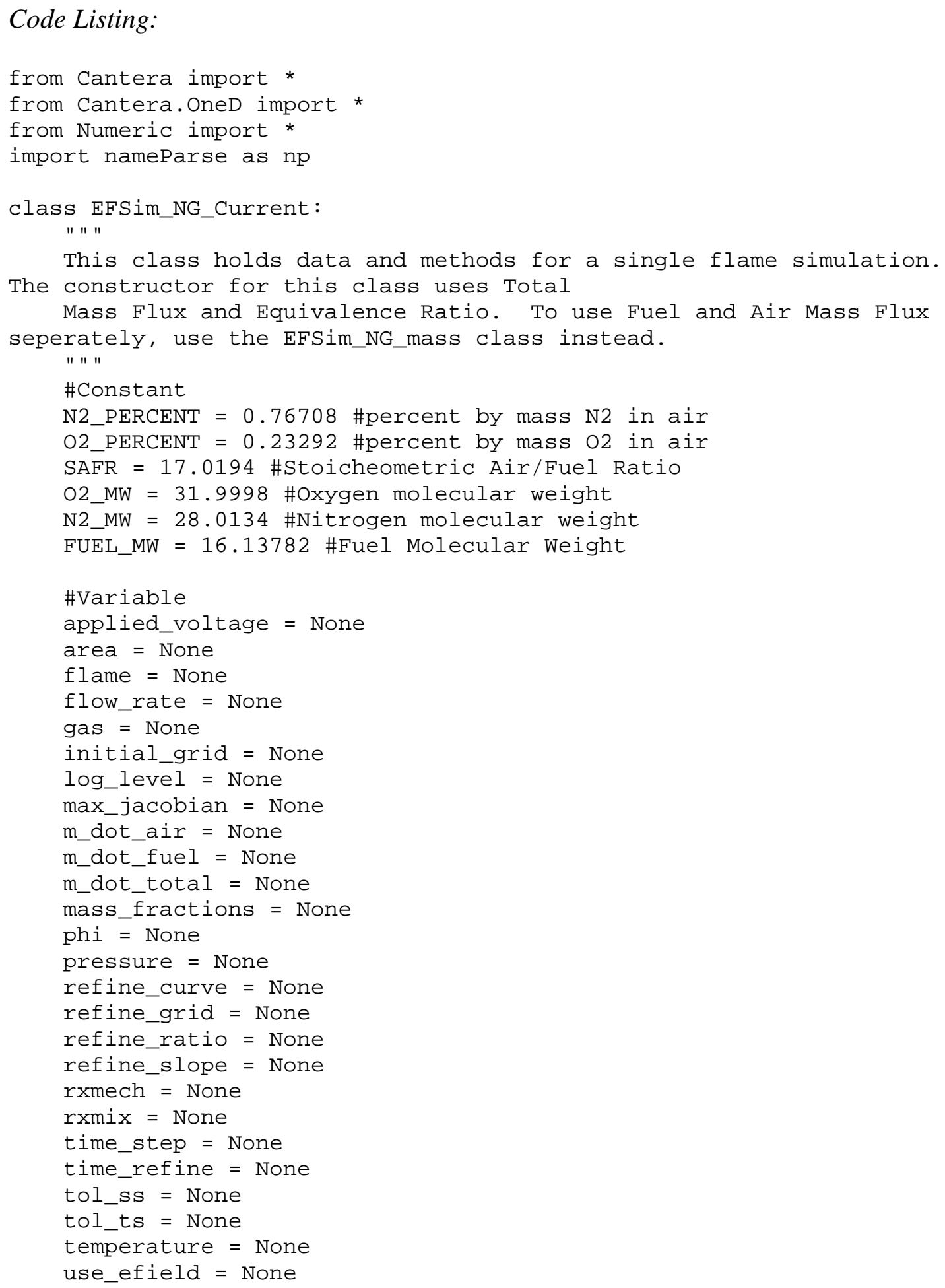




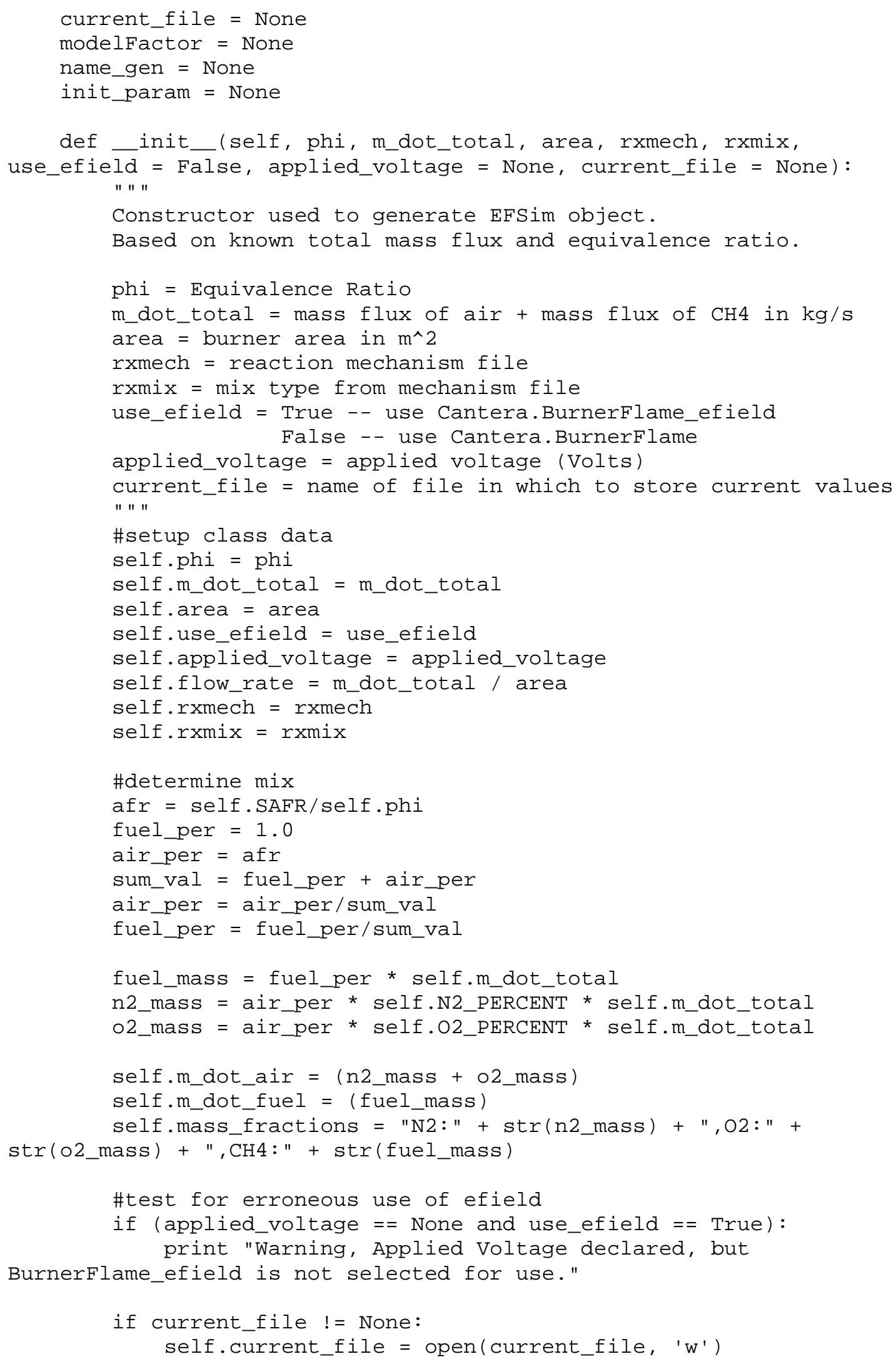


self.current_file.write('ER, total_flux,air_flux,fuel_flux, voltage,curre $n t \backslash n^{\prime}$ )

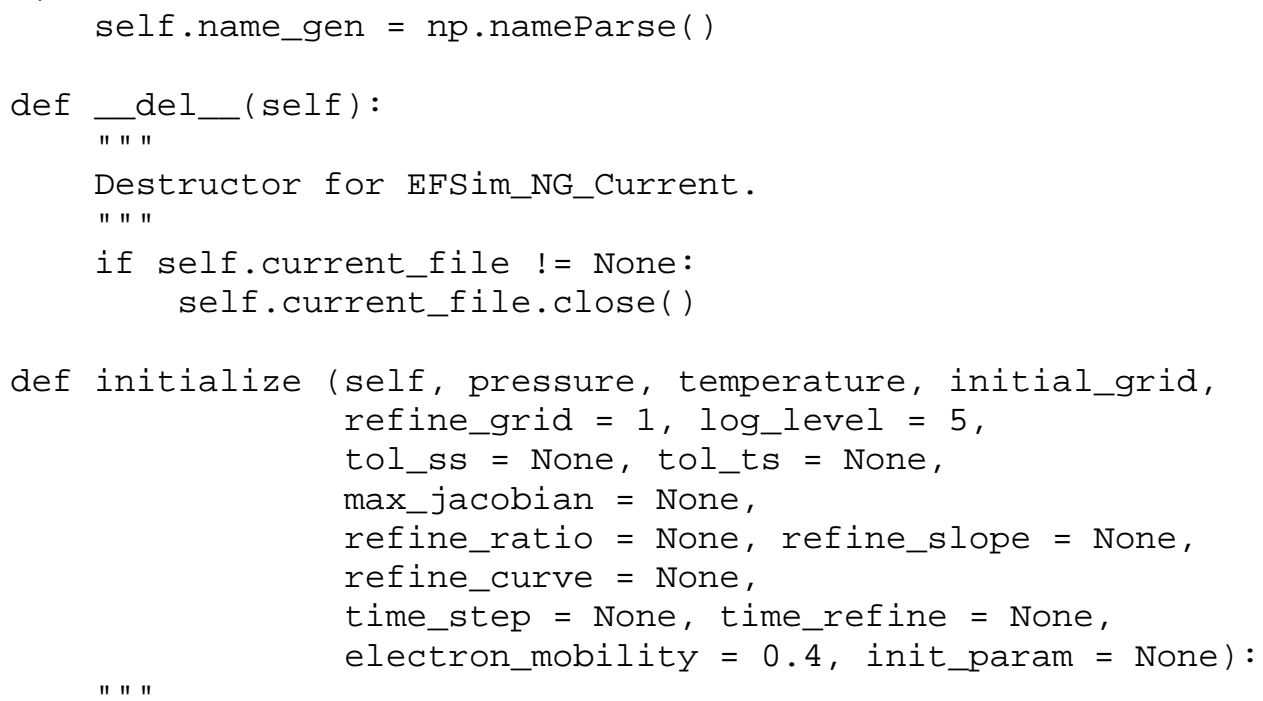

This function is used to initialize a BurnerFlame or BurnerFlame_efield.

Inputs as provided to Cantera are required.

pressure $=$ gas pressure

temperature = burner temperature in Kelvin

initial grid $=$ list of points to start evaluation

refine_grid $=1$ to refine the grid when solvin, $\odot$ otherwise

log_level = level of detail in cantera output, 1 is the

minimum, 5 is the maximum

tol_ss = steady state tolerance (list of 2 values)

tol_ts $=$ transient state tolerance (list of 2 values)

max_jacobian = maximum jacobian ages. (tuple of 2 values)

refine_ratio = ratio to adapt refine criteria

refine_slope = slope to adapt refine criteria

refine_curve $=$ curve to adapt refine criteria

time_step $=$ time in seconds for a single timestep

time_refine $=$ list of number of timesteps to use when refining

electron_mobility = constant value for the electron mobility

- - default value $=0.4$

init_param = normalized starting flame position

pressure, temperature, and initial_grid must be set.

All other attributes will be set to default values if not specified.

In most cases, the default value is the Cantera default, but

for electron

mobility, the default value is 0.4 .

\#store attributes

self. pressure = pressure

self. temperature = temperature

self.initial_grid = initial_grid

self.refine_grid = refine_grid

self.log_level = log_level 


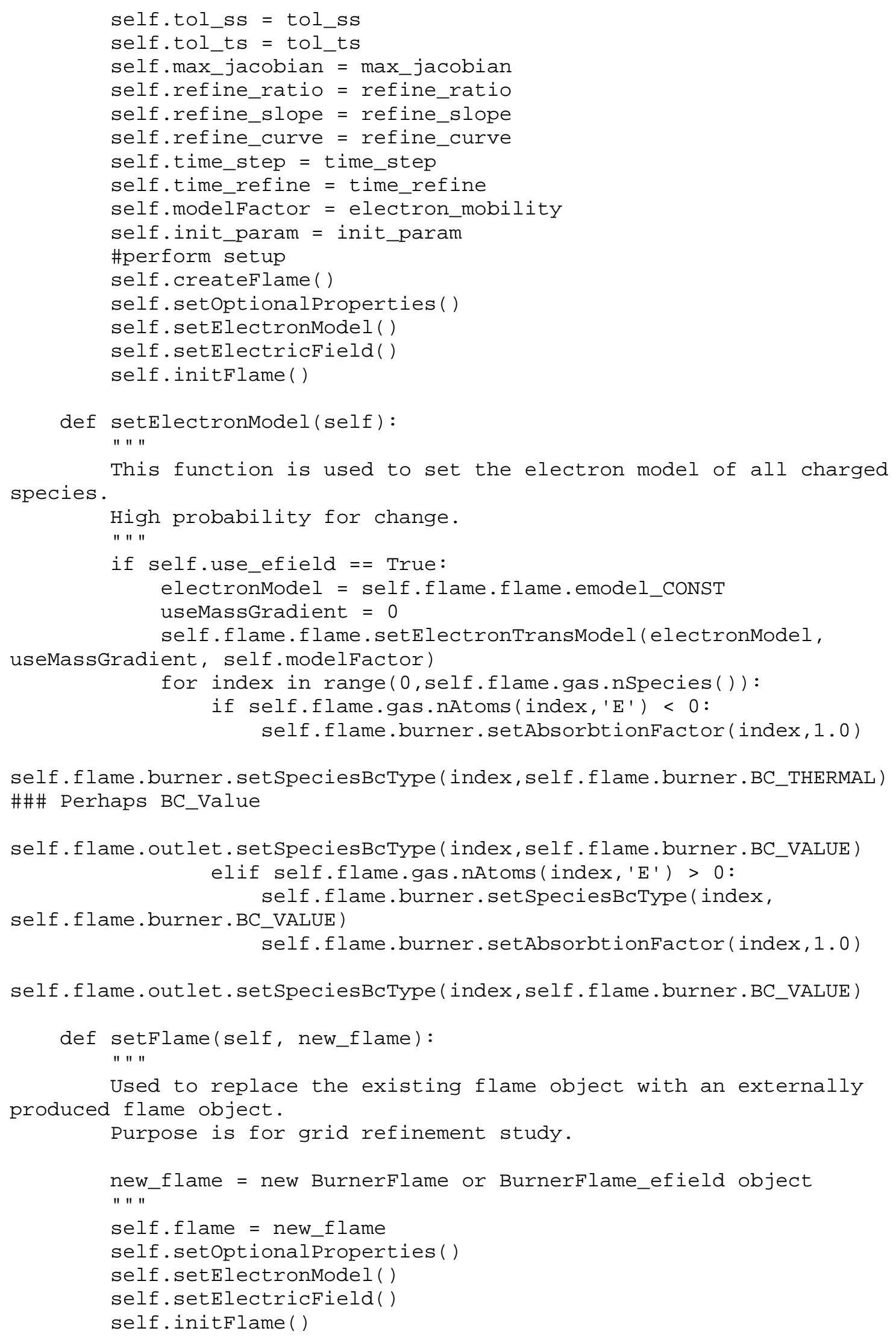




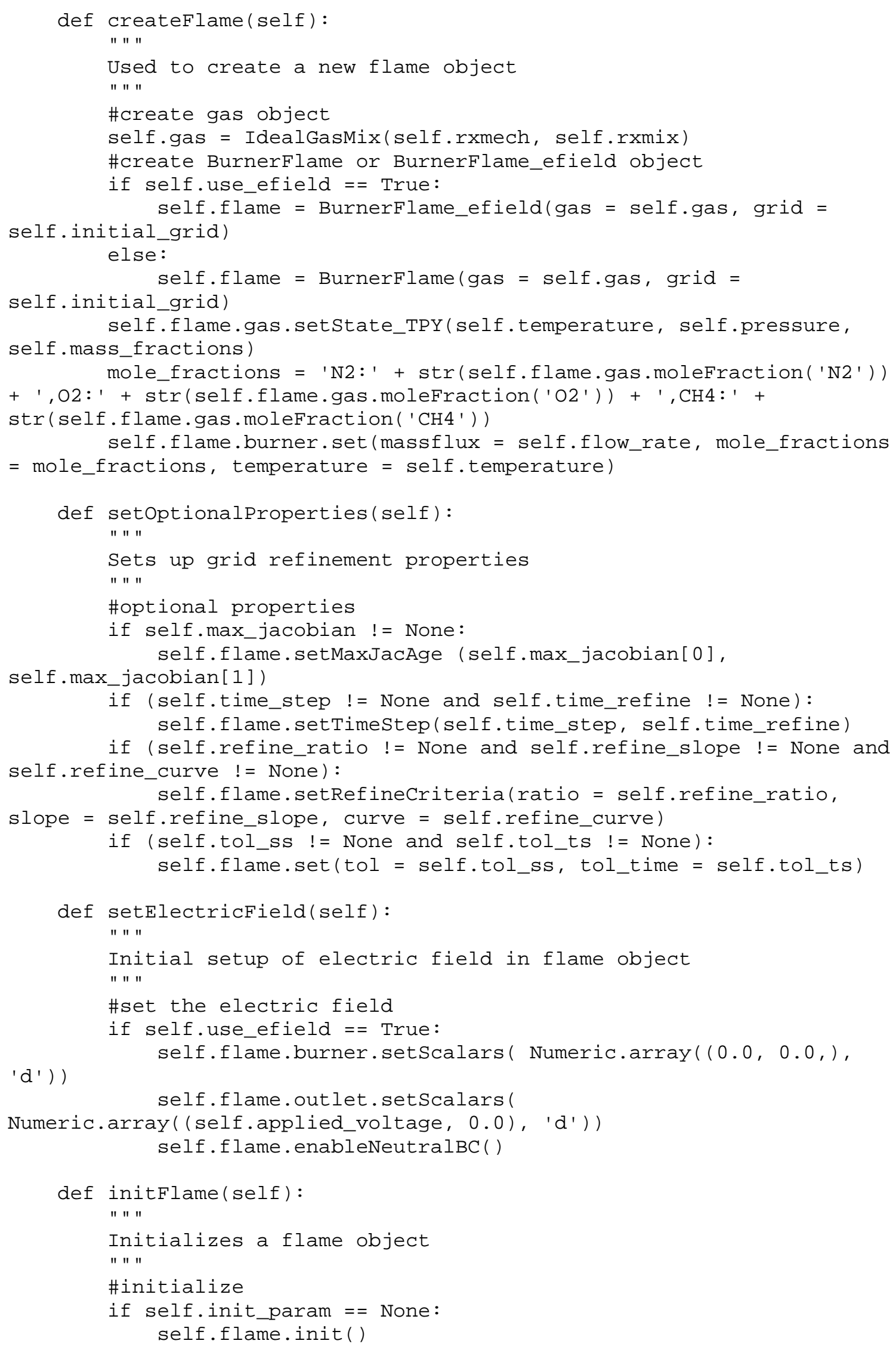




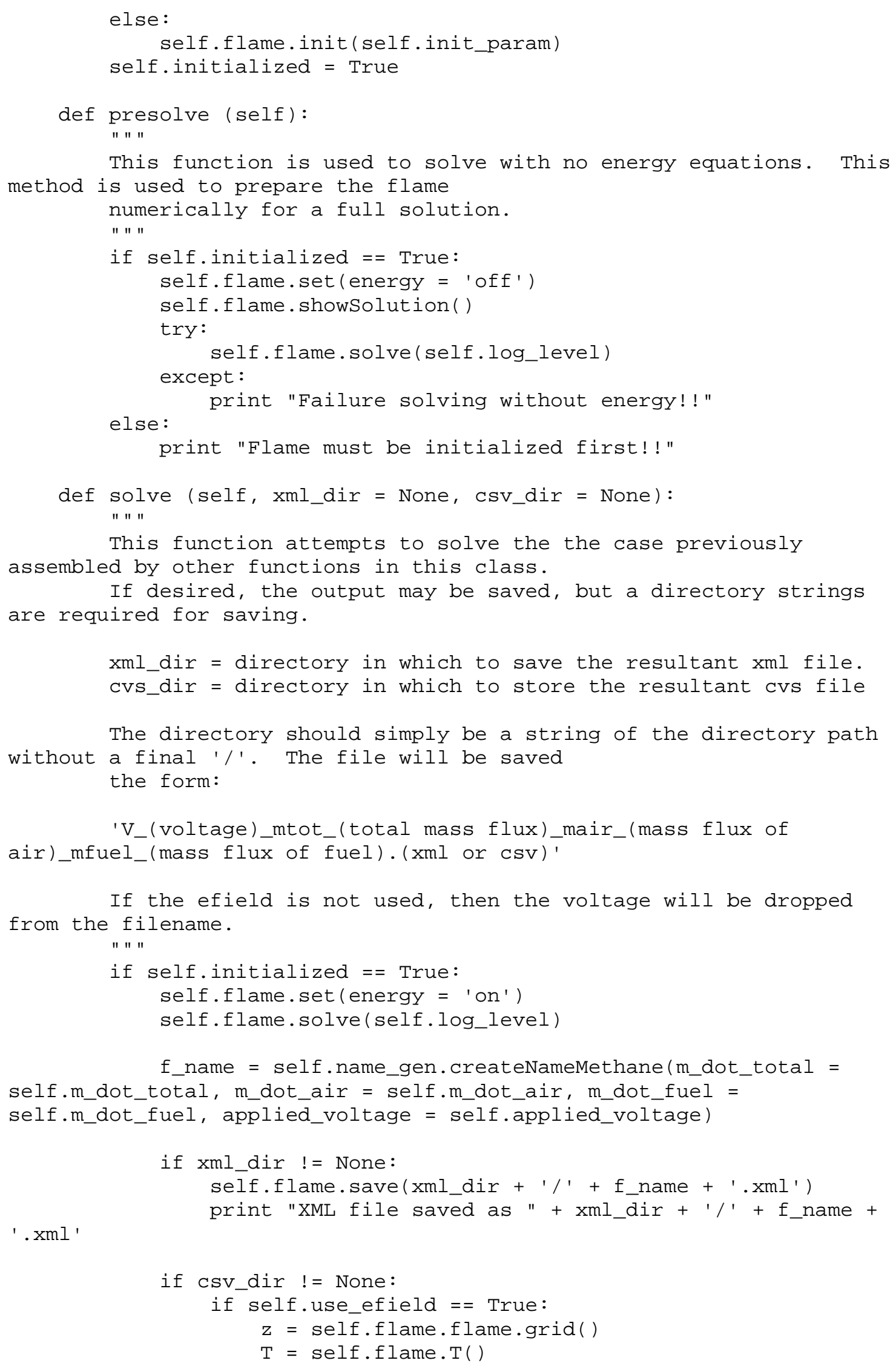




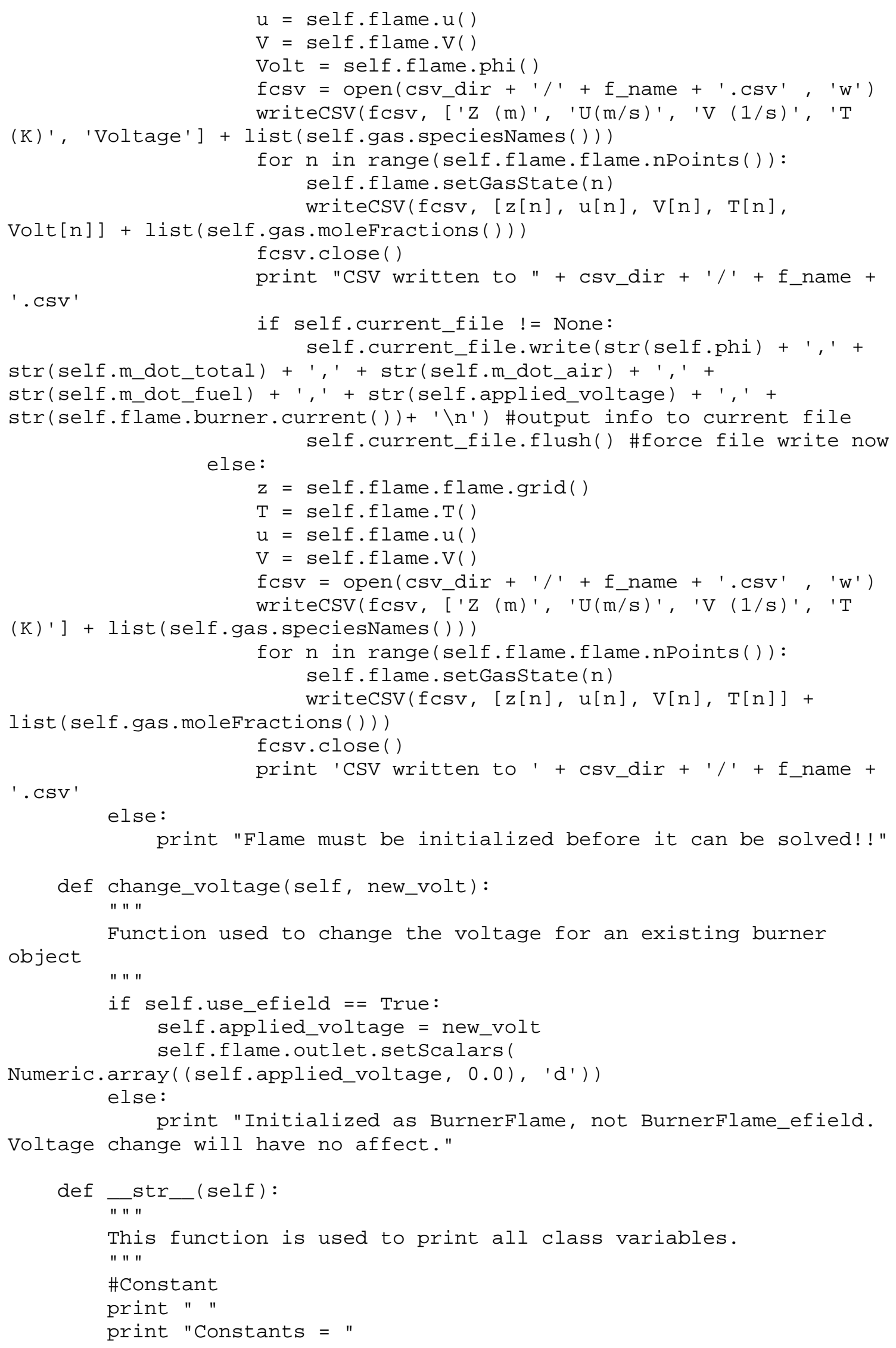




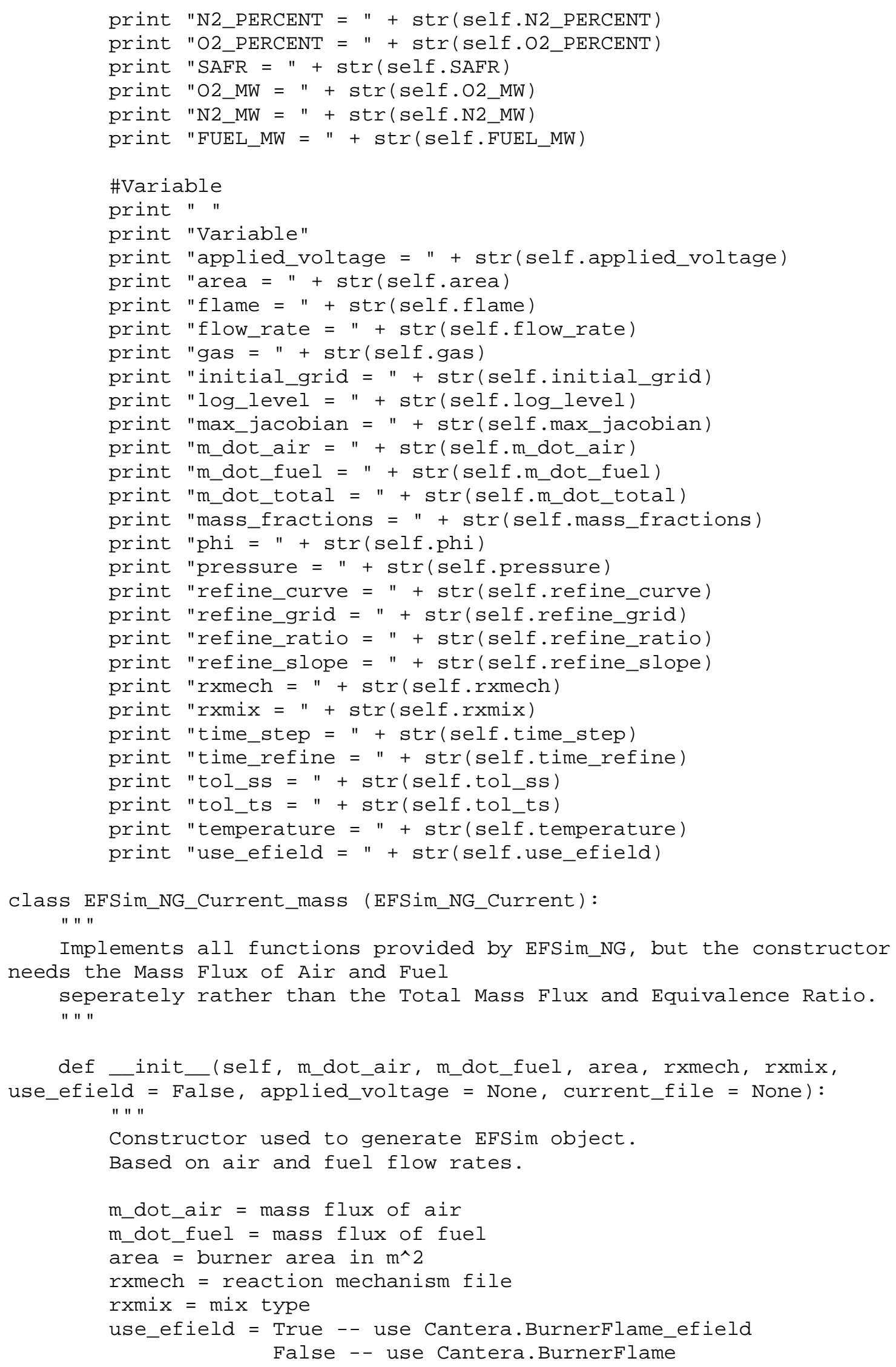

Implements all functions provided by EFSim_NG, but the constructor needs the Mass Flux of Air and Fuel seperately rather than the Total Mass Flux and Equivalence Ratio.

def_init_(self, m_dot_air, m_dot_fuel, area, rxmech, rxmix, use_efield $=$ False, applied_voltage $=$ None, current_file $=$ None $)$ :

Constructor used to generate EFSim object. Based on air and fuel flow rates.

m_dot_air = mass flux of air

m_dot_fuel = mass flux of fuel

area $=$ burner area in $\mathrm{m}^{\wedge} 2$

rxmech = reaction mechanism file

rxmix $=\operatorname{mix}$ type

use_efield = True - - use Cantera.BurnerFlame_efield

False - - use Cantera.BurnerFlame 


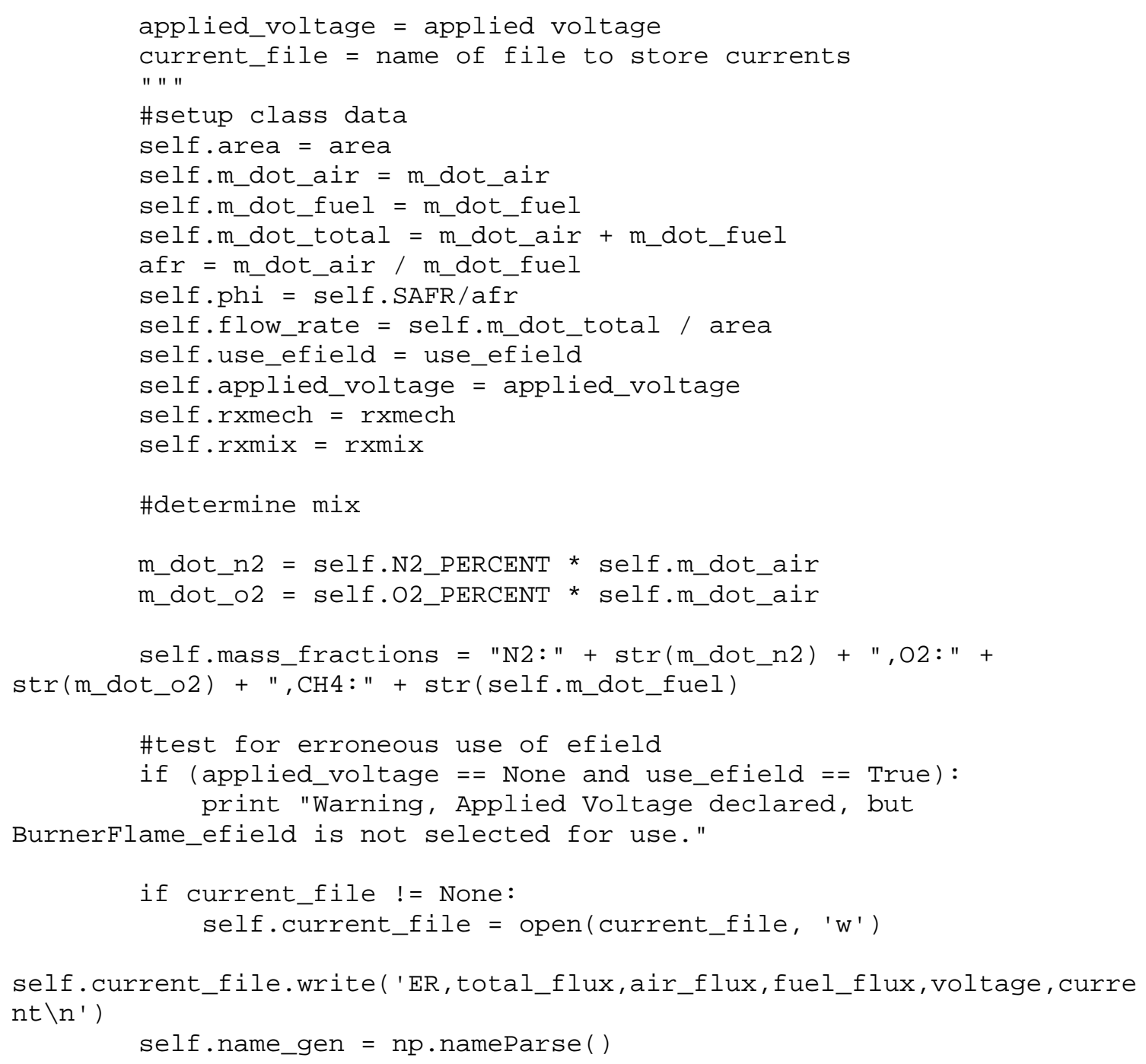




\section{A-2: Synthesis Gas Combustion Driver Code \\ Description:}

The EFSim_Syngas_Current class has been constructed in order to allow for simplified execution and less computationally costly runs of multiple similar simulations for synthesis gas combustion. As with the EFSim_NG_Current class, one major purpose of this class is to allow for the reuse of flame objects for different simulations in which the only parameter to change is the applied voltage. The flame object can only be reliably reused if the major properties of the flame such as flame position, temperature profile, and profiles of major species remain approximately the same. These assumptions can be made because the voltages applied in these simulations are not high enough to create a significant ionic wind and the affected species make up a miniscule fraction of the total gas mixture. In order to include ionic wind effects, an additional governing equation would be required for momentum, but the effect is not strong enough to justify the required additional calculations.

Code Overview:

All of the code used to streamline synthesis gas combustion simulation is included the EFSim_Syngas_Current class. This class contains a single constructor which is used to create a simulation object, and the inputs to this constructor are given in the table below 


\begin{tabular}{|l|l|l|}
\hline \multicolumn{1}{|c|}{ Input Name } & \multicolumn{1}{|c|}{ Purpose } & Units \\
\hline m_dot_air & Mass flux of air in the synthesis gas and air mix. & $\mathrm{kg} / \mathrm{s}$ \\
\hline m_dot_co & $\begin{array}{l}\text { Mass flux of Carbon Monoxide in the synthesis gas and air } \\
\text { mix. }\end{array}$ & $\mathrm{kg} / \mathrm{s}$ \\
\hline m_dot_h2 & Mass flux of Hydrogen gas in the synthesis gas and air mix. & $\mathrm{kg} / \mathrm{s}$ \\
\hline m_dot_n2 & $\begin{array}{l}\text { Mass flux of Nitrogen gas from fuel in the synthesis gas and air } \\
\text { mix. }\end{array}$ & $\mathrm{kg} / \mathrm{s}$ \\
\hline m_dot_ch4 & $\begin{array}{l}\text { Mass flux of Methane added to synthesis gas in the synthesis } \\
\text { gas and air mix. }\end{array}$ & $\mathrm{kg} / \mathrm{s}$ \\
\hline area & Burner area of simulated flame object & $\mathrm{m}^{2}$ \\
\hline rxmech & $\begin{array}{l}\text { Filename of the Cantera "cti" file containing the desired } \\
\text { reaction mechanism file. }\end{array}$ & --- \\
\hline rxmix & $\begin{array}{l}\text { Name of the mix type within the reaction mechanism file to use } \\
\text { for the simulation. }\end{array}$ & --- \\
\hline use_efield & $\begin{array}{l}\text { Boolean flag used to denote if an applied electric field will be } \\
\text { used in the desired simulation. }\end{array}$ & --- \\
\hline applied_voltage & Initial applied voltage for the simulation object. & $\mathrm{V}$ \\
\hline current_file & $\begin{array}{l}\text { Name of file to use for current calculation performed while } \\
\text { running the flame object. }\end{array}$ & --- \\
\hline
\end{tabular}

Table A-4: Constructor Inputs for Synthesis Gas Combustion Modeling Code

Within the EFSim_NG_Current class includes a set of "constants." Because

Python does not allow for easy inclusion of Constant values, it is up the user not to

manipulate these values.

\begin{tabular}{|c|c|c|}
\hline Constant Name & Purpose & Value \\
\hline $\mathrm{MW} \mathrm{CO}$ & Molecular Weight of $\mathrm{CO}$ & 28.0101 \\
\hline MW_H2 & Molecular Weight of $\mathrm{H}_{2}$ & 2.01588 \\
\hline MW_N2 & Molecular weight of $\mathrm{N}_{2}$ & 28.0134 \\
\hline $\mathrm{MW} \mathrm{CH} 4$ & Molecular weight of $\mathrm{CH}_{4}$ & 16.04246 \\
\hline $\mathrm{MW} \mathrm{O} 2$ & Molecular weight of $\mathrm{O}_{2}$ & 31.9998 \\
\hline N2_PERCENT & Percent by mass of $\mathrm{N}_{2}$ in air & 0.76708 \\
\hline O2_PERCENT & Percent by mass of $\mathrm{O}_{2}$ in air & 0.23292 \\
\hline
\end{tabular}

Table A-5: Constants Included in the EFSim_Syngas_Current Class

The remainder of the functions used in synthesis gas simulations are given in the table below. 


\begin{tabular}{|c|c|c|c|c|}
\hline Function & Purpose & Input & Description & Units \\
\hline init & Class constructor & $*_{\text {see Table A-4 }}$ & & \\
\hline \multirow[t]{4}{*}{$\overline{\text { calcSAFR }}$} & \multirow{4}{*}{$\begin{array}{l}\text { Calculates the } \\
\text { stoichiometric air- } \\
\text { fuel ratio for a } \\
\text { methane doped } \\
\text { synthesis gas mix }\end{array}$} & co_mass & $\begin{array}{l}\text { Mass fraction of } \\
\text { carbon monoxide in } \\
\text { synthesis gas }\end{array}$ & --- \\
\hline & & h2_mass & $\begin{array}{l}\text { Mass fraction of } \\
\text { hydrogen gas in } \\
\text { synthesis gas }\end{array}$ & --- \\
\hline & & n2_mass & $\begin{array}{l}\text { Mass fraction of } \\
\text { nitrogen gas in } \\
\text { synthesis gas } \\
\text { mixture }\end{array}$ & --- \\
\hline & & ch4_mass & $\begin{array}{l}\text { Mass fraction of } \\
\text { methane in doped } \\
\text { synthesis gas } \\
\text { mixture }\end{array}$ & --- \\
\hline$\ldots$ del & $\begin{array}{l}\text { Class destructor used } \\
\text { to close all open file } \\
\text { before disposing of } \\
\text { simulation object }\end{array}$ & --- & --- & --- \\
\hline \multirow[t]{6}{*}{ initialize } & \multirow{6}{*}{$\begin{array}{l}\text { Used to initialize a } \\
\text { BurnerFlame or } \\
\text { BurnerFlame_efield } \\
\text { object for use in } \\
\text { simulation }\end{array}$} & pressure & $\begin{array}{l}\text { Gas pressure to use } \\
\text { in the simulation }\end{array}$ & Pascal \\
\hline & & temperature & $\begin{array}{l}\text { Burner temperature } \\
\text { to use in the } \\
\text { simulation }\end{array}$ & $\mathrm{K}$ \\
\hline & & initial_grid & $\begin{array}{l}\text { List of the initial set } \\
\text { of grid points to use } \\
\text { in the simulation. }\end{array}$ & $\mathrm{m}$ \\
\hline & & refine_grid & $\begin{array}{l}\text { Indicates if a } \\
\text { simulation should } \\
\text { attempt to add grid } \\
\text { points as needed. } 1 \\
\text { indicates that points } \\
\text { may be added, and } 0 \\
\text { indicates that points } \\
\text { should not be added }\end{array}$ & --- \\
\hline & & log_level & $\begin{array}{l}\text { Indicates the level of } \\
\text { diagnostic output to } \\
\text { produce during a } \\
\text { simulation. } 1 \text { is the } \\
\text { minimum, and } 5 \text { is } \\
\text { the maximum }\end{array}$ & --- \\
\hline & & tol_ss & $\begin{array}{l}\text { Steady state error } \\
\text { tolerance. }\end{array}$ & --- \\
\hline
\end{tabular}




\begin{tabular}{|c|c|c|c|c|}
\hline & & tol_ts & $\begin{array}{l}\text { Transient state error } \\
\text { tolerance }\end{array}$ & --- \\
\hline & & max_jacobian & $\begin{array}{l}\text { Used to limit the } \\
\text { reuse of jacobian } \\
\text { matrices during } \\
\text { calculations }\end{array}$ & --- \\
\hline & & refine_ratio & $\begin{array}{l}\text { Ratio used to } \\
\text { determine a need for } \\
\text { solution refinement }\end{array}$ & --- \\
\hline & & refine_slope & $\begin{array}{l}\text { Slope used to } \\
\text { determine a need for } \\
\text { solution refinement }\end{array}$ & --- \\
\hline & & refine_curve & $\begin{array}{l}\text { Curve used to } \\
\text { determine a need for } \\
\text { solution refinement }\end{array}$ & $\overline{---}$ \\
\hline & & time_step & $\begin{array}{l}\text { Length of time steps } \\
\text { to use while finding } \\
\text { steady state solutions }\end{array}$ & $\mathrm{s}$ \\
\hline & & time_refine & $\begin{array}{l}\text { List of number of } \\
\text { timesteps to take at a } \\
\text { time while finding a } \\
\text { solution }\end{array}$ & -- \\
\hline & & electron_mobility & $\begin{array}{l}\text { Electron mobility to } \\
\text { be used in a } \\
\text { simulation }\end{array}$ & $m^{2} / V s$ \\
\hline & & init_param & $\begin{array}{l}\text { Normalized starting } \\
\text { flame position used } \\
\text { to aid in flame } \\
\text { calculation by } \\
\text { allowing an } \\
\text { improved initial } \\
\text { guess. }\end{array}$ & --- \\
\hline setElectronModel & $\begin{array}{l}\text { Function used to set } \\
\text { the electron mobility } \\
\text { within the flame } \\
\text { object }\end{array}$ & --- & --- & --- \\
\hline setFlame & $\begin{array}{l}\text { Function used to } \\
\text { allow for the use of } \\
\text { an externally created } \\
\text { BurnerFlame or } \\
\text { BurnerFlame_efield } \\
\text { object for a } \\
\text { simulation. }\end{array}$ & new_flame & $\begin{array}{l}\text { The BurnerFlame or } \\
\text { BurnerFlame_efield } \\
\text { object to use in a } \\
\text { simulation. }\end{array}$ & --- \\
\hline createFlame & $\begin{array}{l}\text { Function intended } \\
\text { for internal use in } \\
\text { creating a }\end{array}$ & --- & --- & --- \\
\hline
\end{tabular}




\begin{tabular}{|c|c|c|c|c|}
\hline & $\begin{array}{l}\text { BurnerFlame or } \\
\text { BurnerFlame_efield } \\
\text { object }\end{array}$ & & & \\
\hline setOptionalProperties & $\begin{array}{l}\text { Function intended } \\
\text { for internal use in } \\
\text { setting optional } \\
\text { properties given as } \\
\text { inputs to the } \\
\text { initialize function }\end{array}$ & --- & --- & --- \\
\hline setElectricField & $\begin{array}{l}\text { Function intended } \\
\text { for internal use in } \\
\text { initially setting up an } \\
\text { electric field for the } \\
\text { flame object }\end{array}$ & --- & --- & --- \\
\hline initFlame & $\begin{array}{l}\text { Used to call } \\
\text { Cantera's initialize } \\
\text { function on the } \\
\text { flame object and flag } \\
\text { the flame object as } \\
\text { initialized }\end{array}$ & --- & --- & --- \\
\hline presolve & $\begin{array}{l}\text { This function solves } \\
\text { the flame object with } \\
\text { the energy equations } \\
\text { turned off in order to } \\
\text { derive a better initial } \\
\text { solution before } \\
\text { running a true } \\
\text { simulation }\end{array}$ & --- & $\begin{array}{ll}-- \\
\end{array}$ & $\begin{array}{ll}-- \\
\end{array}$ \\
\hline \multirow[t]{2}{*}{ solve } & \multirow{2}{*}{$\begin{array}{l}\text { This function solves } \\
\text { the flame object with } \\
\text { the energy equation } \\
\text { turned on and saves } \\
\text { the resulting output } \\
\text { files. }\end{array}$} & xml_dir & $\begin{array}{l}\text { Name of directory in } \\
\text { which to store results } \\
\text { in XML file format }\end{array}$ & --- \\
\hline & & csv_dir & $\begin{array}{l}\text { Name of directory in } \\
\text { which to store results } \\
\text { in CSV file format }\end{array}$ & --- \\
\hline change_voltage & $\begin{array}{l}\text { Function used to } \\
\text { change the voltage } \\
\text { between runs of } \\
\text { similar simulations }\end{array}$ & new_volt & $\begin{array}{l}\text { Value for the new } \\
\text { applied voltage }\end{array}$ & $\mathrm{V}$ \\
\hline _str & $\begin{array}{l}\text { Function used to } \\
\text { display class } \\
\text { constants and } \\
\text { variables }\end{array}$ & --- & --- & --- \\
\hline
\end{tabular}

Table A-6: Class Methods for EFSim_Syngas_Current Class 
As a result of running simulations with these programs, three different types of output files are generated. The first type is a solution in Cantera's 'ctml' file format. The second type is also a solution, but this solution is in comma separated value ('csv') format. The third potential output file is a file listing the currents for each simulation run. All three of these files formats are documented in Appendix D. The names for the first two files are generated using the nameParse class, which is specified in Appendix C.

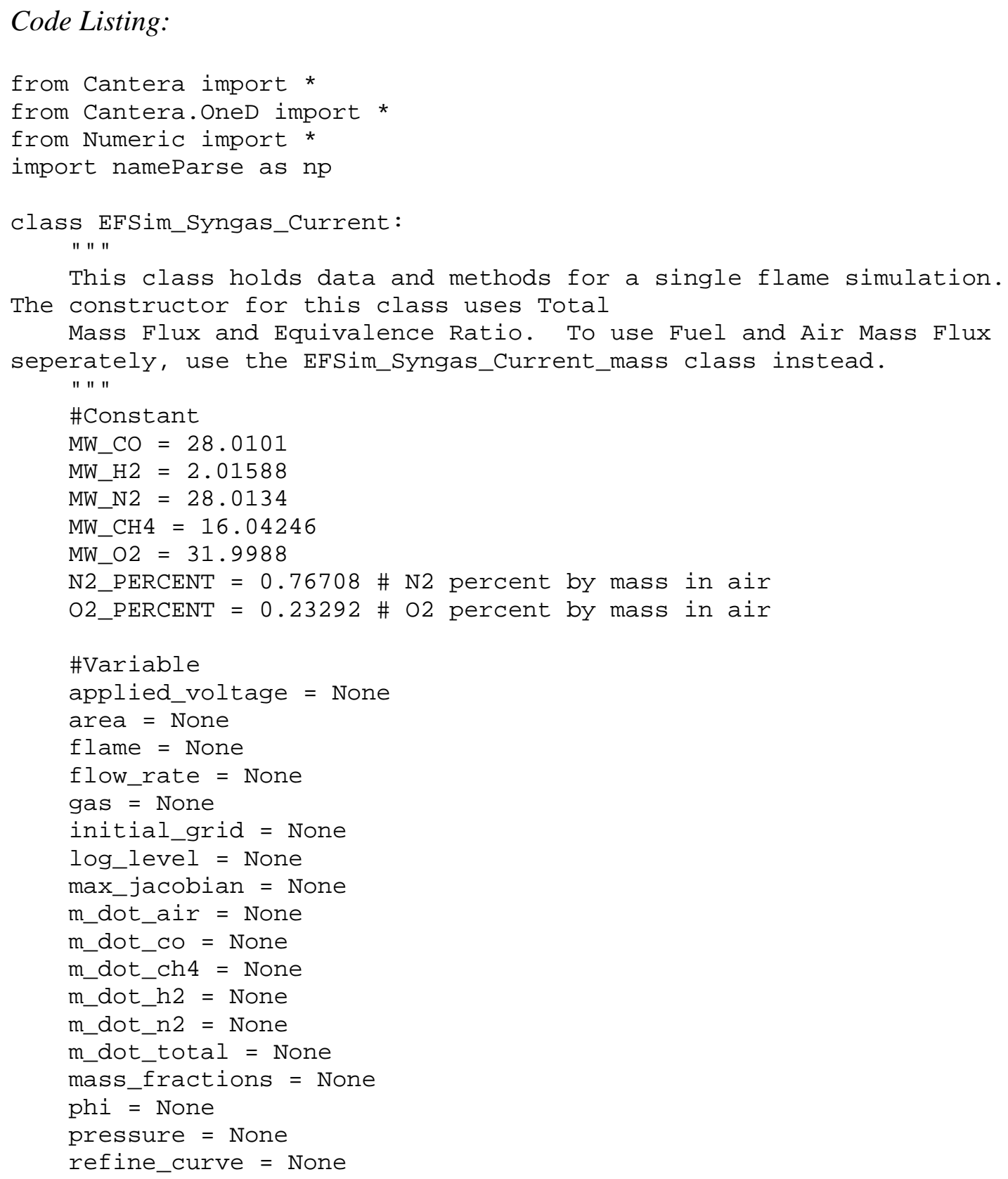




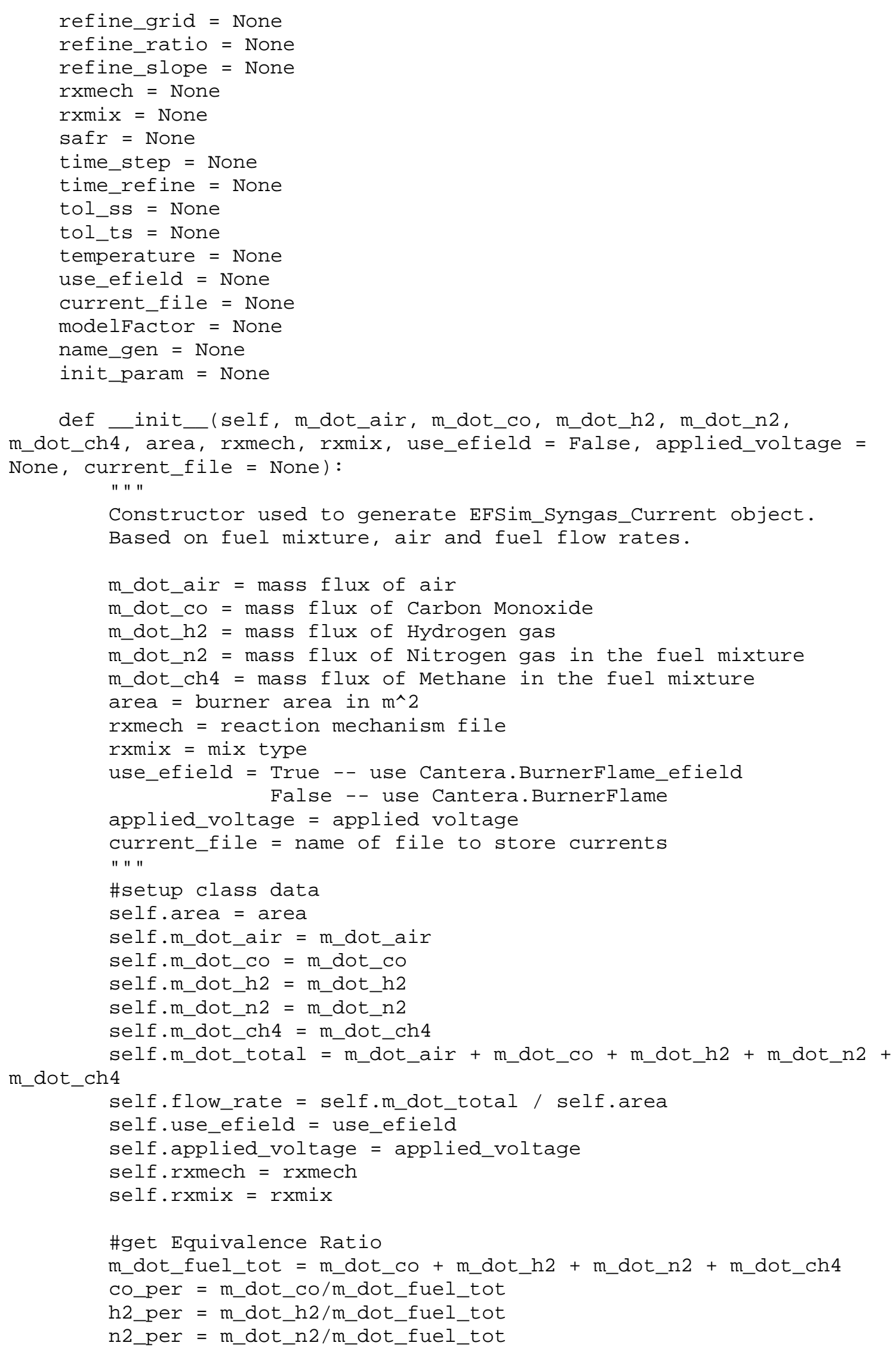




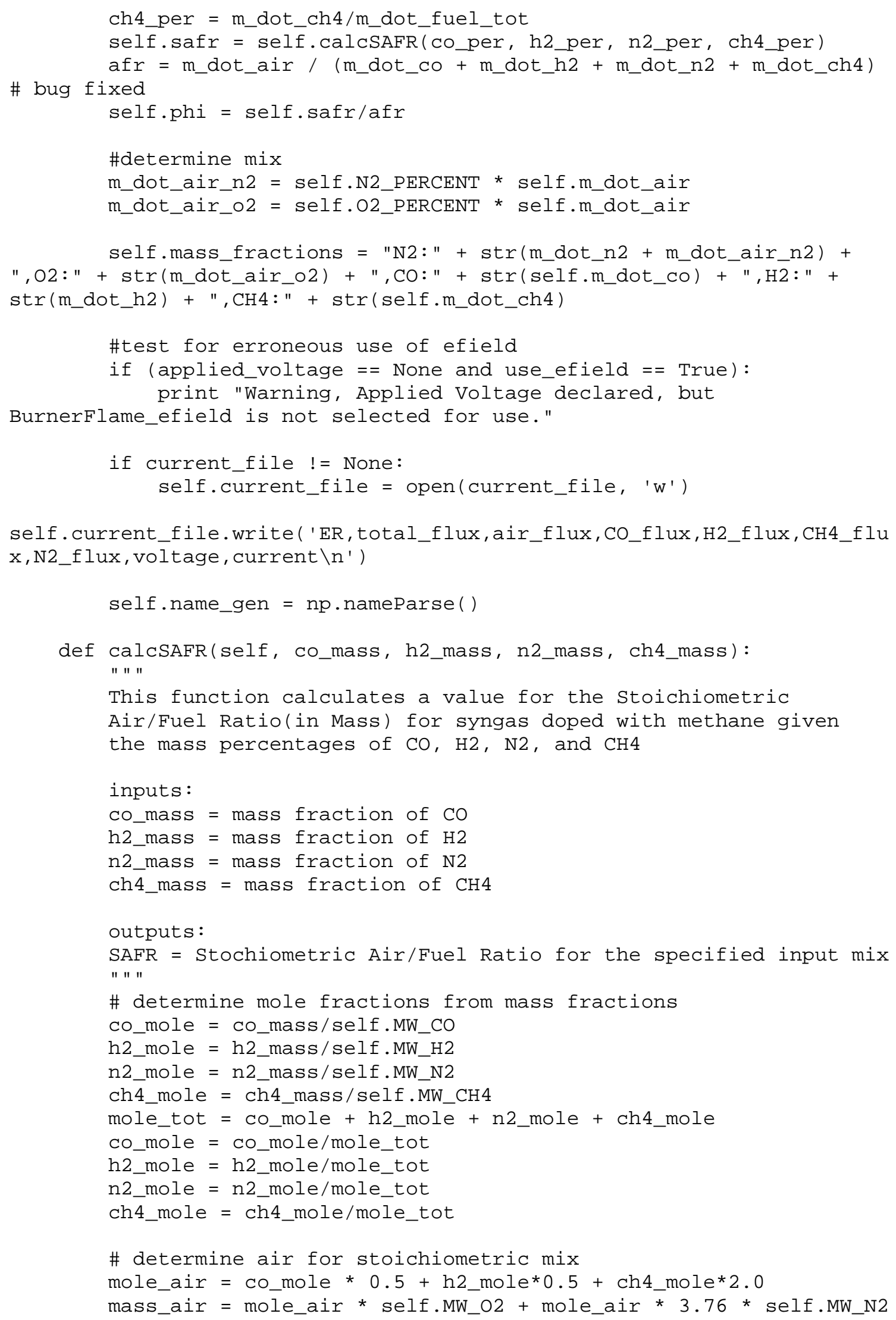




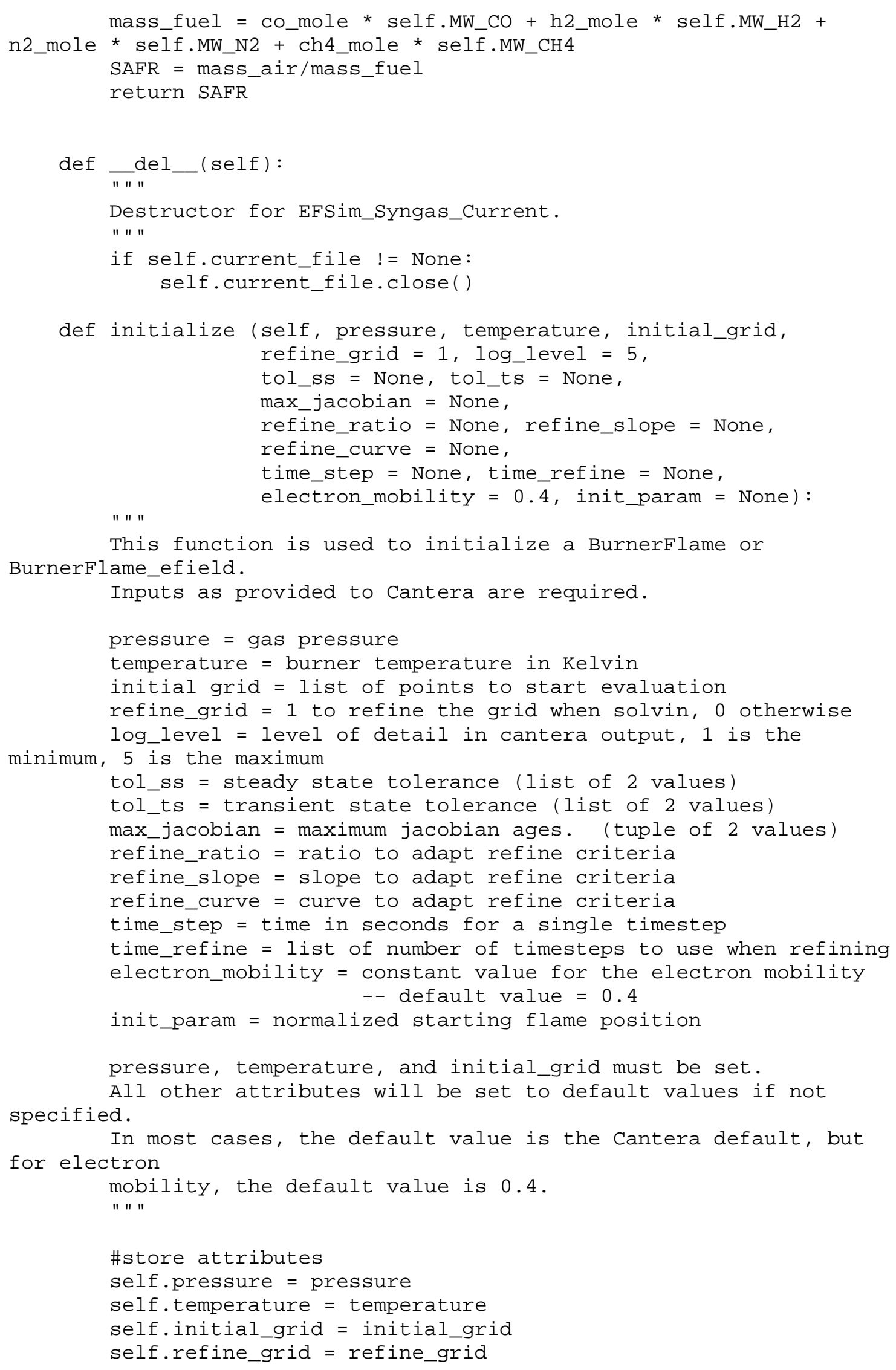

This function is used to initialize a Burnerflame or BurnerFlame_efield.

Inputs as provided to Cantera are required.

pressure $=$ gas pressure

temperature = burner temperature in Kelvin

initial grid $=$ list of points to start evaluation

refine_grid $=1$ to refine the grid when solvin, $\odot$ otherwise

log_level = level of detail in cantera output, 1 is the

minimum, 5 is the maximum

tol_ss = steady state tolerance (list of 2 values)

tol_ts $=$ transient state tolerance (list of 2 values)

max_jacobian = maximum jacobian ages. (tuple of 2 values)

refine_ratio $=$ ratio to adapt refine criteria

refine_slope $=$ slope to adapt refine criteria

refine_curve $=$ curve to adapt refine criteria

time_step $=$ time in seconds for a single timestep

time_refine $=$ list of number of timesteps to use when refining

electron_mobility $=$ constant value for the electron mobility - - default value $=0.4$

init_param $=$ normalized starting flame position

pressure, temperature, and initial_grid must be set.

specified.

All other attributes will be set to default values if not for electron

In most cases, the default value is the Cantera default, but

mobility, the default value is 0.4 .

\#store attributes

self. pressure $=$ pressure

self. temperature = temperature

self.initial_grid = initial_grid

self.refine_grid = refine_grid 


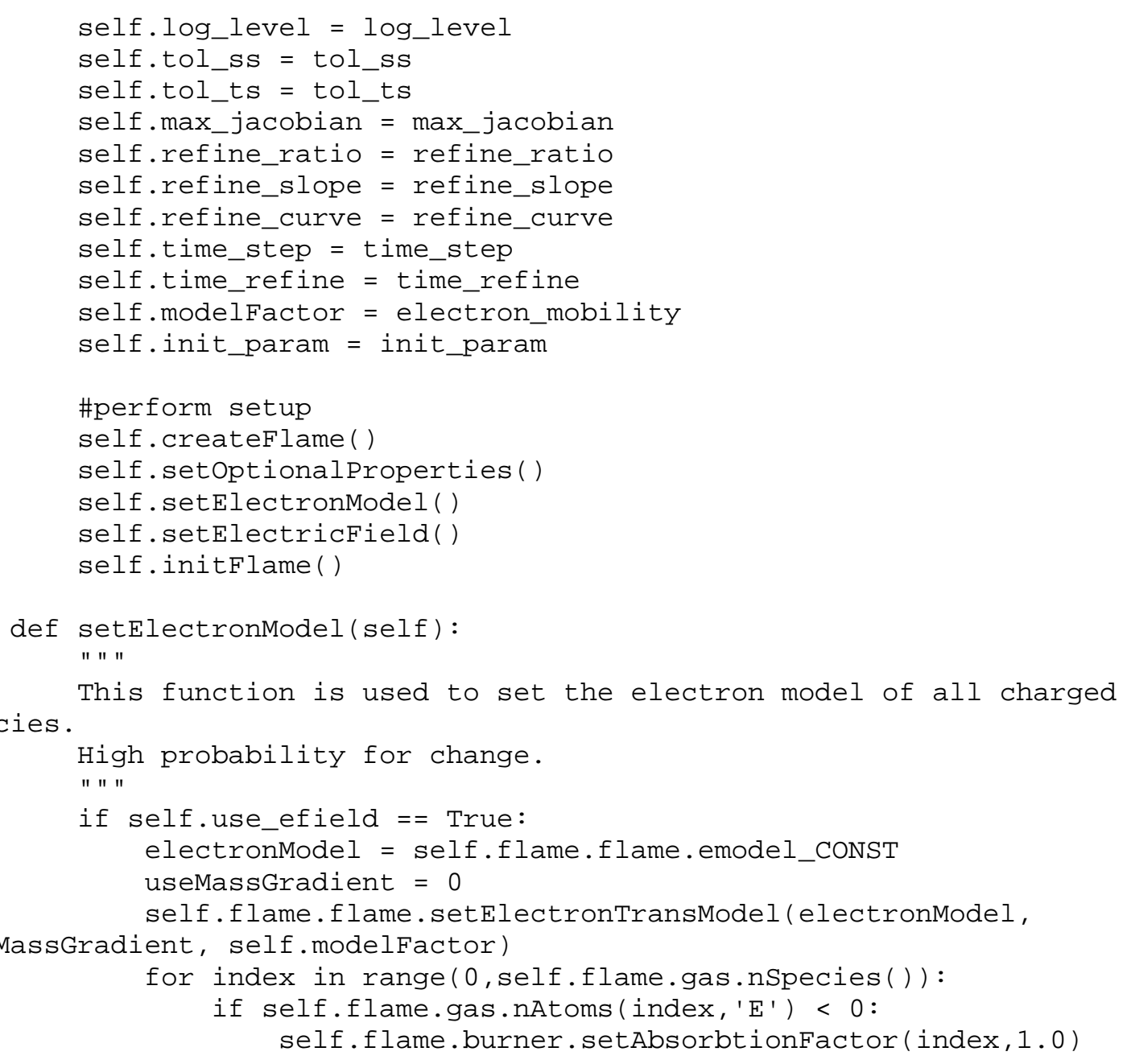




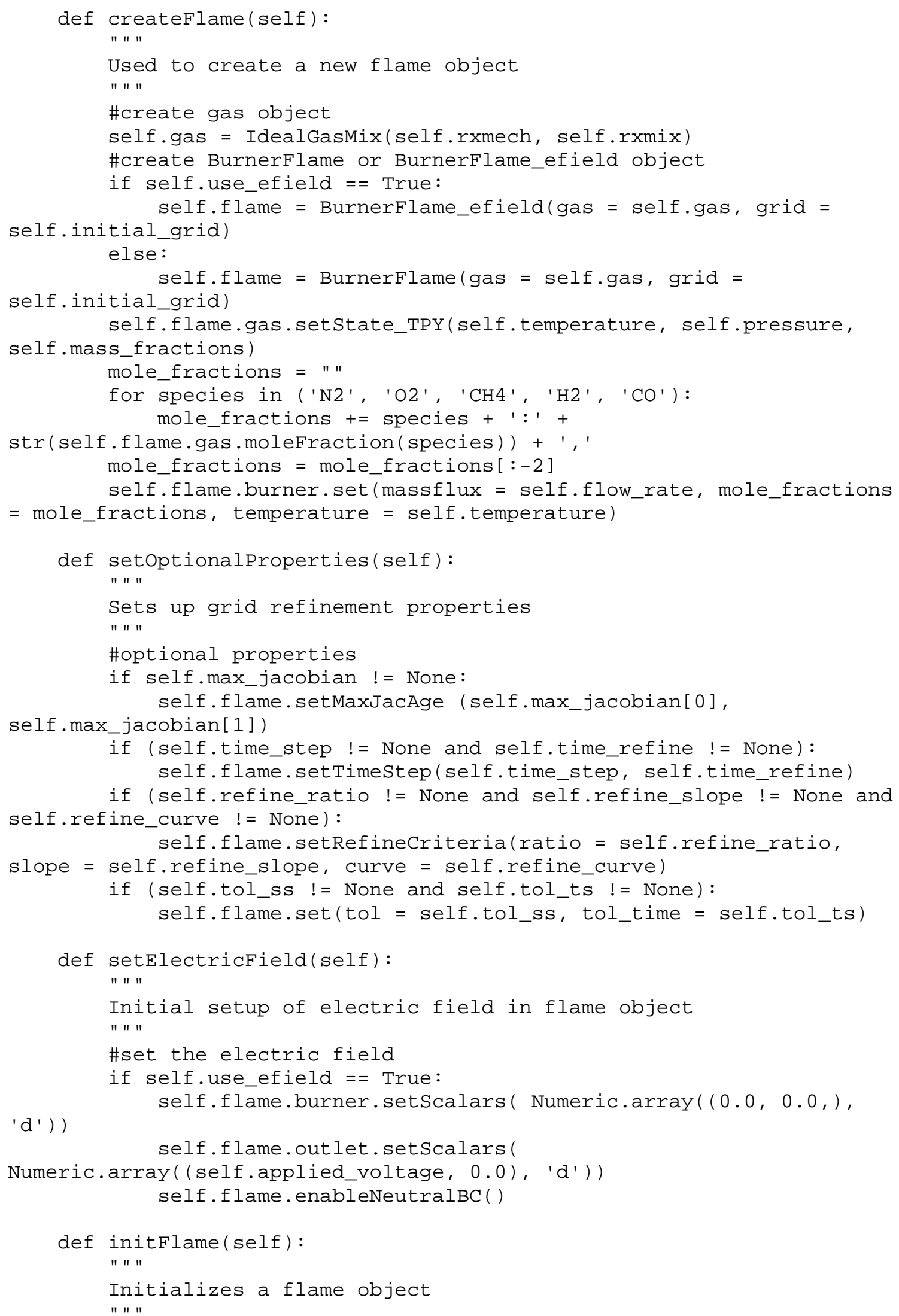


\#initialize

if self.init_param == None:

self.flame.init()

else:

self.flame.init(self.init_param)

self . initialized $=$ True

def presolve (self):

This function is used to solve with no energy equations. This method is used to prepare the flame

numerically for a full solution.

" " "

if self.initialized $==$ True:

self.flame.set (energy $=$ 'off')

self.flame. showSolution( )

try:

except:

self.flame.solve(self.log_level)

else:

print "Failure solving without energy!!"

print "Flame must be initialized first!!"

def solve $($ self, xml_dir = None, csv_dir $=$ None $)$ :

This function attempts to solve the the case previously

assembled by other functions in this class.

If desired, the output may be saved, but a directory strings are required for saving.

xml_dir = directory in which to save the resultant $x m l$ file. cvs_dir = directory in which to store the resultant cvs file

The directory should simply be a string of the directory path without a final '/'. The file will be saved the form:

'V_(voltage)_mtot_(total mass flux)_mair_(mass flux of air)_mfuel_(mass flux of fuel).(xml or csv)'

If the efield is not used, then the voltage will be dropped from the filename.

if self.initialized $==$ True:

self.flame.set (energy $=$ 'on')

self.flame.solve(self.log_level)

$f \_$name $=$self.name_gen.createNamesyngas $\left(m \_d o t \_t o t a l=\right.$

self.m_dot_total, m_dot_air = self.m_dot_air, m_dot_co = self.m_dot_co, m_dot_h2 = self.m_dot_h2, m_dot_n2 =

self.m_dot_n2, m_dot_ch4 = self.m_dot_ch4, applied_voltage = self.applied_voltage)

if $x m 1$ dir != None:

self.flame.save(xml_dir + '/' $\left.+f \_n a m e+' . x m l '\right)$

'. $x m 1$ '

print "XML file saved as " $+x m l \_d i r+1 / 1+f \_n a m e+$

if csv_dir ! = None:

if self.use_efield == True: 


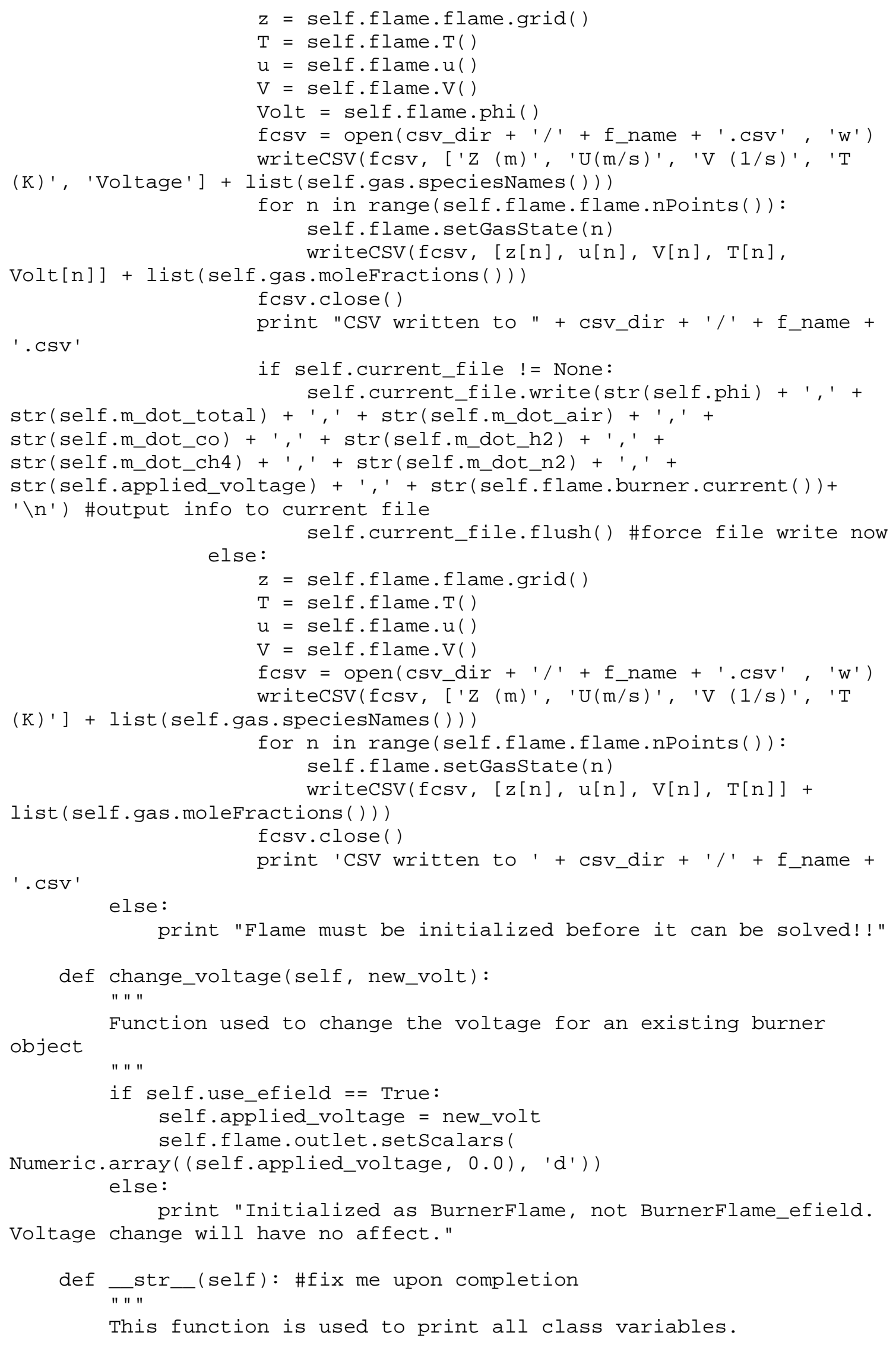




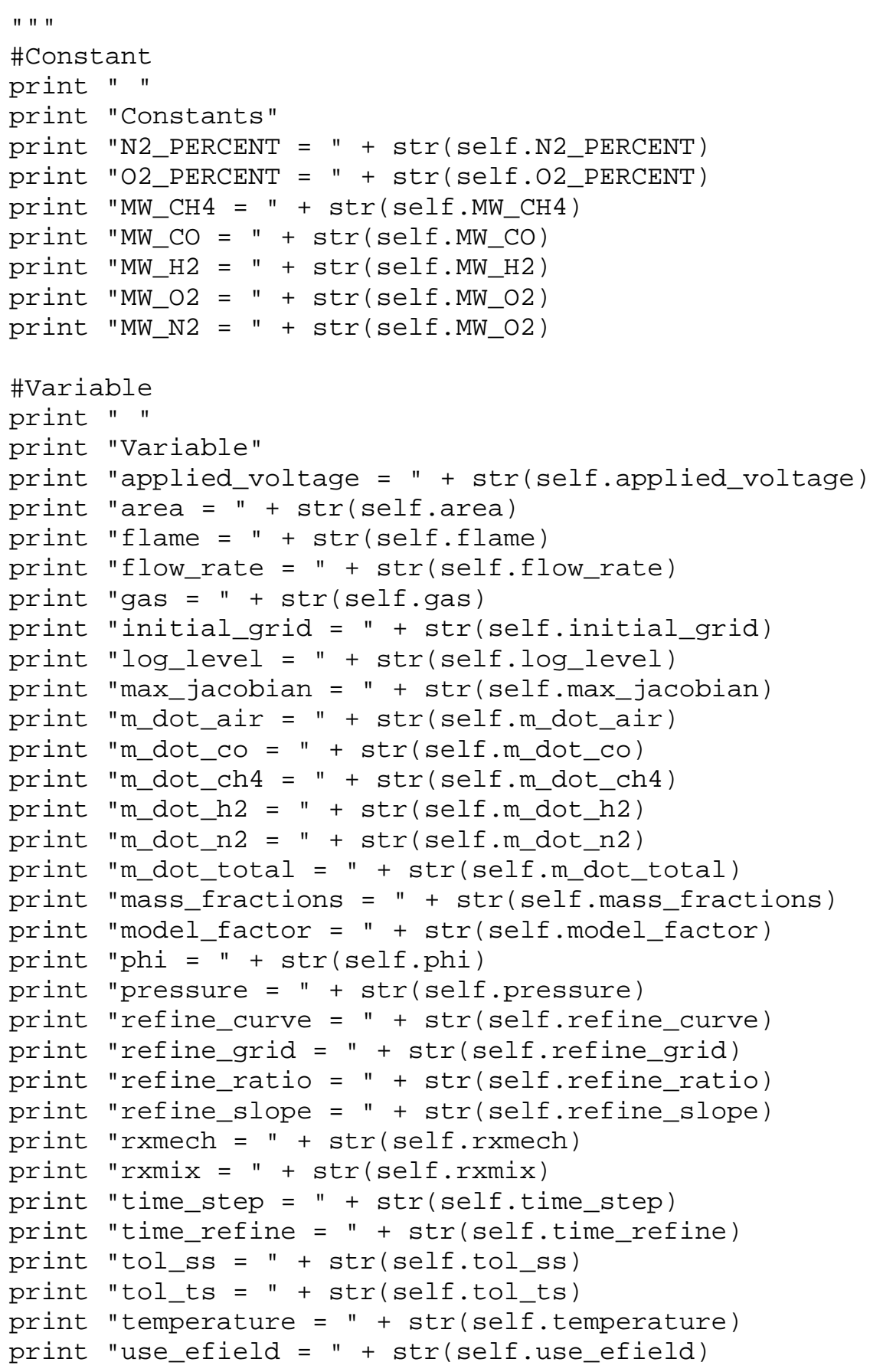




\section{Appendix B: Cantera Reaction Mechanism Files}

\section{B-1: Listing of Jones, Heinsohn and Becker Mechanism}

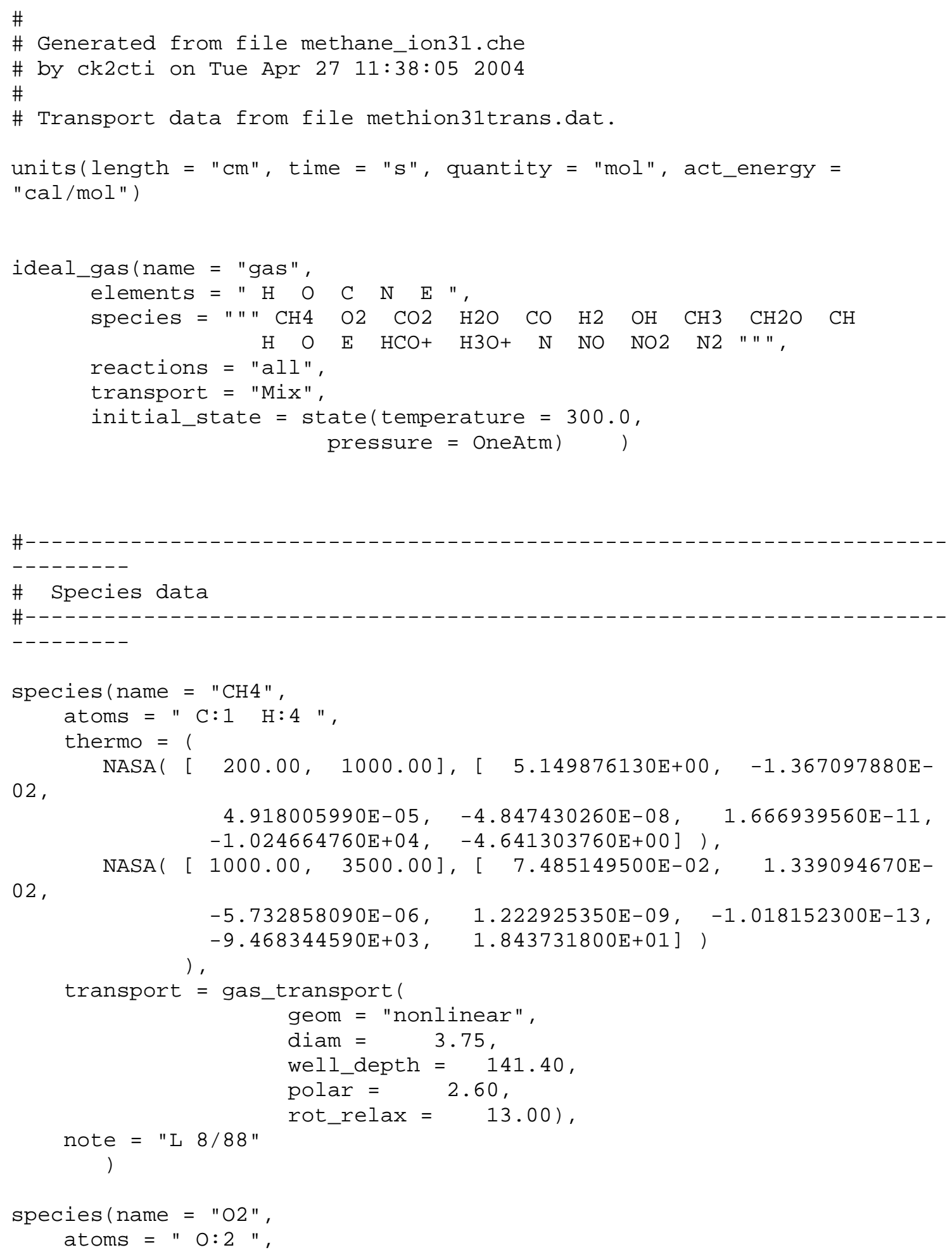




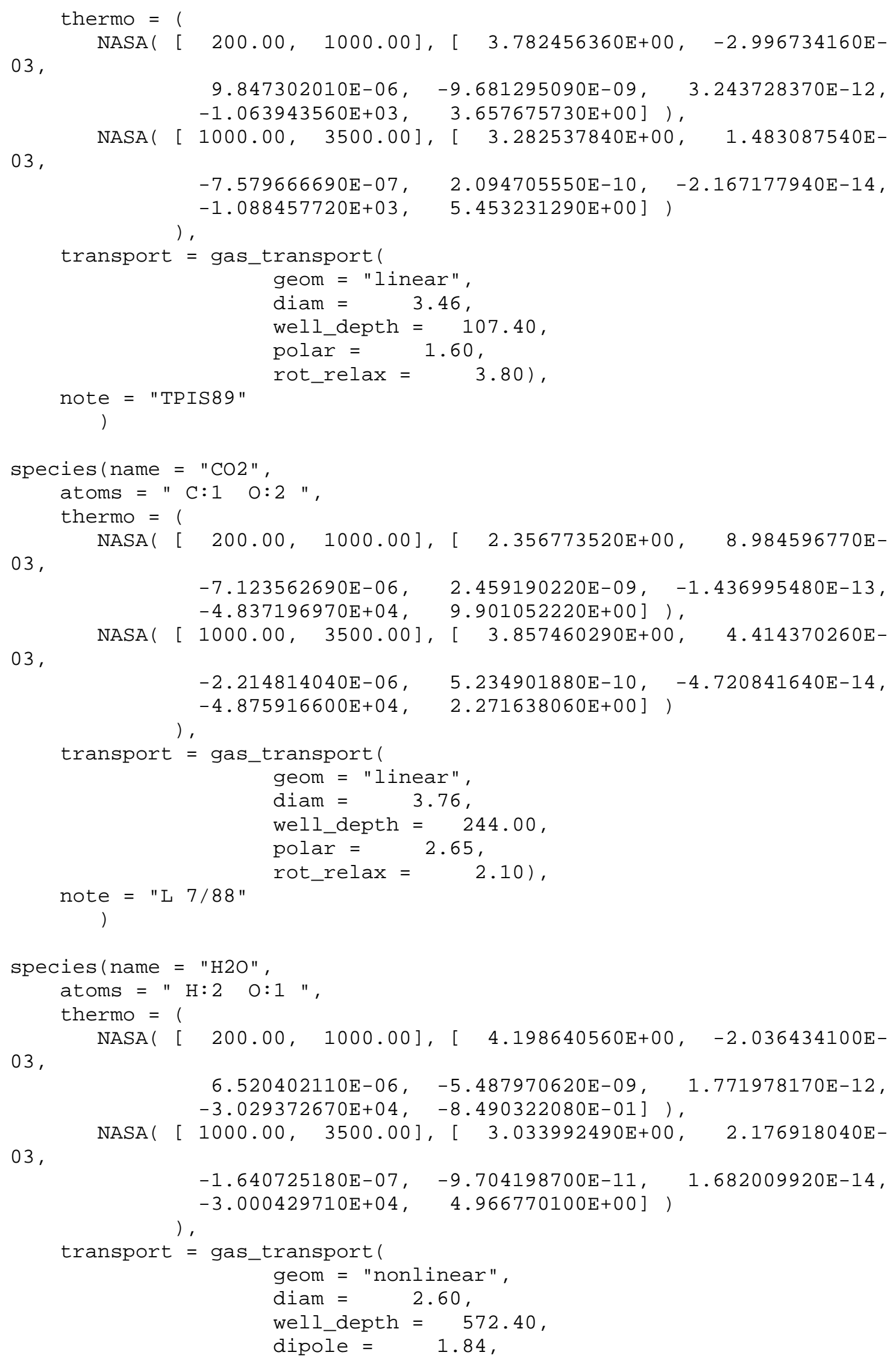




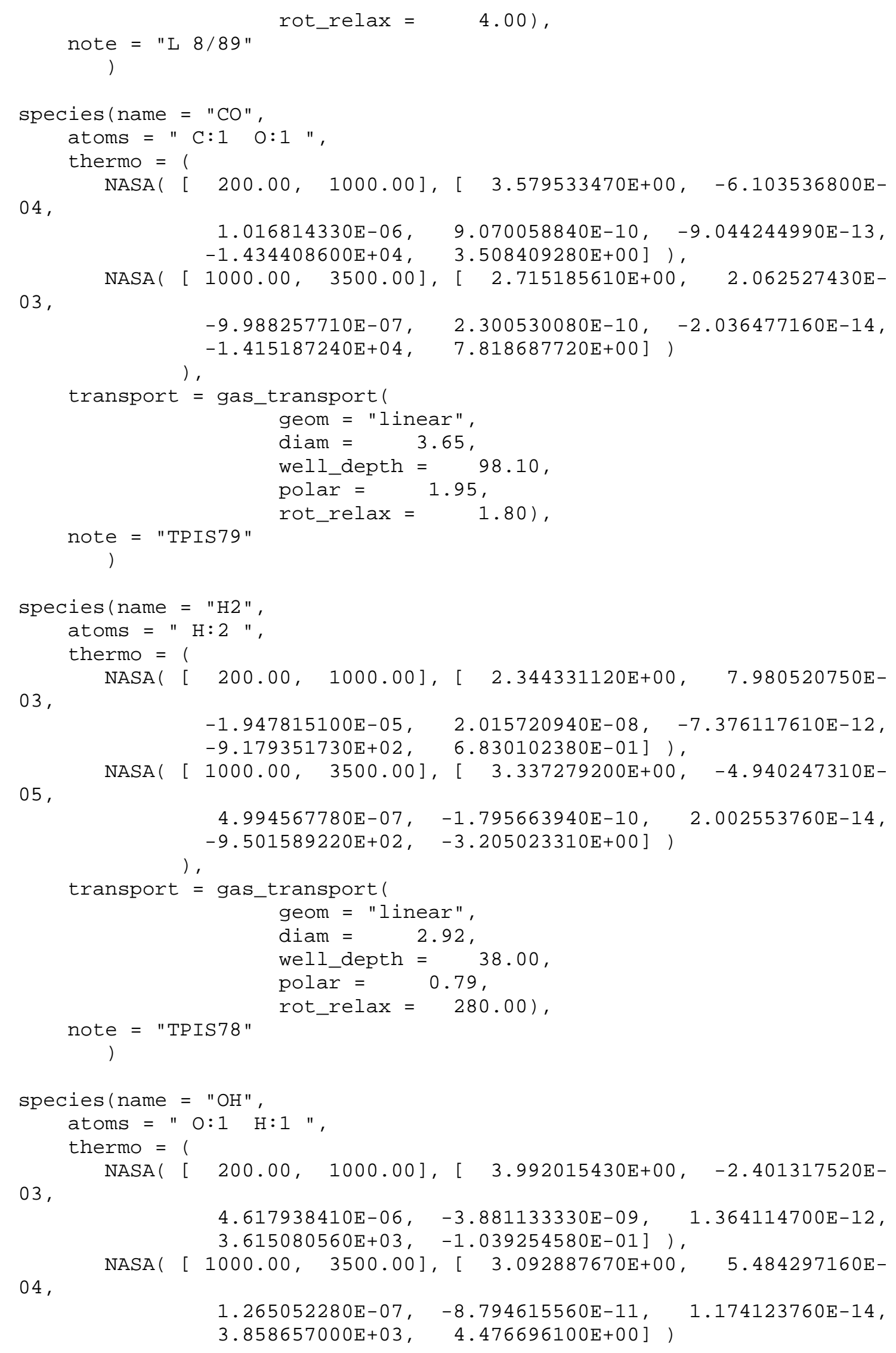




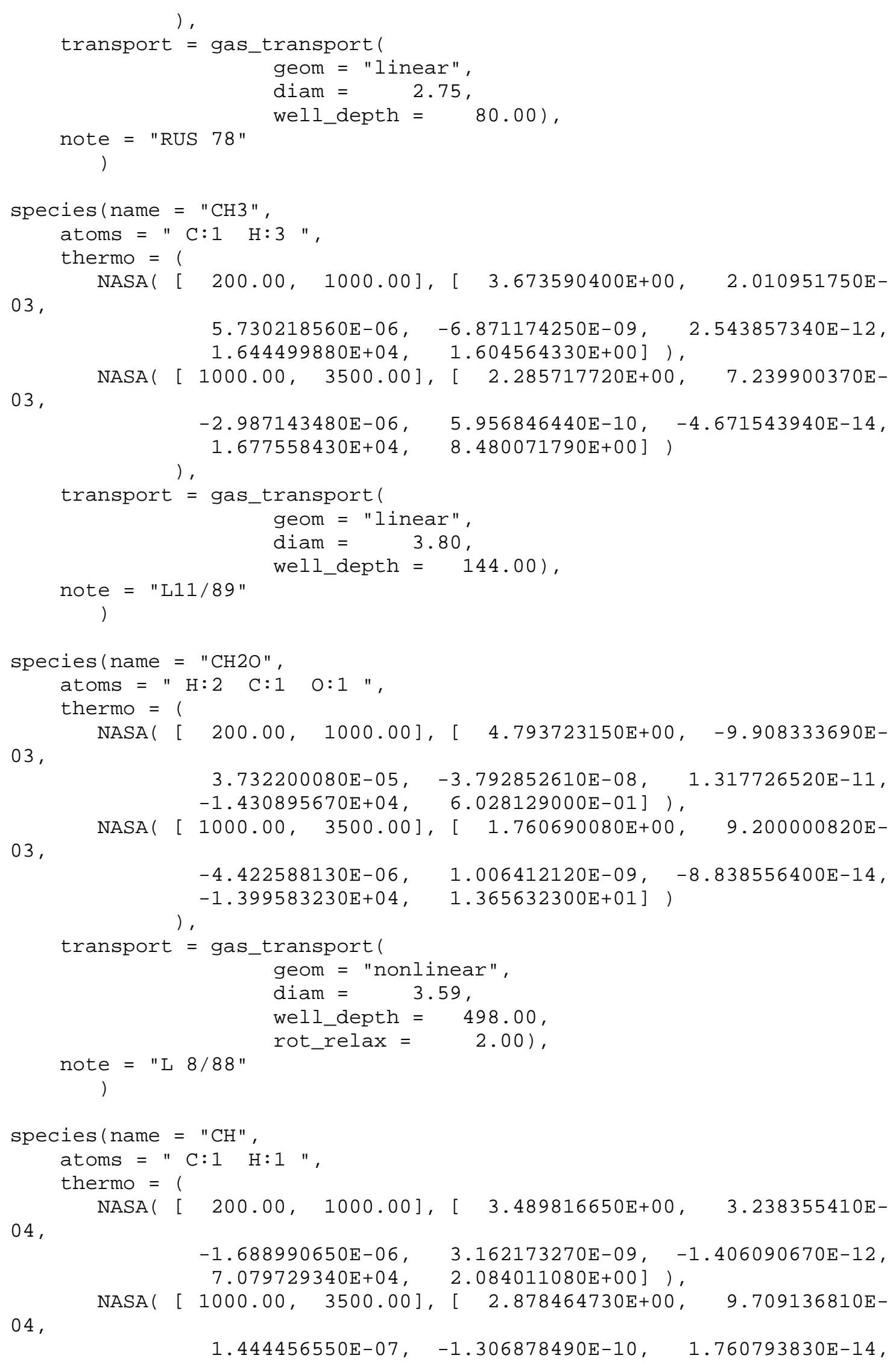




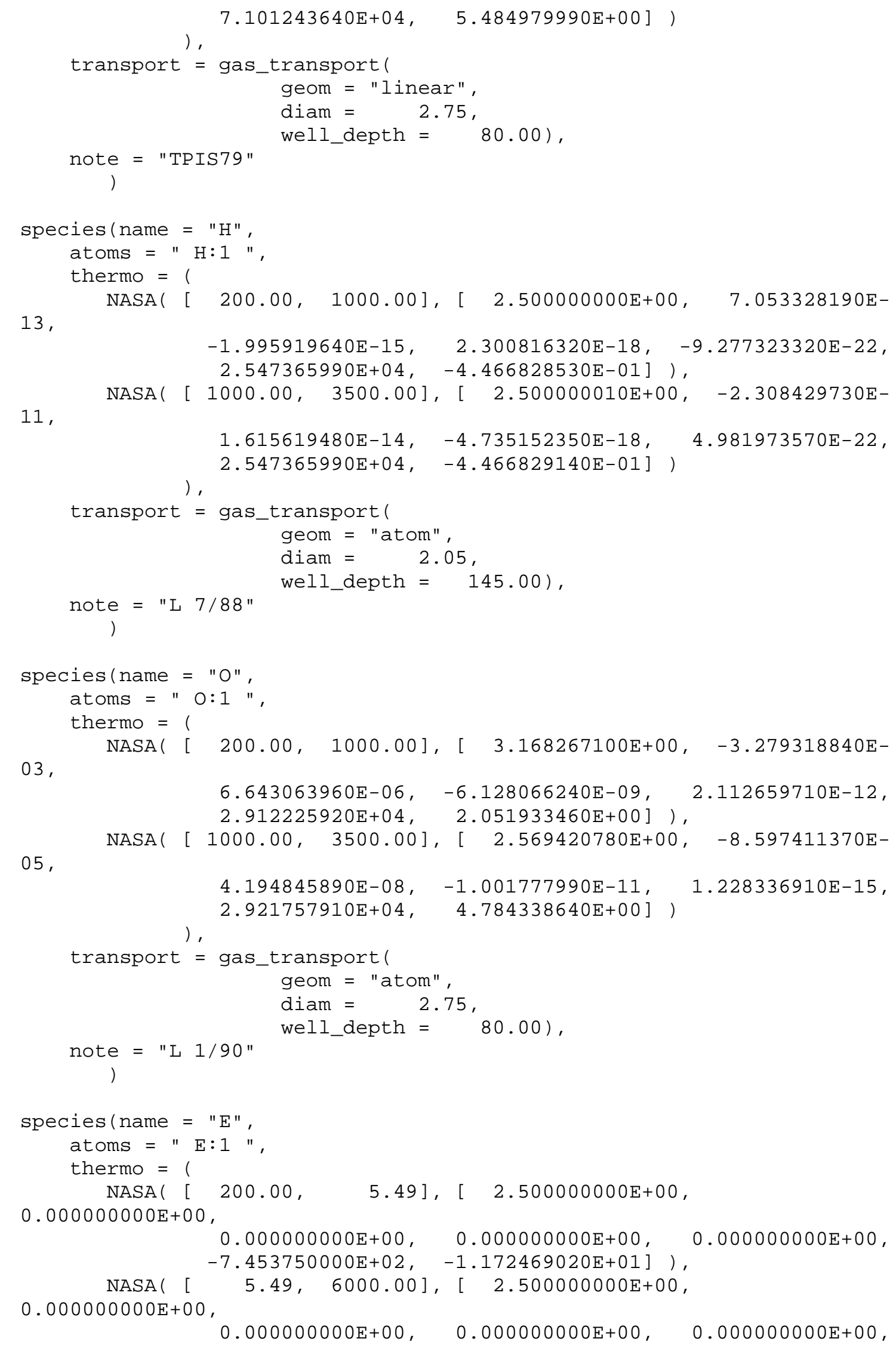




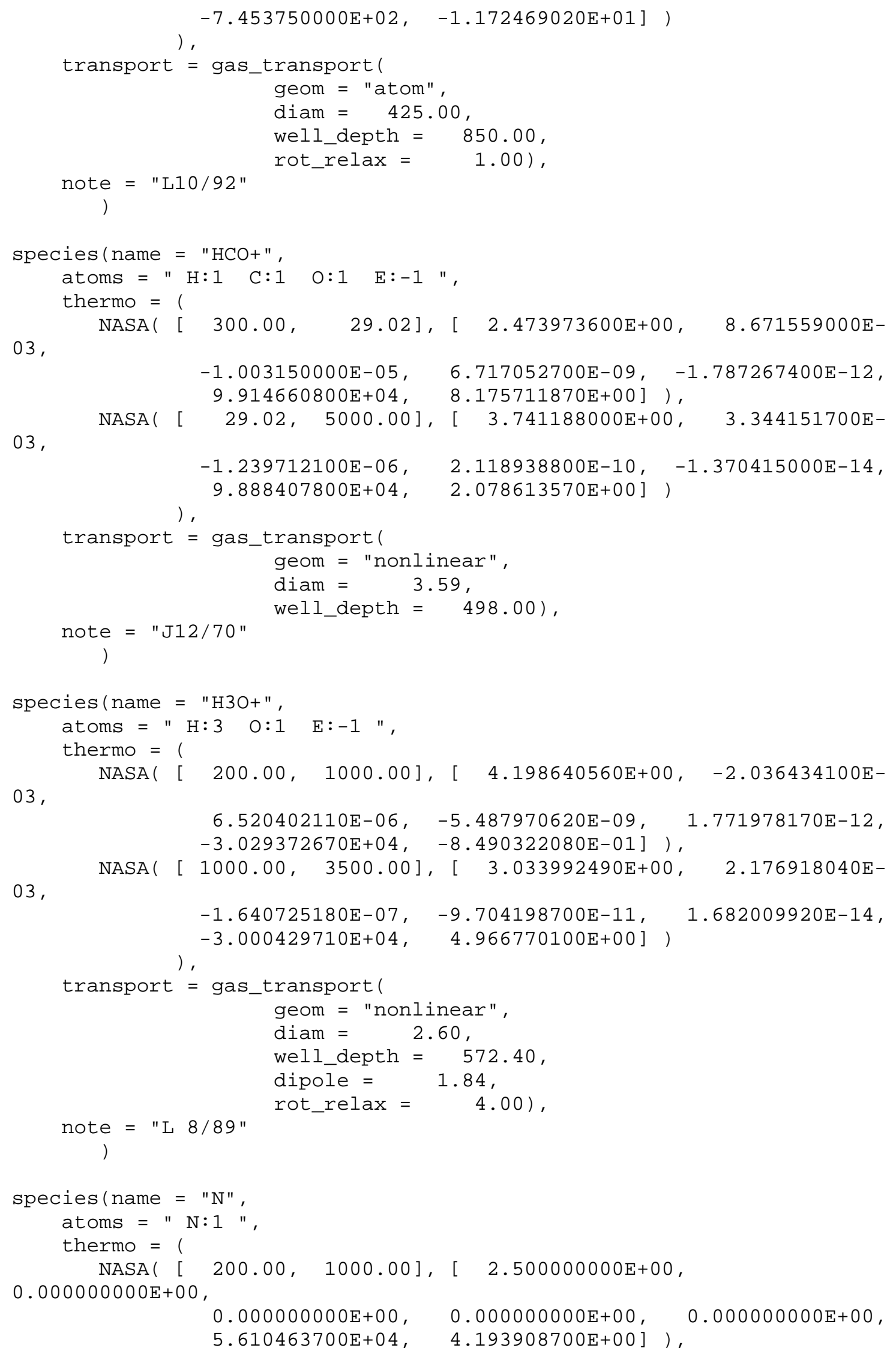




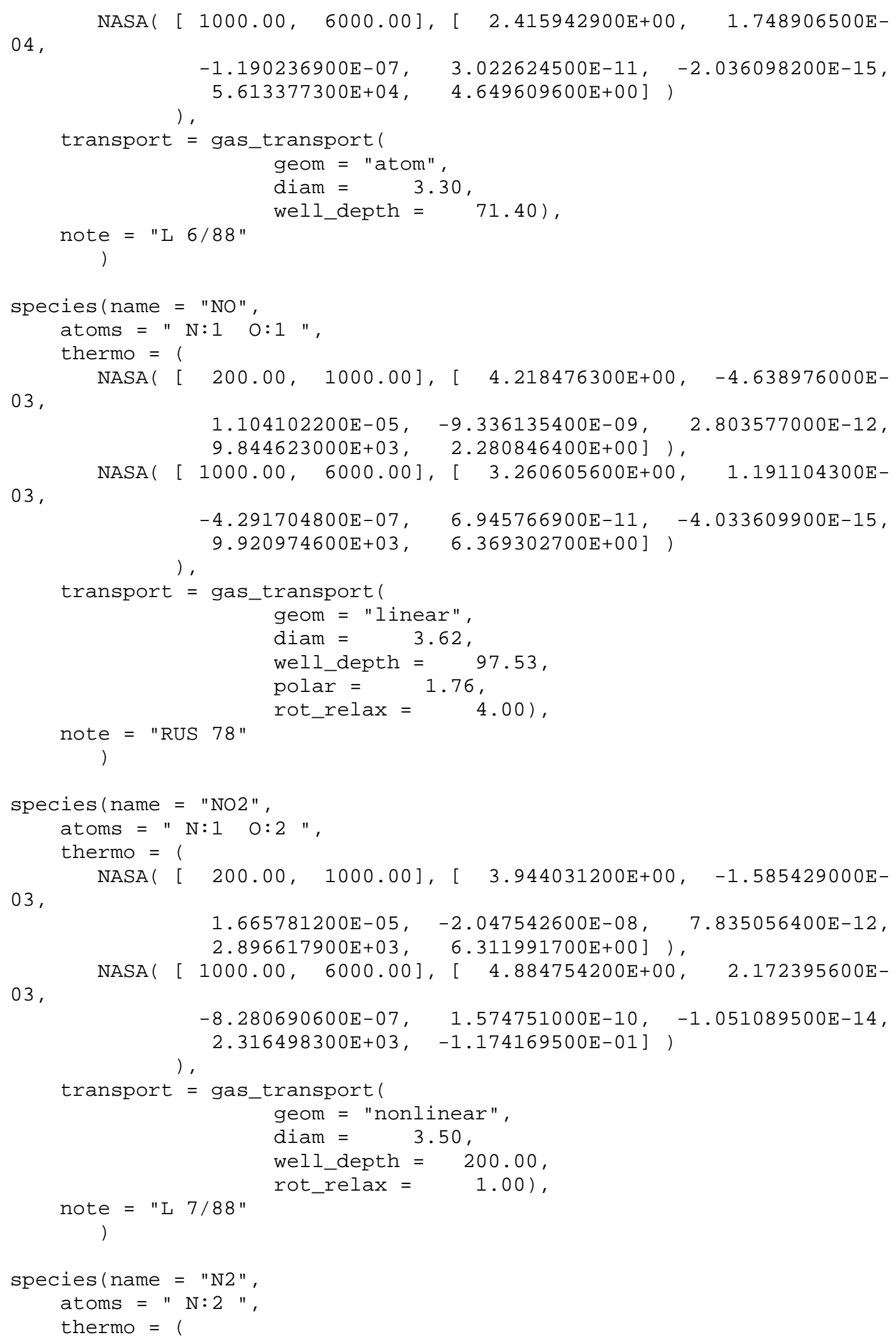




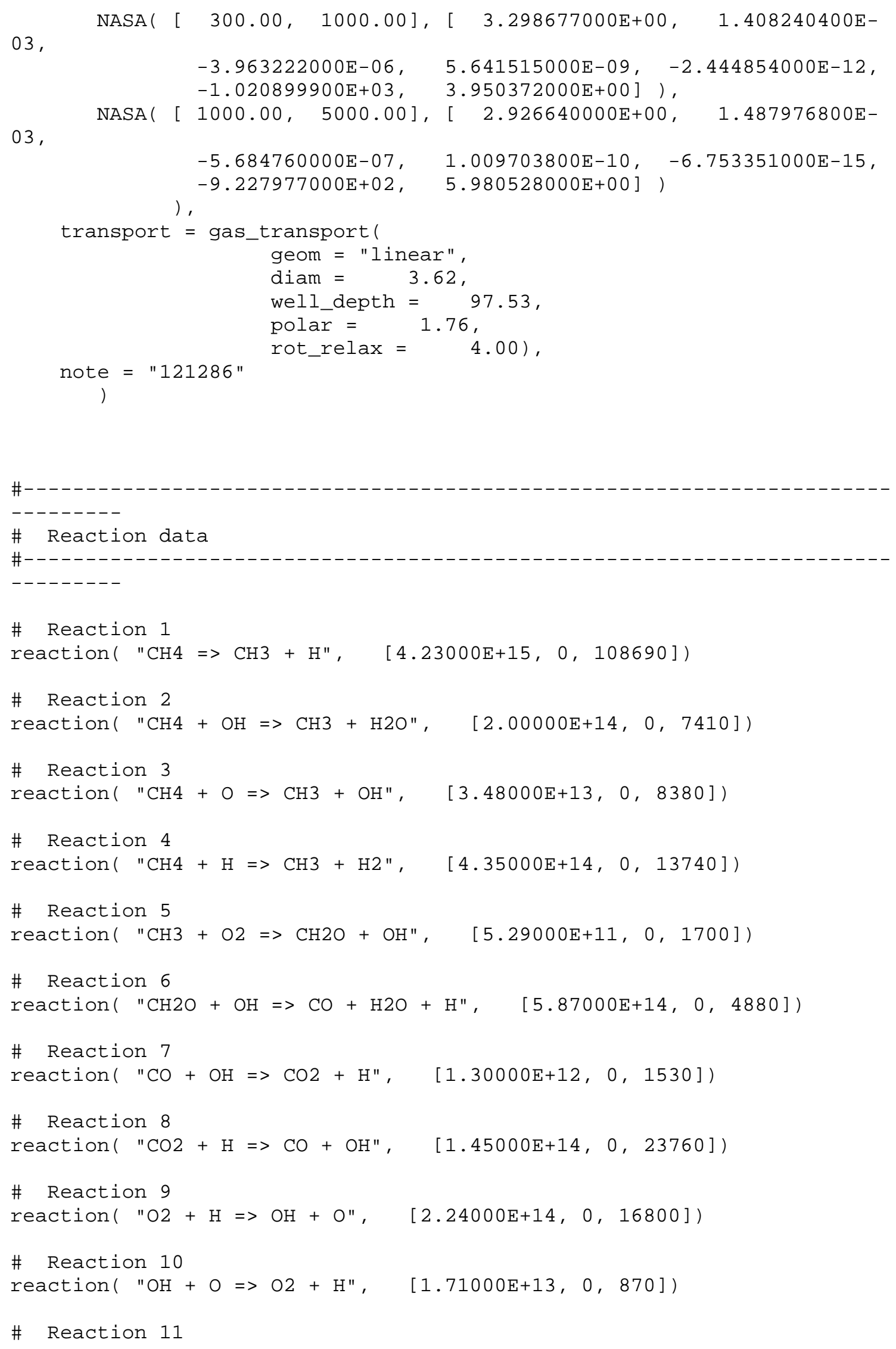




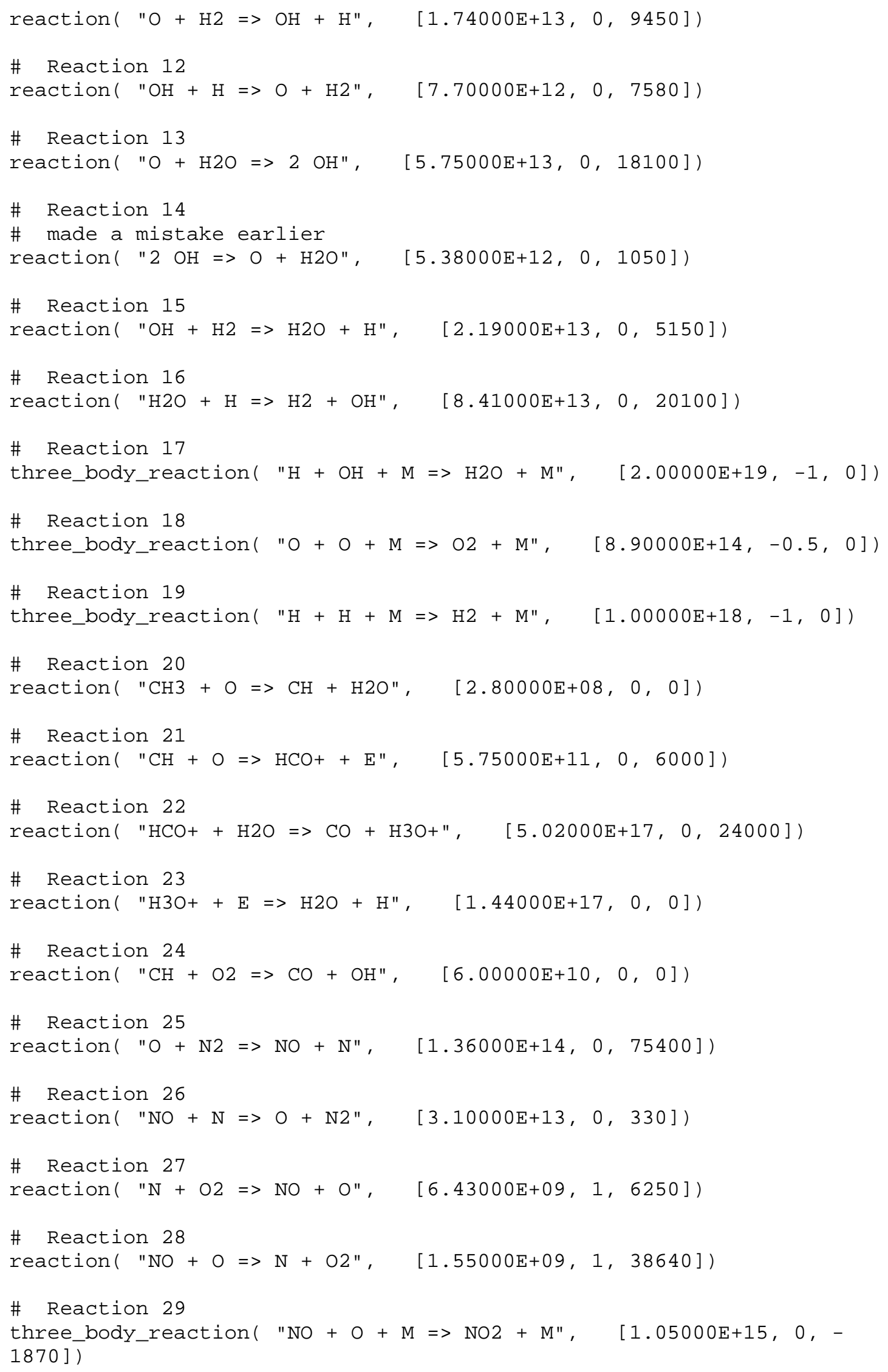


\# Reaction 30

reaction( "NO2 + 0 => NO $+02 ", \quad[2.10000 \mathrm{E}+12, \Theta, 0])$

\# Reaction 31

reaction( $\left.\mathrm{NO} 2+\mathrm{H}=>\mathrm{NO}+\mathrm{OH}^{2}, \quad[3.00000 \mathrm{E}+14, \odot, \odot]\right)$ 


\section{B-2: Listing of Modified GRI 3.0 Mechanism}

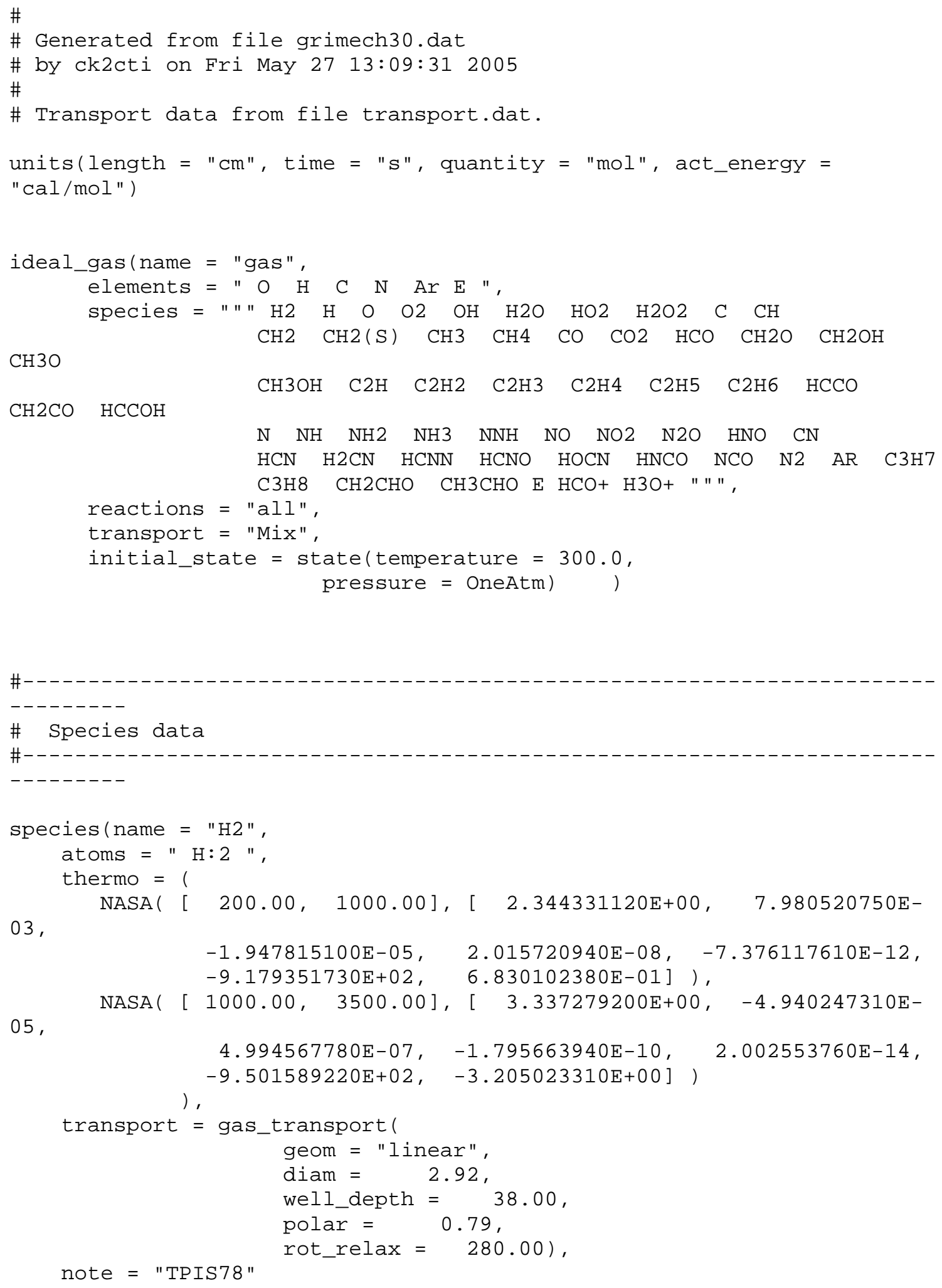




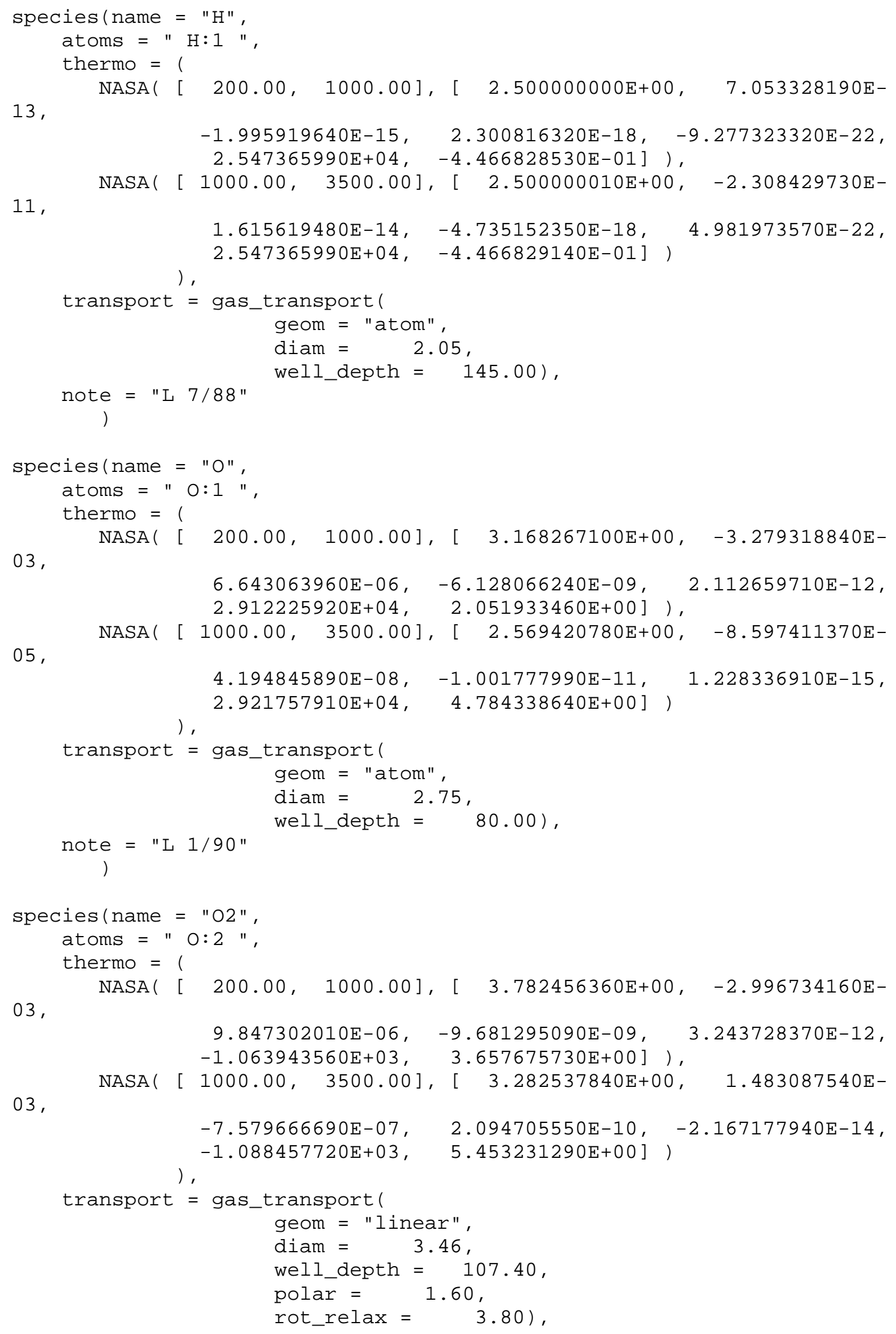




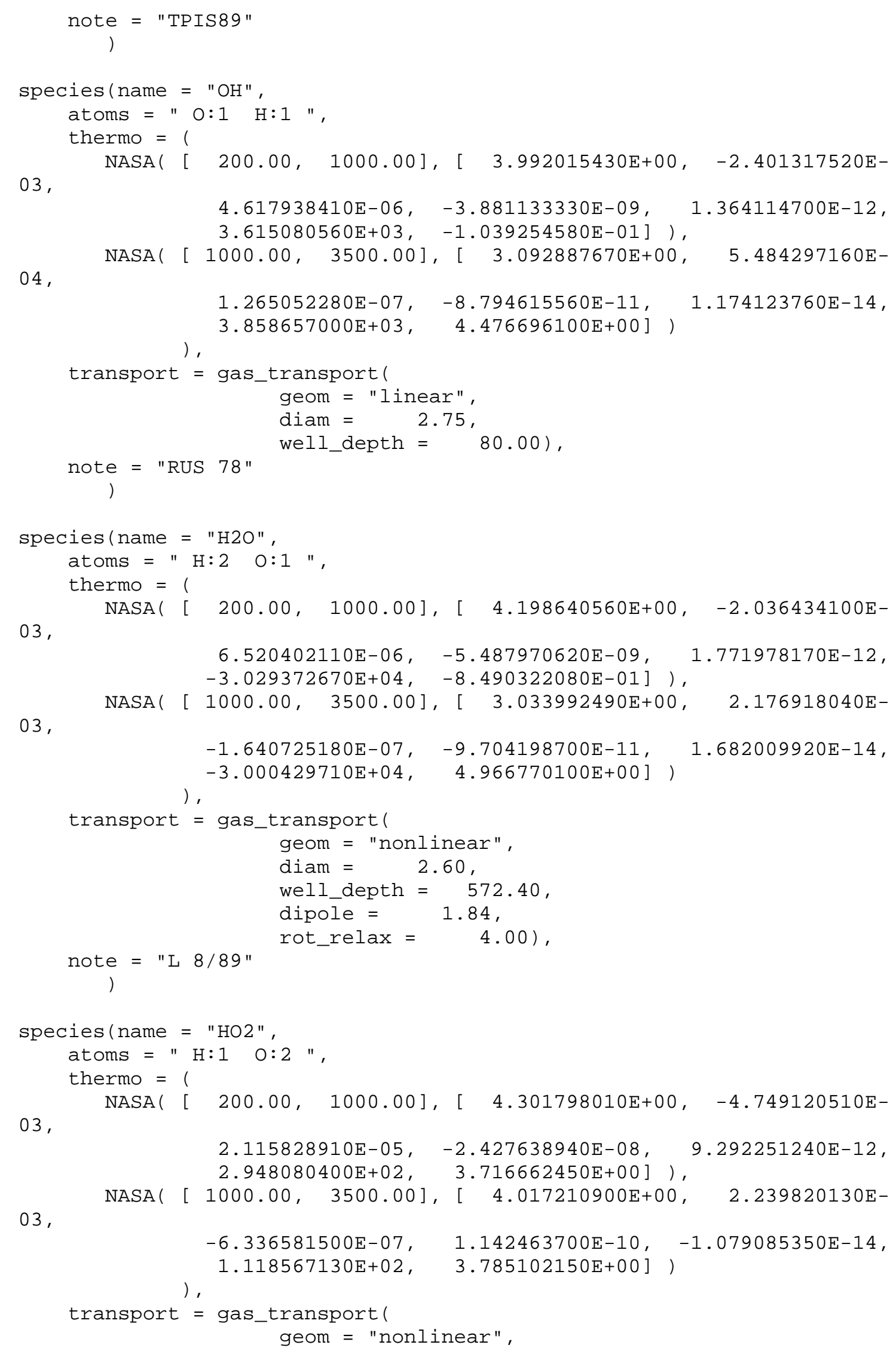




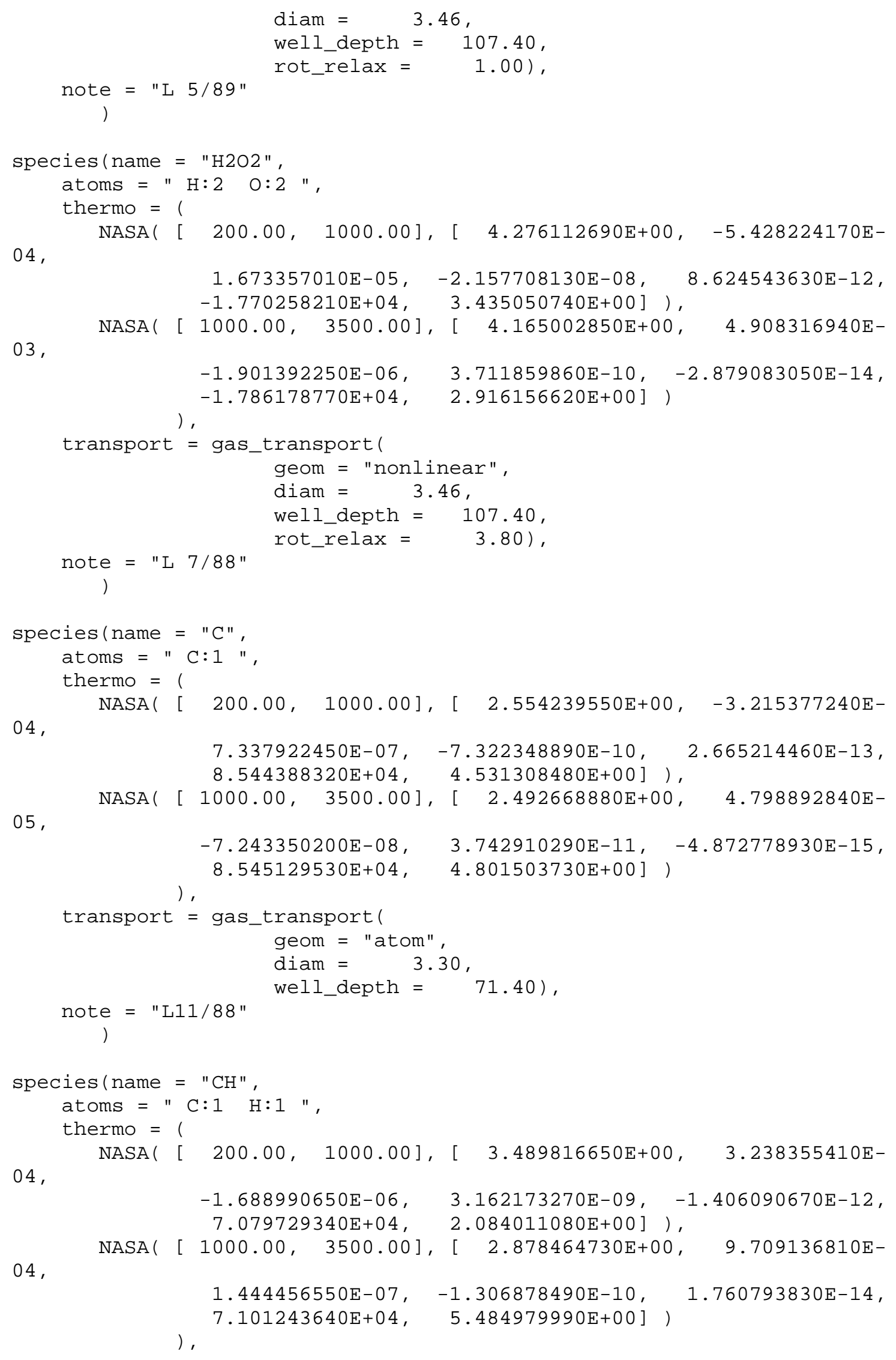




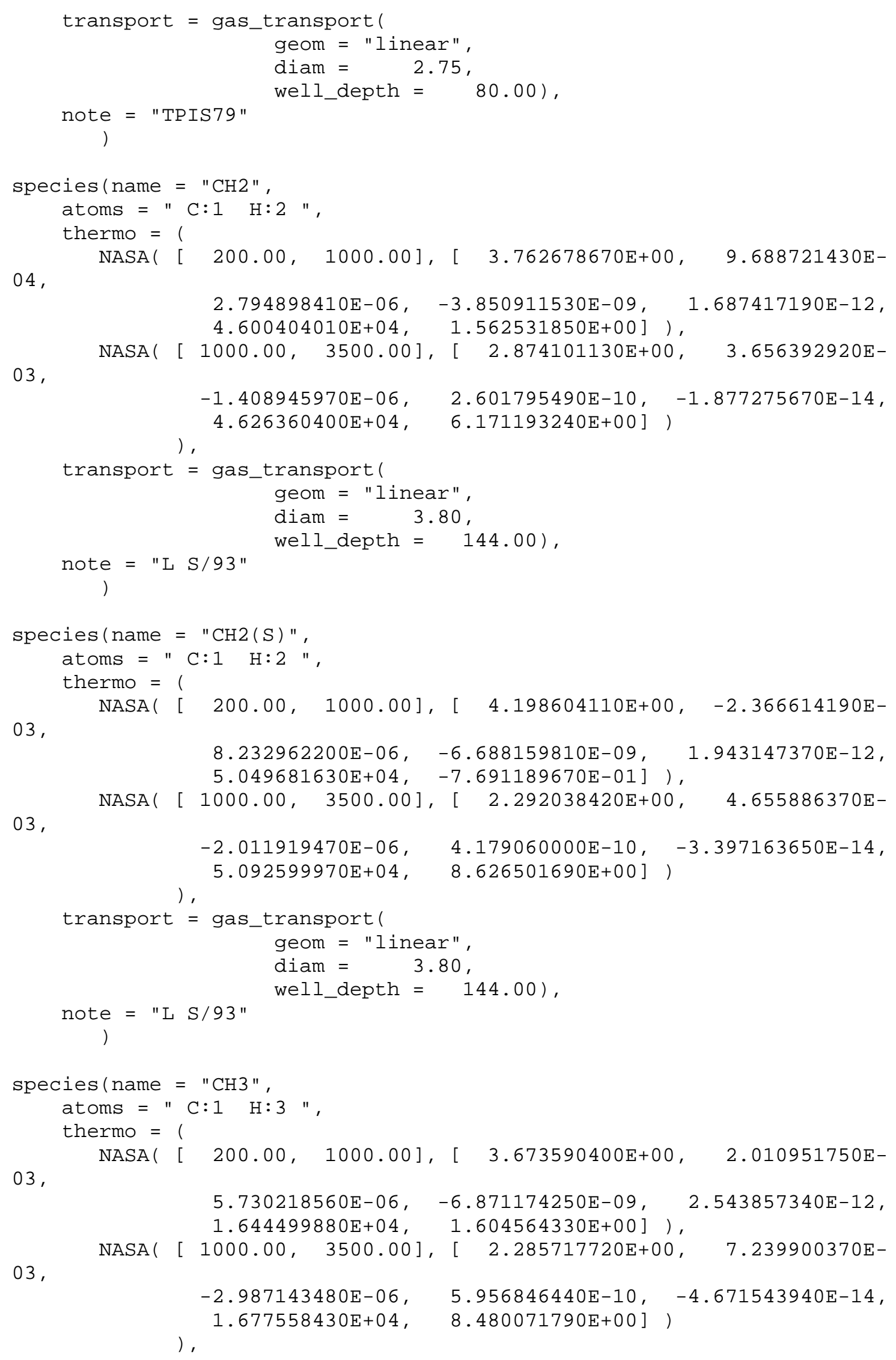




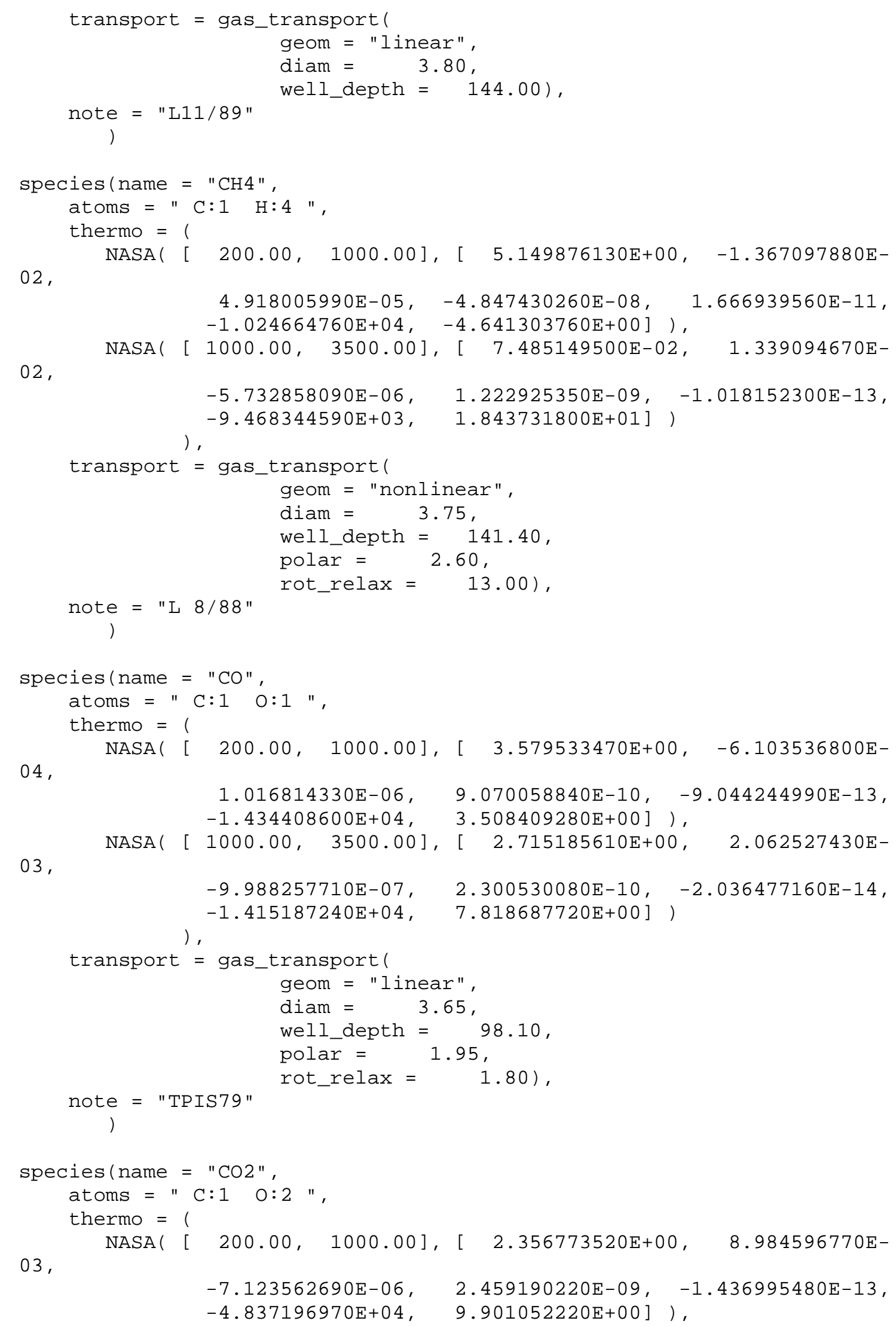




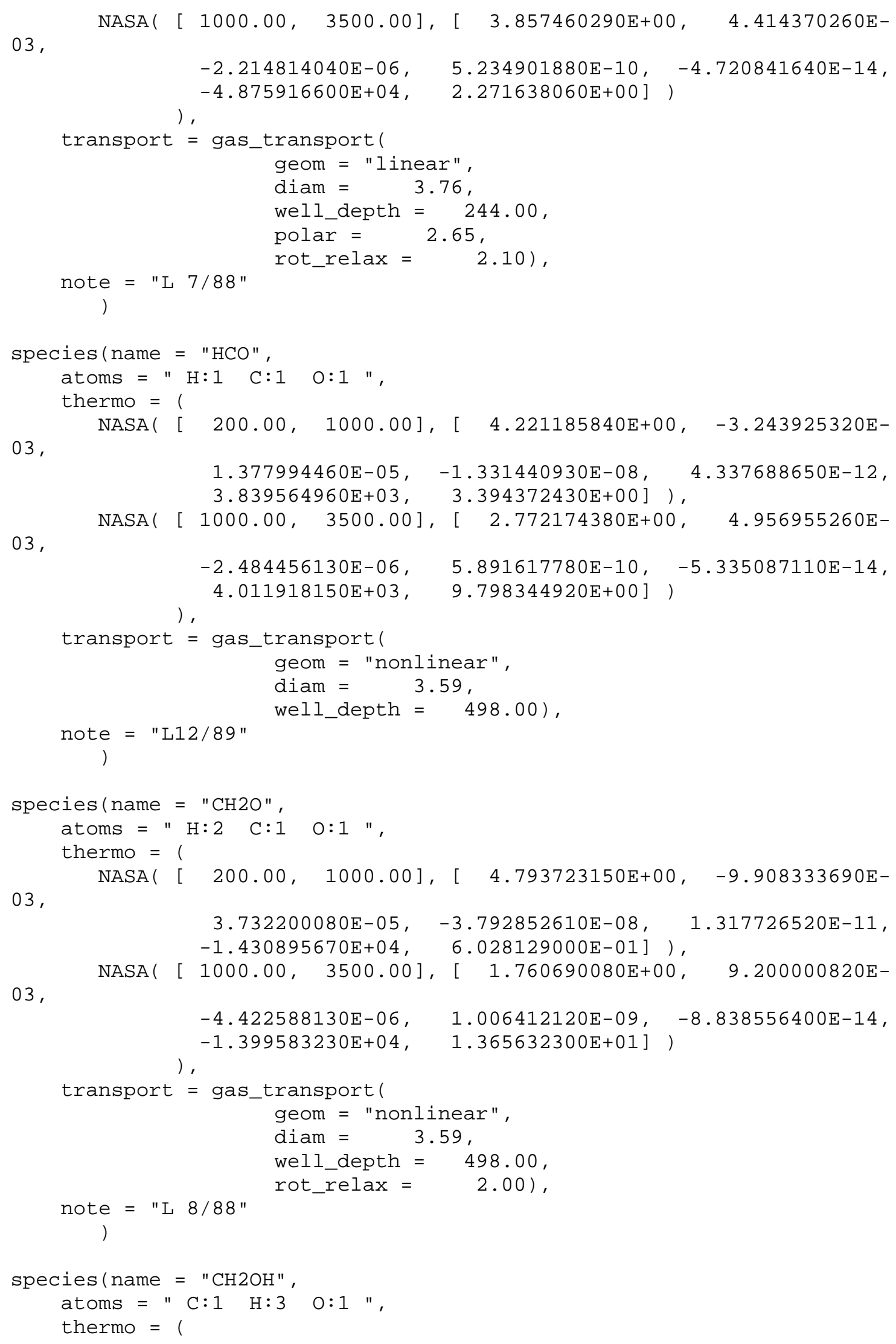




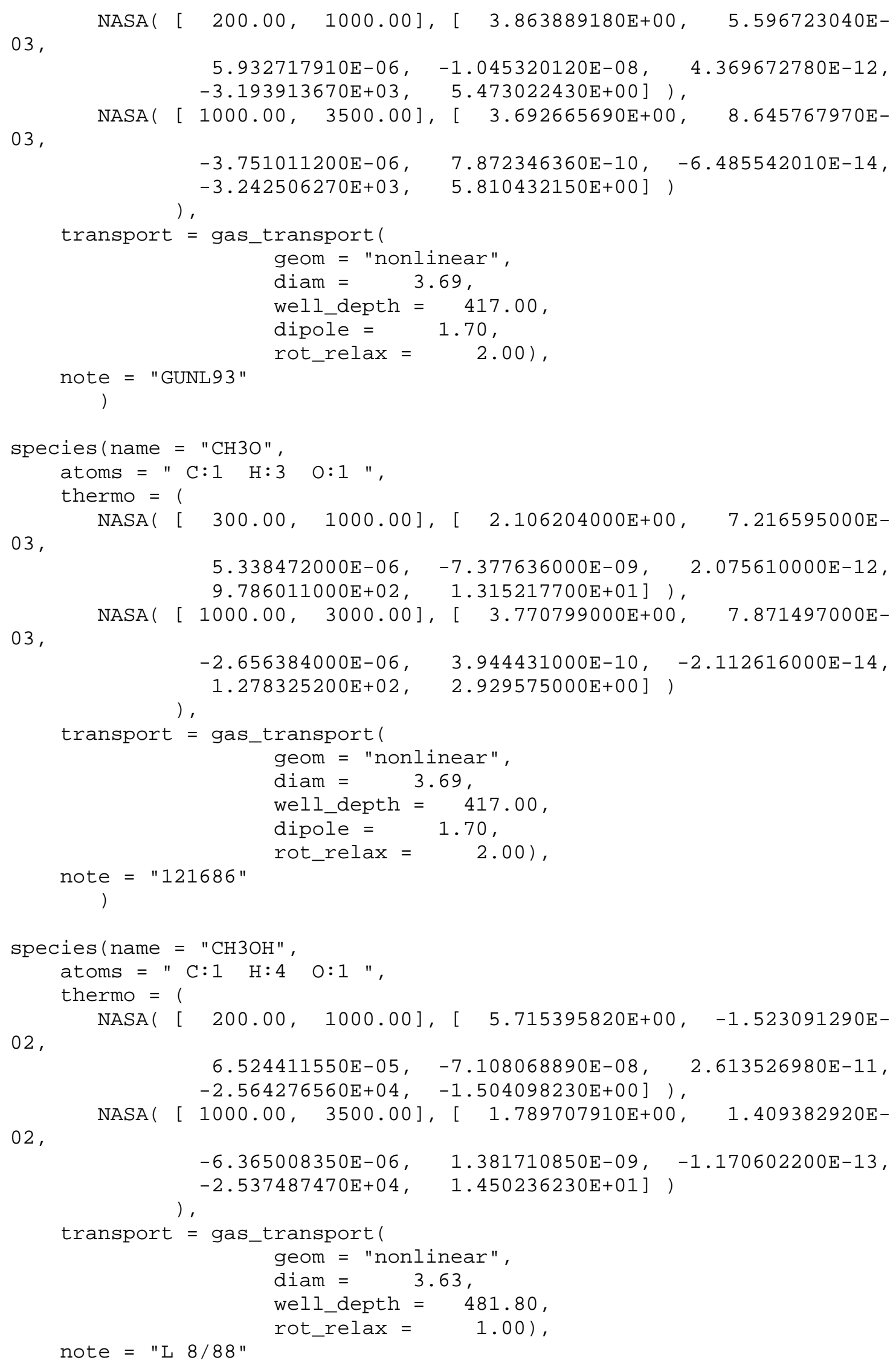




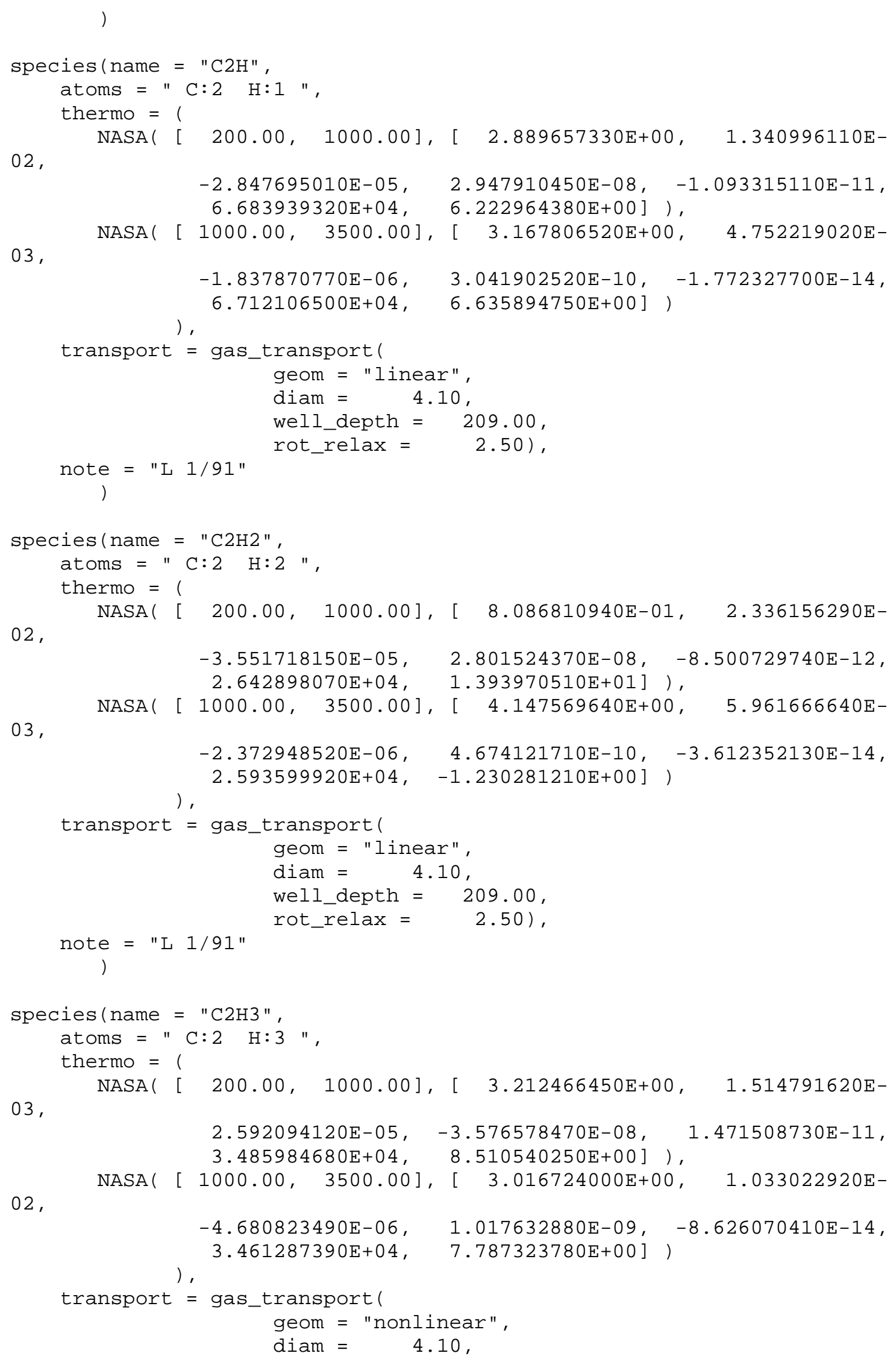




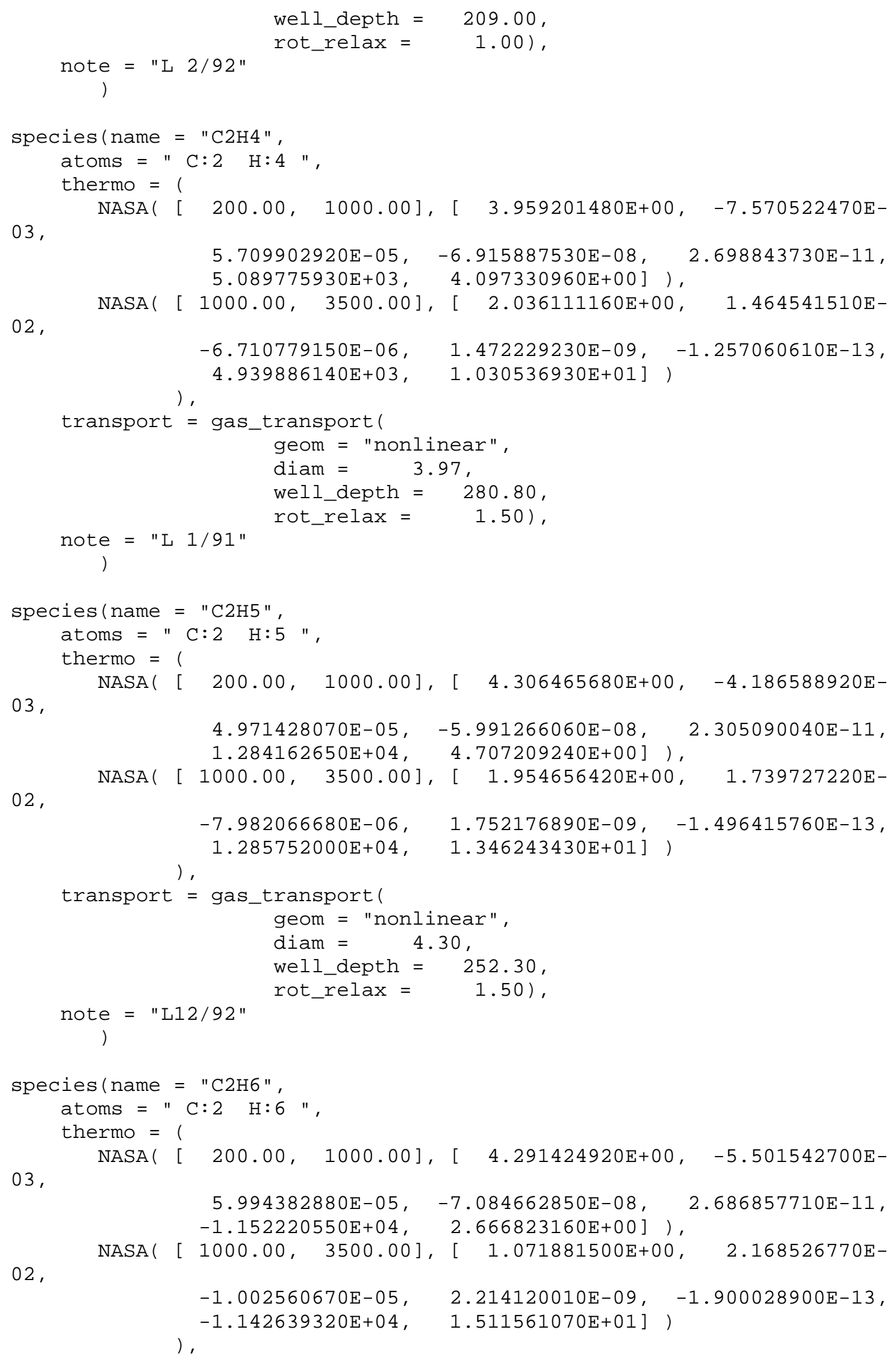




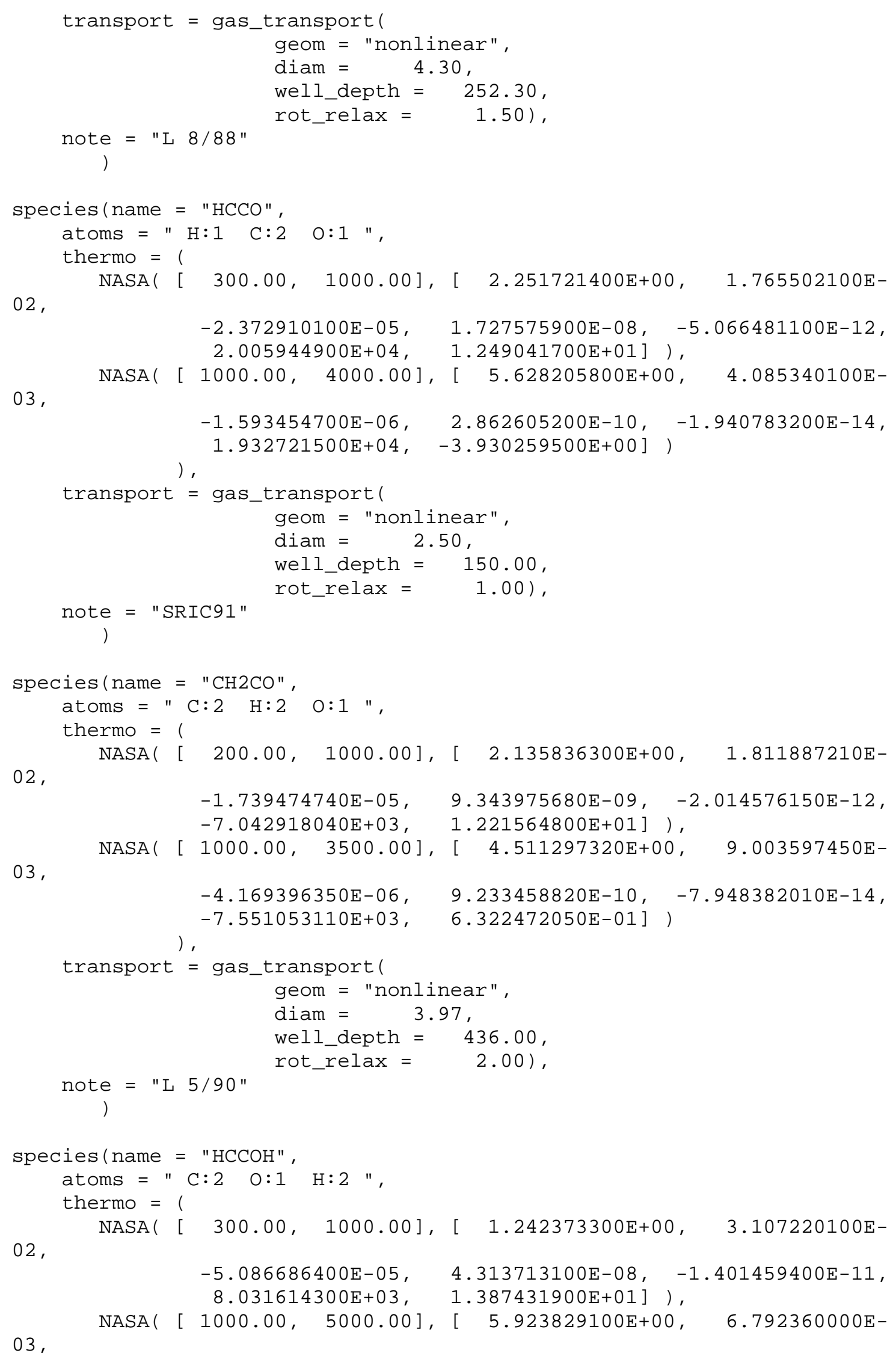




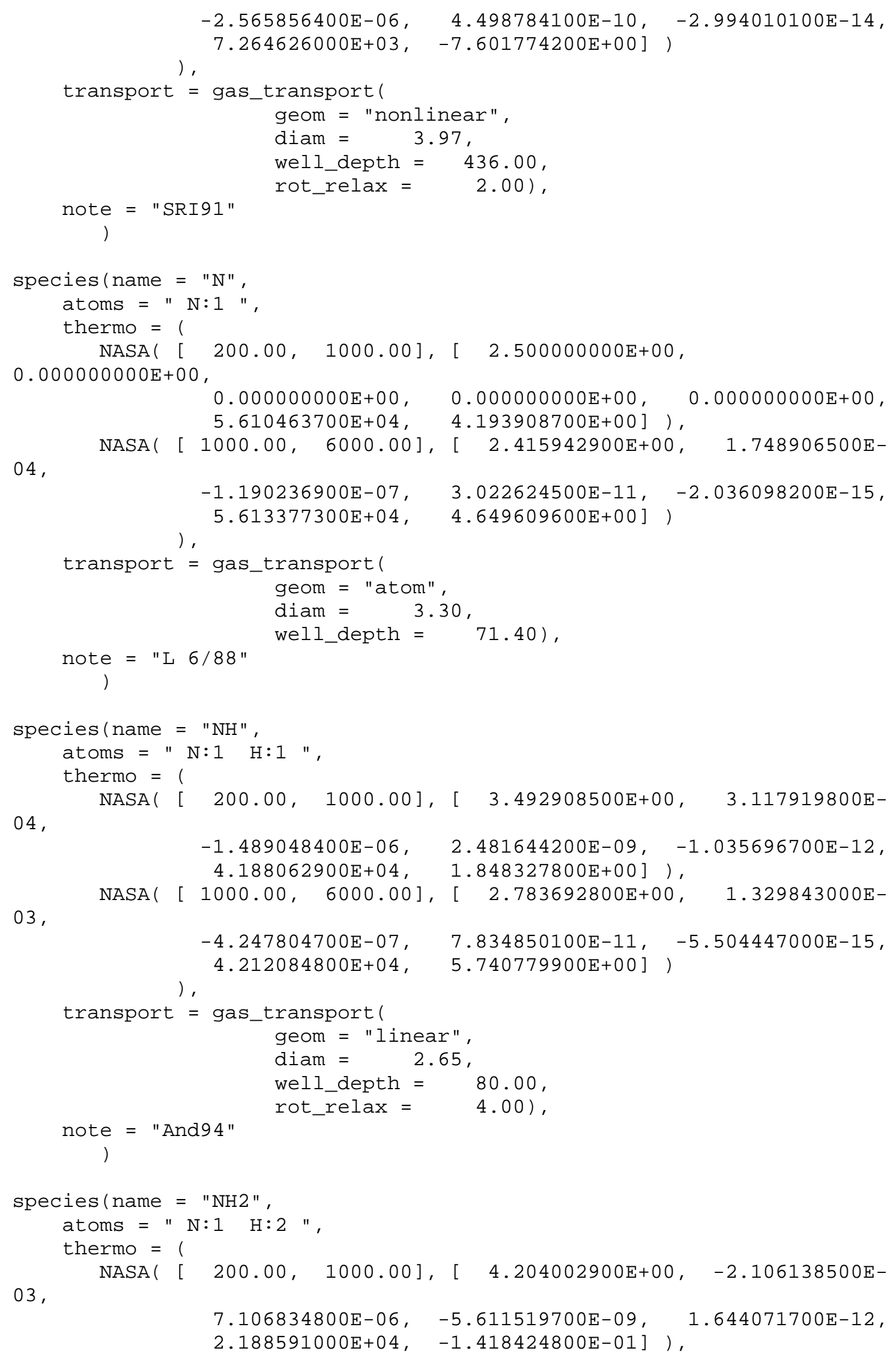




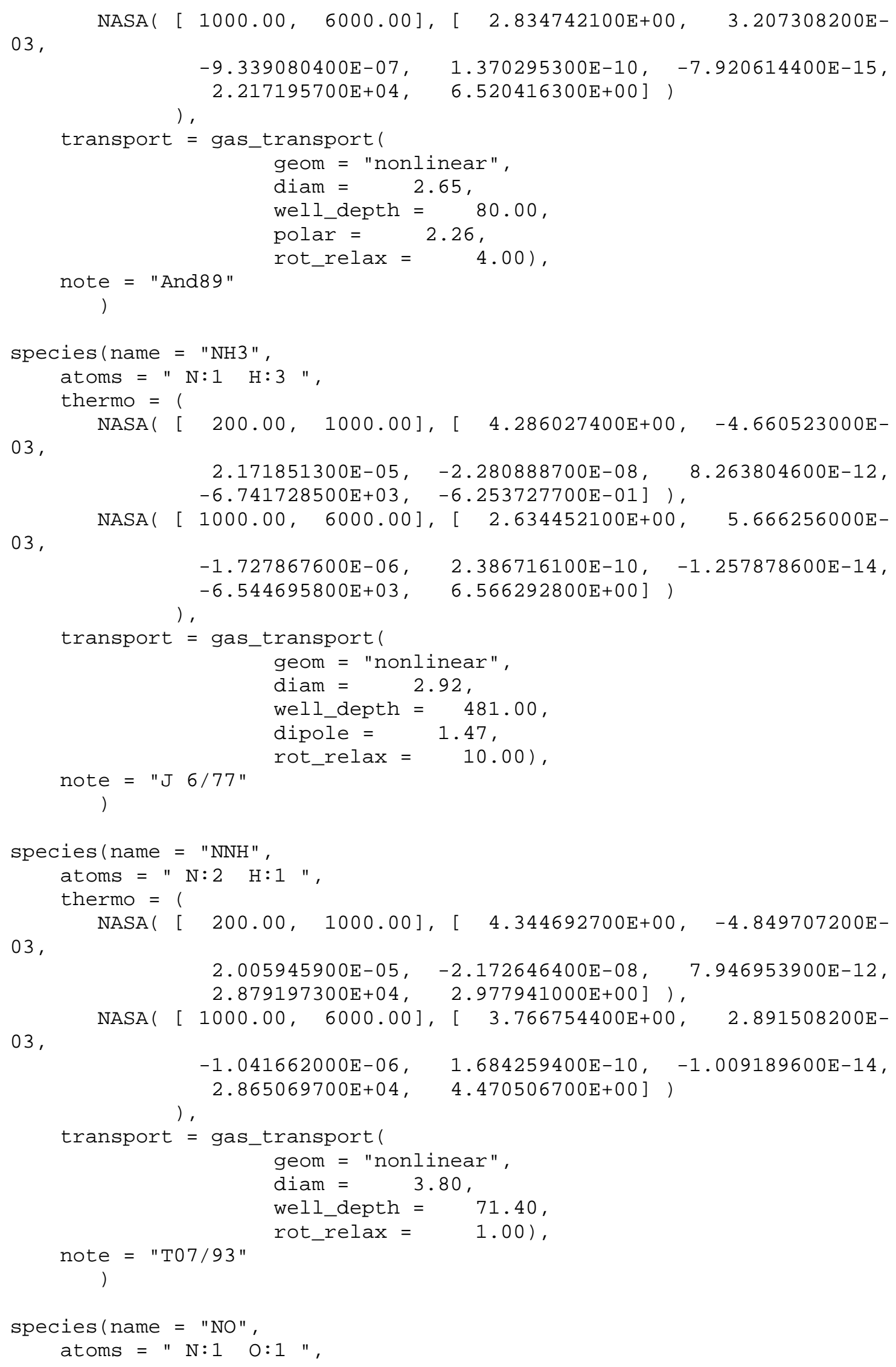




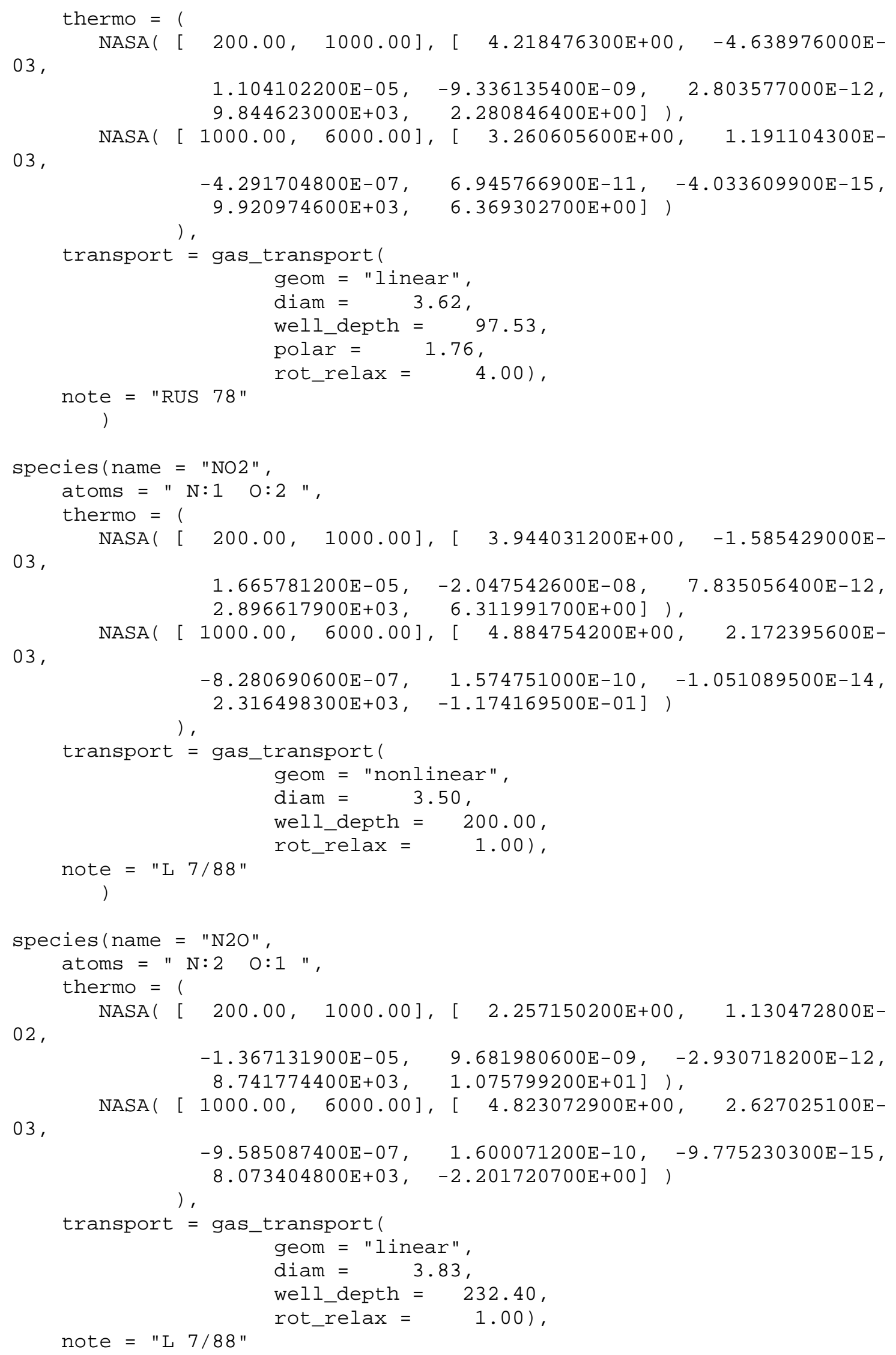




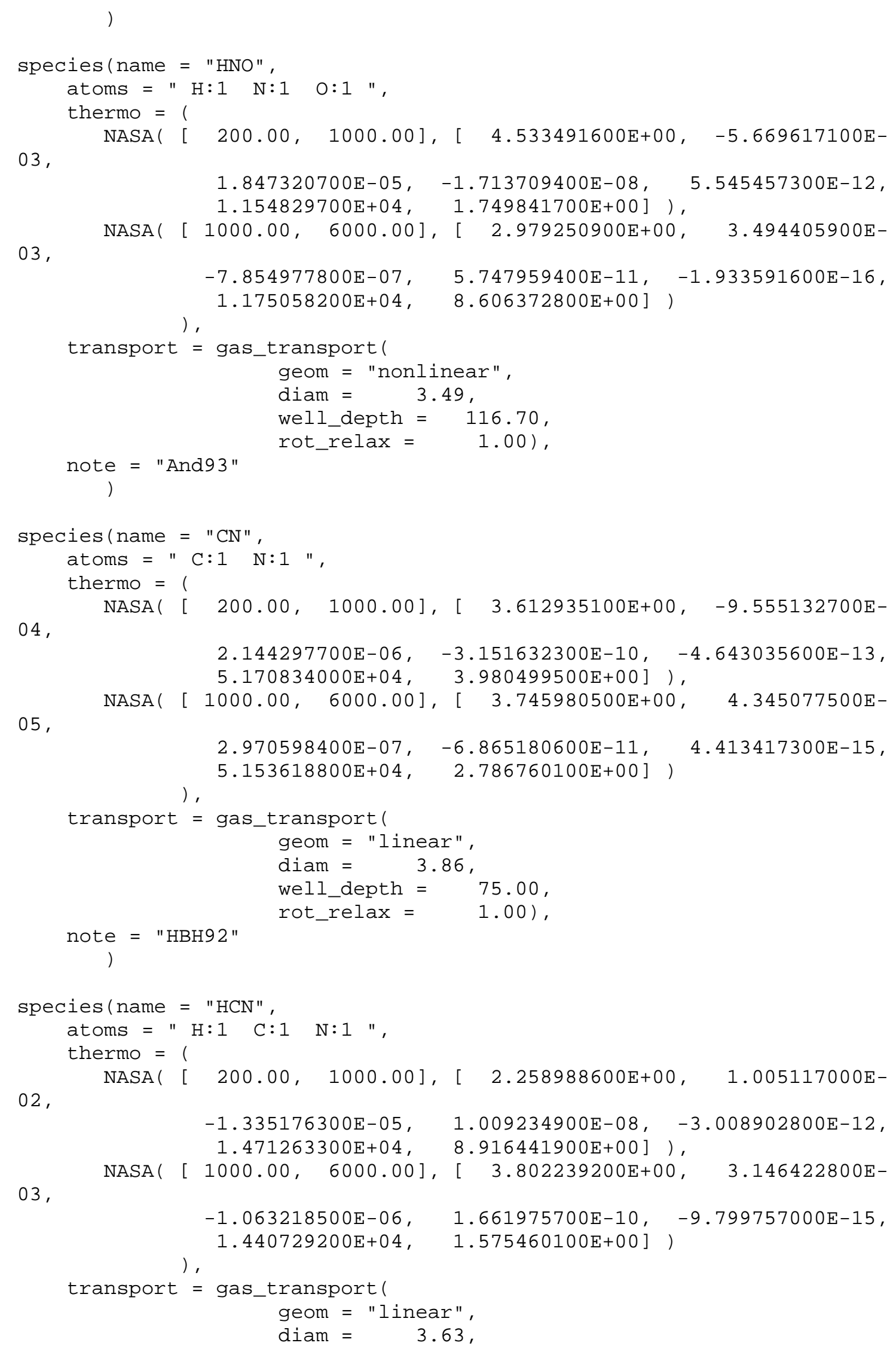




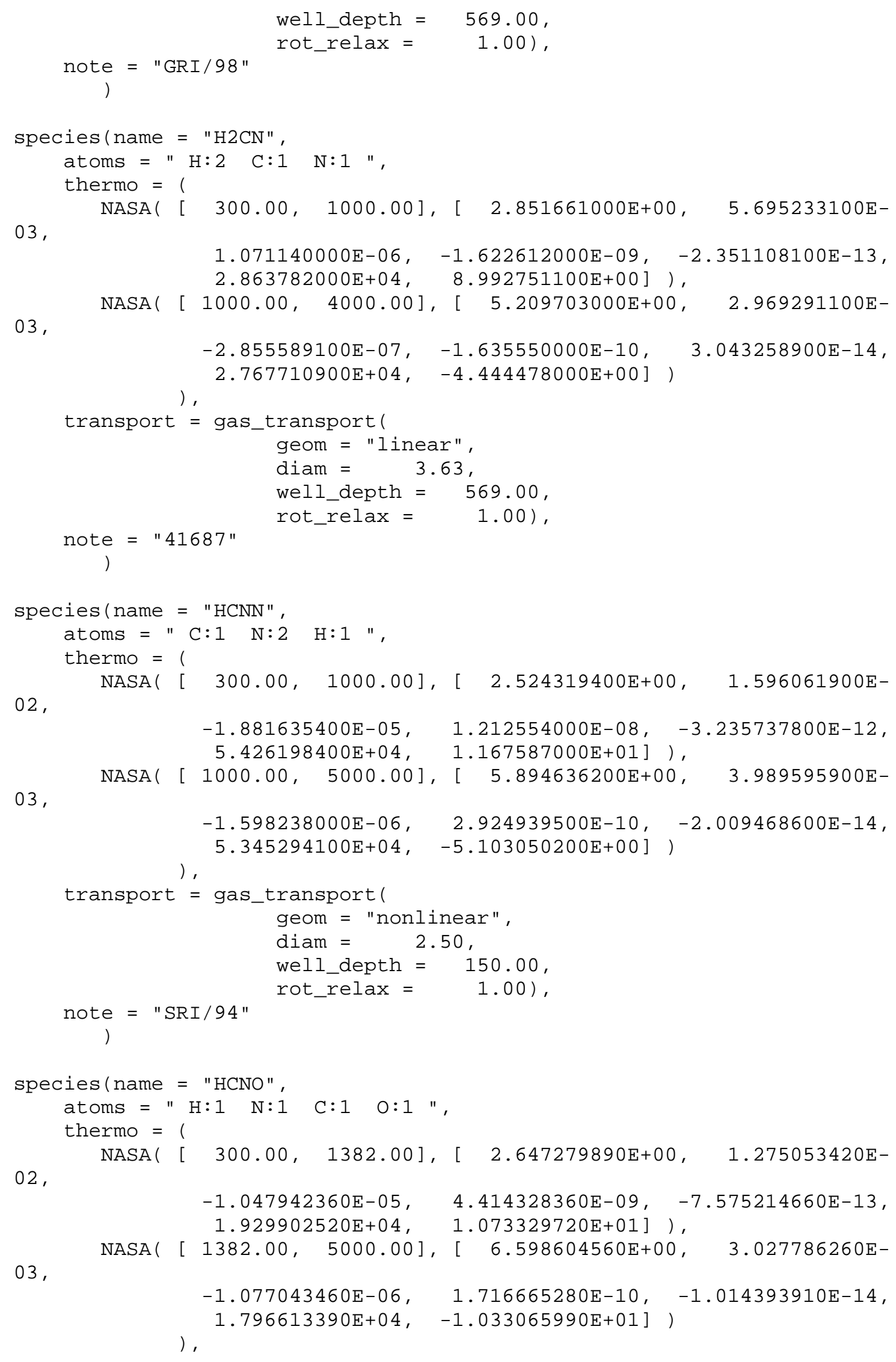




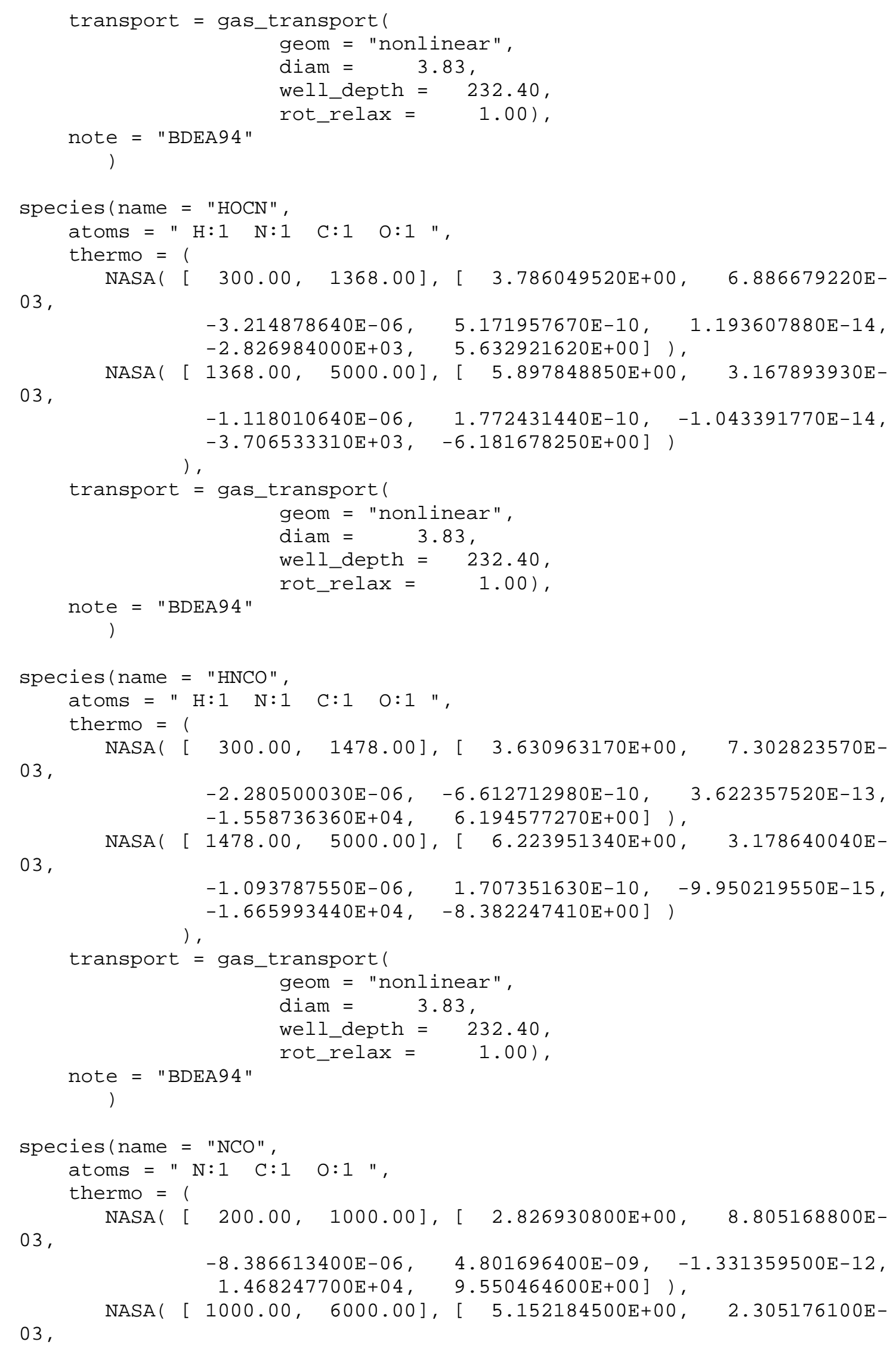




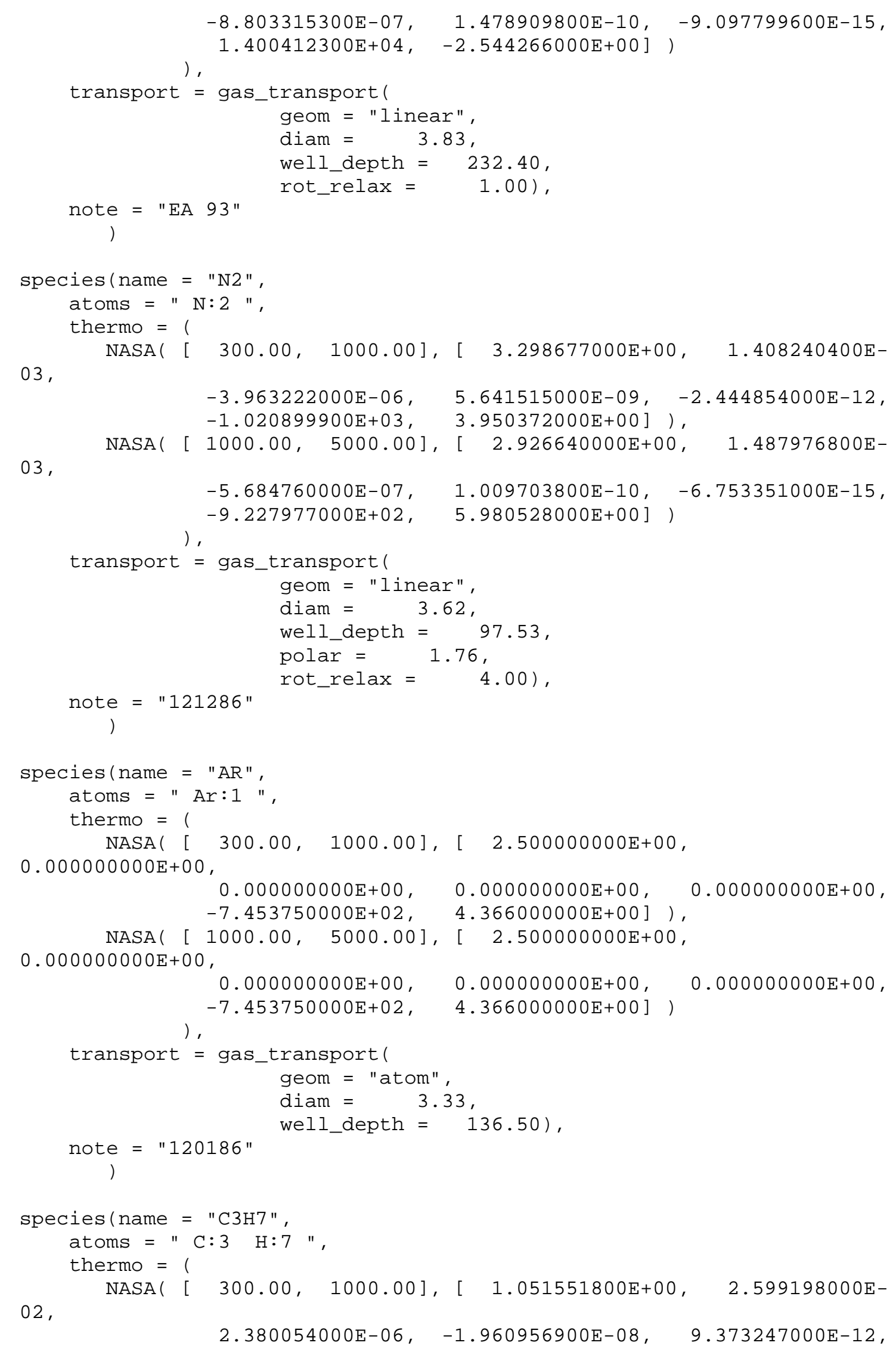




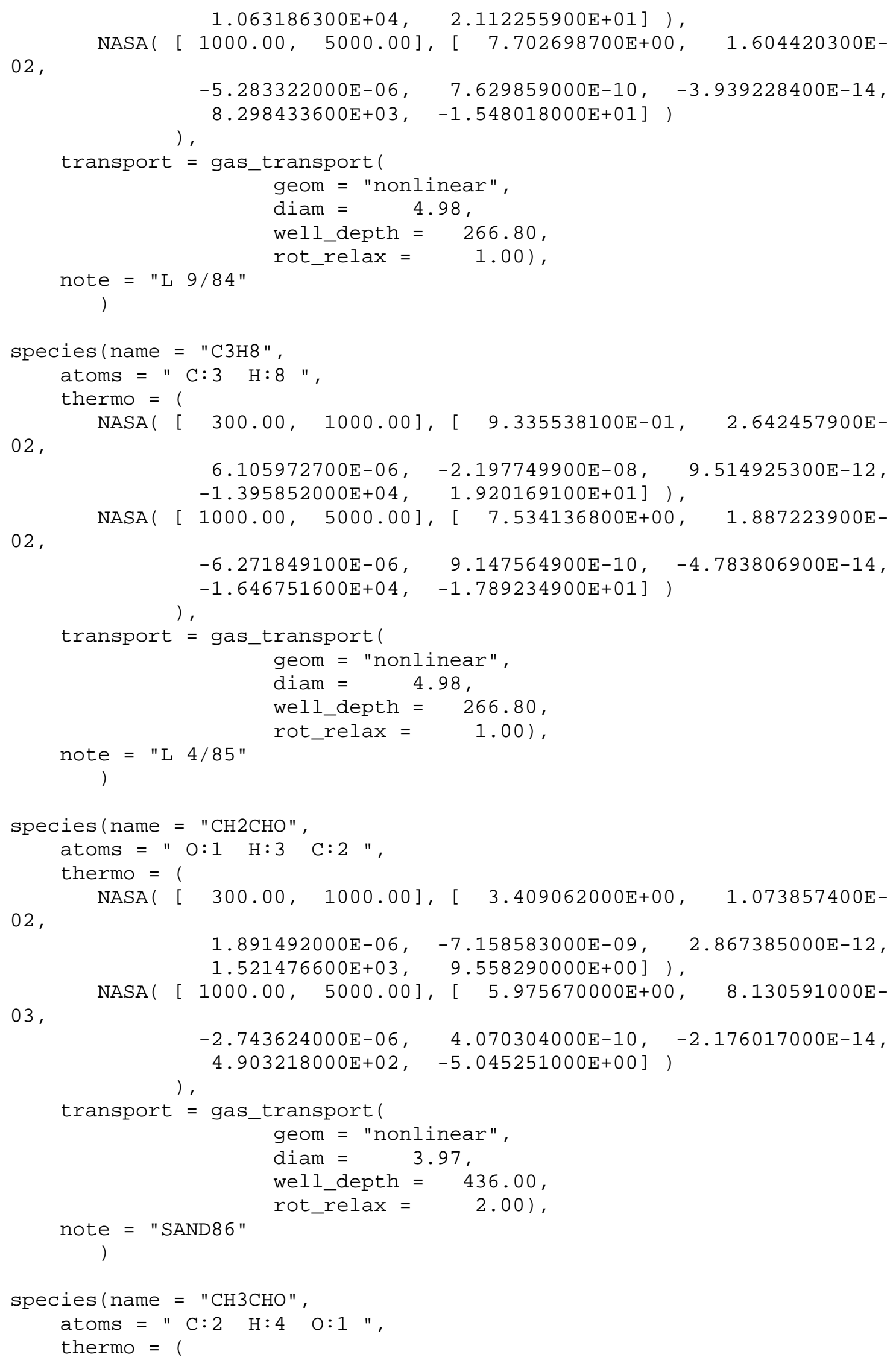




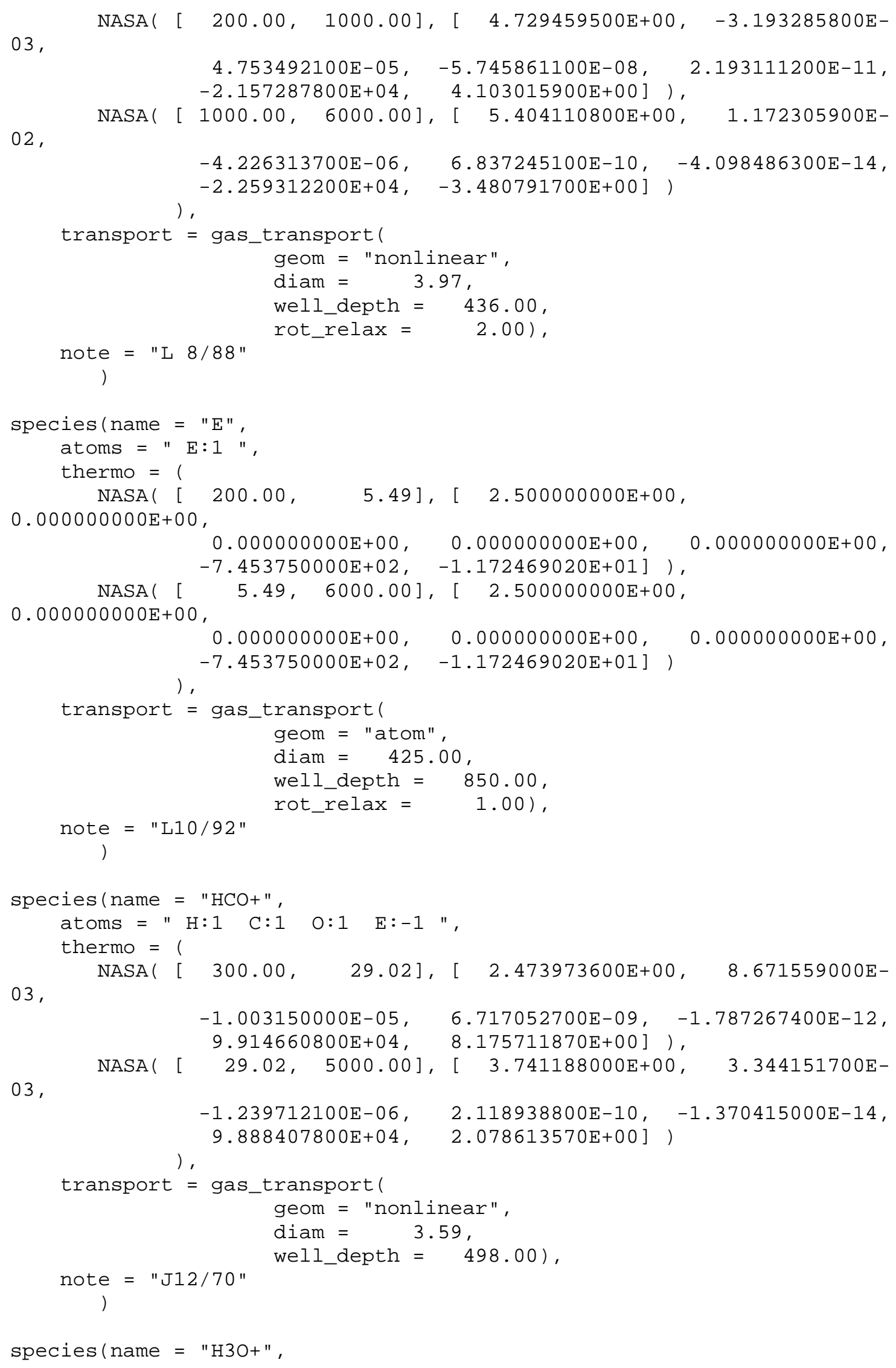




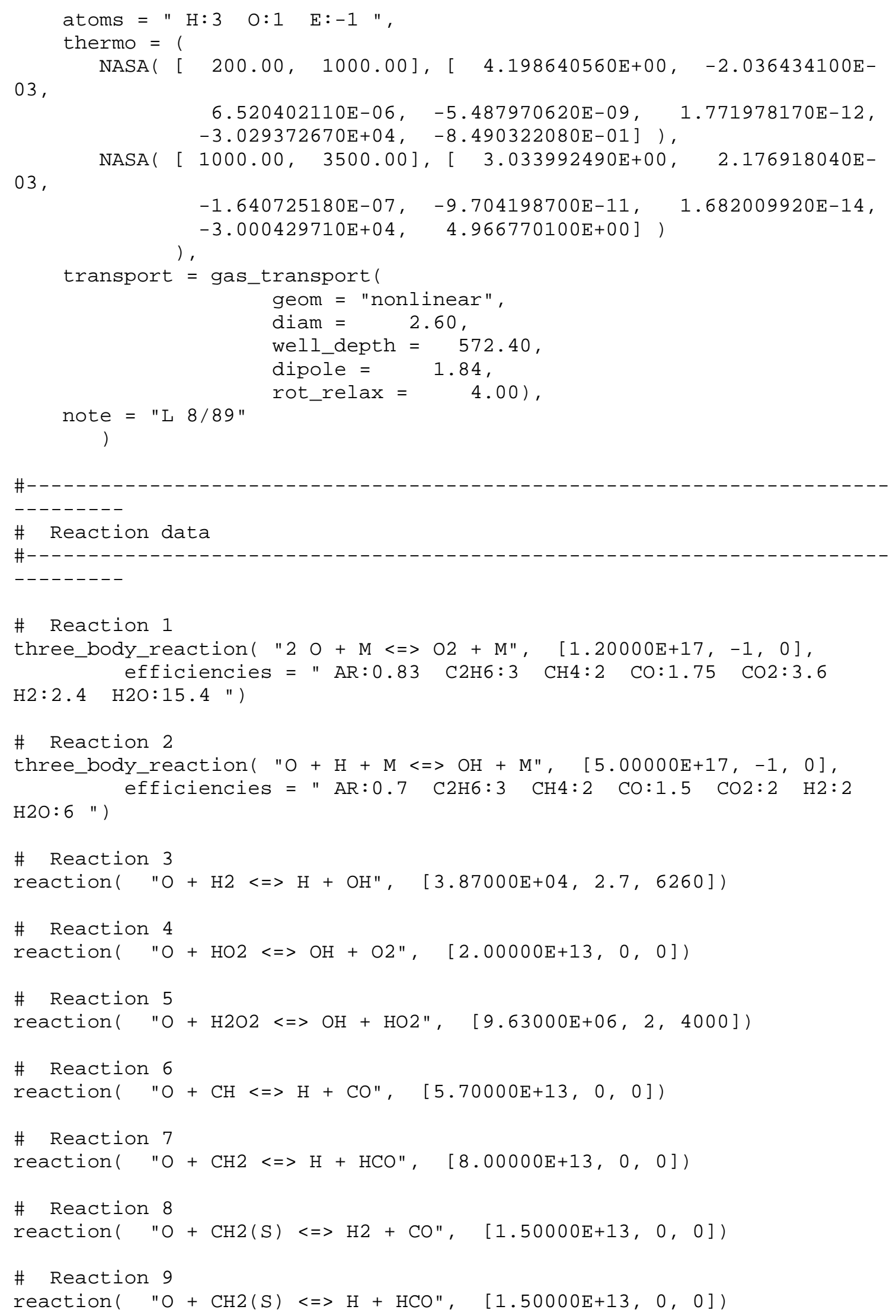




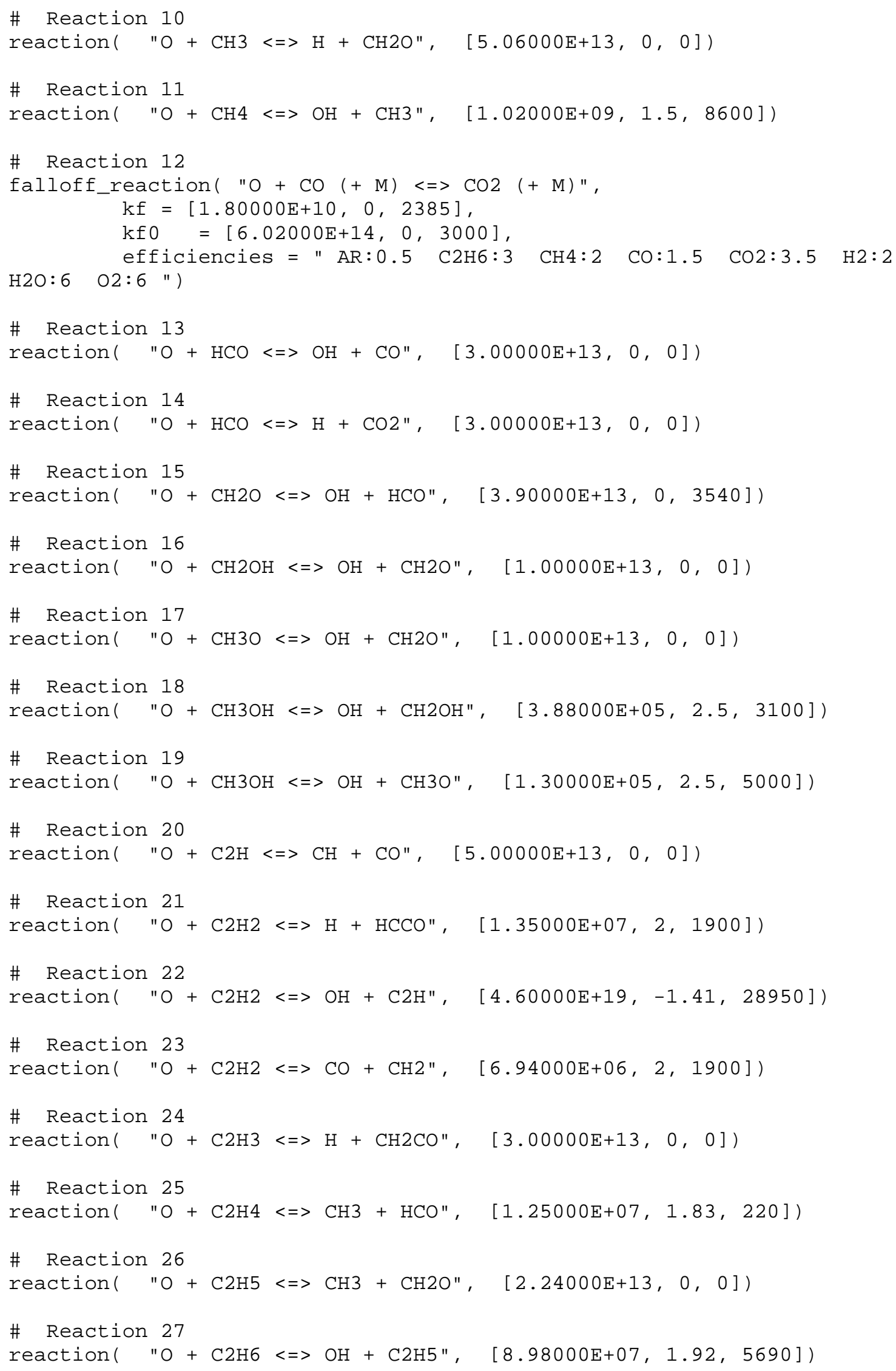




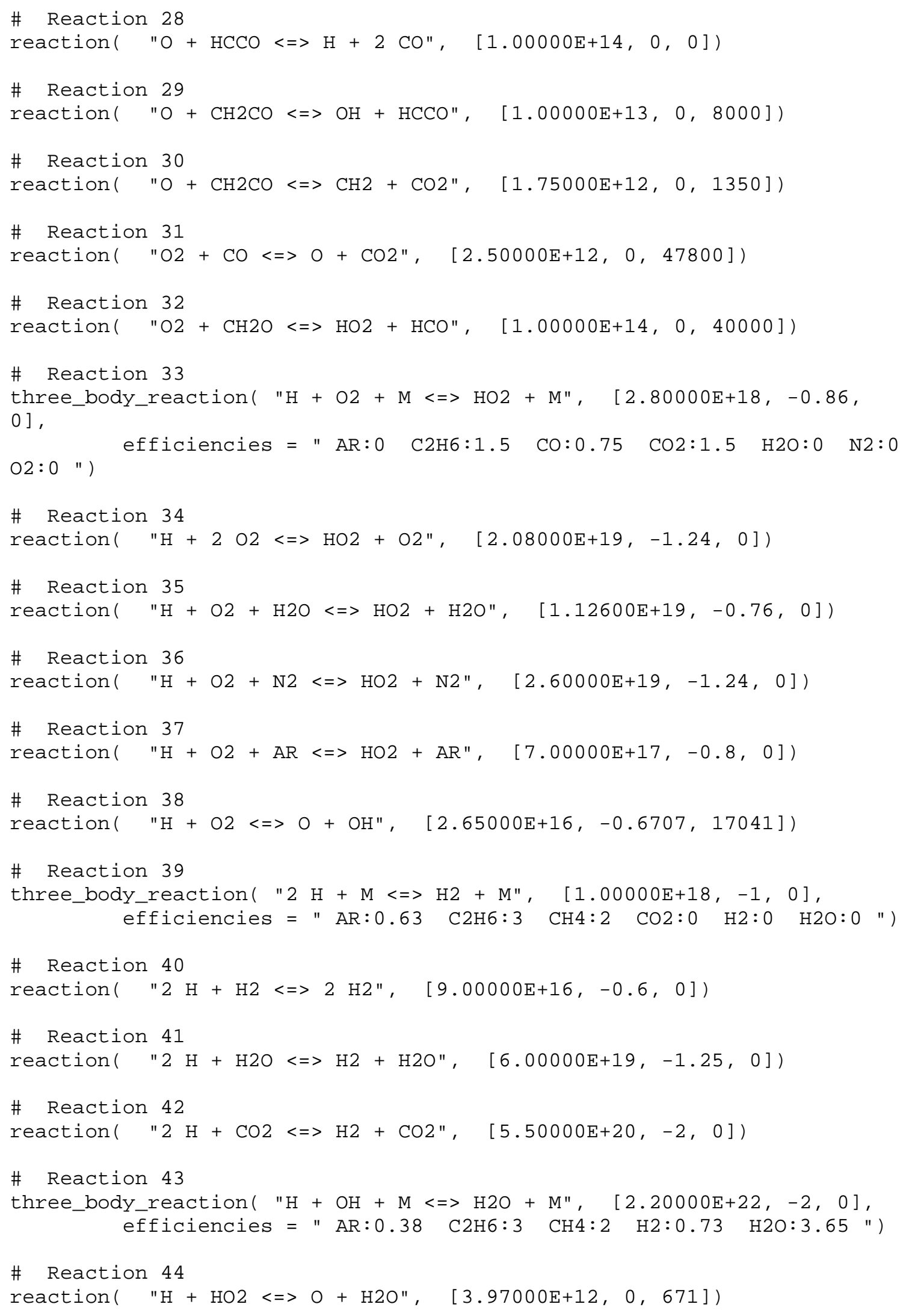




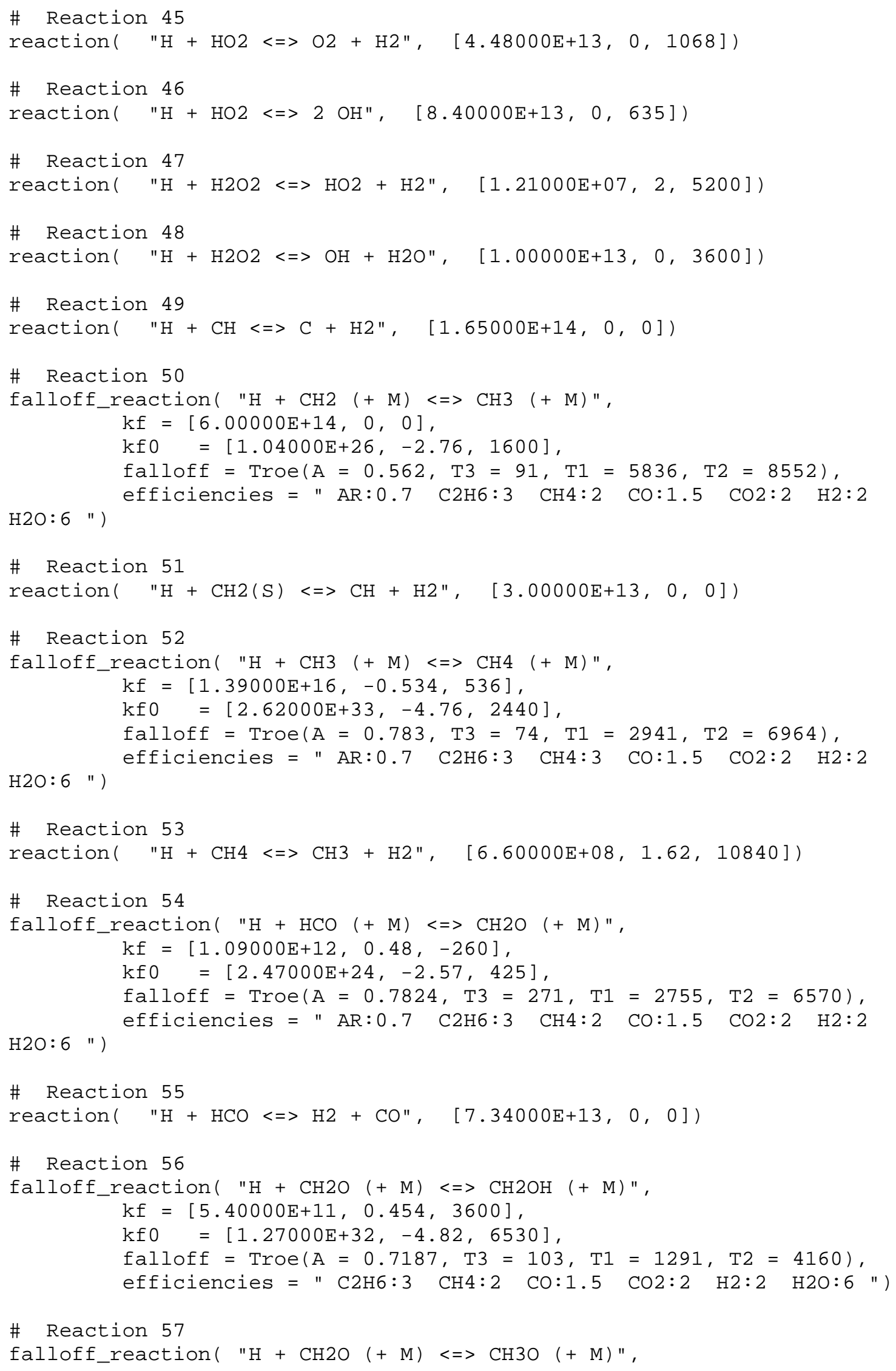




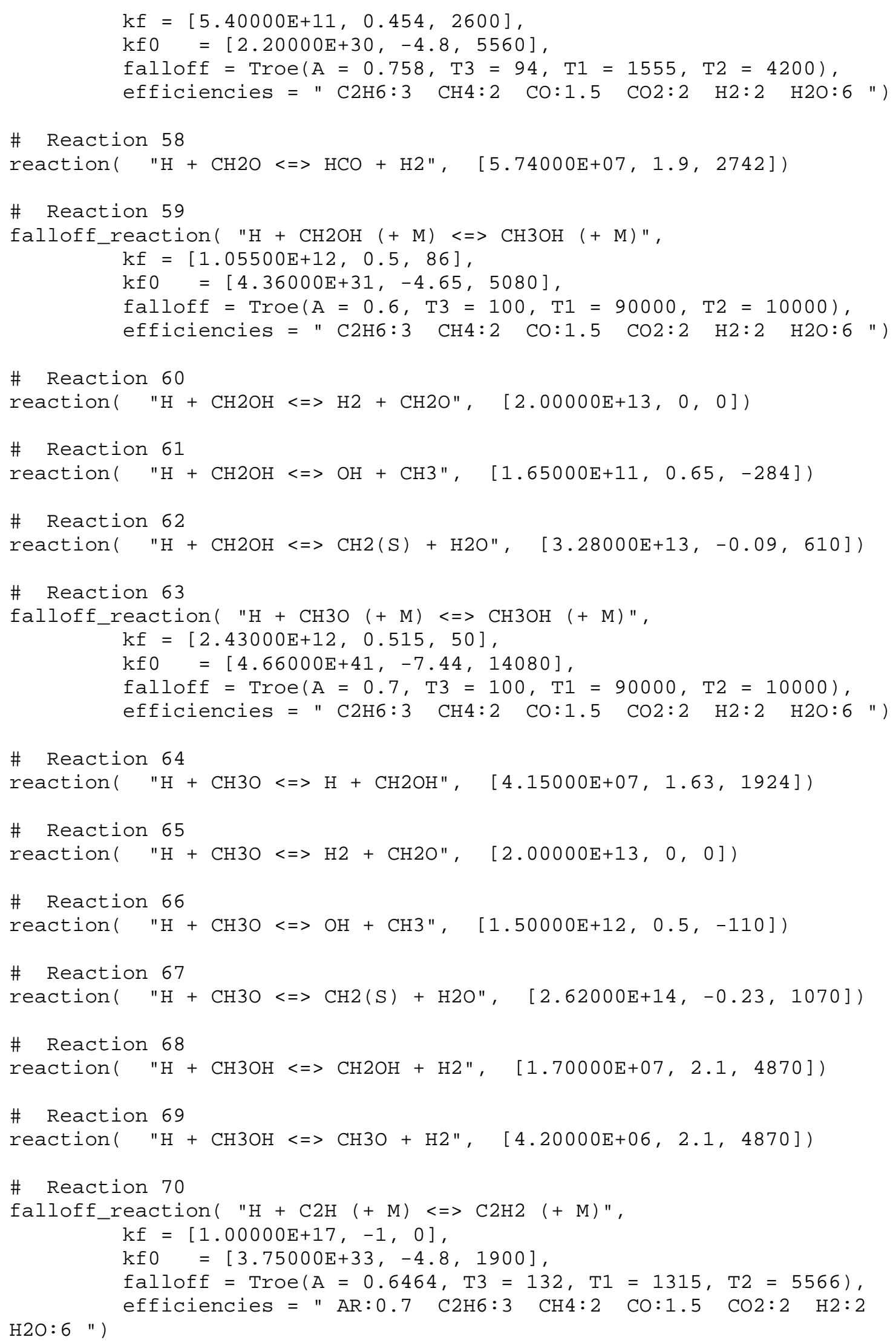




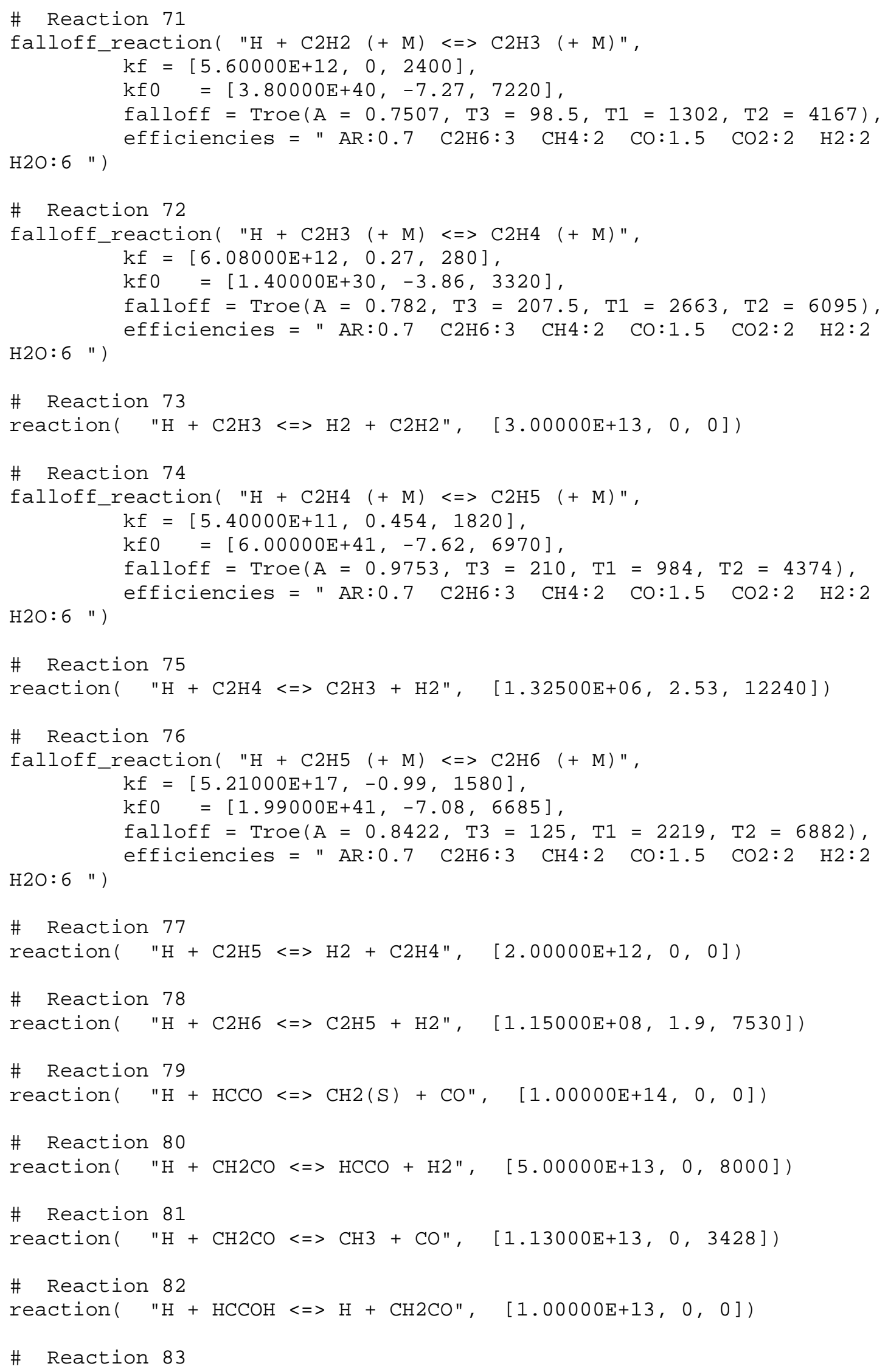




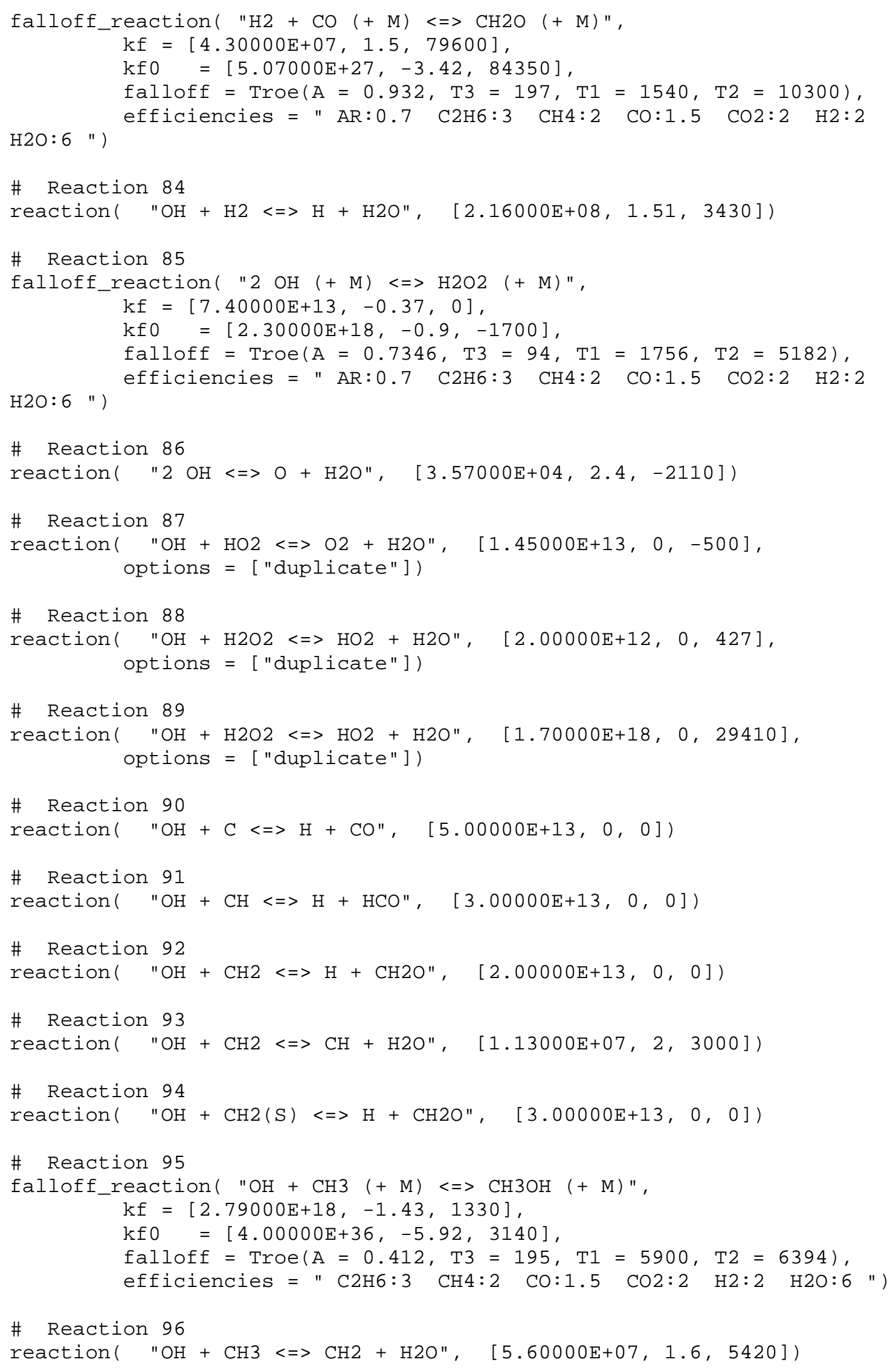




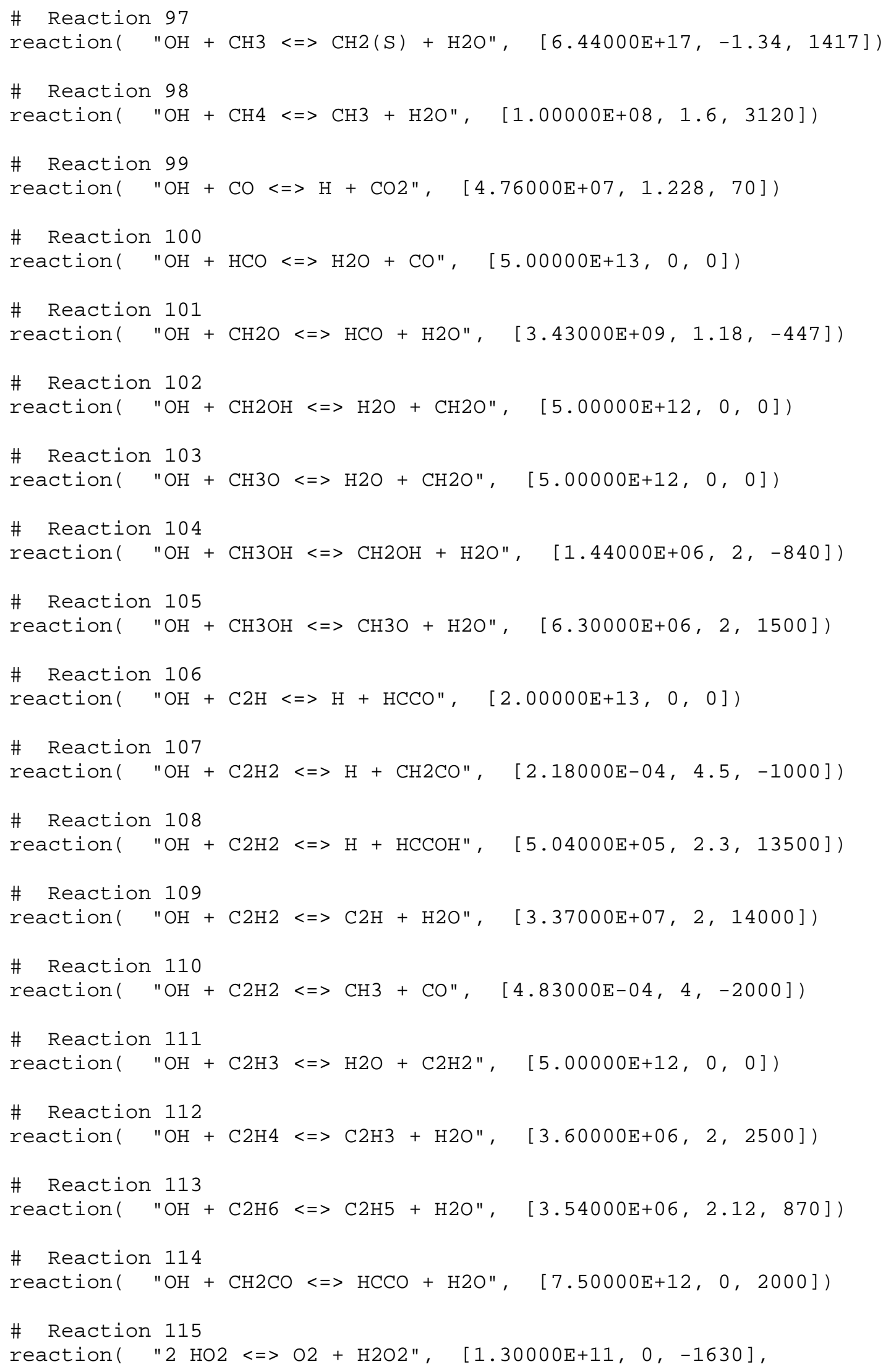




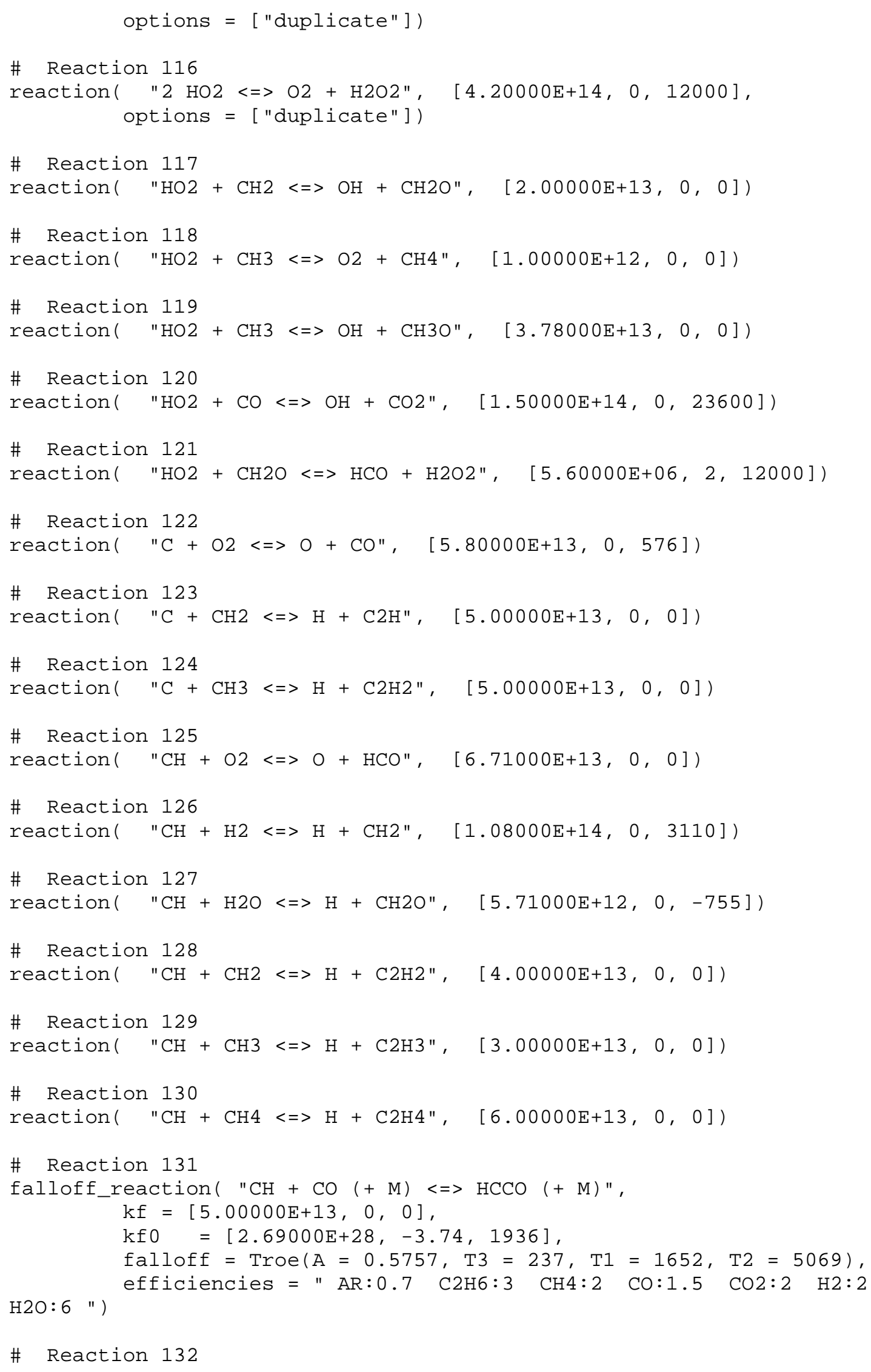




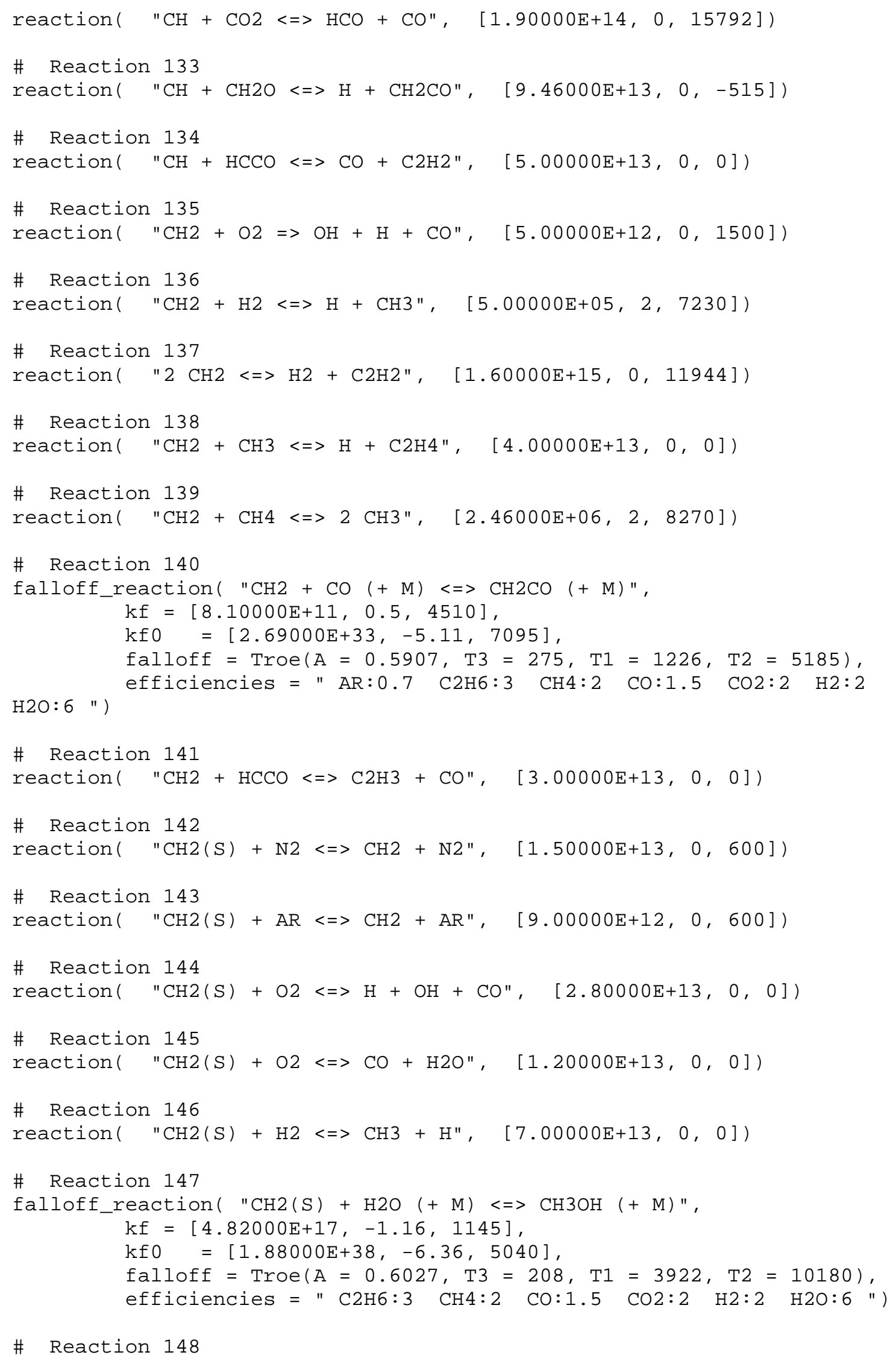




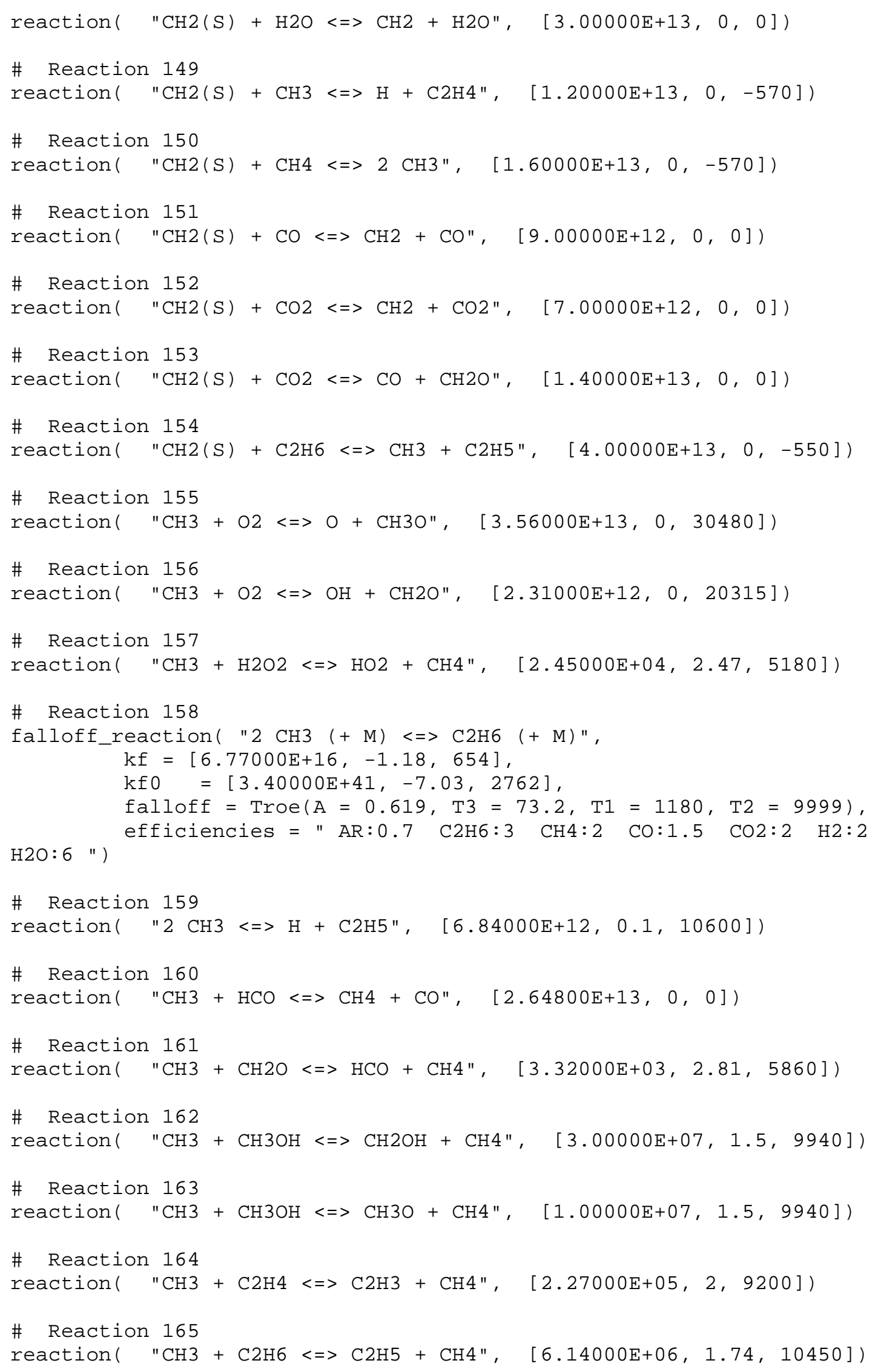




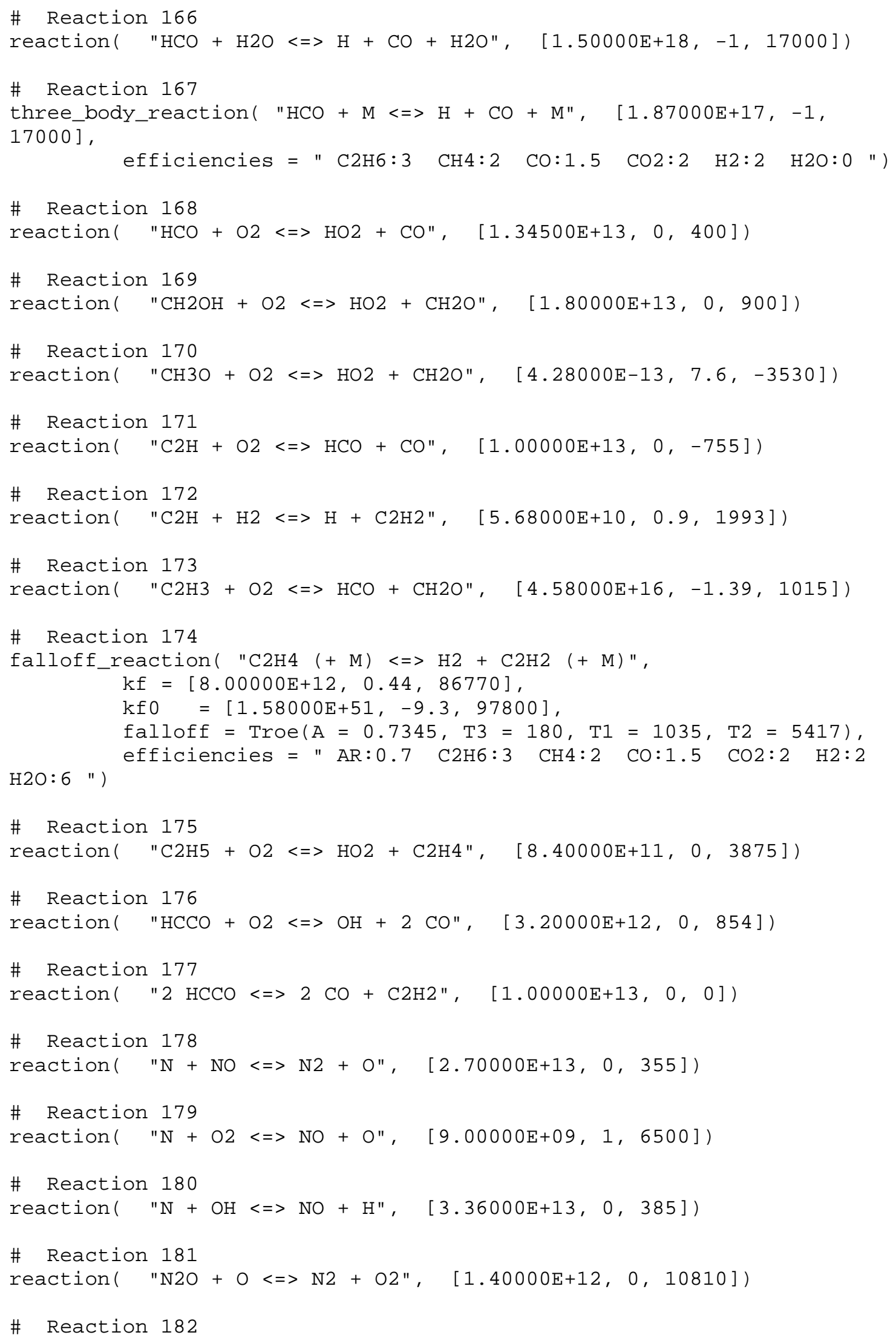




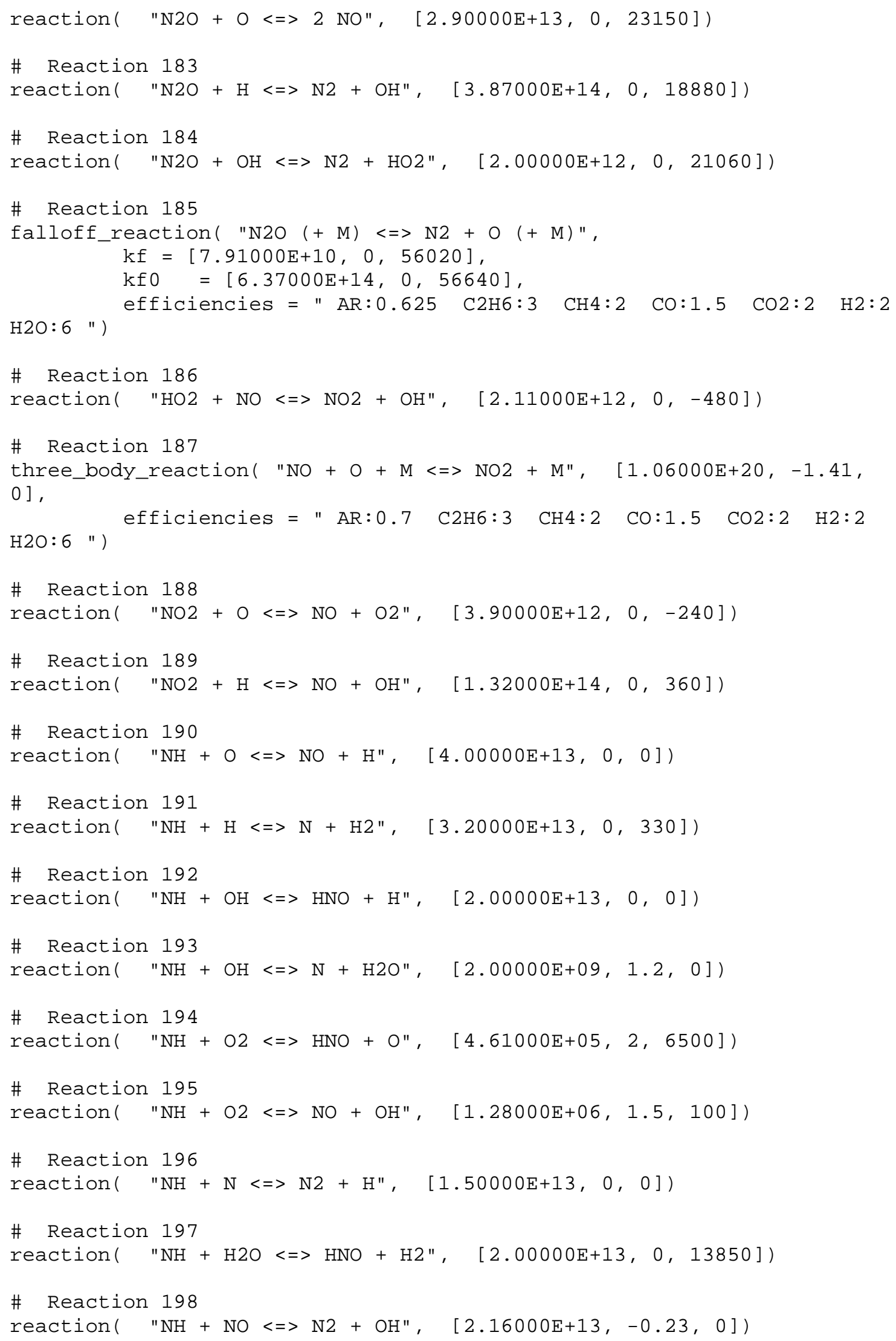




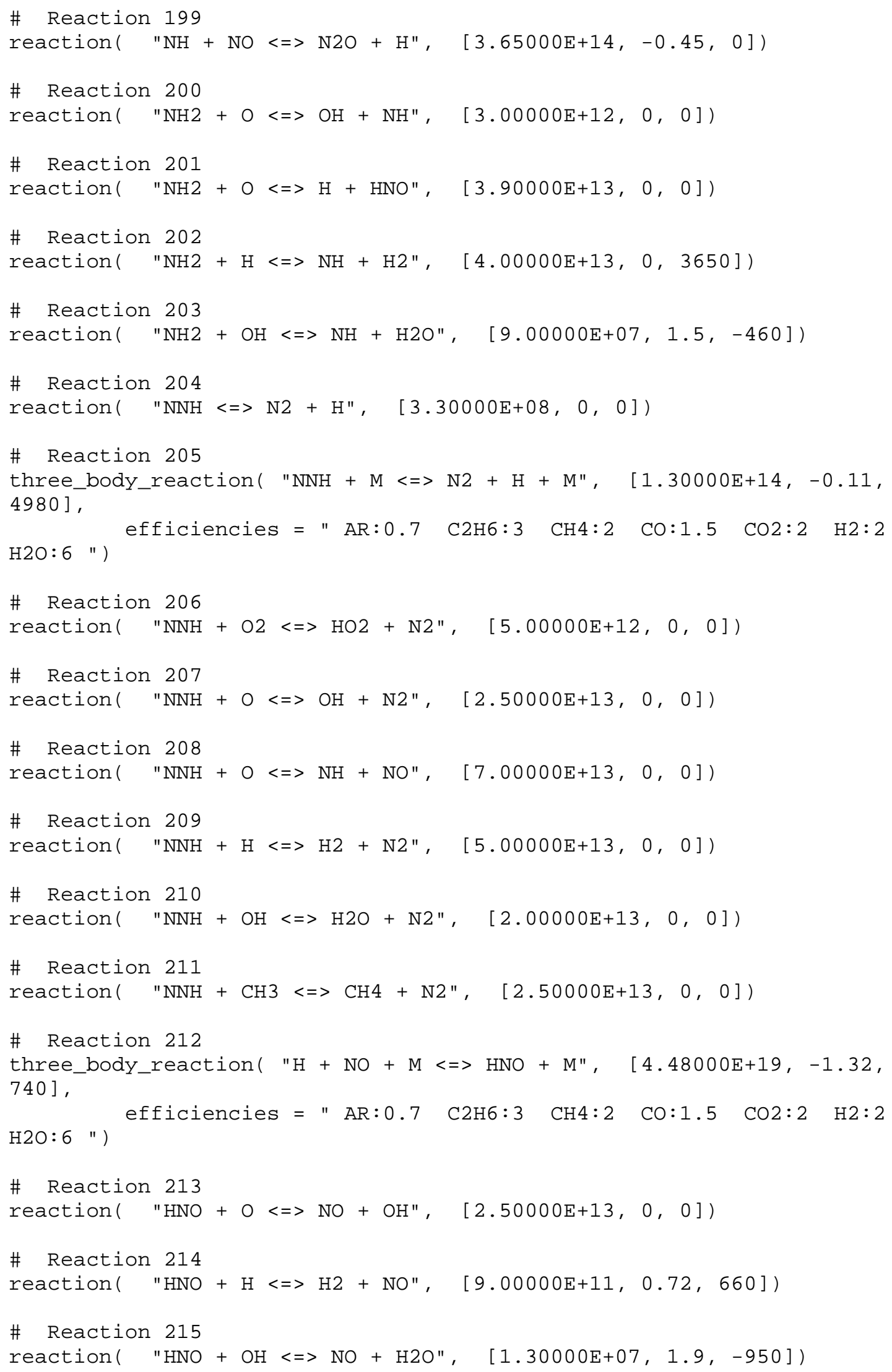




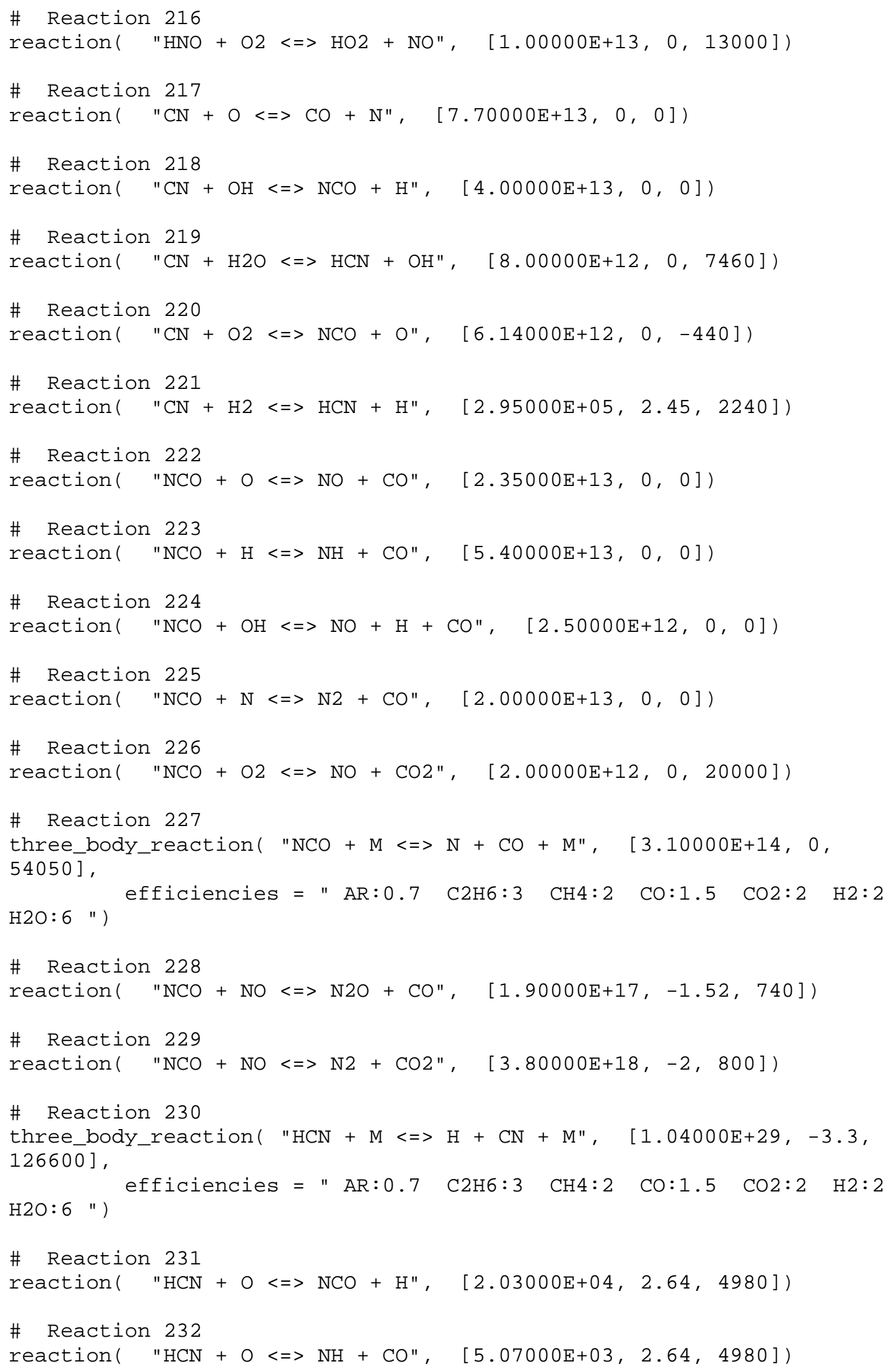




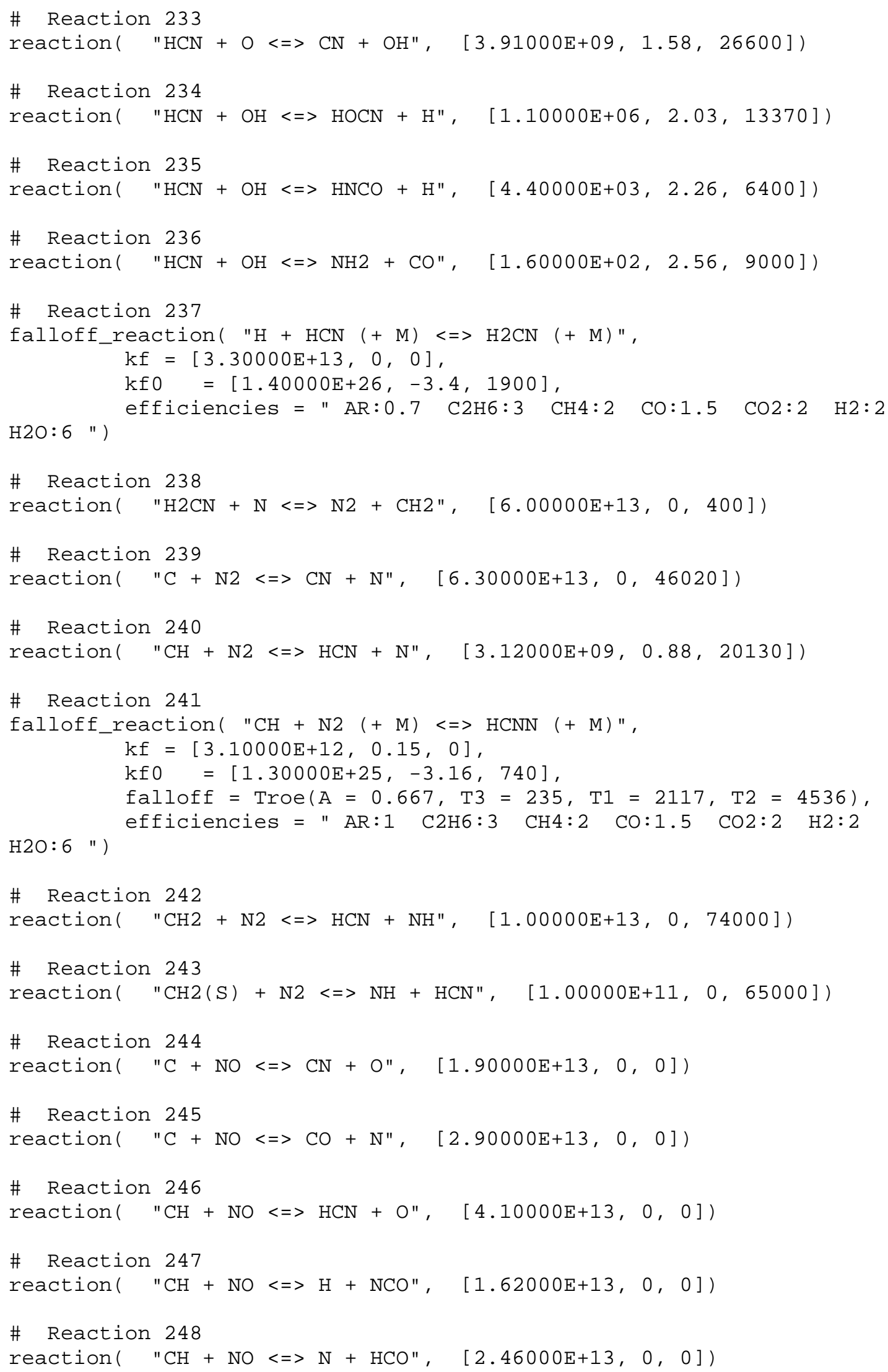




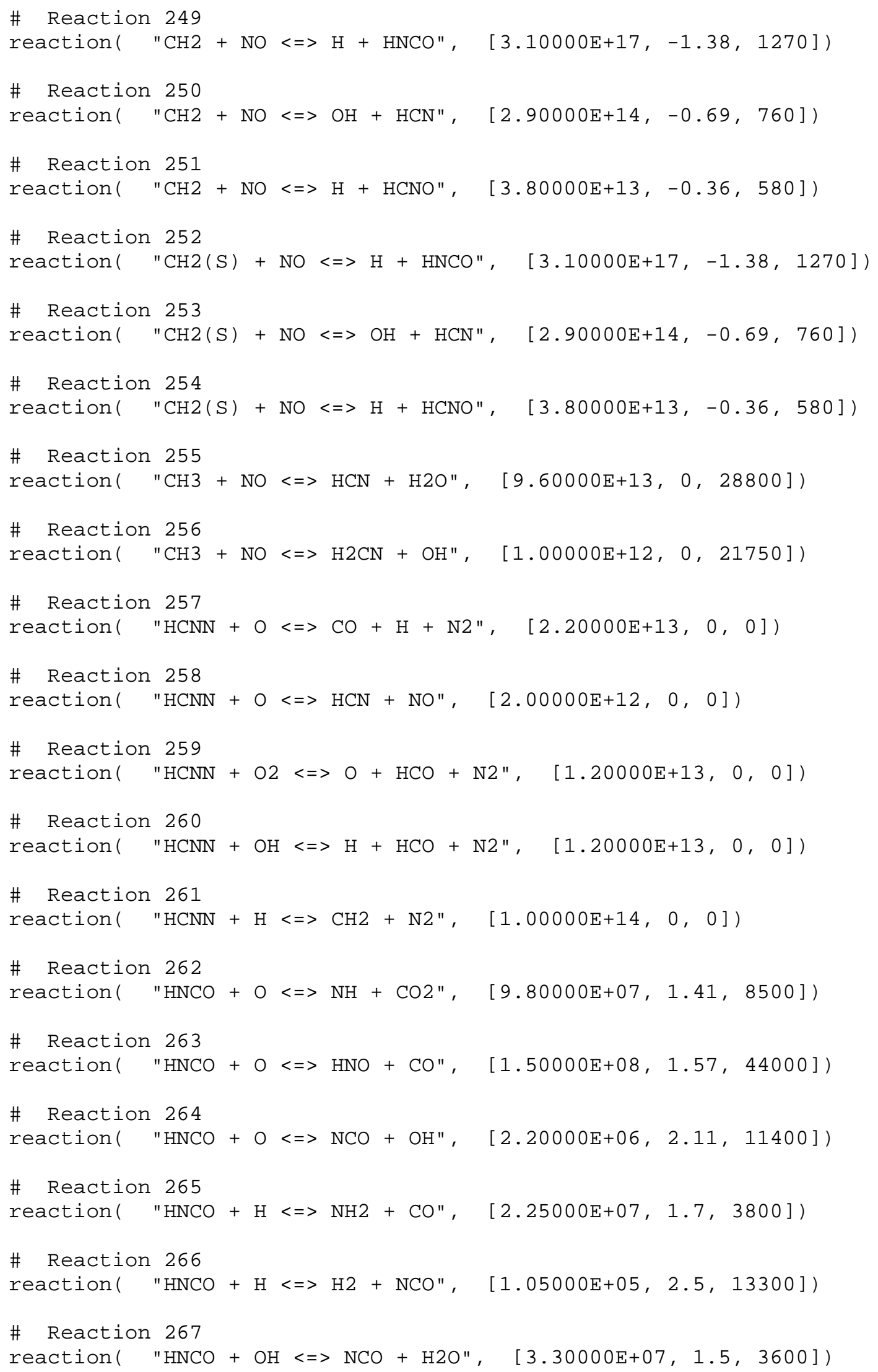




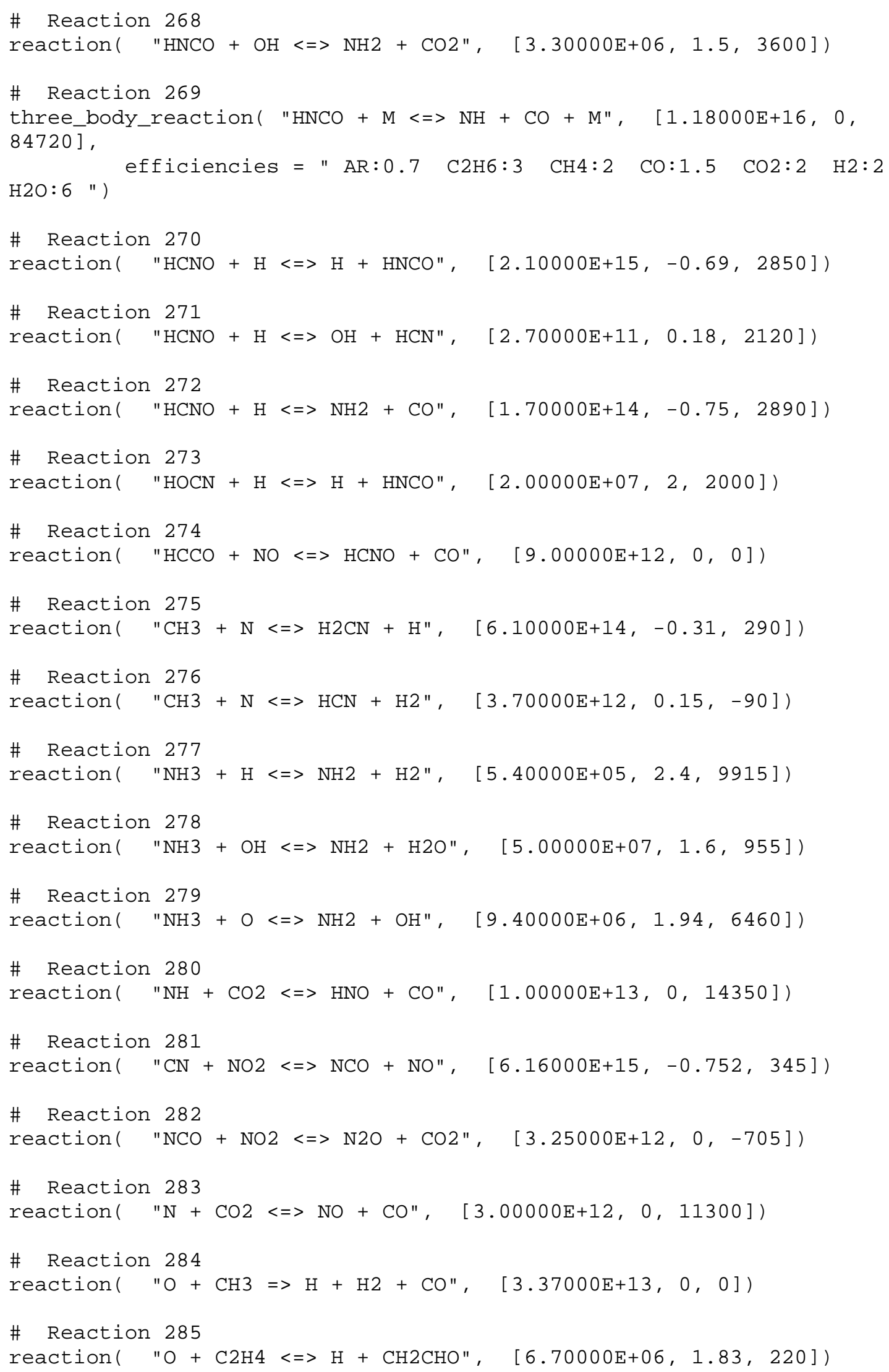




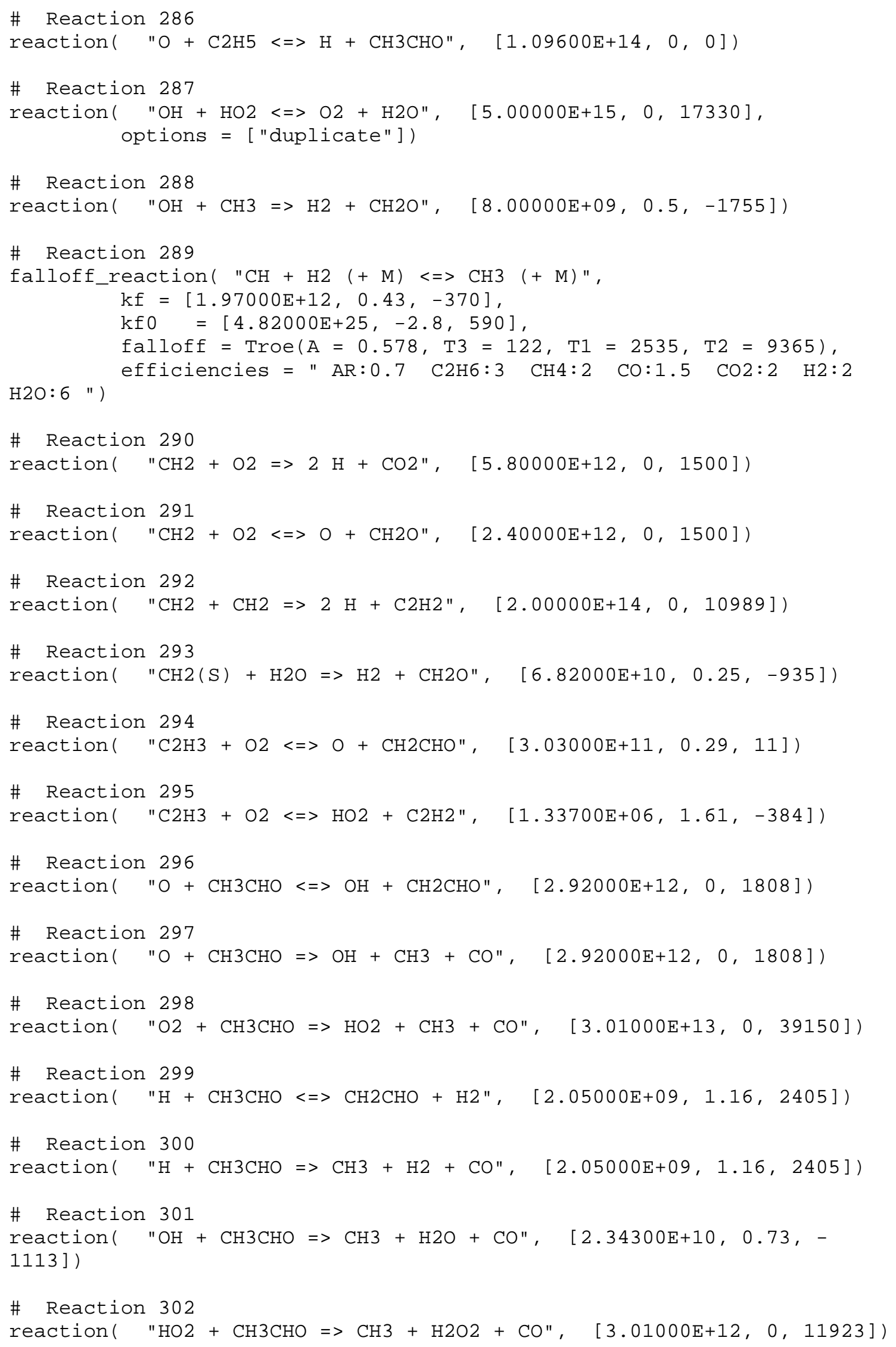




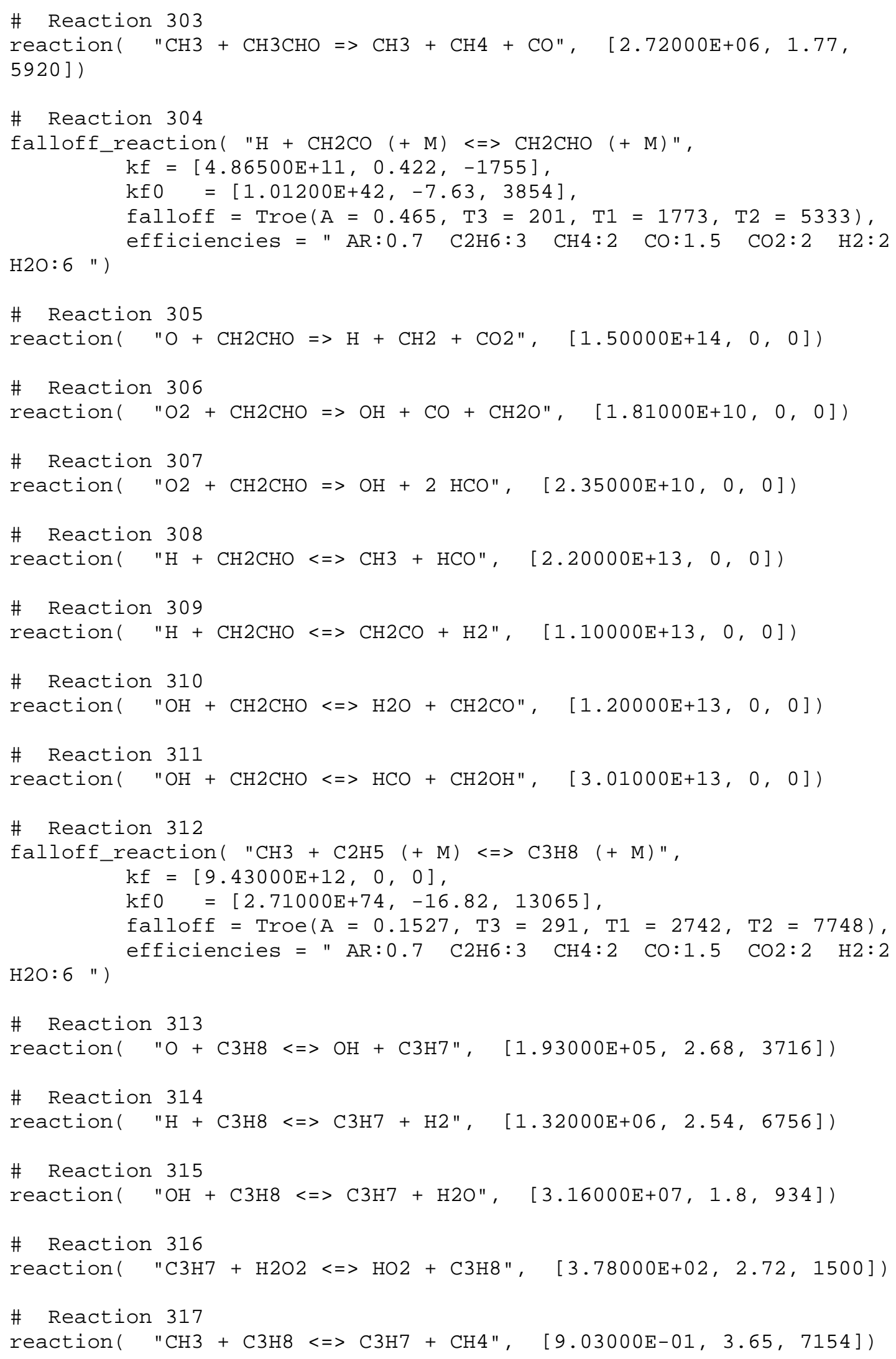




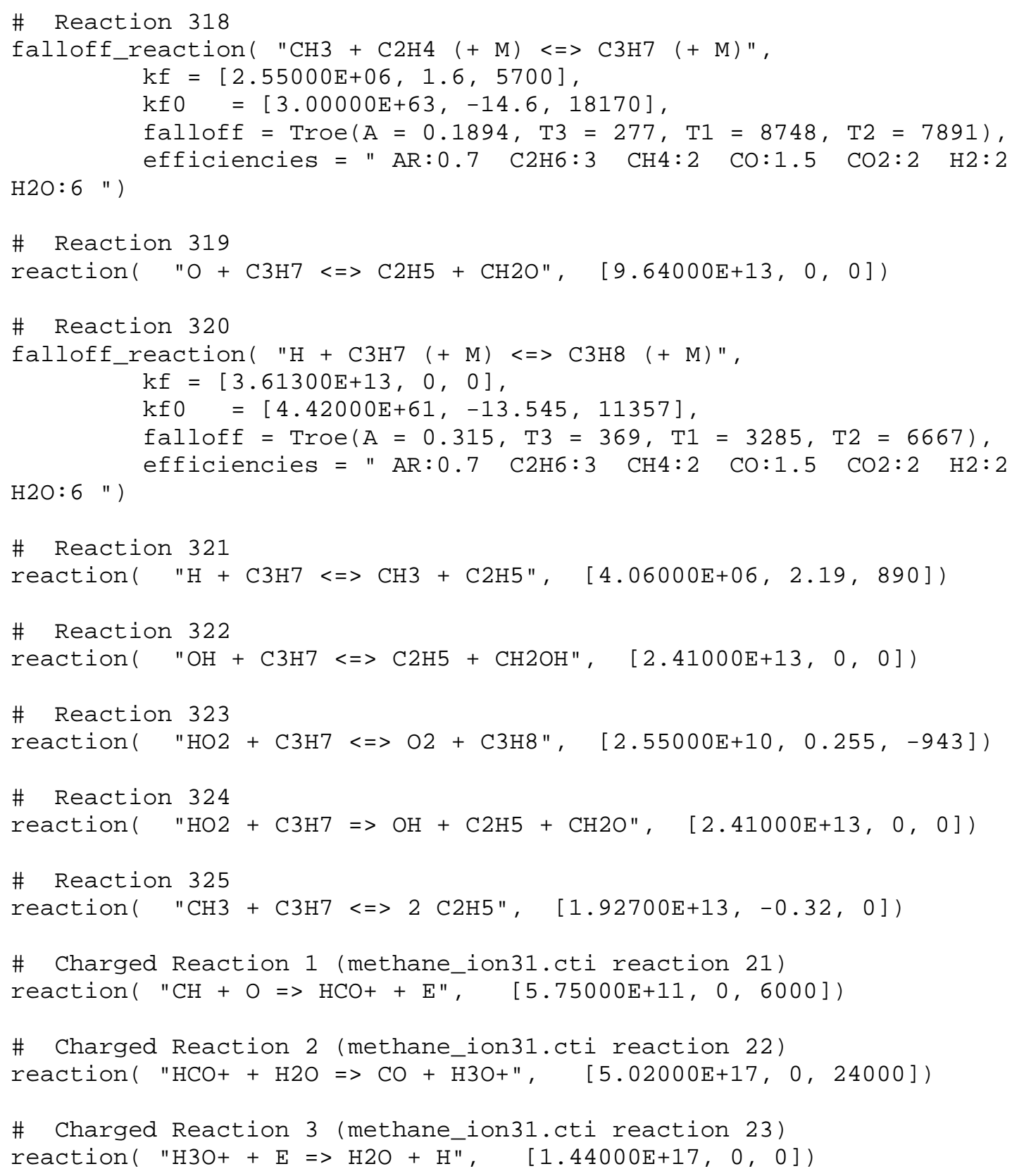




\section{B-3: Listing of Pederson and Brown Mechanism}

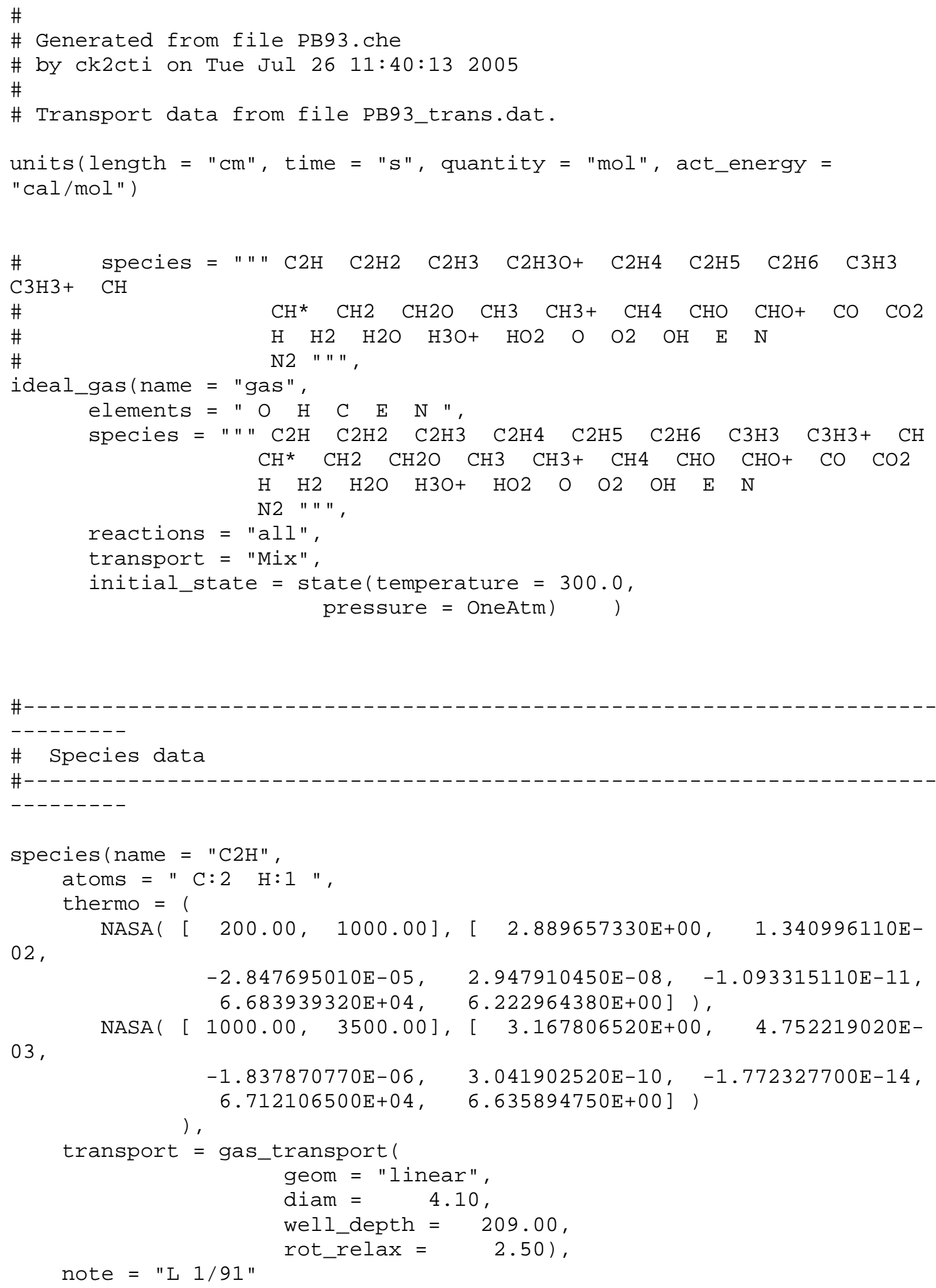




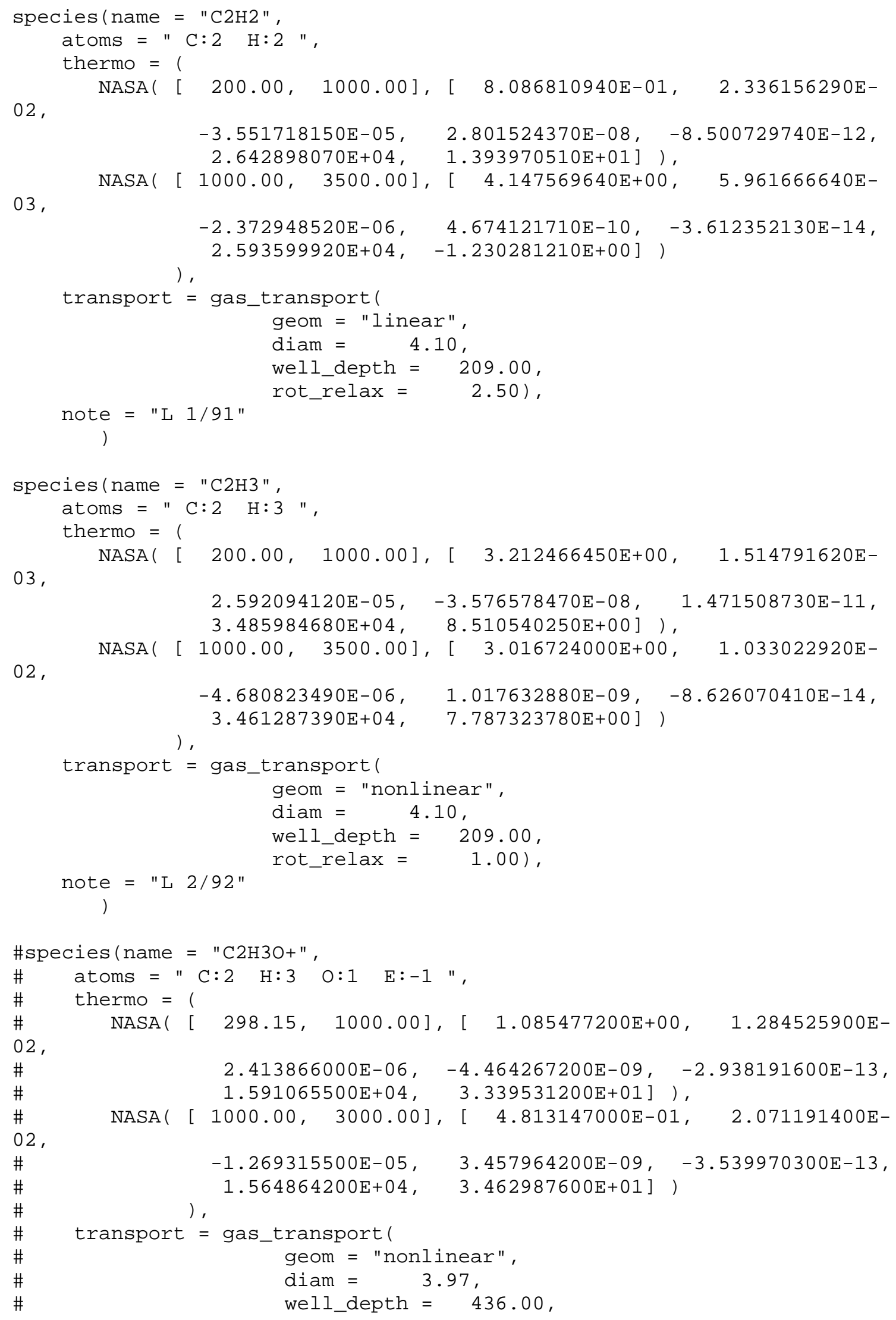




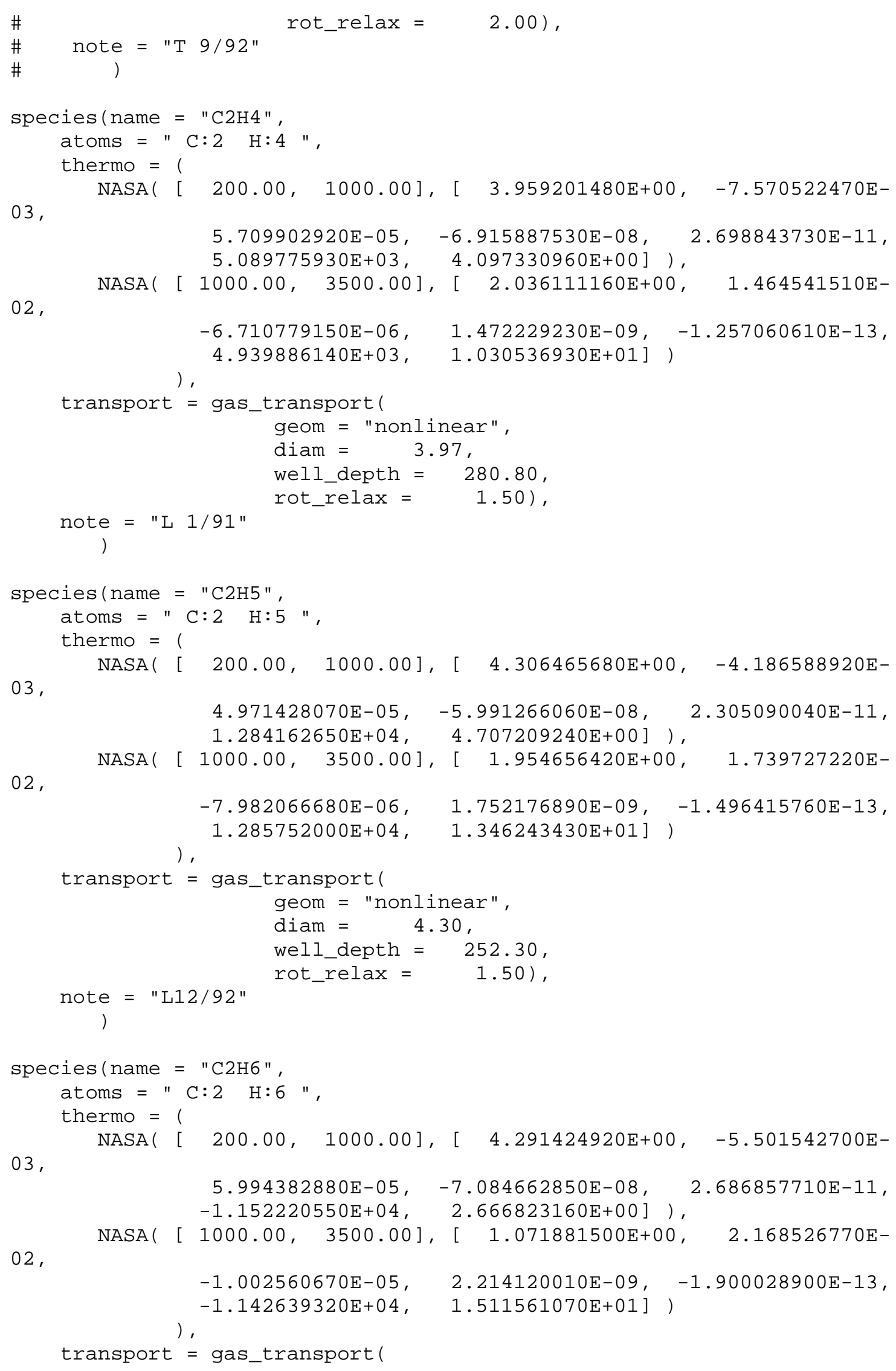




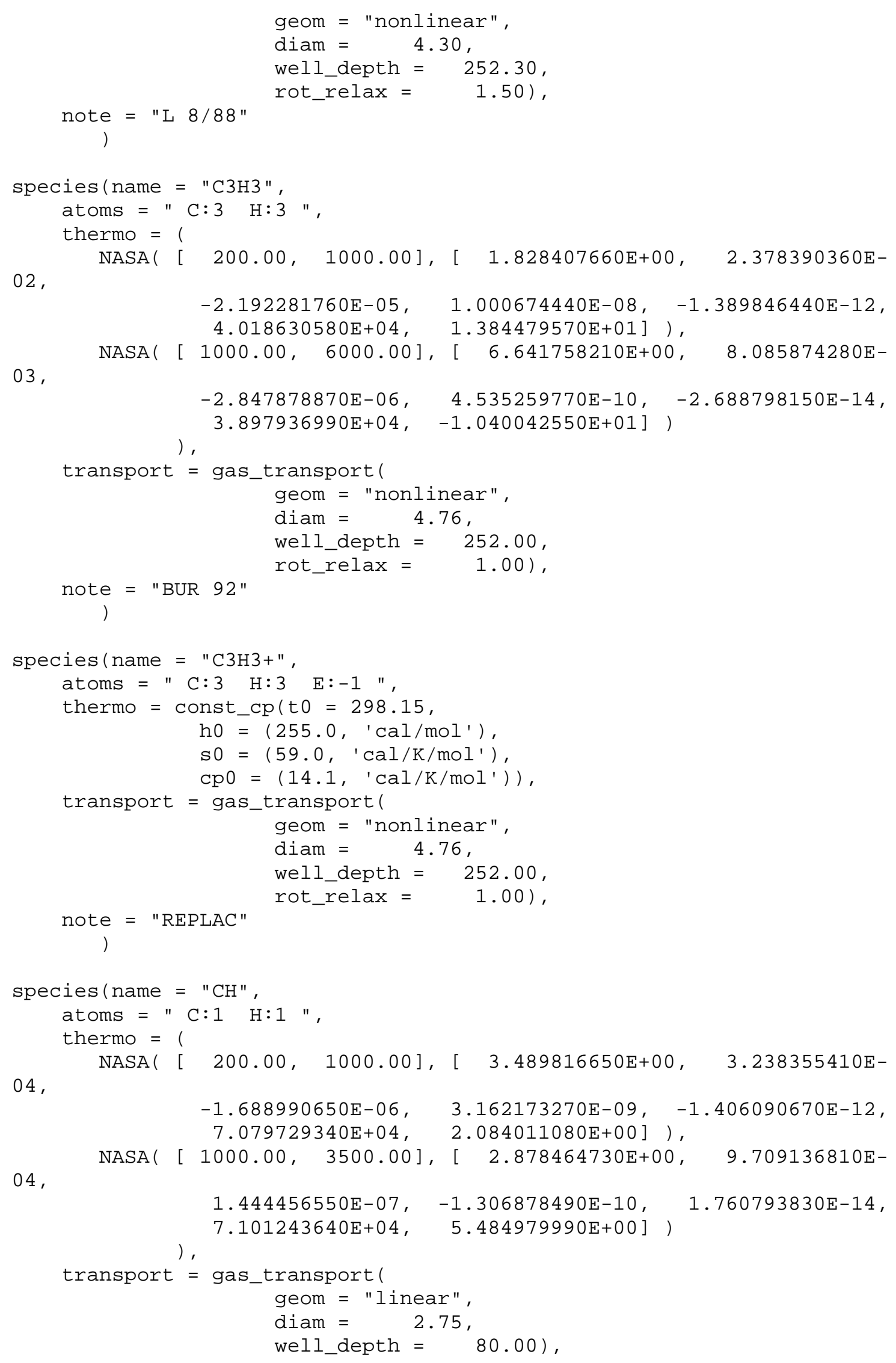




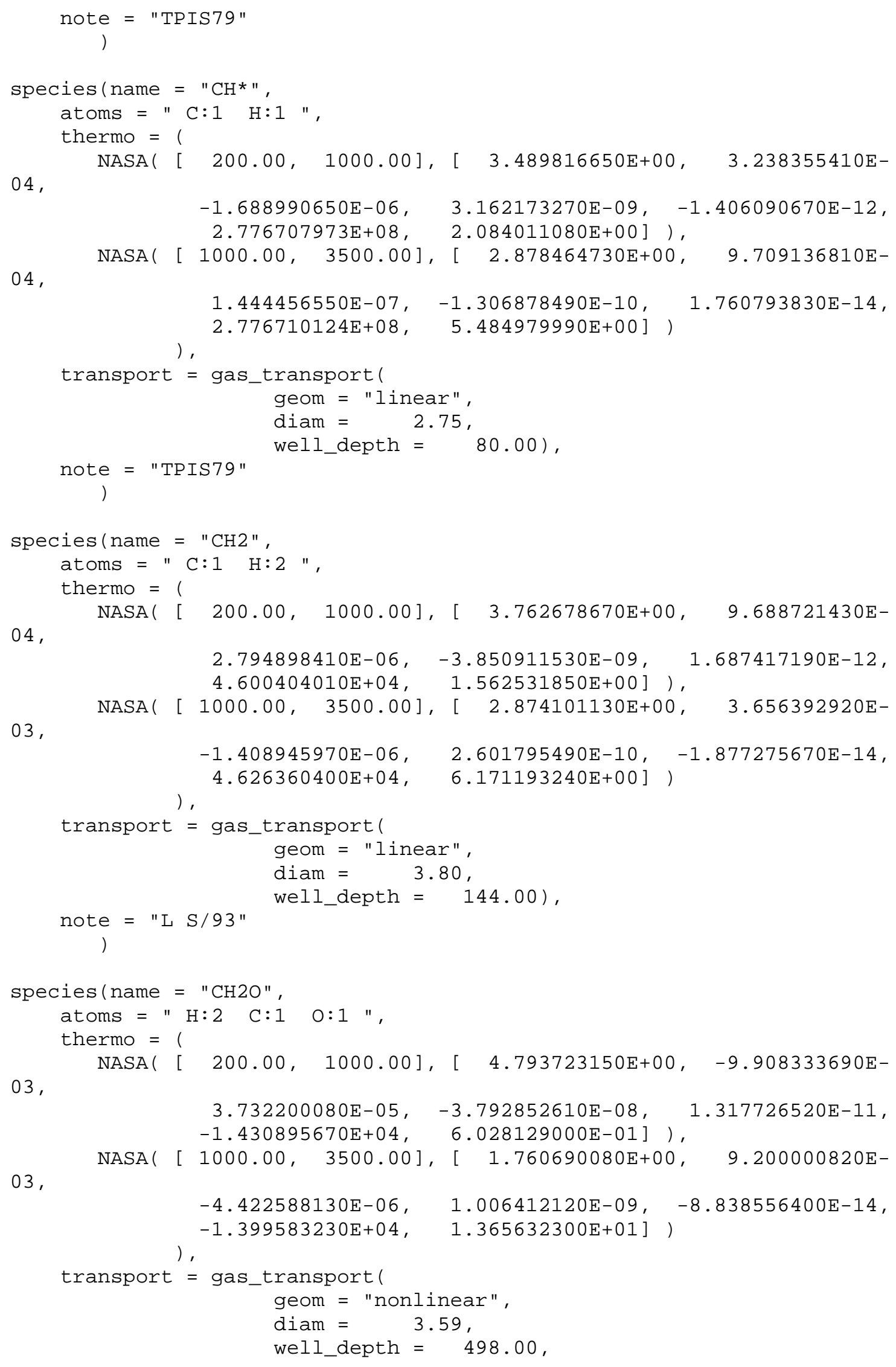




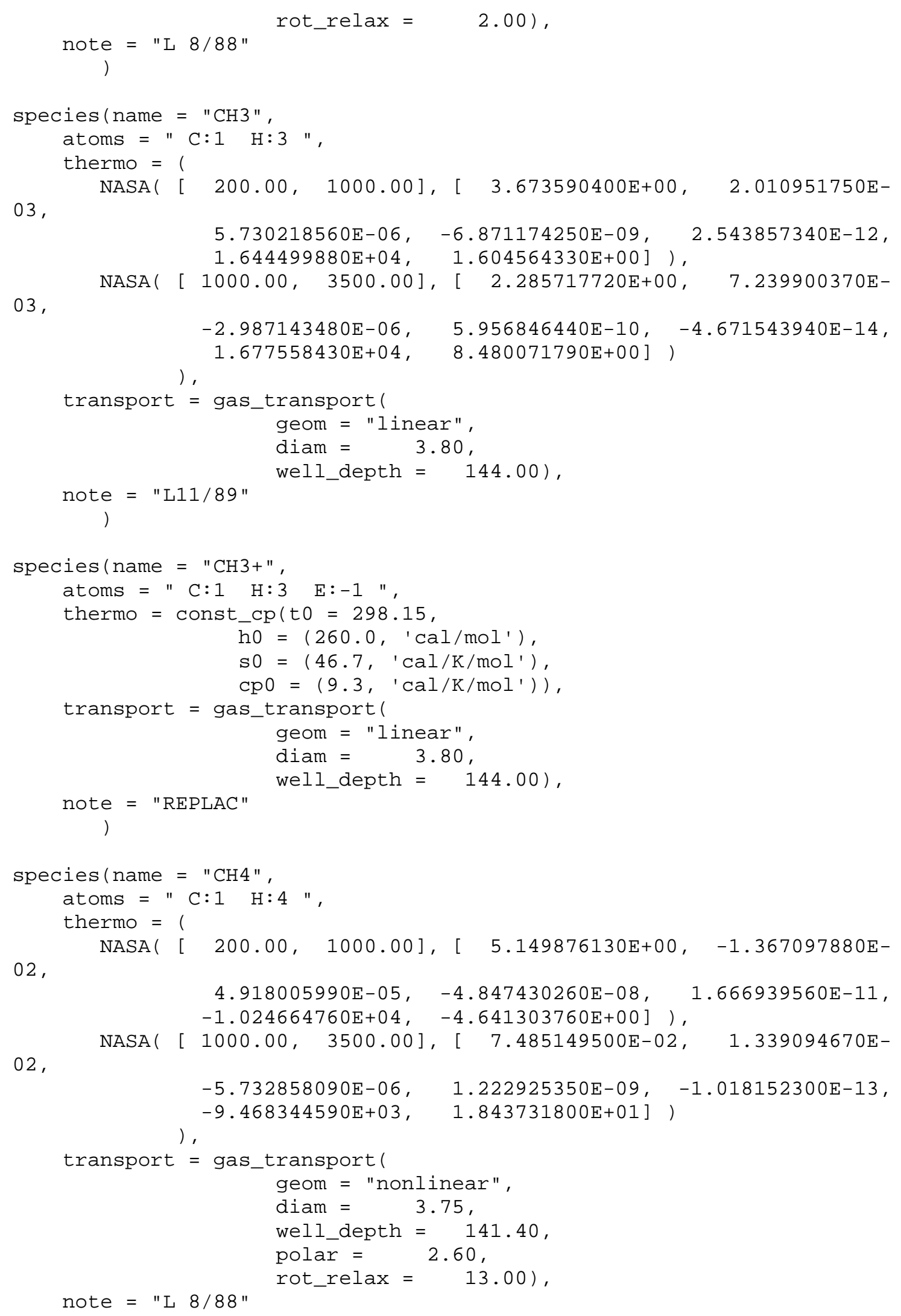




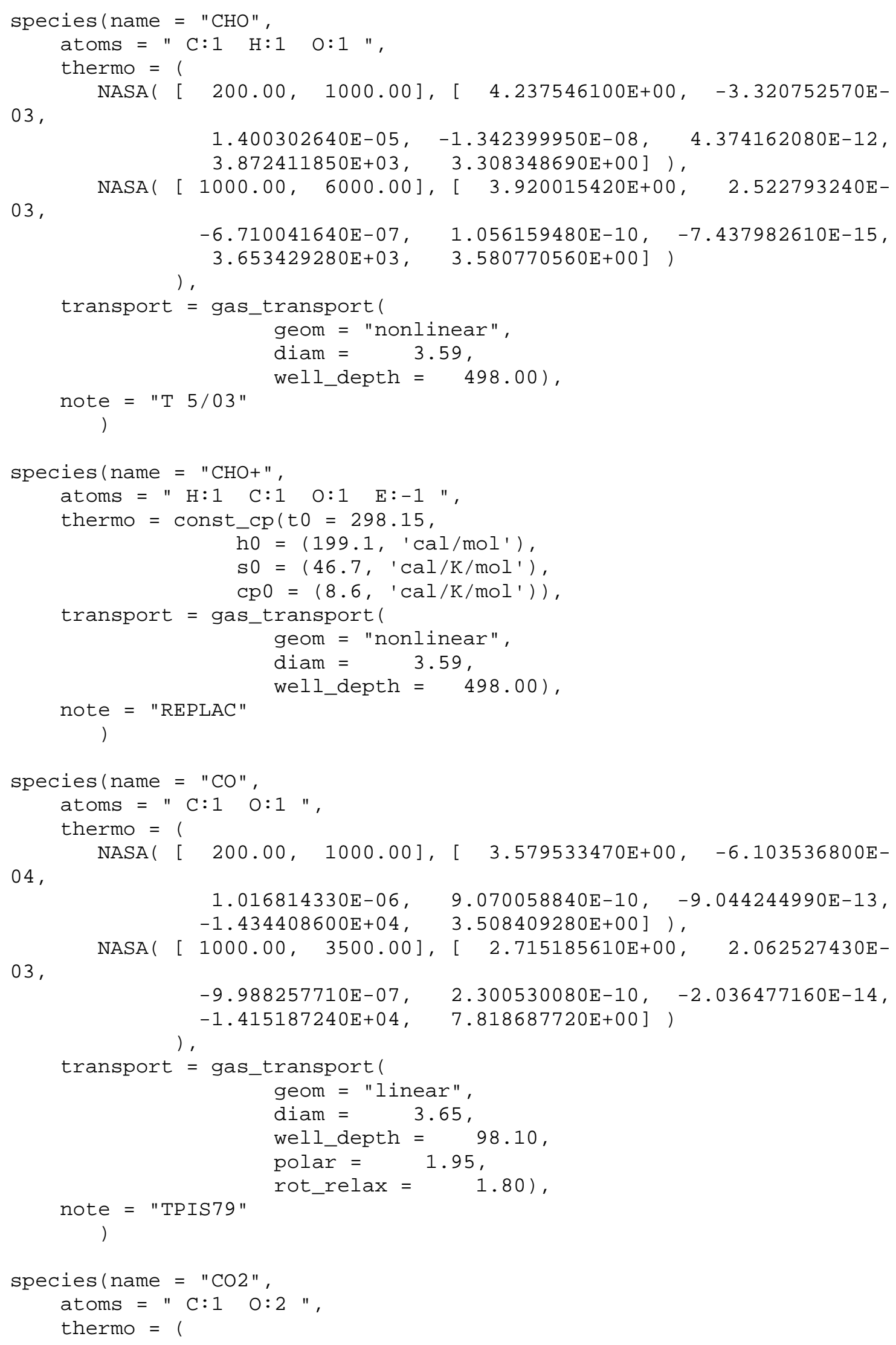




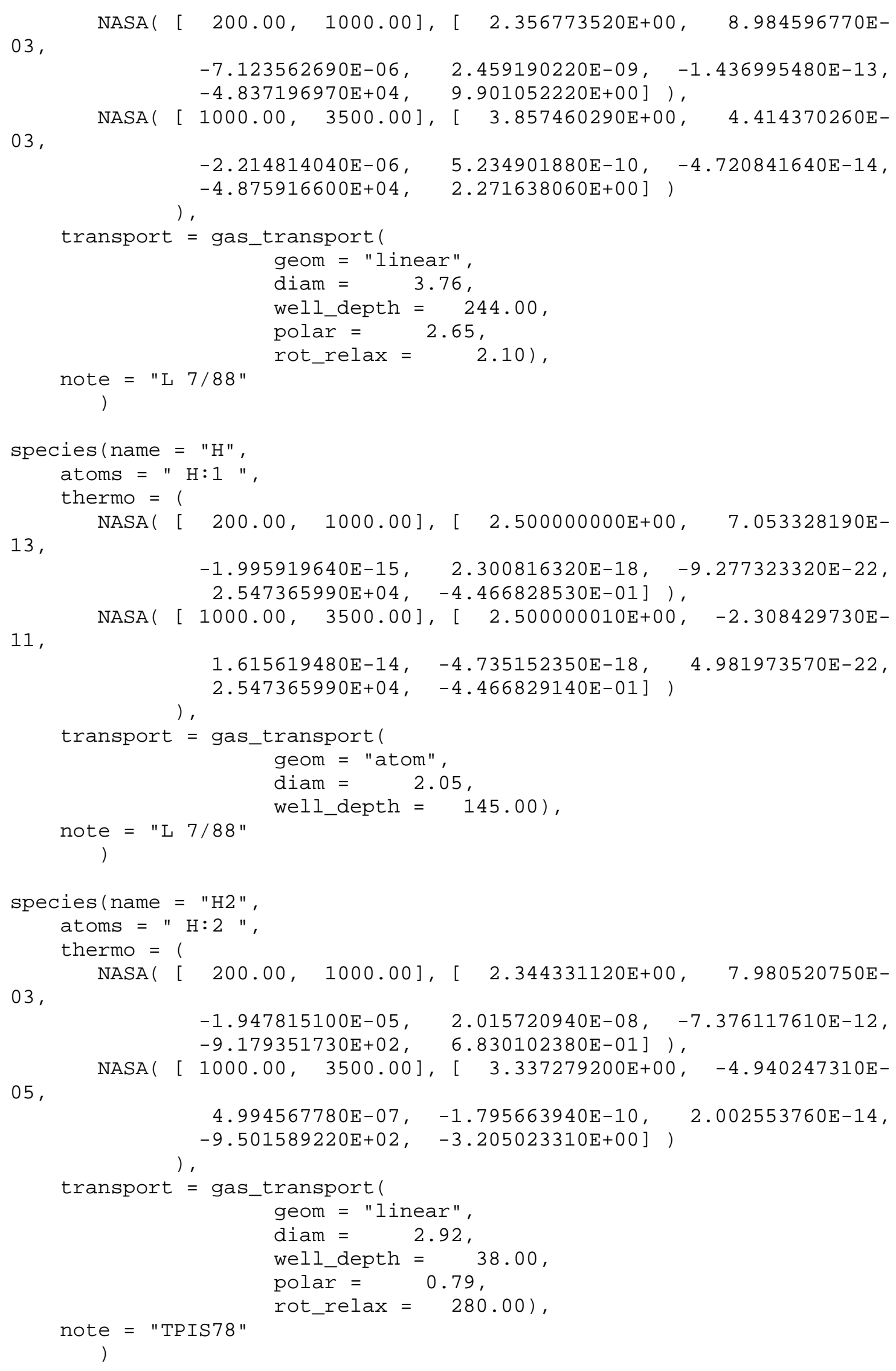




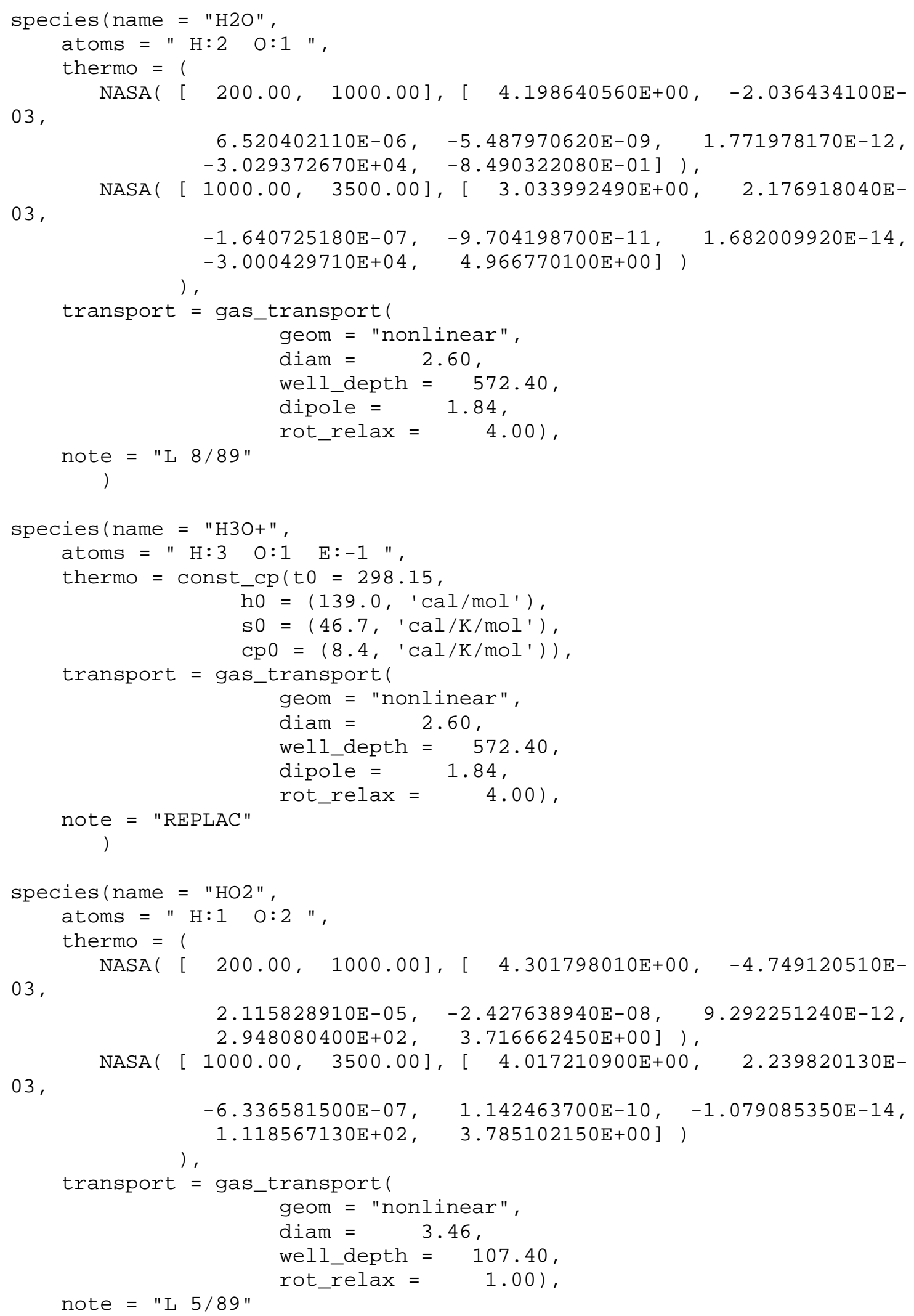




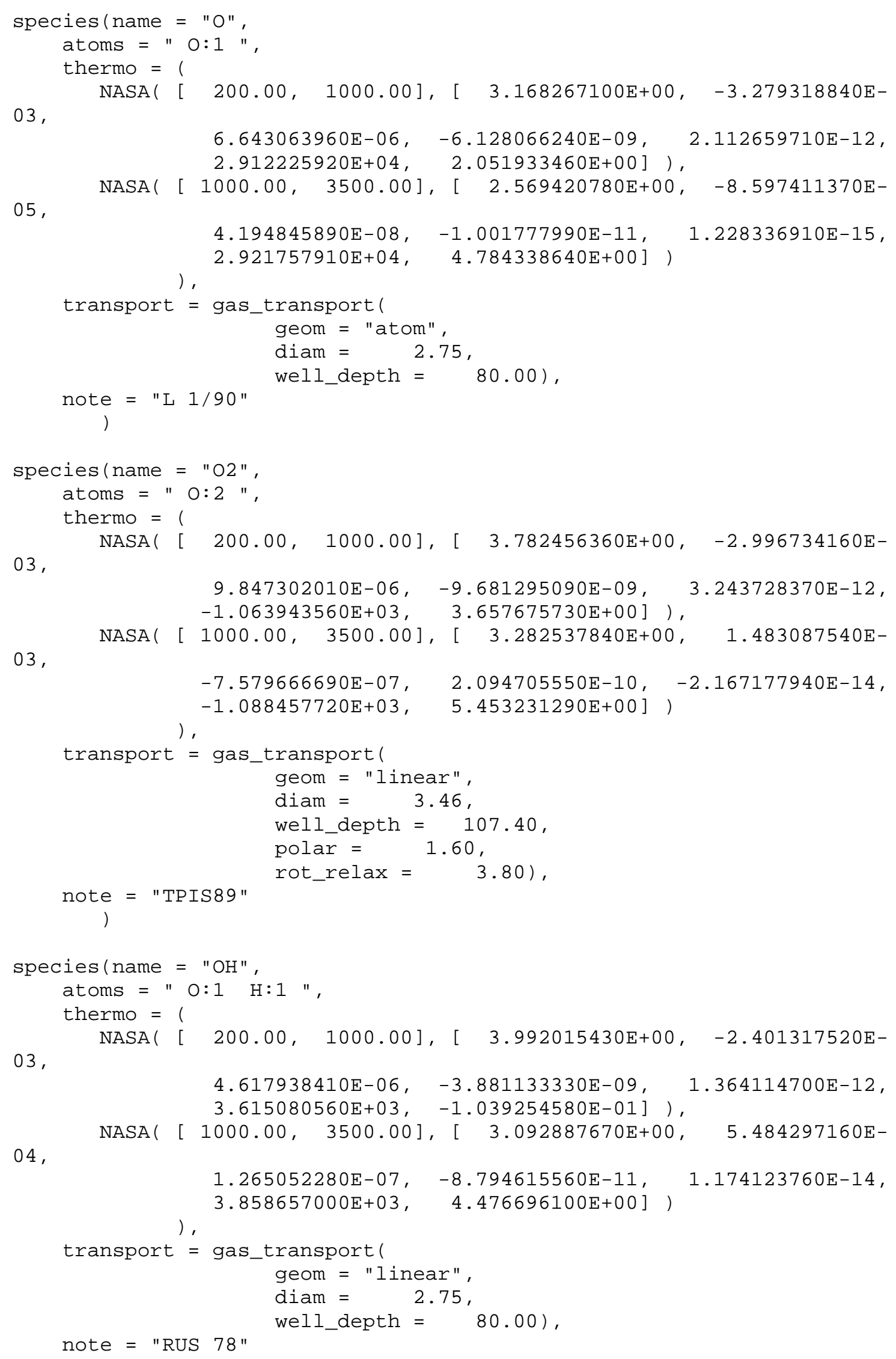




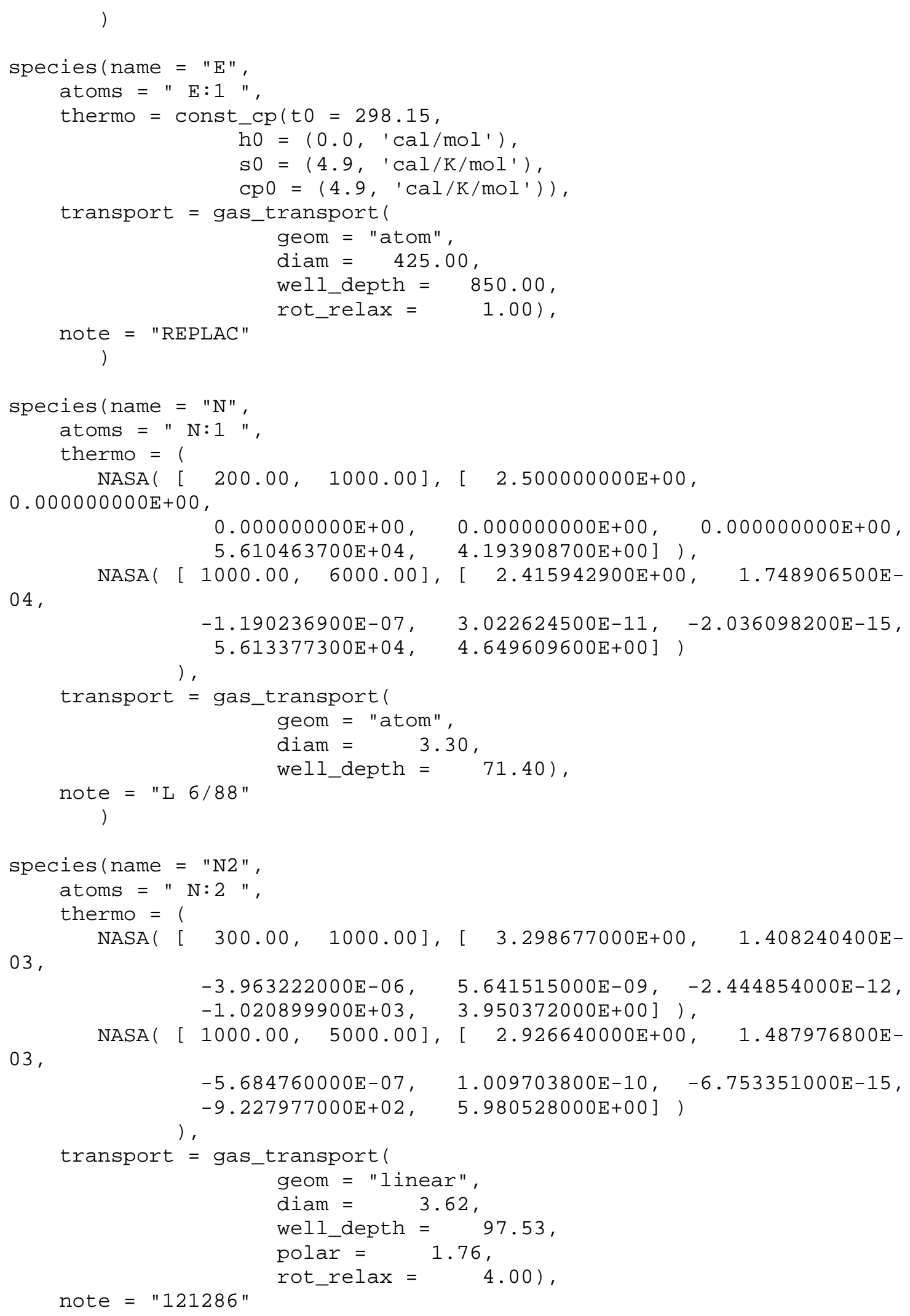




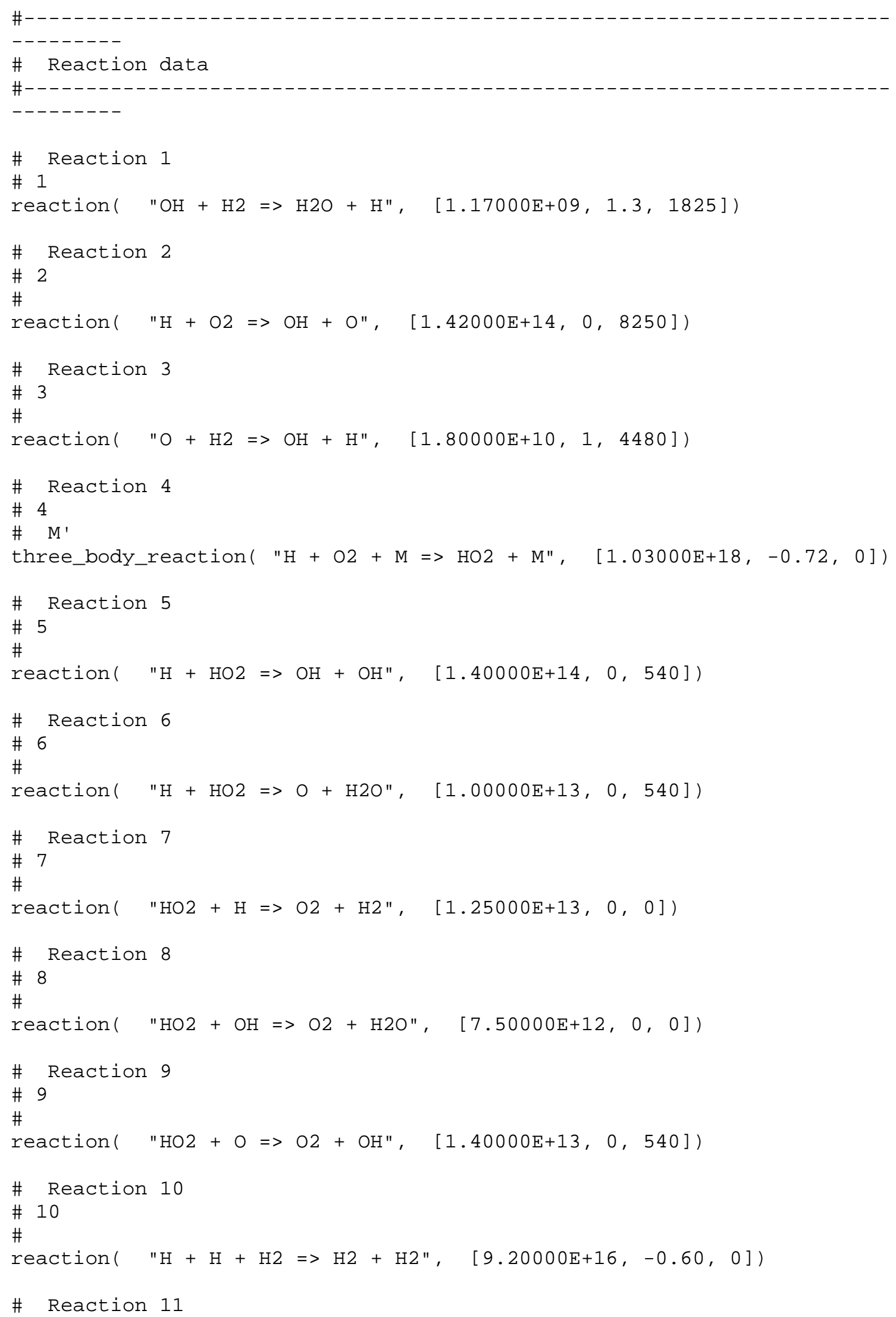




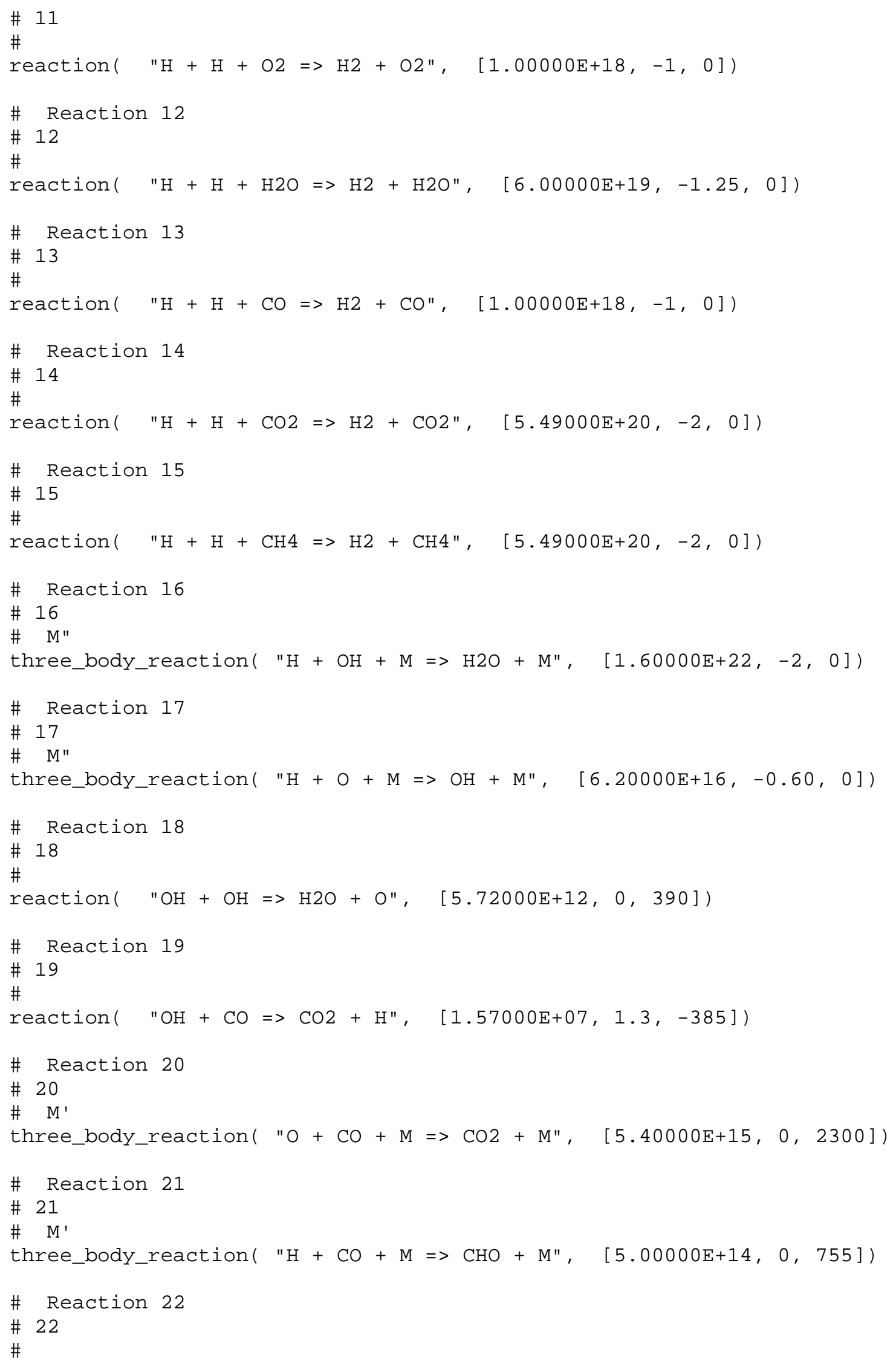




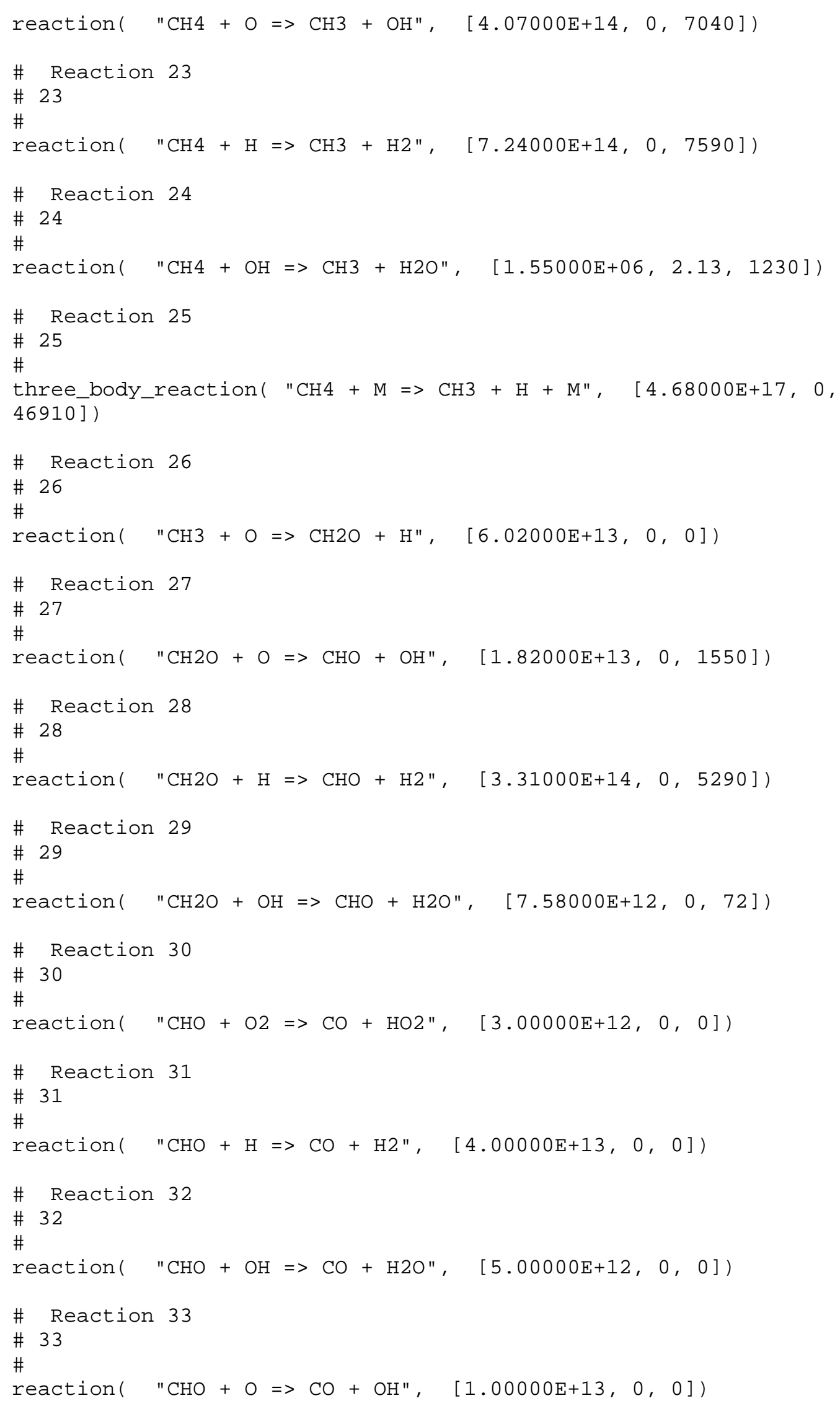




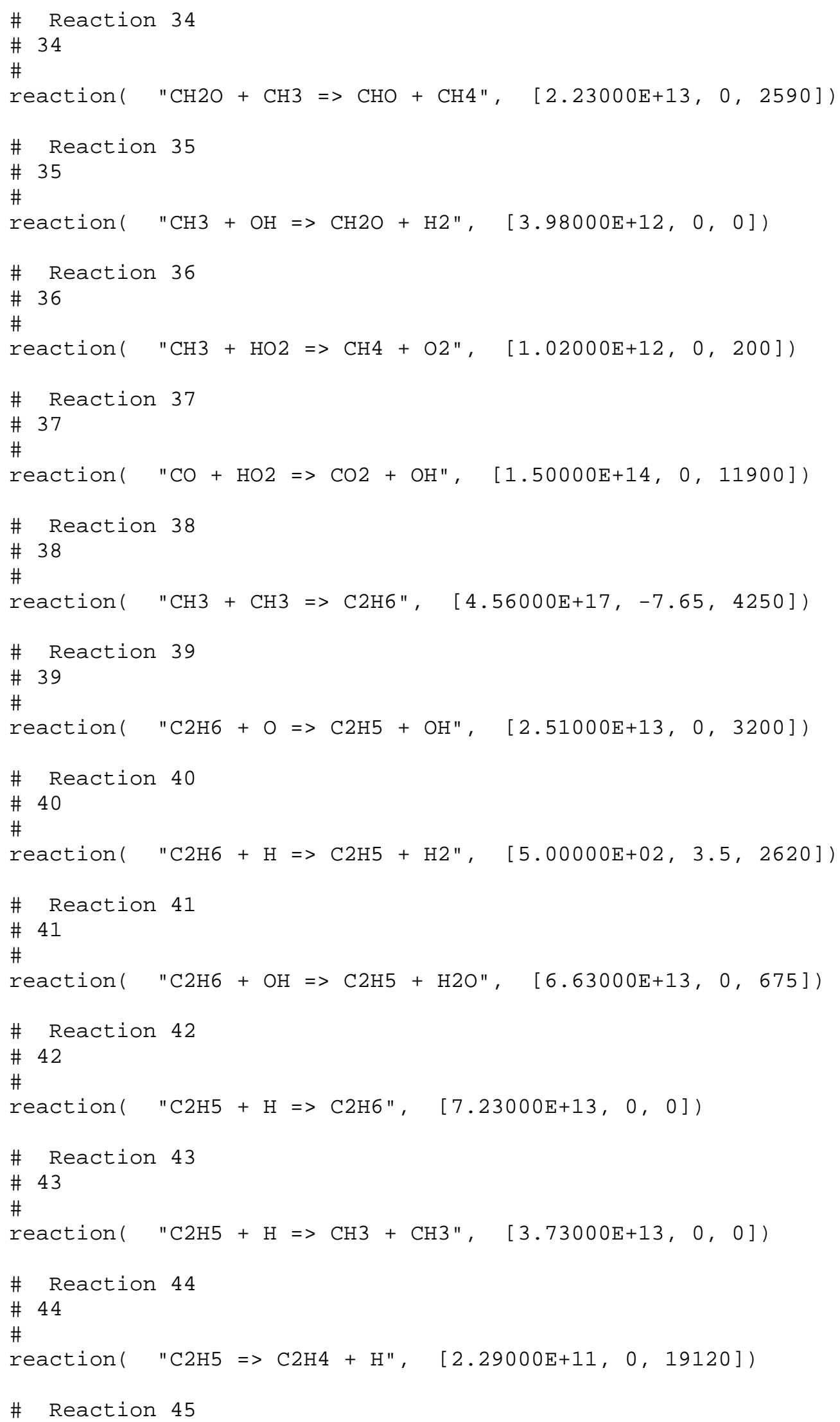




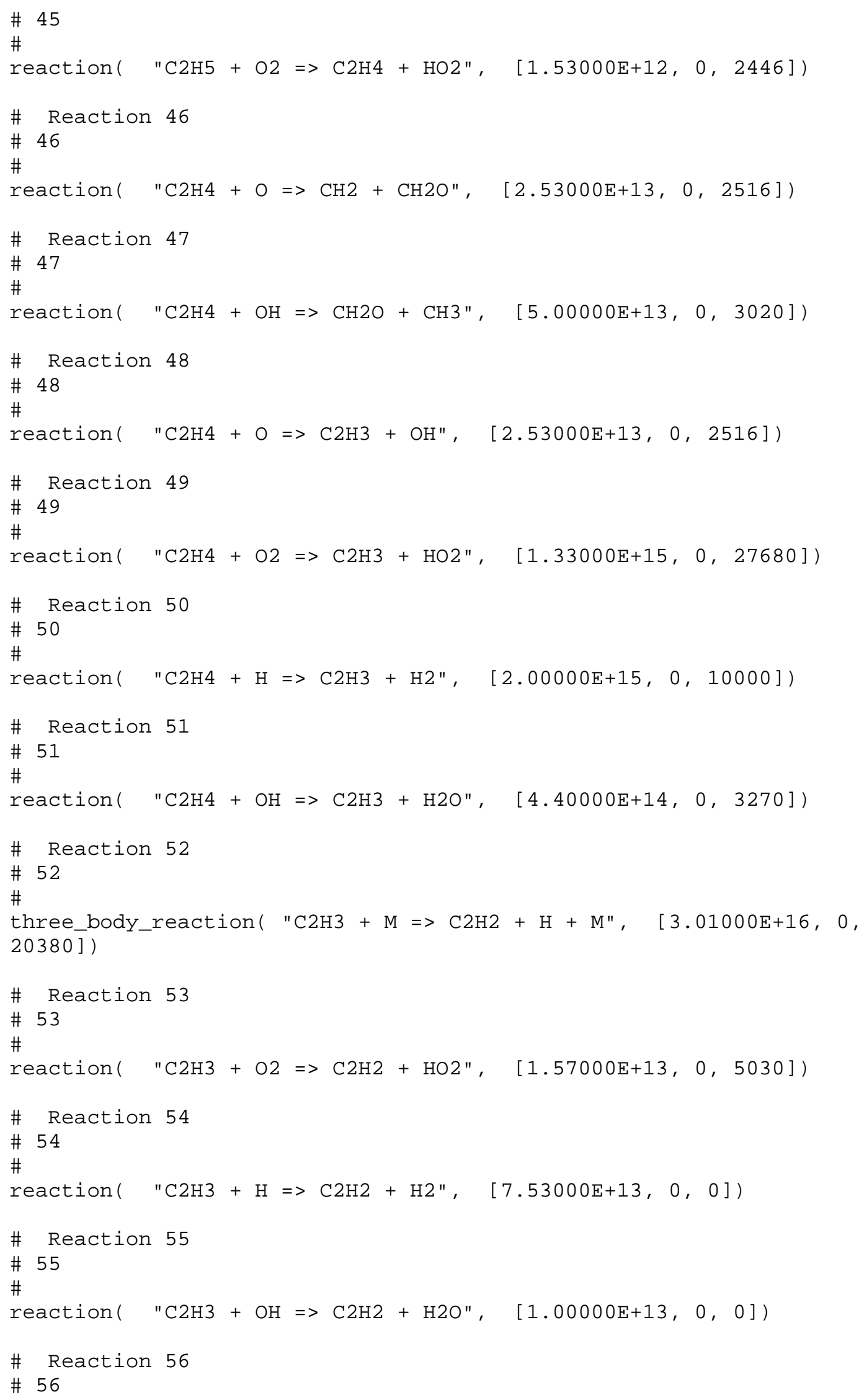




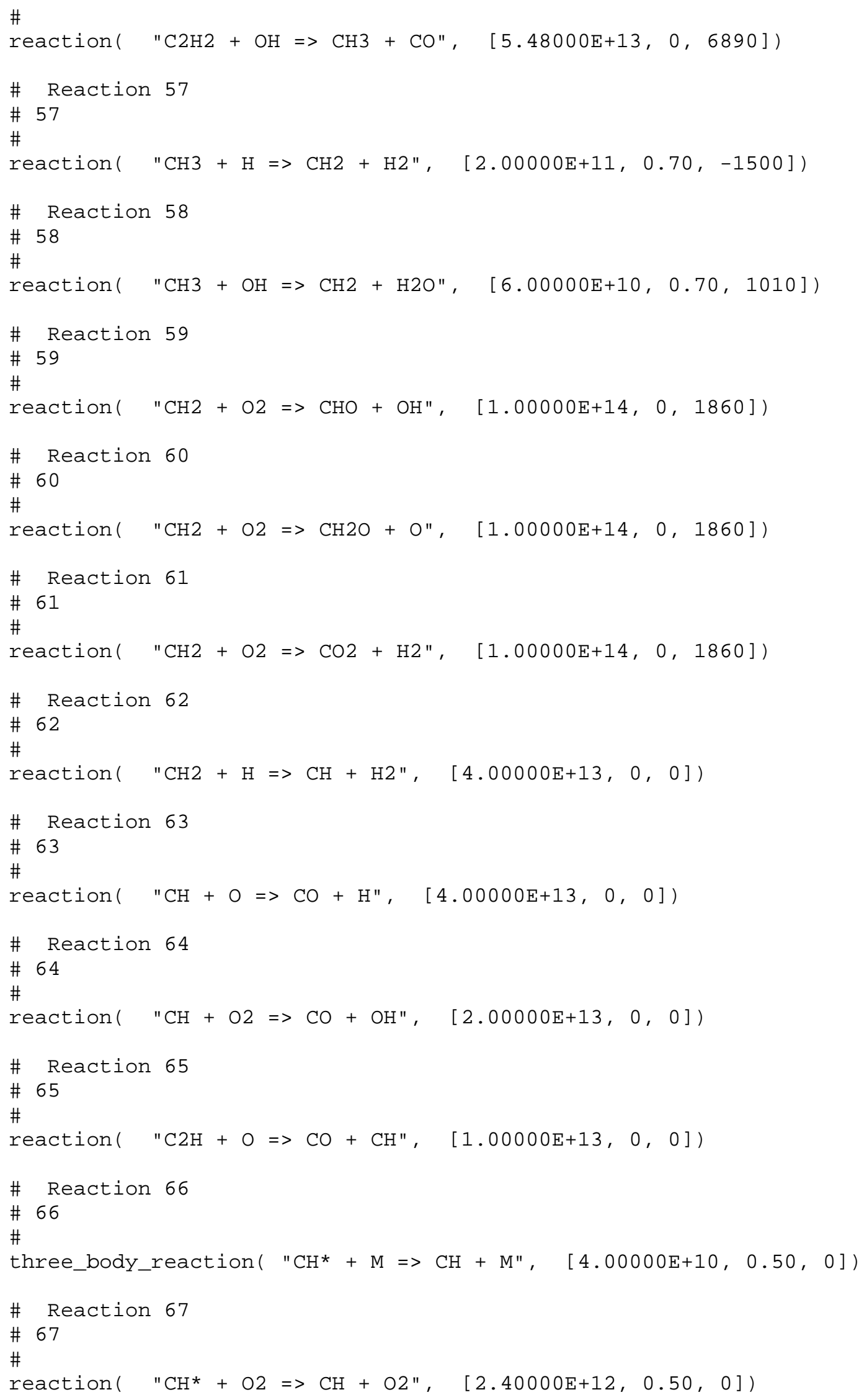




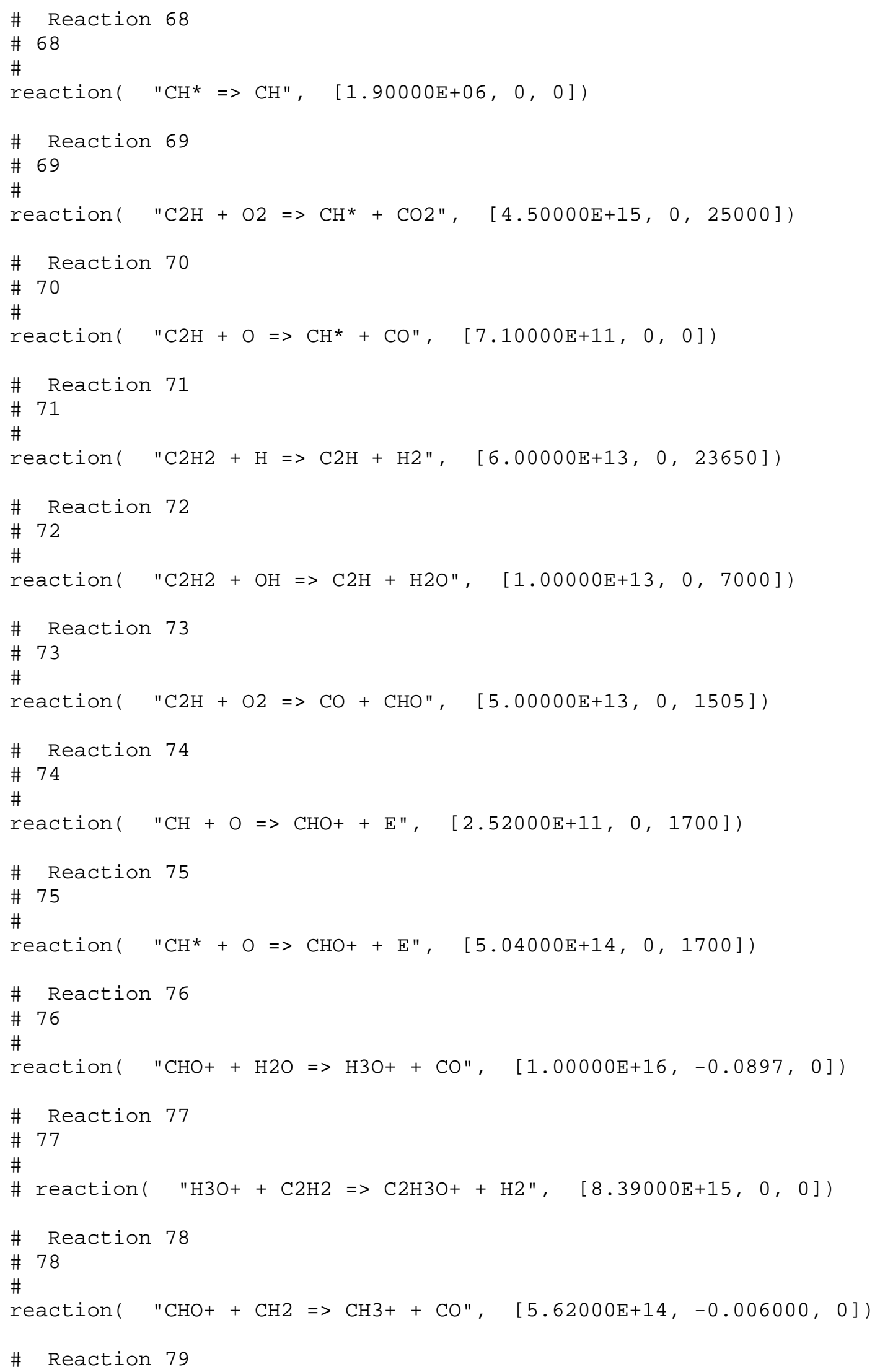




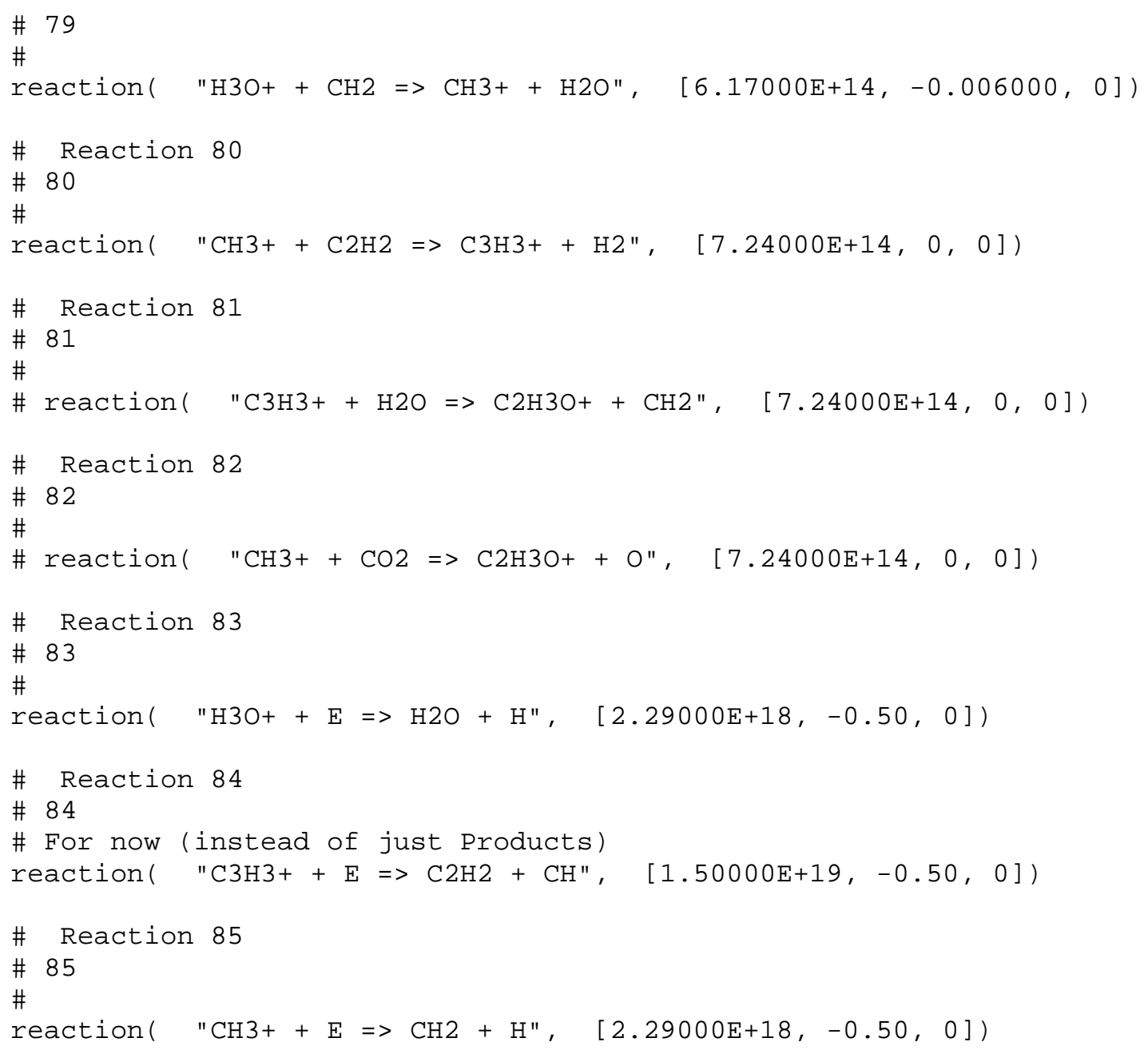




\section{B-4: Listing of Peters Mechanism}

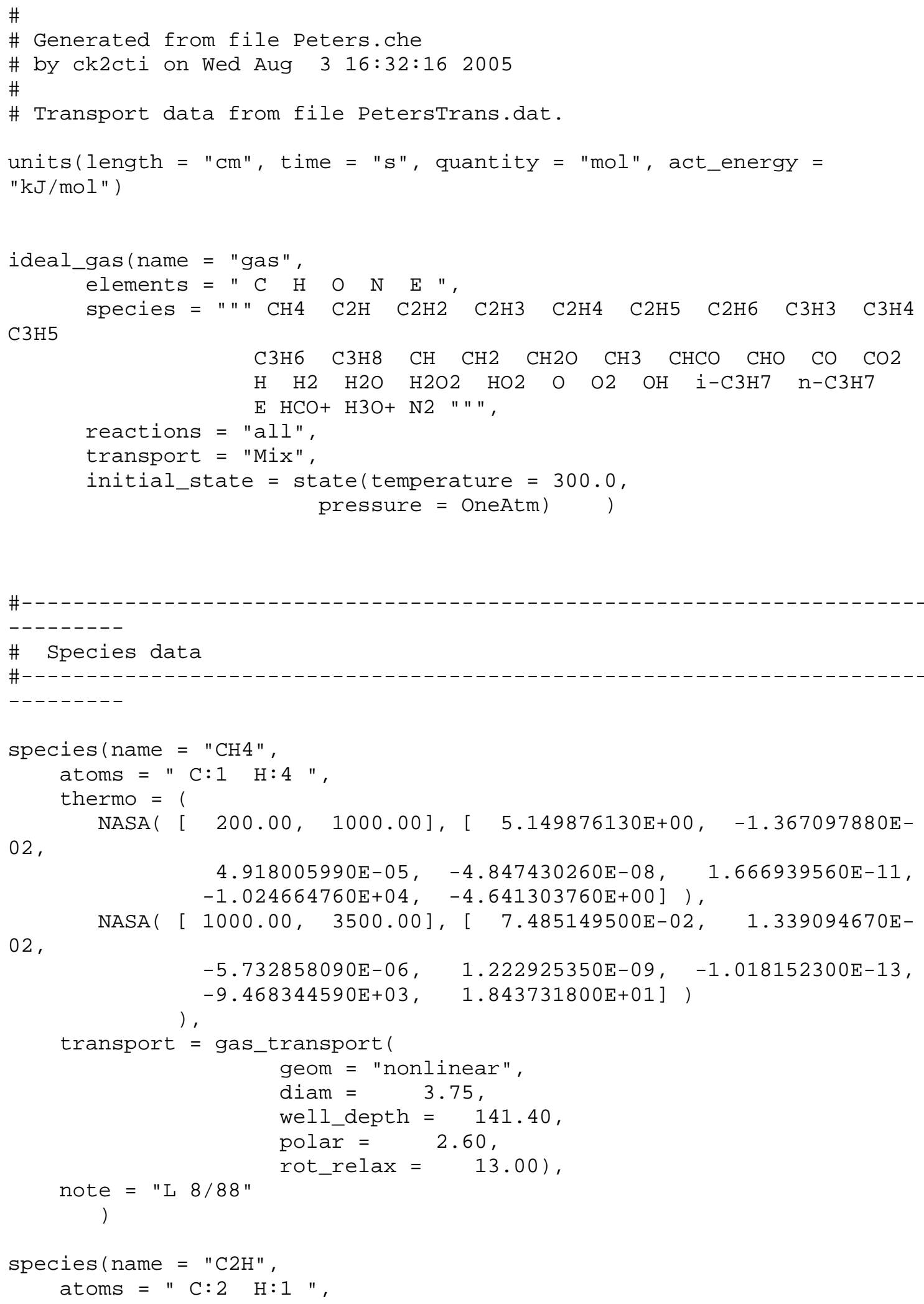




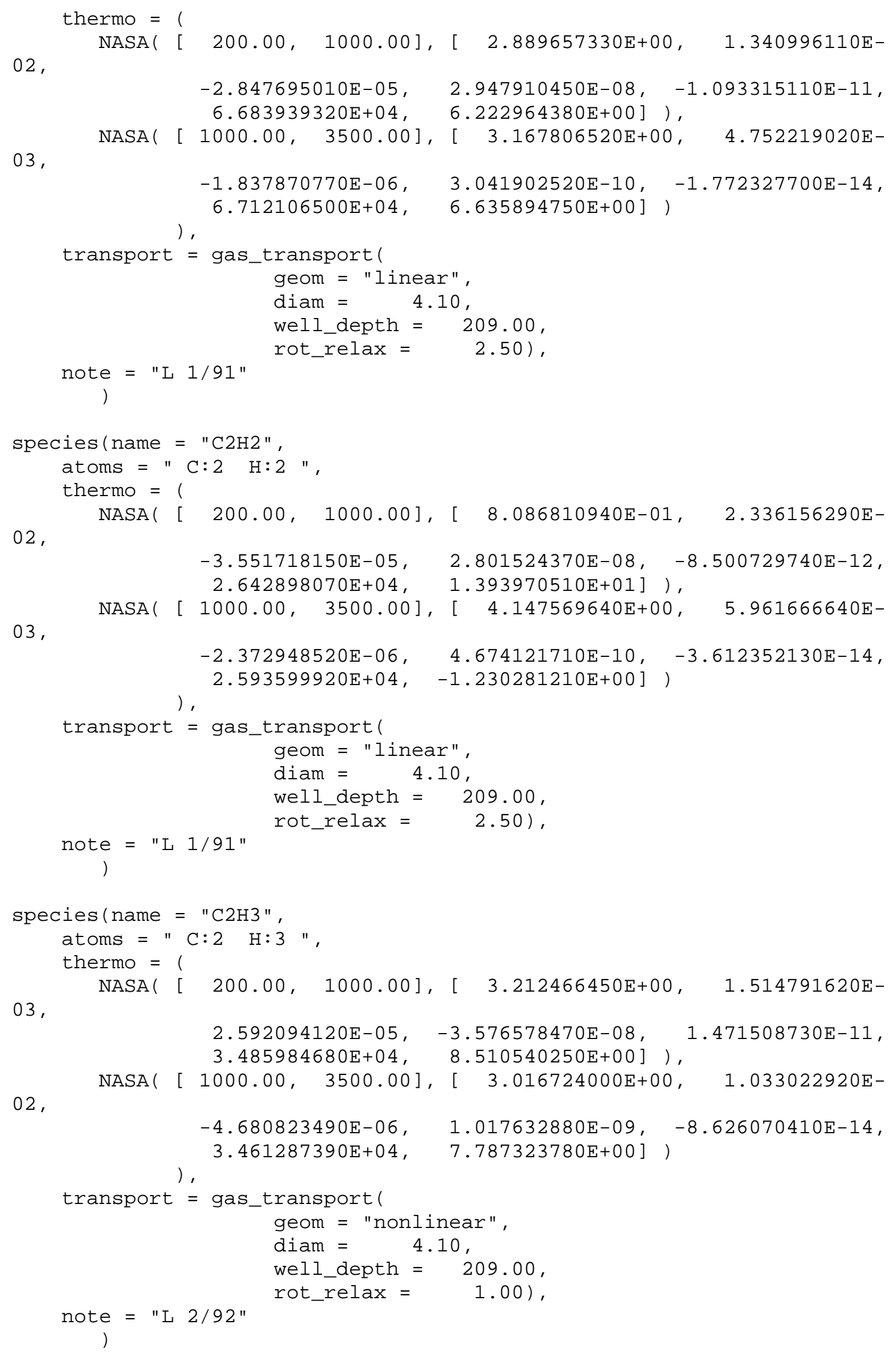




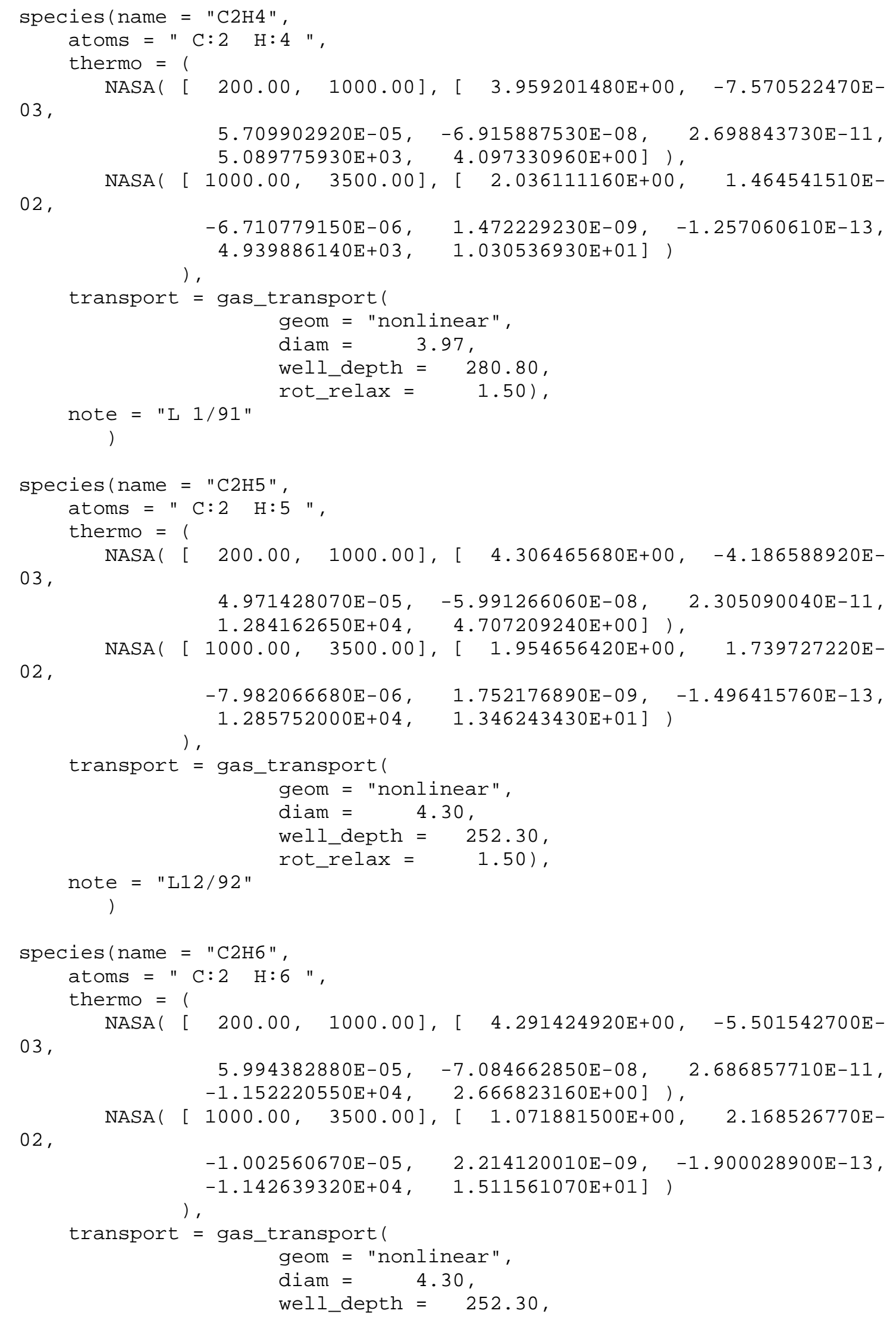




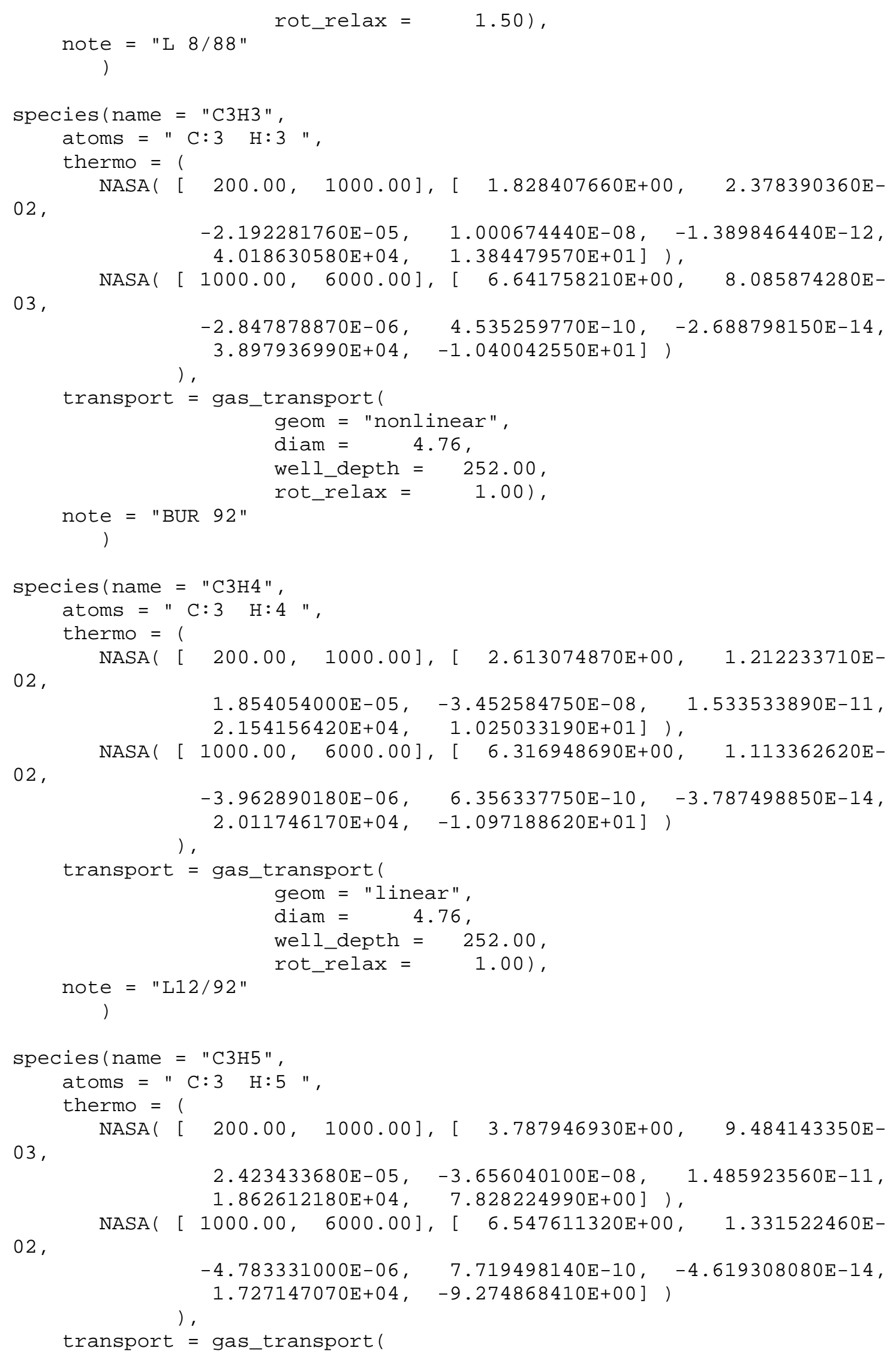




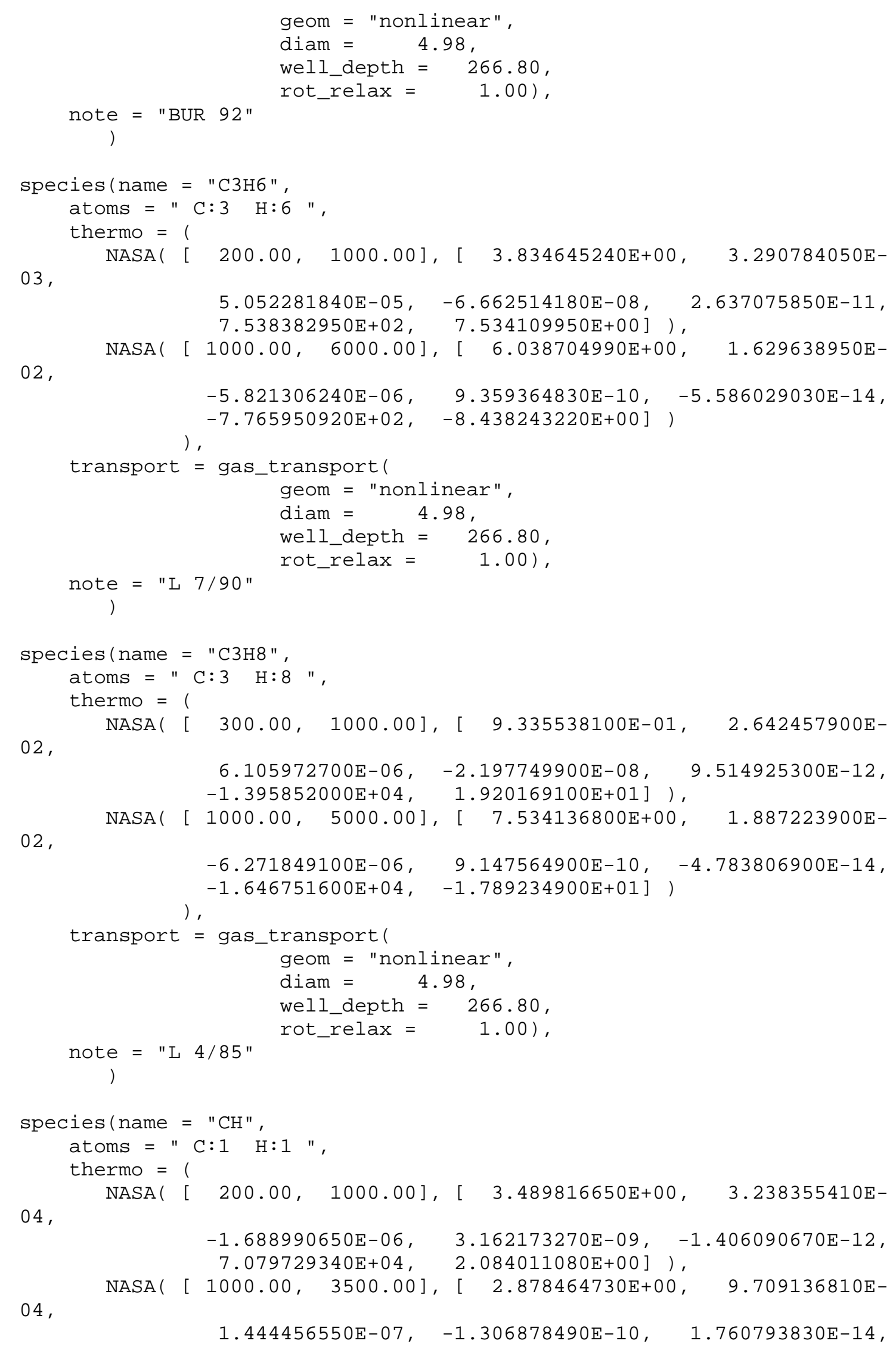




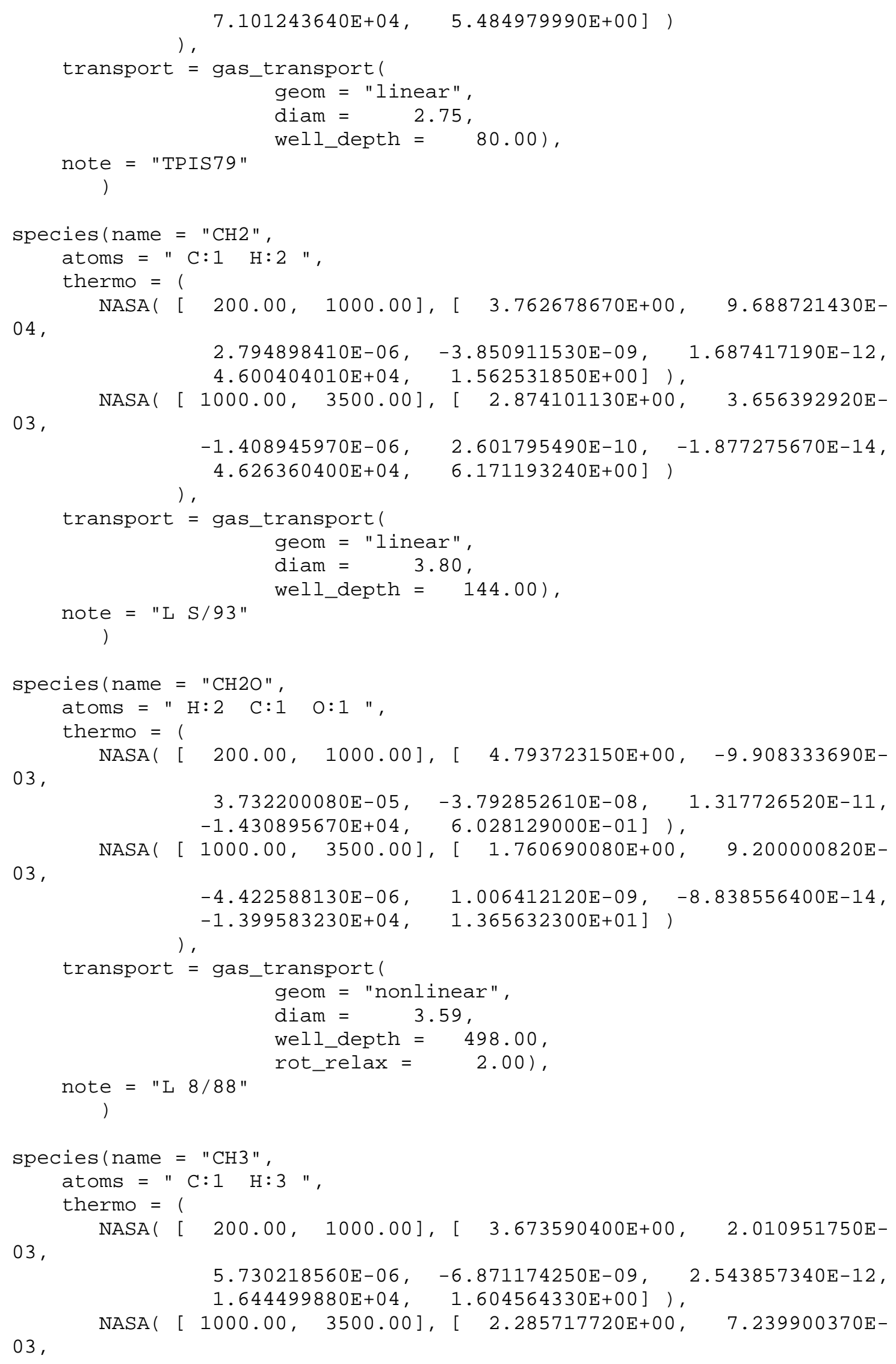




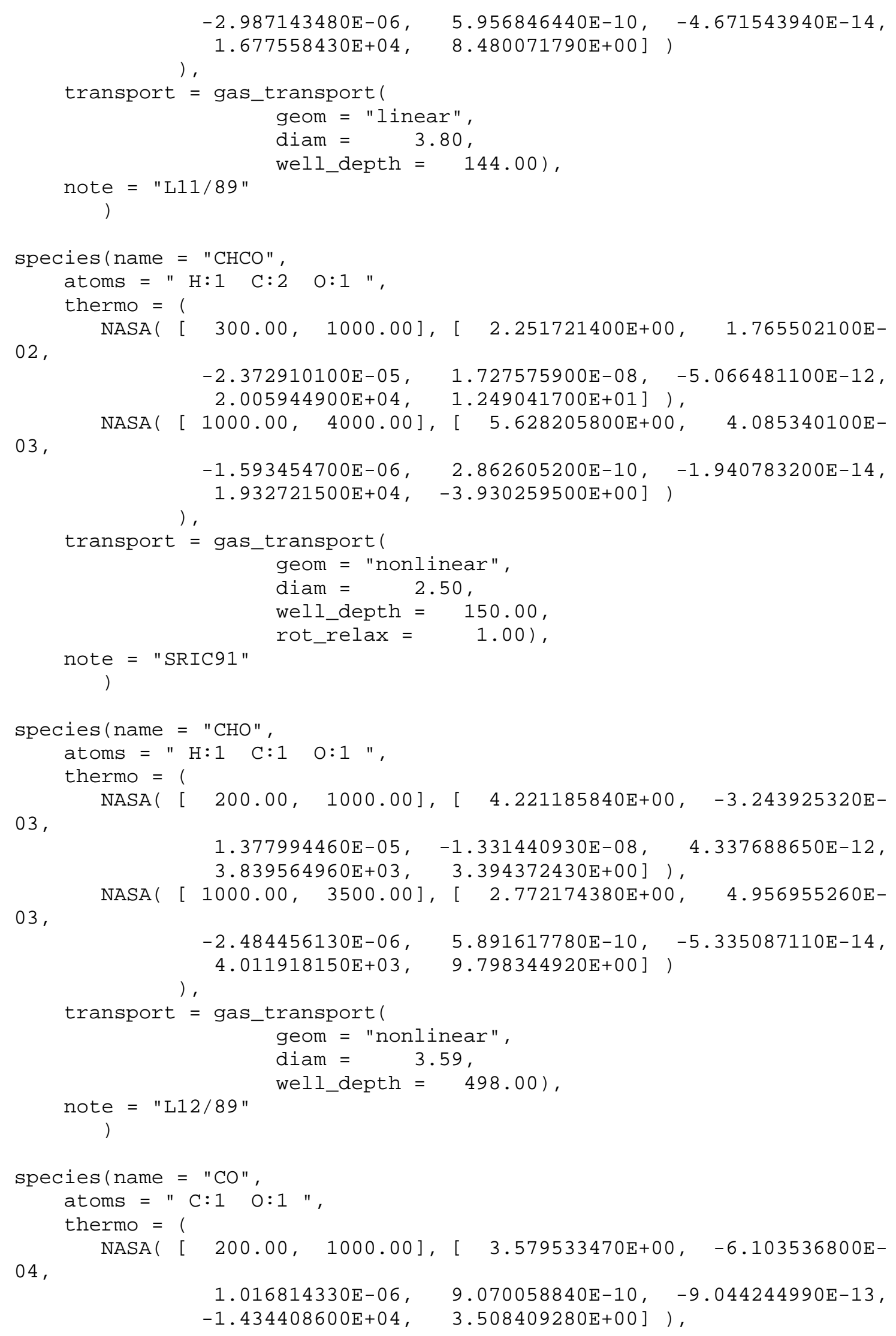




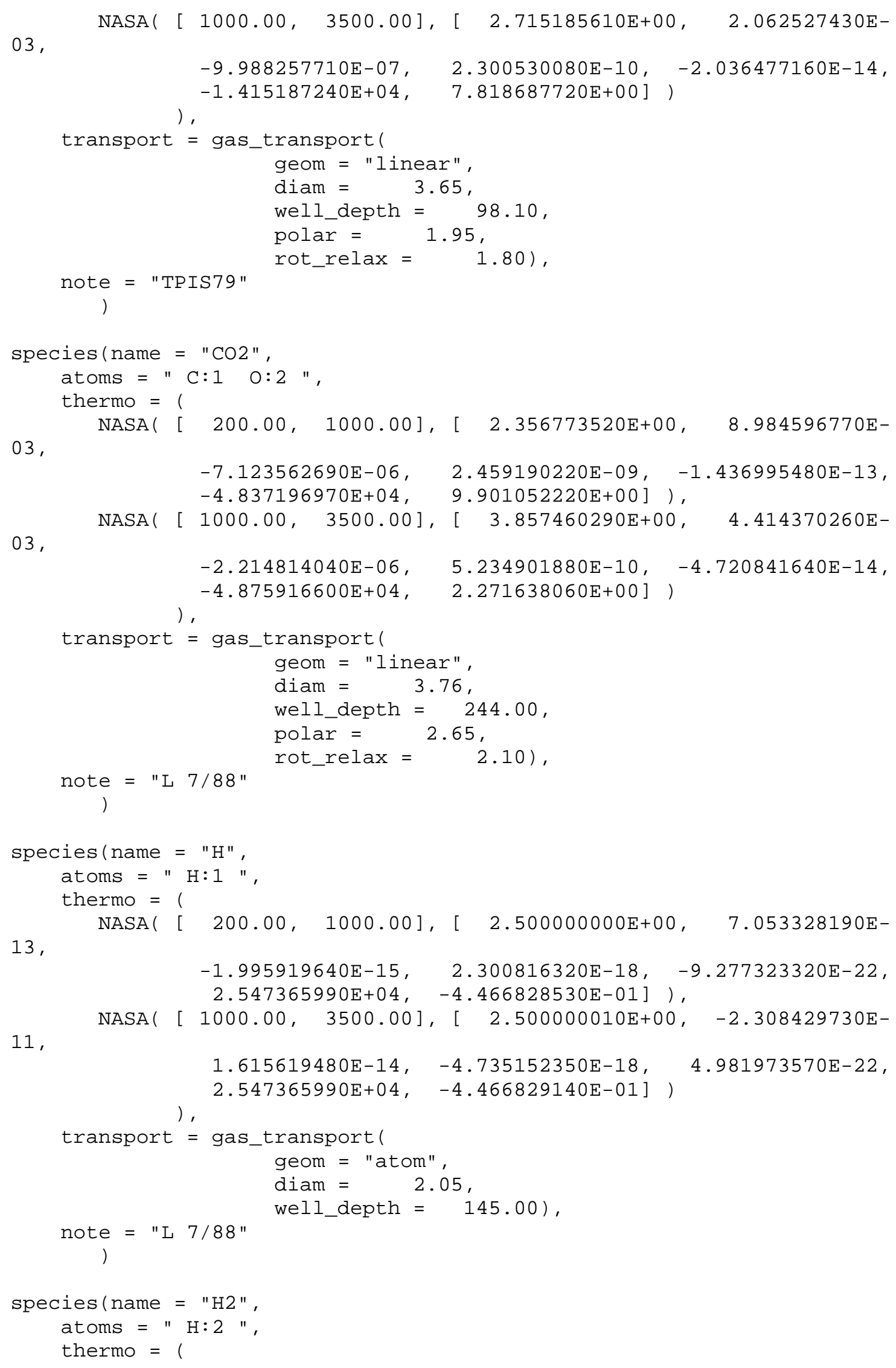




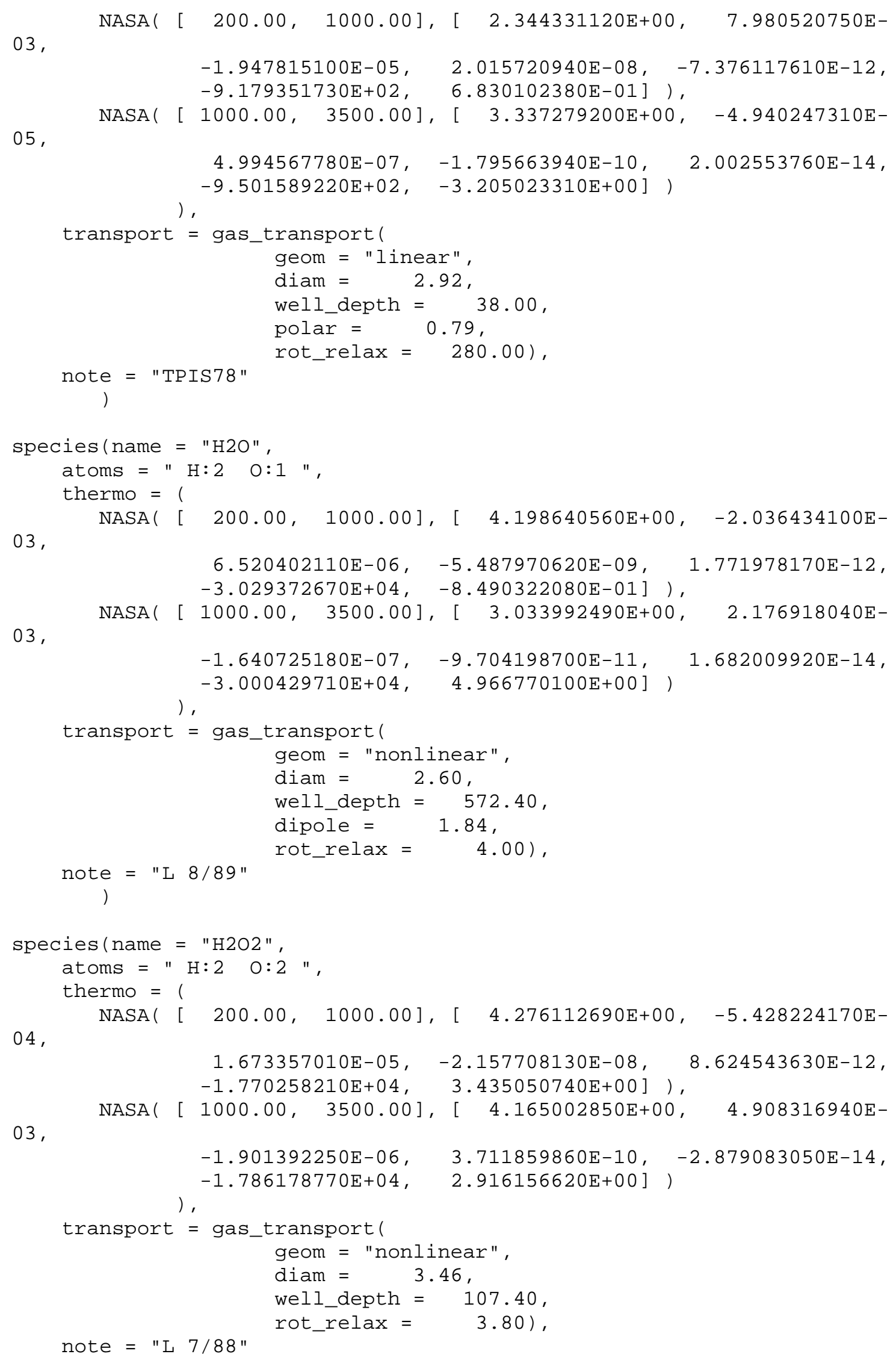




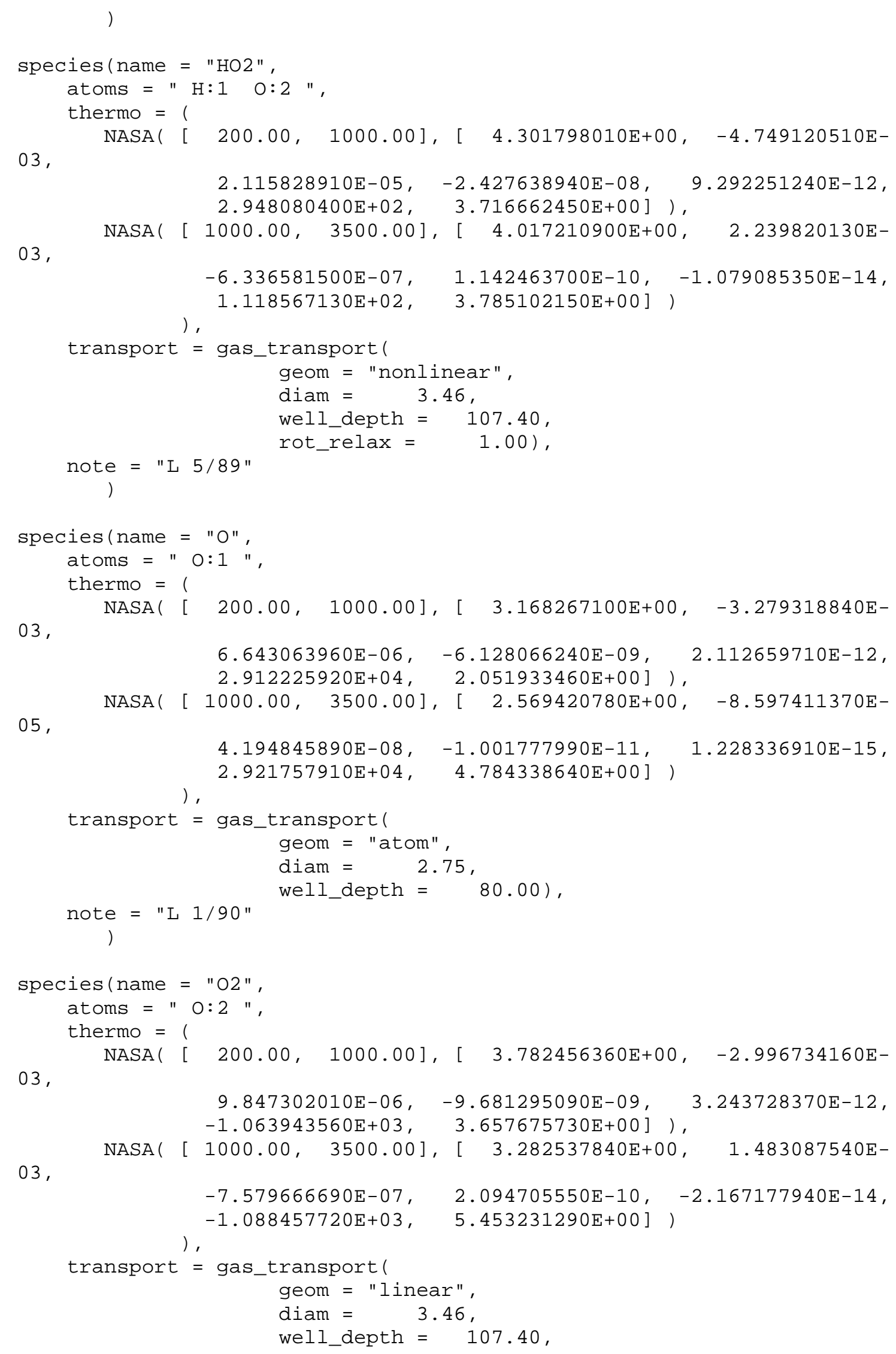




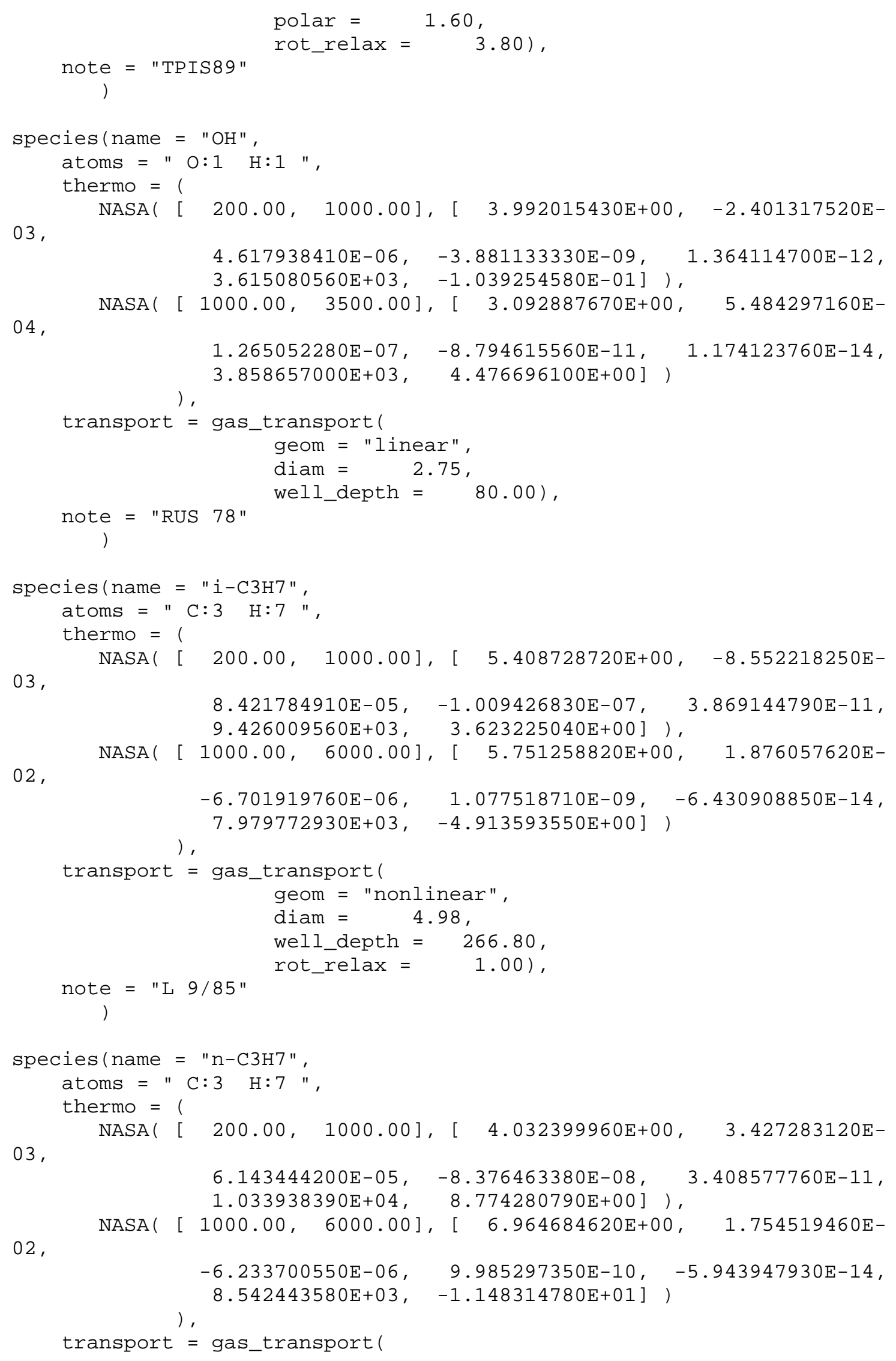




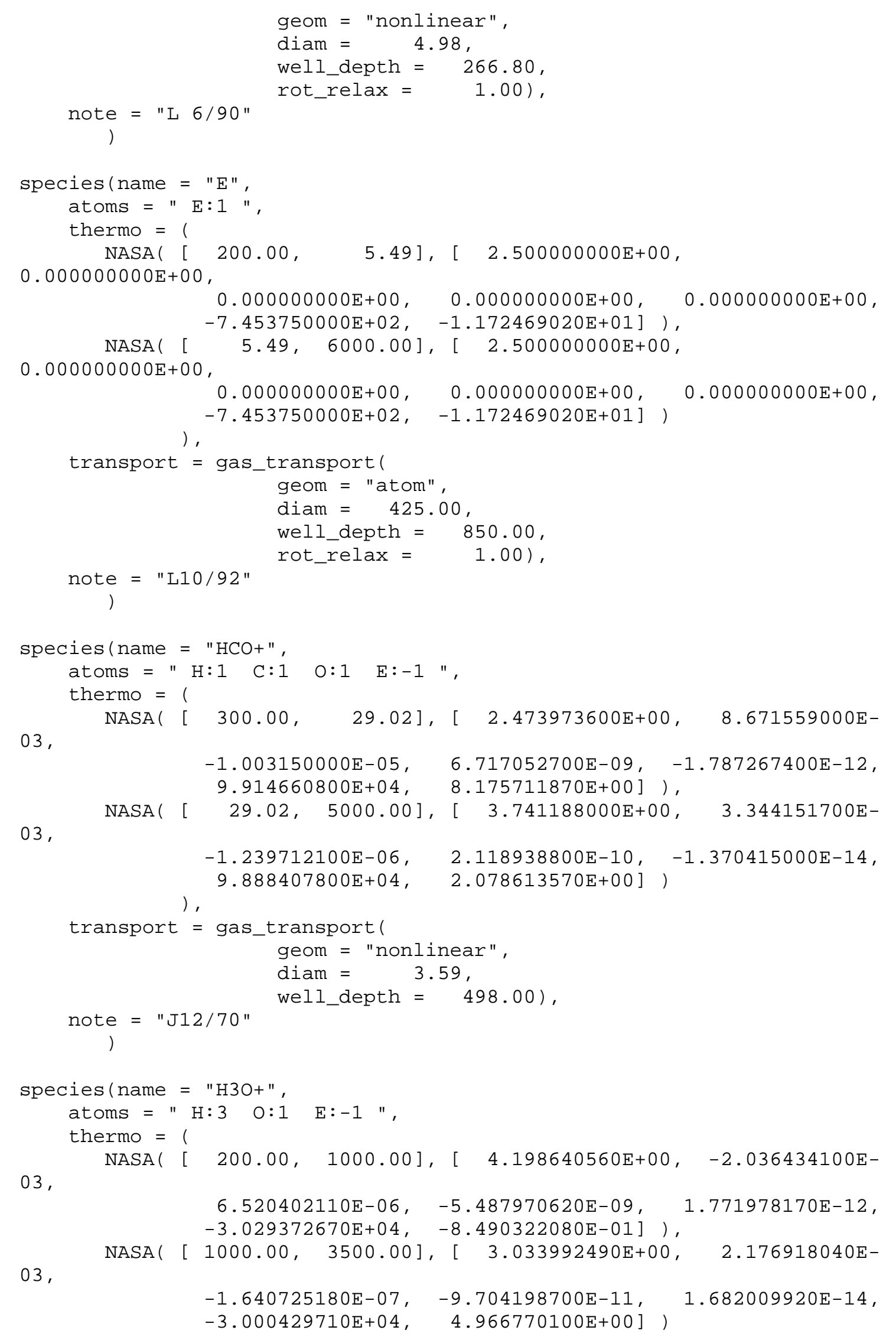




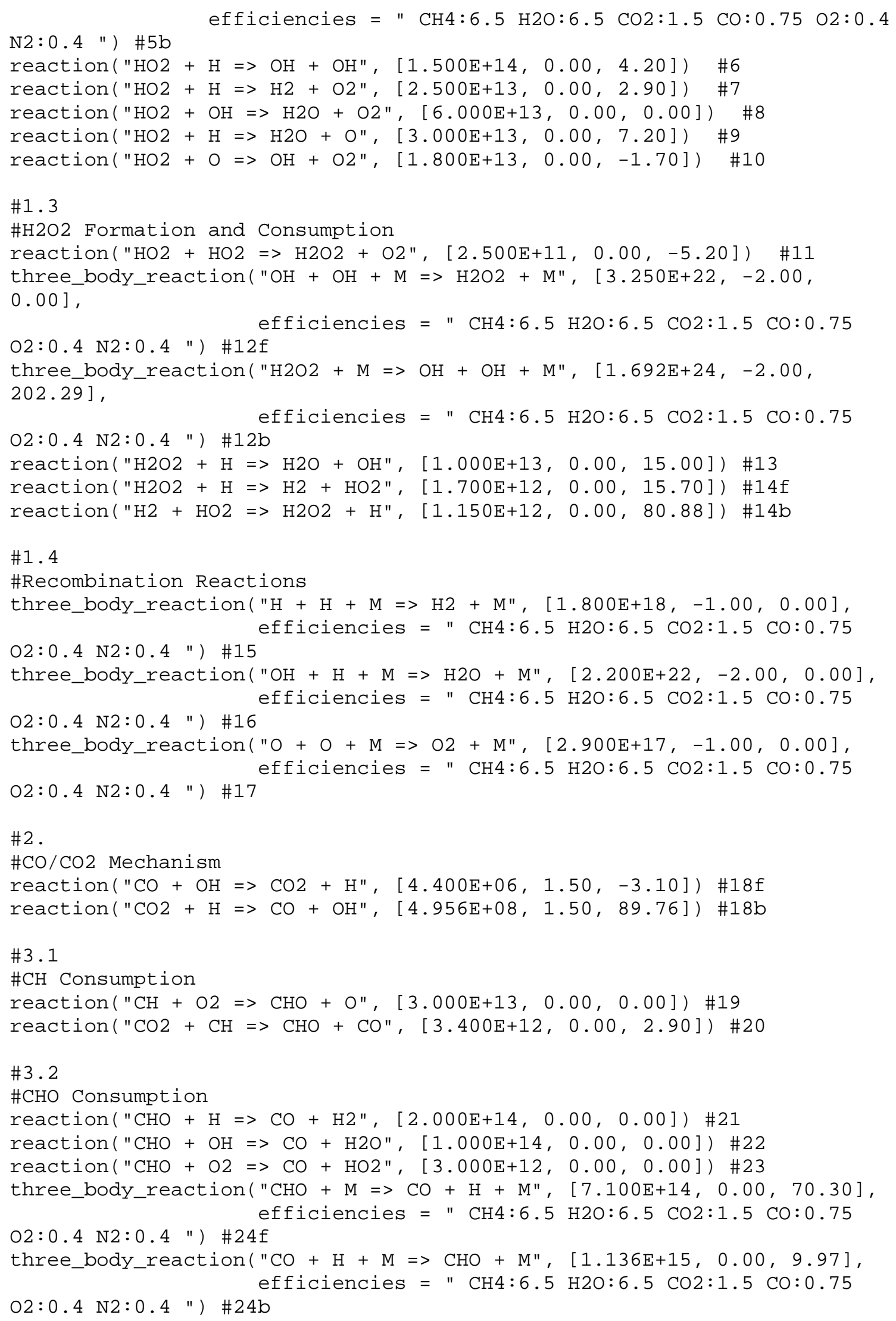




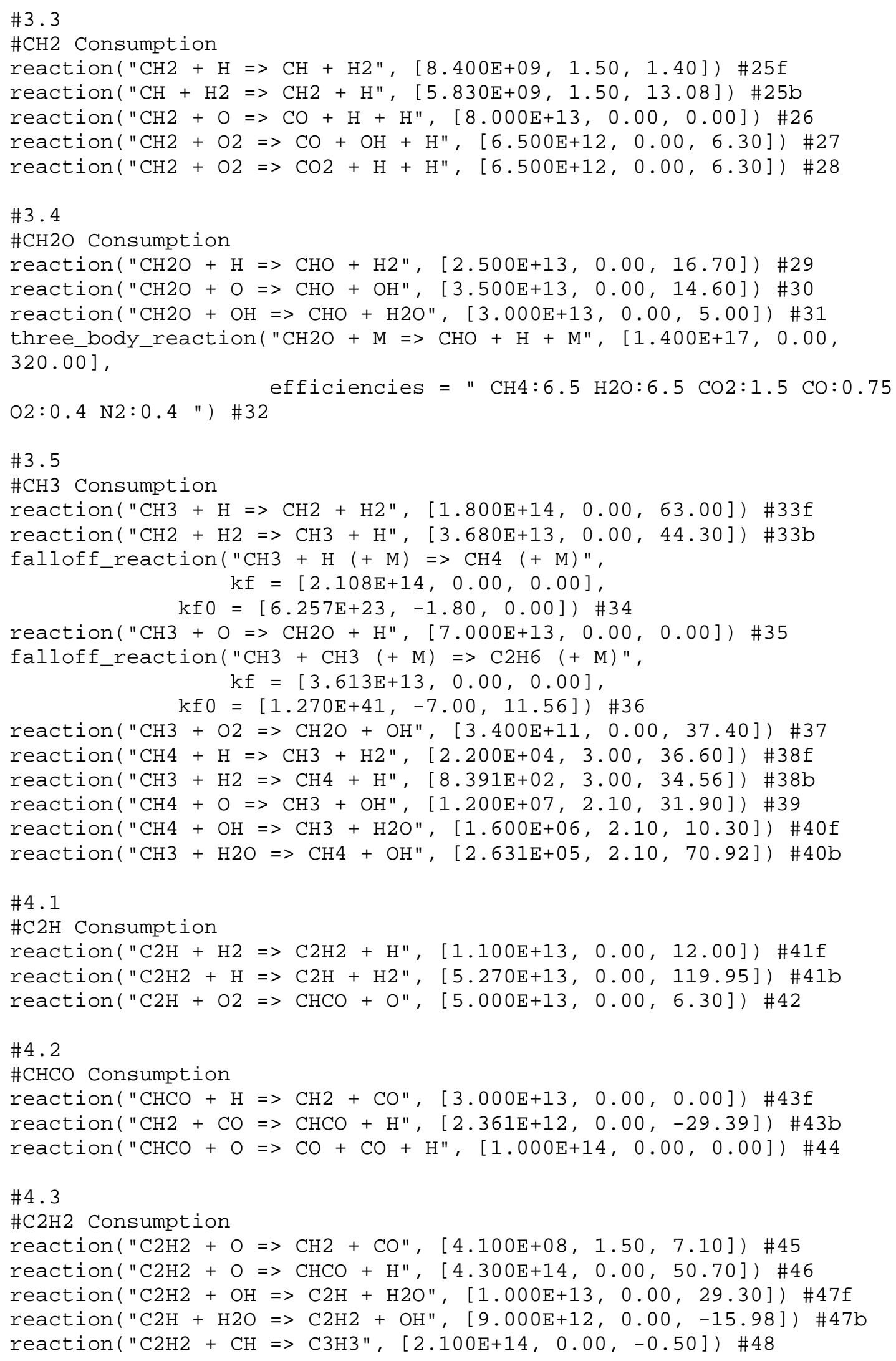




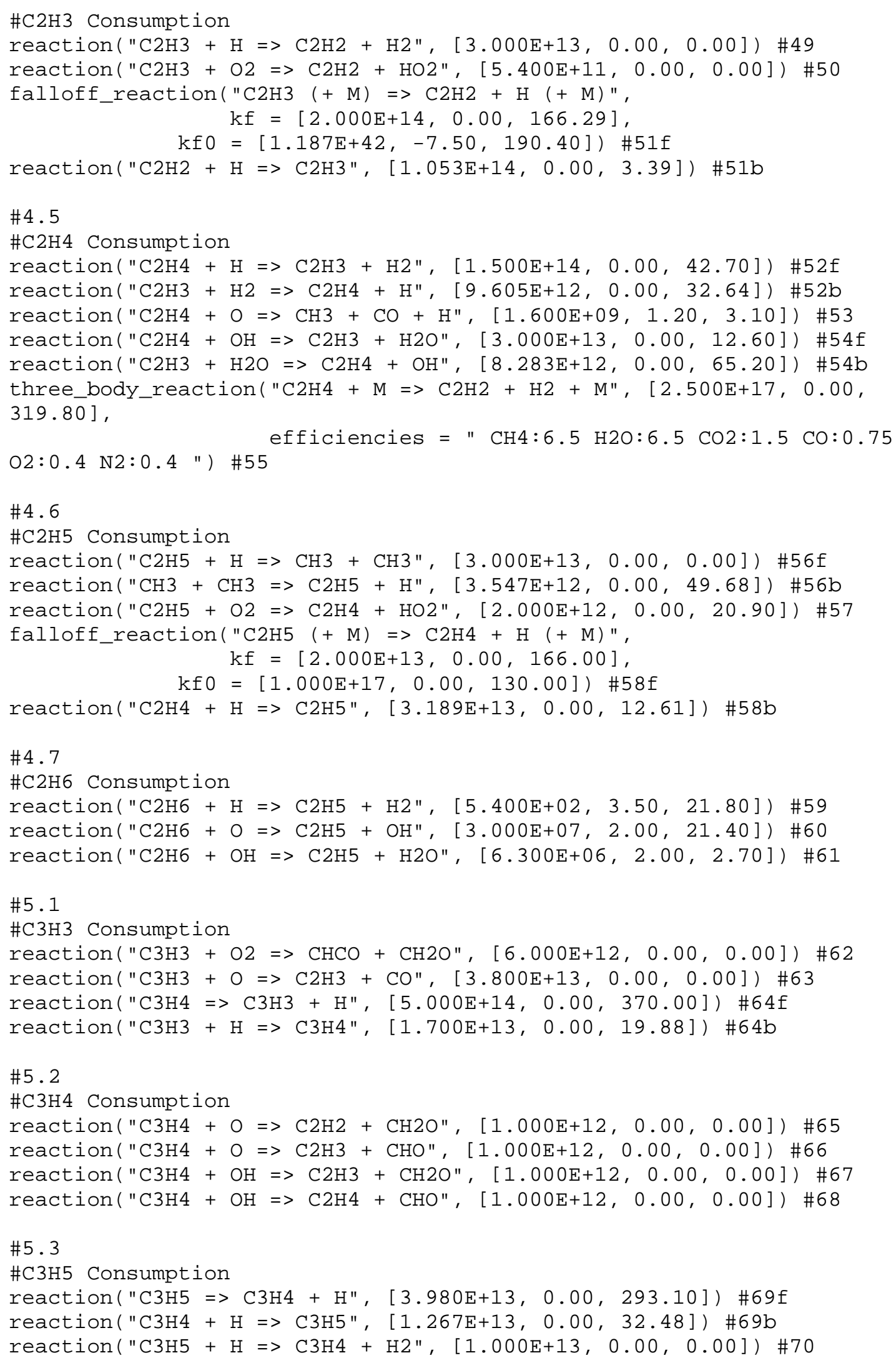




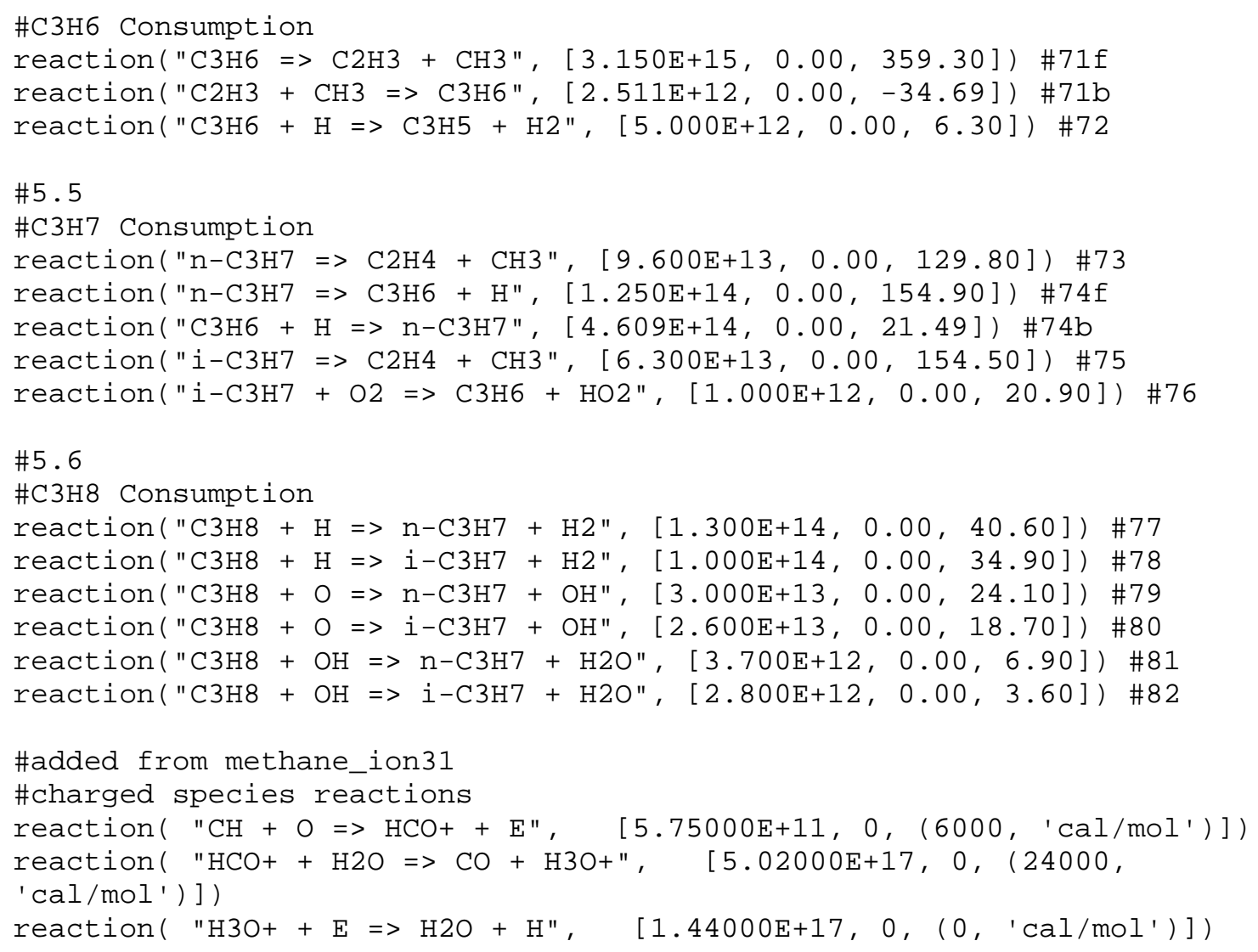




\section{Appendix C: Utility Codes}

\section{C-1: nameParse}

Description:

The nameParse class is used to store essential information about a specific set of modeling results within a result file's name in a standardized format. This information includes the flow rates of each gas within the premixed flame in addition to the applied voltage across the modeled flame.

The nameParse class uses a separate filename format for methane and synthesis gas flames. In each filename format, labels are used prior to each stored attribute, and this label is separated by the corresponding value by an underscore. Examples of generated filenames are shown in the following figures for each type of fuel, and a table is given after each figure stating the meaning of each label.

V_0.0_mtot_0.00027051509604_mair_0.00025858_mfuel_1.193509604e-05.xml

Figure C-1: Example of Filename for a Methane Flame Model Output File

\begin{tabular}{|c|l|}
\hline Label & \multicolumn{1}{c|}{ Meaning } \\
\hline V & Applied Voltage Across the Modeled Flame Object \\
\hline mtot & Total Mass Flux Through the Burner \\
\hline mair & Mass Flux of Air Through the Burner \\
\hline mfuel & Mass Flux of Methane Through the Burner \\
\hline
\end{tabular}

Table C-1: List of Filename Labels for Methane Flame Model Output Files

V 0.0 mtot 0.000230085693251 mair 0.000197160766326 mCO 2.358678636

$1 \overline{\mathrm{e}}-0 \overline{5} \_\mathrm{mH} 2 \overline{2}-1.3724605293 \mathrm{e}-06 \_\overline{\mathrm{mN}} 2 \_-7.5285255675 \mathrm{e}-$

06_mCH4_4.37154466667e-07.xml

Figure C-2: Example of Filename for a Synthesis Gas Flame Model Output File 


\begin{tabular}{|c|l|}
\hline Label & \multicolumn{1}{|c|}{ Meaning } \\
\hline $\mathrm{V}$ & Voltage Applied Across the Modeled Flame Object \\
\hline mtot & Total Mass Flux Through the Burner \\
\hline mair & Mass Flux of Air Through the Burner \\
\hline $\mathrm{mCO}$ & Mass Flux of Carbon Monoxide Through the Burner \\
\hline $\mathrm{mH} 2$ & Mass Flux of Hydrogen Gas Through the Burner \\
\hline $\mathrm{mN} 2$ & $\begin{array}{l}\text { Mass Flux of Nitrogen Gas Through the Burner Separate } \\
\text { From Nitrogen in Air }\end{array}$ \\
\hline $\mathrm{mCH} 4$ & Mass Flux of Methane Through the Burner \\
\hline
\end{tabular}

Table C-2: List of Filename Labels for Synthesis Gas Flame Model Output Files

Code Overview:

The nameParse script contains a set of functions to generate a filename based on given flow rates and also to retrieve information about flow rates from an existing filename. In addition a set of "constants" are included within the script, but these values may be changed by the user. The following tables give explanation of constants and functions included within the nameParse code.

\begin{tabular}{|l|c|l|}
\hline \multicolumn{1}{|c|}{ Name } & Value & \multicolumn{1}{c|}{ Description } \\
\hline N2_PERCENT & 0.76708 & Nitrogen gas percent by weight in air. \\
\hline O2_PERCENT & 0.23292 & Oxygen percent by weight in air. \\
\hline MW_O2 & 31.9998 & Molecular weight of oxygen molecule \\
\hline MW_N2 & 28.0134 & Molecular weight of nitrogen molecule \\
\hline MW_FUEL & 16.13782 & Molecular weight of methane based fuel \\
\hline MW_CO & 28.0101 & Molecular weight of carbon monoxide \\
\hline MW_H2 & 2.01588 & Molecular weight of hydrogen gas \\
\hline MW_CH4 & 16.04246 & Molecular weight of methane \\
\hline
\end{tabular}

Table C-3: Table of Constant Values Included in the nameParse Class 


\begin{tabular}{|c|c|c|c|c|}
\hline Function & Purpose & Inputs & Outputs & Description \\
\hline \multirow[t]{5}{*}{ createNameMethane } & \multirow{5}{*}{$\begin{array}{l}\text { Create a filename } \\
\text { for a methane } \\
\text { flame model output } \\
\text { file }\end{array}$} & m_dot_total & & $\begin{array}{l}\text { Total mass flux at the } \\
\text { burner. }\end{array}$ \\
\hline & & m_dot_air & & $\begin{array}{l}\text { Mass flux of air at the } \\
\text { burner }\end{array}$ \\
\hline & & m_dot_fuel & & $\begin{array}{l}\text { Total mass flux of } \\
\text { methane at the burner }\end{array}$ \\
\hline & & applied_voltage & & $\begin{array}{l}\text { Voltage applied across } \\
\text { the model flame }\end{array}$ \\
\hline & & & ret_str & $\begin{array}{l}\text { Assembled filename for } \\
\text { modeled flame output }\end{array}$ \\
\hline \multirow[t]{7}{*}{ createNameSyngas } & \multirow{7}{*}{$\begin{array}{l}\text { Create a filename } \\
\text { for a synthesis gas } \\
\text { flame model output } \\
\text { file }\end{array}$} & m_dot_total & & $\begin{array}{l}\text { Total mass flux at the } \\
\text { burner. }\end{array}$ \\
\hline & & m_dot_air & & $\begin{array}{l}\text { Mass flux of air at the } \\
\text { burner }\end{array}$ \\
\hline & & m_dot_co & & $\begin{array}{l}\text { Mass flux of carbon } \\
\text { monoxide at the burner }\end{array}$ \\
\hline & & m_dot_h2 & & $\begin{array}{l}\text { Mass flux of hydrogen } \\
\text { gas at the burner }\end{array}$ \\
\hline & & m_dot_n2 & & $\begin{array}{l}\text { Mass flux of nitrogen gas } \\
\text { at the burner }\end{array}$ \\
\hline & & m_dot_ch4 & & $\begin{array}{l}\text { Mass flux of methane at } \\
\text { the burner }\end{array}$ \\
\hline & & & ret_str & $\begin{array}{l}\text { Assembled filename for } \\
\text { modeled flame output }\end{array}$ \\
\hline retrieveNameInfo & $\begin{array}{l}\text { Used internally by } \\
\text { the nameParse } \\
\text { class to retrieve all } \\
\text { information } \\
\text { contained within an } \\
\text { input filename } \\
\text { originally created } \\
\text { by the nameParse } \\
\text { class }\end{array}$ & filename & & $\begin{array}{l}\text { The name of the file for } \\
\text { which modeling } \\
\text { properties are to be } \\
\text { retrieved. }\end{array}$ \\
\hline \multirow[t]{2}{*}{ getAirFlux } & \multirow{2}{*}{$\begin{array}{l}\text { Retrieves the air } \\
\text { flux from a } \\
\text { filename created } \\
\text { using the } \\
\text { nameParse class }\end{array}$} & filename & & $\begin{array}{l}\text { The name of the file } \\
\text { from which to retrieve } \\
\text { the air flux }\end{array}$ \\
\hline & & & air_flux & $\begin{array}{l}\text { The mass flux of air at } \\
\text { the burner }\end{array}$ \\
\hline \multirow[t]{2}{*}{ getExtention } & \multirow[t]{2}{*}{$\begin{array}{l}\text { Retrieves the file } \\
\text { extension for the } \\
\text { input filename }\end{array}$} & filename & & $\begin{array}{l}\text { The name of the file } \\
\text { from which to retrieve } \\
\text { the file extension }\end{array}$ \\
\hline & & & ext & $\begin{array}{l}\text { The file extension } \\
\text { included in the input file }\end{array}$ \\
\hline \multirow[t]{2}{*}{ getFuelFlux } & \multirow{2}{*}{$\begin{array}{l}\text { Retrieves the } \\
\text { methane flux at the } \\
\text { burner for a } \\
\text { methane flame } \\
\text { model }\end{array}$} & filename & & $\begin{array}{l}\text { The name of the file } \\
\text { from which to retrieve } \\
\text { the methane fuel flux }\end{array}$ \\
\hline & & & fuel_flux & $\begin{array}{l}\text { The mass flux of } \\
\text { methane fuel at the } \\
\text { burner for methane flame } \\
\text { models }\end{array}$ \\
\hline getCOFlux & $\begin{array}{l}\text { Retrieves the } \\
\text { carbon monoxide }\end{array}$ & filename & & $\begin{array}{l}\text { The name of the file } \\
\text { from which to retrieve }\end{array}$ \\
\hline
\end{tabular}




\begin{tabular}{|c|c|c|c|c|}
\hline & \multirow{2}{*}{$\begin{array}{l}\text { flux at the burner } \\
\text { for a synthesis gas } \\
\text { flame model }\end{array}$} & & & $\begin{array}{l}\text { the carbon monoxide } \\
\text { flux }\end{array}$ \\
\hline & & & co_flux & $\begin{array}{l}\text { The mass flux of carbon } \\
\text { monoxide at the burner } \\
\text { in synthesis gas flame } \\
\text { models }\end{array}$ \\
\hline \multirow[t]{2}{*}{ getH2Flux } & \multirow{2}{*}{$\begin{array}{l}\text { Retrieves the } \\
\text { hydrogen gas flux } \\
\text { at the burner for a } \\
\text { synthesis gas flame } \\
\text { model }\end{array}$} & filename & & $\begin{array}{l}\text { The name of the file } \\
\text { from which to retrieve } \\
\text { the hydrogen gas flux }\end{array}$ \\
\hline & & & h2_flux & $\begin{array}{l}\text { The mass flux of } \\
\text { hydrogen gas at the } \\
\text { burner in synthesis gas } \\
\text { flame models }\end{array}$ \\
\hline \multirow[t]{2}{*}{ getN2Flux } & \multirow{2}{*}{$\begin{array}{l}\text { Retrieves the } \\
\text { nitrogen gas flux } \\
\text { not including } \\
\text { nitrogen from air at } \\
\text { the burner for a } \\
\text { synthesis gas flame } \\
\text { model }\end{array}$} & filename & & $\begin{array}{l}\text { The name of the file } \\
\text { from which to retrieve } \\
\text { the nitrogen gas flux }\end{array}$ \\
\hline & & & n2_flux & $\begin{array}{l}\text { The mass flux of } \\
\text { nitrogen gas not included } \\
\text { with air at the burner in } \\
\text { synthesis gas flame } \\
\text { models }\end{array}$ \\
\hline \multirow[t]{2}{*}{ getCH4Flux } & \multirow{2}{*}{$\begin{array}{l}\text { Retrieves the } \\
\text { methane flux at the } \\
\text { burner for a } \\
\text { synthesis gas flame } \\
\text { model }\end{array}$} & filename & & $\begin{array}{l}\text { The name of the file } \\
\text { from which to retrieve } \\
\text { the methane flux }\end{array}$ \\
\hline & & & ch4_flux & $\begin{array}{l}\text { The mass flux of } \\
\text { methane at the burner in } \\
\text { synthesis gas flame } \\
\text { models }\end{array}$ \\
\hline \multirow[t]{2}{*}{ getTotalFlux } & \multirow[t]{2}{*}{$\begin{array}{l}\text { Retrieves the total } \\
\text { flux at the burner } \\
\text { for a flame model }\end{array}$} & filename & & $\begin{array}{l}\text { The name of the file } \\
\text { from which to retrieve } \\
\text { the total flux }\end{array}$ \\
\hline & & & total_flux & $\begin{array}{l}\text { The total mass flux at the } \\
\text { burner }\end{array}$ \\
\hline \multirow[t]{2}{*}{ getVoltage } & \multirow{2}{*}{$\begin{array}{l}\text { Retrieves the } \\
\text { voltage applied } \\
\text { across a modeled } \\
\text { flame }\end{array}$} & filename & & $\begin{array}{l}\text { The name of the file } \\
\text { from which to retrieve } \\
\text { the voltage }\end{array}$ \\
\hline & & & voltage & $\begin{array}{l}\text { The applied voltage } \\
\text { across the modeled flame }\end{array}$ \\
\hline \multirow[t]{2}{*}{ getMoleComposition } & \multirow{2}{*}{$\begin{array}{l}\text { Creates a formatted } \\
\text { string containing } \\
\text { the mole fractions } \\
\text { of each species at } \\
\text { the burner }\end{array}$} & filename & & $\begin{array}{l}\text { The name of the file } \\
\text { from which to retrieve } \\
\text { the molar composition }\end{array}$ \\
\hline & & & ret_str & $\begin{array}{l}\text { A formatted string } \\
\text { containing the names of } \\
\text { species input at the } \\
\text { burner of the modeled } \\
\text { flame and the } \\
\text { corresponding mole } \\
\text { fractions for each species }\end{array}$ \\
\hline \multirow[t]{2}{*}{ getMassComposition } & \multirow{2}{*}{$\begin{array}{l}\text { Creates a formatted } \\
\text { string containing } \\
\text { the mass fractions } \\
\text { of each species at } \\
\text { the burner }\end{array}$} & filename & & $\begin{array}{l}\text { The name of the file } \\
\text { from which to retrieve } \\
\text { the mass composition }\end{array}$ \\
\hline & & & ret_str & $\begin{array}{l}\text { A formatted string } \\
\text { containing the names of } \\
\text { species input at the } \\
\text { burner of the modeled }\end{array}$ \\
\hline
\end{tabular}




\begin{tabular}{|l|l|l|l|l|}
\hline & & & $\begin{array}{l}\text { flame and the } \\
\text { corresponding mass } \\
\text { fractions for each species }\end{array}$ \\
\hline isValidFile & $\begin{array}{l}\text { Determines if a } \\
\text { given filename } \\
\text { conforms to the } \\
\text { format used by } \\
\text { nameParse }\end{array}$ & filename & $\begin{array}{l}\text { The name of the file to } \\
\text { check for validity }\end{array}$ \\
\cline { 2 - 4 } & & valid_file & $\begin{array}{l}\text { Returns true if the input } \\
\text { filename corresponds to } \\
\text { the format used by } \\
\text { nameParse, and false } \\
\text { otherwise }\end{array}$ \\
\hline
\end{tabular}

Table C-4: Function Descriptions for the nameParse Class

Code Listing:

\# Class used to create and interpret simulation file names for methane and syngas mixes

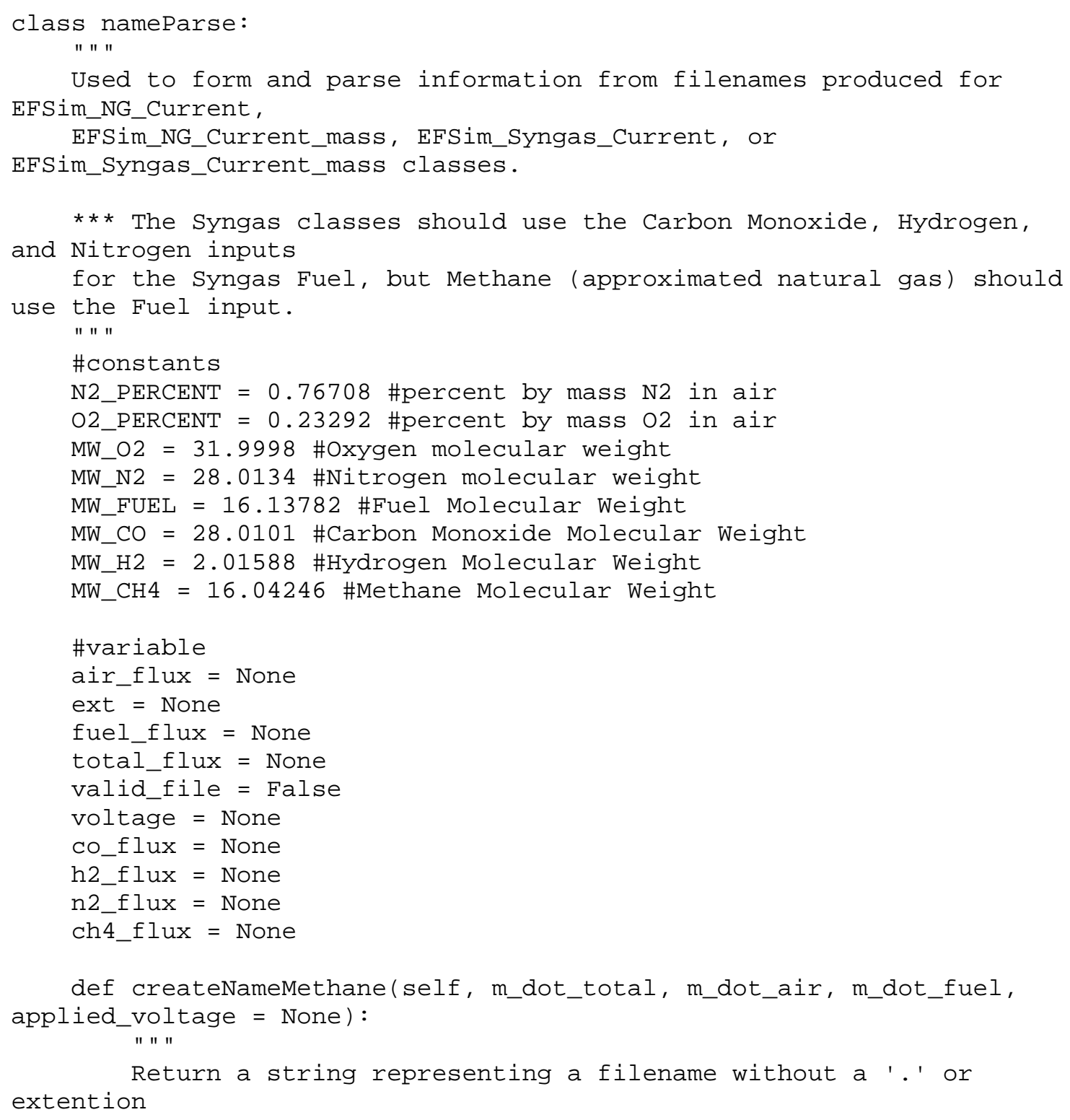


Inputs:

m_dot_total $=$ total mass flux

m_dot_air = mass flux of air

m_dot_fuel = mass flux of fuel in methane and air premix applied_voltage = applied voltage

Outpus:

ret_str $=$ assembled filename string

" I" "

ret_str $=$ ' '

if applied_voltage != None:

ret_str $=$ ret_str + 'V_' + str(applied_voltage $)+{ }^{\prime}$ '

ret_str $=$ ret_str + 'mtot_' + str $($ m_dot_total $)+{ }^{\prime}$ '

ret_str $=$ ret_str + 'mair ${ }_{-}^{\prime}+\operatorname{str}($ m_dot_air $)+{ }^{-}{ }^{\prime}{ }^{-}$

ret_str $=$ ret_str + 'mfue $\bar{l}_{-}$' + str $\left(\bar{m}_{-}\right.$dot_fuel $)$

return ret_str

def createNamesyngas(self, m_dot_total, m_dot_air, m_dot_co, m_dot_h2, m_dot_n2, m_dot_ch4 = None, applied_voltage = None) : extention

Return a string representing a filename without a '.' or

Inputs:

m_dot_total $=$ total mass flux

m_dot_air = mass flux of air

$\operatorname{mix}$

m_dot_co = mass flux of carbon monoxide in syngas and air

m_dot_h2 = mass flux of hydrogen gas in syngas air mix

m_dot_n2 = mass flux of nitrogen gas from simulated syngas

in a syngas and air premix

m_dot_ch4 = mass flux of methane in doped syngas mix

applied_voltage = applied voltage

Outpus:

ret_str $=$ assembled filename string

" " "

ret_str $=$ ' '

if applied_voltage != None:

ret_str $=$ ret_str + ' $\mathrm{v}_{-}$' + str(applied_voltage ) + '_'

ret_str $=$ ret_str + 'mtot_' + str $($ m_dot_total $)+$ ' $^{\prime}$ '

ret_str $=$ ret_str + 'mair_' + str (m_dot_air $)+$ ' $^{-}$

ret_str $=$ ret_str + 'mCo_' + str $($ m_dot_co $)+{ }^{\prime}{ }^{\prime}$ '

ret_str $=$ ret_str + 'mH2_' + str $($ m_dot_h2 $)+{ }^{-}-'$

if m_dot_ch4 != None:

ret_str $=$ ret_str + 'mN2_' + str $\left(m \_d o t \_n 2\right)+$ '

ret_str $=$ ret_str $+{ }^{\prime m C H} 4{ }_{-}+\operatorname{str}\left(\bar{m} \_d o t \_c h 4\right)$

else:

ret_str $=$ ret_str + 'mN2_' + str (m_dot_n2)

return ret_str

def retrieveNameInfo(self, filename): 
Break a filename into voltage and flow information, if possible.

\section{Input:}

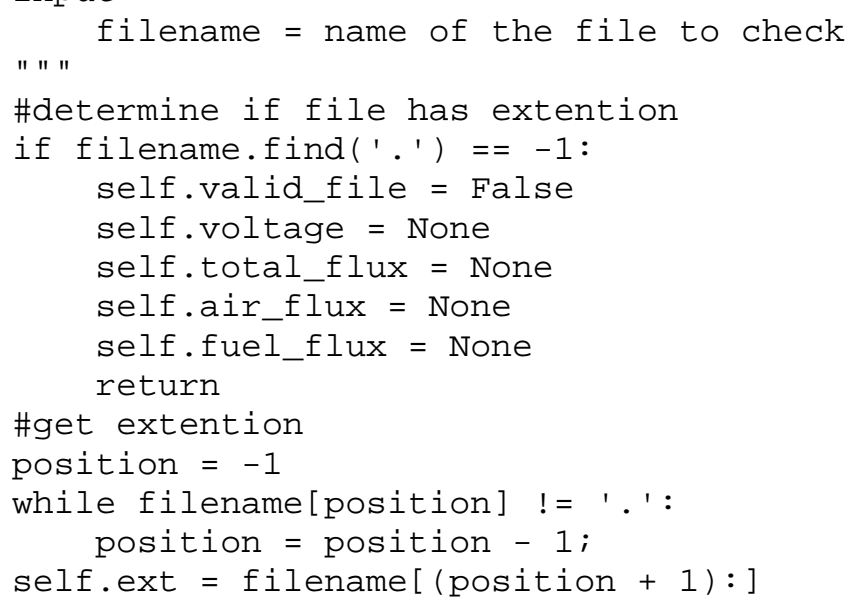




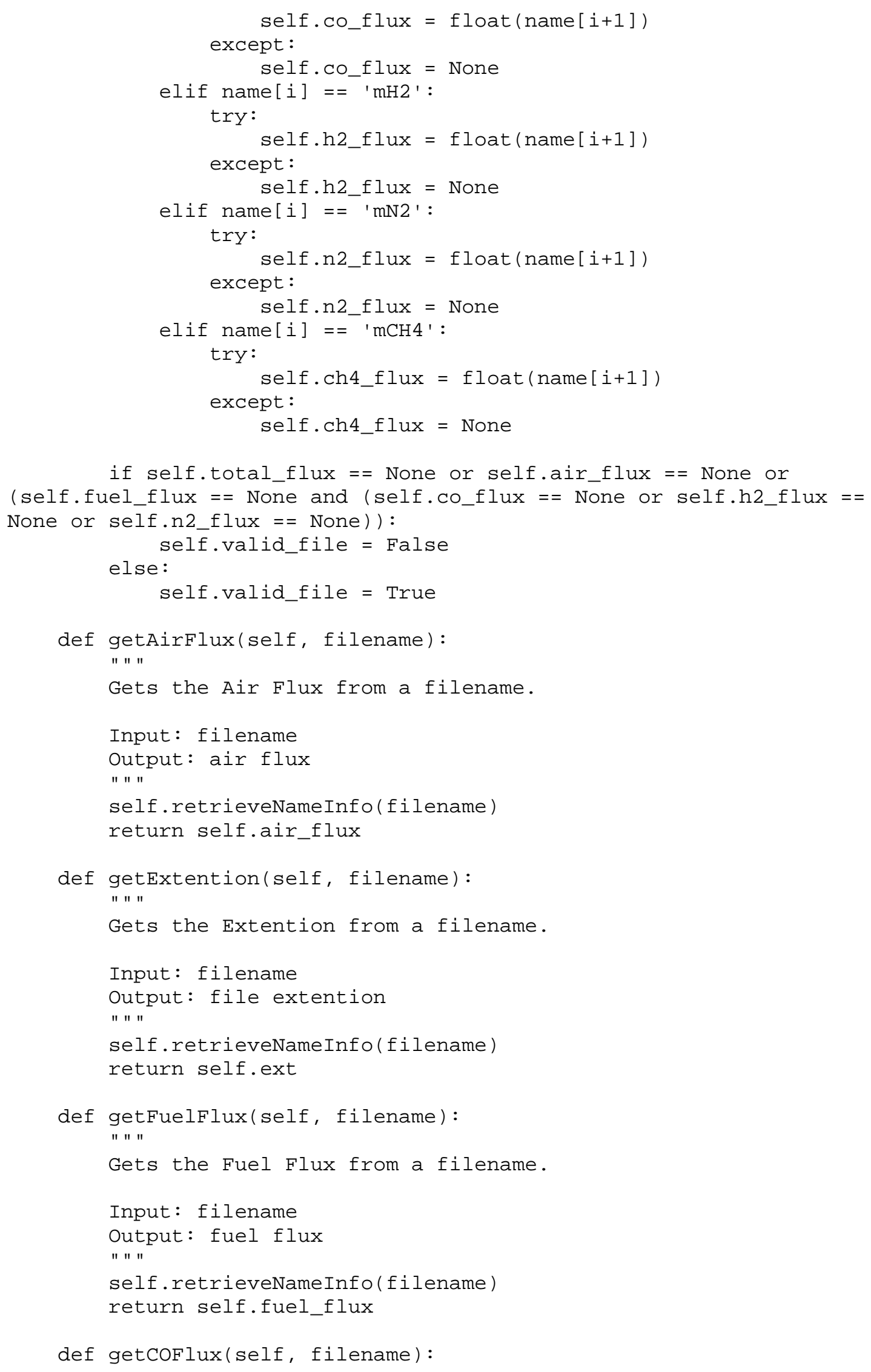




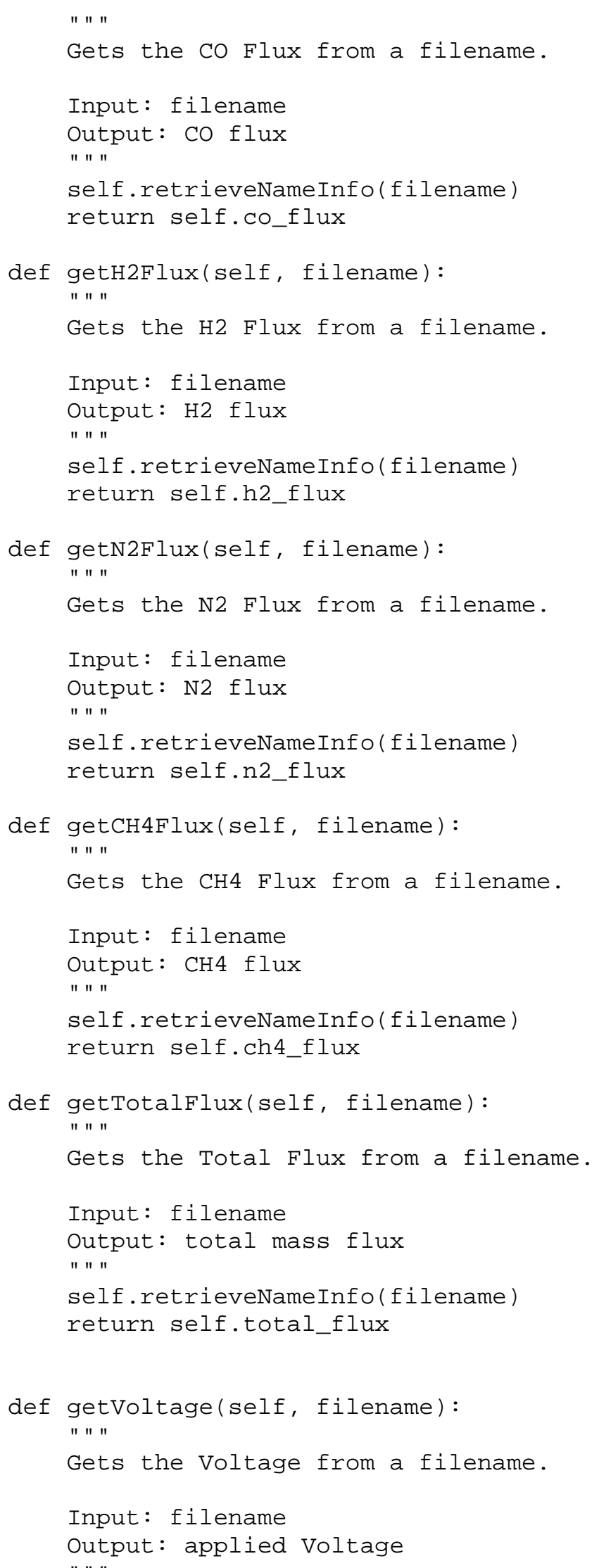




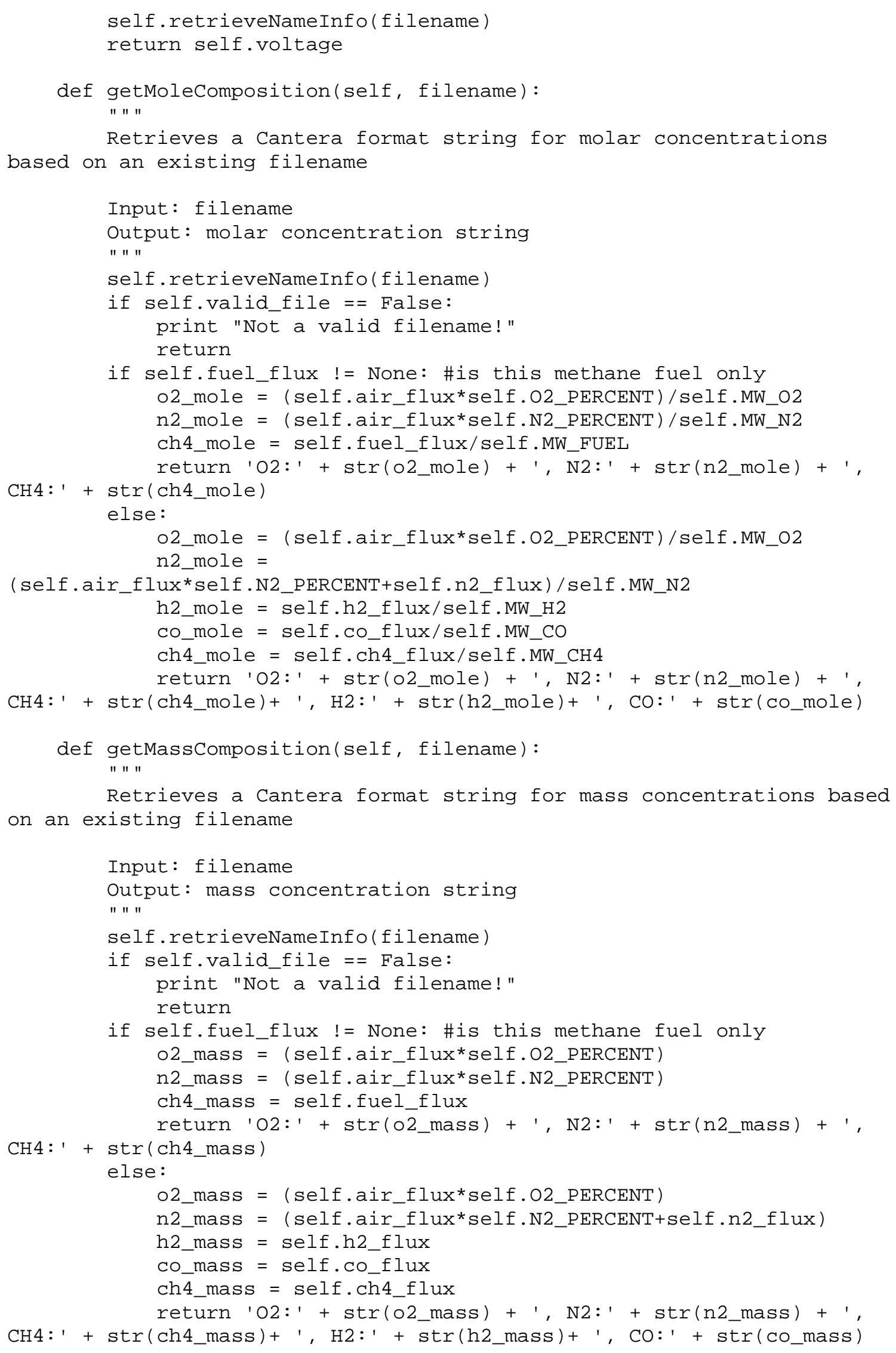

Retrieves a Cantera format string for mass concentrations based on an existing filename

Input: filename Output: mass concentration string

self.retrieveNameInfo(filename)

if self.valid_file == False:

print "Not a valid filename!" return

if self.fuel_flux != None: \#is this methane fuel only

02_mass $=$ (self.air_flux*self.02_PERCENT)

n2_mass $=$ (self.air_flux*self.N2_PERCENT)

ch4_mass = self.fuel_flux

$\mathrm{CH} 4:^{\prime}+\operatorname{str}($ ch4_mass) 
def isValidfile(self, filename):

Determines if the filename conforms to that of simulation output.

Input: filename

Output: True $=>$ Valid Simulation Output

" " " False $=>$ Invalid File

self.retrieveNameInfo(filename)

return self.valid_file 


\section{C-2: parseChemkin2}

\section{Description:}

The parseChemkin2 plot script one class and a grouping of functions which allow thermodynamic data stored in Chemkin2 format to be plotted, saved in comma separated file format, and store values for the difference between the low-temperature and hightemperature polynomial results at the boundaries between temperature ranges.

The figure below shows a typical Chemkin 2 format thermodynamic data entry. The actual thermodynamic data is stored in the form of two 7-coefficient NASA thermodynamic polynomials. Each of the two polynomials covers a temperature range which may be either globally specified for all entries within a file or included directly within each entry. Each of the fourteen polynomial values within an entry occupies an exact position within that entry.

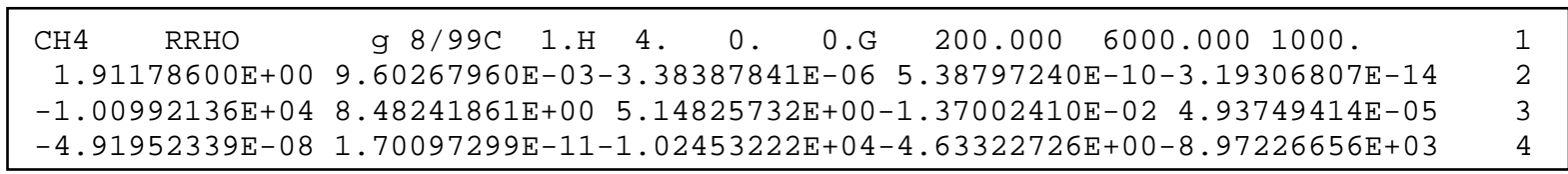

Figure C-3: Example of a Chemkin2 Format Thermodynamic Polynomial Data Entry(Burcat 2005) Code Overview:

The parseChemkin2 code contains one class with functions and a few standalone functions. The class, ThermoData, stores species names, temperature ranges, and NASA polynomial coefficients lists for each Chemkin2 format thermodynamic data file, while the standalone functions are used to analyze and plot all species contained within the thermodynamic data file. The following tables give descriptions of constants used by the parseChemkin 2 code, the ThermoData class functions, and each standalone function. These variables are intended for internal use by the parseChemkin 2 code, but it is possible for users to make modification. 


\begin{tabular}{|c|c|c|}
\hline Constant & Value & Purpose \\
\hline$\overline{D O N E}$ & -1 & $\begin{array}{l}\text { Used to indicate that not all thermodynamic data has } \\
\text { been read. }\end{array}$ \\
\hline NOT_DONE & 1 & $\begin{array}{l}\text { Used to indicate that all thermodynamic data has been } \\
\text { read. }\end{array}$ \\
\hline name_start & 0 & $\begin{array}{l}\text { The character position on a row for the start of a species } \\
\text { name. }\end{array}$ \\
\hline name_end & 14 & $\begin{array}{l}\text { The character position on a row for the end of a species } \\
\text { name. }\end{array}$ \\
\hline low_start & 46 & $\begin{array}{l}\text { The character position on a row for the start of a low } \\
\text { temperature range value. }\end{array}$ \\
\hline low_end & 55 & $\begin{array}{l}\text { The character position on a row for the end of a low } \\
\text { temperature range value. }\end{array}$ \\
\hline mid_start & 66 & $\begin{array}{l}\text { The character position on a row for the start of a low } \\
\text { temperature range value. }\end{array}$ \\
\hline mid_end & 75 & $\begin{array}{l}\text { The character position on a row for the end of a low } \\
\text { temperature range value. }\end{array}$ \\
\hline high_start & 56 & $\begin{array}{l}\text { The character position on a row for the start of a high } \\
\text { temperature range value. }\end{array}$ \\
\hline high_end & 65 & $\begin{array}{l}\text { The character position on a row for the end of a high } \\
\text { temperature range value. }\end{array}$ \\
\hline nCoeff & 7 & $\begin{array}{l}\text { The number of coefficients needed for one "old" NASA } \\
\text { polynomial for a single temperature range. Note that } \\
\text { one thermodynamic file entry contains two sets of } \\
\text { NASA polynomial coefficients. }\end{array}$ \\
\hline $\mathrm{R}$ & 8314.0 & The ideal gas constant. \\
\hline end_string & "END” & $\begin{array}{l}\text { The text used to mark the end of a Chemkin } 2 \text { format } \\
\text { thermodynamic data file. }\end{array}$ \\
\hline begin_string & "THERMO" & $\begin{array}{l}\text { The text used to mark the beginning of a Chemkin } 2 \\
\text { format thermodynamic data file. }\end{array}$ \\
\hline
\end{tabular}

Table C-5: Table of Constants Used by the parseChemkin2 Code 


\begin{tabular}{|c|c|c|c|c|}
\hline \multicolumn{5}{|c|}{ ThermoData Class Functions } \\
\hline Function & Description & Inputs & Outputs & Purpose \\
\hline init & $\begin{array}{l}\text { Used to initialize } \\
\text { a ThermoData } \\
\text { object }\end{array}$ & & & \\
\hline \multirow[t]{2}{*}{ read } & \multirow[t]{2}{*}{$\begin{array}{l}\text { Reads a single } \\
\text { thermodynamic } \\
\text { data entry and } \\
\text { stores data to } \\
\text { class variables. }\end{array}$} & infile & & $\begin{array}{l}\text { A pointer to the a } \\
\text { Chemkin2 format } \\
\text { thermodynamic } \\
\text { data file opened } \\
\text { for reading. }\end{array}$ \\
\hline & & & status & $\begin{array}{l}\text { Indicates if the last } \\
\text { entry for the input } \\
\text { Chemkin } 2 \\
\text { thermodynamic } \\
\text { data file has been } \\
\text { found. }\end{array}$ \\
\hline \multirow[t]{2}{*}{ getName } & \multirow{2}{*}{$\begin{array}{l}\text { Gets the name of } \\
\text { a species for } \\
\text { which } \\
\text { thermodynamic } \\
\text { data has been } \\
\text { read. }\end{array}$} & species_position & & $\begin{array}{l}\text { The number of the } \\
\text { entry for which a } \\
\text { species name is } \\
\text { needed. }\end{array}$ \\
\hline & & & name & $\begin{array}{l}\text { The name of the } \\
\text { species } \\
\text { corresponding to } \\
\text { the entry number. }\end{array}$ \\
\hline \multirow[t]{2}{*}{ getLowCoef } & \multirow{2}{*}{$\begin{array}{l}\text { Retrieves the low } \\
\text { temperature } \\
\text { NASA } \\
\text { thermodynamic } \\
\text { coefficients for a } \\
\text { specified species } \\
\text { entry }\end{array}$} & species_position & & $\begin{array}{l}\text { The number of the } \\
\text { entry for which the } \\
\text { low temperature } \\
\text { coefficients are } \\
\text { needed }\end{array}$ \\
\hline & & & coeff_low & $\begin{array}{l}\text { A list containing } \\
\text { the low } \\
\text { temperature range } \\
\text { NASA polynomial } \\
\text { coefficients for the } \\
\text { species } \\
\text { corresponding to } \\
\text { the input entry } \\
\text { number. }\end{array}$ \\
\hline \multirow[t]{2}{*}{ getHighCoef } & \multirow[t]{2}{*}{$\begin{array}{l}\text { Retrieves the } \\
\text { high temperature } \\
\text { NASA } \\
\text { thermodynamic } \\
\text { coefficients for a } \\
\text { specified species }\end{array}$} & species_position & & $\begin{array}{l}\text { The number of the } \\
\text { entry for which the } \\
\text { low temperature } \\
\text { coefficients are } \\
\text { needed. }\end{array}$ \\
\hline & & & coeff_high & A list containing \\
\hline
\end{tabular}




\begin{tabular}{|c|c|c|c|c|}
\hline & entry. & & & $\begin{array}{l}\text { the high } \\
\text { temperature range } \\
\text { NASA polynomial } \\
\text { coefficients for the } \\
\text { species } \\
\text { corresponding to } \\
\text { the input entry } \\
\text { number. }\end{array}$ \\
\hline \multirow[t]{2}{*}{ getT_low } & \multirow{2}{*}{$\begin{array}{l}\text { Retrieves the low } \\
\text { temperature } \\
\text { value for the low } \\
\text { temperature } \\
\text { range of a } \\
\text { specified } \\
\text { Chemkin2 } \\
\text { format } \\
\text { thermodynamic } \\
\text { entry. }\end{array}$} & species_position & & $\begin{array}{l}\text { The number of the } \\
\text { entry for which the } \\
\text { low value of the } \\
\text { low temperature } \\
\text { range is needed. }\end{array}$ \\
\hline & & & T_low & $\begin{array}{l}\text { The low } \\
\text { temperature value } \\
\text { for the low } \\
\text { temperature NASA } \\
\text { thermodynamic } \\
\text { polynomial of the } \\
\text { species } \\
\text { corresponding to } \\
\text { the input entry } \\
\text { number }\end{array}$ \\
\hline \multirow[t]{2}{*}{ getT_mid } & \multirow{2}{*}{$\begin{array}{l}\text { Retrieves the } \\
\text { temperature } \\
\text { value between } \\
\text { the two } \\
\text { temperature } \\
\text { ranges in a } \\
\text { specified } \\
\text { Chemkin2 } \\
\text { format } \\
\text { thermodynamic } \\
\text { entry. }\end{array}$} & & & $\begin{array}{l}\text { The number of the } \\
\text { entry for which the } \\
\text { midpoint } \\
\text { temperature range } \\
\text { is needed. }\end{array}$ \\
\hline & & & T_mid & $\begin{array}{l}\text { The temperature } \\
\text { value between the } \\
\text { two temperature } \\
\text { ranges of the } \\
\text { NASA } \\
\text { thermodynamic } \\
\text { polynomials of the } \\
\text { species } \\
\text { corresponding to } \\
\text { the input entry } \\
\text { number }\end{array}$ \\
\hline \multirow[t]{2}{*}{ getT_high } & \multirow{2}{*}{$\begin{array}{l}\text { Retrieves the } \\
\text { high temperature } \\
\text { in the high } \\
\text { temperature } \\
\text { range of a } \\
\text { Chemkin2 } \\
\text { format }\end{array}$} & species_position & & $\begin{array}{l}\text { The number of the } \\
\text { entry for which the } \\
\text { high value of the } \\
\text { high temperature } \\
\text { range is needed. }\end{array}$ \\
\hline & & & T_high & $\begin{array}{l}\text { The high } \\
\text { temperature value }\end{array}$ \\
\hline
\end{tabular}




\begin{tabular}{|c|c|c|c|c|}
\hline & $\begin{array}{l}\text { thermodynmamic } \\
\text { data entry. }\end{array}$ & & & $\begin{array}{l}\text { for the high } \\
\text { temperature NASA } \\
\text { thermodynamic } \\
\text { polynomial of the } \\
\text { species } \\
\text { corresponding to } \\
\text { the input entry } \\
\text { number }\end{array}$ \\
\hline numSpecies & $\begin{array}{l}\text { Gives the } \\
\text { number of } \\
\text { thermodynamic } \\
\text { data entries read } \\
\text { from the } \\
\text { provided } \\
\text { Chemkin2 } \\
\text { format } \\
\text { thermodynamic } \\
\text { data file }\end{array}$ & & num & $\begin{array}{l}\text { The number of } \\
\text { species that have } \\
\text { been read in from } \\
\text { the current } \\
\text { Chemkin2 format } \\
\text { thermodynamic } \\
\text { data file. }\end{array}$ \\
\hline \multirow[t]{4}{*}{ calcAll } & \multirow{4}{*}{$\begin{array}{l}\text { Calculates } \\
\text { enthalpy, } \\
\text { entropy, and } \\
\text { specific heat at a } \\
\text { specific } \\
\text { temperature for a } \\
\text { particular } \\
\text { thermodynamic } \\
\text { data entry. }\end{array}$} & $\mathrm{T}$ & & $\begin{array}{l}\text { Temperature in } \\
\text { Kelvin }\end{array}$ \\
\hline & & species_position & & $\begin{array}{l}\text { The number of the } \\
\text { entry for the } \\
\text { species in which } \\
\text { the properties need } \\
\text { to be calculated. }\end{array}$ \\
\hline & & L_or_H & & $\begin{array}{l}\text { Specifies whether } \\
\text { to use the low } \\
\text { temperature } \\
\text { coefficients ('L'), } \\
\text { high temperature } \\
\text { coefficients ('H'), } \\
\text { or pick based upon } \\
\text { temperature range } \\
\text { ('U'). }\end{array}$ \\
\hline & & & values & $\begin{array}{l}\text { A python tuple } \\
\text { containing specific } \\
\text { heat, enthalpy, and } \\
\text { entropy in that } \\
\text { order. }\end{array}$ \\
\hline plot & $\begin{array}{l}\text { Plots specific } \\
\text { heat, entropy, } \\
\text { and enthalpy } \\
\text { over a specified } \\
\text { temperature } \\
\text { range for a } \\
\text { specified species. }\end{array}$ & T_list & & $\begin{array}{l}\text { A list containing } \\
\text { temperature values } \\
\text { for which to } \\
\text { compute } \\
\text { thermodynamic } \\
\text { properties for } \\
\text { plots. }\end{array}$ \\
\hline
\end{tabular}




\begin{tabular}{|c|c|c|c|c|}
\hline & & species_position & & $\begin{array}{l}\text { The number of the } \\
\text { thermodynamic } \\
\text { entry to plot. }\end{array}$ \\
\hline \multirow[t]{2}{*}{ toCSV } & \multirow{2}{*}{$\begin{array}{l}\text { Stores values of } \\
\text { specific heat, } \\
\text { enthalpy, and } \\
\text { entropy for a } \\
\text { specified species } \\
\text { and set of } \\
\text { temperatures in a } \\
\text { comma separated } \\
\text { value file. }\end{array}$} & $\mathrm{T}$ & & $\begin{array}{l}\text { A list of } \\
\text { temperatures for } \\
\text { which to calculate } \\
\text { thermodynamic } \\
\text { properties. }\end{array}$ \\
\hline & & species_position & & $\begin{array}{l}\text { The number of the } \\
\text { thermodynamic } \\
\text { entry for which } \\
\text { calculation is } \\
\text { needed. }\end{array}$ \\
\hline \multirow[t]{2}{*}{ midPointError } & \multirow{2}{*}{$\begin{array}{l}\text { Calculates the } \\
\text { difference in } \\
\text { values produced } \\
\text { from the use of } \\
\text { the high } \\
\text { temperature and } \\
\text { low temperature } \\
\text { coefficients at } \\
\text { the point } \\
\text { between the two } \\
\text { ranges for a } \\
\text { specified species. }\end{array}$} & species_position & & $\begin{array}{l}\text { The number of the } \\
\text { thermodynamic } \\
\text { entry for which the } \\
\text { error between high } \\
\text { and low } \\
\text { temperature ranges } \\
\text { is needed. }\end{array}$ \\
\hline & & & Values & $\begin{array}{l}\text { A Python tuple } \\
\text { containing the } \\
\text { difference between } \\
\text { calculated value } \\
\text { between } \\
\text { temperature } \\
\text { polynomials for } \\
\text { the overlapping } \\
\text { temperature of } \\
\text { specific heat, } \\
\text { enthalpy, and } \\
\text { entropy in that } \\
\text { order. }\end{array}$ \\
\hline
\end{tabular}

Table C-6: Class Methods for the ThermoData Class Contained in parseChemkin2 Code 


\begin{tabular}{|c|c|c|c|c|}
\hline Function & Description & Inputs & Outputs & Purpose \\
\hline cleanFile & $\begin{array}{l}\text { Deletes all } \\
\text { instances of the } \\
\text { characters '[' } \\
\text { and ']' from a } \\
\text { given file. }\end{array}$ & filename & & $\begin{array}{l}\text { The name of } \\
\text { the file for } \\
\text { which brackets } \\
\text { need to be } \\
\text { deleted. }\end{array}$ \\
\hline \multirow[t]{2}{*}{ parseThermo } & \multirow{2}{*}{$\begin{array}{l}\text { Drives the } \\
\text { reading of a } \\
\text { Chemkin2 } \\
\text { format } \\
\text { thermodynamic } \\
\text { data file until it } \\
\text { is complete }\end{array}$} & infile & & $\begin{array}{l}\text { A file pointer to } \\
\text { a Chemkin2 } \\
\text { format } \\
\text { thermodynamic } \\
\text { data file. }\end{array}$ \\
\hline & & & thermo_list & $\begin{array}{l}\text { A list } \\
\text { containing all } \\
\text { NASA } \\
\text { polynomial data } \\
\text { contained in a } \\
\text { Chemkin2 } \\
\text { format } \\
\text { thermodynamic } \\
\text { data file. }\end{array}$ \\
\hline parseFile & $\begin{array}{l}\text { Drive the full } \\
\text { parsing of a } \\
\text { Chemkin2 } \\
\text { format } \\
\text { thermodynamic } \\
\text { data file }\end{array}$ & filename & & $\begin{array}{l}\text { Name of a } \\
\text { Chemkin2 } \\
\text { format } \\
\text { thermodynamic } \\
\text { data file. }\end{array}$ \\
\hline runThermo & $\begin{array}{l}\text { Similar to a } \\
\text { main function, } \\
\text { this function } \\
\text { calls all other } \\
\text { functions and } \\
\text { creates } \\
\text { ThermoData } \\
\text { objects to be } \\
\text { used for } \\
\text { plotting specific } \\
\text { heat, enthalpy, } \\
\text { entropy, and } \\
\text { errors between } \\
\text { temperature } \\
\text { ranges. }\end{array}$ & filename & & $\begin{array}{l}\text { The name of } \\
\text { the Chemkin } 2 \\
\text { format } \\
\text { thermodynamic } \\
\text { data file to be } \\
\text { processed. }\end{array}$ \\
\hline
\end{tabular}

Table C-7: Standalone Methods Contained in the parseChemkin2 Code 


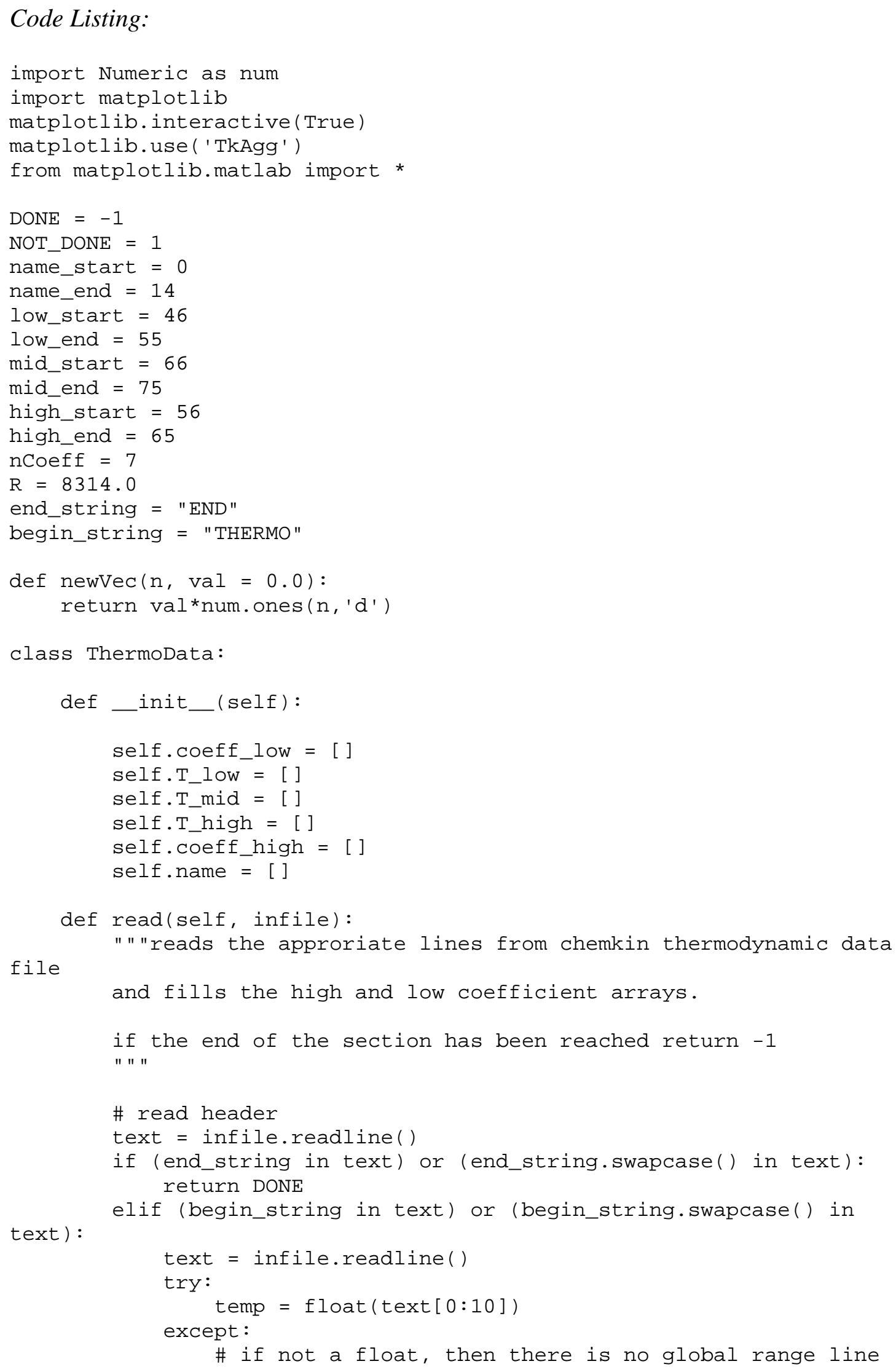




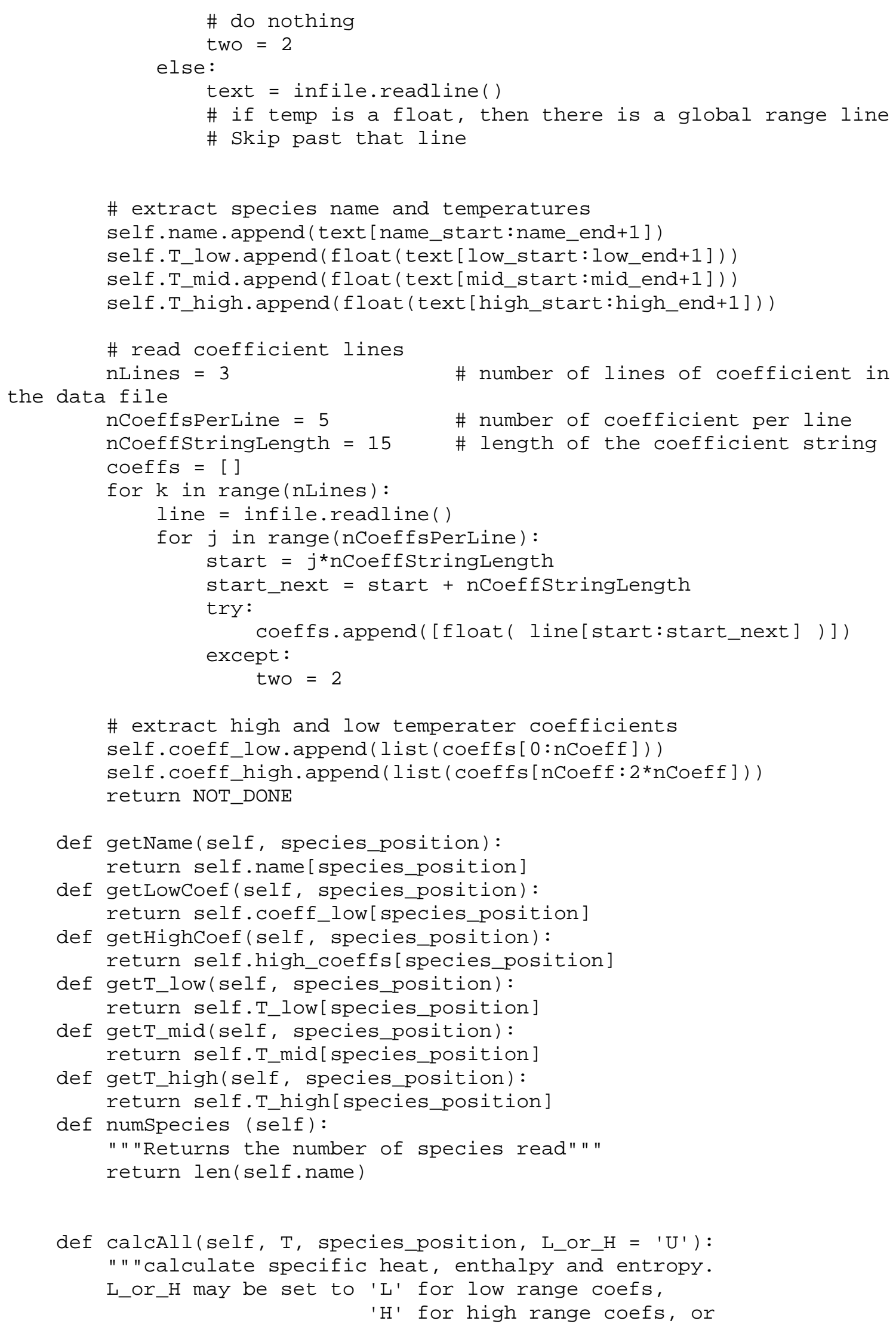




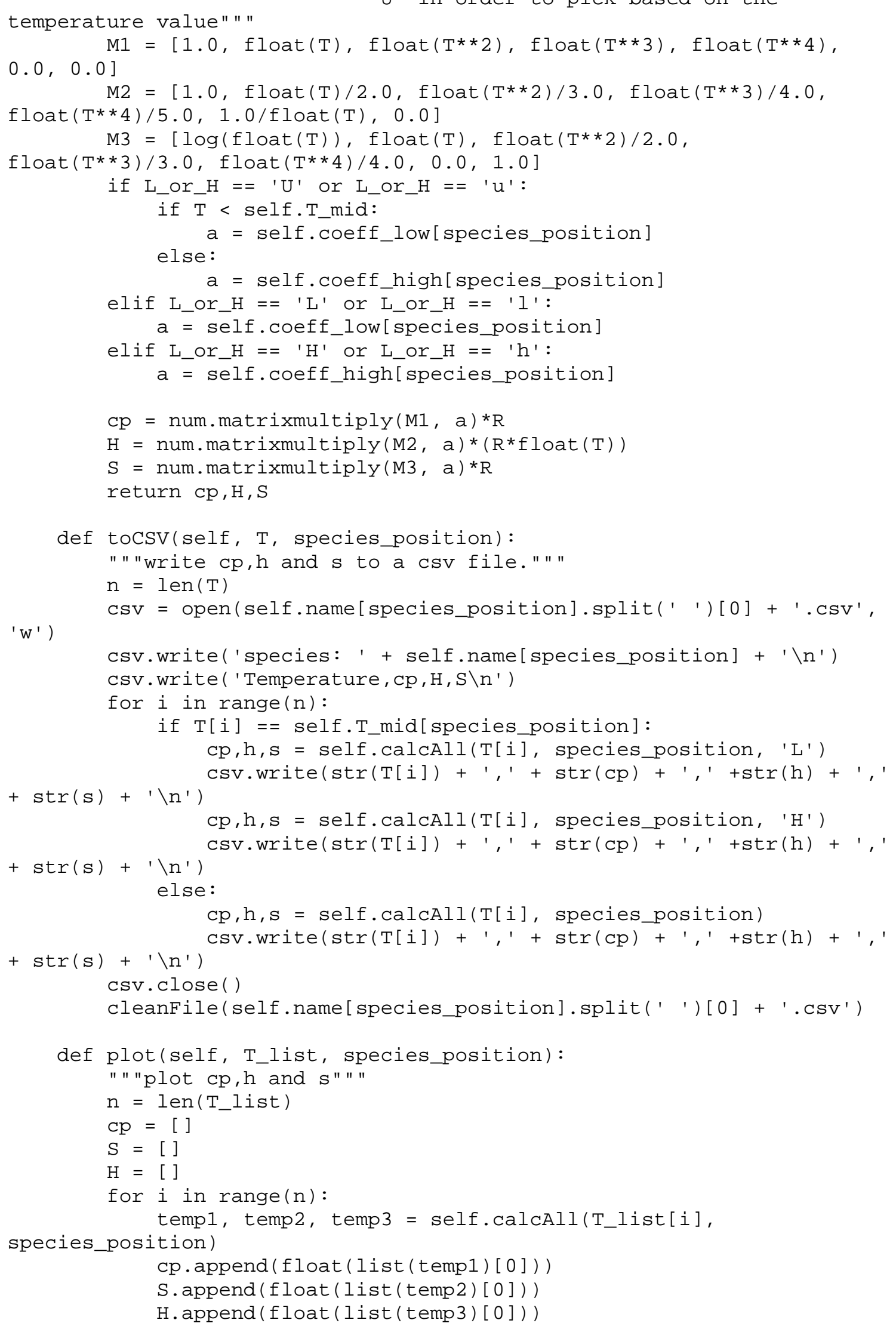




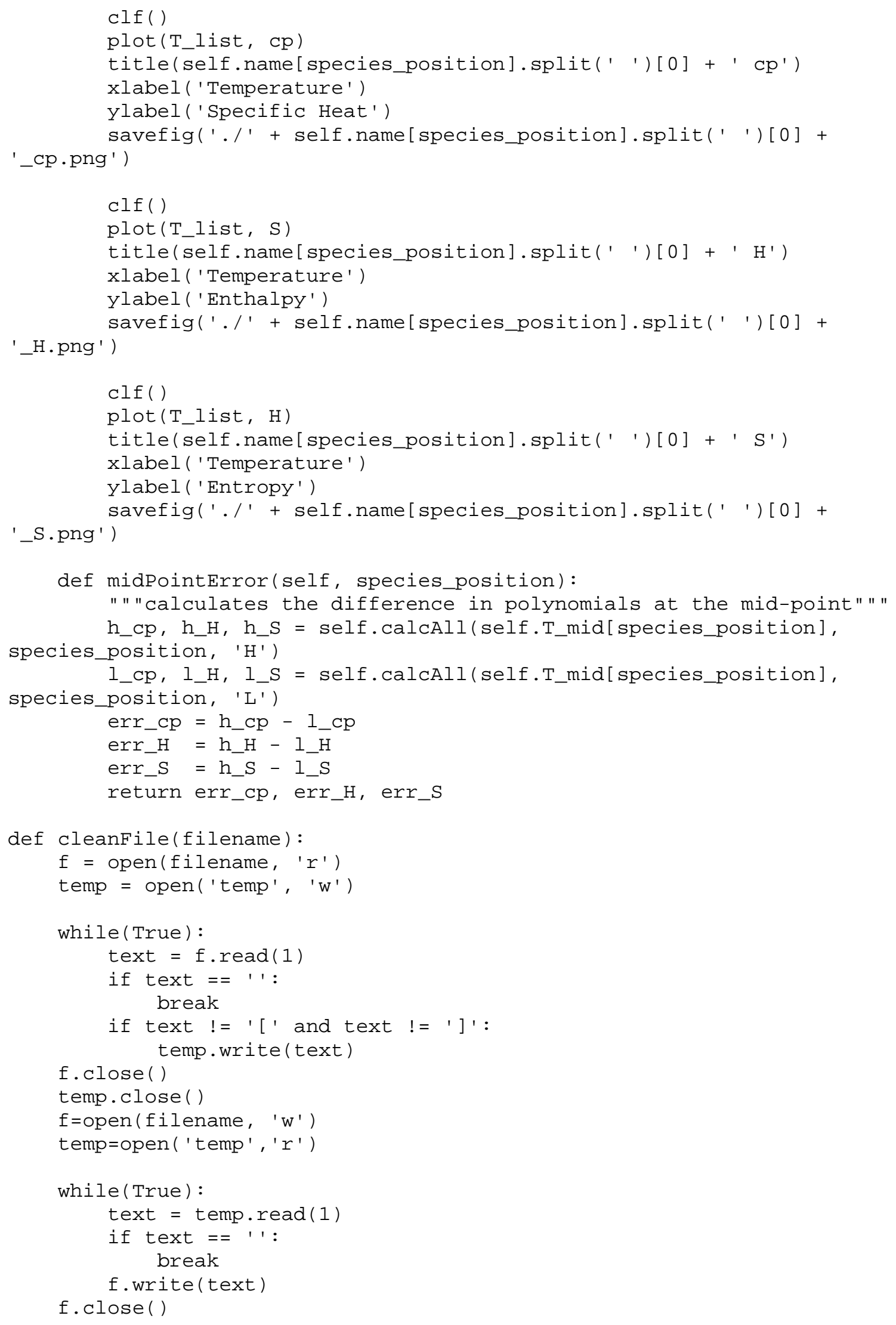


temp.close( )

def parseThermo(infile): format

"""reads thermodynamic section for all the species in a chemkin

data file and returns a list of ThermoData objects""

thermo_list $=[]$

while(True):

data $=$ ThermoData (infile)

if ( data.read () == NOT_DONE):

else: thermo_list.append( data )

break

return thermo_list

def parsefile(filename):

"""parse a Chemkin format thermodynamic file"""

\# file is read/parsed line by line

\# an alternative would be to read the entire file using read then split lines using

\# the string method split

comment $="$ !"

start_string = "THERMO"

end_string = "END"

$f=$ open(filename, ' $r$ ')

logfile $=$ open (filename, ' $w$ ')

\# search file for keyword

line = "stuff"

thermo_list

while(len(line) $>0)$ :

line $=f$.readline ()

if (start_string in line) or (start_string.swap_case() in

line):

thermo_list $=$ parseThermo $(f)$

\# use thermo_data list to

\# generate csv files

\# generate plots

\# check mid-point errors

$T=$ num. arange $(300.0,3100.0,100.0)$

for thermo_data in thermo_list:

thermo_data.tocsV(T)

thermo_data.plot $(\mathrm{T})$

print thermo_data.name, thermo_data.midPointError()

def runThermo(filename):

"" Generates files containing plots and tables of $\mathrm{cp}, \mathrm{H}$, and $\mathrm{S}$ for each species, 
and the midpoint error for all species contained in a old NASA format thermodynamic

data file."""

therm $=$ ThermoData ()

input $=$ open $\left(f i l e n a m e, ' r^{\prime}\right)$

while (therm.read (input) == NOT_DONE):

\#read each species from thermo file

two $=2$

input.close( )

mpr = open('mp_err.csv', ' $w$ ') \#file for midpoint errors

mpr.write("Species, Err_cp, Err_H, Err_S, Midpoint\n")

$\mathrm{T}=\operatorname{range}(300.0,5025.0,25.0)$

for $i$ in range $(\odot$, therm.numspecies ()$)$ : therm. $\operatorname{tocsV}(T, i)$

therm. plot $(T, i)$

err_cp, err_H, err_S = therm.midPointError(i)

mpr.write(therm.getName $(i)+1, '+\operatorname{str}($ err_cp) + ', ' +

$\operatorname{str}($ err_H $)+{ }^{\prime}, '+\operatorname{str}($ err_S $)+{ }^{\prime}, '+\operatorname{str}($ therm.getT_mid $(i))+\left(\backslash n^{\prime}\right)$

mpr.close( )

cleanfile('mp_err.csv') 


\section{Appendix D: Output File Formats \\ D-1: CSV Simulation Output File}

The Comma Separated Value Simulation Output File is provided for its compatibility with existing spreadsheet software. As the name implies, this file format stores a series of values separated by commas within each row. Additional rows are produced by simply adding additional lines in the file. The contents are generated from a solved flame object and stored as columns in a 'csv' file. These contents include grid points, gas velocity, rate, temperature, voltage (if used), and mole fractions of all species at each grid point. Data labels are provided in the first row of the file. Figure E-1 gives a truncated example this file type.

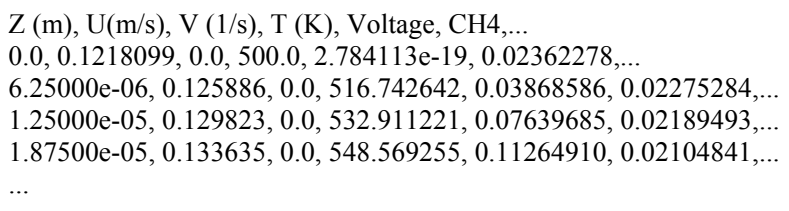

Figure D-1: CSV Simulation Output File Truncated Example

Although this file may be difficult to read in a standard word processor, most common spreadsheet software, including Excel, will place each entry into cells for simplified viewing, plotting, and analysis.

Within the simulation driver programs which generated this output file type, the name is generated using the nameParse class, which is fully documented in Appendix C. 


\section{D-2: CTML Simulation Output File}

A CTML Simulation Output File is automatically generated from Cantera's BurnerFlame and BurnerFlame_efield object using the objects 'save' function. This file format uses XML style flags and entries to store listings of much of the essential properties of the flame object including grid points, velocity, temperature, and species mass fractions.

Flame property values may be retrieved within a program by creating a BurnerFlame or BurnerFlame_efield object and using the objects 'restore' function to load values from the 'ctml' file into the newly created Flame object. Despite the ability to restore data from a 'ctml' file, not enough data is restored to directly rerun a simulation from the 'ctml' file contents.

Figure D-2 gives a truncated example of a 'ctml' format file. The file contains a series of tags which mark various data structures within the file. These data structure make use of a starting tag which includes the tag type and any additional arguments between a set of angle brackets and an ending tag which includes the tag type with a leading '/' between angle brackets. The ctml tags located at the beginning and end of the file mark the entire file as a ctml document. The next major tag is the simulation tag, which marks all the data included in one simulation. There may be multiple simulation tags within a file, each pair representing a single simulation, but each simulation will contain a unique 'id' attribute. Next, each simulation contains two string tags, one for the timestamp which saves the data and time of the simulation and a second tag for an optional description. Also within the simulation object is a set of three domains, which include the inlet, STFlow or STFlowEfield, and outlet. Each of these domain types is 
specified by the type attribute. The inlet domain stores the mass flux and temperature of the burner. The STFlow or STFlowEfield domains contain the grid, flame attributes, species concentrations in mass fractions stored in a series of floatarray objects inside a grid_data object, and the gas pressure stored in a pressure tag. The outlet domain contain simply marks the flame outlet and contains no other useful data. 


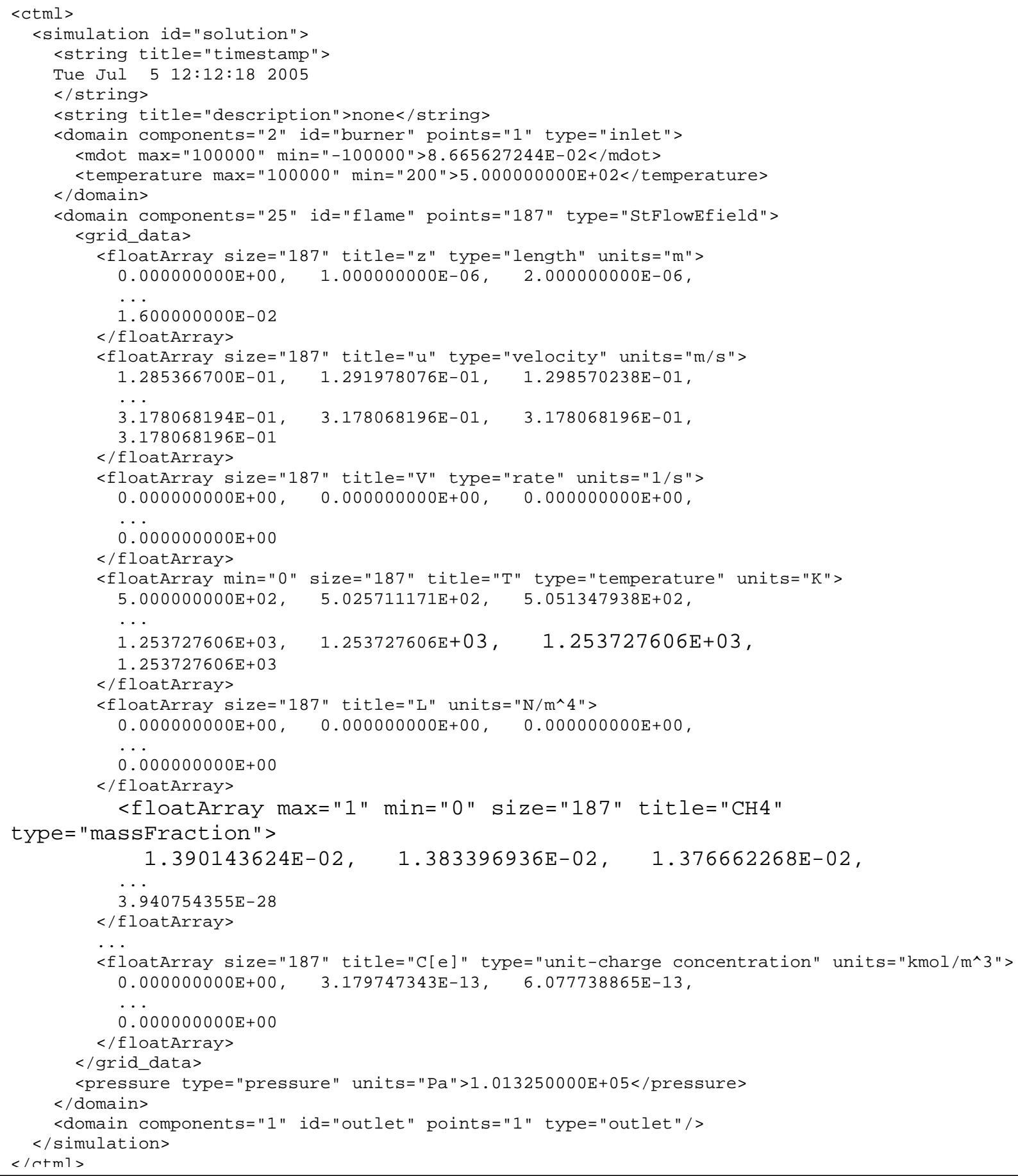

Figure D-2: CTML Output File Truncated Example

Although it is not mandatory, the filenames for this type of output file have been created using the nameParse class which is documented in Appendix C. 


\section{D-3: Running Current Output File}

The Running Current Output File is a file which may be optionally produced by the EFSim_NG_Current or EFSim_Syngas_Current program which are documented in Appendix A. These files store data concerning simulation flow rates, applied voltage, and current produced by the 'current' function provided by a BurnerFlame_efield object. The name is specified by the 'current_file' input to the constructors of the EFSim_NG_Current, EFSim_NG_Current_mass, and EFSim_Syngas_Current classes.

The Running Currrent Output File stores its data in Comma Seperated Value (CSV) format which separates values within each row with a comma, and allows for multiple rows by creating additional lines. CSV are easily read by most spreadsheet software. This particular stores equivalence ratio, total flux, air flux, fuel flux, applied voltage and current for methane and air simulation. For synthesis gas and air simulations equivalence ratio, total flux, air flux, carbon monoxide flux, hydrogen gas flux, methane flux, fuel nitrogen gas flux, applied voltage and current are stored. Figures D-3 and D-4 give examples of these output file formats.

ER, total_flux, air_flux, fuel_flux, voltage, current $0.94266303,0.000227418429,0.000215483333,1.193509604$ e - $05,0.0,-0.000356916694486$ $0.94266303,0.000227418429373,0.000215483333333,1.193509604 \mathrm{e}-05,0.1,-0.000423609085041$ $0.94266303,0.000227418429373,0.000215483333333,1.193509604 \mathrm{e}-05,0.2,-0.000508797391377$ $\ldots$

Figure D-3: Example of Running Current Output File Using Methane and Air

ER,total_flux,air_flux,CO_flux,H2_flux,CH4_flux,N2_flux,voltage,current

$0.56338 \overline{8} 1,0.000 \overline{2} 300856 \overline{9}, 0.000197160766,2.358678 \overline{6} 36 \mathrm{e}-05,1.3724605 \mathrm{e}-06,4.37154 \mathrm{e}-07,7.528525 \mathrm{e}-06,0.0,-1.53849575 \mathrm{e}-05$ $0.5633881,0.00023008569,0.000197160766,2.358678636 \mathrm{e}-05,1.3724605 \mathrm{e}-06,4.37154 \mathrm{e}-07,7.528525 \mathrm{e}-06,0.1,-1.85000574 \mathrm{e}-05$ $0.5633881,0.00023008569,0.000197160766,2.358678636 \mathrm{e}-05,1.3724605 \mathrm{e}-06,4.37154 \mathrm{e}-07,7.528525 \mathrm{e}-06,0.2,-2.15547048 \mathrm{e}-05$ $0.5633881,0.00023008569,0.000197160766,2.358678636 \mathrm{e}-05,1.3724605 \mathrm{e}-06,4.37154 \mathrm{e}-07,7.528525 \mathrm{e}-06,0.3,-2.40812775 \mathrm{e}-05$

Figure D-4: Example of Running Current Output File Using Synthesis Gas and Air 


\section{Appendix E: Plots of Results}

\section{E-1: V-I Plots of Methane Combustion Using GRI Mech 3.0}

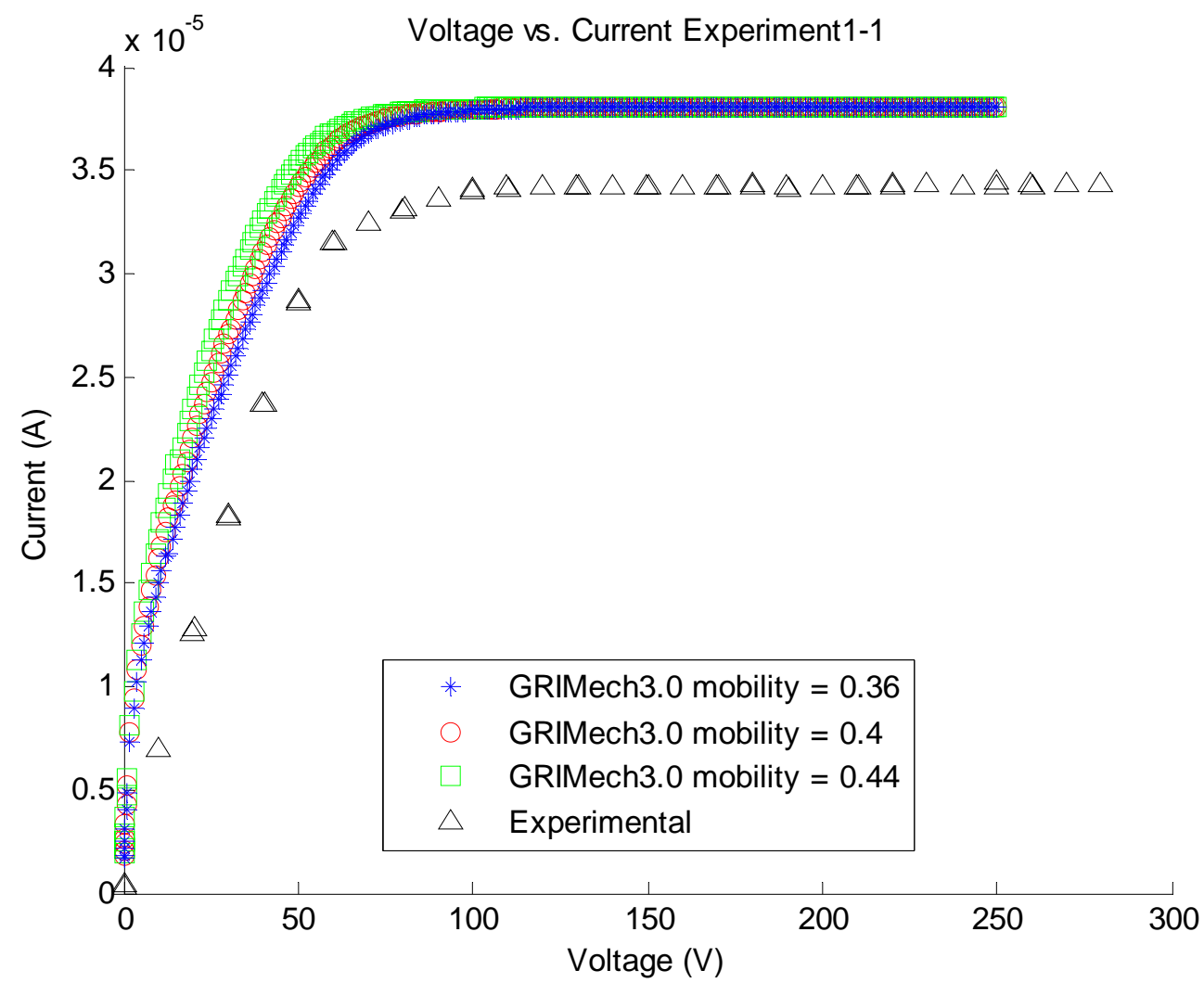

Figure E-1: Voltage vs. Current with Methane for GRI Experiment 1-1 


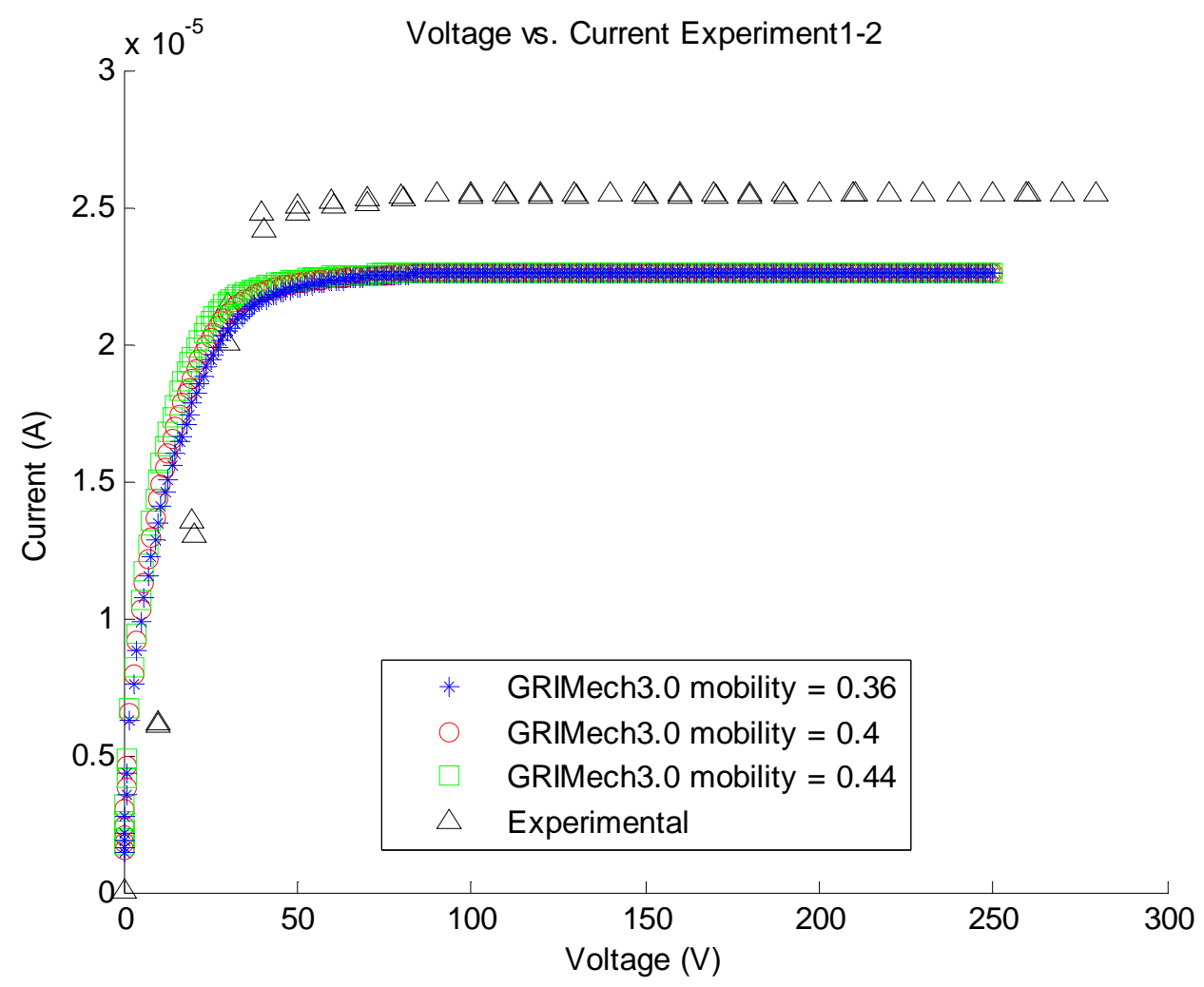

Figure E-2: Voltage vs. Current with Methane for GRI Experiment 1-2

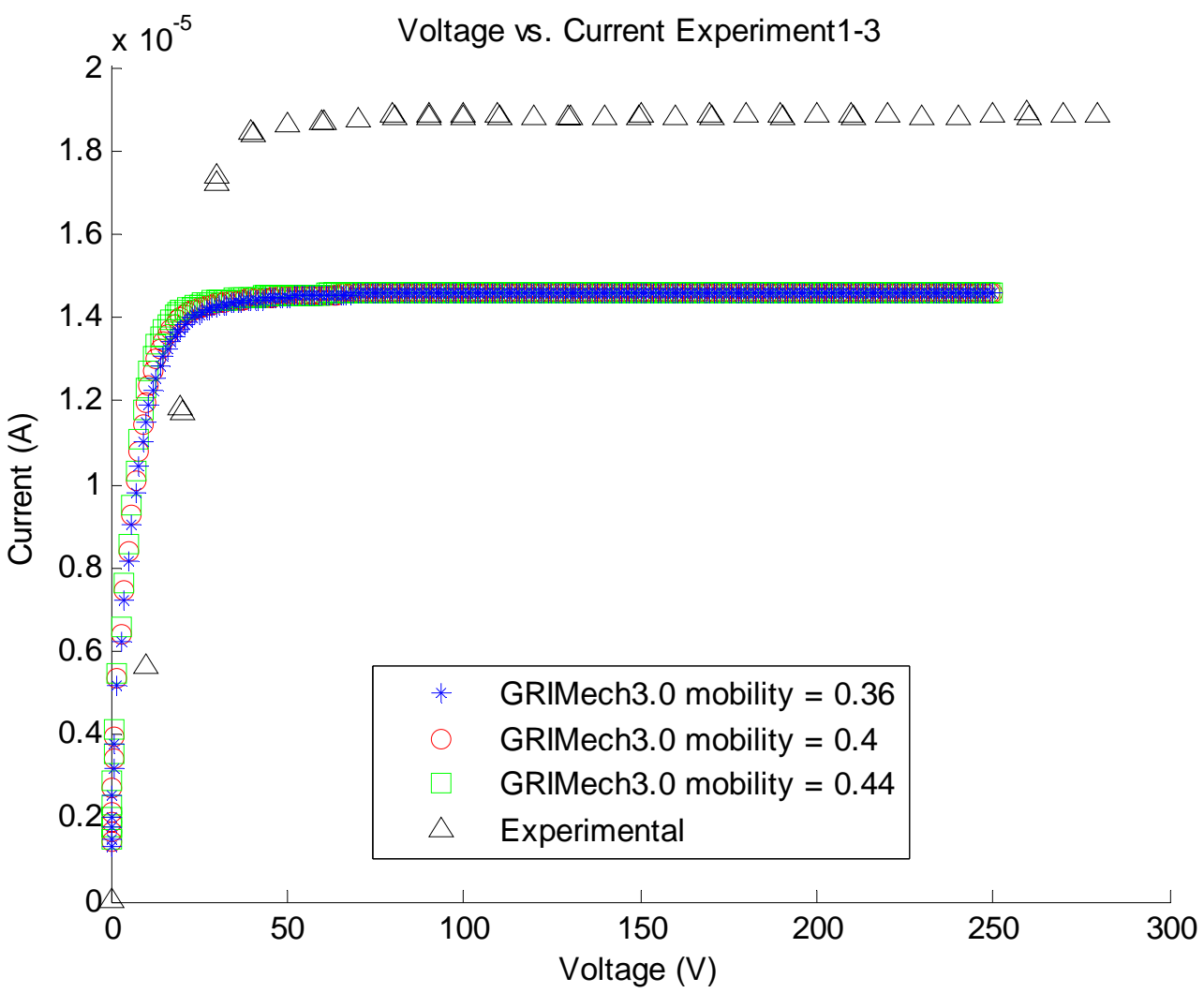

Figure E-3: Voltage vs. Current with Methane for GRI Experiment 1-3 


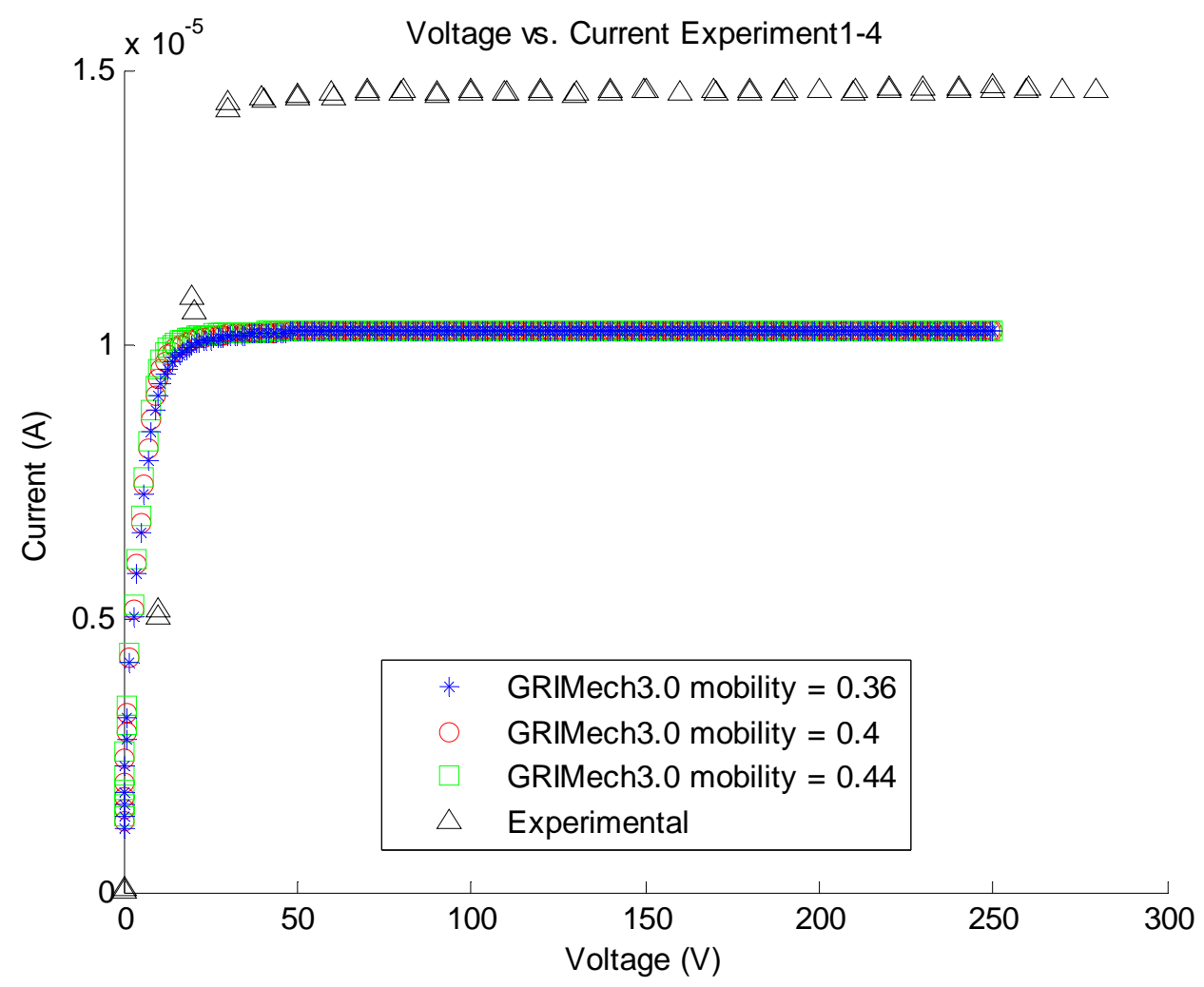

Figure E-4: Voltage vs. Current with Methane for GRI Experiment 1-4

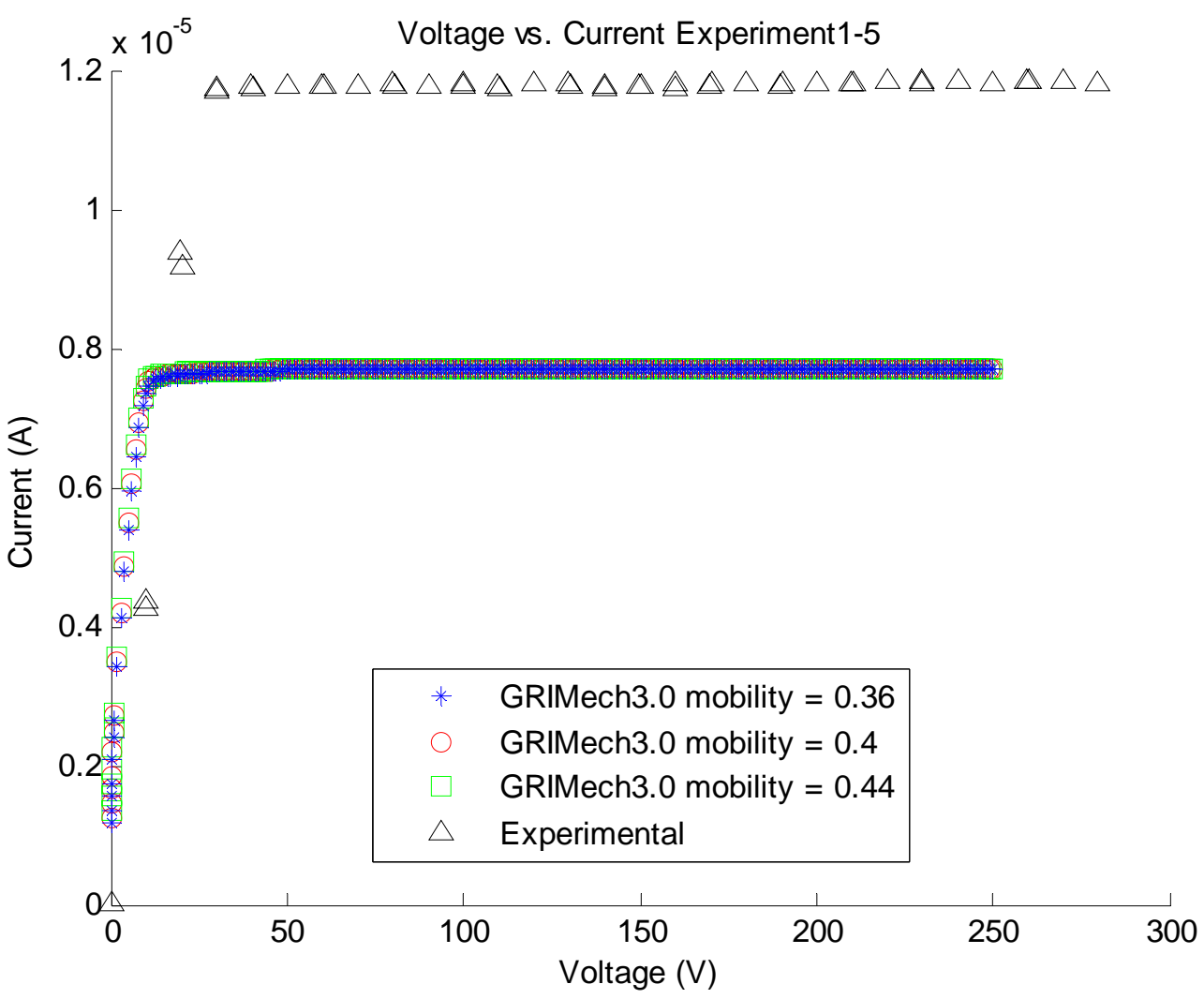

Figure E-5: Voltage vs. Current with Methane for GRI Experiment 1-5 


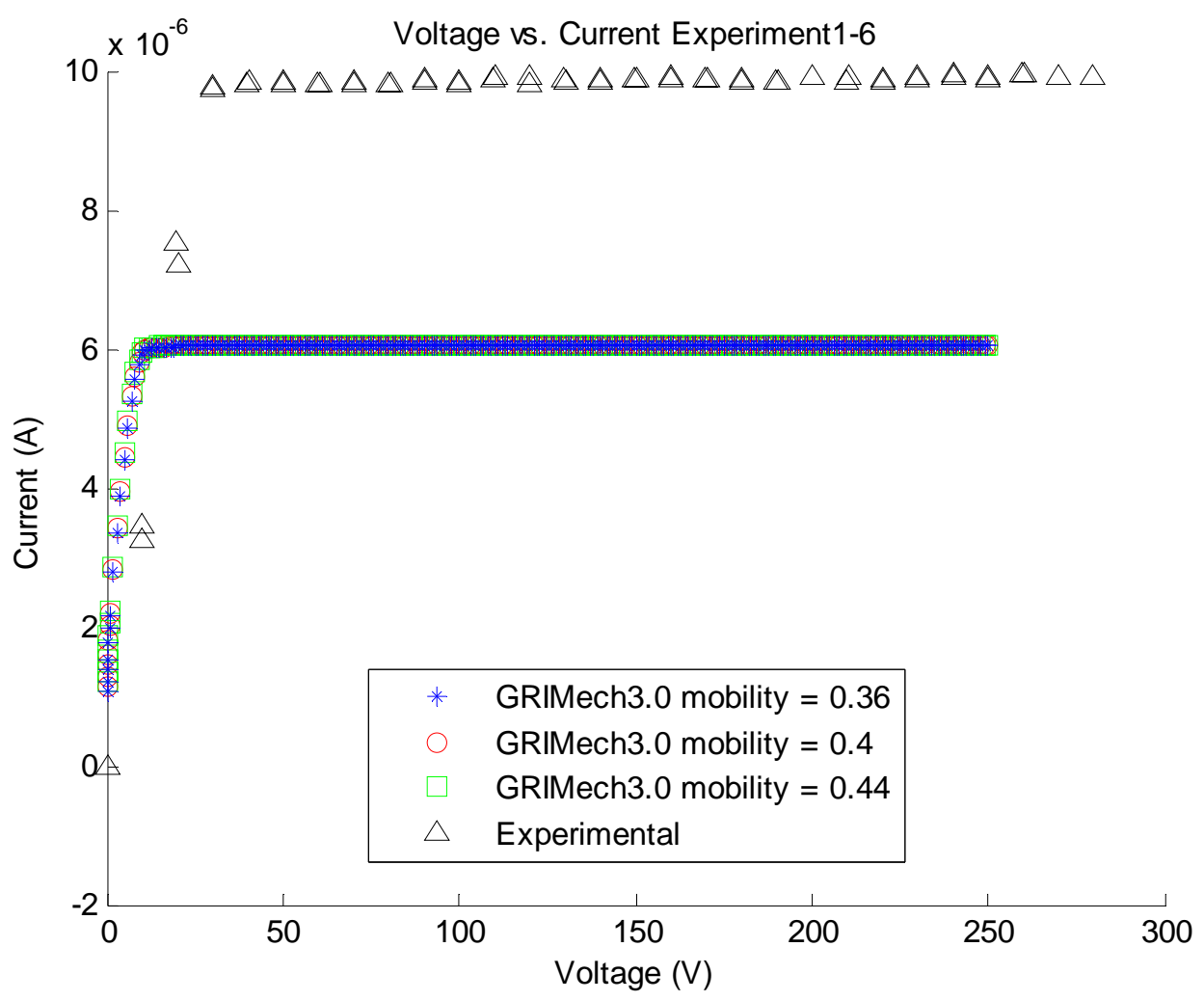

Figure E-6: Voltage vs. Current with Methane for GRI Experiment 1-6

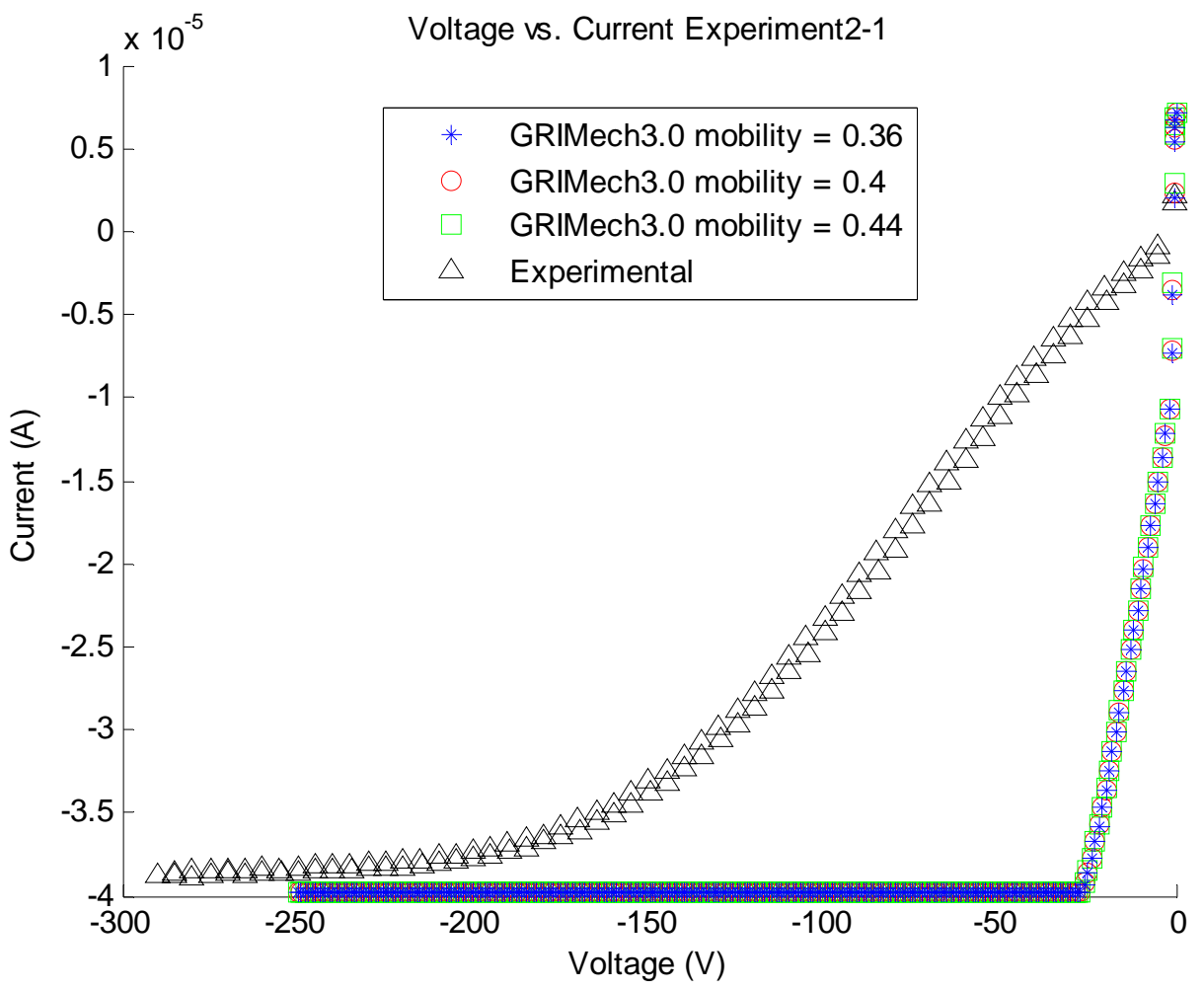

Figure E-7: Voltage vs. Current with Methane for GRI Experiment 2-1 


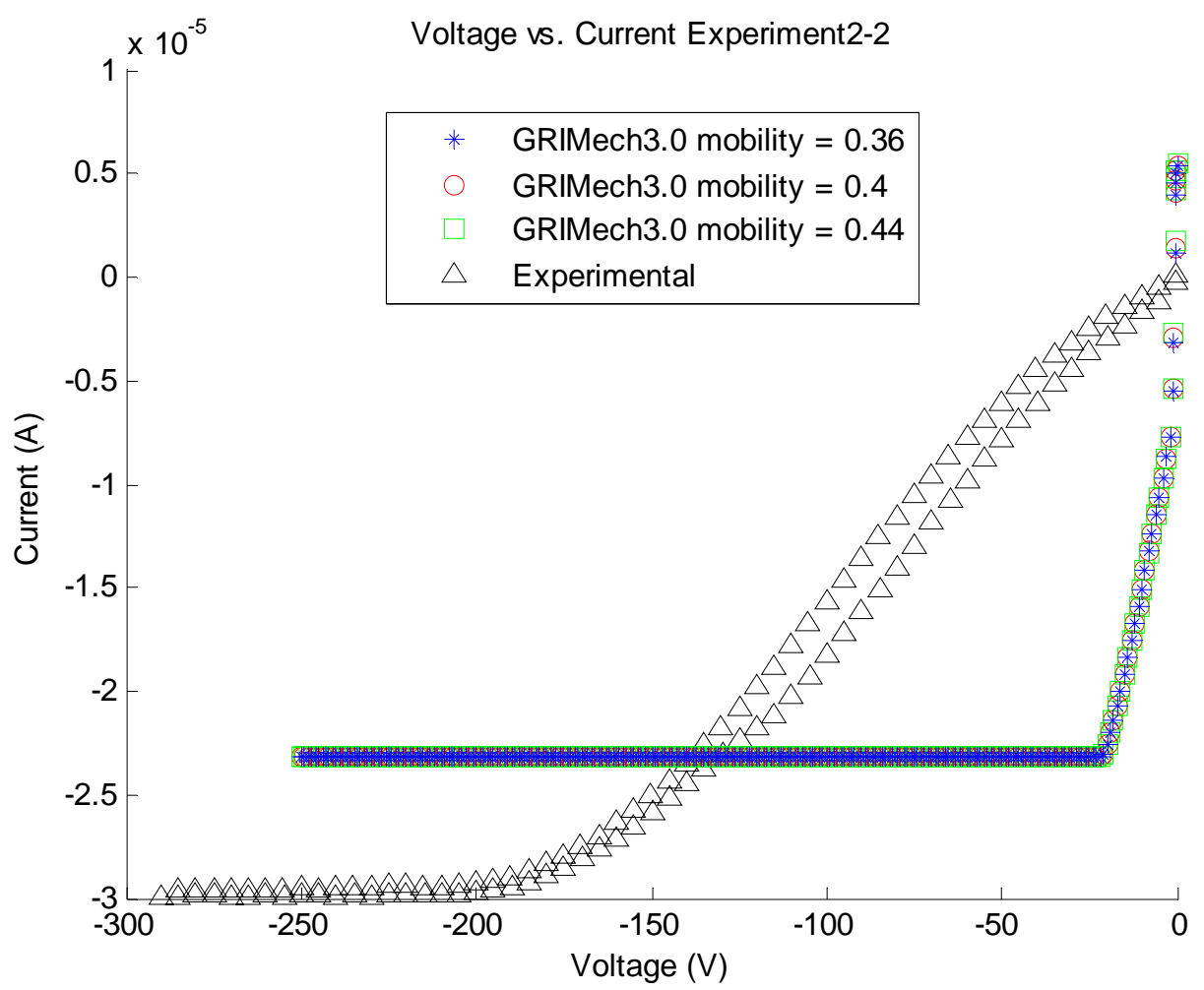

Figure E-8: Voltage vs. Current with Methane for GRI Experiment 2-2

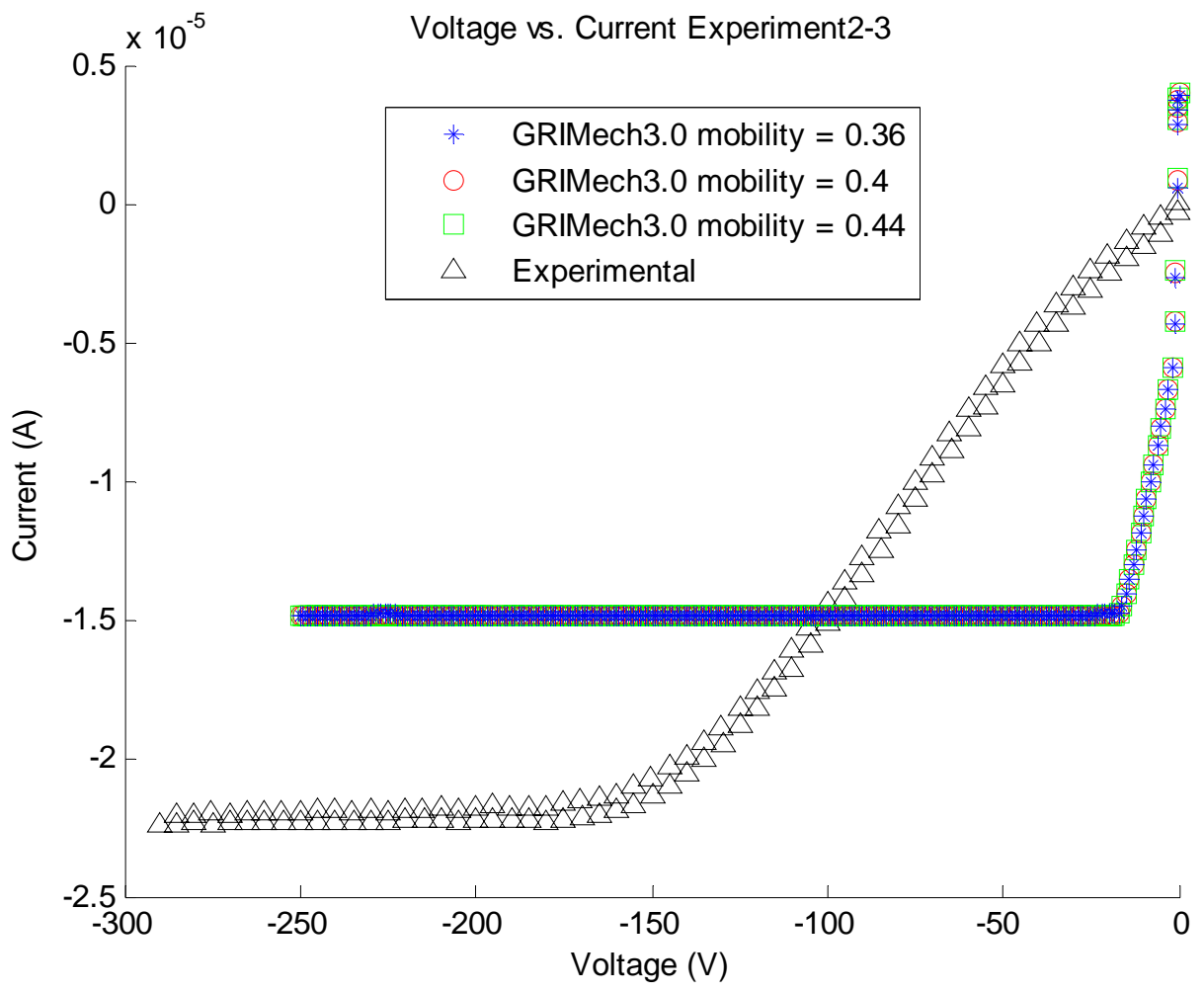

Figure E-9: Voltage vs. Current with Methane for GRI Experiment 2-3 


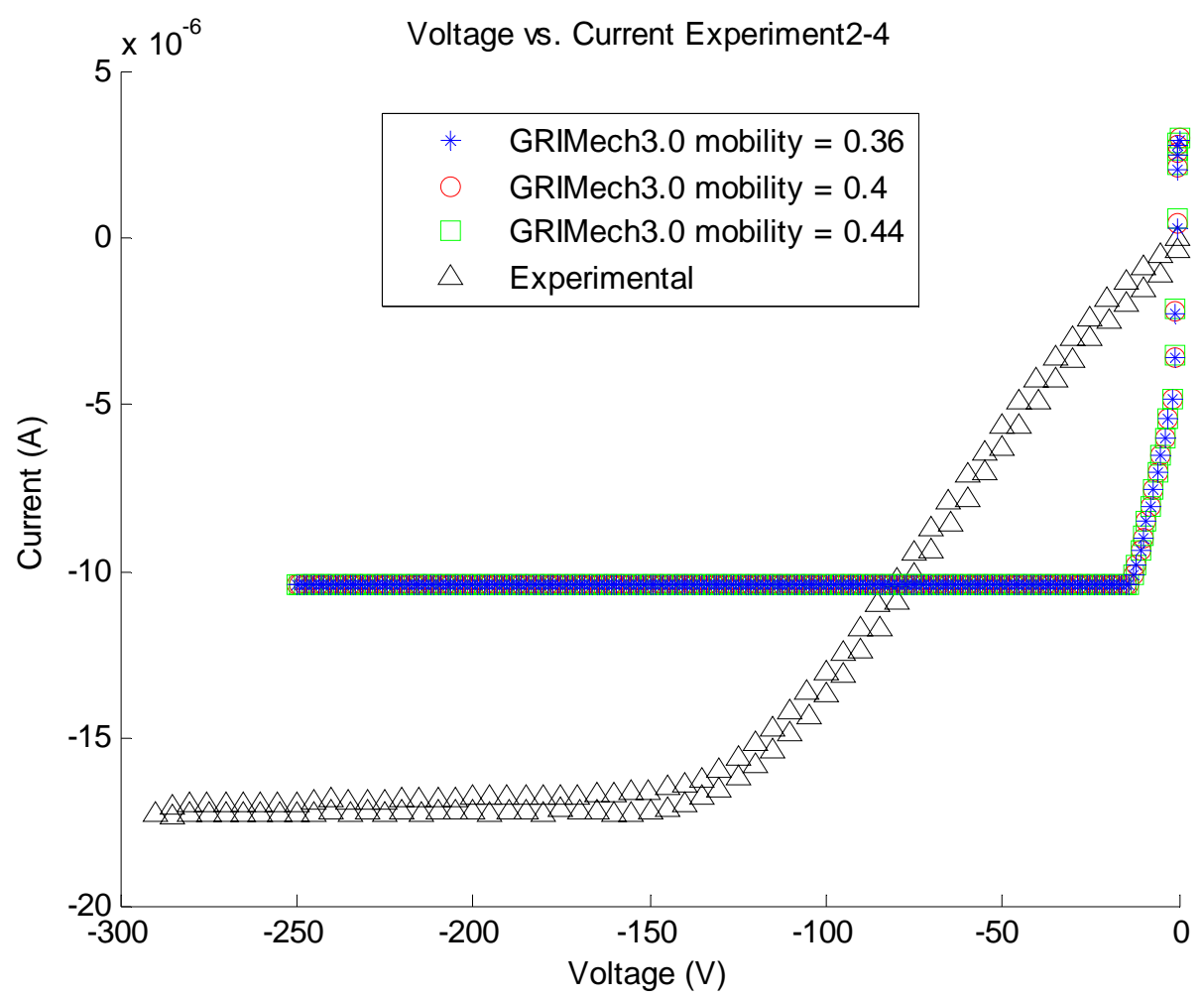

Figure E-10: Voltage vs. Current with Methane for GRI Experiment 2-4

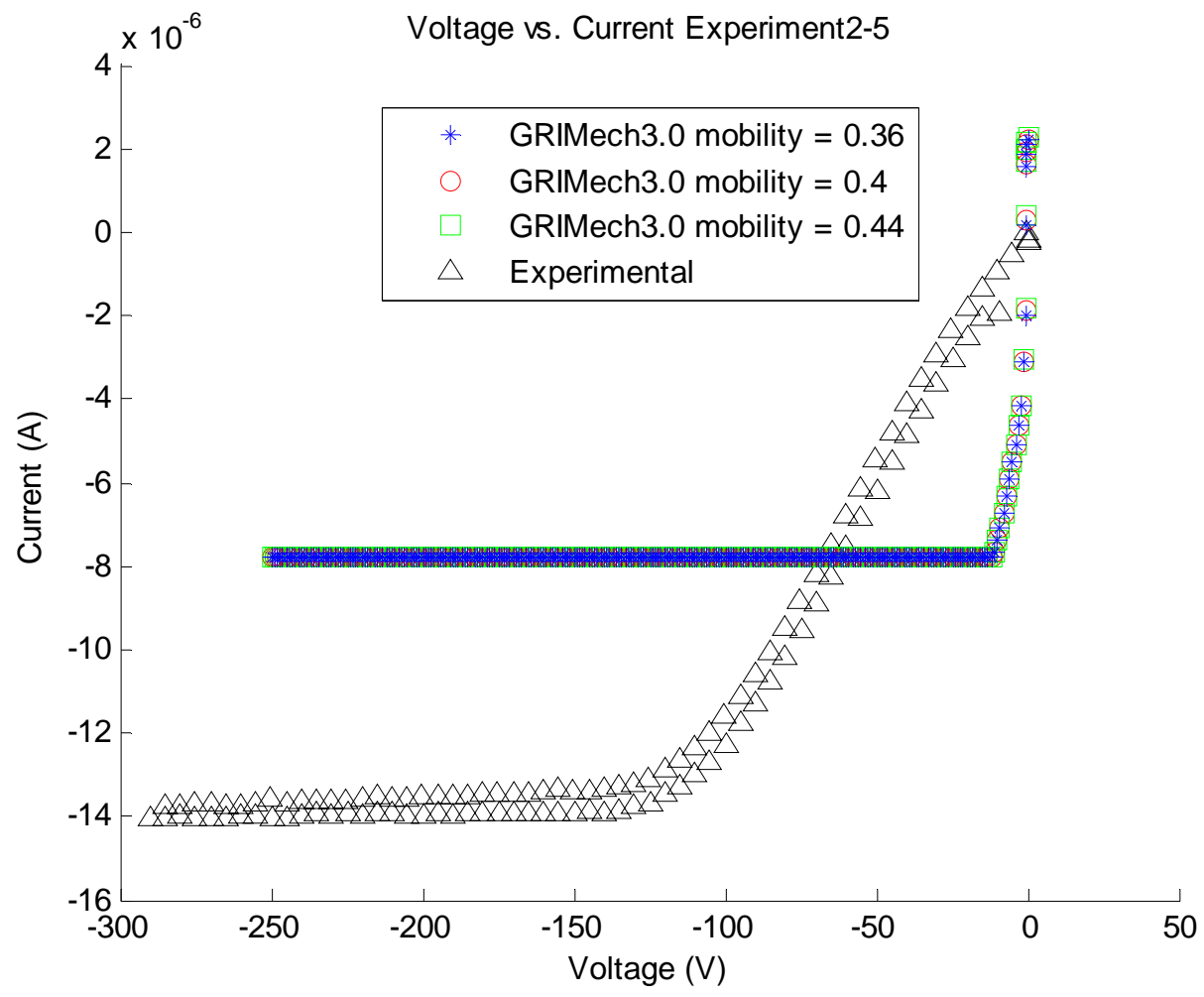

Figure E-11: Voltage vs. Current with Methane for GRI Experiment 2-5 


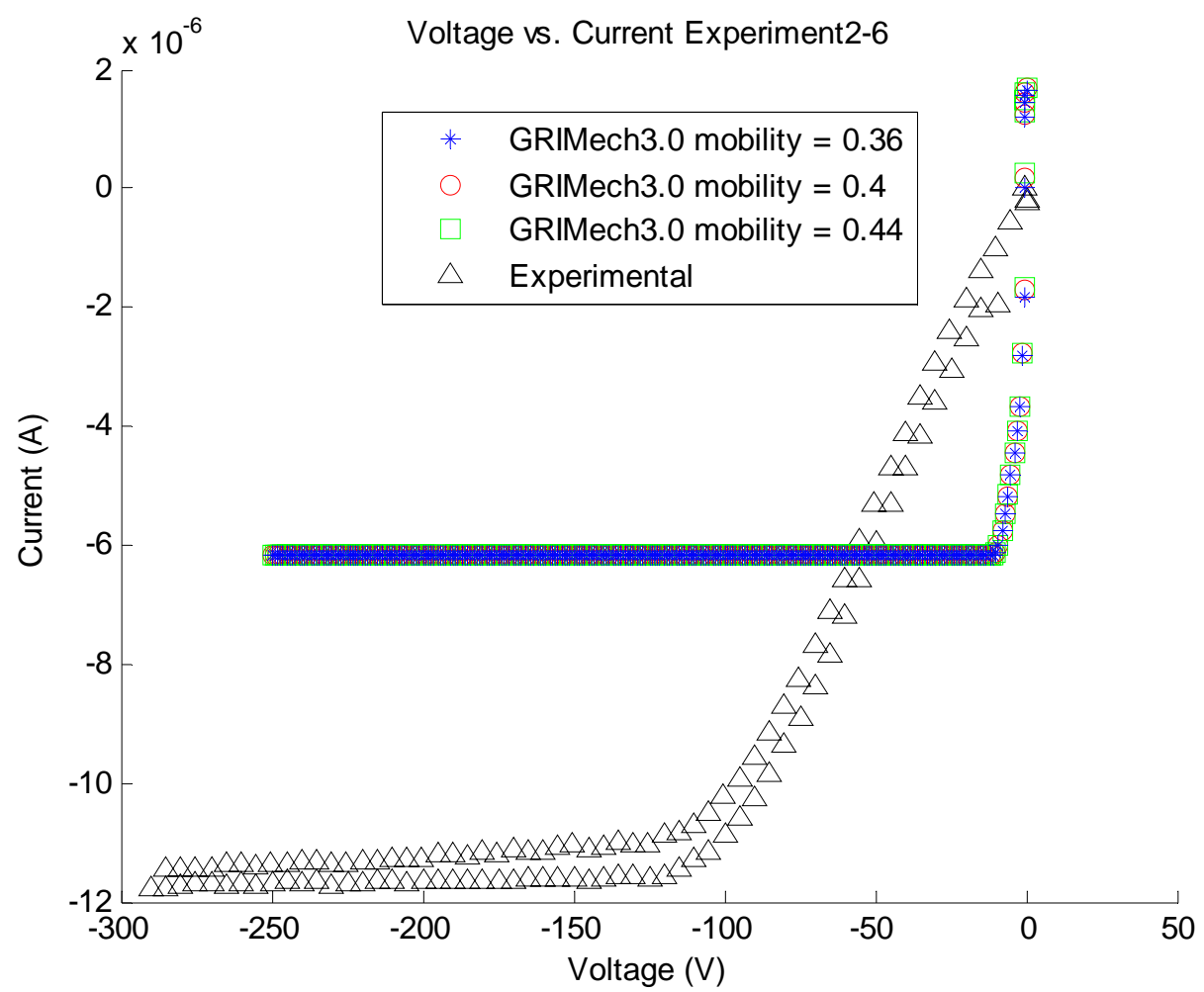

Figure E-12: Voltage vs. Current with Methane for GRI Experiment 2-6

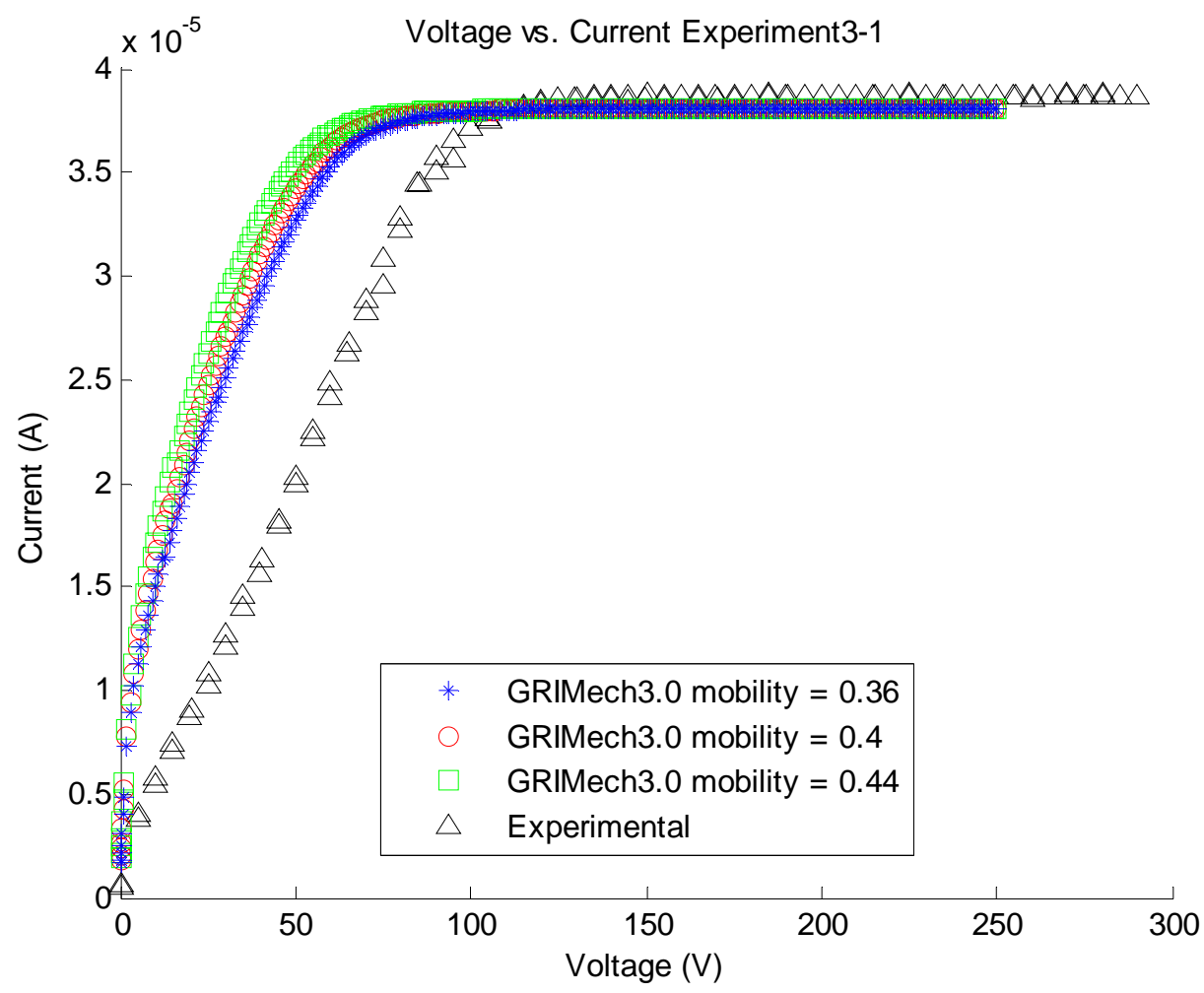

Figure E-13: Voltage vs. Current with Methane for GRI Experiment 3-1 


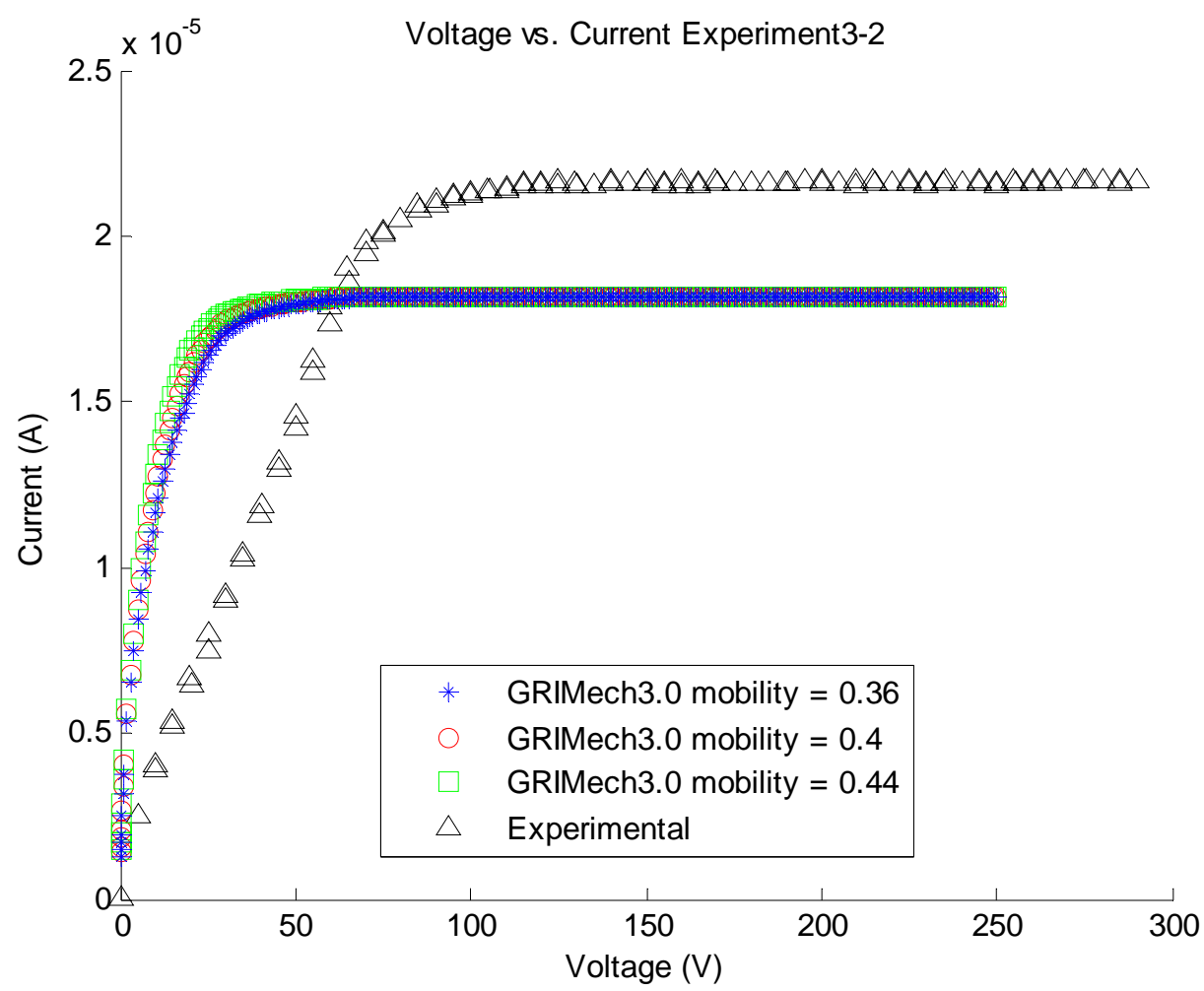

Figure E-14: Voltage vs. Current with Methane for GRI Experiment 3-2

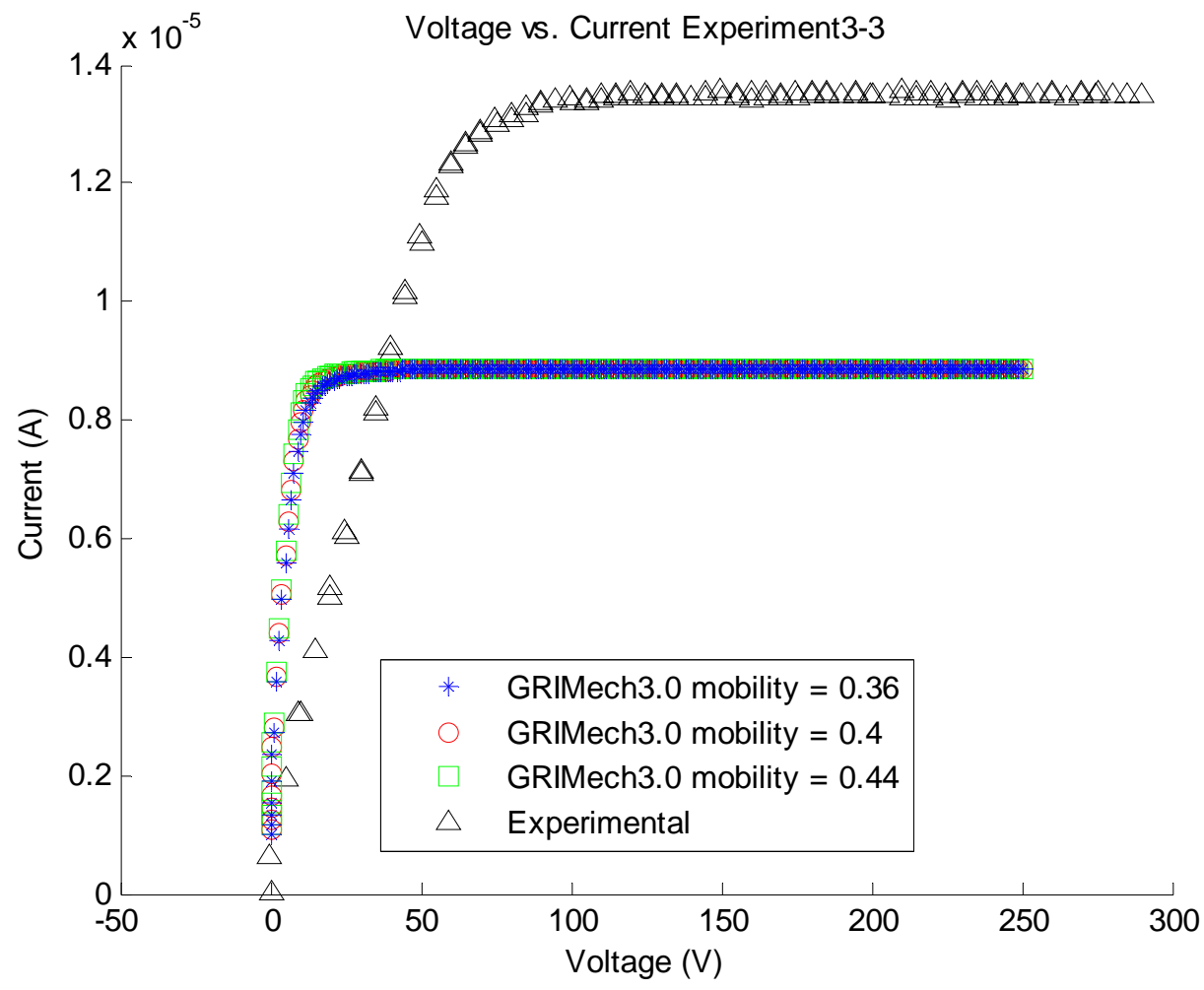

Figure E-15: Voltage vs. Current with Methane for GRI Experiment 3-3 


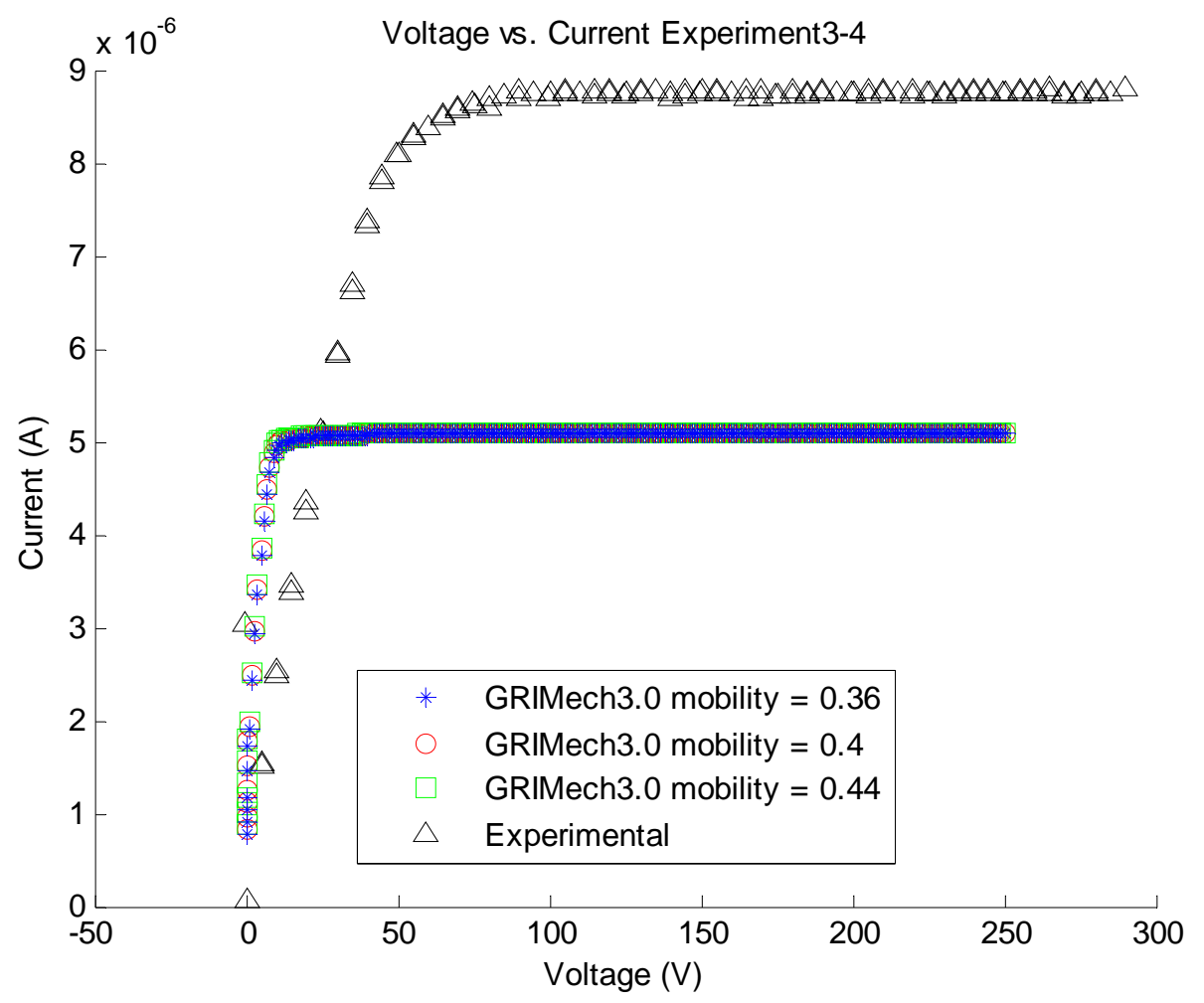

Figure E-16: Voltage vs. Current with Methane for GRI Experiment 3-4

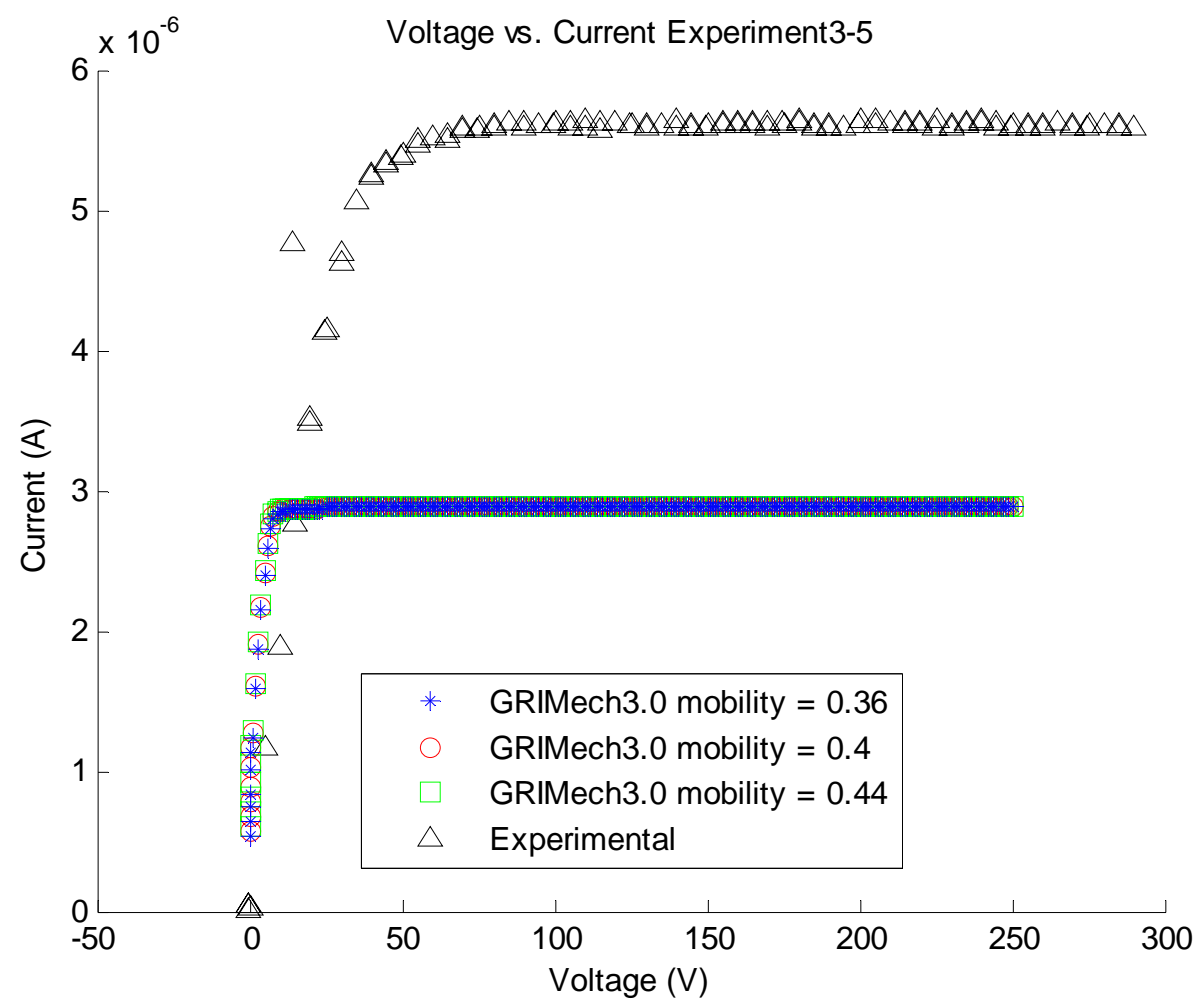

Figure E-17: Voltage vs. Current with Methane for GRI Experiment 3-5 


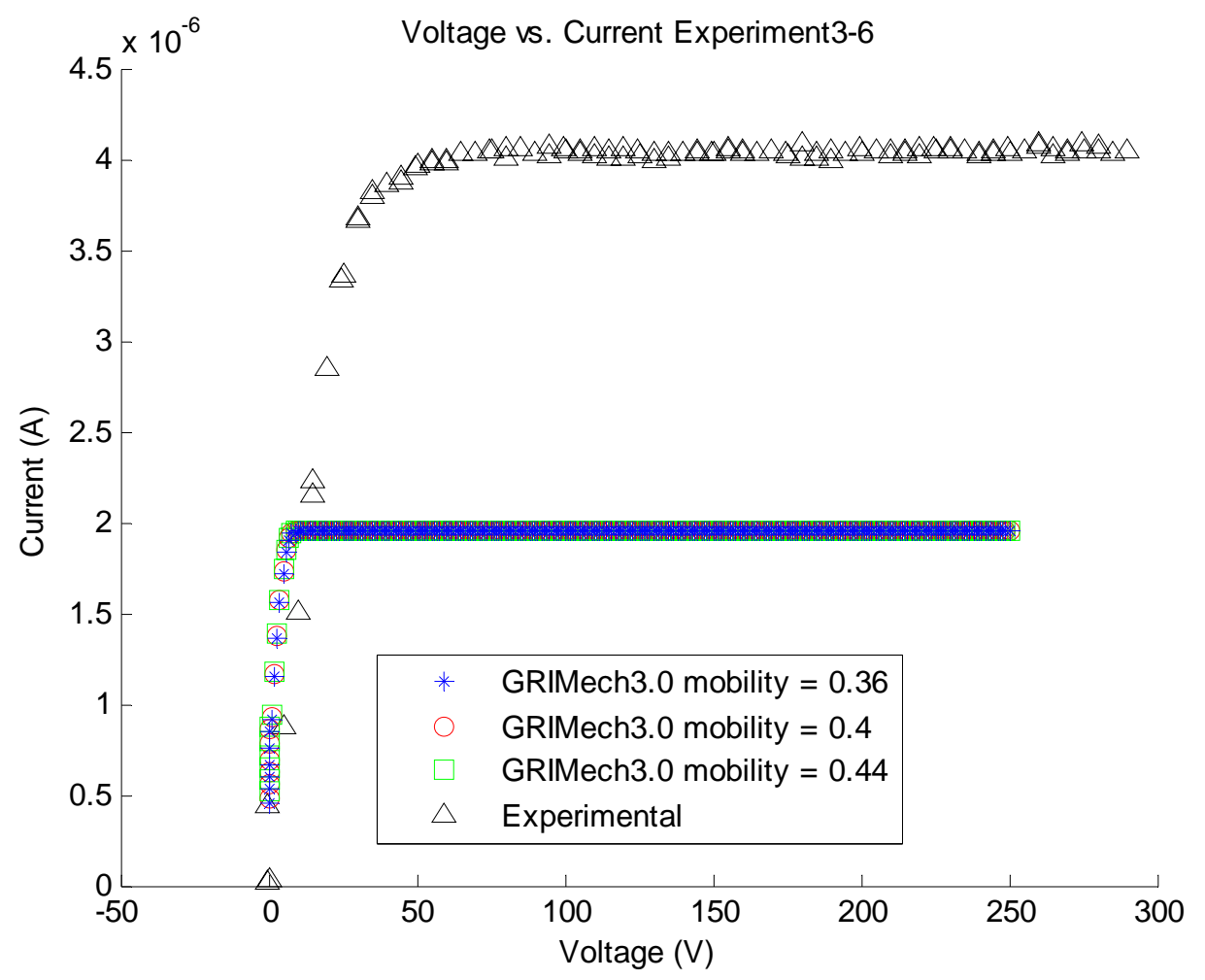

Figure E-18: Voltage vs. Current with Methane for GRI Experiment 3-6 


\section{E-2: V-I Plots of Methane Combustion Using Jones, Becker and Heinsohn}

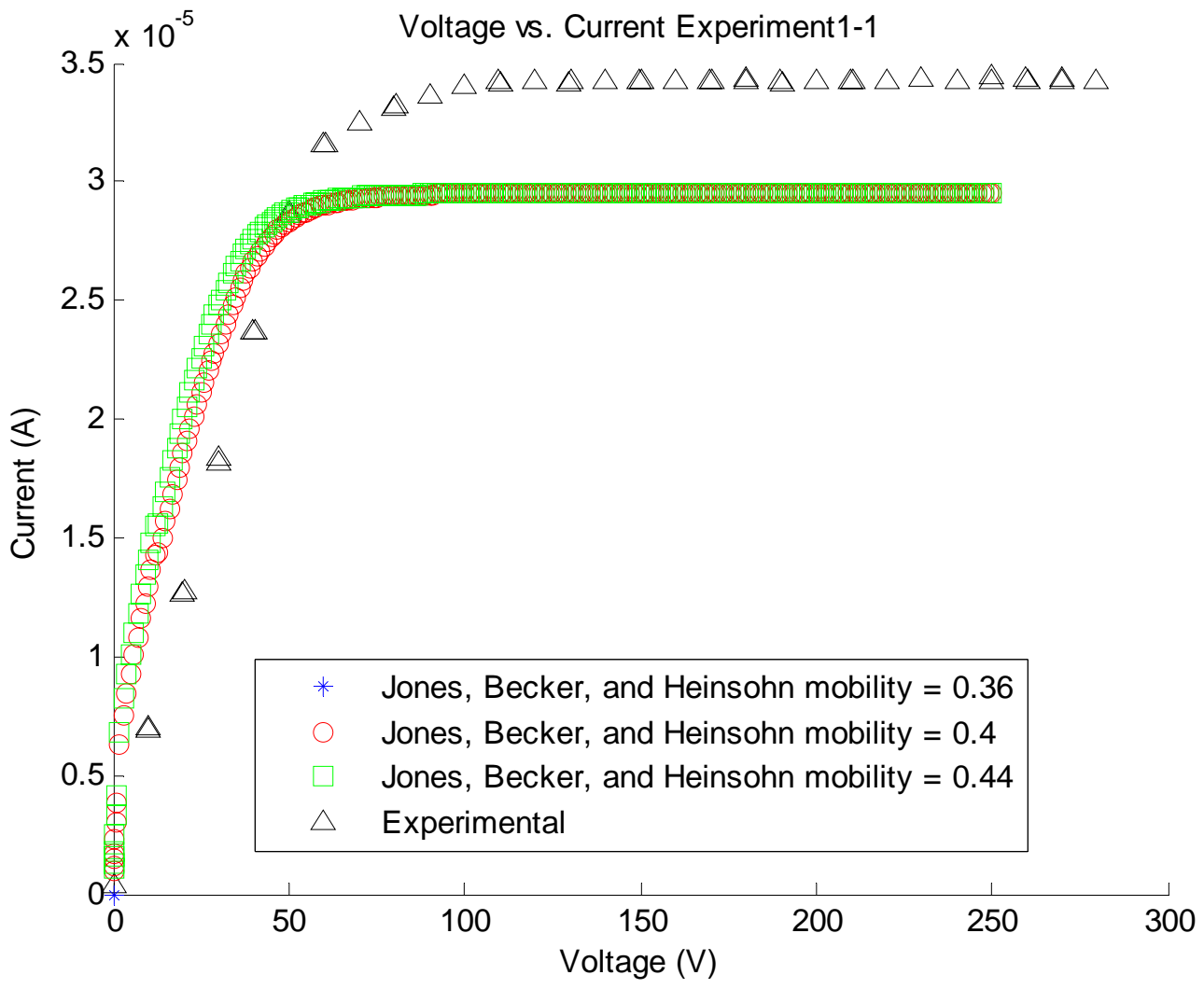

Figure E-19: Voltage vs. Current with Methane for Jones, Becker and Heinsohn Experiment 1-1 


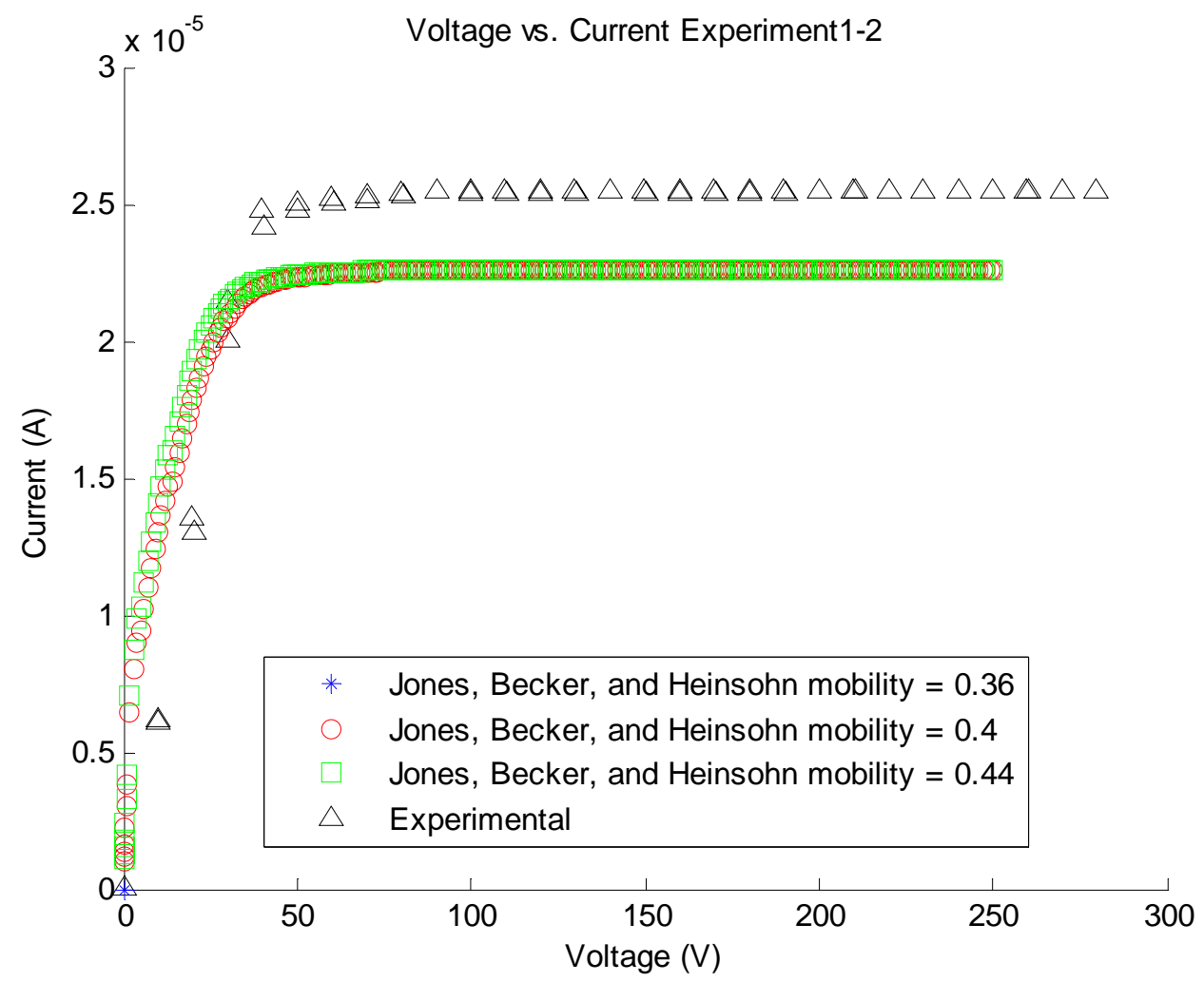

Figure E-20: Voltage vs. Current with Methane for Jones, Becker and Heinsohn Experiment 1-2

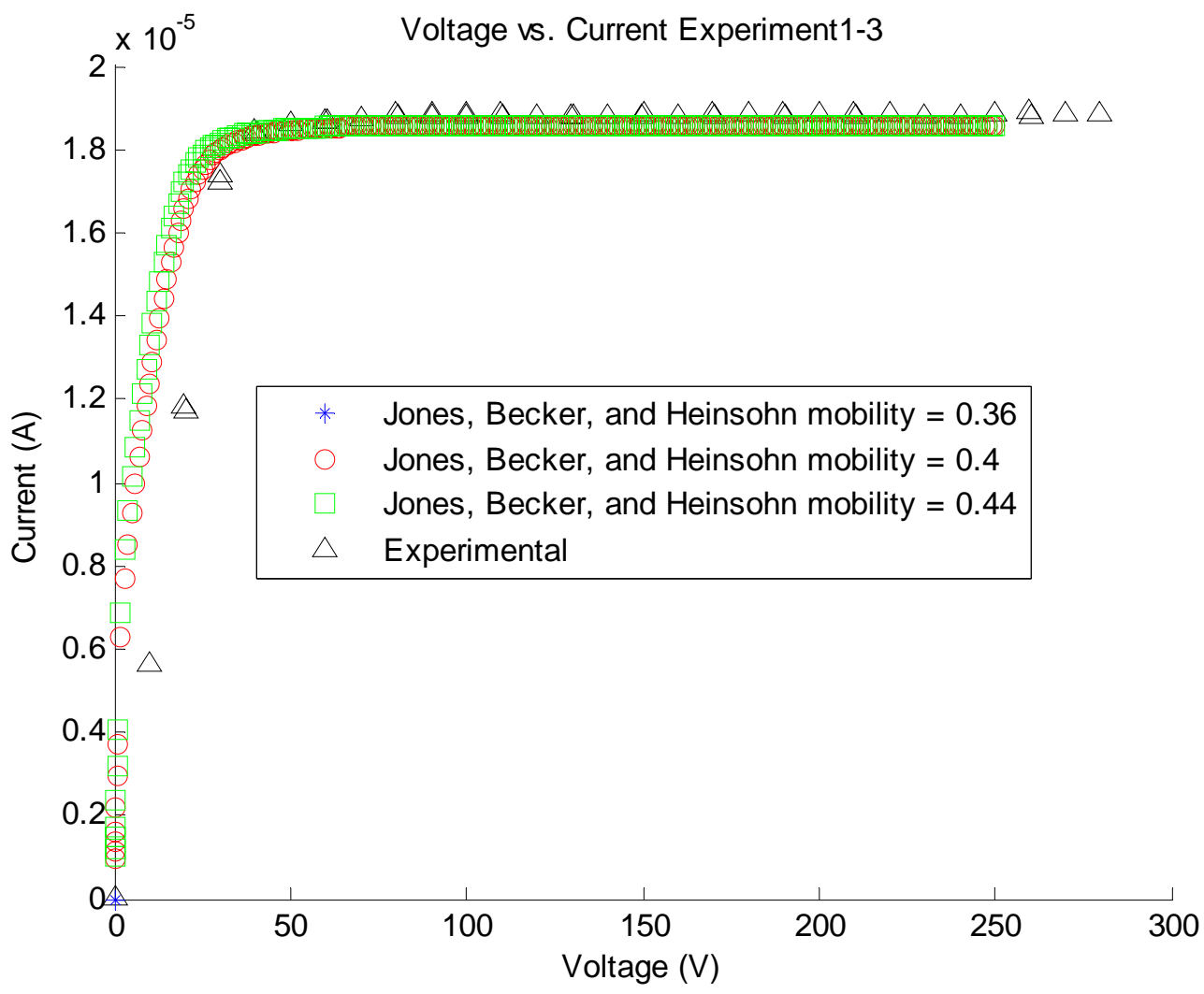

Figure E-21: Voltage vs. Current with Methane for Jones, Becker and Heinsohn Experiment 1-3 


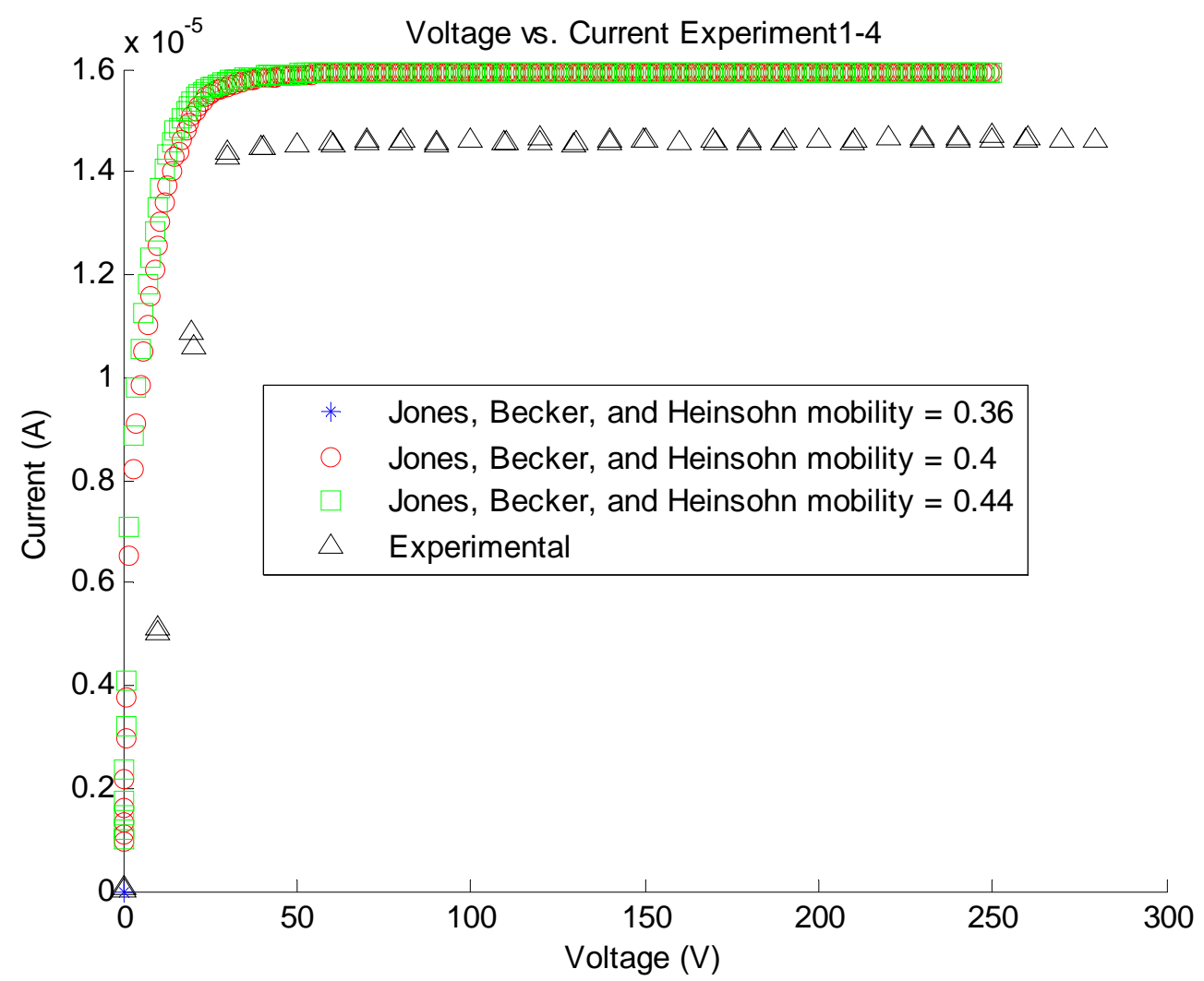

Figure E-22: Voltage vs. Current with Methane for Jones, Becker and Heinsohn Experiment 1-4

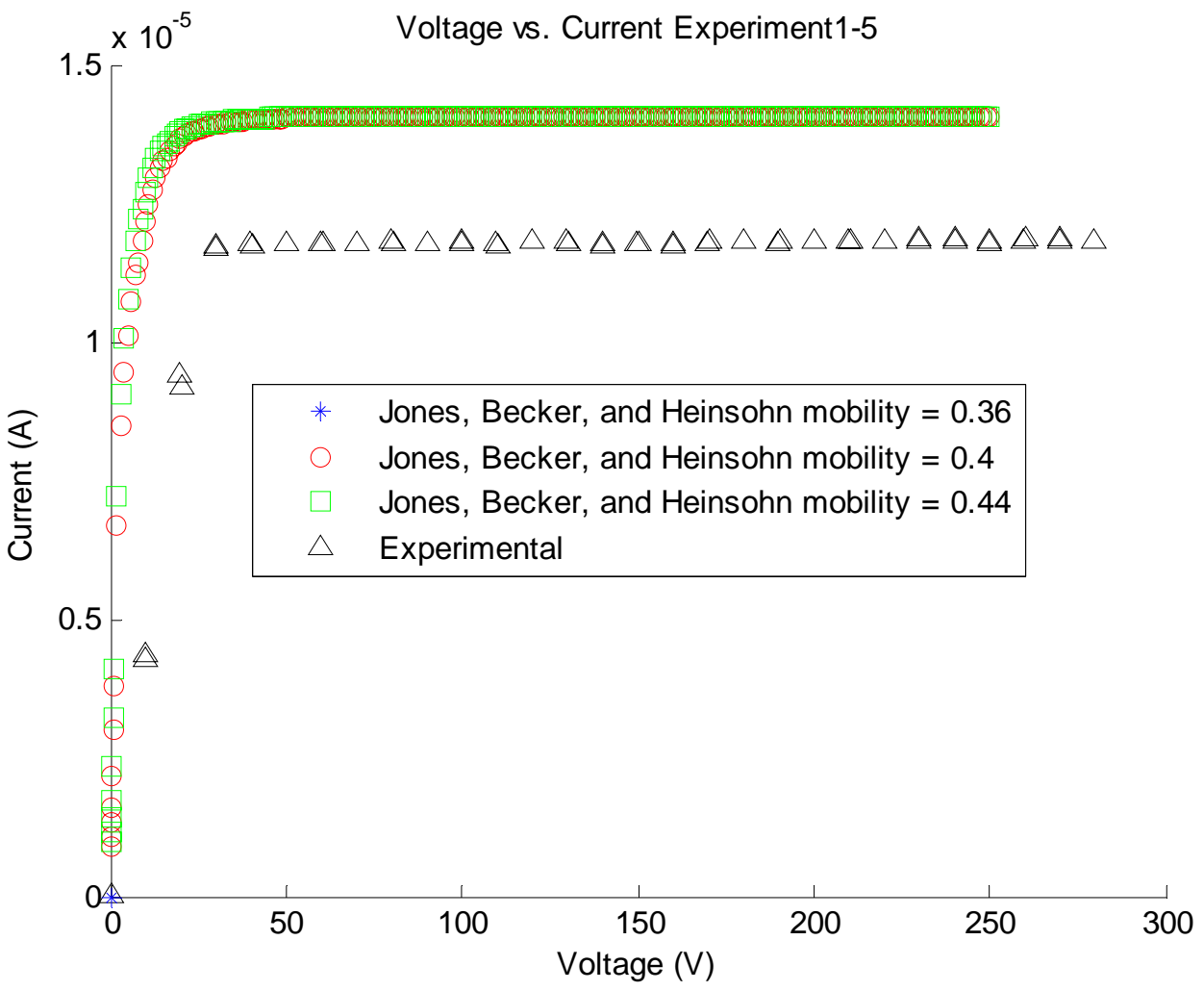

Figure E-23: Voltage vs. Current with Methane for Jones, Becker and Heinsohn Experiment 1-5 


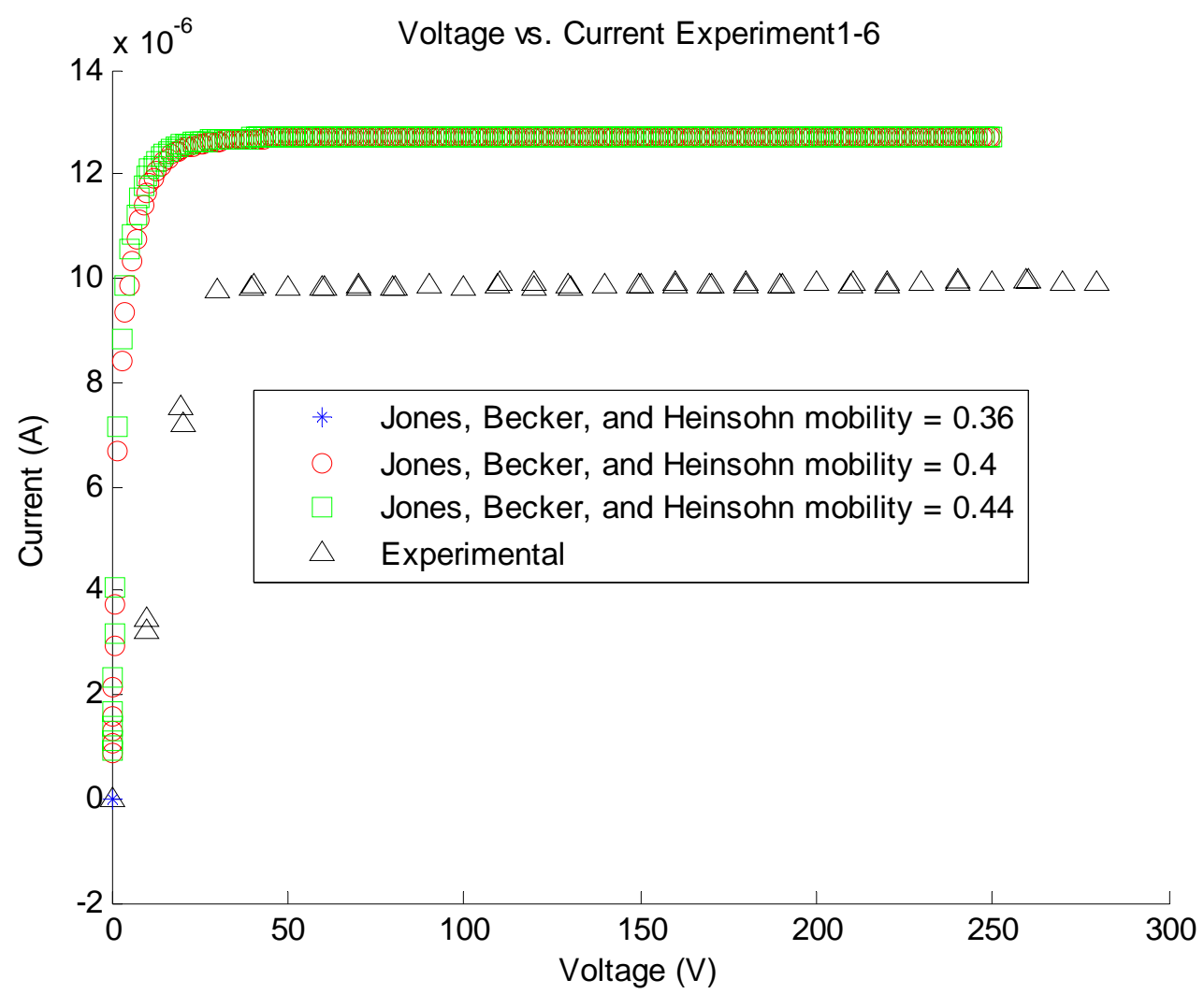

Figure E-24: Voltage vs. Current with Methane for Jones, Becker and Heinsohn Experiment 1-6

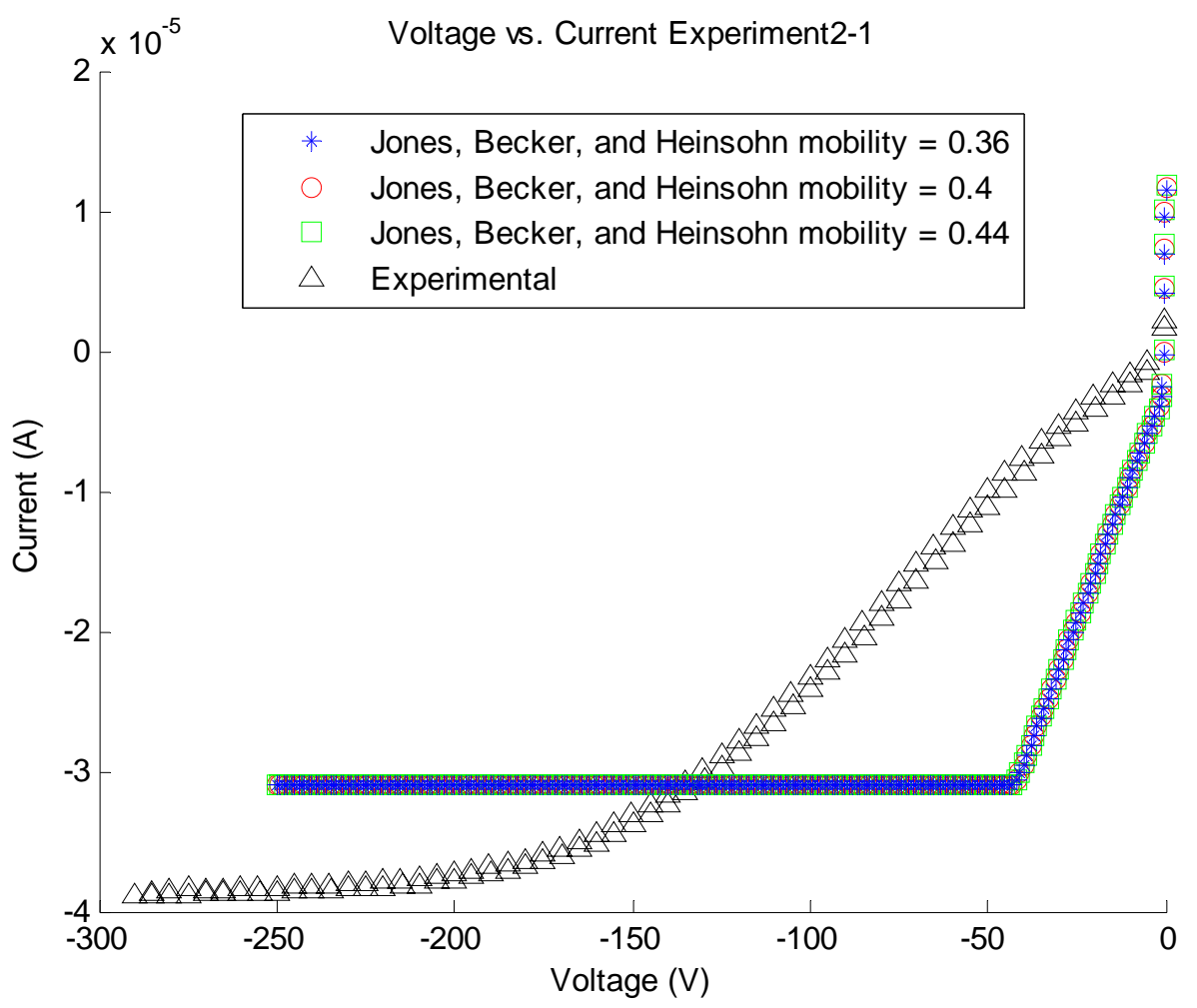

Figure E-25: Voltage vs. Current with Methane for Jones, Becker, and Heinsohn Experiment 2-1 


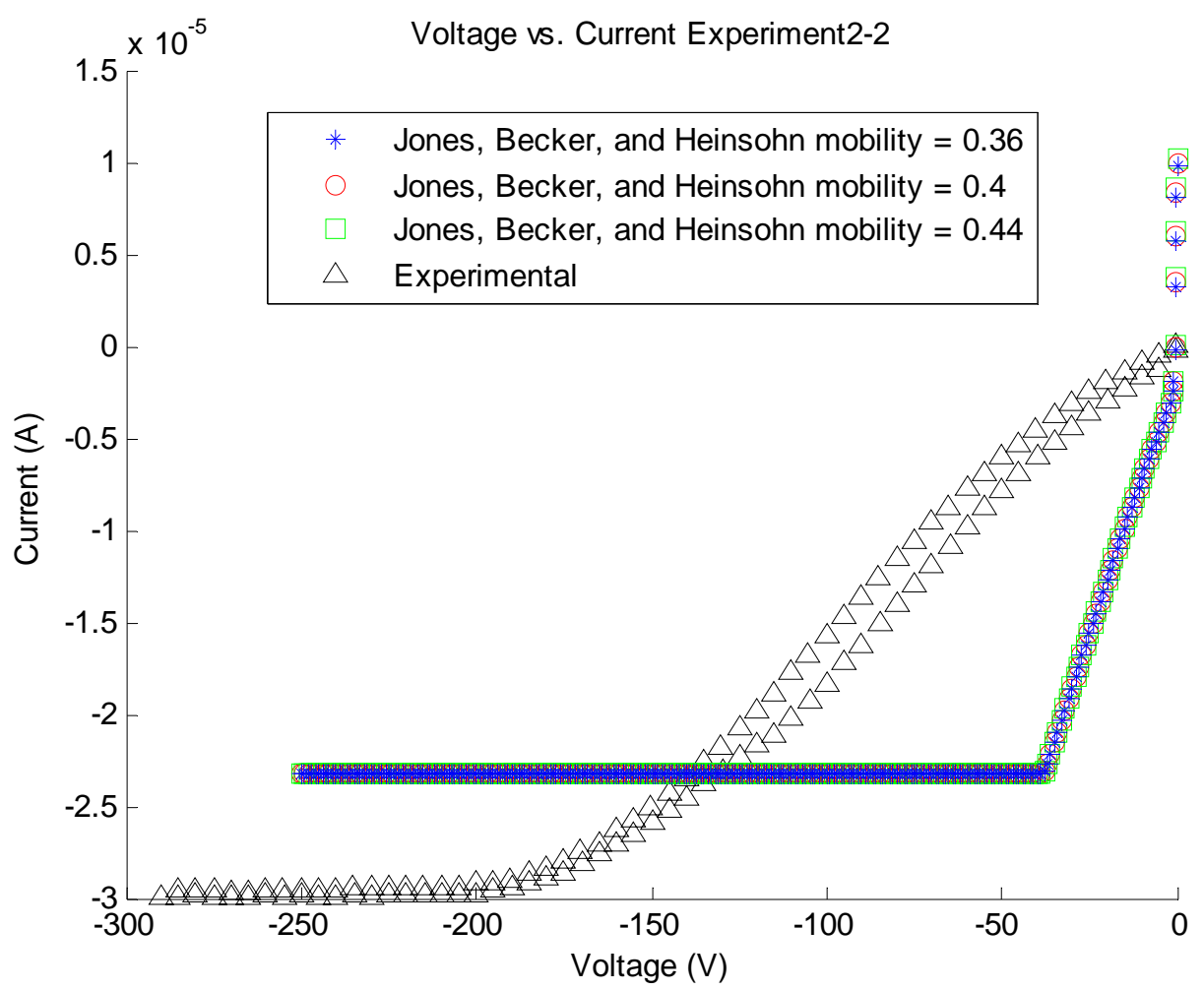

Figure E-26: Voltage vs. Current with Methane for Jones, Becker, and Heinsohn Experiment 2-2

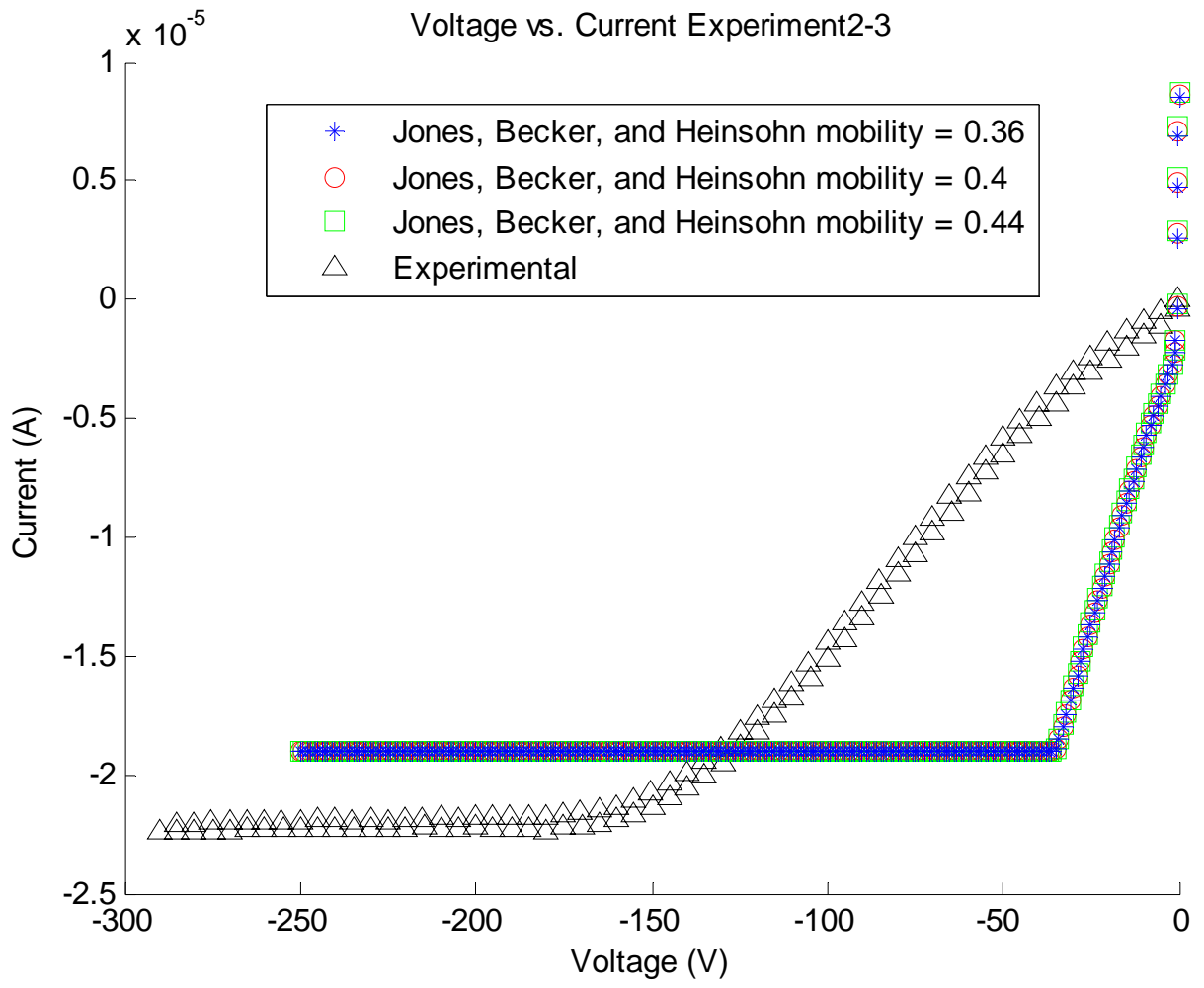

Figure E-27: Voltage vs. Current with Methane for Jones, Becker, and Heinsohn Experiment 2-3 


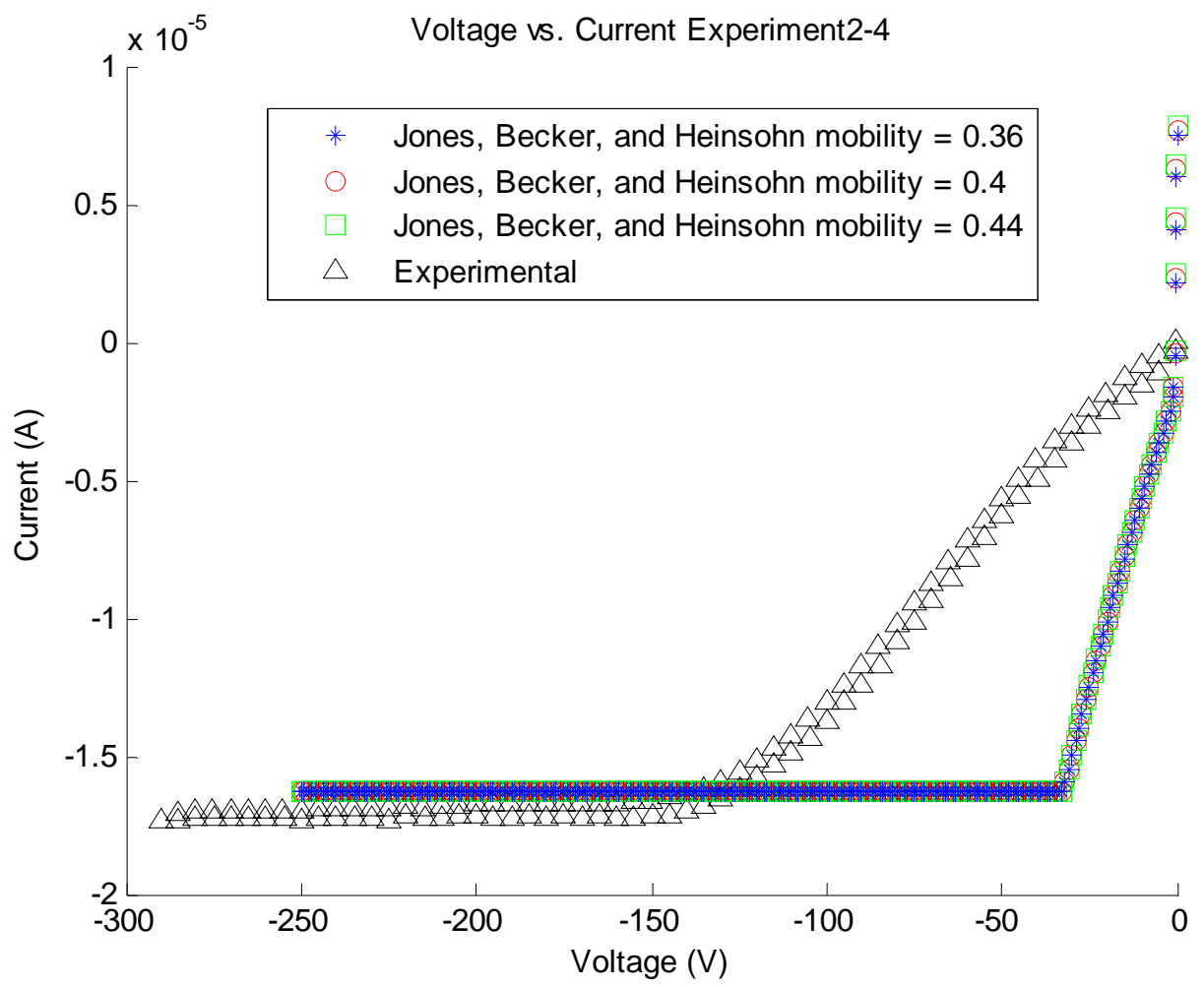

Figure E-28: Voltage vs. Current with Methane for Jones, Becker, and Heinsohn Experiment 2-4

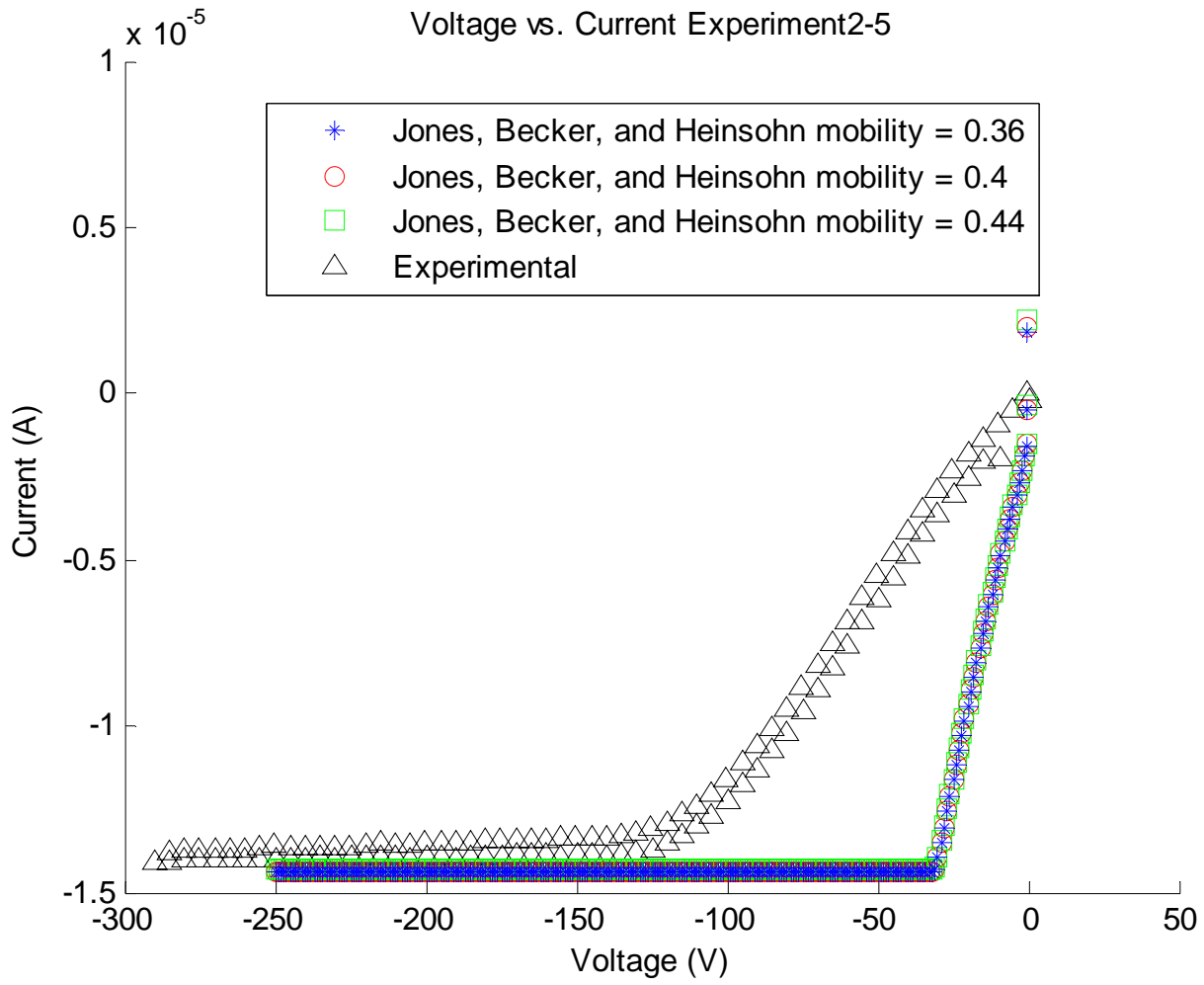

Figure E-29: Voltage vs. Current with Methane for Jones, Becker, and Heinsohn Experiment 2-5 


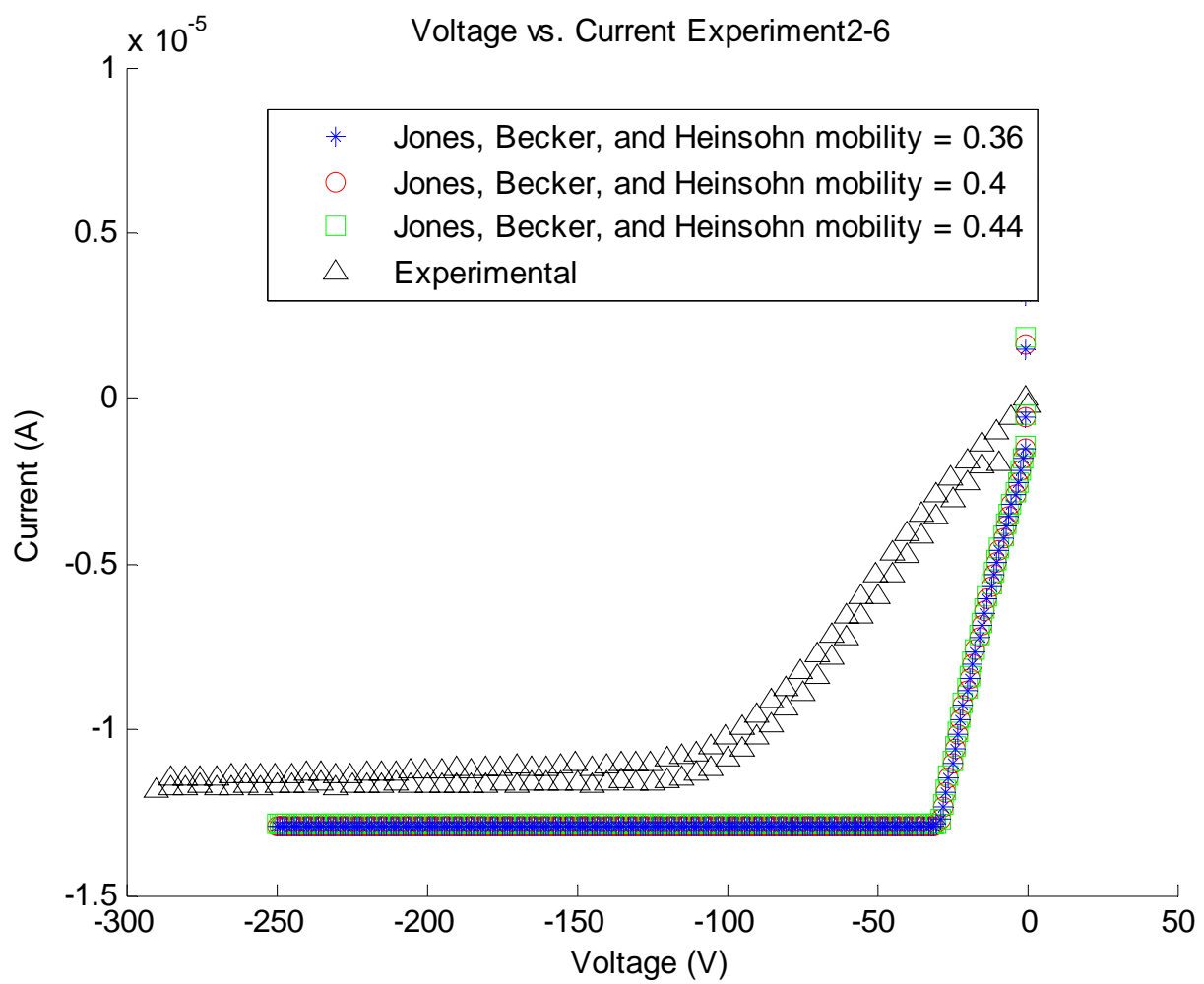

Figure E-30: Voltage vs. Current with Methane for Jones, Becker, and Heinsohn Experiment 2-6

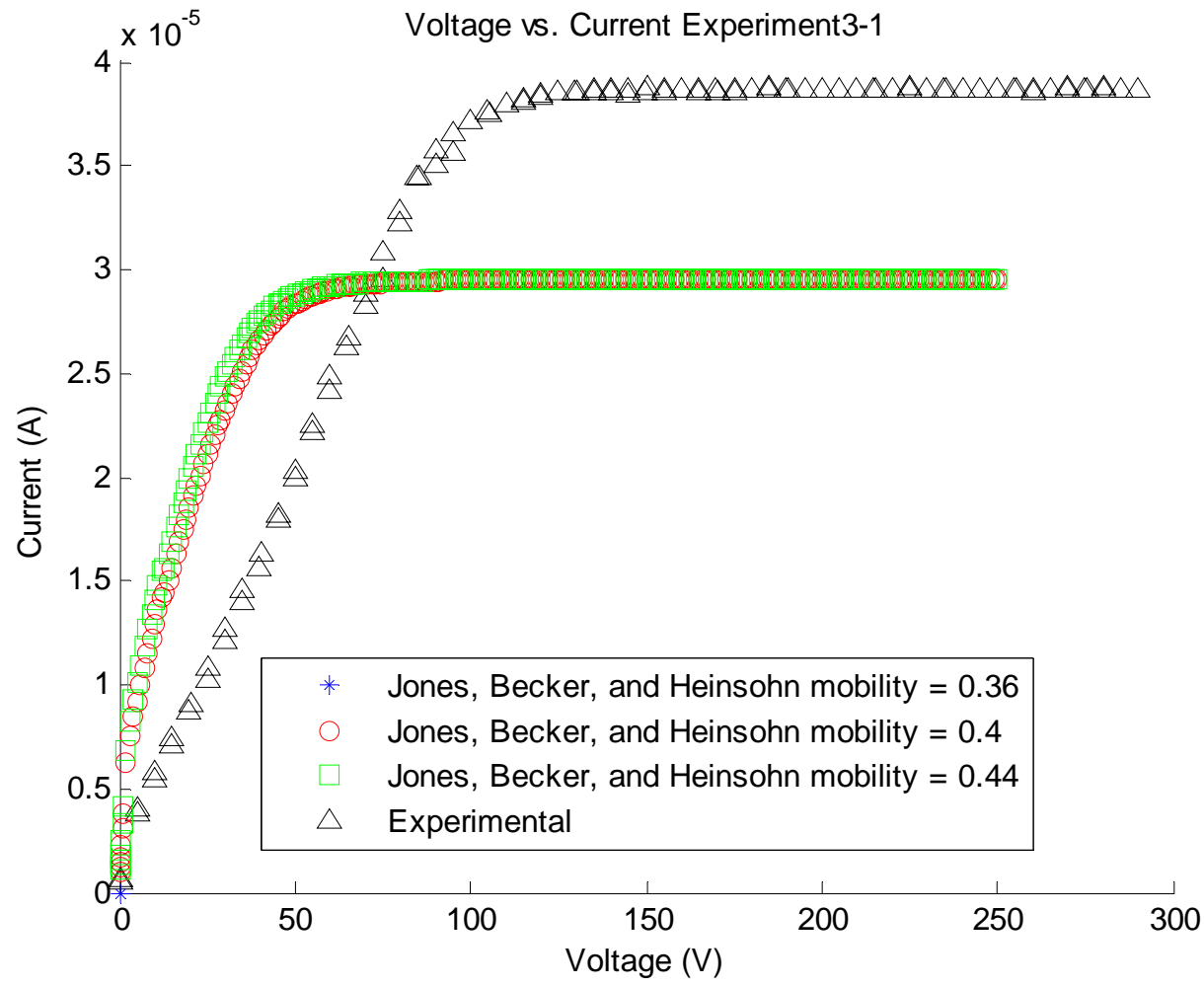

Figure E-31: Voltage vs. Current with Methane for Jones, Becker, and Heinsohn Experiment 3-1 


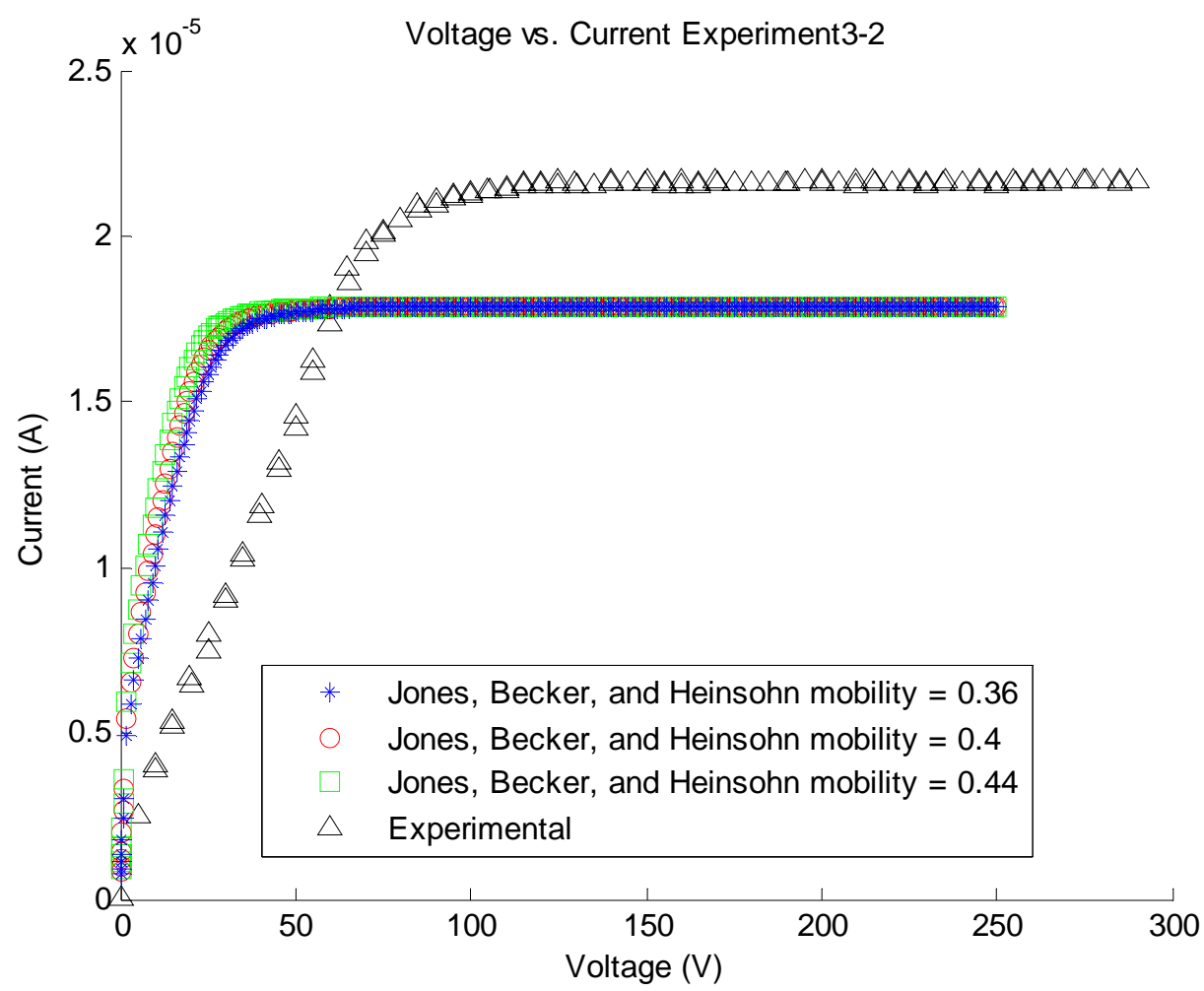

Figure E-32: Voltage vs. Current with Methane for Jones, Becker, and Heinsohn Experiment 3-2

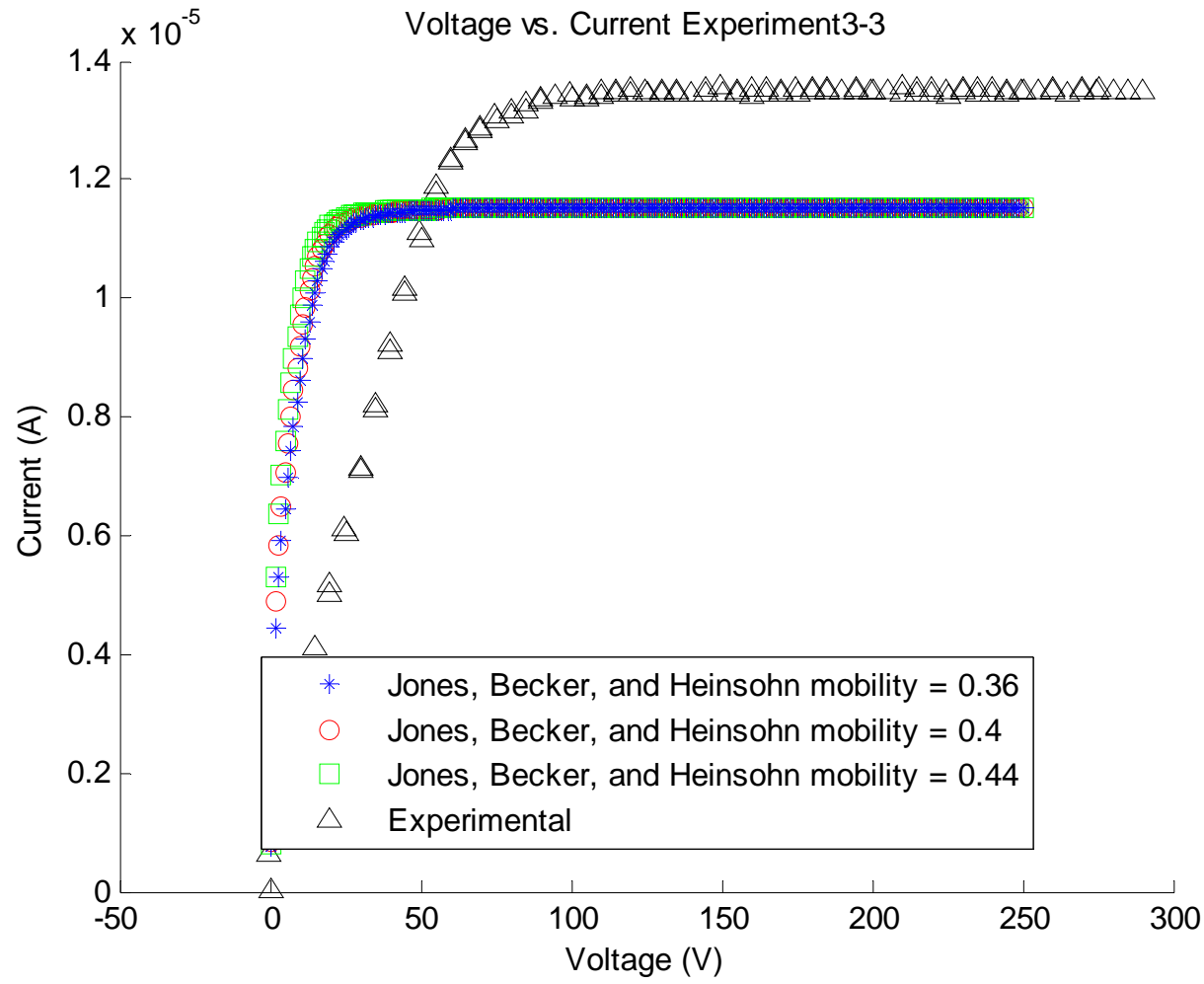

Figure E-33: Voltage vs. Current with Methane for Jones, Becker, and Heinsohn Experiment 3-3 


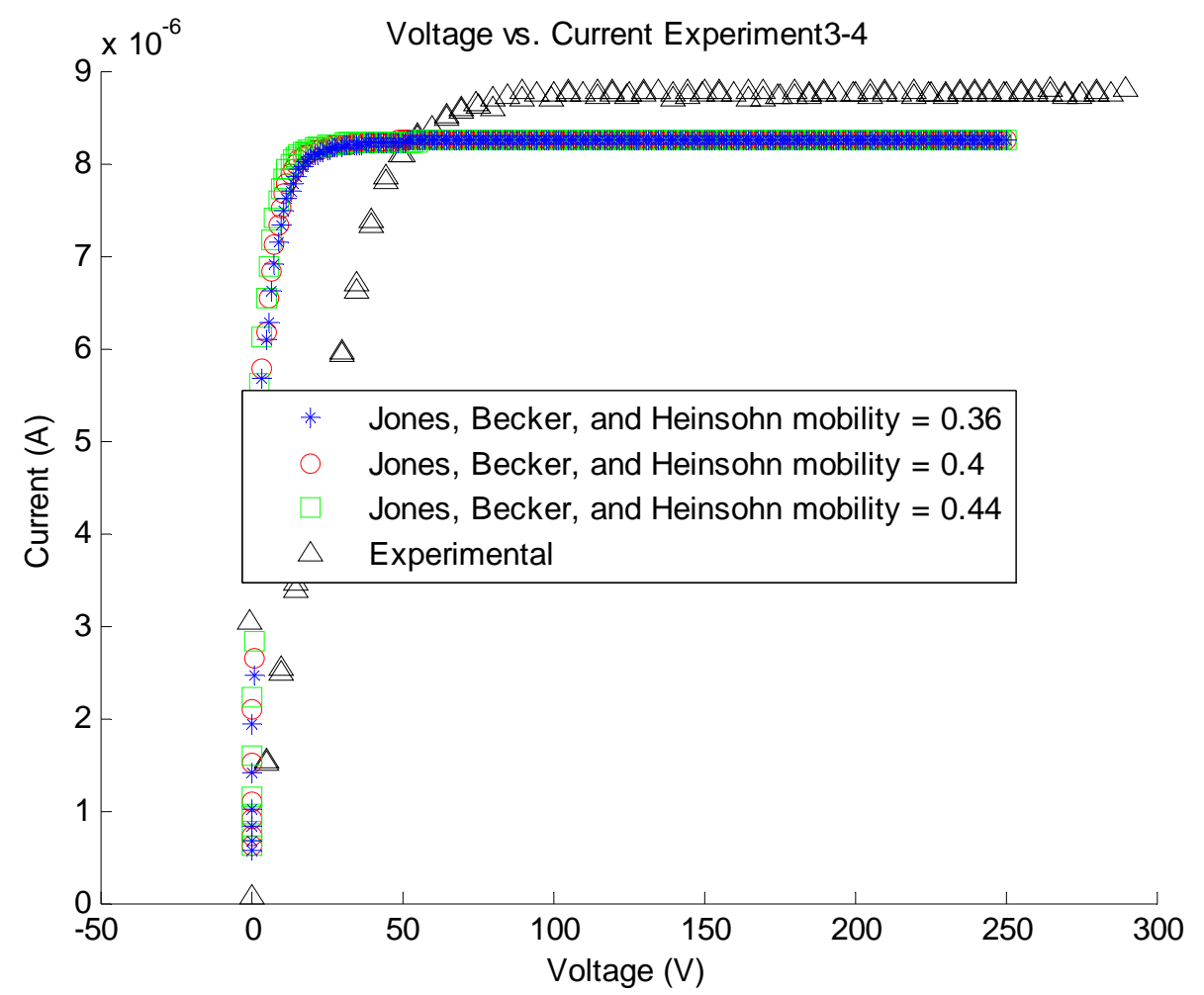

Figure E-34: Voltage vs. Current with Methane for Jones, Becker, and Heinsohn Experiment 3-4

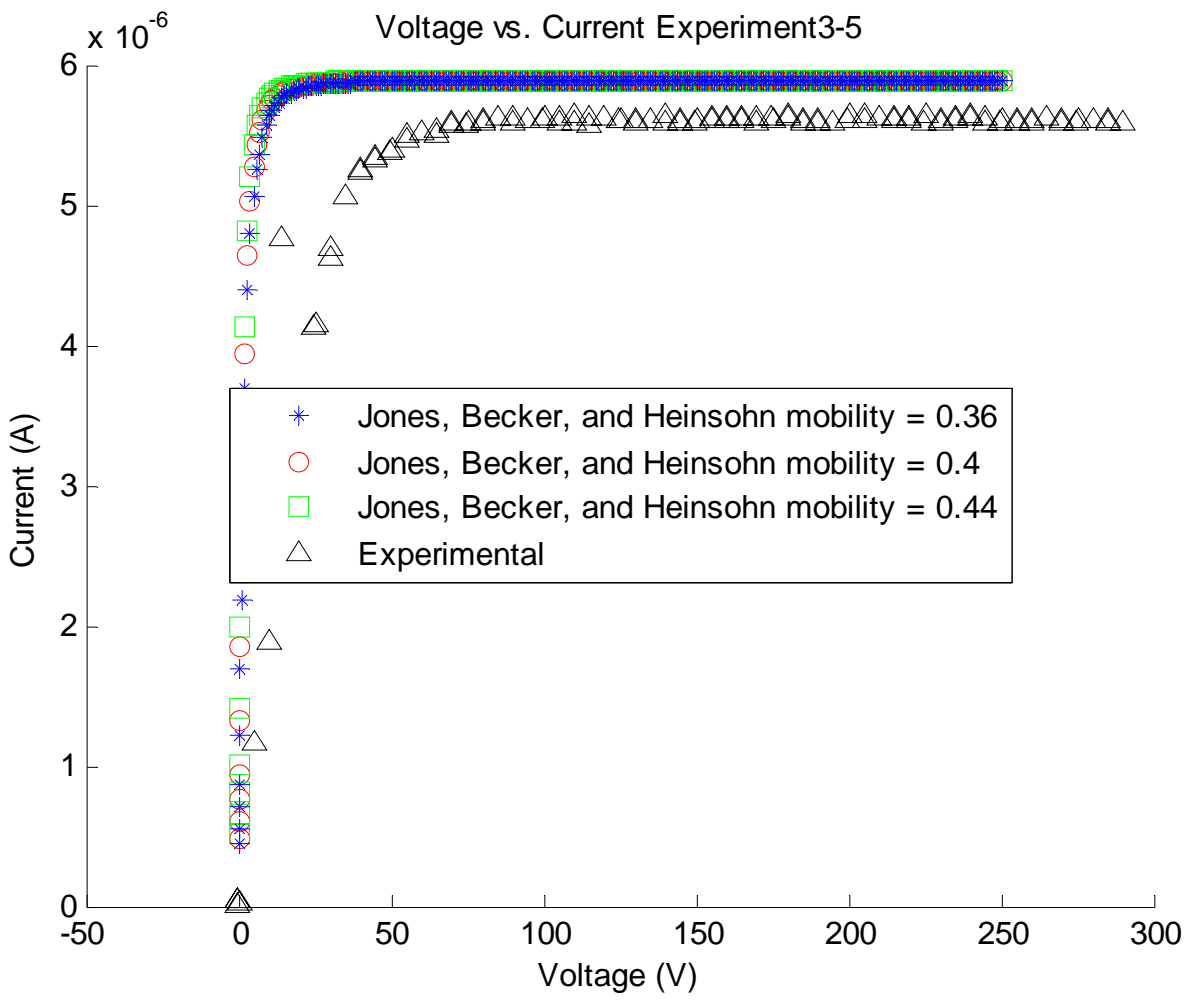

Figure E-35: Voltage vs. Current with Methane for Jones, Becker, and Heinsohn Experiment 3-5 


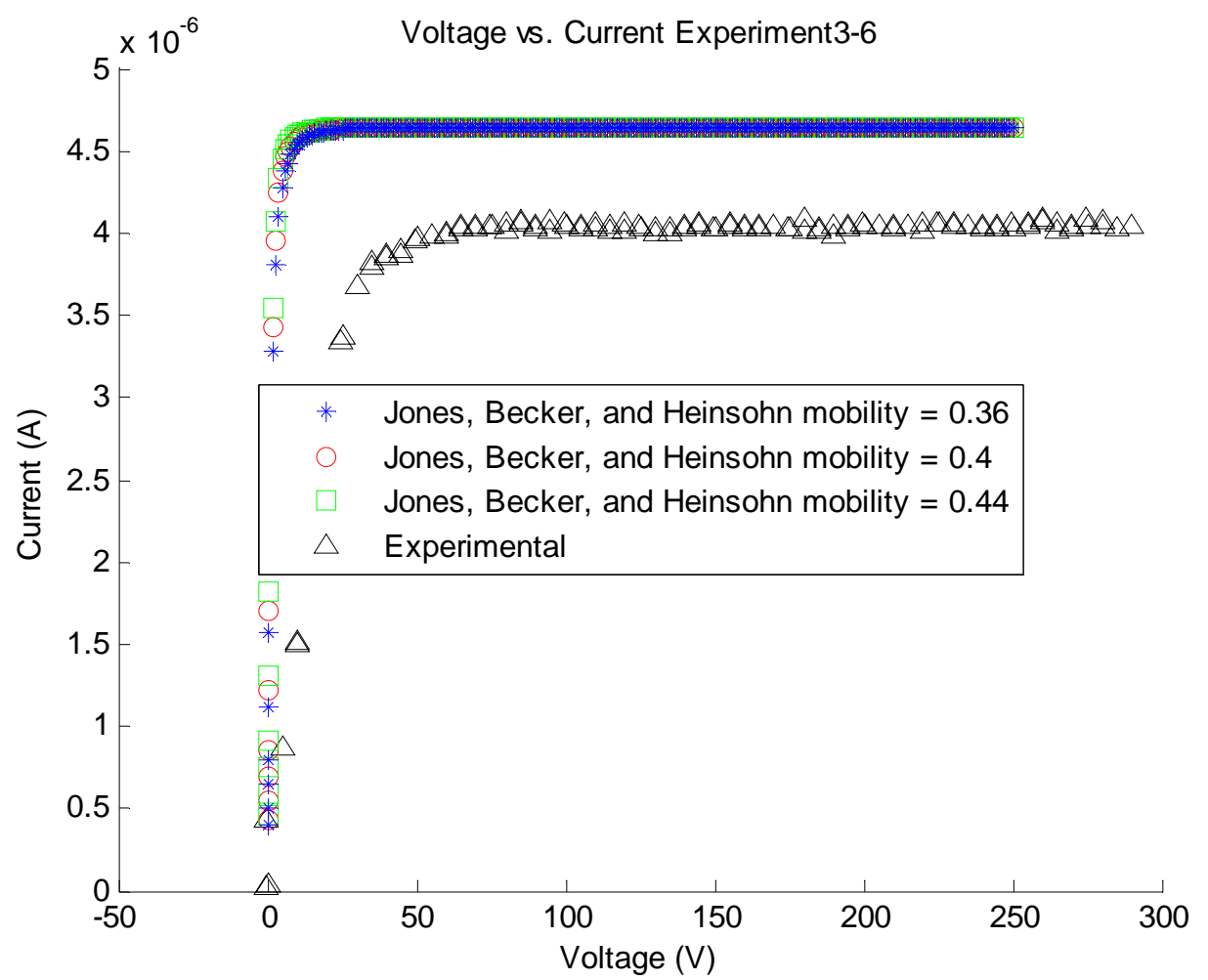

Figure E-36: Voltage vs. Current with Methane for Jones, Becker, and Heinsohn Experiment 3-6 


\section{E-3: V-I Plots of Methane Combustion Using Pederson and Brown}

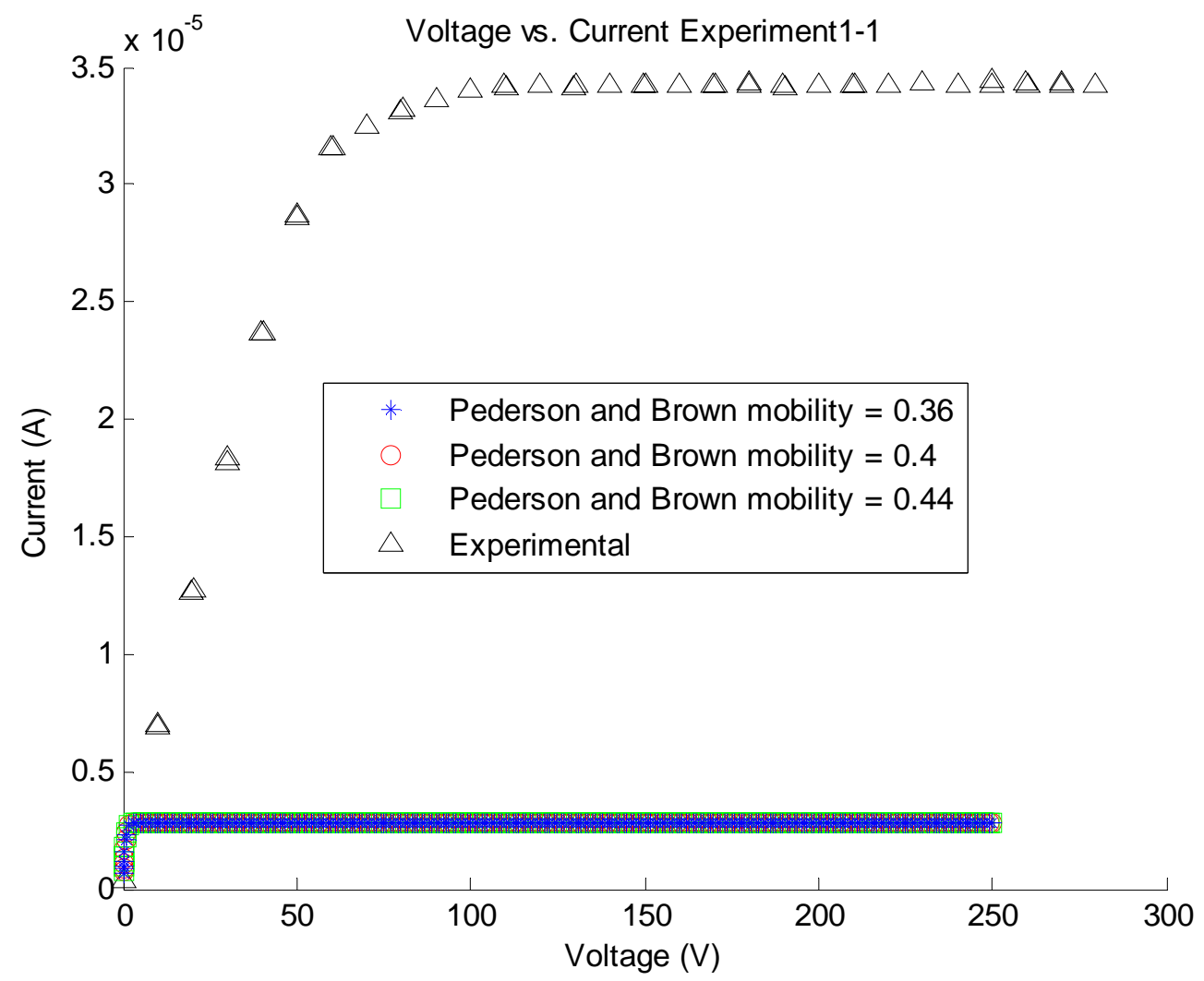

Figure E-37: Voltage vs. Current with Methane for Pederson and Brown Experiment 1-1 


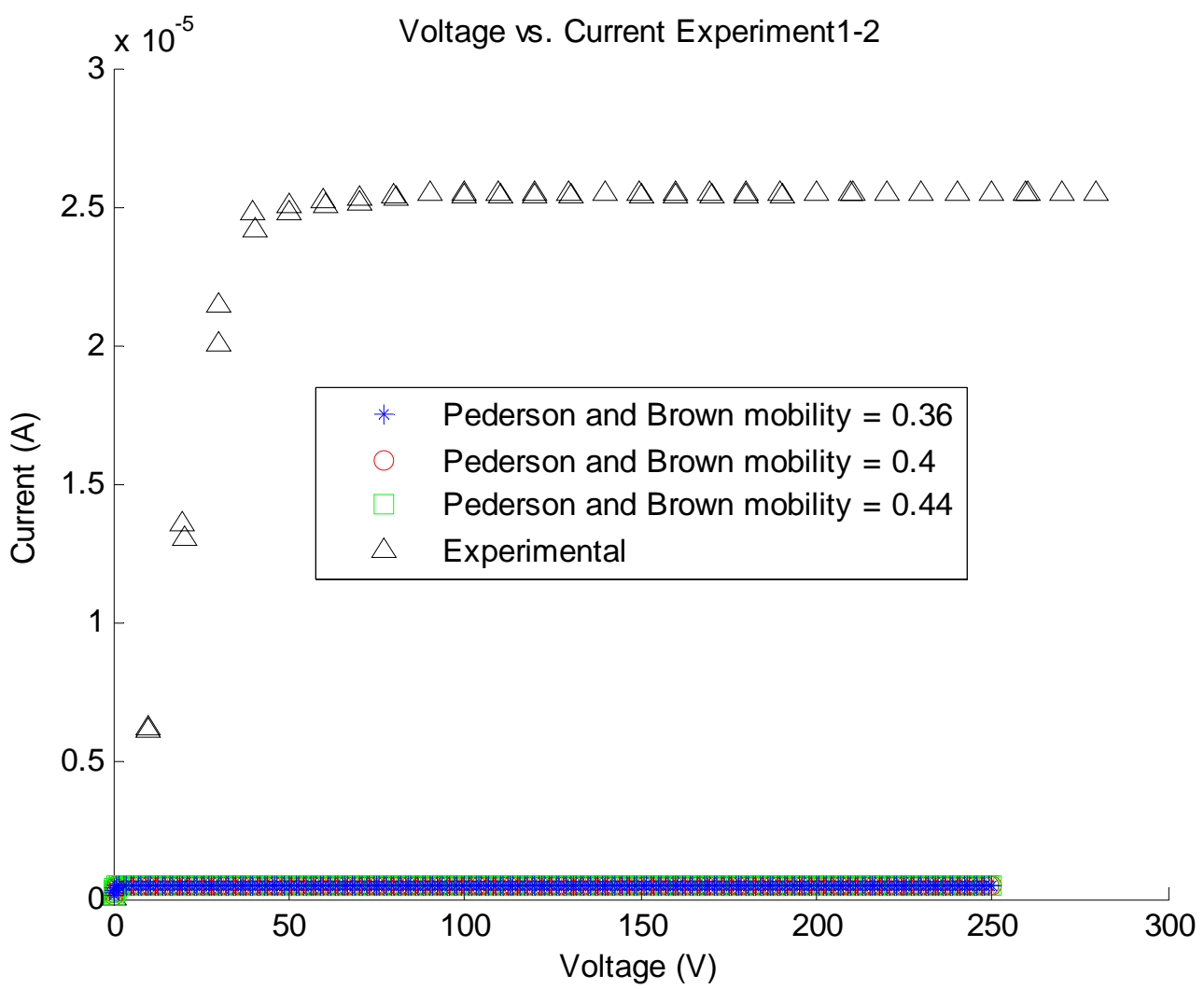

Figure E-38: Voltage vs. Current with Methane for Pederson and Brown Experiment 1-2

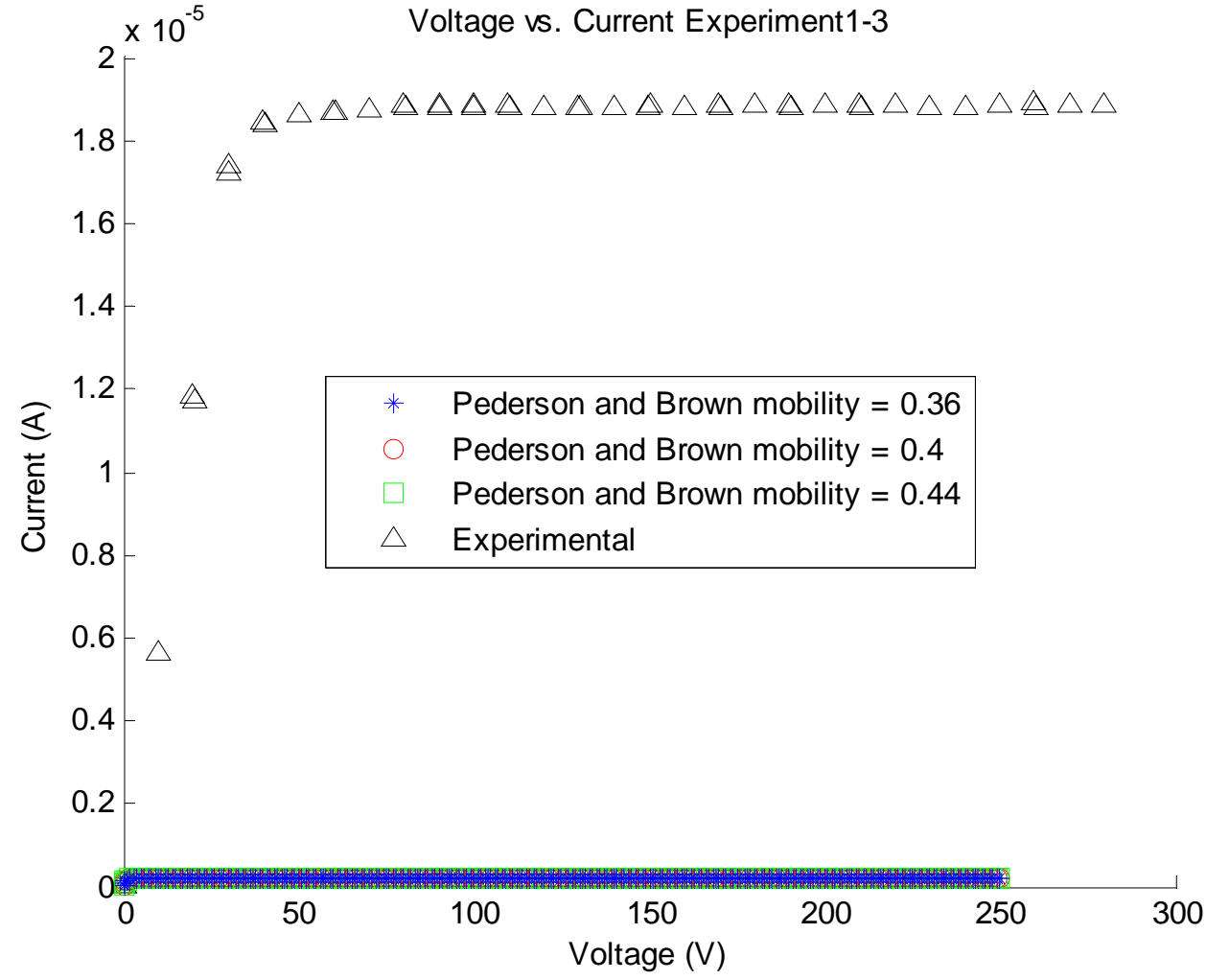

Figure E-39: Voltage vs. Current with Methane for Pederson and Brown Experiment 1-3 


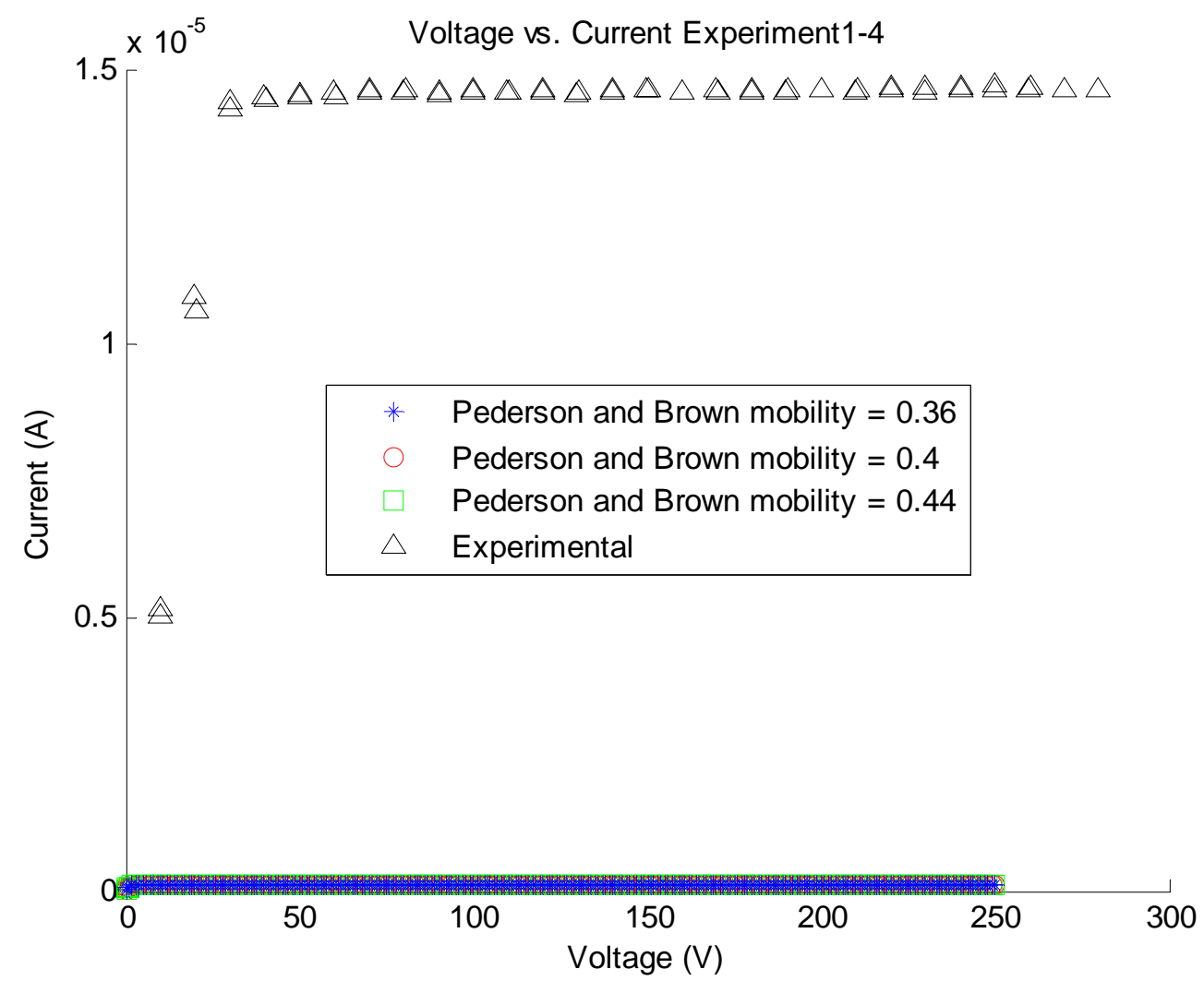

Figure E-40: Voltage vs. Current with Methane for Pederson and Brown Experiment 1-4

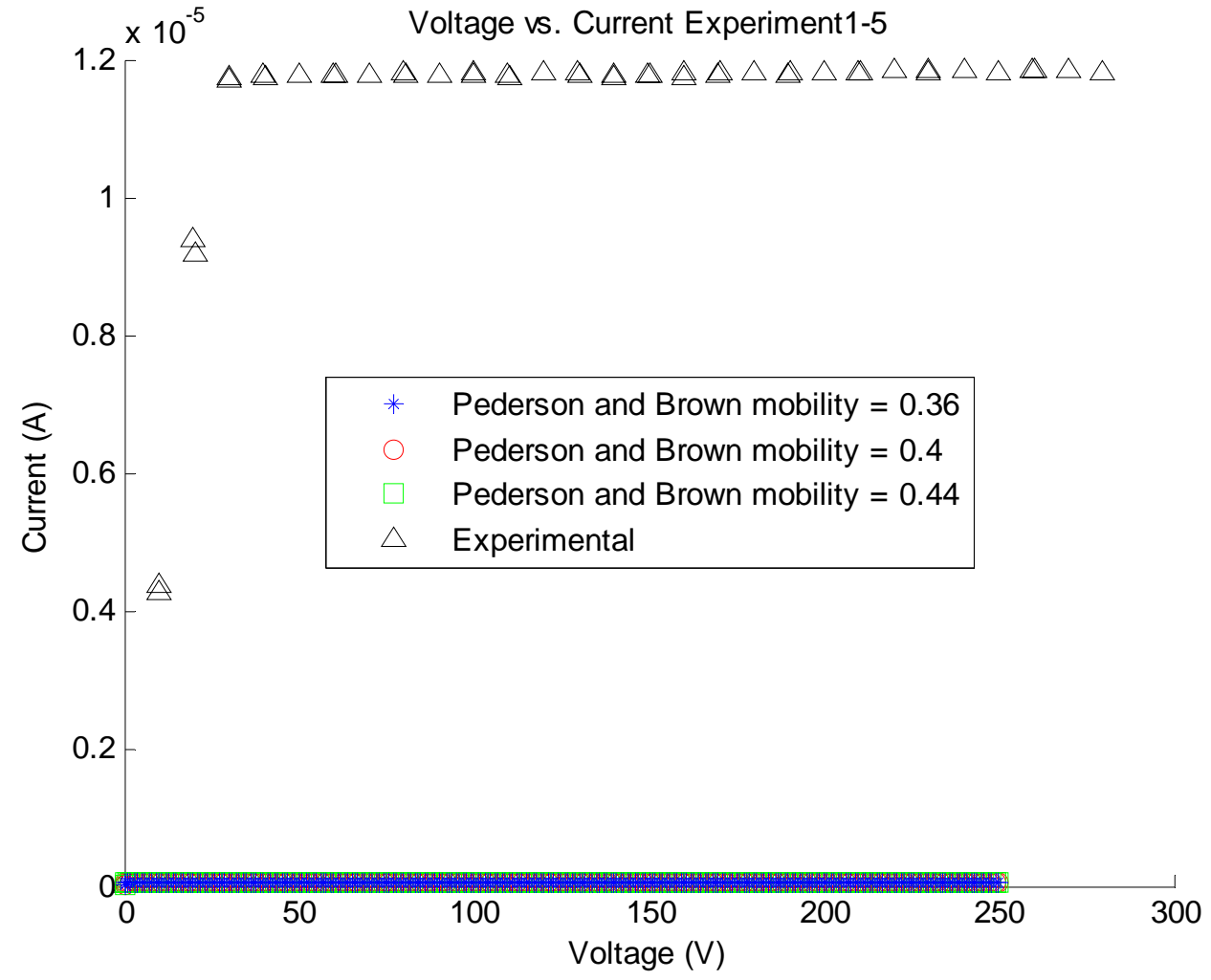

Figure E-41: Voltage vs. Current with Methane for Pederson and Brown Experiment 1-5 


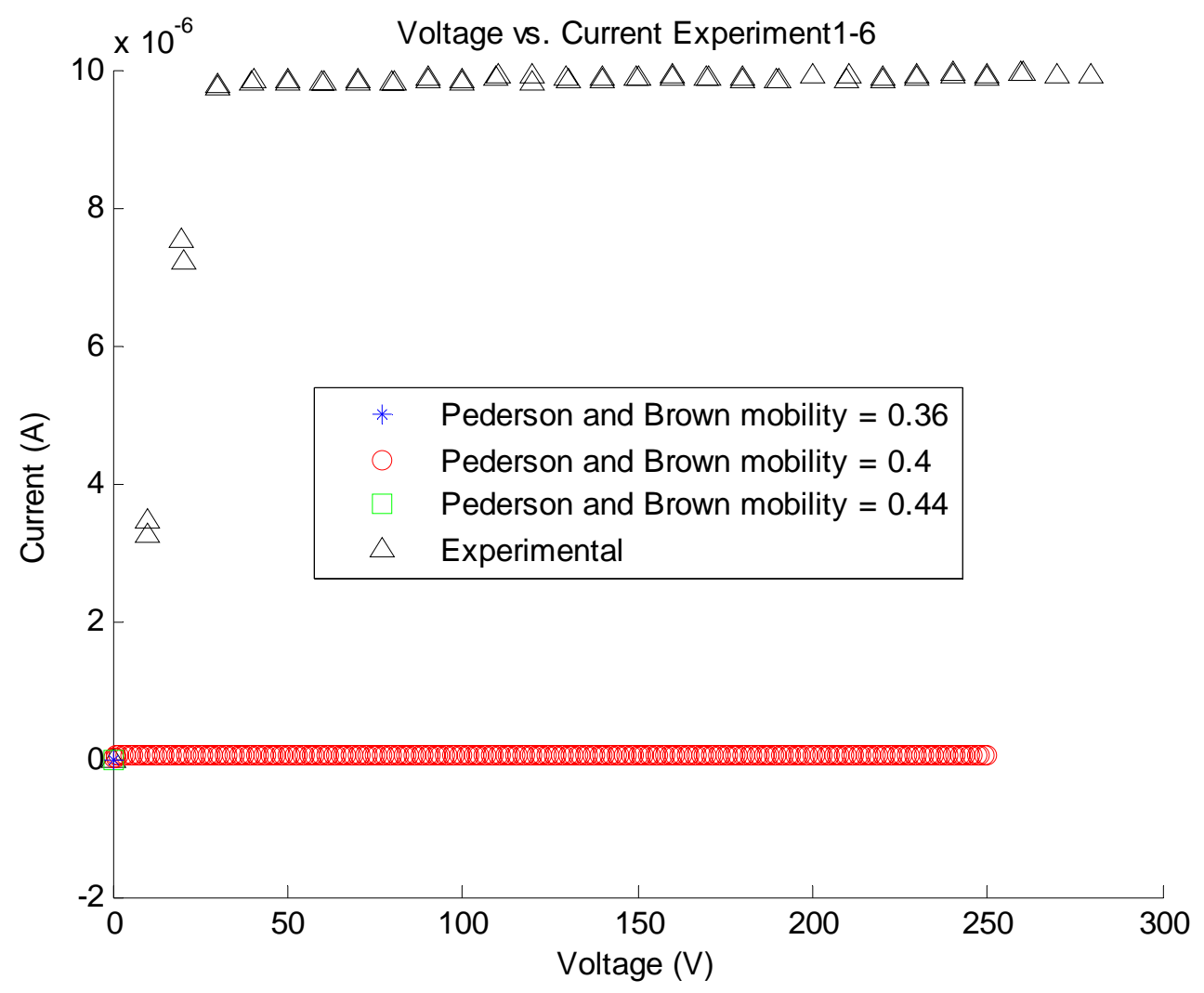

Figure E-42: Voltage vs. Current with Methane for Pederson and Brown Experiment 1-6

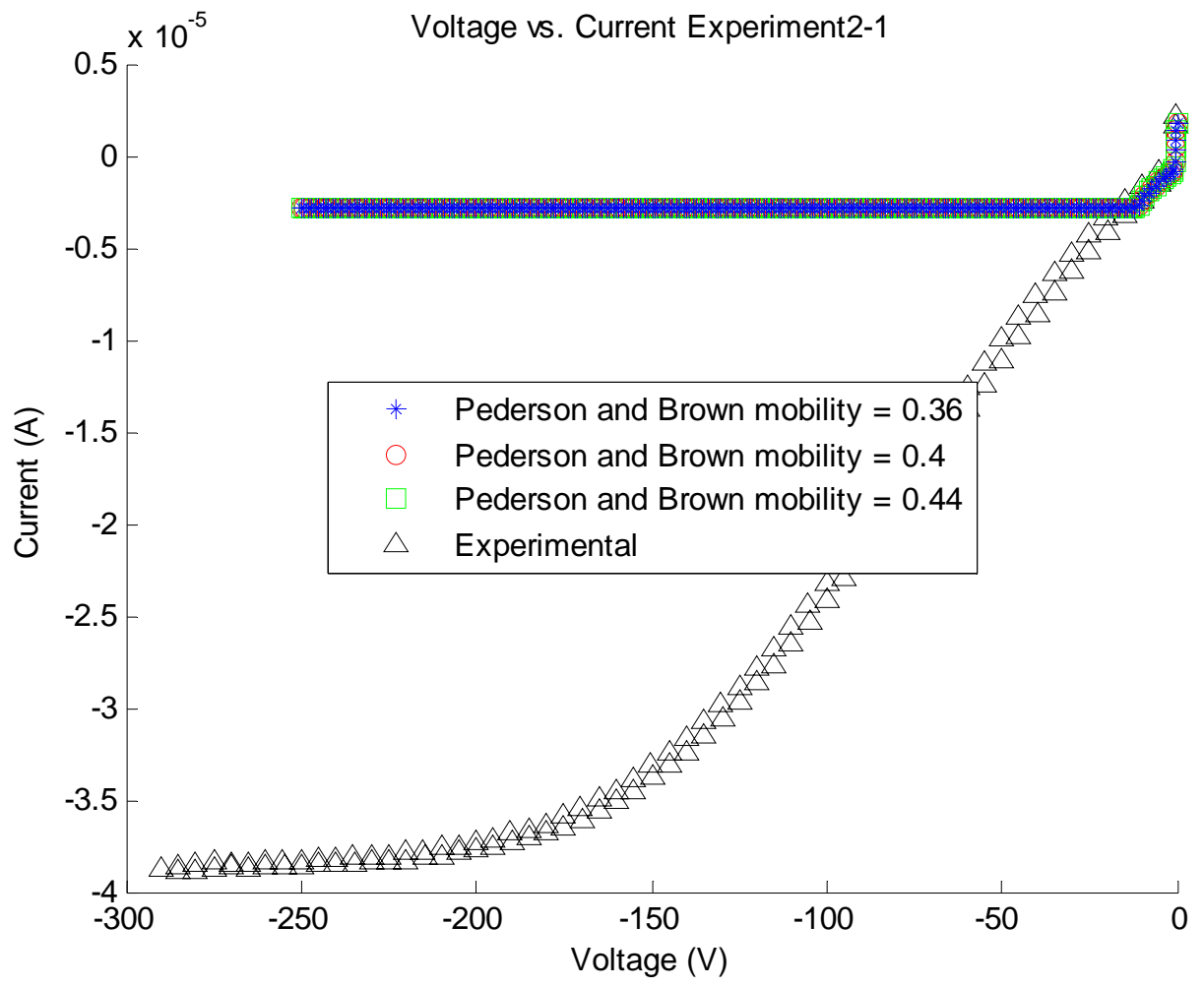

Figure E-43: Voltage vs. Current with Methane for Pederson and Brown Experiment 2-1 


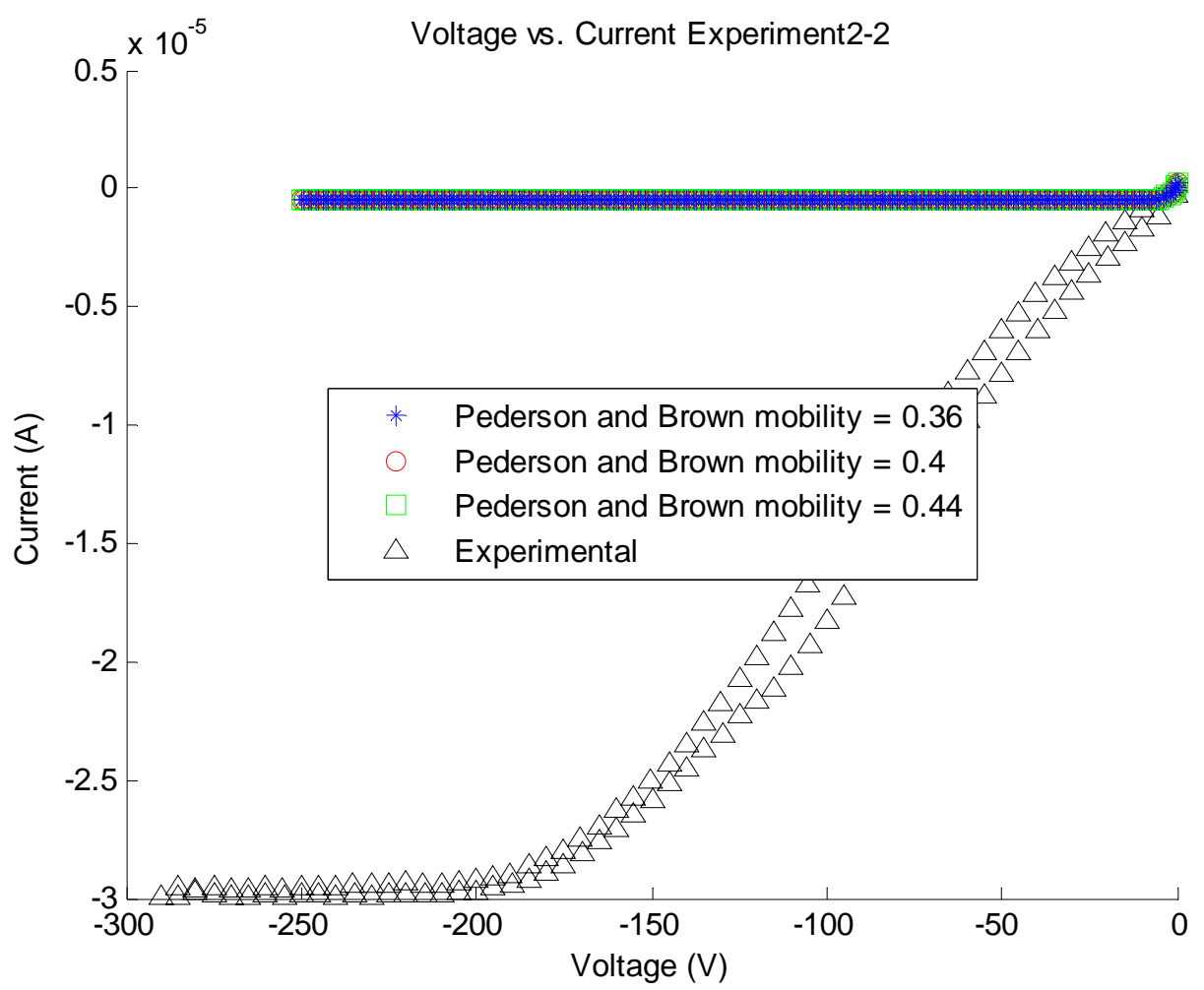

Figure E-44: Voltage vs. Current with Methane for Pederson and Brown Experiment 2-2

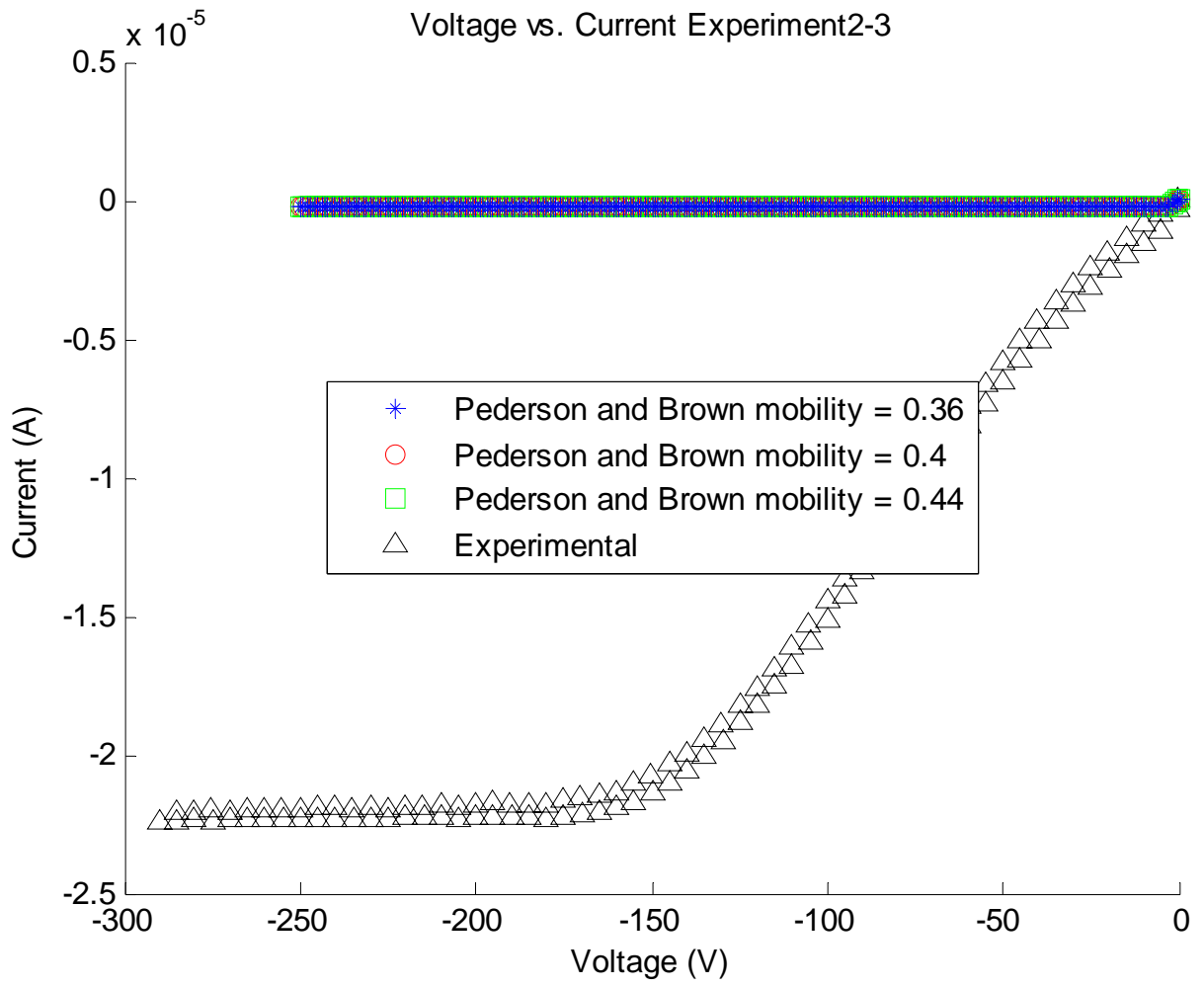

Figure E-45: Voltage vs. Current with Methane for Pederson and Brown Experiment 2-3 


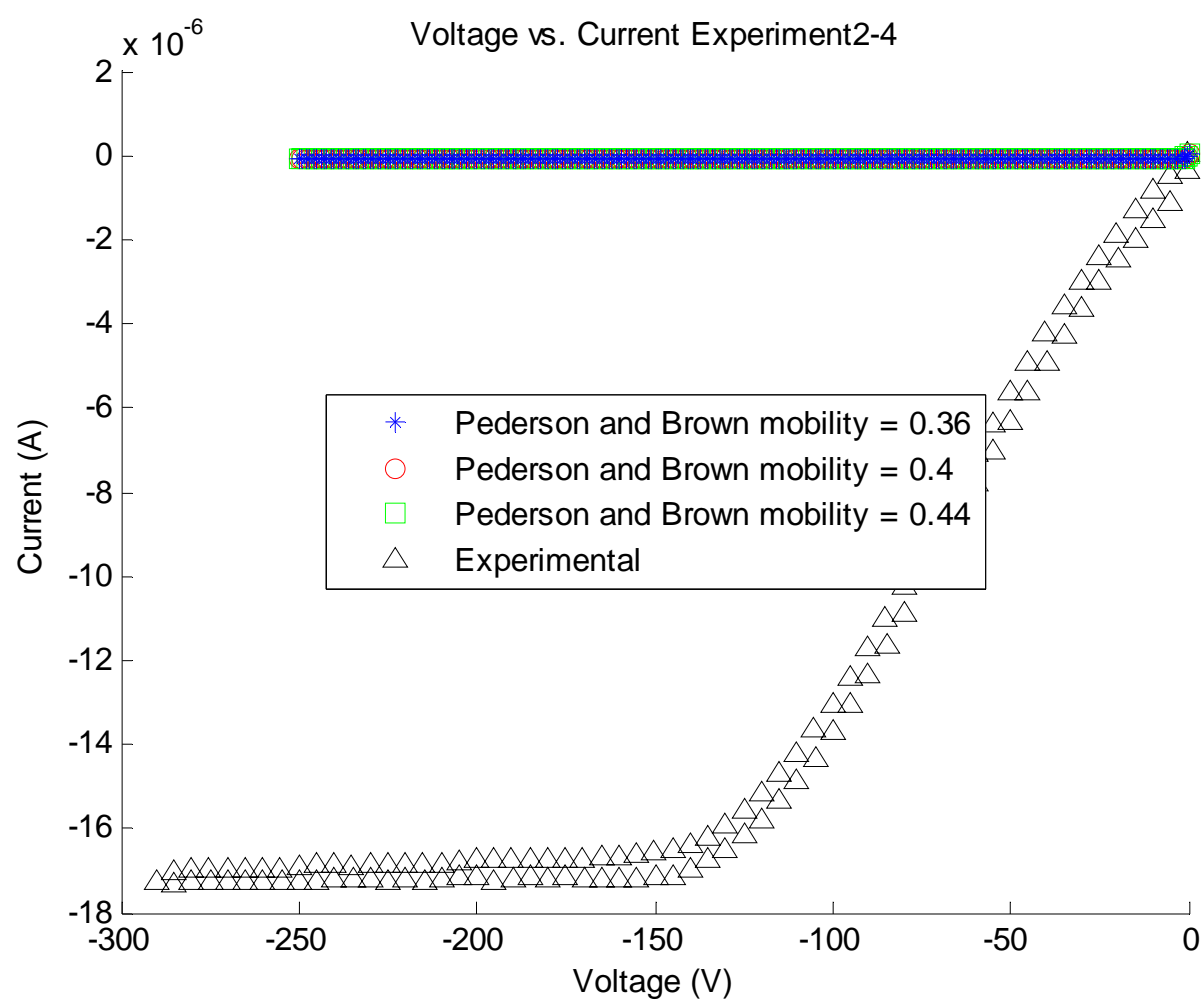

Figure E-46: Voltage vs. Current with Methane for Pederson and Brown Experiment 2-4

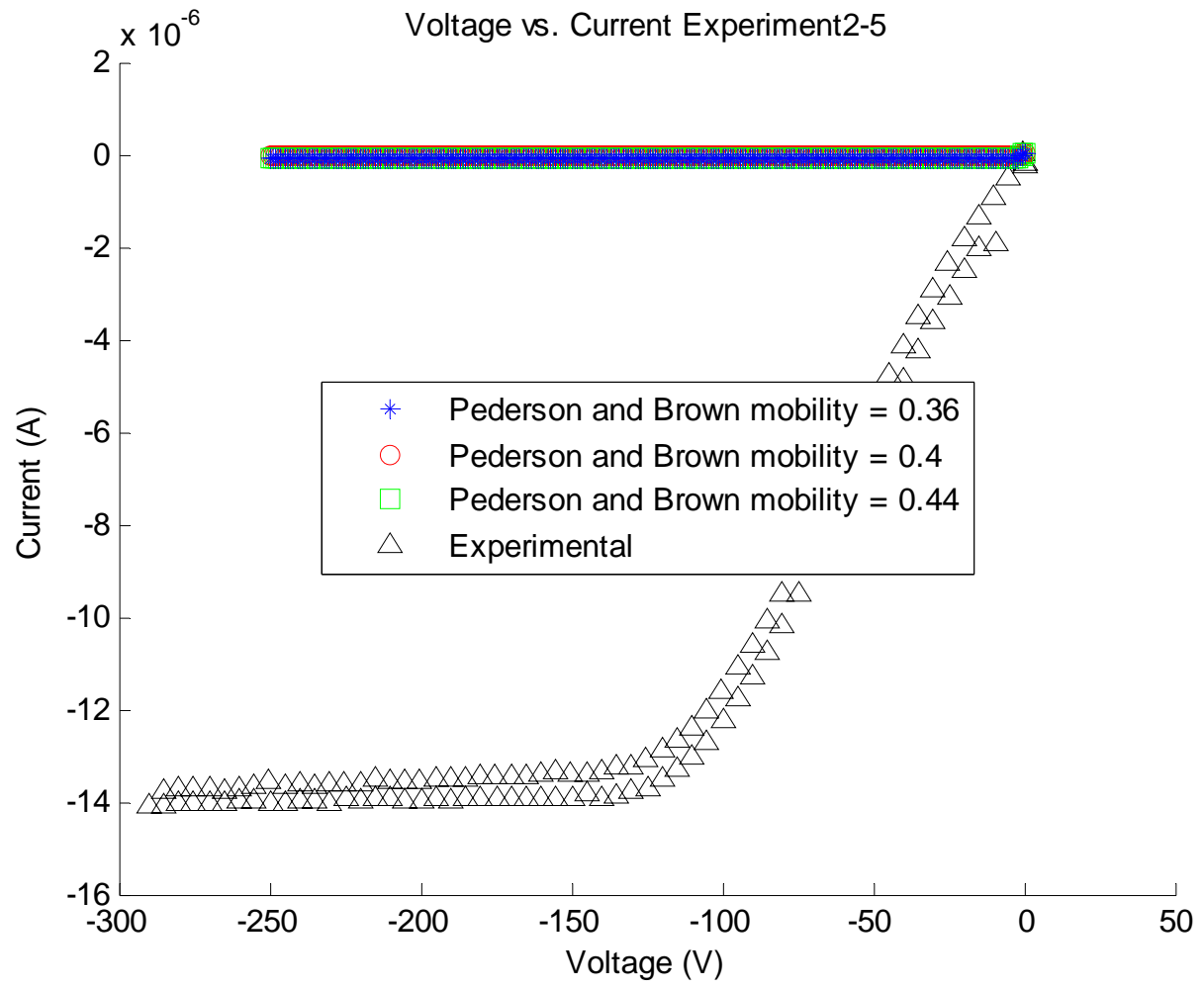

Figure E-47: Voltage vs. Current with Methane for Pederson and Brown Experiment 2-5 


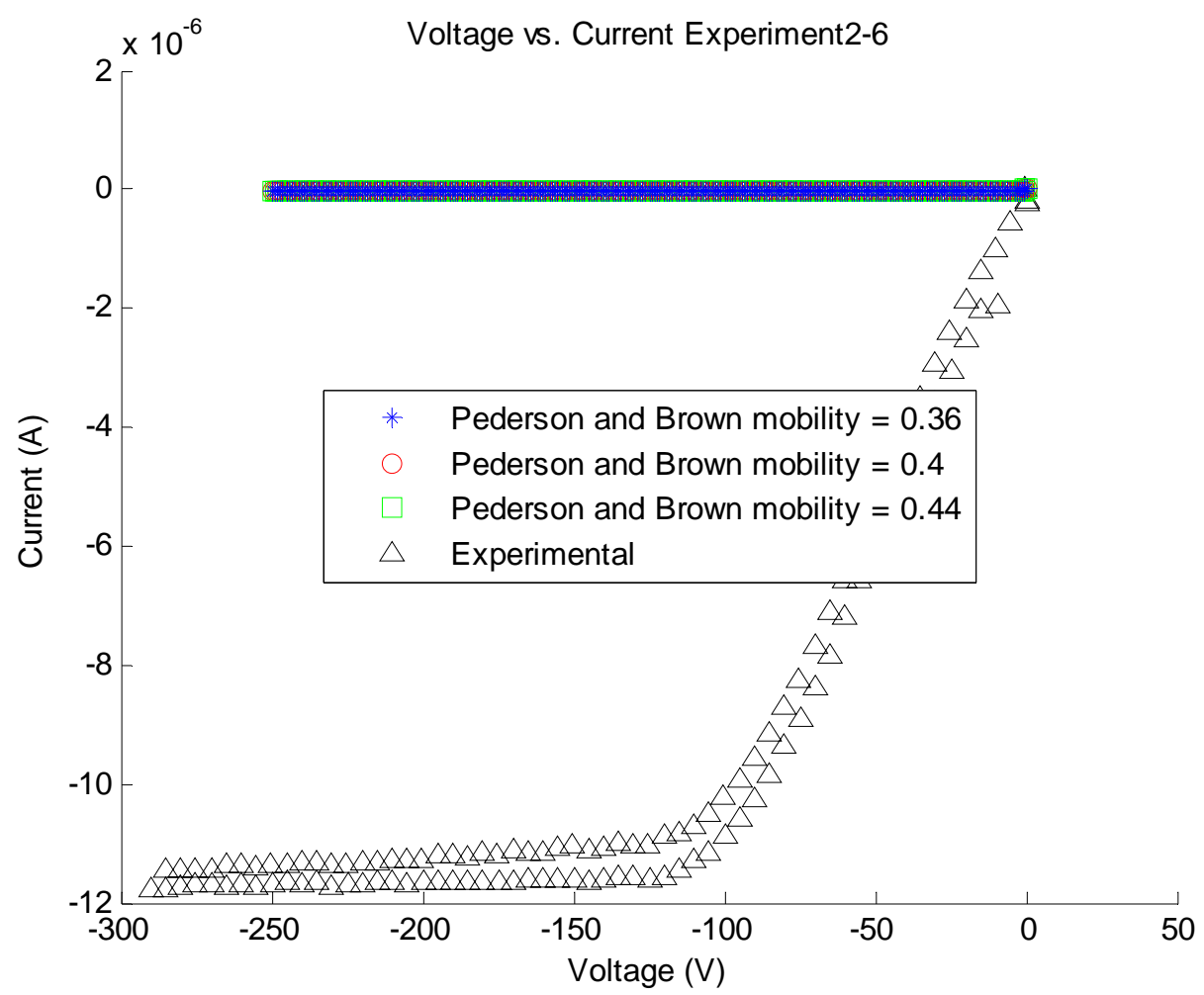

Figure E-48: Voltage vs. Current with Methane for Pederson and Brown Experiment 2-6

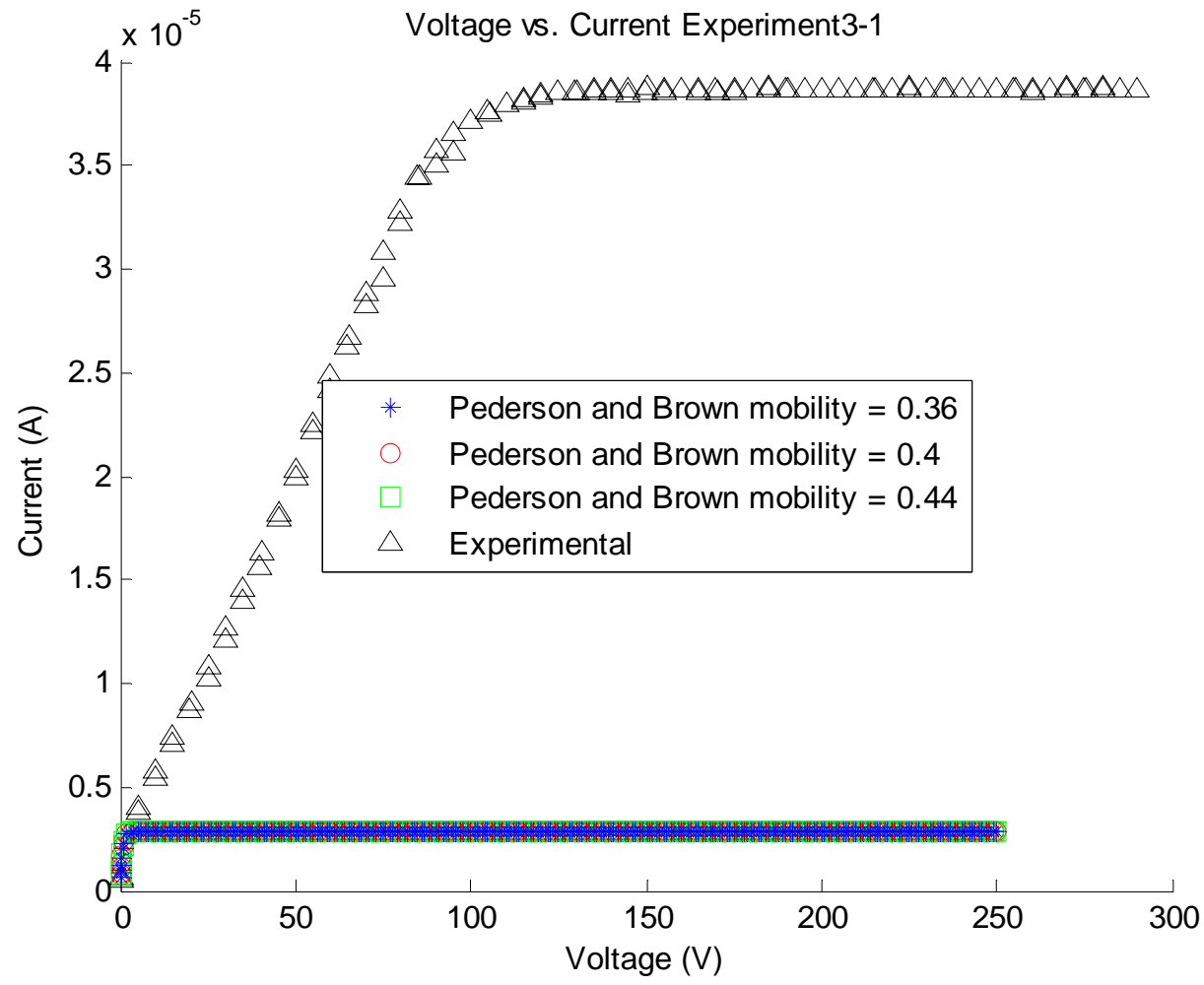

Figure E-49: Voltage vs. Current with Methane for Pederson and Brown Experiment 3-1 


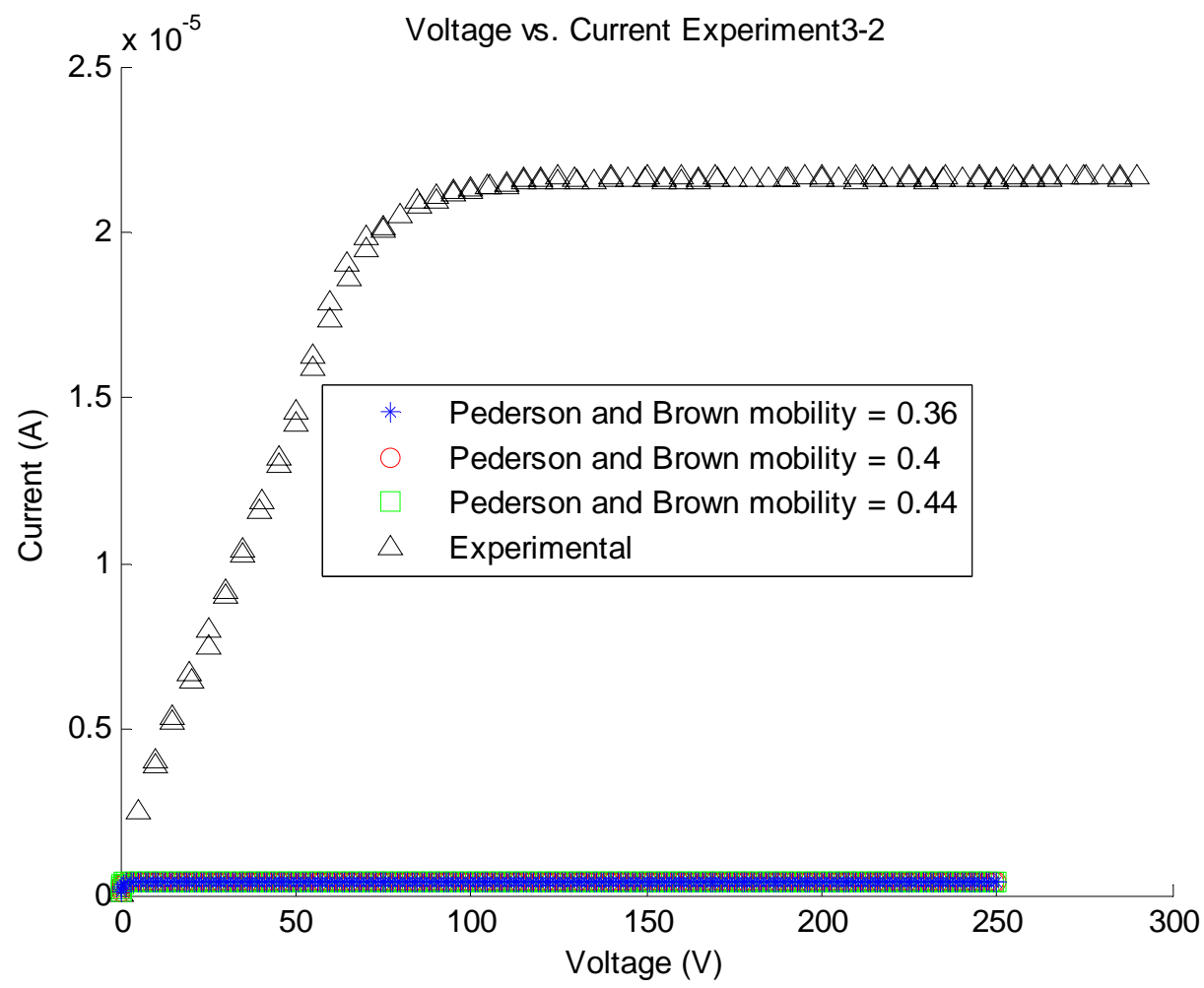

Figure E-50: Voltage vs. Current with Methane for Pederson and Brown Experiment 3-2

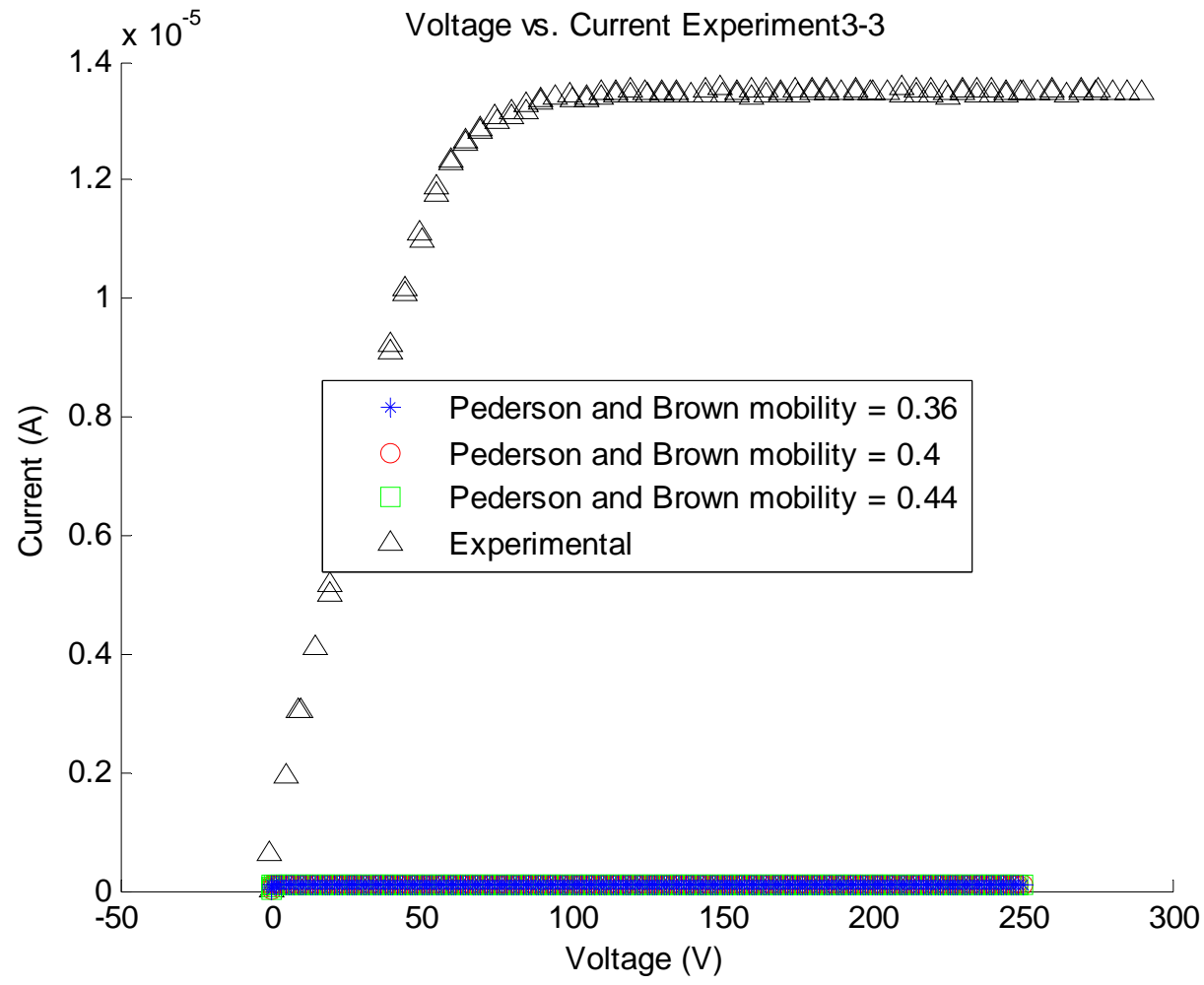

Figure E-51: Voltage vs. Current with Methane for Pederson and Brown Experiment 3-3 


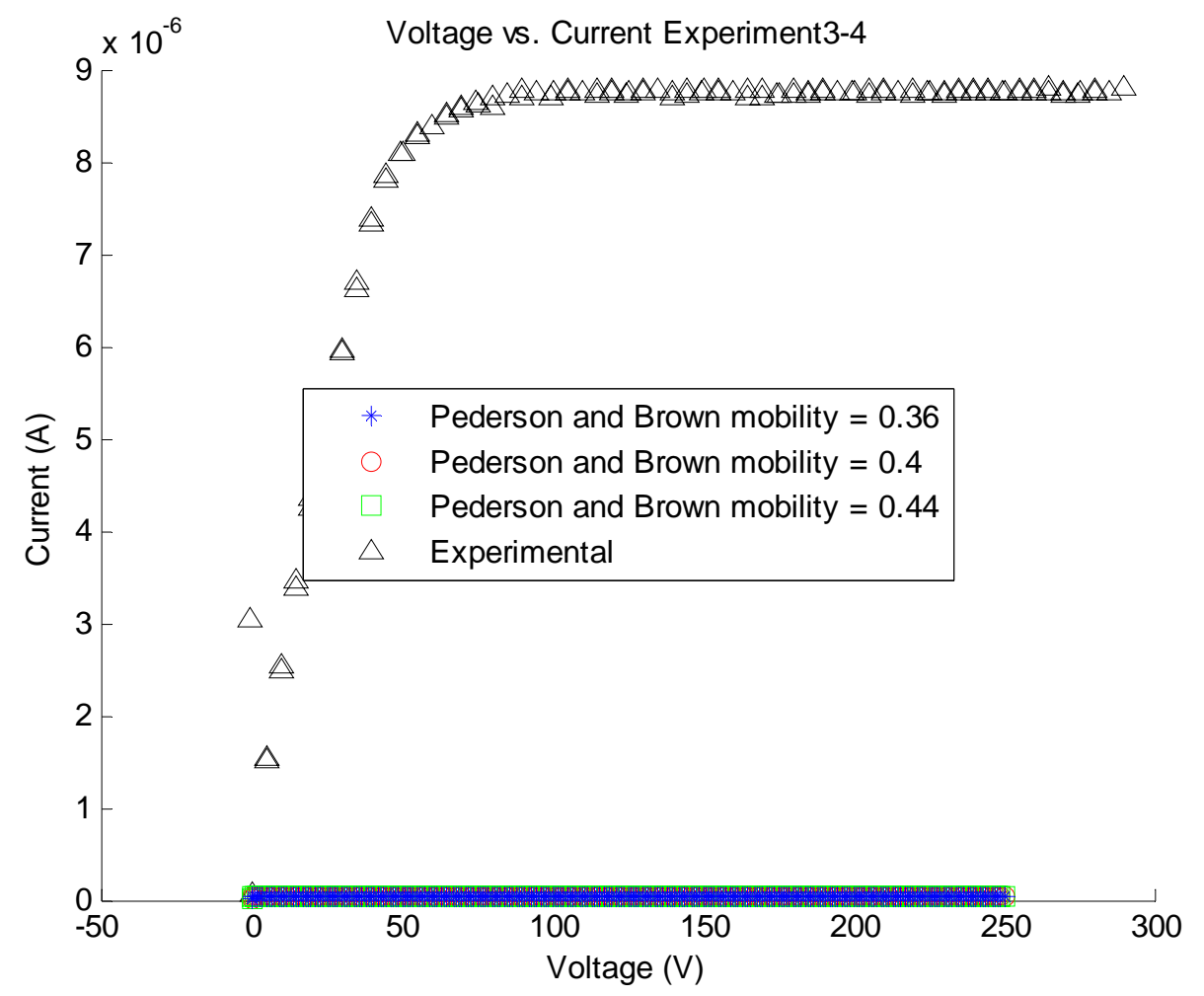

Figure E-52: Voltage vs. Current with Methane for Pederson and Brown Experiment 3-4

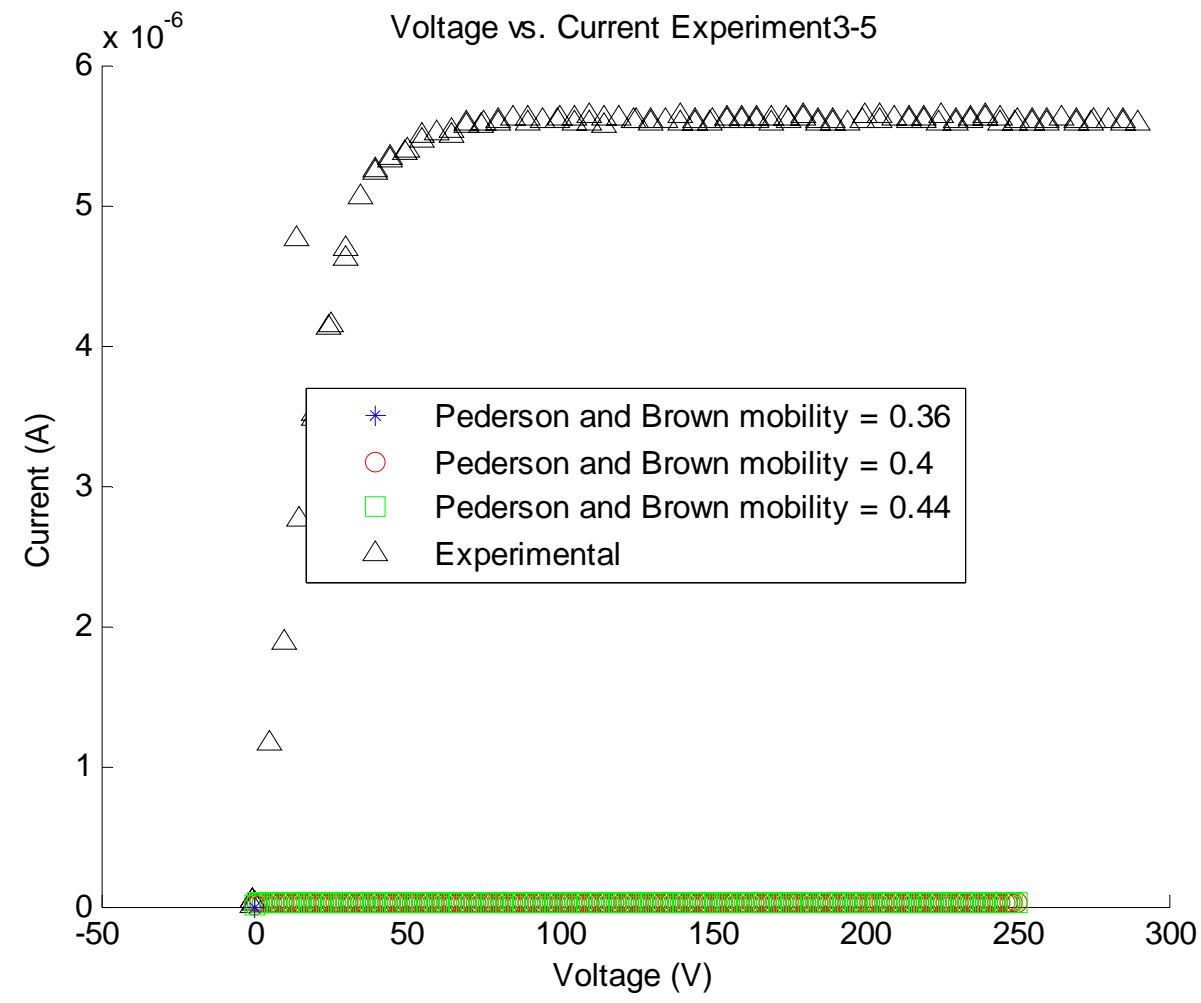

Figure E-53: Voltage vs. Current with Methane for Pederson and Brown Experiment 3-5 


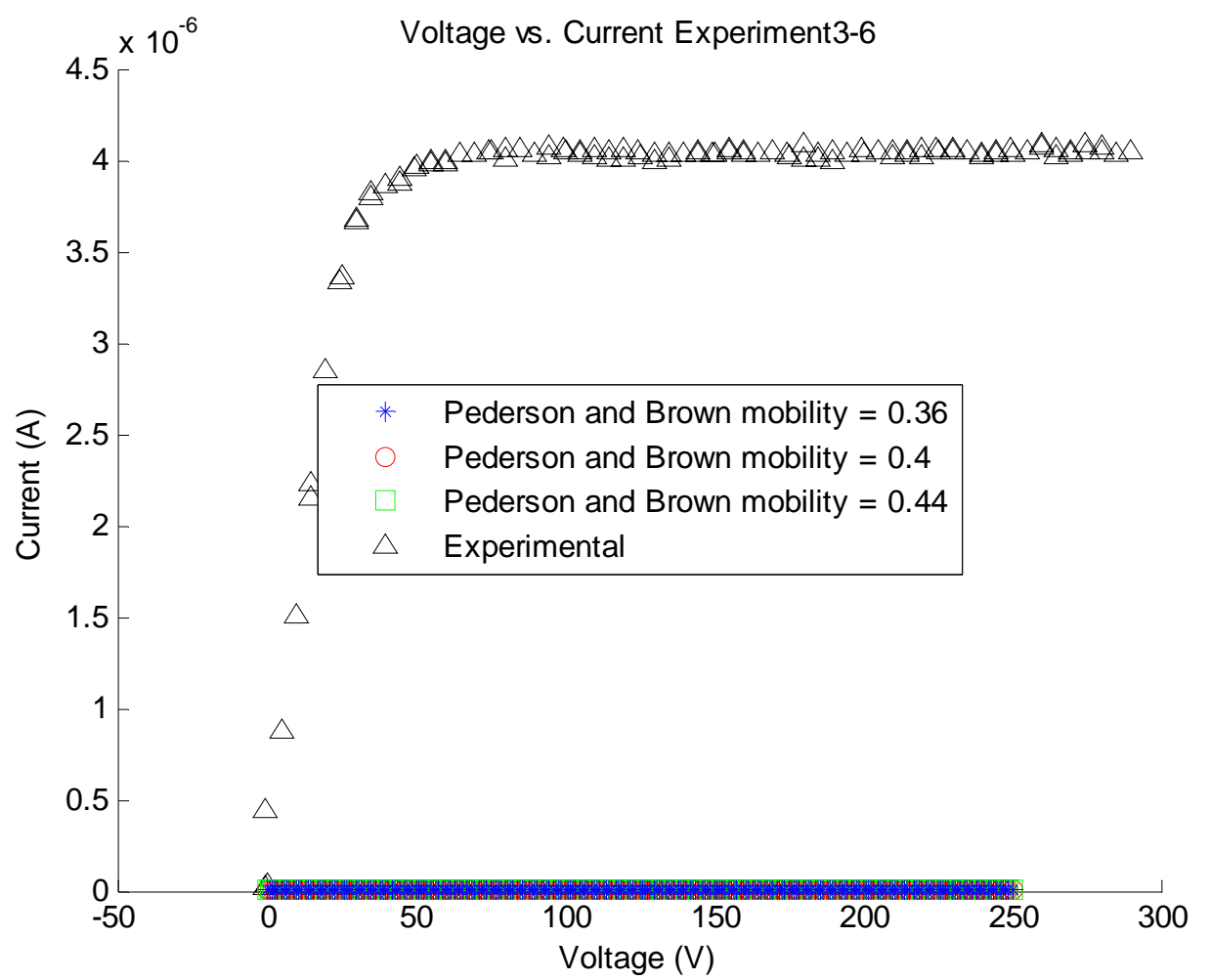

Figure E-54: Voltage vs. Current with Methane for Pederson and Brown Experiment 3-6 


\section{E-4: V-I Plots of Methane Combustion Using Peters}

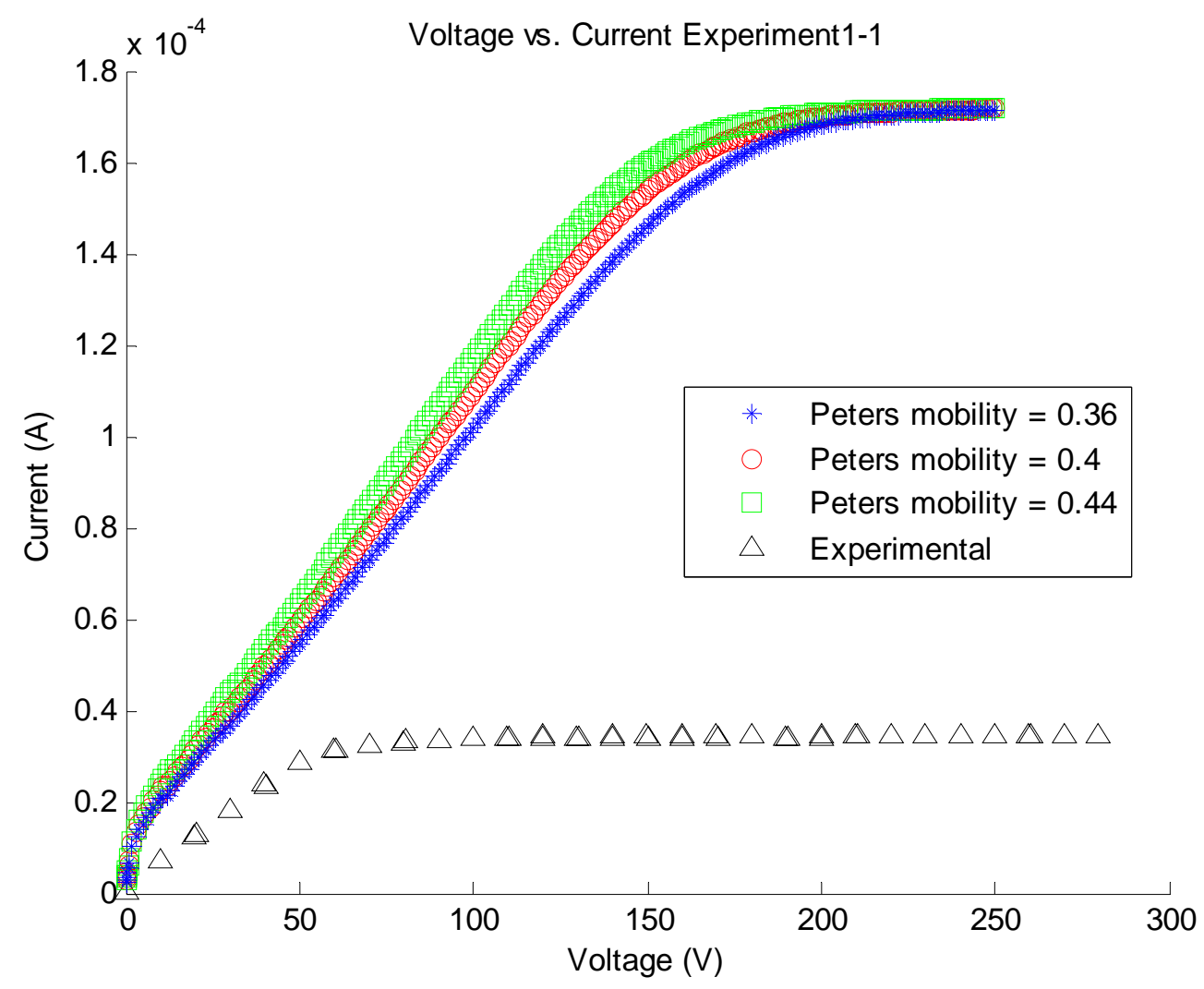

Figure E-55: Voltage vs. Current with Methane for Peters Experiment 1-1 


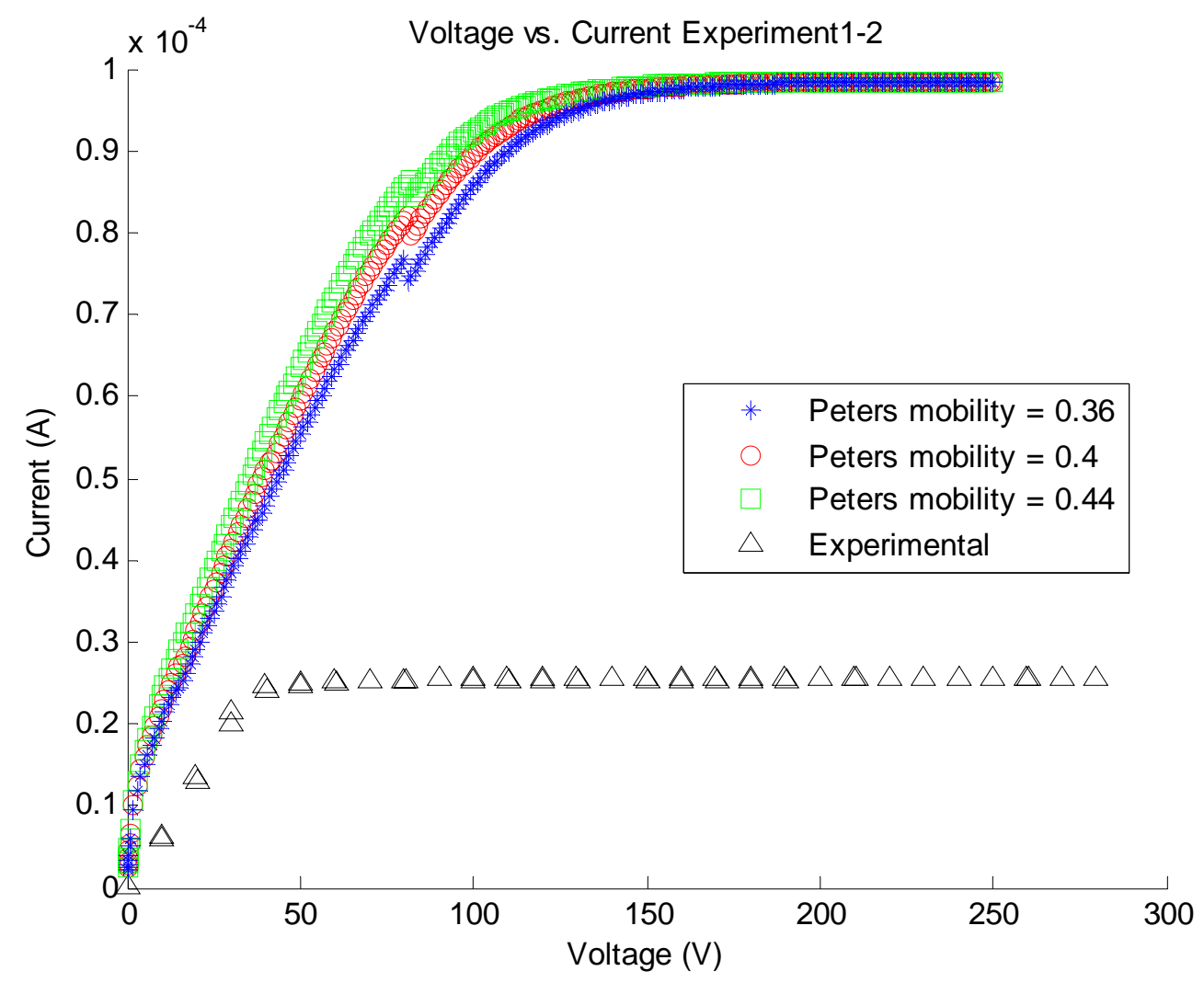

Figure E-56: Voltage vs. Current with Methane for Peters Experiment 1-2

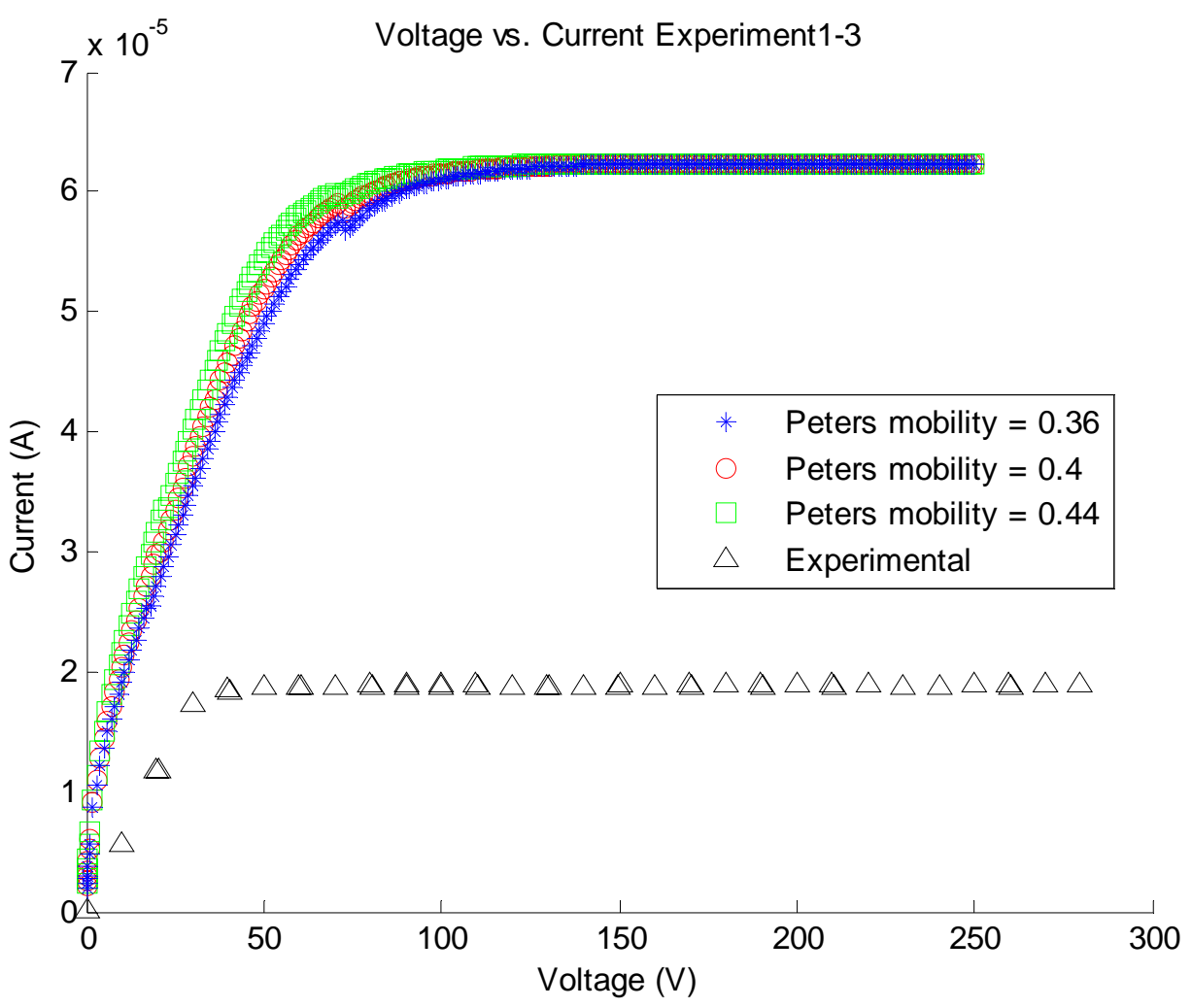

Figure E-57: Voltage vs. Current with Methane for Peters Experiment 1-3 


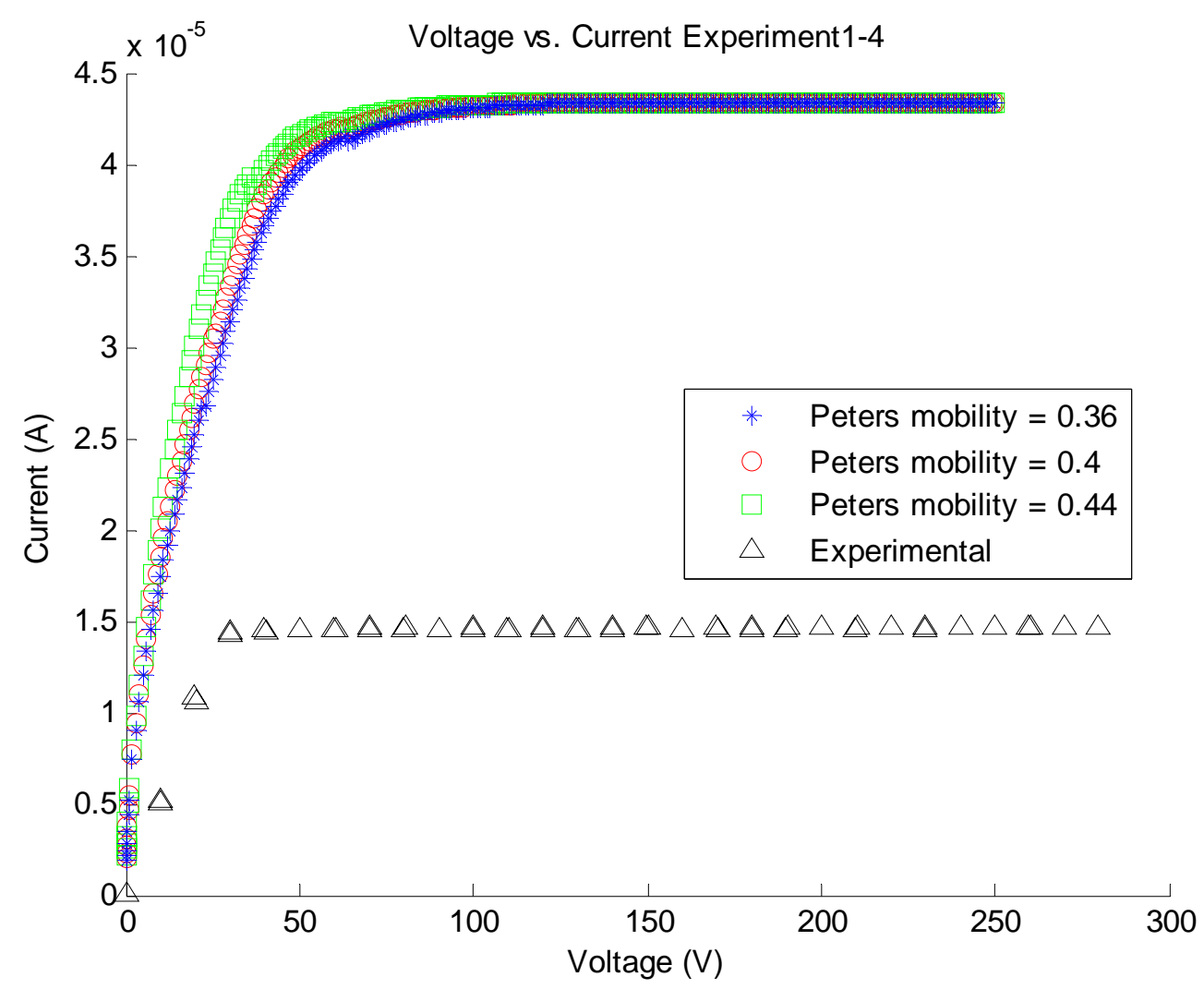

Figure E-58: Voltage vs. Current with Methane for Peters Experiment 1-4

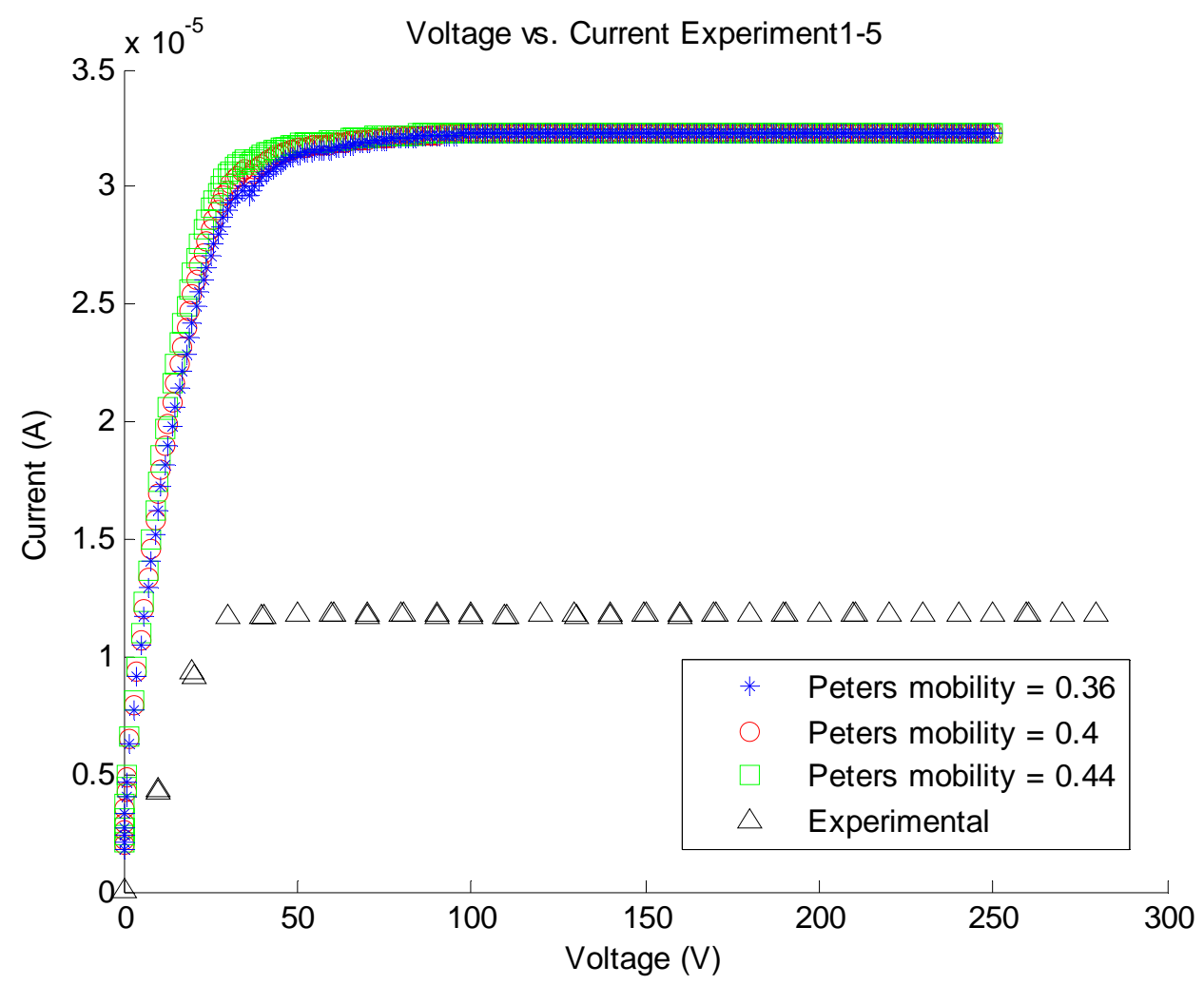

Figure E-59: Voltage vs. Current with Methane for Peters Experiment 1-5 


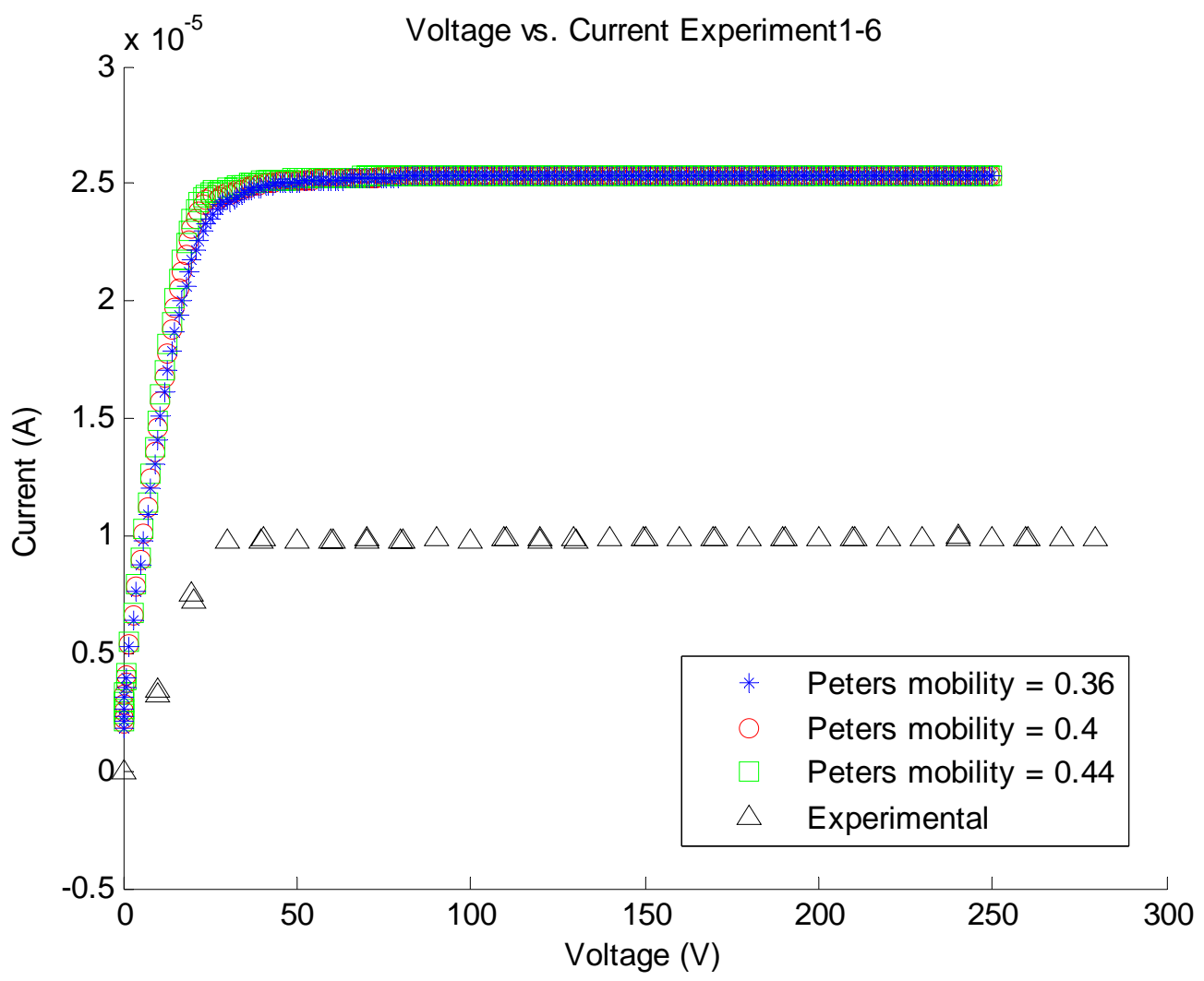

Figure E-60: Voltage vs. Current with Methane for Peters Experiment 1-6

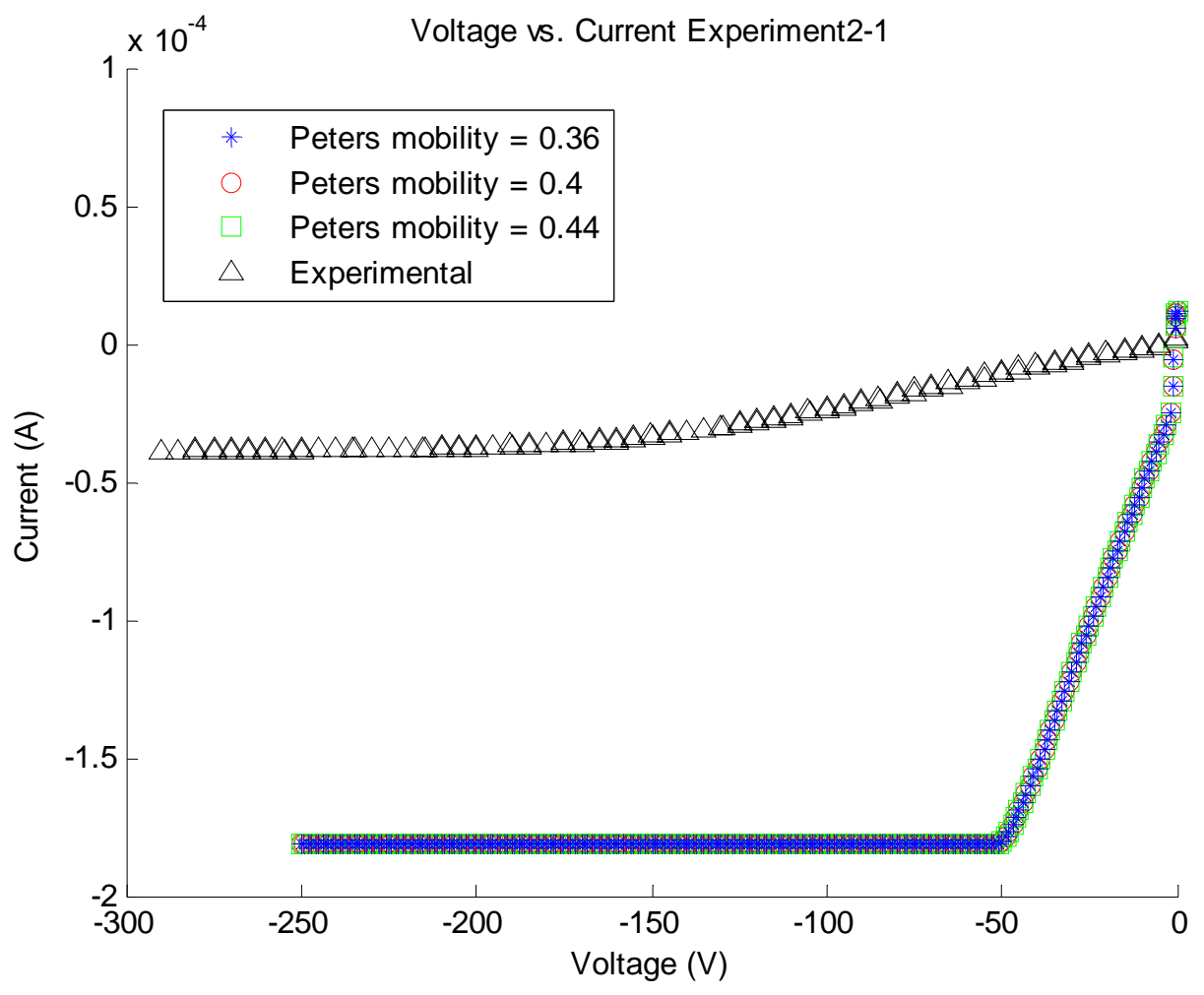

Figure E-61: Voltage vs. Current with Methane for Peters Experiment 2-1 


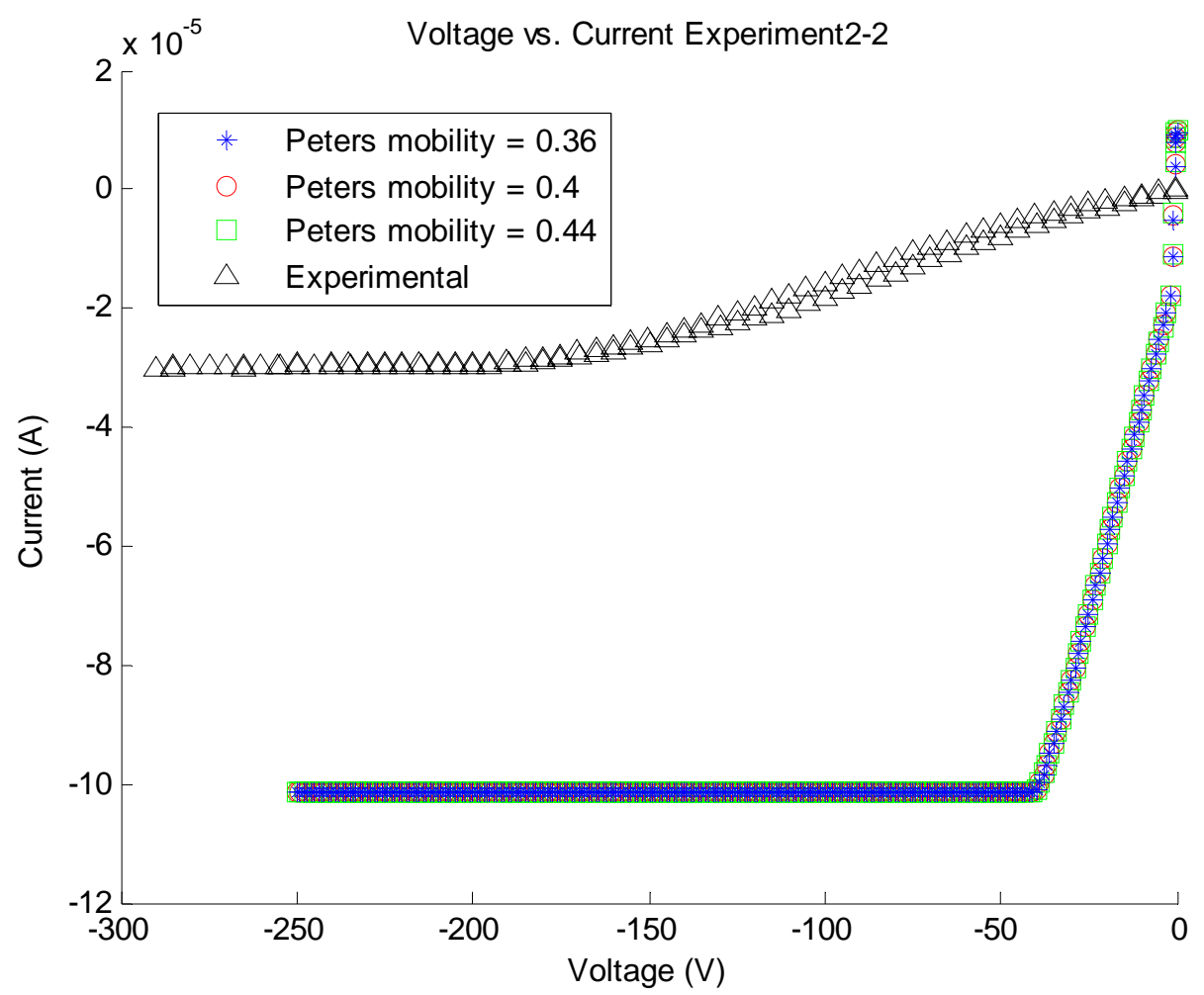

Figure E-62: Voltage vs. Current with Methane for Peters Experiment 2-2

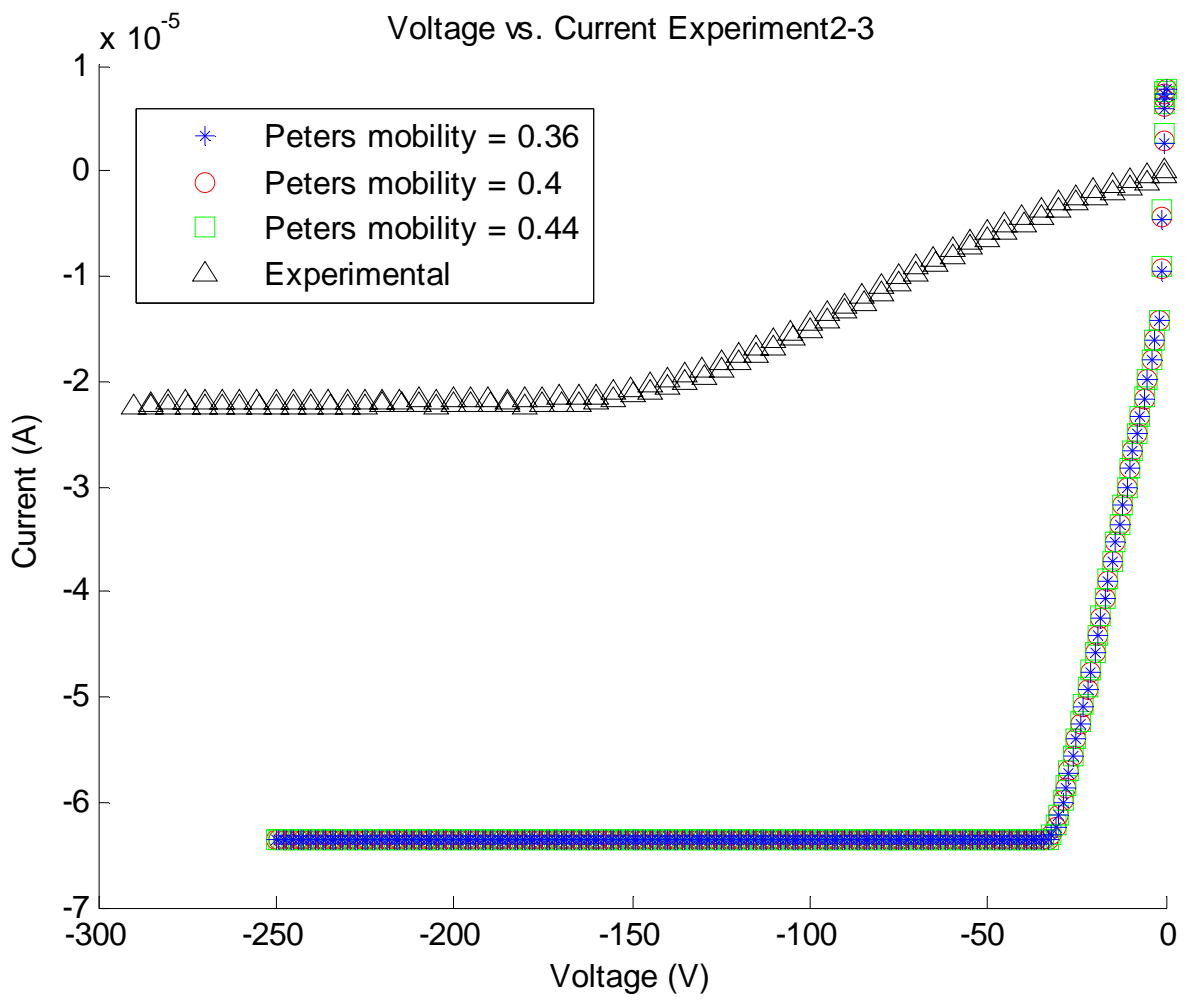

Figure E-63: Voltage vs. Current with Methane for Peters Experiment 2-3 


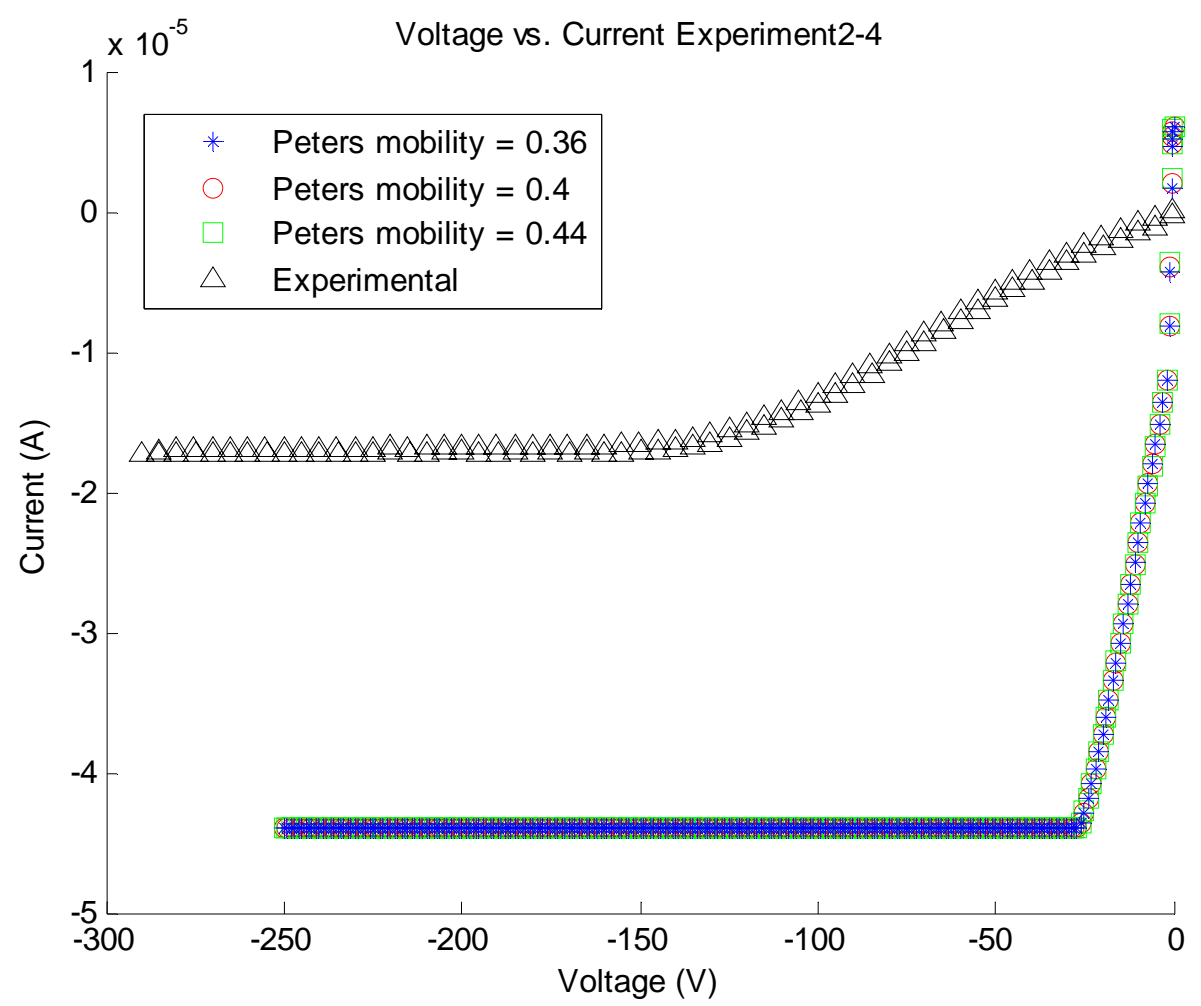

Figure E-64: Voltage vs. Current with Methane for Peters Experiment 2-4

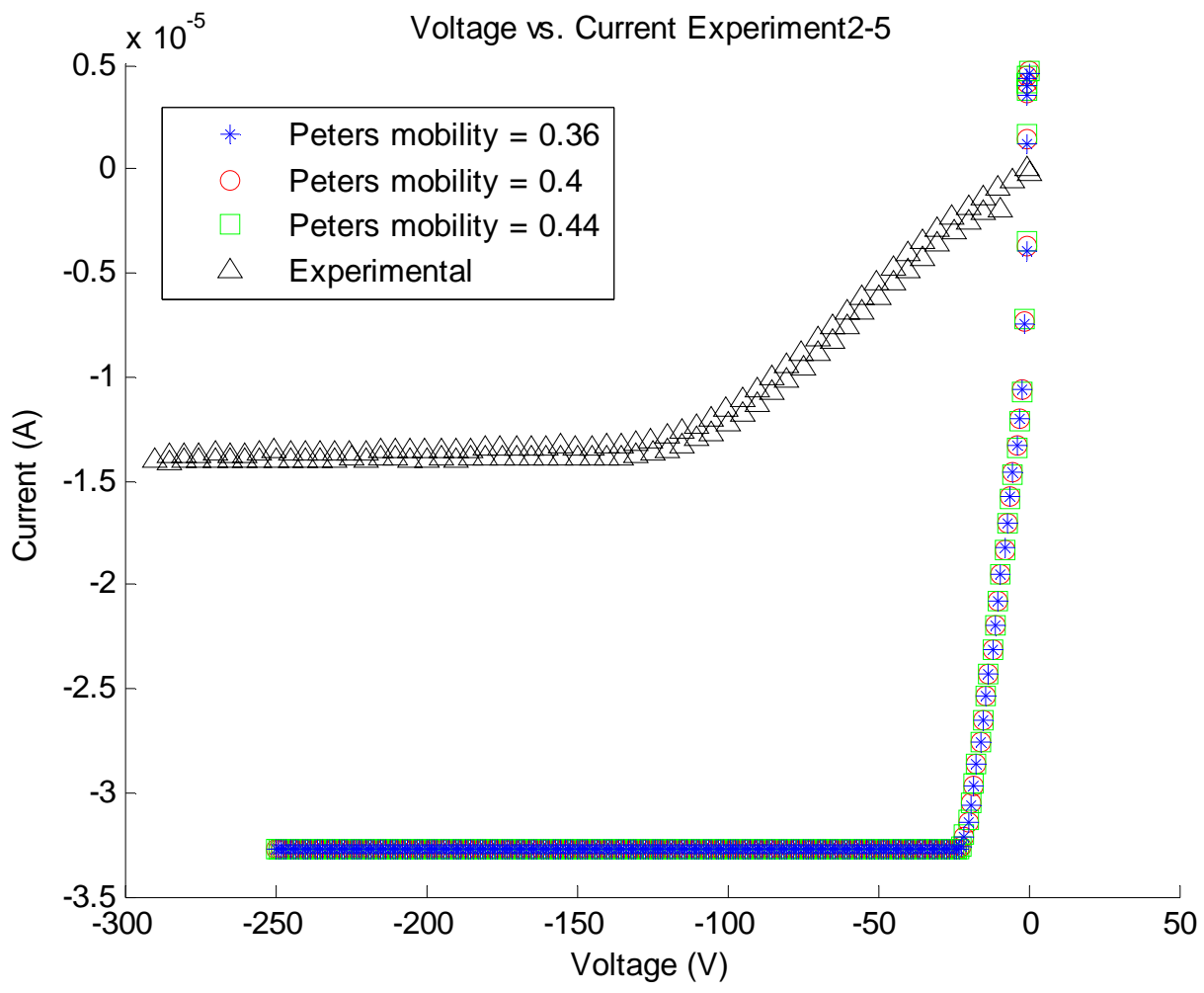

Figure E-65: Voltage vs. Current with Methane for Peters Experiment 2-5 


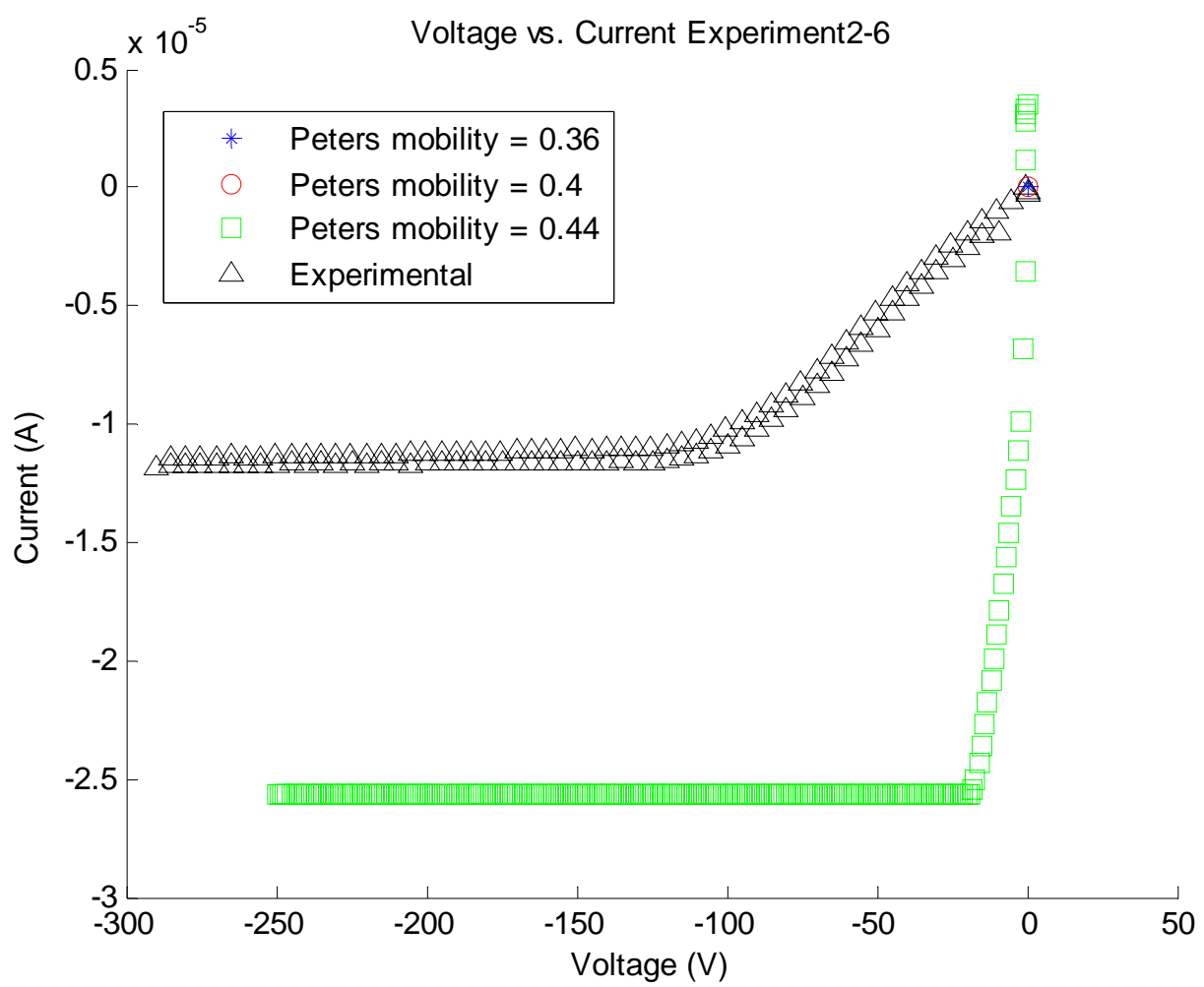

Figure E-66: Voltage vs. Current with Methane for Peters Experiment 2-6

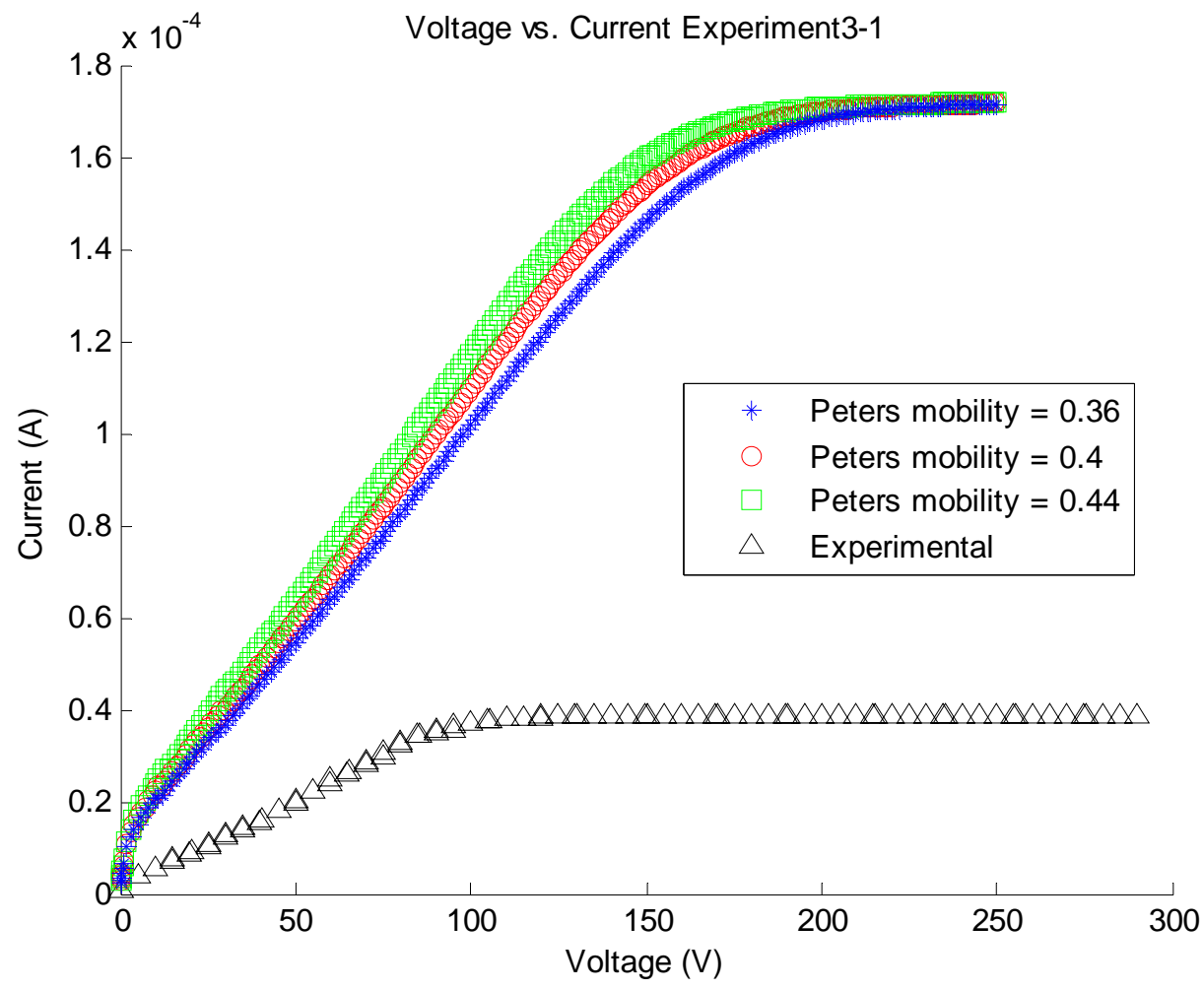

Figure E-67: Voltage vs. Current with Methane for Peters Experiment 3-1 


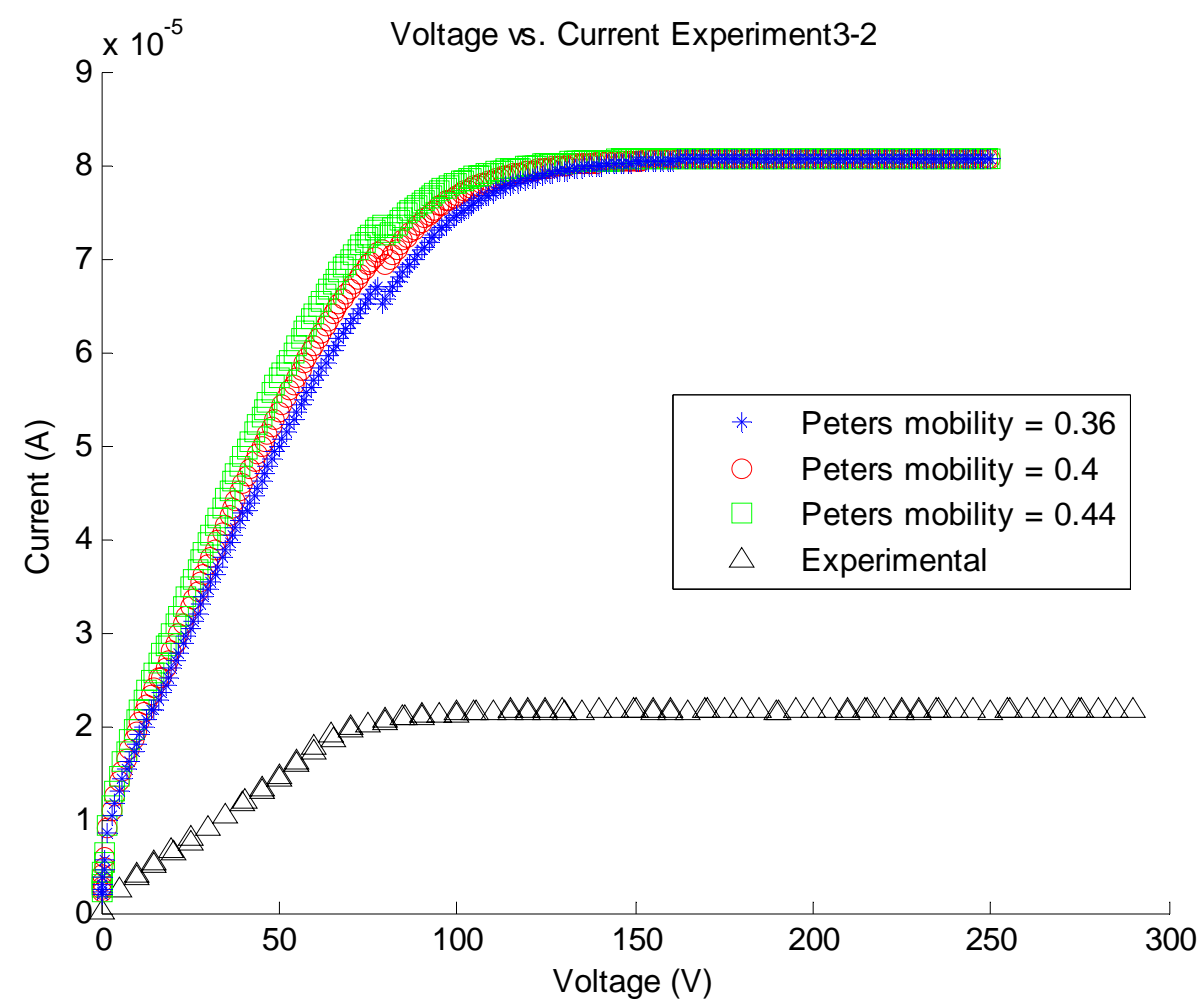

Figure E-68: Voltage vs. Current with Methane for Peters Experiment 3-2

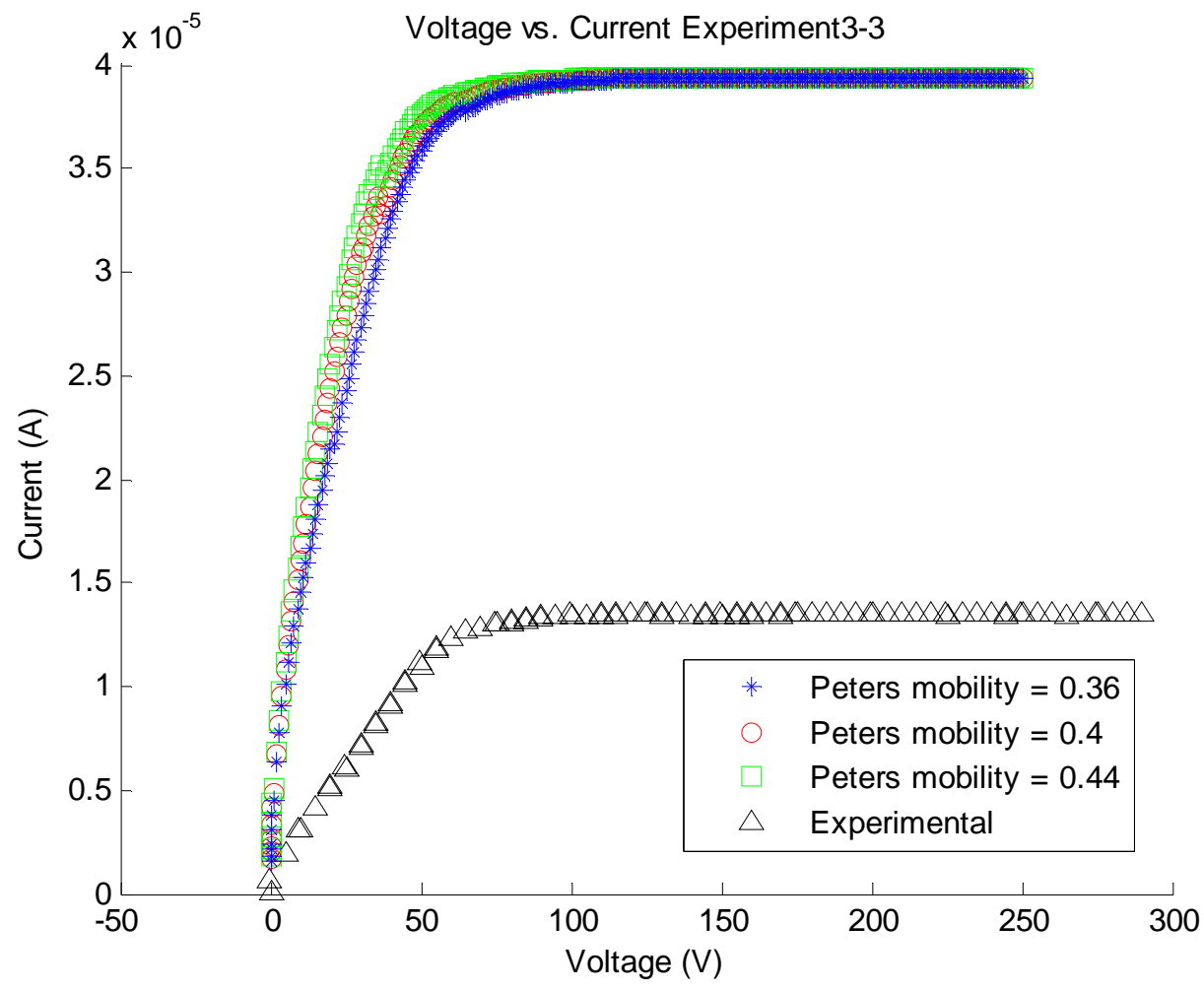

Figure E-69: Voltage vs. Current with Methane for Peters Experiment 3-3 


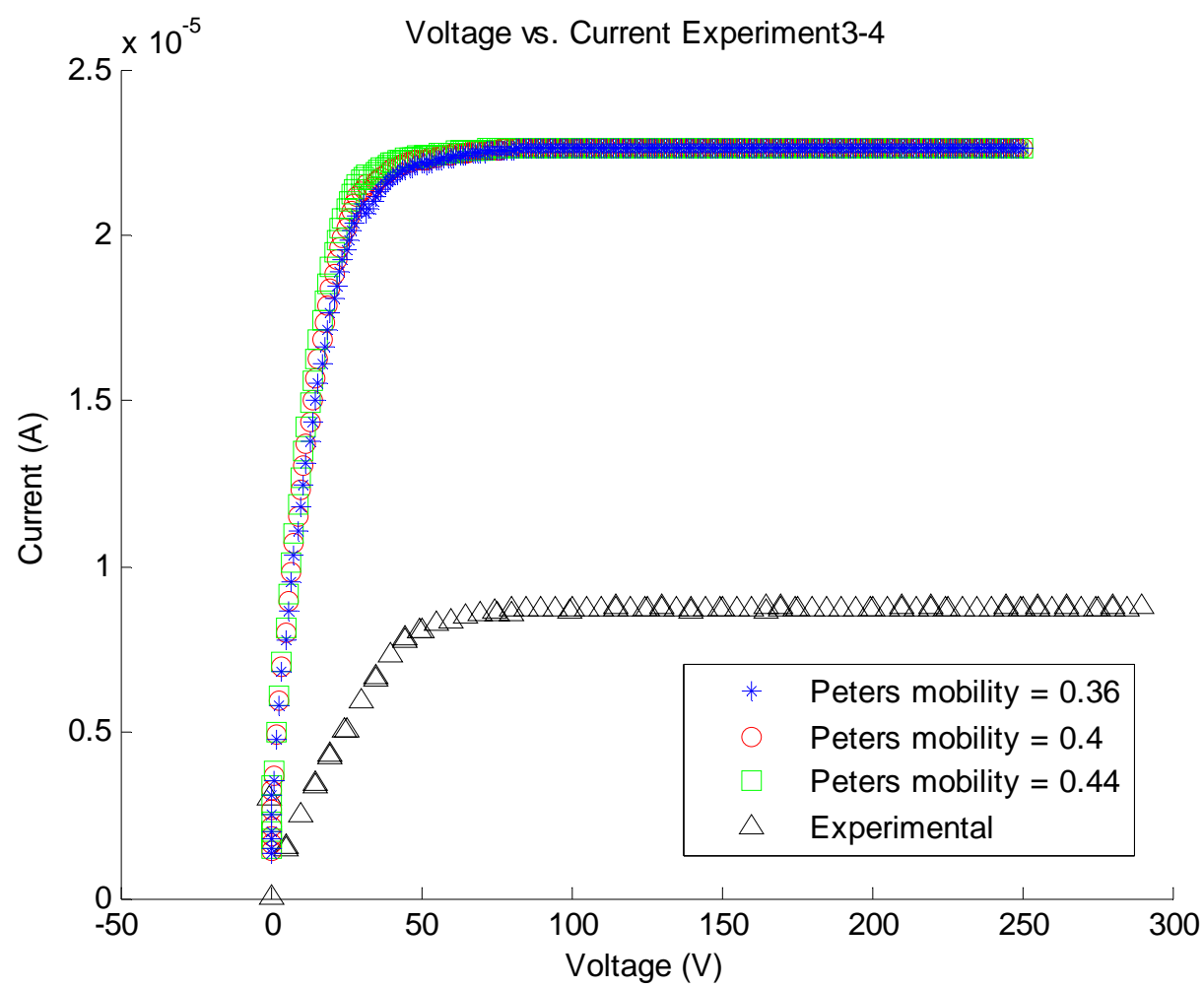

Figure E-70: Voltage vs. Current with Methane for Peters Experiment 3-4

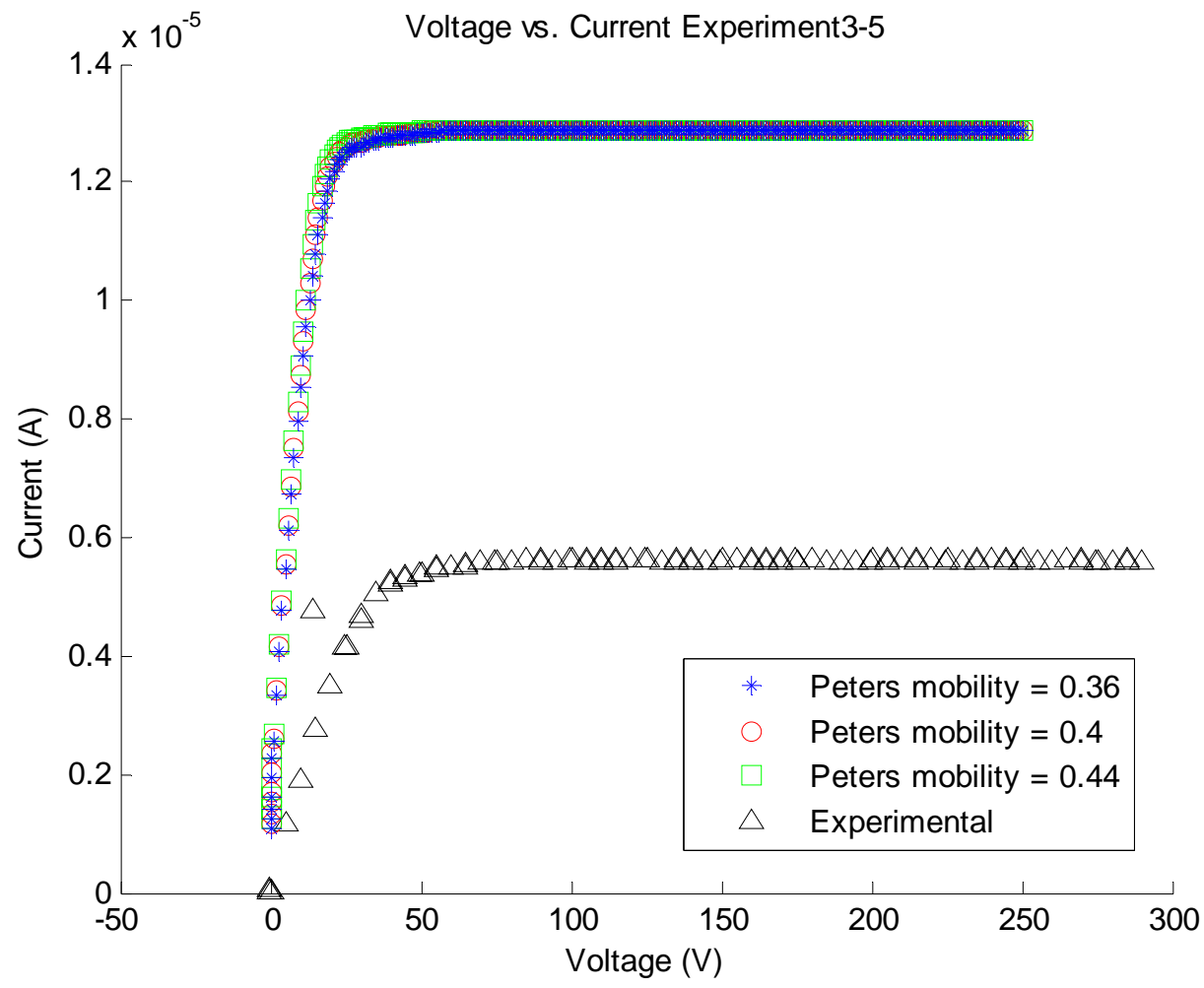

Figure E-71: Voltage vs. Current with Methane for Peters Experiment 3-5 


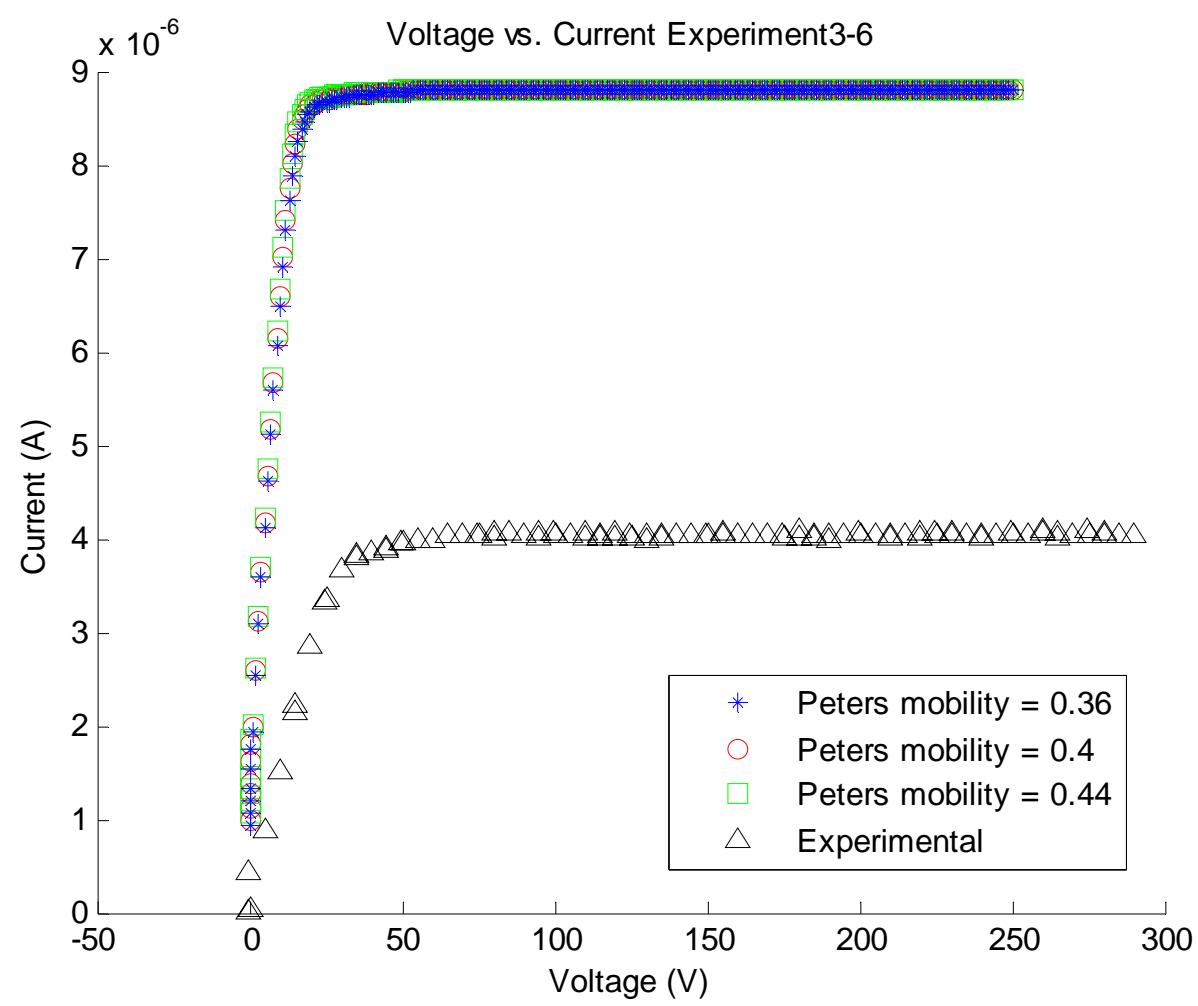

Figure E-72: Voltage vs. Current with Methane for Peters Experiment 3-6 


\section{E-5: Plots of Methane Combustion Using Four Mechanisms}

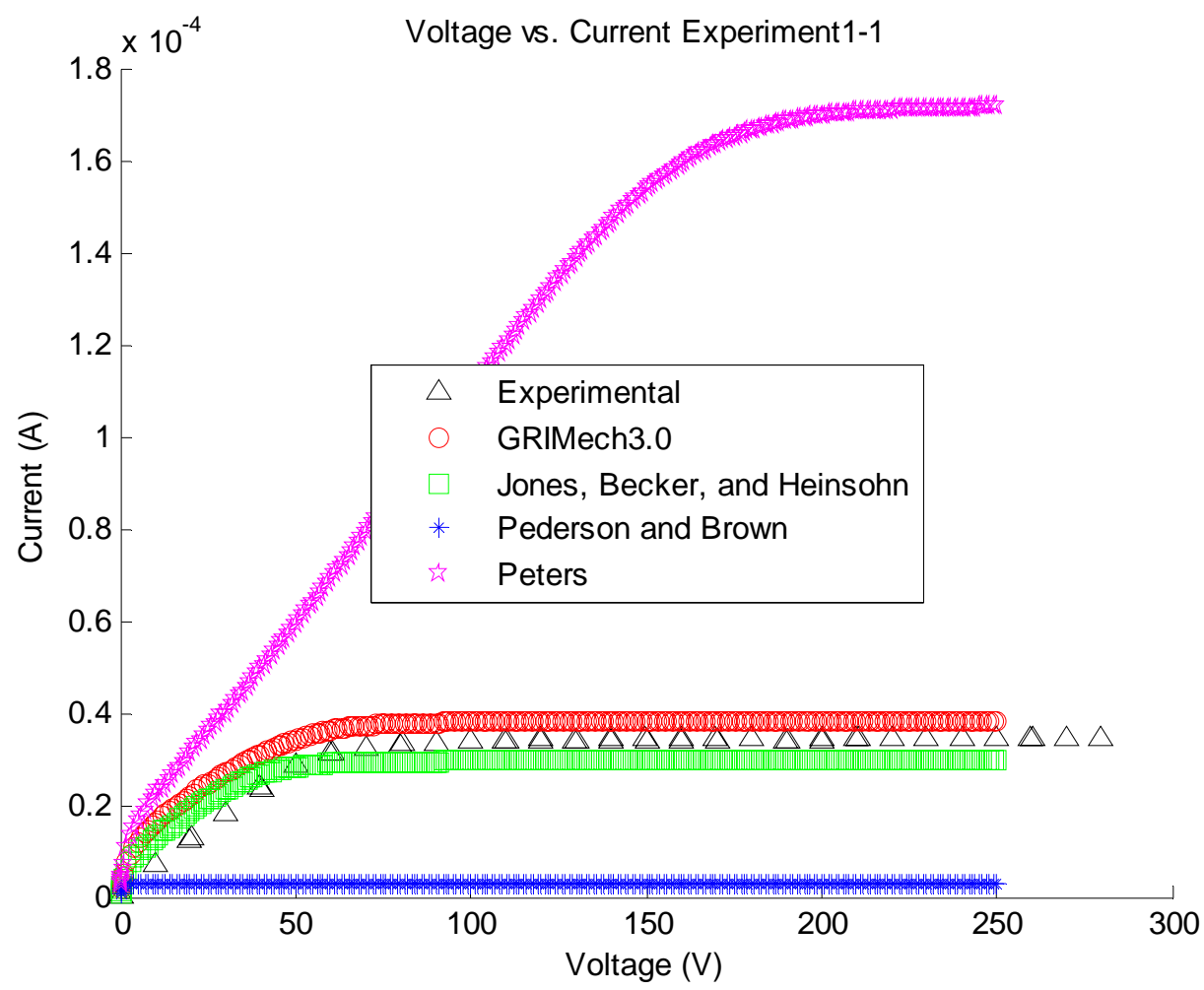

Figure E-73: Voltage vs. Current with Methane for All Mechanisms Experiment 1-1

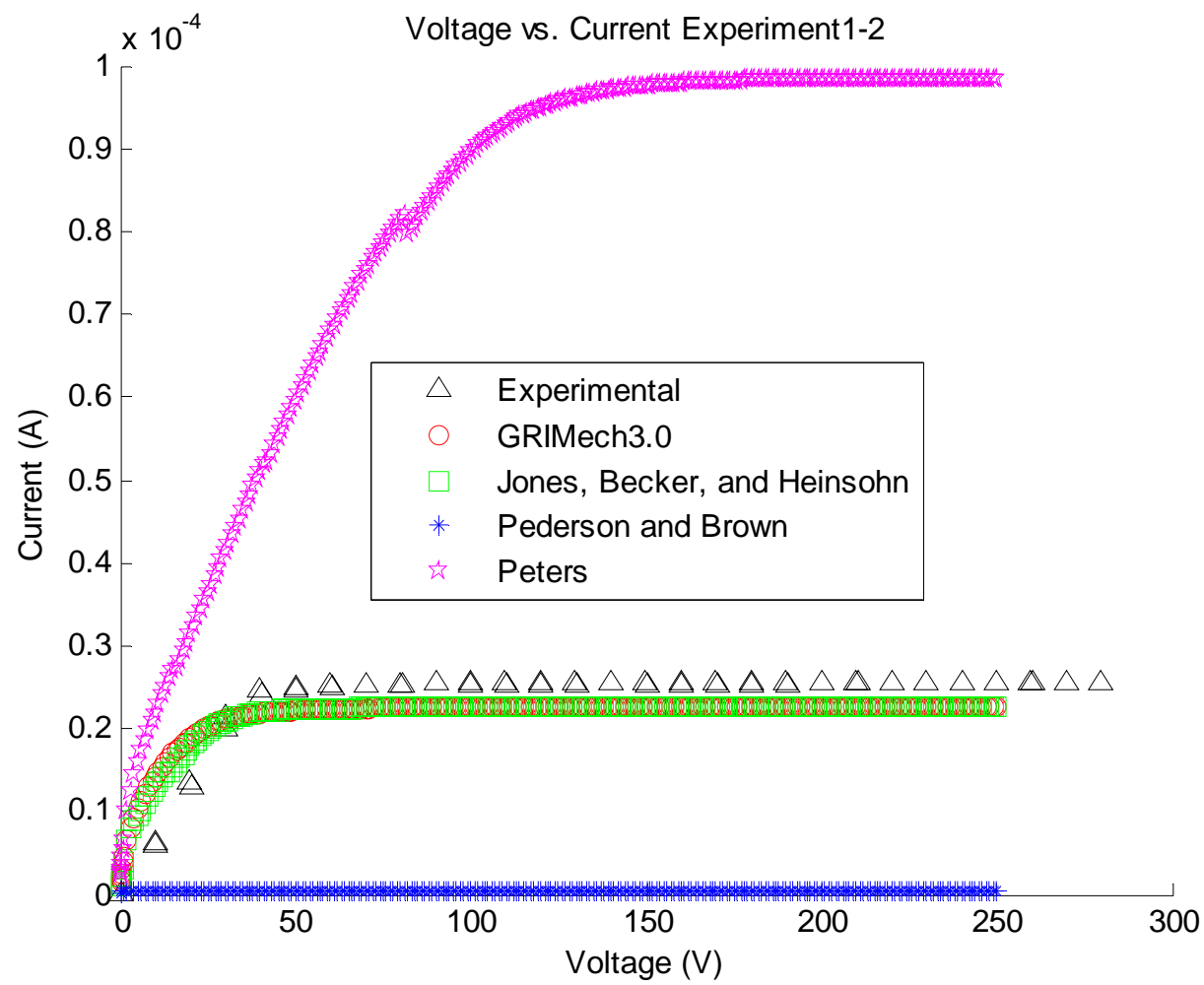

Figure E-74: Voltage vs. Current with Methane for All Mechanisms Experiment 1-2 


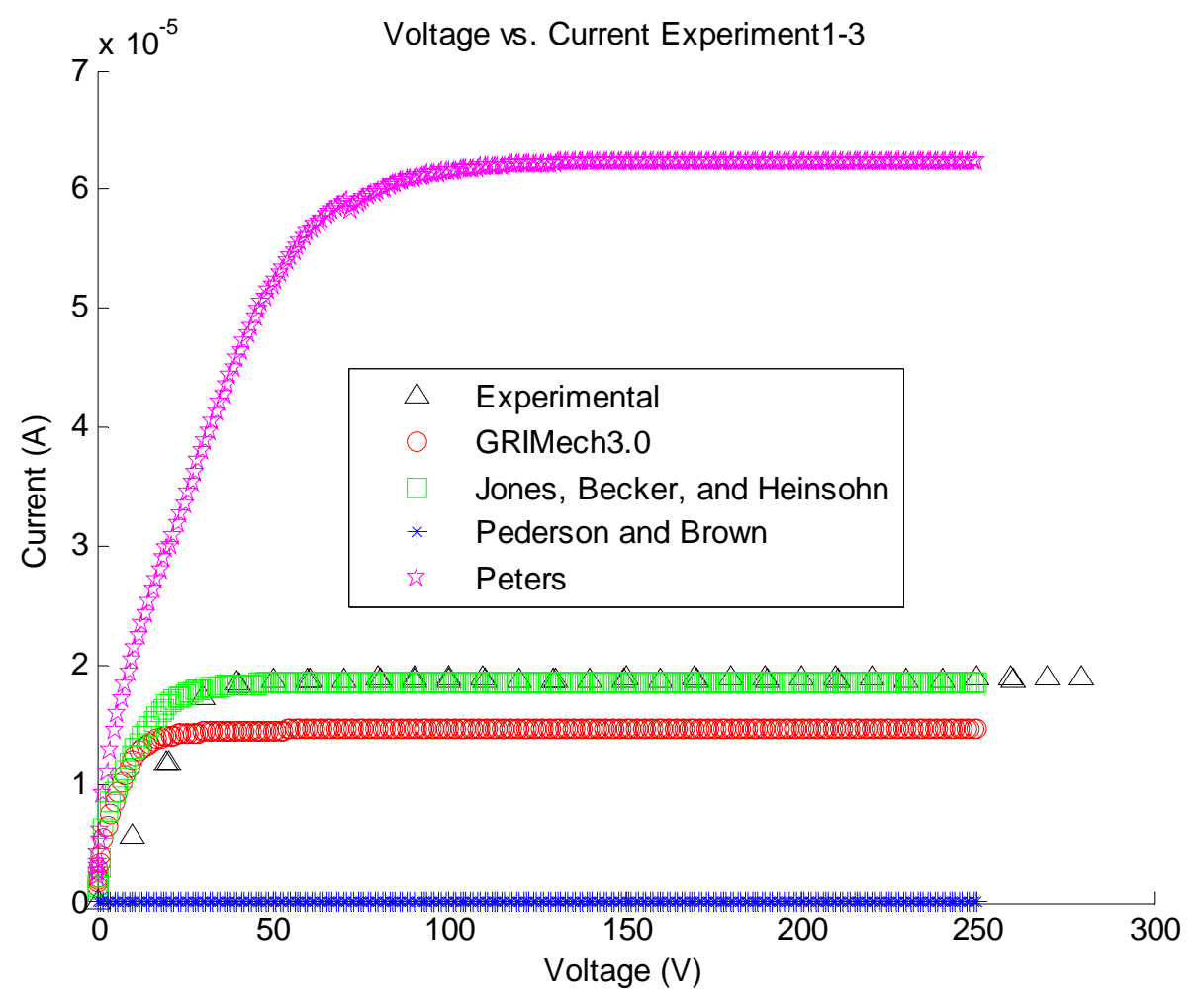

Figure E-75: Voltage vs. Current with Methane for All Mechanisms Experiment 1-3

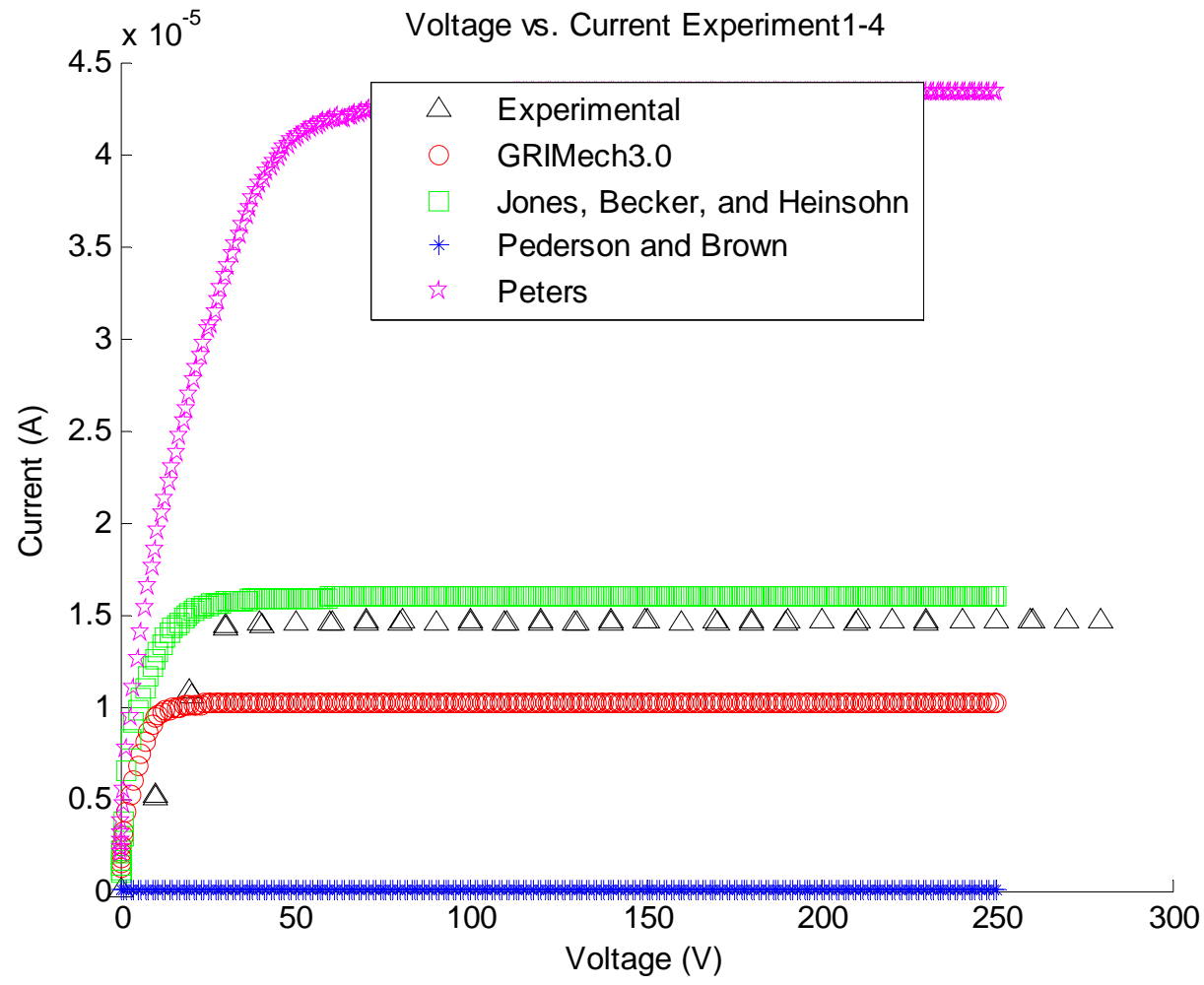

Figure E-76: Voltage vs. Current with Methane for All Mechanisms Experiment 1-4 


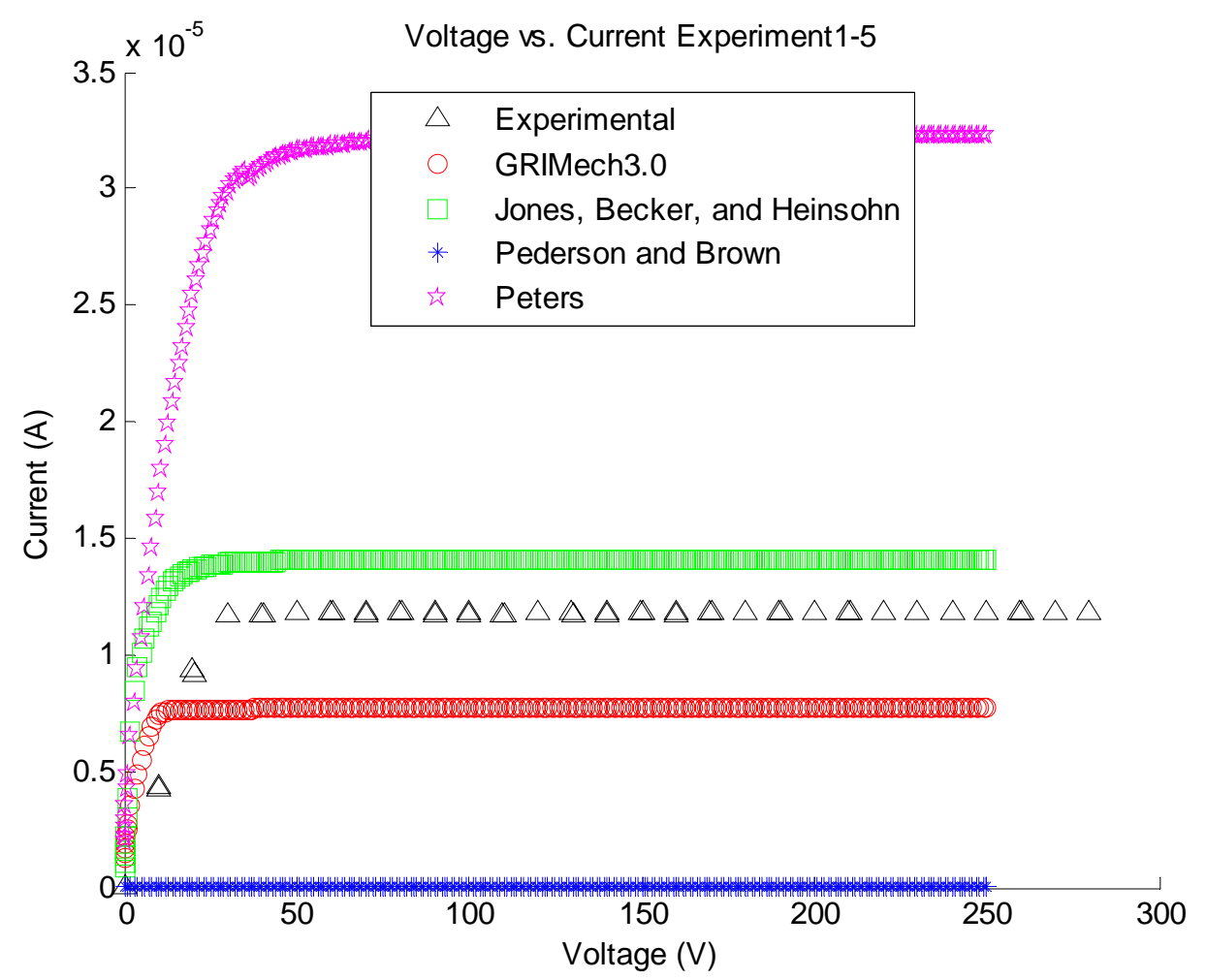

Figure E-77: Voltage vs. Current with Methane for All Mechanisms Experiment 1-5

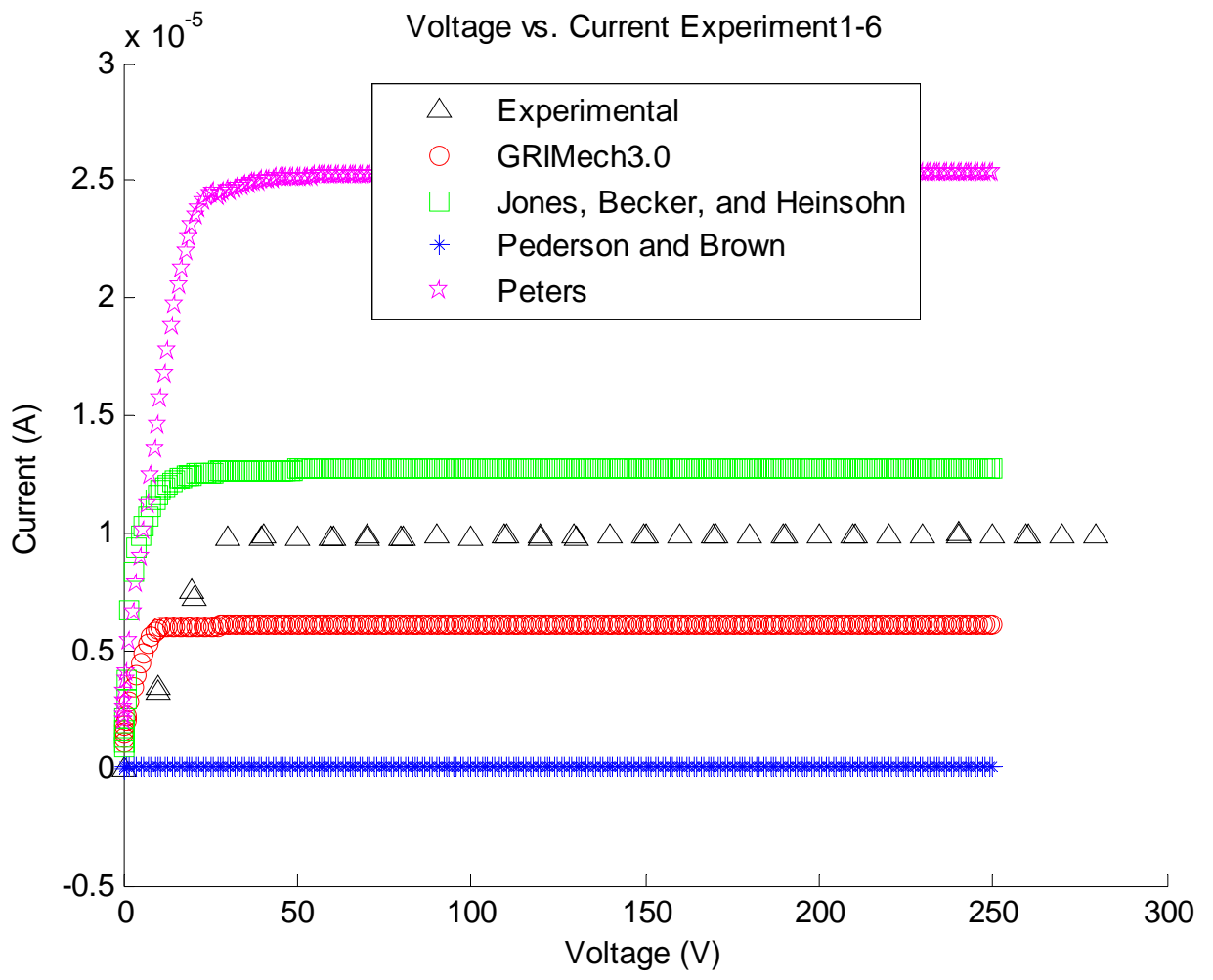

Figure E-78: Voltage vs. Current with Methane for All Mechanisms Experiment 1-6 


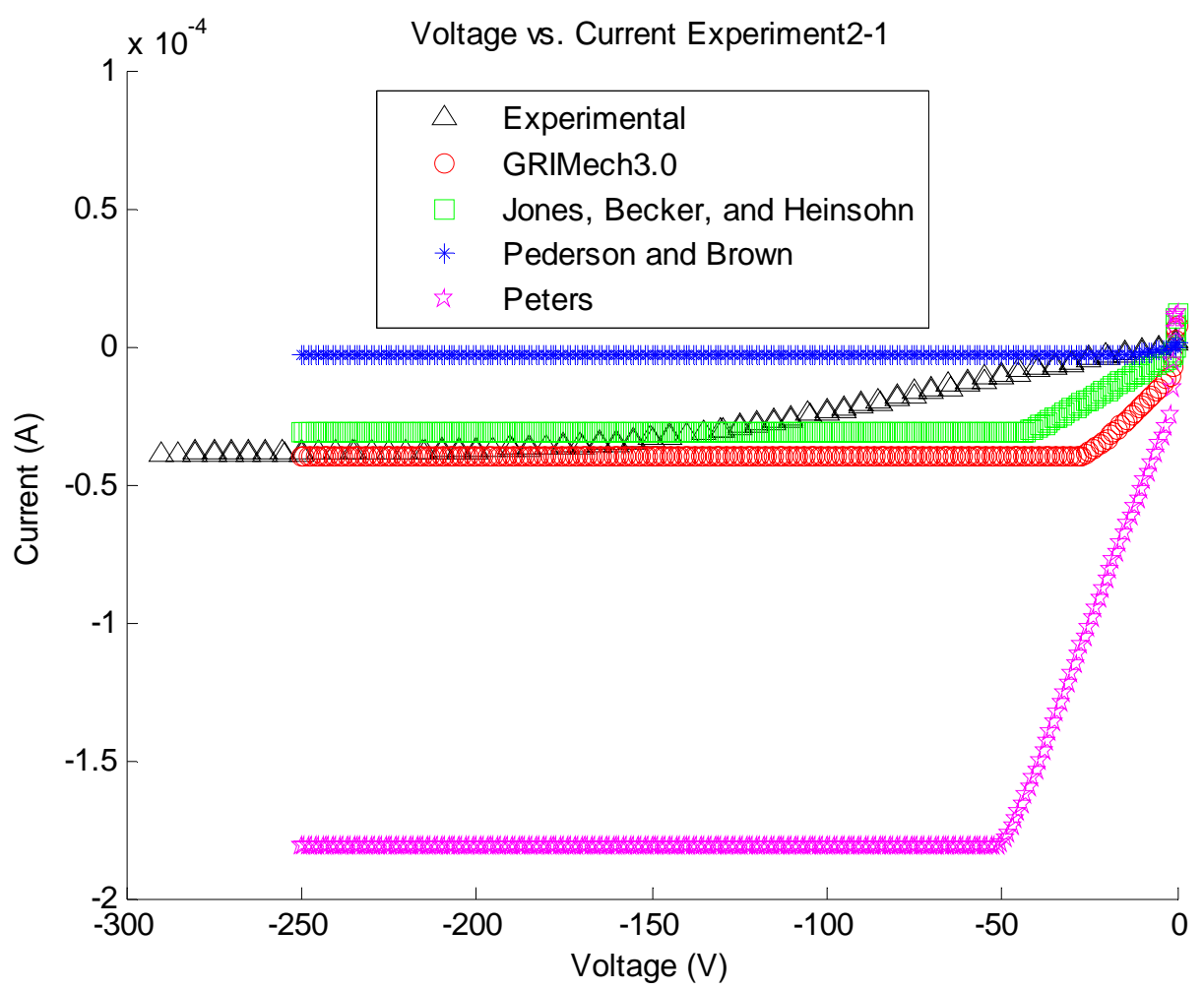

Figure E-79: Voltage vs. Current with Methane for All Mechanisms Experiment 2-1

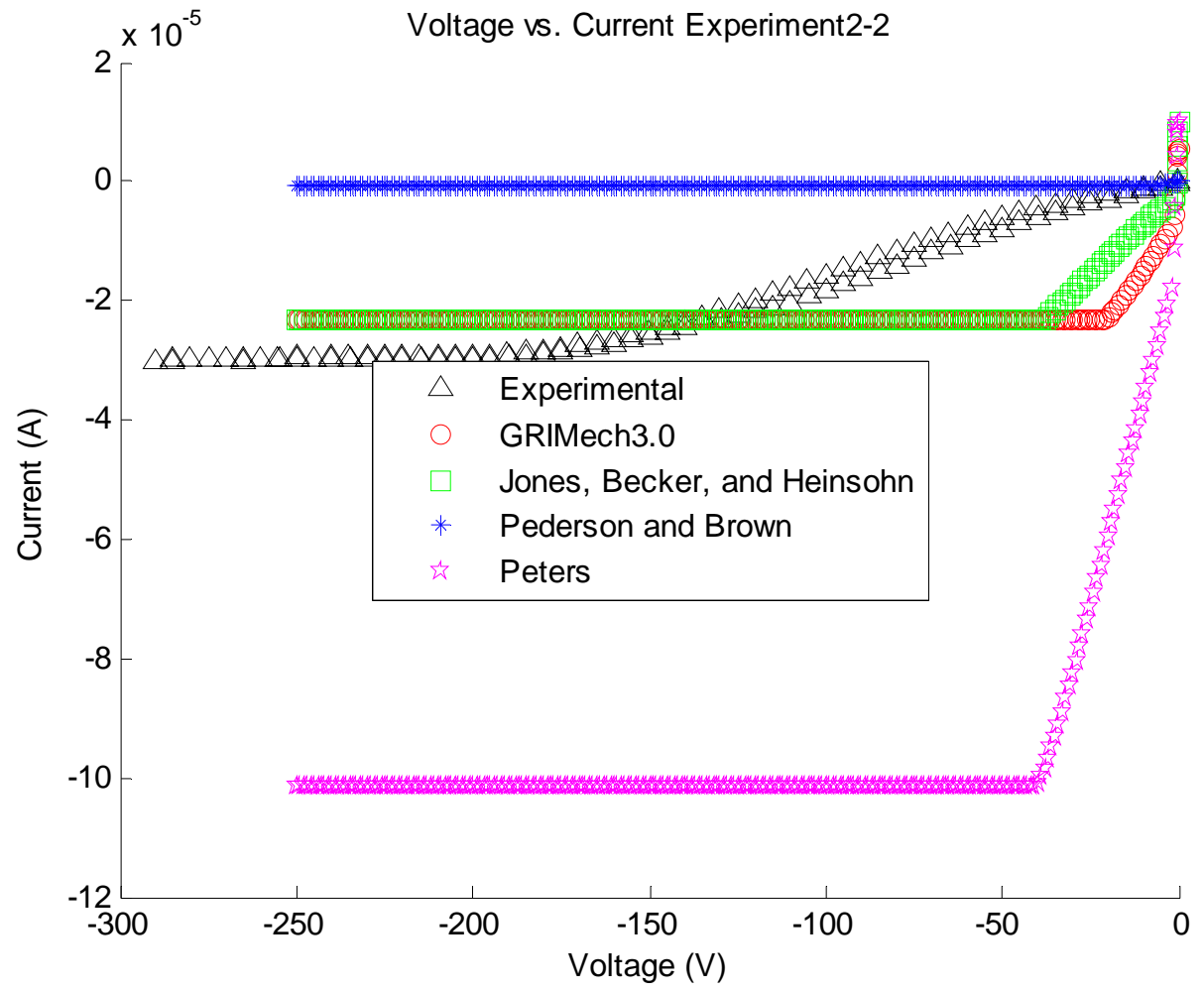

Figure E-80: Voltage vs. Current with Methane for All Mechanisms Experiment 2-2 


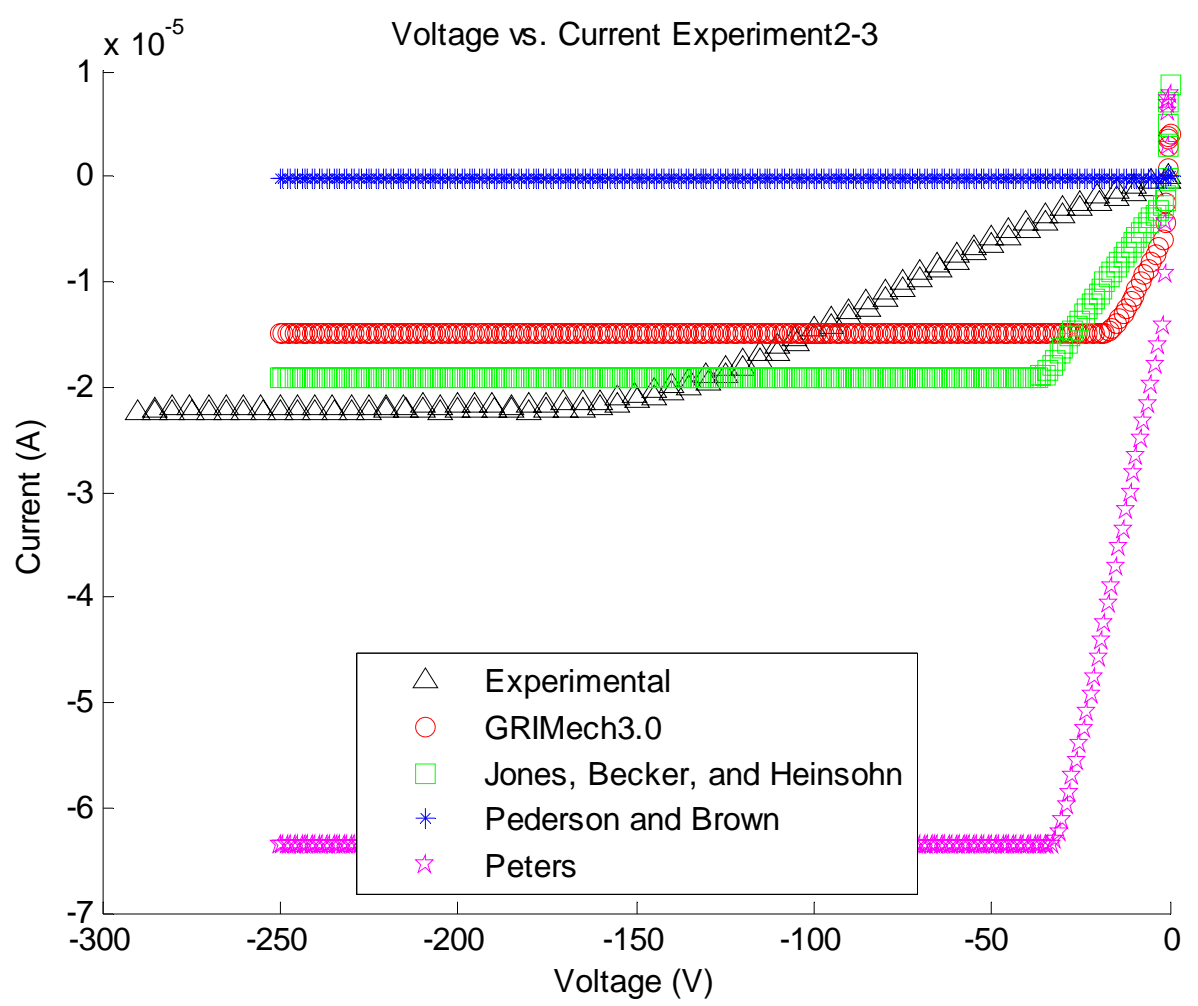

Figure E-81: Voltage vs. Current with Methane for All Mechanisms Experiment 2-3

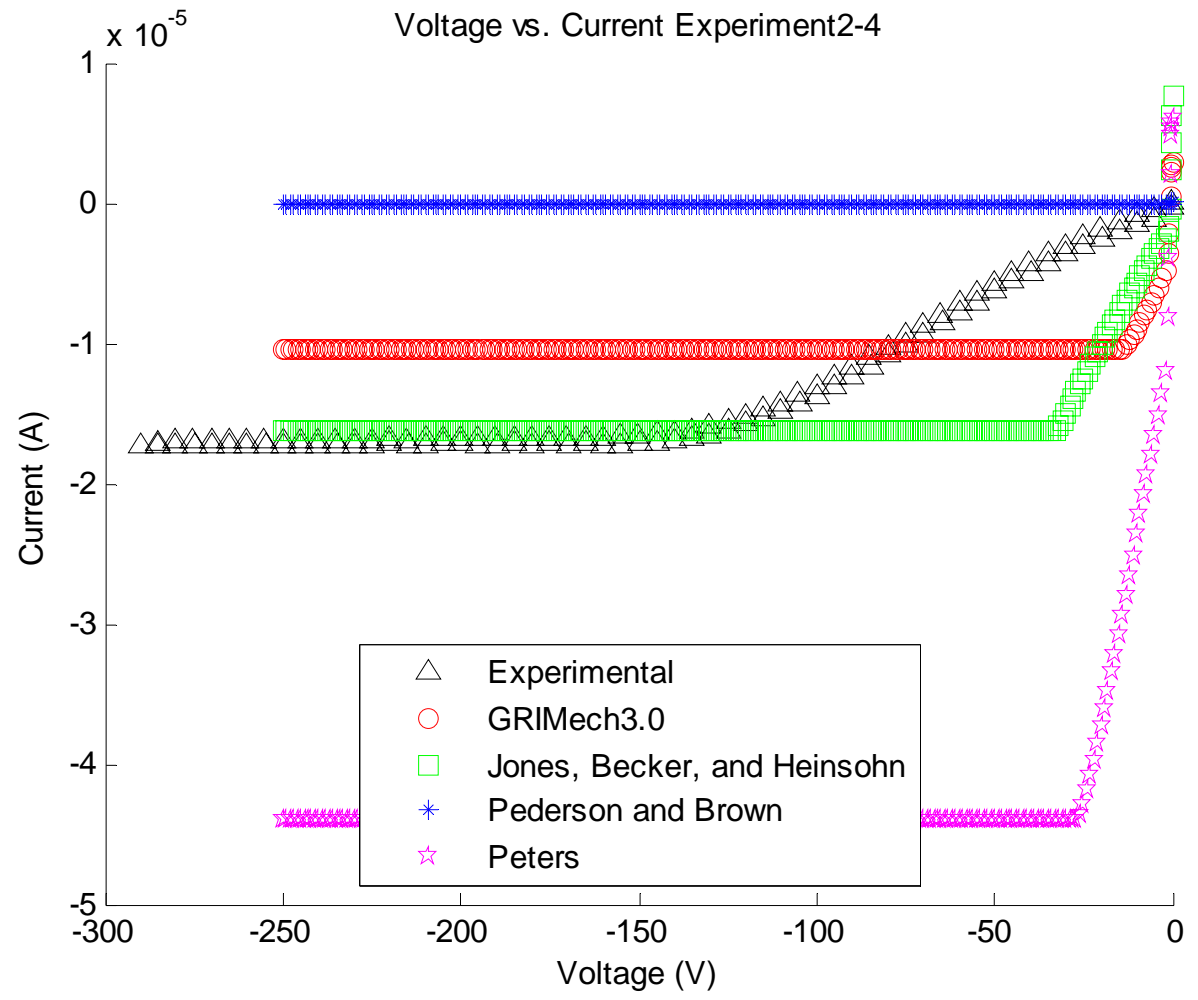

Figure E-82: Voltage vs. Current with Methane for All Mechanisms Experiment 2-4 


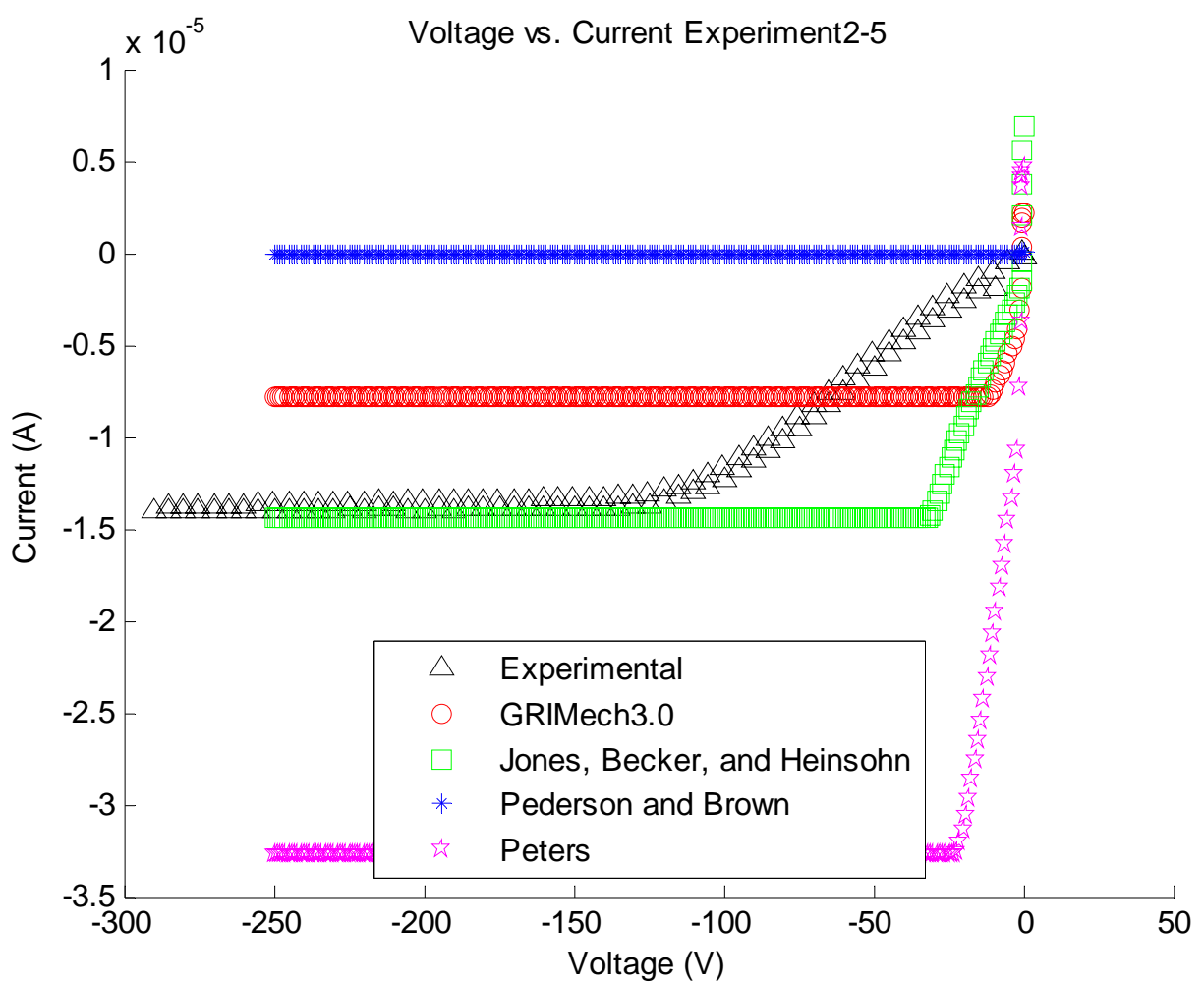

Figure E-83: Voltage vs. Current with Methane for All Mechanisms Experiment 2-5

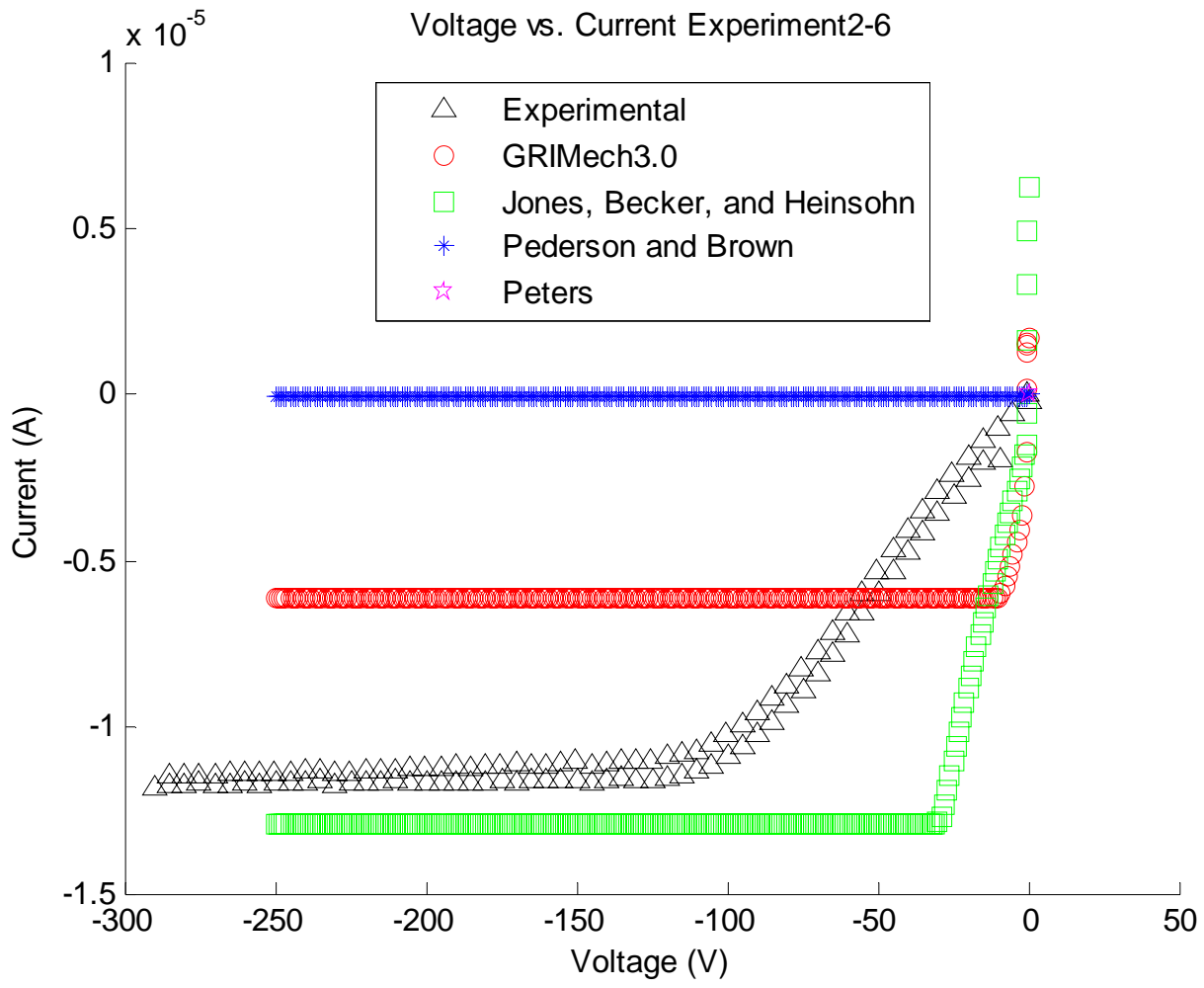

Figure E-84: Voltage vs. Current with Methane for All Mechanisms Experiment 2-6 


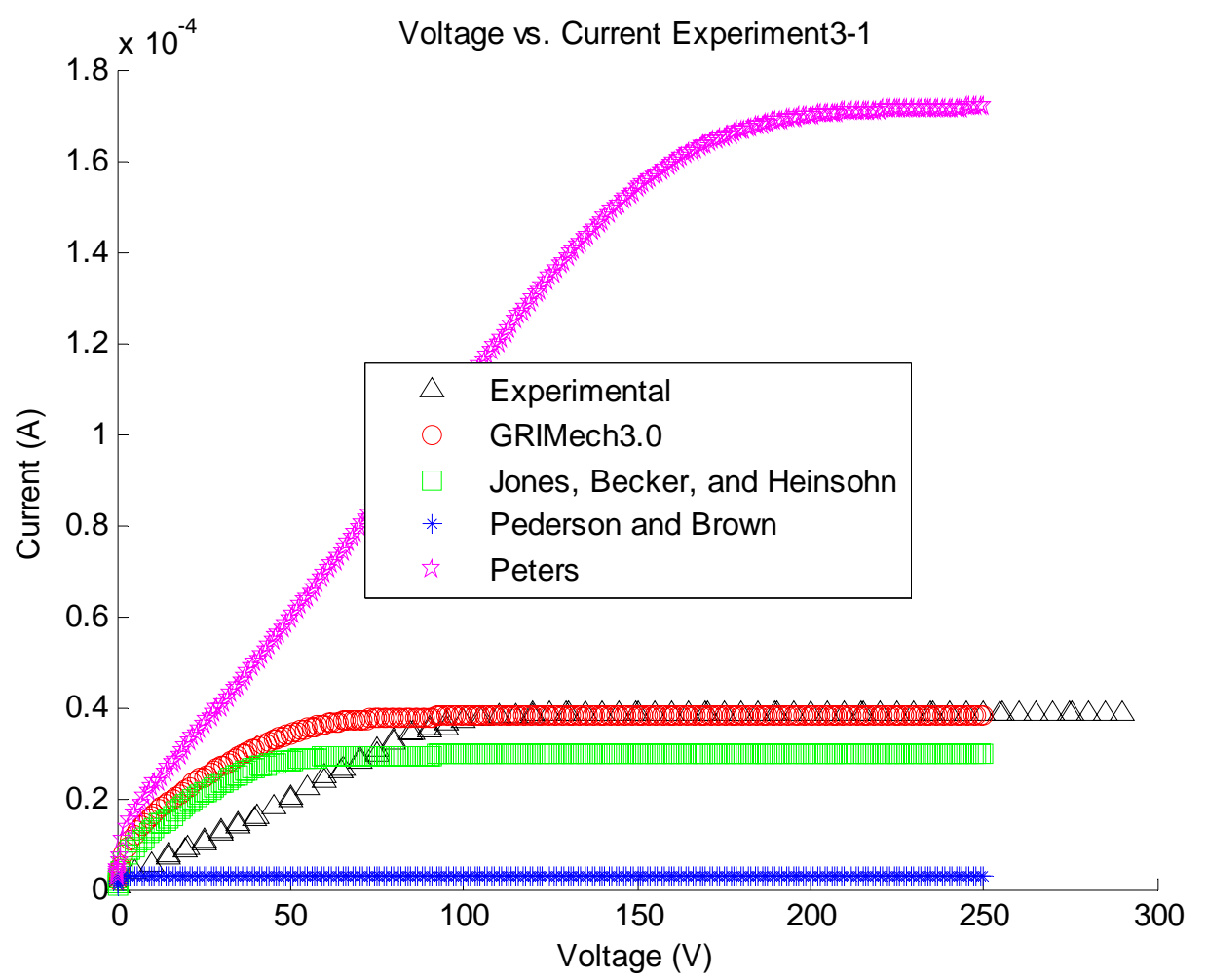

Figure E-85: Voltage vs. Current with Methane for All Mechanisms Experiment 3-1

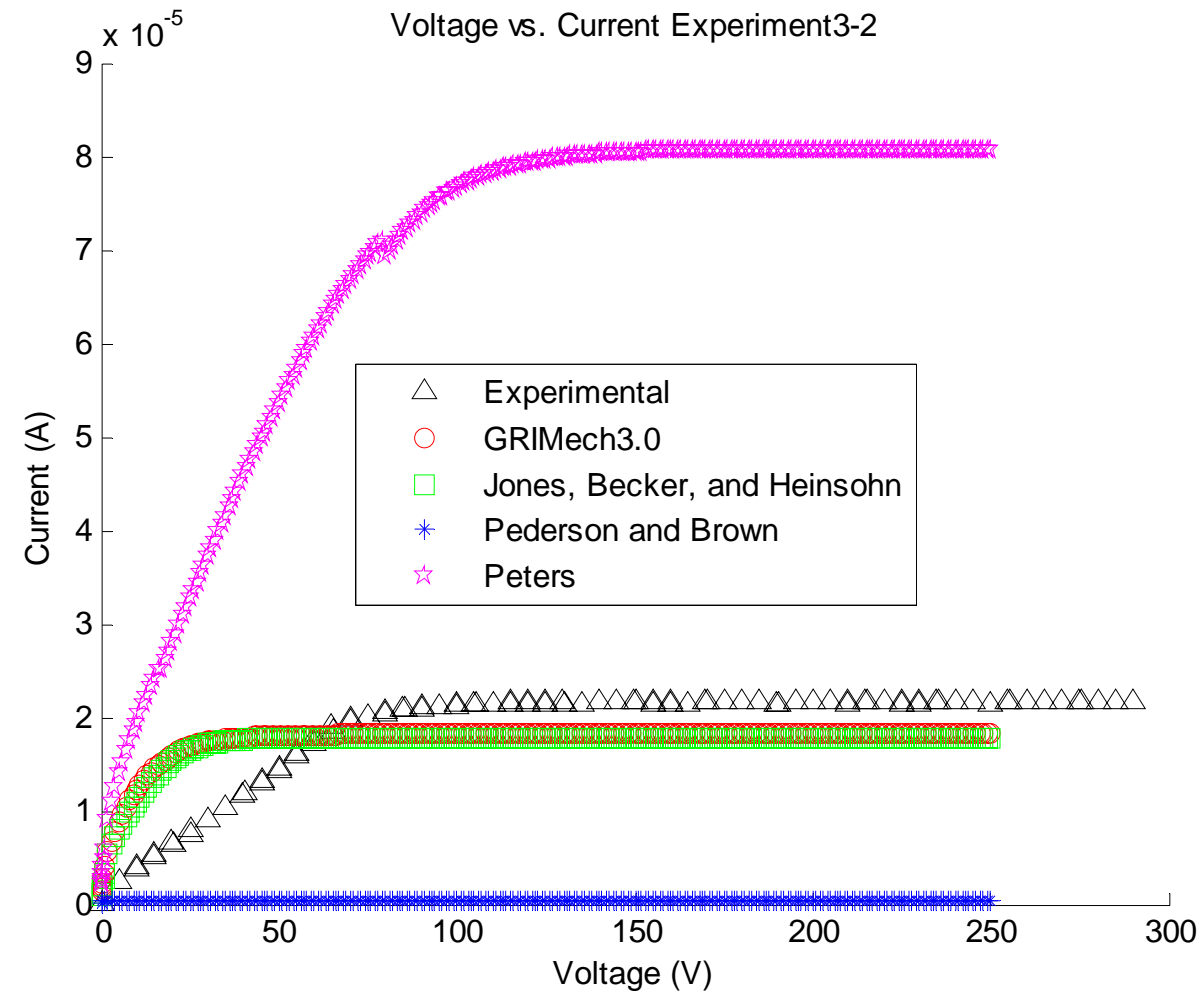

Figure E-86: Voltage vs. Current with Methane for All Mechanisms Experiment 3-2 


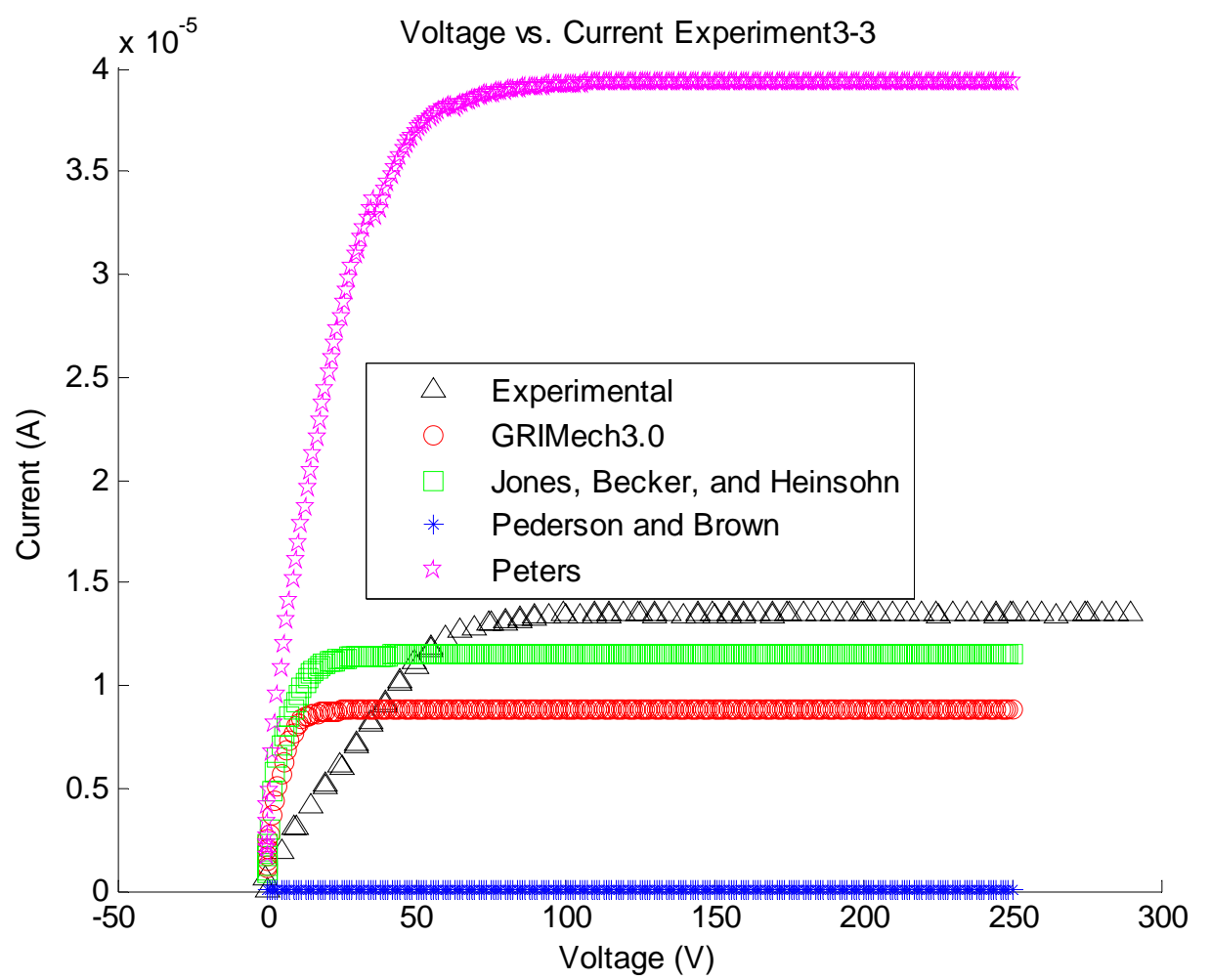

Figure E-87: Voltage vs. Current with Methane for All Mechanisms Experiment 3-3

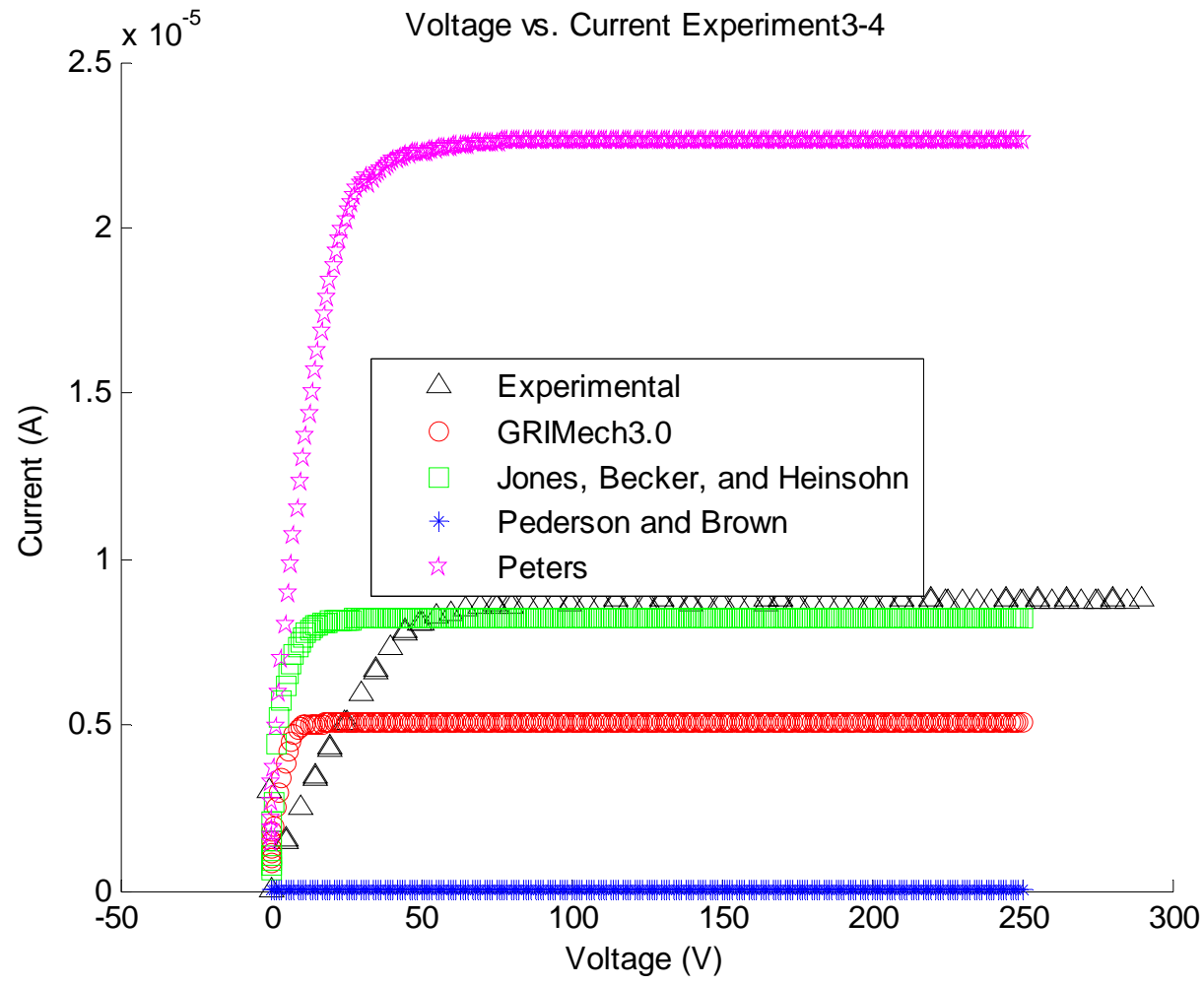

Figure E-88: Voltage vs. Current with Methane for All Mechanisms Experiment 3-4 


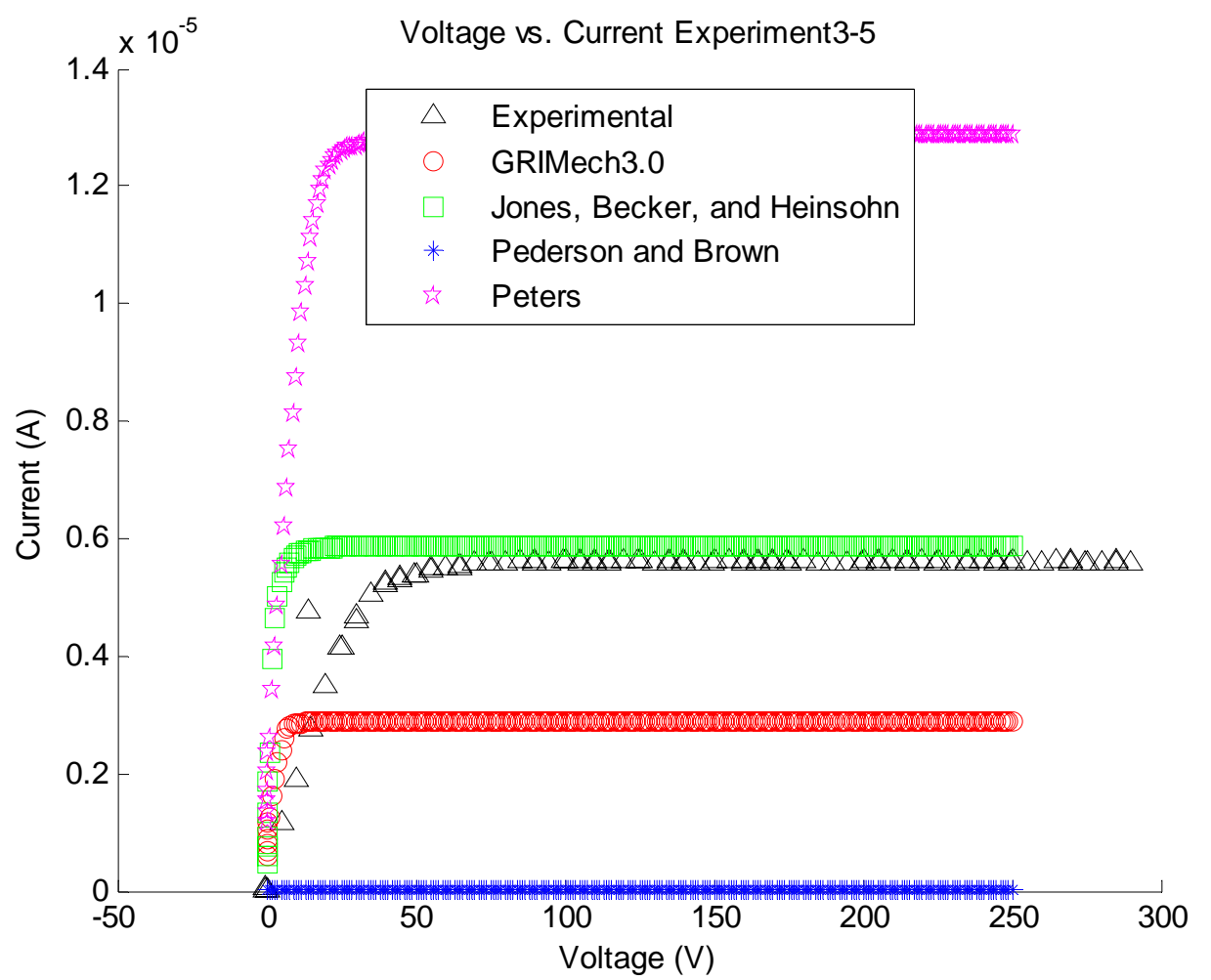

Figure E-89: Voltage vs. Current with Methane for All Mechanisms Experiment 3-5

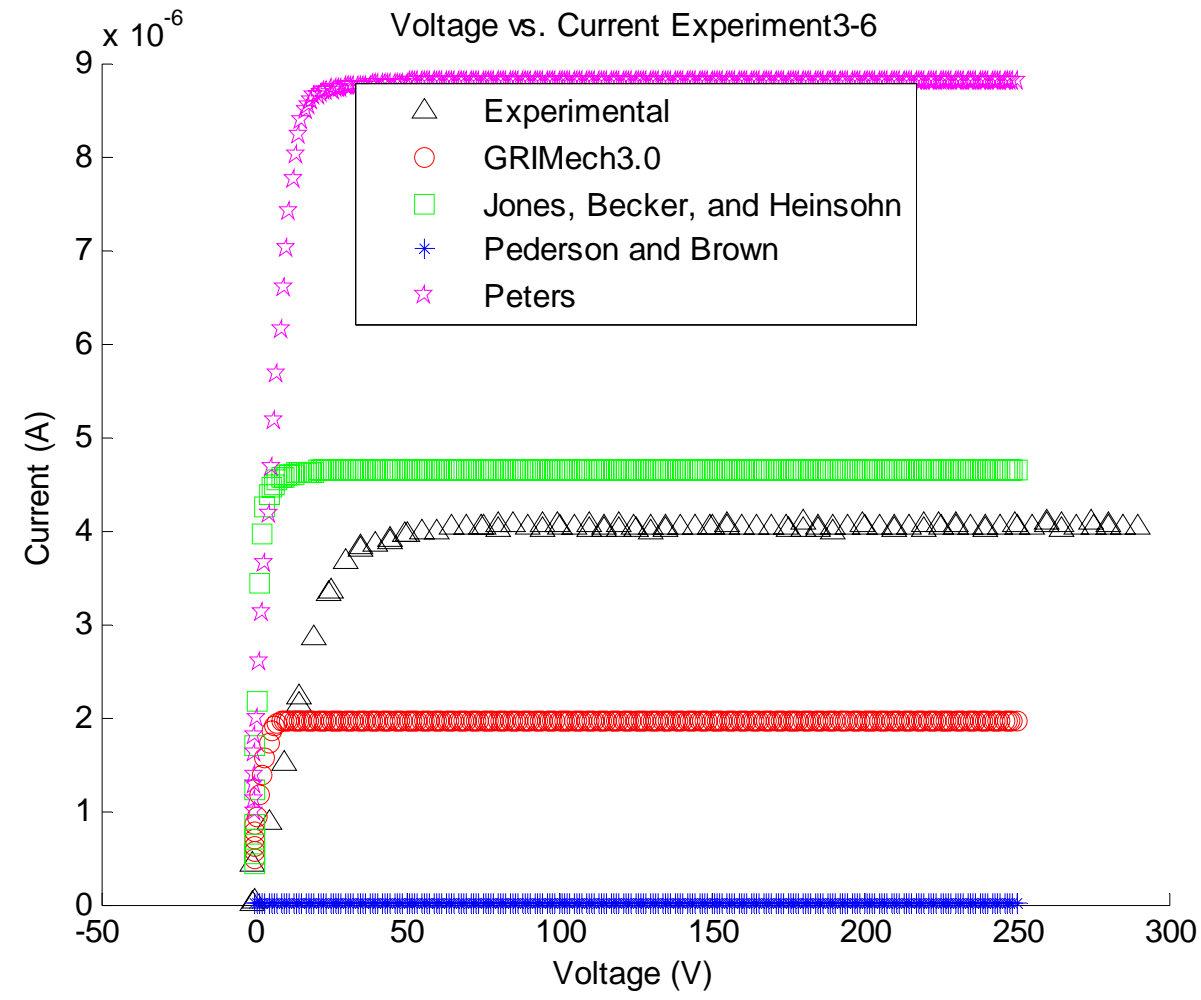

Figure E-90: Voltage vs. Current with Methane for All Mechanisms Experiment 3-6 


\section{E-6: Plots of Synthesis Gas Combustion Using Pederson and Brown}

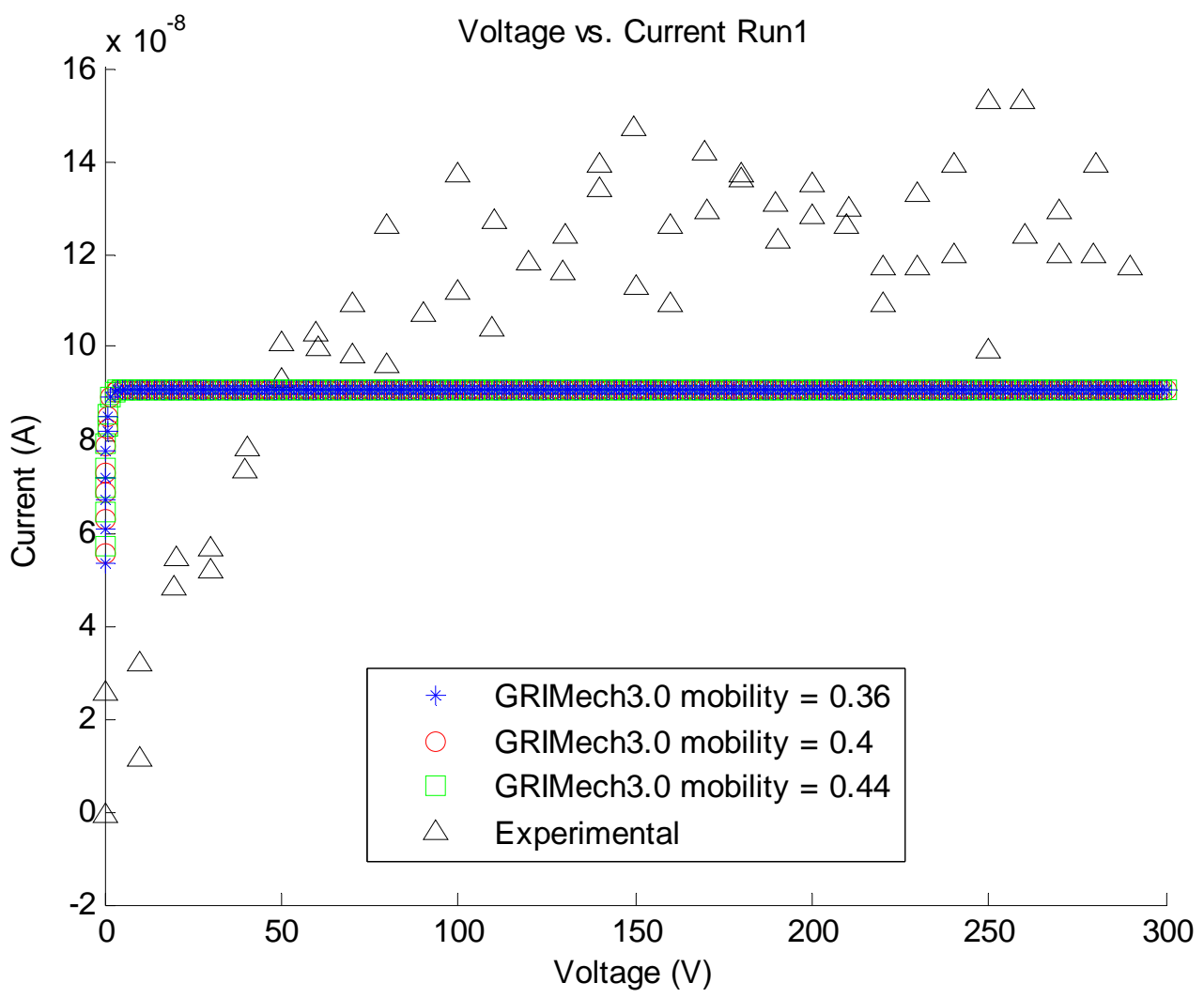

Figure E-91: Voltage vs. Current with Synthesis Gas for GRI Run 1 


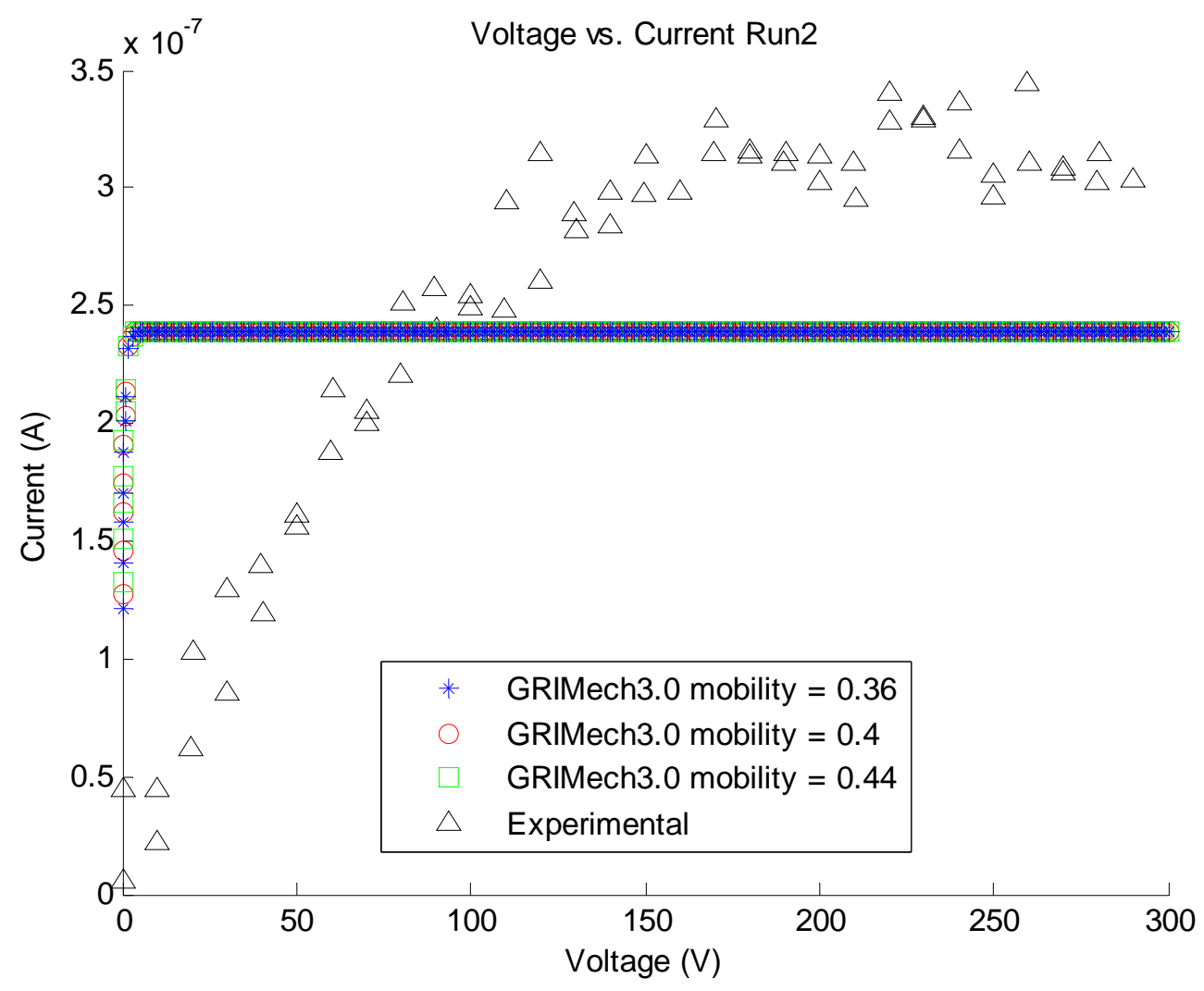

Figure E-92: Voltage vs. Current with Synthesis Gas for GRI Run 2

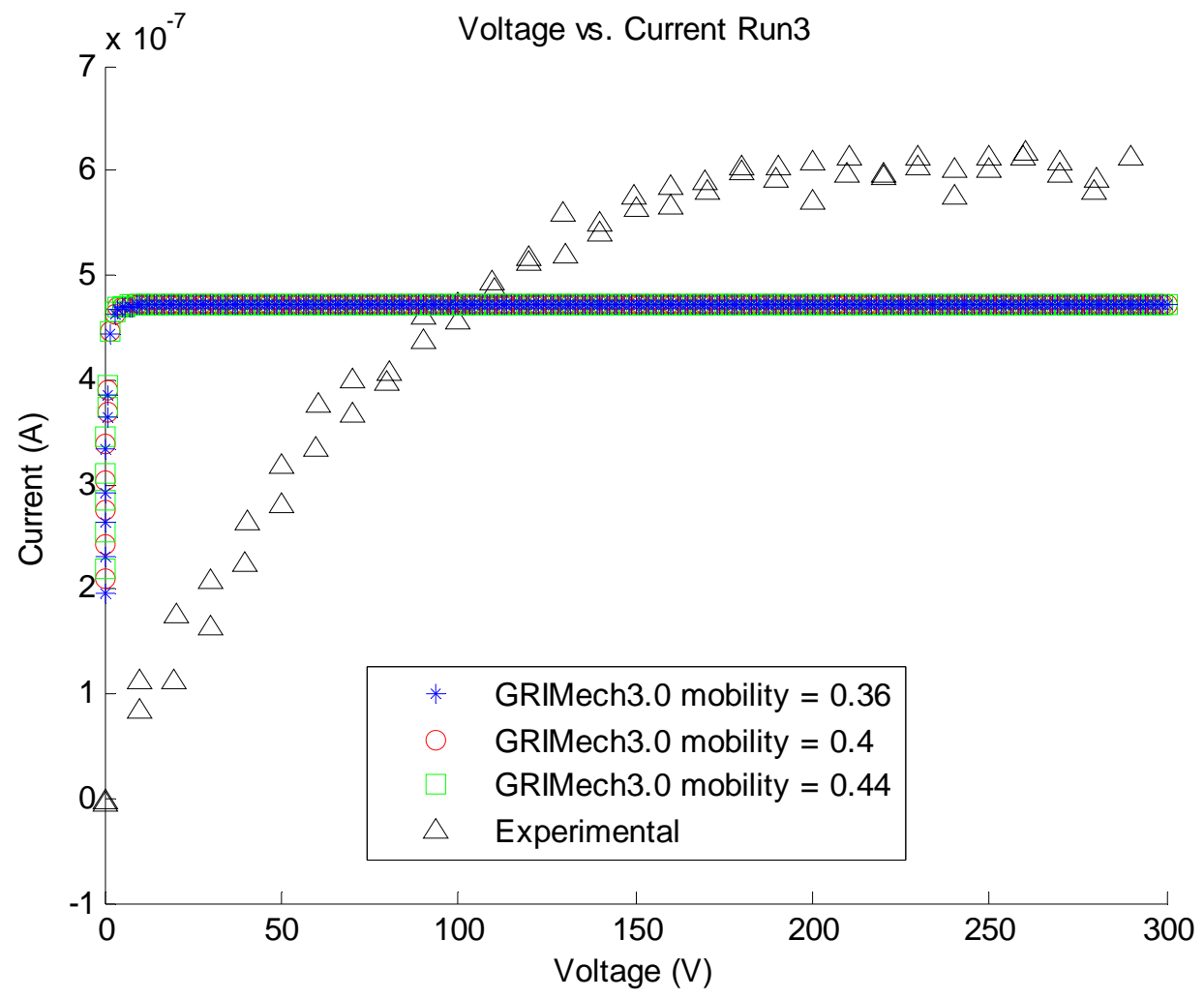

Figure E-93: Voltage vs. Current with Synthesis Gas for GRI Run 3 


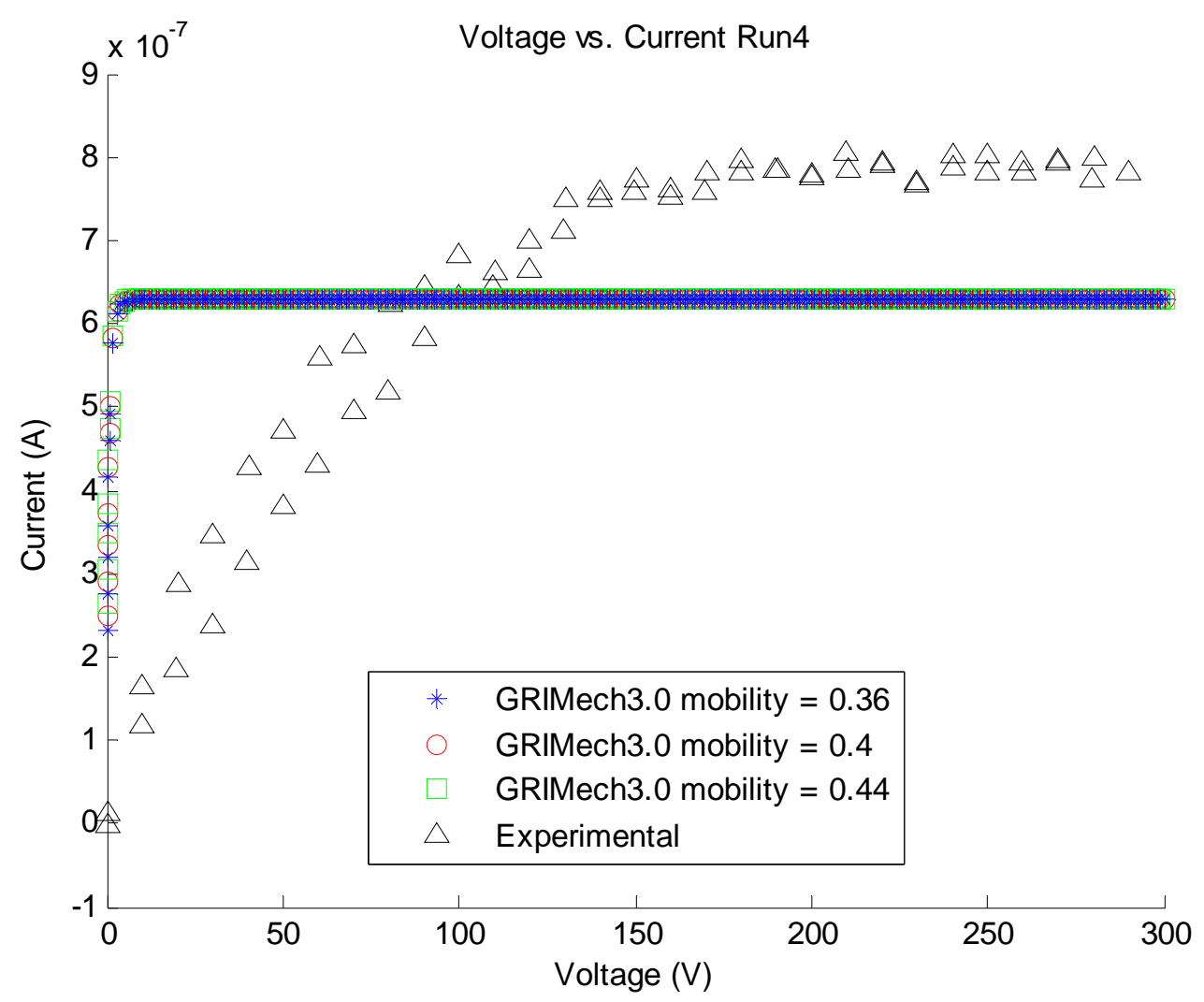

Figure E-94: Voltage vs. Current with Synthesis Gas for GRI Run 4

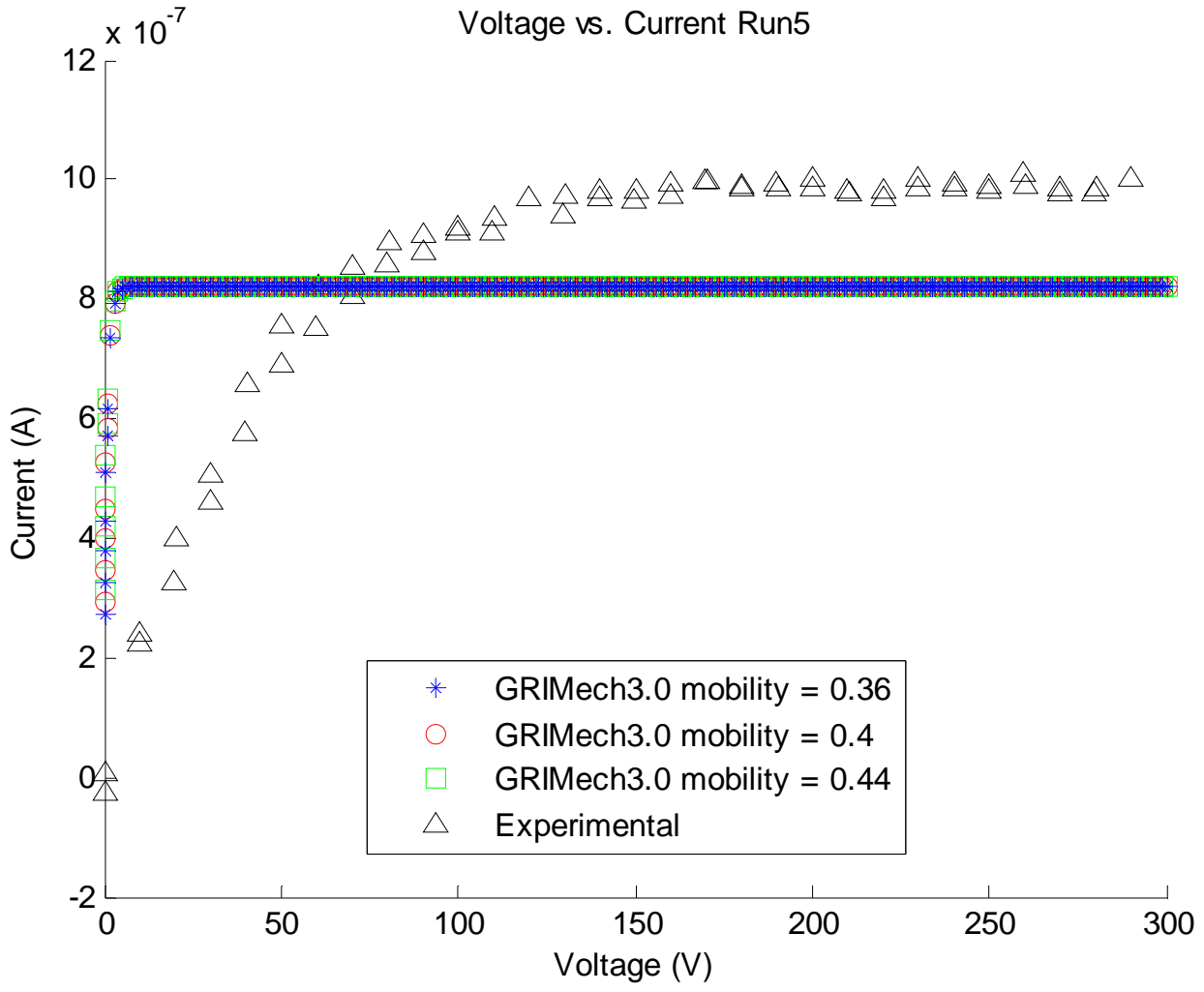

Figure E-95: Voltage vs. Current with Synthesis Gas for GRI Run 5 


\section{Bibliography}

[1] Benson, Kelly A., Thornton, Jimmy D., Staub, Douglas L., Huckaby, E. David, and Richards, Geo. A., "Flame Ionization Sensor Integrated into Gas Turbine Fuel Nozzle," ASME Paper GT2003-38470, 2003.

[2] Burcat, Alexander and Ruscic, Branko, Ideal Gas Thermodynamic Data in Polynomial Form for Combustion and Air Pollution Use, http://garfield.chem.elte.hu/Burcat/burcat.html, 2005.

[3] Cheney, W., and Kincaid, D., Numerical Mathematics and Computing, $5^{\text {th }}$ ed., Belmont, CA: Brooks/Cole-Thomson Learning, 2004, pp. 205-215.

[4] Eraslan, Ahmet N., and Brown, Robert C., "Chemiionization and Ion-Molecule Reactions in Fuel-Rich Acetylene Flames," Combustion and Flame, v. 74, pp. 19-37, 1988.

[5] Goodings, John M., Guo, Jingzhong, Hayhurst, Allan N., and Taylor, Stephen G., "Current-Voltage Characteristics in a Flame Plasma: Analysis for Positive and Negative Ions with Applications," International Journal of Mass Spectrometry, 2001, v. 206, pp. 137-151, 2001.

[6] Goodwin, David G., Cantera: Object-Oriented Software for Reacting Flows, http://www.cantera.org, 2005.

[7] Goodwin, David G., Defining Phases and Interfaces. http://prdownloads.sourceforge.net/cantera/definingphases.pdf?download, 2003.

[8] Goodwin, David G., Sourceforge.net: Project Info - Cantera, http://sourceforge.net/projects/cantera, 2005.

[9] Gordon, Sanford, and McBride, Bonnie J., "Computer Program for Calculation of Complex Chemical Equilibrium Compositions and Applications: I. Analysis", NASA Reference Publication 1311, 1994

[10] Holm, Torkil, "Aspect of the Mechanism of the Flame Ionization Detector," Journal of Chromatography A, v. 842, pp. 221-227, 1999.

[11] Huckaby, E. David, Customizing Cantera's One-Dimensional Flame Code, http://prdownloads.sourceforge.net/cantera/ModifyingLaminarRev3.pdf?download, rev. $3,2005$.

[12] Huckaby, E. David, Chorpening, Benjamin T., and Lilly, Jonathan P., Work-inProgress Poster: "A Laminar Flame Model with Electric Field Effects," $30^{\text {th }}$ Symposium on Combustion, July 2004. 
[13] Jones, Fred L., Becker, Philip M., Heinsohn, Robert, J., “A Mathematical Model of the Opposed-Jet Diffusion Flame: Effect of an Electric Field on Concentration and Temperature Profiles," Combustion and Flame, v. 19, pp. 351-362, 1972.

[14] Kee, Robert J., Coltrin, Michael E., and Glasborg, Peter., Chemically Reacting Flow: Theory and Practice, Hoboken, New Jersey: John Wiley \& Sons, 2003.

[15] Kee, Robert J., Dixon-Lewis, G., Warnatz, J., Coltrin, M., and Miller, J., A Fortran Computer Code Package for the Evaluation of Gas-Phase Multicomponent Transport Properties, Sandia National Laboratories, SAND-8246, 1986.

[16] Natarajan, J., Nandula, S., Liewen, T., and Seitzman, J., "Laminar Flame Speeds of Synthetic Gas Fuel Mixtures," Proceedings of 2005ASME Turbo Expo - Power for Land, Sea, and Air, Reno-Tahoe, NV, 6-9 June 2005, ASME Paper GT2005-68917.

[17] Oran, Elaine S., and Boris, Jay P., Numerical Simulation of Reactive Flow, New York: Elevier Science Publishing Co, Inc., 1987.

[18] Pederson, Timothy, and Brown, Robert C., "Simulation of Electric Field Effects in Premixed Methane Flames," Combustion and Flame, v. 94, pp. 433-448, 1993.

[19] Peters, Norbert, Fifteen Lectures on Turbulent Combustion, http://www.itv.rwthaachen.de/Downloadarea/Summerschool92/SummerSchool.pdf, 1992.

[20] Python Software Foundation, Python Programming Language, http://www.python.org, 2005.

[21] Smith, Gregory P., Golden, David M., Frenklach, M., Moriarty, Nigel W., Eiteneer, B., Goldenberg, M, Bowman, C. T., Hanson, Ronald K., Song, S., Gardiner, Jr., William C., Lissianski, Vitali V., and Qin, Zhiwei, GRI-Mech version 3.0, http://www.me.berkeley.edu/gri mech/, 1997.

[22] Straub, Douglas L., Thornton, Jimmy T., Chorpening, Benjamin T., and Richards, Geo. A., "In-Situ Flame Ionization Measurements in Lean Premixed Natural Gas Combustion Systems," Western States Section - Combustion Institute Spring Meeting, San Diego, CA, 25-26 March 2004.

[23] Streetman, Ben G., Banerjee, Sanjay, Solid State Electronics, $5^{\text {th }}$ ed., Upper Saddle River, New Jersey: Prentice Hall, Inc., 2000.

[24] Thornton, Jimmy D., Richards, Geo. A., Robey, E., "Detecting Flashback in Premix Combustion Systems," American Flame Research International Symposium, Newport Beach, CA, 25-26 March 2000. 
[25] Thornton, Jimmy D., Straub, Douglas L., Richards, Geo. A., Nutter, Roy S., Robey, E., "An In-Situ Monitoring Technique for Control and Diagnostics of Natural Gas Combustion Systems," $2^{\text {nd }}$ Joint Meeting of the U.S. Sections of the Combustion Institute, Oakland, CA, 25-28 March 2001.

[26] Thornton, Jimmy D., Straub, Douglas L., Chorpening, Benjamin T., Huckaby, E. David, Richards, Geo. A., and Benson, Kelly, "A Combustion Control and Diagnostics Sensor for Gas Turbines," Proceedings of 2004 ASME/IGTI TurboExpo Meeting: TurboExpo Power for Land, Sea, and Air, Vienna, Austria, 14-17 June 2004, ASME Paper GT2004-53392. 